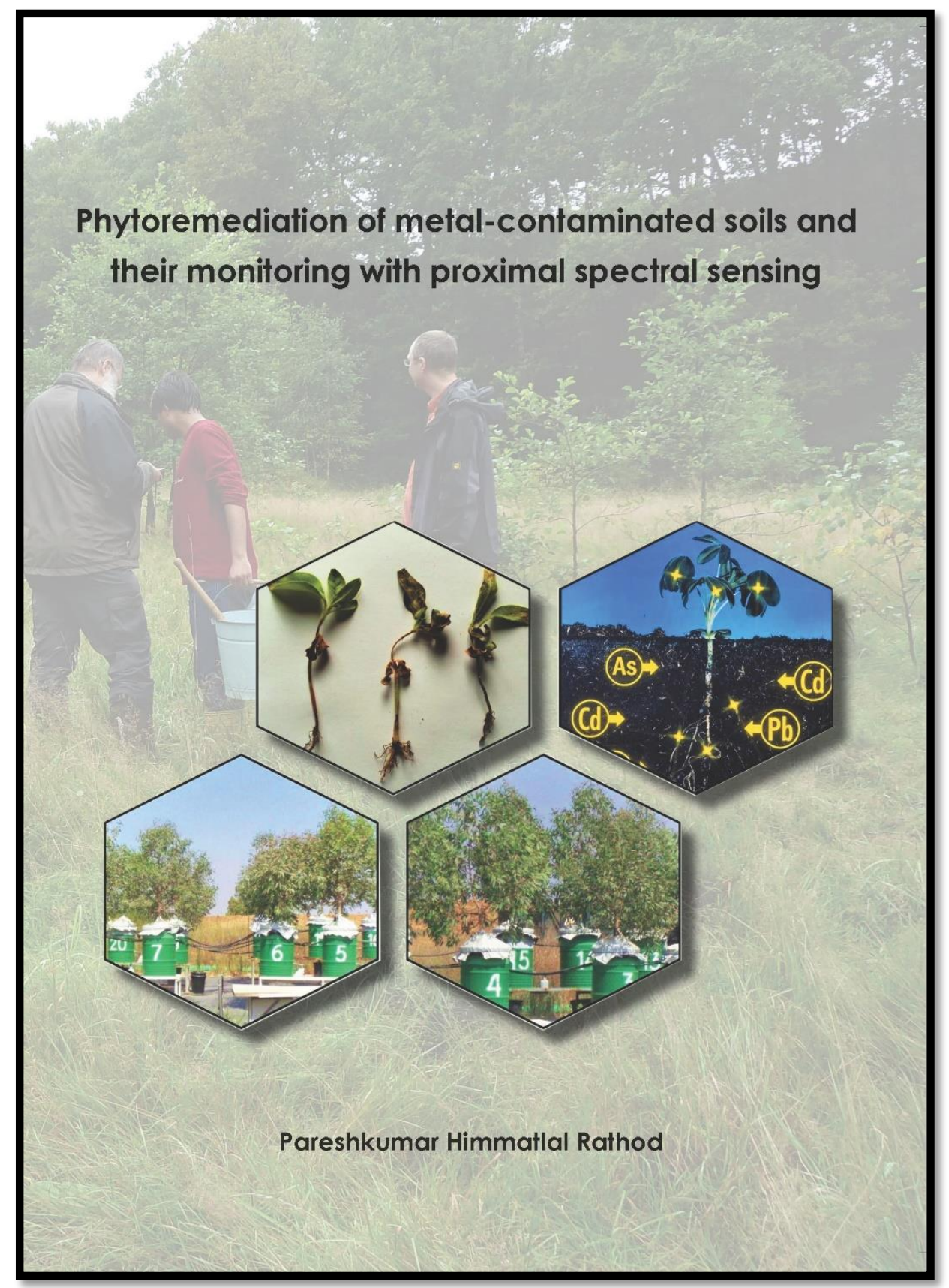




\section{PHYTOREMEDIATION OF METAL- CONTAMINATED SOILS AND THEIR \\ MONITORING WITH PROXIMAL SPECTRAL SENSING}


Graduation committee:

\section{Chair}

Prof. dr. ir. A. Velkamp University of Twente

\section{Promoter}

Prof. dr. Freek D. van der Meer University of Twente

\section{Co-promoter}

Dr. Marleen F. Noomen, ITC-ESA University of Twente

\section{Members}

Prof. dr. ing. Wouter Verhoef

University of Twente

Prof. dr. Victor G. Jetten,

Prof. dr. Mike D. Steven

University of Twente

Prof. dr. rer. nat. habil. E. Gert Dudel

University of Nottingham, UK

Dr. ir. Lammert Kooistra

\section{Germany}

Wageningen University

ITC dissertation number: 294

ITC, P.O. Box 217, 7500 AA Enschede, The Netherlands

ISBN 978-90-365-4236-4

DOI 10.3990/1.9789036542364

Cover designed by Benno Masselink

Printed by ITC Printing Department

Copyright (c) 2016 by Pareshkumar Himmatlal Rathod

U1C Faculty of geo-information SCIENCE AND EARTH observation 


\title{
PHYTOREMEDIATION OF METAL- CONTAMINATED SOILS AND THEIR MONITORING WITH PROXIMAL SPECTRAL SENSING
}

\author{
DISSERTATION
}

to obtain

the degree of doctor at the University of Twente, on the authority of the rector magnificus, Prof. Dr. H. Brinksma, on account of the decision of the graduation committee, to be publicly defended on Wednesday, November 16, 2016 at 14.45 hrs

by

\section{Pareshkumar Himmatlal Rathod}

born on January 18, 1979

in Botad, Gujarat State, India 
This dissertation has been approved by:

\section{Promoter}

Prof. dr. Freek D. van der Meer

University of Twente

\section{Co-promoter}

Dr. Marleen F. Noomen, ITC-ESA

University of Twente 


\section{DECLARATION}

I hereby declare that this submission is my own work and that, to the best of my knowledge and belief, it contains no material previously published or written by another person nor material which has been accepted for the award of any other degree or diploma of the university or other institute of higher learning, except where due acknowledgment has been made in the text.

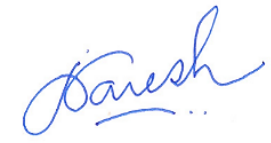

(Pareshkumar Himmatlal Rathod) 


\section{TABLE OF CONTENTS}

Table of Contents ........................................................................ i

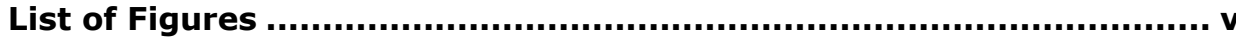

List of Tables..................................................................................... ix

CHAPTER 1 : General Introduction ........................................ 1

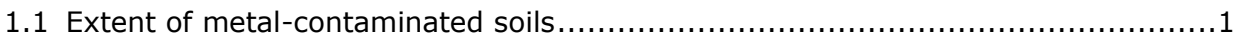

1.2 Phytoremediation for remediation of metal-contaminated soils ........................

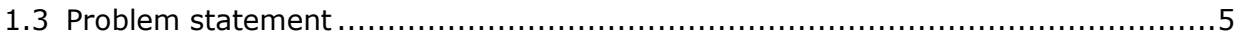

1.3.1 Phytoextraction and phytostabilization ...................................... 5

1.3.2 Monitoring of phytoremediation system ...................................... 6

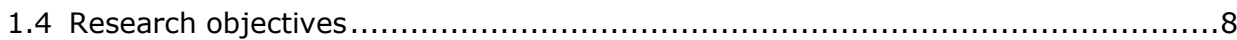

Section-I: Phytoextraction and phytostabilization strategies...................... 8

Section-II: Proximal visible and infrared spectral sensing ........................... 8

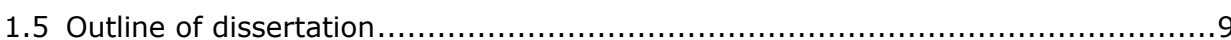

CHAPTER 2 : Cadmium phytoextraction by Eucalyptus camaldulensis saplings and effects of ligands - hydroponic studies ...................................................................................... 11

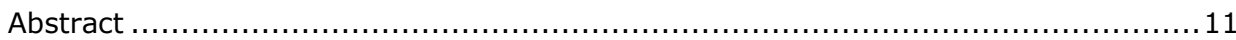

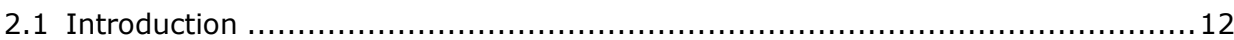

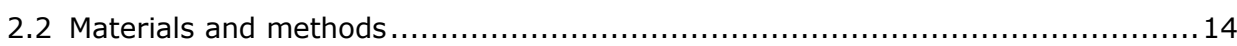

2.2.1 SOL-1 Cadmium uptake study .............................................. 14

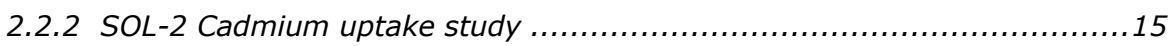

2.2.3 Sample preparation and chemical analysis................................... 16

2.2.4 Cadmium binding to root tissue...........................................17

2.2.5 Translocation and accumulation factors and statistical analysis ..............17

2.3 Results and discussion ............................................................. 17

2.3.1 Effect of the addition of organic ligands and cadmium on the growth of $E$. camaldulensis saplings ................................................. 17

2.3.2 Cadmium uptake and translocation in E. camaldulensis saplings.............20

2.3.3 Uptake of cadmium and other trace elements as affected by the concentration of cadmium and organic ligands in the growth medium ......23

2.3.4 Cadmium binding to root tissue............................................24

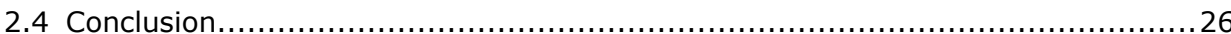

CHAPTER 3 : Chelate-enhanced metal uptake by Eucalyptus trees under controlled deficit irrigation - a lysimeter study............ 27

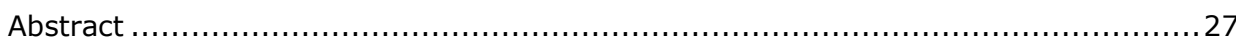

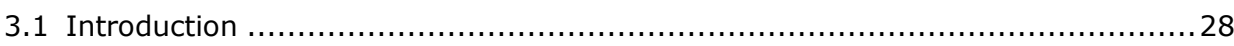

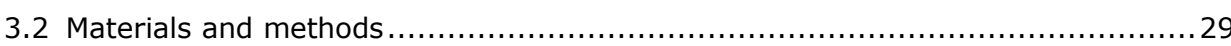




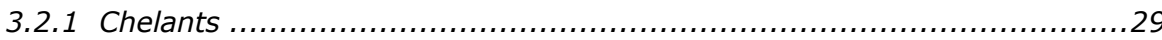

3.2.2 Batch extraction study - Metal dissolution from sludge ........................29

3.2 .3 Lysimeter study ......................................................... 30

3.2 .4 Statistical analysis....................................................... 34

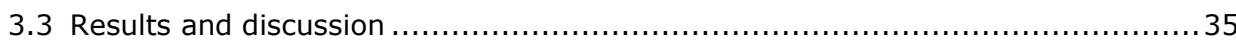

3.3.1 Batch extraction study: Metal dissolution from Tel-Nof sludge by citric acid, EDDS and EDTA ........................................................ 35

3.3.2. Salinity build-up in the lysimeters' soil profile under $C D I$...................... 35

3.3.3 Growth of E. camaldulensis under increasing salinity and chelants concentrations ....................................................................... 38

3.3.4 Fate of EDTA and EDDS in the soil environment .............................40

3.3.5 Chelant-enhanced heavy metal solubilization ..............................43

3.3.6 Heavy metal content in Eucalyptus leaves: 2008-09 trial.....................47

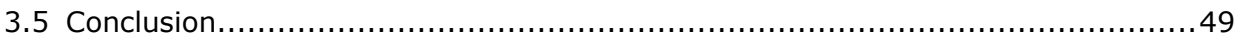

CHAPTER 4 : Proximal spectral sensing of metalcontaminated soils - a technology review.................................. 51

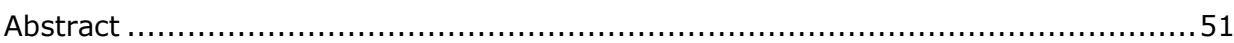

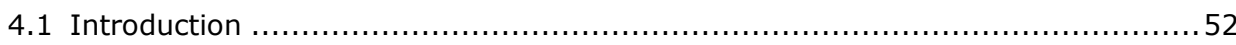

4.1.2 Potential of remote sensing for monitoring phytoremediation ................53

4.2 Near/proximal spectral sensing for assessing metal contamination in soils...........54

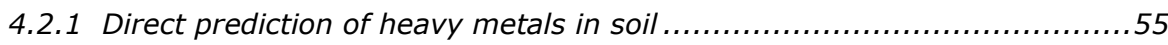

4.2.2 Indirect prediction of heavy metals in soil................................... 55

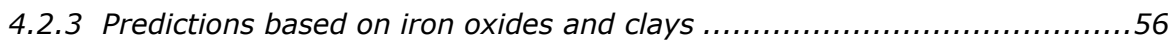

4.2.4 Predictions based on organic matter or organic carbon.......................57

4.2.5 Predictions using mid-infrared spectra ....................................... 58

4.2.6 Challenges to indirect prediction models ....................................59

4.3 Proximal spectral sensing for monitoring vegetation in phytoremediation

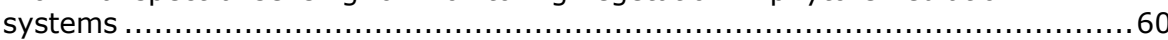

4.3.1 Red-edge position relevant to metal and metal-induced stress..............63

4.3.2 Vegetation indices relevant to metals and metal-induced stress .............64

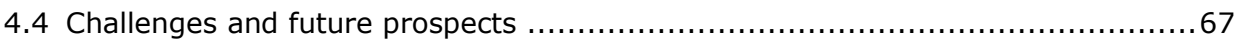

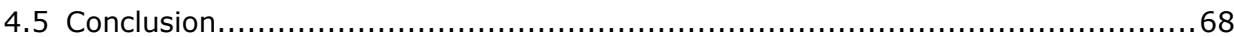

CHAPTER 5 : Feasibility study of visible and near infrared reflectance spectroscopy for assessing metals in soil .................... 69

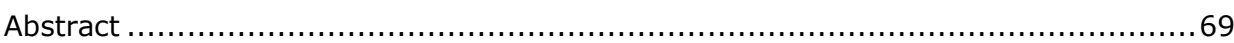

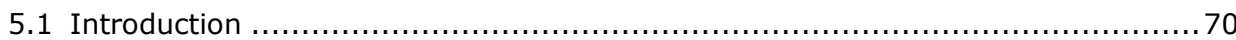

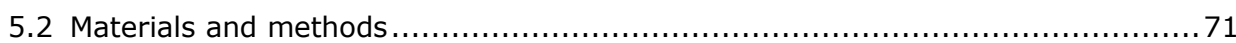

5.2.1 Artificially metal-contaminated soils............................................ 71

5.2 .2 In-situ metal-contaminated soils ........................................ 71

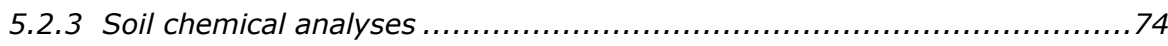

5.2.4 Spectral measurements and transformations .............................. 74

5.2 .5 Statistical analyses........................................................ 75

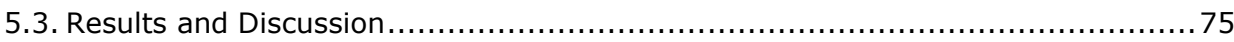


5.3.1 Statistics of soil properties and metals ..................................... 75

5.3.2 Soil spectral reflectance features............................................... 79

5.3 .3 Prediction of soil metals .................................................. 85

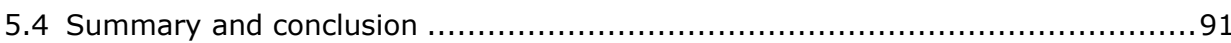

CHAPTER 6 : Spectral changes in the leaves of barley plant due to phytoremediation of metals - results from a pot study ......... 93

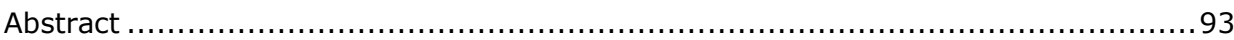

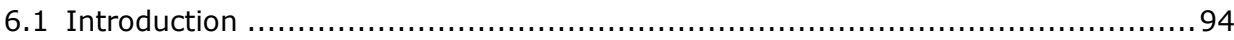

6.2 Materials and methods ............................................................. 95

6.2.1 Experimental set-up ........................................................ 95

6.2.2 Spectral reflectance measurement of leaves ....................................99

6.2.3 Biometric measurements and chemical analyses ............................. 98

6.2 .4 Statistical analysis............................................................. 98

6.3 Results and Discussion................................................................ 101

6.3.1 Effect of metals on barley growth ............................................. 101

6.3.2 Metal accumulation in the plant above ground parts ........................ 101

6.3.3 Spectral reflectance analysis............................................ 106

6.3.4 Vegetation indices and continuum removal spectra......................... 111

6.3 .5 Regression analysis .................................................... 116

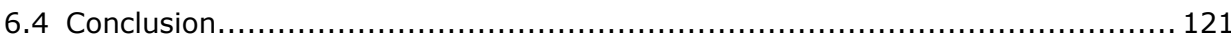

CHAPTER 7 : Spectral response of sunflower, wheat and ryegrass to metal-contaminated soils .................................. 123

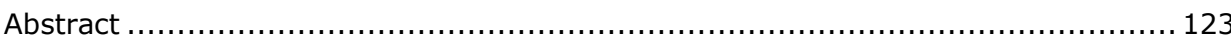

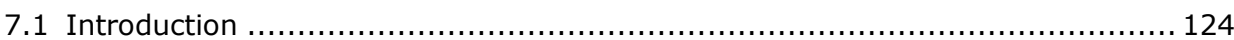

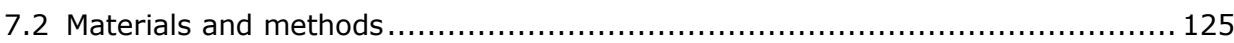

7.2.1 Sunflower (Helianthus annuus) - Pot experimental set-up.................. 125

7.2.2 Wheat and ryegrass - Arsenic uptake study .................................. 128

7.2.3 Spectral reflectance measurement of leaves ............................... 128

7.2 .4 Chemical analyses....................................................... 130

7.2 .5 Statistical analyses................................................... 130

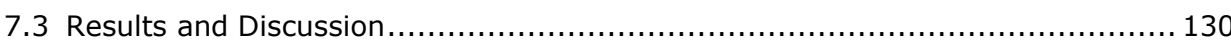

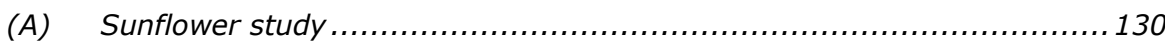

7.3.1 Metal phytoaccumulation............................................... 130

7.3.2 Leaf spectral reflectance ................................................ 134

7.3.3 Vegetation indices and continuum removed spectra........................ 139

7.3.4 Regression analysis ....................................................... 143

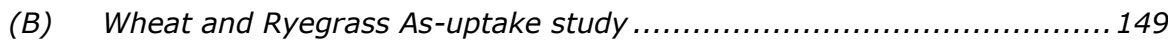

7.3.5 Leaf spectral reflectance and vegetation indices ........................... 150

7.4 Summary and conclusion .............................................................. 157

CHAPTER 8 : Synthesis ..................................................... 159

8.1 Phytoremediation of Cadmium-polluted soils by trees ................................ 159

8.1.1 Cadmium-uptake by the trees: Hydroponic studies.......................... 159 
8.1.2 Chelant-enhanced metal uptake by Eucalyptus trees - A lysimeter study

8.2 Proximal spectral sensing of contaminated soils and metal-induced plant stress .....

8.2.1 Proximal spectral sensing as tool for phytoremediation monitoring ........ 161

8.2.2 VNIR reflectance spectroscopy for assessment of soil-metals - A

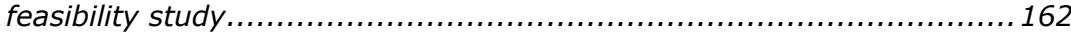

8.2.3 Spectral responses of various plants grown for phytoremediation of

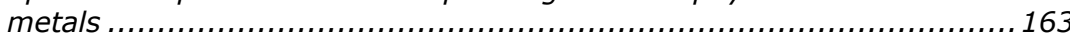

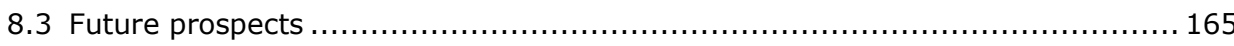

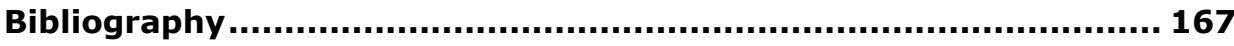

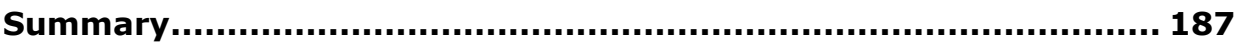

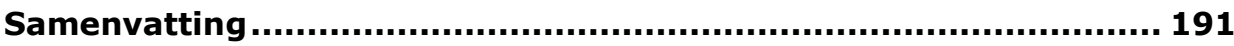

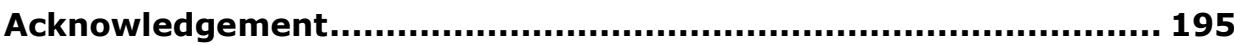

Author's biography...................................................................... 199

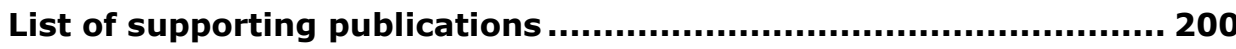

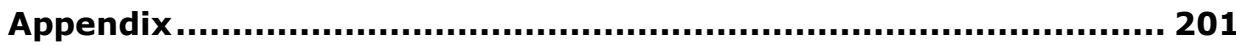

ITC Dissertation List ............................................................. 203 


\section{LIST OF FIGURES}

Figure 1.1: Overview of typical contaminants affecting soils in Europe ..................

Figure 1.2: Schematic illustration of phytotechnology mechanisms .................... 4

Figure 1.3: Natural $(A)$ and chemically enhanced $(B)$ phytoextraction ...................

Figure 2.1: Developed new root system (white fibrous roots) and canopy of $E$. camaldulensis used in the solution culture experiments.................................. 15

Figure 2.2: General view of assembly for hydroponic study using Eucalyptus camaldulensis (SOL-2 study)

Figure 2.3: Dry weight of parts of $E$. camaldulensis grown in a nutrient solution with or without organic ligands (EDTA or S,S-EDDS), and with or without $0.5 \mathrm{mg}$ $\mathrm{Cd} \mathrm{L}^{-1}$ (SOL-1 experiment).

Figure 2.4: Dry weight of parts of $E$. camaldulensis saplings grown in buckets in a nutrient solution with or without EDTA or S,S-EDDS, and with or without 0.5

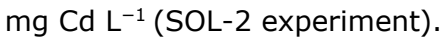

Figure 2.5: Relative fresh weight ratio (final plant weight divided by its initial weight) in whole $E$. camaldulensis saplings grown for one month in buckets in a nutrient solution (SOL-2 experiment) with EDTA (A) or S,S-EDDS (S) or without $(\mathrm{NL})$, and with $10 \mathrm{mg} \mathrm{Cd} \mathrm{L}^{-1}$ or without $\mathrm{Cd}(\mathrm{NL}=$ no ligand)...

Figure 2.6: (a) Cadmium concentration in parts of $E$. camaldulensis saplings grown in buckets in a nutrient solution with $0.5 \mathrm{mg} \mathrm{Cd} \mathrm{L}^{-1}$ (SOL-1 experiment) as affected by the presence of an organic ligand (EDTA or S,S-EDDS) at various concentrations (b) Cadmium concentration in parts of $E$. camaldulensis saplings grown in buckets in a nutrient solution with $10 \mathrm{mg} \mathrm{Cd} \mathrm{L}^{-1}$ (SOL-2 experiment) as affected by the presence of an EDTA (A) or S,S-EDDS (S) at various concentrations ( $\mathrm{NL}=$ no ligand).

Figure 2.7: $\mathrm{Cd}$ adsorption to $E$. camaldulensis ground dry root tissue as affected by a $0.1 \mathrm{mM}$ concentration of either EDTA or S,S-EDDS. (A) Amount of Cd adsorbed vs. Cd concentration in solution (B) percent of amount of $\mathrm{Cd}$ added that adsorbed onto the root tissue.

Figure 3.1: General view of lysimeter experimental setup

Figure 3.2: Dissolution of metals by chelates in batch extraction as affected chelate type (EDTA, EDDS, and citric acid), chelate concentration and time (black columns: 1 day; gray coloured columns: 7 weeks).

Figure 3.3: Electrical conductivity (EC) of the leachates from the lysimeters in (a) 2007-08 and (b) 2008-09 treatment periods.

Figure 3.4: E. camaldulensis trunk diameter and the height at 6, 17, and 22 months after planting of tree in the lysimeters under chelate fertigation with tap and RO water....

Figure 3.5: Recovery of EDTA and EDDS during their incubation in four types of lysimeter media.

Figure 3.6: Concentration of EDTA in the 2008-09 leachates from lysimeters in the 3 treatments that received EDTA.

Figure 3.7: Concentration of dissolved organic carbon (DOC) in the 2008-09 leachates from the lysimeters in all 8 treatments.

Figure 3.8: The concentration of $\mathrm{Cd}$ in the leachates from the lysimeters in the 2007-08 season (a) and the 2008-09 season (b)... 
Figure 3.9: Cadmium and $\mathrm{Cu}$ solubilization after 3 and 85 days of EDTA and EDDS incubation in four types of lysimeter media...................................... 47

Figure 4.1: Changes in Visible infrared reflectance spectra of sunflower leaves due to metal-induced stress............................................................. 63

Figure 5.1: Location of permanent soil monitoring sites (BDF) sites in the State of Saxony, Germany. Source: http://www.umwelt.sachsen.de/ .............................73

Figure 5.2: ASD FieldSpec spectroradiometer, ASD's standard contact probe and aluminium cup filled with BDF soils for spectral measurements.......................... 75

Figure 5.3: Reflectance spectra of (a) Cd, (b) $\mathrm{Pb},(\mathrm{c}) \mathrm{As}$, and (d) metal mixture

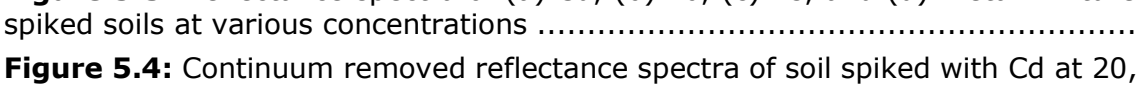
$\mathrm{Pb}$ at $1200, \mathrm{As}$ at $900 \mathrm{mg} \mathrm{kg} \mathrm{kg}^{-1}$ and their metal-mixture................................ 80

Figure 5.5: Pearson's correlations between continuum removed reflectance spectra (within the 450-600,1100-1200, 1380-1450,1715-1850, 1860-2030, 2140-2250 and 2300-2375 nm) and the concentrations of $\mathrm{Cd}, \mathrm{Pb}$, As and $\mathrm{Fe}$ in metal-spiked soils...

Figure 5.6: Reflectance ( $a, b)$ and continuum removed reflectance $(c, d)$ spectra of surface soils sampled from eight in-situ metal-contaminated BDF sites.

Figure 5.7: Pearson's correlation coefficients between the CR absorption features within 780-1000, 1100-1200, 1715-1850 nm and metal, total Fe and OM concentration in surface $(a, b)$ and subsurface $(c, d)$ soils of eight BDF sites.

Figure 5.8: CR band depth difference between least metal-contaminated soils (i.e., BDF-25) and elevated metal-contaminated soils within CR absorption features for (a) surface soil and (b) subsurface soils

Figure 5.9 Scatter plot of measured vs. predicted metal concentration ( $\mathrm{mg} \mathrm{kg}^{-1}$ ) using PLS1 regression model $(a, b, c)$ with significant first derivatives of reflectance spectra of metal-spiked soil, (d, e) with CR spectra of selected BDF surface soils, and ( $f$ ) with reflectance spectra in 450-1000 nm region of selected BDF surface soils.

Figure 6.1: Glass-chambers at Ökologisches Prüffeld, TU Dresden, Tharandt ............95

Figure 6.2: General view of experimental set-up in glass-chambers. ....................97

Figure 6.3: Growth of barley plants (at 3.5 months after sowing) in cadmium $(a, b)$ and lead (c, d) spiked soils, showing no-different between levels of treatment.

Figure 6.4: Cadmium, lead and arsenic concentration (in $\mathrm{mg} \mathrm{kg}^{-1}$; dry weight basis) in roots, leaves*, straw and grains of barley.

Figure 6.5: Barley growth (at 3.5 months after sowing) in arsenic (a, c) and multi-metals $(b, d)$ treatments, showing intensified As-phytotoxic effects on barley growth

Figure 6.6: Reflectance of barley leaves for three levels of cadmium $(a, b, c)$ and lead $(d, e, f)$ treatments in comparison to untreated control spectra at 1,3 and 4 months.

Figure 6.7: Pearson's correlation $(r)$ of the leaf-metal concentration and leaf reflectance spectra under (a) single metal and (b) multi-metals treatments.

Figure 6.8: Reflectance of barley leaves for three levels of arsenic ( $a, b, c)$ and multi-metals $(d, e, f)$ treatments in comparison to untreated control spectra at 1 , 3 and 4 months.

Figure 6.9: Reflectance spectra of barley leaves ( $a, b, c)$ and differences in reflectance values between treated and untreated plants $(d, e, f)$ for control and higher level of treatments at 1,3 , and 4 months. . 
Figure 6.10: First derivatives of leaf reflectance $(475-775 \mathrm{~nm})$ for higher level of arsenic (a) and multi-metals (b) at 1 and 3 months

Figure 6.11: Comparison between values of chlorophyll indices (a-d) and water indices (e-h) for different metal treatments.

Figure 6.12: Difference (\%) in band depth values between control and levels of metal-treatments on 1 and 3 months after sowing.

Figure 6.13: Band depth at selected wavelength for different treatments.

Figure 6.14: PLSR scatter plots of measured leaf-As vs. predicted leaf-As concentration ( $\mathrm{mg} \mathrm{kg}^{-1}$ ) at 1-month for (a) selected significant wavelengths* from absorption features at 425-750, 1370-2170 nm; PC\#7, (b) mean normalized spectra of 415-2170 nm; PC\#10, (c) selected significant wavelengths* from absorption features at 1370-1570, 1875-2170 nm; PC\#5 and (d) first derivative spectra of 1370-1570, 1875-2170 nm; PC\#6...

Figure 6.15: MLR scatter plots of measured leaf-As vs. predicted leaf-As concentration ( $\mathrm{mg} \mathrm{kg}^{-1}$ ) at 1 month for (a) all calculated VIs and BDs, (b) VIs and BDs excluding LIC, REIP and BDs at 680, 970, $1435 \mathrm{~nm}(n=21)$ (c) VIs, NDWI, MSI and BDs at 680,1435, $1925 \mathrm{~nm}$ (d) VIs, NDVI, LCI, REIP, NDWI, NDWI_MIR, and MSI.

Figure 7.1: Glass-chambers with facility of filtered air circulation and temperature control, and view of pot-grown sunflowers in them.

Figure 7.2: Cadmium, lead and arsenic concentration (in $\mathrm{mg} \mathrm{kg}^{-1}$; dry weight basis) in roots and leaves (mean of all sampling dates) of sunflower.....

Figure 7.3: Sunflower growth into $(A) S_{1}-A s_{2}$ and (B) $S_{1}$-Mix soil at 30 days after seedling transplantation. (C) The sunflower plants were not survived under the condition of extreme higher concentration of As $\left(900 \mathrm{mg} \mathrm{kg}^{-1}\right)$ and metal-mixture $\left(20 \mathrm{mg} \mathrm{Cd}+1200 \mathrm{mg}+\mathrm{Pb}\right.$ and $900 \mathrm{mg} \mathrm{kg}^{-1}$ ). Plants were also stunted in in-situ metal-contaminated floodplain soils.

Figure 7.4: Reflectance spectra of (a) $S_{1}$-Mix and (b) $S_{3}$-contaminated floodplain soil treatments at different spectral measurement intervals.

Figure 7.5: Reflectance spectra $(a, b)$ and their first derivatives reflectance spectra (c, d) of leaves of sunflower grown in metal-spiked soils at 30 and 60 days of growth.

Figure 7.6: Leaf reflectance spectra (a) and first derivatives reflectance spectra (a) from sunflower grown in metal mixture-spiked soils and in-situ metalcontaminated soils at 45 days of plant growth.

Figure 7.7: Pearson's correlation ( $r$ ) of reflectance spectra against leaf-metal concentration for $(\mathrm{a}, \mathrm{b}) \mathrm{S}_{1}-\mathrm{Cd},-\mathrm{Pb}$, and -As spiking treatments at 30 and 60 days and (c) for $\mathrm{S}_{1}$-metal mixture, $\mathrm{S}_{2}$, and $\mathrm{S}_{3}$ treatments at 30 days.

Figure 7.8: Changes in chlorophyll vegetation indices (NDVI and SR705) and REIP (SG $1^{\text {st }}$ order) for different metal contamination treatments.

Figure 7.9: Continuum removed spectra of control and metal-contamination treatments at (a) 30 and (b) 45 days of plant growth.

Figure 7.10: Band depth difference between control and metal-contamination treatments at (a) 30 and (b) 45 days

Figure 7.11: Scatter plot of measured versus predicted leaf-Cd concentration using PLSR calibration models. Blue and red colour respectively represents the result of calibration and validation models.

Figure 7.12: Scatter plot of measured versus (a) predicted leaf- $\mathrm{Pb}(\mathrm{b}, \mathrm{c})$ leaf-As concentration using PLSR calibration models.

Figure 7.13: Scatter plot of measured versus (a) predicted leaf- $\mathrm{Pb},(\mathrm{b})$ predicted leaf- $\mathrm{Pb}$, and (c) predicted leaf-As concentration using MLR calibration models. 
Figure 7.14: Total As concentrations in different plant parts of Triticum aestivum on the sandy soil $\mathrm{S}_{1}(\mathrm{a})$ and on the loamy soil $\mathrm{S}_{2}(\mathrm{~b})$ with moisture treatment $(70 \% ; 100 \%)$, P-treatment $\left(P_{0} ; P_{1}\right)$ and $N$-treatment $\left(N_{0} ; N_{1}\right)$.

Figure 7.15: Arsenic, cadmium and lead concentration in shoot of ryegrass grown in two different soils with $70 \%$ and $100 \%$ field capacity moisture treatments at $\sim 80$ and $\sim 120$ days after sowing.

Figure 7.16: Leaf reflectance $(a, c)$ and first derivatives reflectance spectra $(b$, d) from wheat grown in sandy soil, $S_{1}$ with moisture treatment $(70 \%, 100 \% \mathrm{FC})$, P-treatment $\left(\mathrm{P}_{0}, \mathrm{P}_{1}\right)$ and $\mathrm{N}$-treatment $\left(\mathrm{N}_{0}, \mathrm{~N}_{1}\right)$.

Figure 7.17: Leaf reflectance $(\mathrm{a}, \mathrm{c})$ and first derivatives reflectance spectra (b, d) from wheat grown in loamy soil, $\mathrm{S}_{2}$ with moisture treatment $(70 \%, 100 \% \mathrm{FC})$, P-treatment $\left(\mathrm{P}_{0}, \mathrm{P}_{1}\right)$ and $\mathrm{N}$-treatment $\left(\mathrm{N}_{0}, \mathrm{~N}_{1}\right)$

Figure 7.18: REIPS (SG $1^{\text {st }}$ order) for treatments combinations of FC, $\mathrm{P}$ - and $\mathrm{N}$ fertilizations given to wheat grown in $\mathrm{S}_{1}$-sandy and $\mathrm{S}_{2}$-loamy soils.

Figure 7.19: Leaf reflectance $(a, b)$ and first derivatives of reflectance spectra within 450-800 $\mathrm{nm}(\mathrm{c}, \mathrm{d})$ from ryegrass grown in two different soils with two moisture treatment (70\%, 100\% FC) at 80- and 120-days after sowing

Figure 7.20: REIPs (SG $1^{\text {st }}$ order) for two moisture treatments given to ryegrass grown in $\mathrm{S}_{1}$-sandy and $\mathrm{S}_{2}$-loamy soils at $\sim 80$ and $\sim 120$ days.... 156 


\section{LIST OF TABLES}

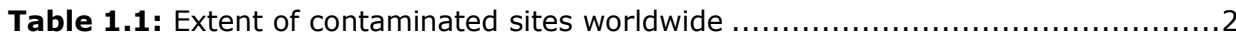

Table 1.2: Phytotechnology mechanisms - overview................................... 5

Table 1.3: Parameters to be monitored during remediation program ...................7

Table 2.1: Content of selected elements (in $\mathrm{mg} \mathrm{kg}^{-1}$ )* of $E$. camaldulensis saplings grown in hydroponics with $10 \mathrm{mg} \mathrm{Cd} \mathrm{L}^{-1}$ and without $\mathrm{Cd}$. The values are

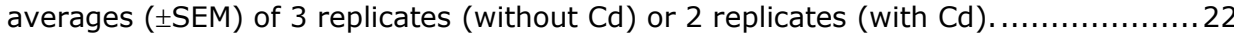

Table 3.1: Composition of the sludge and quartz sand-sludge mixture (sludge: average of 5 grab samples; mixture: average of samples from 24 lysimeters) ...........30

Table 3.2: Treatments and allocation of lysimeters to treatments in 2007-08 and in 2008-09 year.

Table 3.3: The molar ratio between the amount chelant in the solution and the

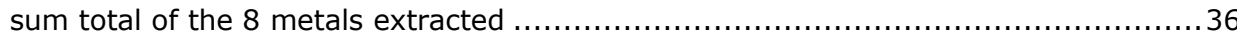

Table 3.4: Average concentrations (in $\mathrm{mg} \mathrm{L}^{-1}$ ) of constituents in the leachates

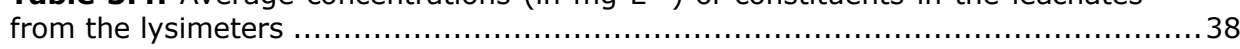

Table 3.5: Average concentrations (in $\mathrm{mg} \mathrm{kg}^{-1}$ ) of elements in diagnostic leaves of $E$. camaldulensis during the second trial (2008-09)

Table 4.1: Summary of indirect predictions of heavy metal through soil

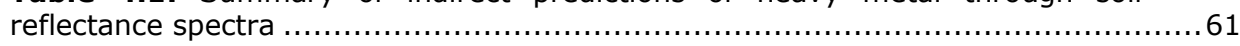

Table 4.2: Vegetation indices* studied for heavy metals induced plant stress ........66

Table 5.1: Details of artificially metal-spiked soil samples obtained from Barley and Sunflower studies

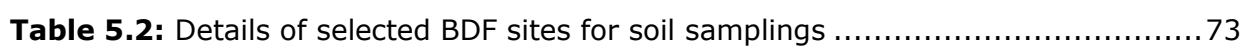

Table 5.3: Physico-chemical characteristics ${ }^{1,2}$ of soil at selected BDF sites .............73

Table 5.4: Metals' concentration and other physico-chemicals properties of surface and subsurface soils of eight BDF sites

Table 5.5: Metals' concentration and organic matter content of surface and subsurface soils sampled from eight BDF sites $(n=40$ each for surface- and subsurface-soils).

Table 5.6: Descriptive statistics for metals' concentration and other physicochemicals properties of soils from BDF sites $(n=36)$. .

Table 5.7: Descriptive statistics for $\mathrm{As}, \mathrm{Pb}$, and $\mathrm{Cd}$ concentration in metal-spiked soil samples of barley and sunflower studies $(n=80)$

Table 5.8: Pearson correlation coefficients* between continuum removed spectral band depths within the considered absorption domains and soil variables of the surface-soil samples

Table 5.9: Best fit PLSR models for estimation of soil-metal concentration using metal-spiked soils data set, expressed in terms of coefficients of determination $\left(R^{2}\right)$ and root mean square error (RMSE) of calibration, cal and cross-validation, val models.

Table 5.10: Best fit PLSR models for estimation of soil-metal concentration using eight BDF surface soils data set $(n=40)$, expressed in terms of coefficients of determination $\left(\mathrm{R}^{2}\right)$ and root mean square error (RMSE) of calibration, cal and cross-validation, val models

Table 5.11: Best fit PLSR models for estimation of soil-metal concentration using eight BDF subsurface soils data set $(n=40)$, expressed in terms of coefficients of 
determination $\left(\mathrm{R}^{2}\right)$ and root mean square error (RMSE) of calibration, cal and cross-validation, val models

Table 6.1: Physico-chemical characteristics of soil substrate used for phytoextraction pot study

Table 6.2: Treatment details, initial pre-concentration of metals in soil*, and biometric parameters of barley grown with metal-spiked soil ....

Table 6.3: Vegetation indices calculation and absorption regions for which continuum removal was applied in present study.....

Table 6.4: Metal concentration (in $\mathrm{mg} \mathrm{kg}^{-1}$; dry weight basis)* in leaves of barley

Table 6.5: Best fit PLSR and MLR models for estimation of leaf-As concentration in barley for As- and Mix-treatments set $(n=19-22)$ on 1 and 3 months after sowing, expressed in terms of coefficients of determination $\left(R^{2}\right)$ and root mean square error (RMSE) of calibration, cal and cross-validation, val models.

Table 7.1: Physico-chemical characteristics ${ }^{1}$ of soil substrate used in sunflower study ..... 126

Table 7.2: Treatment details and metal pre-concentration after metal-spiking to uncontaminated soils

Table 7.3: Treatment* details of wheat and ryegrass experiments.

Table 7.4: Metal concentration (in $\mathrm{mg} \mathrm{kg}^{-1}$; dry weight basis)* in leaves of sunflower 131

Table 7.5: Correlation coefficient $(r)$ of leaf-metal concentration to vegetation indices and band depths at selected wavelengths within the CR absorption regions

Table 7.6: Best fit PLSR and MLR models for estimation of sunflower leaf-metal

concentration. 


\section{CHAPTER 1 : General INTRODUCTION}

\subsection{EXTENT OF METAL-CONTAMINATED SOILS}

Heavy metal ${ }^{\mathbf{1}}$ or trace metallic ions viz., cadmium (Cd), lead (Pb), arsenic (As), chromium ( $\mathrm{Cr}$ ) and nickel $(\mathrm{Ni})$ contaminate soils worldwide, and there has been an increasing environmental concern about these metal-contaminated ${ }^{2}$ soils, owed to their long-term persistence (unlike organic contaminants, metallic ions cannot be biodegraded) in the agro-ecosystems (Adriano 2001). Metalcontamination to the soils arise through either natural routes (volcanic eruptions, weathering of metal-enriched rocks and minerals) or in most cases, caused by human activities, i.e., mining, smelting, urbanisation, usage of metal-enriched sewage sludge in agriculture, injudicious uses of fertilizers etc. (Alloway 2013). These diverse anthropogenic sources have resulted in the contamination on the order of $10^{7}$ sites globally (Horta et al. 2015).

In European Union, there are estimated to be $\sim 2.5$ million potentiallycontaminated $^{3}$ sites, of which about $14 \%$ are expected to be contaminated (34,000 sites) and they are in need of remediation. Typical contaminants include heavy metals and mineral oils that contribute respectively to $35 \%$ and $23 \%$ of soil-contamination in Europe (Figure 1.1) (Liedekerke et al. 2014). Worldwide, the extent of soil contamination is even much larger and the number of potential sites is staggering (Table 1.1). The bio-magnification of ubiquitous metals and/or their compounds in food chains and serious human health consequences involved with metal-contaminated soils, have prompted environmental agencies to initiate characterization and remediation of contaminated soils. An appropriate remediation of metal-contaminated soil is rather complex, time consuming and often soil specific. Common remediation techniques for soil-metals involves physical, chemical and thermal processes, and usually require the physical removal of metal from the soil or minimization of in-situ metal exposure.

${ }^{1}$ The term 'heavy metals' refers to metals and metalloids with density $>5 \mathrm{~g} \mathrm{~cm}^{-3}$ (Martin 2012) or atomic number $>20$, and is usually associated with pollution and toxicity, although some are essential metals required by plants at low concentrations (Adriano 2001).

${ }^{2}$ Contaminated site/soil refers to a well-defined area where the presence of soil contamination has been confirmed and this presents a potential risk to humans, water, ecosystems or other receptors. (Liedekerke et al. 2014).

${ }^{3}$ Potentially-contaminated site refers to site where unacceptable soil-contamination is suspected but not verified (Liedekerke et al. 2014). 
These technologies include: solidification and stabilization, soil flushing, electrokinetics, chemical reduction and oxidation, soil washing, excavation and landfill disposal (Jankaite and Vasarevičius 2005; Yao et al. 2012). However, they are typically expensive and soil destructive. Consequently, the potential role of bioremediation, mostly using higher plants (phytoremediation) has gained momentous scientific research interest.

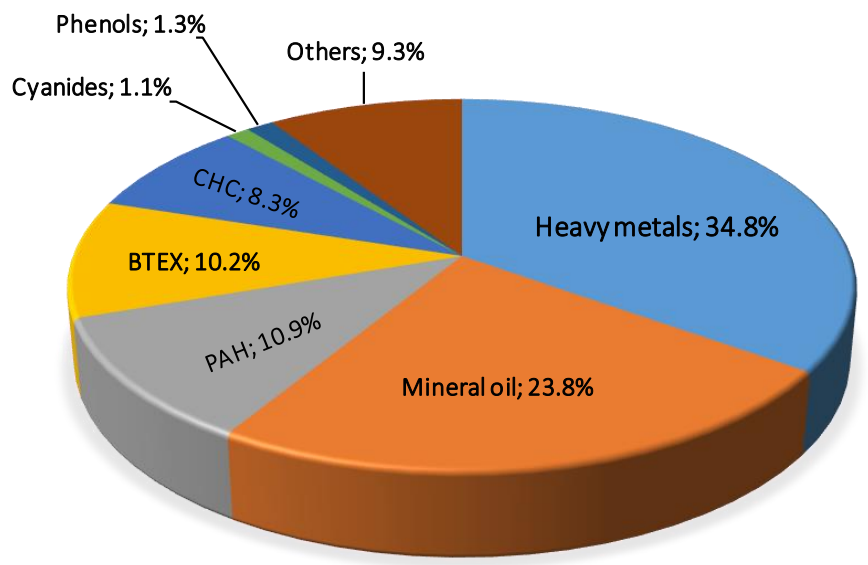

Source: Liedekerke et al. (2014)

Figure 1.1: Overview of typical contaminants affecting soils in Europe

(BTEX = benzene, toluene, ethylbenzene, and xylenes; aromatic hydrocarbons, $\mathrm{CHC}=$ chlorinated hydrocarbons, $P A H=$ polycyclic aromatic hydrocarbons).

Table 1.1: Extent of contaminated sites worldwide

\begin{tabular}{|l|l|l|}
\hline Country & Particulars & Reference \\
\hline Australia & $\begin{array}{l}\text { N160,000 contaminated sites. 60-80\% of } \\
\text { these sites exist in urban environment }\end{array}$ & SoE (2011) \\
\hline Canada & $\begin{array}{l}\text { There are over 21,000 federal sites listed in } \\
\text { the Federal Contaminated Sites Inventory. Of } \\
\text { which, }>6500 \text { sites are metal-contaminated. }\end{array}$ & $\begin{array}{l}\text { Government of } \\
\text { Canada } \\
\text { (2012) }\end{array}$ \\
\hline USA & $\begin{array}{l}\text { According to Nationwide soil pollution survey } \\
\text { conducted by Ministry of Land and Resources } \\
\text { from 2005-13, 16.1\% of soil and 19.4\% of its } \\
\text { arable land showed contamination. Also, heavy } \\
\text { metal pollution is prevalent in south central } \\
\text { and southwest regions. }\end{array}$ & Zhang (2014) \\
\hline $\begin{array}{l}\text { 21300 contaminated sites are on the national } \\
\text { priority list for the remediation treatment, and } \\
\text { of which, 63\% are metal-contaminated }\end{array}$ & $\begin{array}{l}\text { Mulligan et al. } \\
\text { (2001); }\end{array}$ \\
USEPA (2012) \\
\hline
\end{tabular}

Refer to Brandon (2013) for more information 


\subsection{PhYTOREMEDIATION FOR REMEDIATION OF METAL- CONTAMINATED SOILS}

A Greek word, 'phyto' (plants) and a Latin word 'remedium' (to correct a problem) are put together and the term specifies an emerging technology to clean contaminated sites. Phytoremediation (or phytotechnologies) are a set of technologies using plants to remediate contaminants in soil, water and sediments (ITRC 2009; USEPA 2010). Although, phytoremediation is believed to be a novel approach, it is an ancient concept as over 200 years ago, Roman civilization reportedly used Eucalyptus trees to de-water the saturated soils (Carman and Crossman 2001).

Phytotechnologies have been increasingly recognized and applied both in-situ (right where the contamination has taken place) and ex-situ (excavation of contaminated soil, followed by phytoremediation). Scientific studies on phytoremediation initiated in 1970-80s, and the implication increased in 198090s (Lasat 2000), as it has been shown to be economical, versatile, ecofriendly and aesthetic in usage compared to the conventional remediation techniques (Ali et al. 2013; and references therein). Phytoremediation was first employed by Briggs et al. (1982) to remediate pesticides residues from soils. Phytotechnologies remediate contaminants using several mechanisms. Table 1.2 and Figure 1.2 show these mechanisms of phytotechnology, and of these, phytoextraction and phytostabilization are most widespread methods for the sites that are marginally to moderately polluted, where it is not economical to apply expensive extraction or chemical washing treatments.

Review articles by Marmiroli et al. (2006), Evangelou and Deram (2014), Padmavathiamma et al. (2014), Conesa et al. (2012) and Chen et al. (2015) focused on technical aspects, new concepts and current reports of phytoremediation. Sharma and Pandey (2014) reviewed the status of phytoremediation in global prospects. Stephenson and Black (2014) presented a review on the evaluation of phytoremediation from its potentiality to its commercial application today. These authors explain the paradigmatic shift of phytoremediation from simple direct action of plants towards phytotechnologies or phytomanagement, as there are still several major limitations associated with phytoremediation. These limitations include (ITRC 2009; USEPA 2010):

(i) Long-term clean-up technologies are required to achieve remedial goals.

(ii) High initial contaminant concentrations at a site may be phytotoxic and inhibit or prevent plant growth.

(iii) A limited number of metal-hyperaccumulator ${ }^{\mathbf{1}}$ plant exit in nature, and they are slow-growing with low-biomass yield.

\footnotetext{
${ }^{1}$ Hyperaccumulators are plants that tolerate high concentrations of soil-metals and accumulate them at greater rate into plant parts. By definition, a hyperaccumulator must accumulate at least $100 \mathrm{mg} \mathrm{g}^{-1}(0.01 \%$ dry weight), Cd, As and some other trace metals, $1000 \mathrm{mg} \mathrm{g}^{-1}$ ( 0.1 dry weight) $\mathrm{Co}, \mathrm{Cu}, \mathrm{Cr}$, Ni and $\mathrm{Pb}$ and 10,000 $\mathrm{mg} \mathrm{g}^{-1}$ (1\% dry weight) $\mathrm{Mn}$ and $\mathrm{Ni}$ (Reeves and Baker 2000).
} 
(iv) A risk analysis may be necessary before disposal of any contaminated plant material (in case of phytoextraction strategy).

(v) Phytotechnologies may not be suitable for sites with sub-surface contamination due to shallow distribution of plant roots.

(vi) Continuous monitoring is required to optimize the phytoremediation systems.

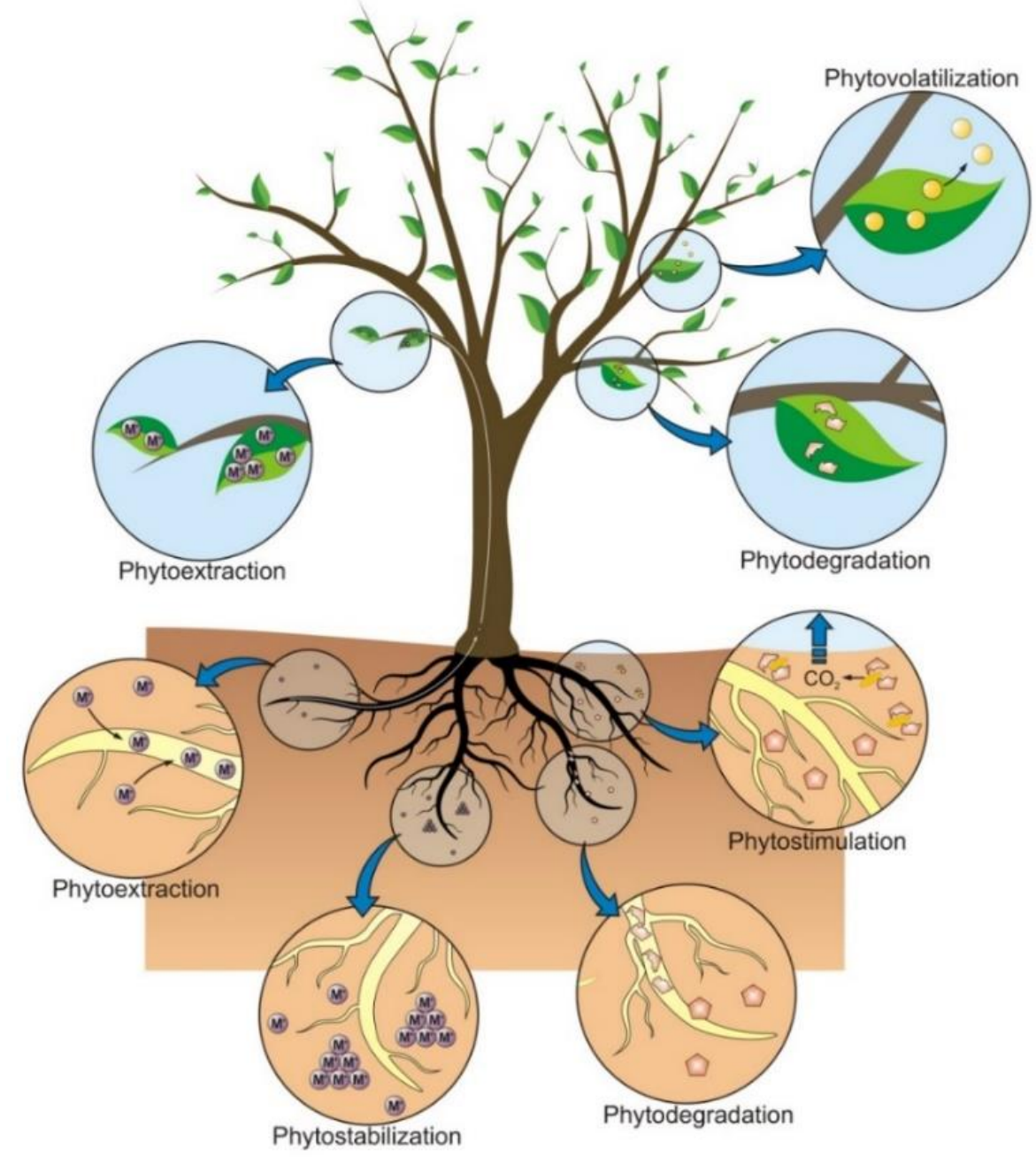

Figure 1.2: Schematic illustration of phytotechnology mechanisms Source: Favas et al. (2014) 
Table 1.2: Phytotechnology mechanisms - overview

\begin{tabular}{|l|l|l|}
\hline Mechanisms & Description; Ability of plants... & $\begin{array}{l}\text { Clean-up goals; } \\
\text { Contaminants treated }\end{array}$ \\
\hline $\begin{array}{l}\text { Phyto- } \\
\text { degradation }\end{array}$ & $\begin{array}{l}\text { to take up and break down } \\
\text { contaminants within plant tissues via } \\
\text { internal enzymatic activity }\end{array}$ & $\begin{array}{l}\text { Remediation by destruc- } \\
\text { tion; Organic compounds }\end{array}$ \\
\hline $\begin{array}{l}\text { Phyto- } \\
\text { volatilization }\end{array}$ & $\begin{array}{l}\text { to take up, translocate, and then } \\
\text { volatilize contaminants in the } \\
\text { transpiration stream }\end{array}$ & $\begin{array}{l}\text { Remediation by removal } \\
\text { through plants; Organic } \\
\text { molecules, Hg, Se, and As }\end{array}$ \\
\hline $\begin{array}{l}\text { Phyto- } \\
\text { extraction or } \\
\text { Phyto- } \\
\text { sequestration }\end{array}$ & $\begin{array}{l}\text { to take up contaminants into the } \\
\text { plant and sequester contaminant } \\
\text { within the plant tissue }\end{array}$ & $\begin{array}{l}\text { Remediation by removal of } \\
\text { plants containing the } \\
\text { metals; Heavy metals } \\
\text { (e.g., Pb, Cd, Ni, Co, Cr, } \\
\text { Zn) and radionuclides }\end{array}$ \\
\hline $\begin{array}{l}\text { phyto- } \\
\text { stimulation } \\
\text { and/or Rhizo- } \\
\text { degradation }\end{array}$ & $\begin{array}{l}\text { to release phytochemicals to } \\
\text { enhance microbial biodegradation of } \\
\text { contaminants in rhizosphere }\end{array}$ & $\begin{array}{l}\text { Remediation by destruc- } \\
\text { tion; Organic compounds, } \\
\text { Chlorinated solvents, } \\
\text { Herbicides, Phenols }\end{array}$ \\
\hline $\begin{array}{l}\text { Phyto- } \\
\text { stabilization }\end{array}$ & $\begin{array}{l}\text { to immobilize contaminants in soil } \\
\text { through absorption and accumulation } \\
\text { by roots, adsorption onto roots or } \\
\text { precipitation within root-zone }\end{array}$ & $\begin{array}{l}\text { Containment. Remediation } \\
\text { by reducing bioavailability } \\
\text { of contaminants; Heavy } \\
\text { metals and radionuclides }\end{array}$ \\
\hline
\end{tabular}

Source: Conesa et al. (2012) and ITRC (2009)

\subsection{Problem Statement}

\subsubsection{Phytoextraction AND Phytostabilization}

In view of the limitations cited in the previous section, the success of phytoremediation, particularly for the phytoextraction approach, depends on an efficient translocation of soil-metals from the plant's root to above-ground harvestable parts, and consequently as well on ample biomass yield of plants. However, there are only few natural hyperaccumulator plant species, and most documented hyperaccumulator plants exhibit as slow growth rate and lowbiomass yield that makes them unfeasible for use at field-scale phytoextraction.

Irrespective of plant species, metal-bioavailability to the plant roots and its phytoextraction rate (i.e., root-to-shoot translocation of metals) are mainly governed by the metals' solubility and their diffusion to the root surface, and are therefore considered the key factors that limit the effectiveness of phytoextraction. To overcome this, chelating agents ${ }^{1}$ (i.e., organic ligands) plays a significant role in making metal mobile into soil solution to the plant's

${ }^{1}$ Chelating agent is a substance whose molecules can form several bonds to a single metallic ion, and make them bioavailable at plant roots. In other words, a chelating agent is a multi-dentate ligand. EDTA (ethylene diamine tetra acetic acid) is a versatile chelating agent. 
root and their further translocation into shoots. Figure 1.3 shows a conceptual representation of natural and chemically enhanced phytoextraction.

A considerable number of studies has focused on screening high biomass plant species for their phytoextraction potentiality (Ansari et al. 2013; Prasad and Freitas 2003 and references therein; Pulford and Watson 2003), and/or uses of chelating agents to enhance metal uptake into high biomass nonhyperaccumulating species (Evangelou et al. 2007b; Leštan et al. 2008b and refereces therein). However, a threat to the environment is associated with use of non-biodegradable chelating agents, since the chelated metalcomplexes tend to be persistent and leach from the root zone.

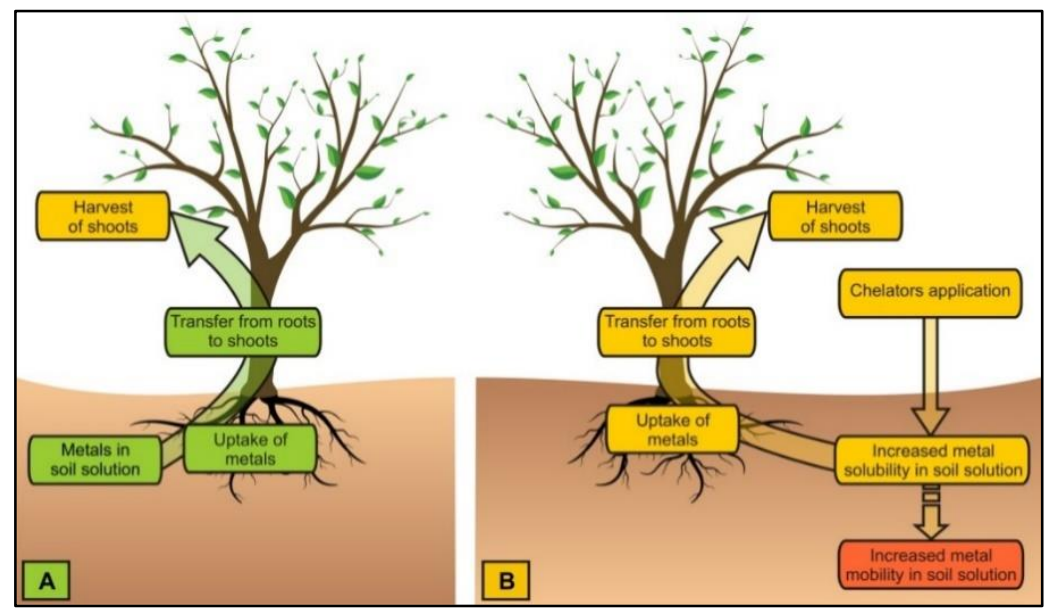

Source: Favas et al. (2014)

Figure 1.3: Natural (A) and chemically enhanced (B) phytoextraction

Considering these limitations, the phytoextraction and phytostabilization strategies by Eucalyptus trees are examined in present study. Relatively little attention has been paid to the potential use of Eucalypti in metal phytoextraction and phytostabilization, whereas the species are capable of thriving under extreme saline and drought conditions while maintaining high transpiration rates and removing substantial amounts of nutrients and trace elements under effluent irrigation and biosolids application (Fine et al. 2006; Mani et al. 2012; Myers et al. 1999; Singh and Bhati 2003). As the limiting step in phytoextraction is the solubilization of target metals within the contaminated sediments, the capacity of two organic ligands, EDTA (nonbiodegradable) and EDDS (S,S-ethylene diamine disuccinic acid; biodegradable), were also tested for solubilization of metals, their toxicity to Eucalyptus and metal uptake \& translocation.

\subsubsection{MONITORING OF PHYTOREMEDIATION SYSTEM}

Phytoremediation, like any remediation program, requires a periodic monitoring plan to measure progress toward the remedial objectives (Flechas and Latady 2003; ITRC 2009; Lai et al. 2007; USEPA 2000). This is especially 
true for phytoremediation, since the remediation process requires a long timespan (5-10 years) to decontaminate a site. It also requires healthy, activelygrowing plants which are removing contaminants. Monitoring can also continue after clean-up in order to determine the effect of phytoremediation on an ecosystem. Hence, a continuous monitoring program is needed to determine the success of phytoremediation in reaching regulatory limits for soil-metals. Table 1.3 lists common parameters to be monitored during phytoremediation.

Table 1.3: Parameters to be monitored during remediation program

\begin{tabular}{|c|c|}
\hline Monitoring parameters & Reason for monitoring \\
\hline \multicolumn{2}{|l|}{ Soils } \\
\hline $\begin{array}{l}\text { - Physico-chemical properties, nutrient } \\
\text { concentration, water content, and } \\
\text { contaminant levels } \\
\text { - Contaminant speciation and } \\
\text { bioavailability } \\
\text { - Mass balance of contaminant (soil } \\
\text { versus plant concentration) }\end{array}$ & $\begin{array}{l}\text { - To optimize vegetative and } \\
\text { root growth } \\
\text { - To quantify contaminants } \\
\text { - To quantify and/or predict } \\
\text { system operation }\end{array}$ \\
\hline \multicolumn{2}{|l|}{ Plants } \\
\hline $\begin{array}{l}\text { - Visual characteristics such as symptom } \\
\text { of stress, leaf mass, density, etc. } \\
\text { - Plant tissue (root, shoot, stem, leaves) } \\
\text { contaminant composition } \\
\text { - Root density and transpiration rate }\end{array}$ & $\begin{array}{l}\text { - System maintenance } \\
\text { - To quantify contaminants } \\
\text { - To quantify and/or predict } \\
\text { system operation }\end{array}$ \\
\hline \multicolumn{2}{|l|}{ Climatic data } \\
\hline $\begin{array}{l}\text { - Weather parameter data (temperature, } \\
\text { precipitation, relative humidity, solar } \\
\text { radiation, evapotranspiration, etc.) }\end{array}$ & $\begin{array}{l}\text { - Maintenance (irrigation } \\
\text { management) and to } \\
\text { determine water balance and } \\
\text { evapotranspiration rates }\end{array}$ \\
\hline
\end{tabular}

Source: USEPA (2000)

Usually, monitoring requires determination of metal concentrations in soil and plant samples, and their spatial distribution in soils, as well as monitoring the status of plant health i.e., metal-induced stress response. All of these require destructive sampling of soils and plants, followed by laboratory analyses, and these would be expensive and not feasible over large areas. Besides, chemical analyses, other available instruments for phytoremediation monitoring are: (Source: http://www.dynamax.com/Phytoremediation.htm).

- Sap flow logger - for measuring plant water use and transpiration rate

- Photosynthetically active radiation (PAR; 400-700 nm) sensor

- Dendrometer - for measuring plant growth or stress indicators

- Leaf area and root measurement system

- $\quad$ Soil moisture probe to measure or control moisture levels in soils

- Root and shoot hydraulic conduction system 
An obvious alternative for monitoring is remote sensing techniques, which can cover large areas at low cost and with relatively high temporal resolution. This technique is commonly used to assess agricultural conditions, and this can also be used at phytoremediation sites (Burckhard 1998, 1999). Although the potential of proximal spectral sensing techniques for assessing properties of soils and plants are recognized, the practical application of these techniques has not been studied for monitoring soil remediation program. There are several challenges to this, including:

(i) Metallic ions are spectrally inactive within Vis-IR regions.

(ii) Spectral characteristics of metal-contaminated soil have been mainly studied in the laboratory or field, and no generalized prediction mechanisms have been obtained due to compositional diversity of soils and presence of various metallic ions-complexes in soil.

(iii) Imaging spectroscopy can be complicated due to mixed pixels, inappropriate spectral resolution at the desired wavelengths, low signal-to-noise ratio, and atmospheric attenuation.

(iv) Most effects of metal-induced stress (specifically toxicity) on plant reflectance resembles plant-stress caused by others stressors. Further research is therefore needed to distinguish metal-induced stress from natural stress and to delineate species-specific spectral responses of metal-stress. This should be done considering the sources and nature of metal contamination, for a realistic plant monitoring in phytoremediation.

In the second section of this dissertation, the proximal spectral reflectance technique is explored for assessing metal-contamination in soils, metalinduced stress in plants, and its feasibility for monitoring phytoremediation.

\subsection{RESEARCH OBJECTIVES}

General objectives of this work are: (i) to test the suitability of Eucalyptus trees for the phytoremediation of metal-contaminated sediments, and (ii) to explore the spectral reflectance sensing to assess the metal-contaminated site and metal-induced stresses in plants during phytoremediation process. It is divided into two sections, and the specific objectives are as follows:

\section{Section-I: Phytoextraction and PHytostabilization StRategies}

1. To assess the effect of the ligands, EDTA and EDDS, on Eucalyptus camaldulensis and on uptake of cadmium by the tree.

2. To test simulated agronomic scenarios for enhancement of metal uptake by Eucalyptus camaldulensis with minimum leaching of metal-complexes below root zone.

\section{SECTION-II: PROXIMAL VISIBLE AND INFRARED SPECTRAL SENSING}

3. To explore the feasibility of spectral reflectance technique for monitoring metal-contaminated soils. 
4. To examine the changes in spectral reflectance in leaves of barley and sunflower plants grown into various metal-spiked soils, and so to monitor the metal-induced plant stress.

5. To examine spectral changes in leaves of wheat and ryegrass due to natural arsenic-contamination in soils.

\subsection{OUTLINE OF DISSERTATION}

To present a clear concept of the dissertation, the chapters have been divided into two major sections, essentially a collection of five experiments. Section one consist of two experiments i.e., hydroponic and lysimeter studies, which were performed in Israel at the Volcani Centre, Agricultural Research Organization, Bet-Dagan. Section two comprises the rest of the experiments that deal with studying the spectral changes in the plants and assessing the metal-contaminated soils, which were performed at Institute for General Ecology and Environmental Protection (TU Dresden, Germany), Faculty of Geoinformation Science and Earth Observation (ITC, University of Twente, Netherlands) in collaboration with Saxon State Office for Environment, Agriculture and Geology, Freiberg, Germany.

Altogether, this dissertation is organized into a total of eight chapters. Apart from general introduction (this chapter) and synthesis chapter (chapter 8), chapter 2, 3, 4 and 6 are published in peer-reviewed journals, while chapters 5 and 7 are in preparation for the research publication. The underlying structure of the dissertation is as follows:

\section{Chapter 1}

This chapter presents a general overview in context to this research project that covers the issues of soil contamination with heavy metals, an introduction to phytoremediation technology, problem statements, research objectives and outline of the dissertation.

\section{Chapter 2}

A fundamental work on phytoextraction using Eucalyptus trees is reported in this chapter. The potential of Eucalyptus camaldulensis was evaluated for the chemically enhanced phytoextraction of cadmium in solution culture study. The effect of chelating agents EDTA and EDDS was tested for metal bioavailability and metal translocation from root to shoot.

\section{Chapter 3}

This chapter describes the result of simulated controlled deficit irrigation agrotechnique for phytostabilization of heavy metals in contaminated sludgesediments using Eucalyptus for minimizing a risk of metal-complexes leaching. 


\section{Chapter 4}

This chapter provides a technology review on the prospective of proximal spectral sensing techniques to monitor the phytoremediation of metalcontaminated soils. The review focuses on an application of visible and infrared spectral reflectance that could be useful in assessing the soil contamination, metal-induced plant stresses and therefore, monitoring of the progress of phytoremediation.

\section{Chapter 5}

This chapter discusses the feasibility of visible and near infrared reflectance spectroscopy for assessing the soil-borne metallic ions in the artificially and insitu elevated metal-contaminated soil substrates.

\section{Chapter 6}

This chapter reports a result of a pot-study with barley grown into various metal-spiked soils. The spectral reflectance changes in the leaves of plants are discussed in relation to the metal-induced stress and metal-phytoextraction.

\section{Chapter 7}

Similar to chapter 6 , the results of spectral changes in leaves of sunflower, wheat and ryegrass that grown into metal-contamination soils are described in this chapter. The study with sunflower was done in same manner as it for barley, but with higher concentration of metals. The experiment with wheat and ryegrass was conducted with an aim to test readily available phosphorous and nitrogen counteract for arsenic uptake and distribution in the plants by Brackhage et al. (2014). In conjunction with their main research objective, we additionally measured the spectral reflectance of plant leaves and discussed the spectral changes concerning arsenic-uptake into plants' parts.

\section{Chapter 8}

This chapter summarizes the findings reported in chapter 2 to 7 . In conclusion, final chapter discusses the chelate-enhanced phytoextraction and phytostabilization strategies using Eucalyptus trees and the application of remote sensing (here, proximal spectral sensing; field or laboratory-scale) for optimizing phytoremediation program.

Chapter 2 and 3 are based on the two jointly published research articles, and are included in the present dissertation with permission from first author, Dr. Pinchas Fine (a permission letter is attached at Appendix section of the dissertation). 


\title{
CHAPTER 2 : CADMIUM PHYTOEXTRACTION BY EUCALYPTUS CAMALDULENSIS SAPLINGS AND EFFECTS OF LIGANDS - HYDROPONIC STUDIES ${ }^{1}$
}

\begin{abstract}
The potential suitability of Eucalyptus camaldulensis for Cd phytoextraction was tested in a hydroponic study. Saplings were exposed to 4.5 and $89 \mu \mathrm{M} \mathrm{Cd}$ for one month, with and without EDTA and S,S-EDDS at $0.1,1$, and $5 \mathrm{mM}$. The saplings' growth was not affected at the $4.5 \mu \mathrm{M}$ Cd concentration, yet it decreased 3-fold at $89 \mu \mathrm{M}$, and almost all the Cd taken up was immobilized in the roots, reaching 360 and $5300 \mathrm{mg} \mathrm{Cd} \mathrm{kg}^{-1}$, respectively (approximately $75 \%$ of which was non-washable in acid). The respective Cd root-to-shoot translocation factors were 0.14 and $\approx 5 \times 10^{-4}$. At $0.1 \mathrm{mM}$ concentration, EDTA and EDDS had no effect or even a positive effect on the saplings growth. This was reversed at $1 \mathrm{mM}$, and the chelants became lethal at the $5 \mathrm{mM}$ concentration. At $89 \mu \mathrm{M}$ Cd in the growth medium, $0.1 \mathrm{mM}$ EDTA increased Cd translocation into the shoots by almost 10-fold, however it strongly reduced $\mathrm{Cd}$ content inside the roots. This hydroponic study indicates the feasibility of E. camaldulensis use for cleanup Cd-contaminated soils at environmental concentrations, both for site stabilization (phytostabilization) and gradual remediation (phytoextraction). EDTA was shown to be much more efficient in enhancing Cd translocation than S,S-EDDS.
\end{abstract}

\footnotetext{
${ }^{1}$ This chapter is based on following paper:

Pinchas Fine, Paresh H. Rathod*, Anna Beriozkin and Uri Mingelgrin (2013). Uptake of cadmium by hydroponically grown, mature Eucalyptus camaldulensis saplings and the effect of organic ligands. International Journal of Phytoremediation, 15 (6): 585-601. DOI: $10.1080 / 15226514.2012 .723061$ (*shared first authorship).
} 


\subsection{INTRODUCTION}

Contamination of soils by heavy metals is of special concern due to the metals' long-term persistence and toxicity (Adriano 2001). Among these, cadmium is immaterial for plants and is considered one of the most important contaminant from the time when an epidemic occurrence of itai-itai disease in Japan, after human consumption of rice grown on fields irrigated with highly cadmium polluted water in Jinzu river basin in 1940s (Cai and Braids 2002; Godt et al. 2006). The background cadmium level in agricultural soils is less than $1 \mathrm{mg}$ $\mathrm{kg}^{-1}$. However, Cd concentrations are increasing in many agricultural soils due to long-term use of phosphorus fertilizers and sewage sludge (Chaney 1980; $\mathrm{Li}$ et al. 2011). The relatively high mobility of $\mathrm{Cd}$ in the soil-plant system facilitates its entrance into the food chain (Kabata-Pendias and Pendias 2001; Ryan et al. 1982). Cadmium is naturally present in the soil, non-essential and highly toxic to most organisms, having 2-20 times toxicity over other toxic metallic elements (Vassilev and Yordanov 1997).

Several techniques are available for the successful management of Cdcontaminated soils and sediments. Of these, phytoremediation by either (phyto)stabilization or (phyto)extraction, is both economical and ecologically sustainable (Salt et al. 1998). Successful phytoextraction of heavy metals from polluted soils involves the metals' solubilization, uptake into the plant roots and translocation into the canopy. Enhanced phytoextraction of metals often involves the application of organic ligands. EDTA (ethylene diamine tetra acetic acid) and EDDS [S, S-(ethylenediamine N,N'-disuccinic acid)] are the most commonly used chelating agents in phytoremediation (Blaylock et al. 1997; Epstein et al. 1999; Grčman et al. 2001; Huang et al. 1997; Vassil et al. 1998). EDTA is gradually being phased out because of its low degradation rate in the environment and ever increasing concentrations in water bodies (Panwar et al. 2011). Of the three existed stereoisomers, S,S-EDDS is replacing EDTA in chelate-assisted phytoremediation because it has a similar metal binding capacity, yet it has been shown to very effectively biodegraded even in highly polluted soils (Grčman et al. 2003; Meers et al. 2005; Tandy et al. 2006a).

Although complexation with organic ligands was shown to increase plant shoot uptake of trace elements at physiological concentrations, plant uptake of heavy elements is often actually retarded by the use of organic ligands (Halvorson and Lindsay 1977; Nowack et al. 2006; Tandy et al. 2006b; Taylor and Foy $1985)$. This is attributed to the high stability constant and larger size of the metal complexes, and to the lack of suitable membrane transporters. Han et al. (2005) concluded that metal-organic complexes with lower stability constants may promote higher rates of metal uptake. They attributed it to a competitive adsorption mechanism. Thus, in columns packed with intact cores from a salt marsh, Duarte et al. (2011) found a small, yet significant, positive effect of low molecular weight organic acids (citric, acetic but not malic) on the uptake and translocation of $\mathrm{Cd}, \mathrm{Zn}, \mathrm{Pb}, \mathrm{Cu}, \mathrm{Cr}$, and $\mathrm{Ni}$ in Spartina maritima. Still, nearly the entire metal load that was taken up by the plant remained in the roots. When growing Helianthus annuus in solution culture, Tandy et al. (2006b) found that while EDDS at $500 \mu \mathrm{M}$ reduced the root content of $\mathrm{Cu}, \mathrm{Zn}$ and $\mathrm{Pb}$ (each at $125 \mu \mathrm{M}$ ), it substantially increased the metals' translocation into the shoot. They attributed this effect to the apoplastic pathway (Nowack 
et al. 2006; Tanton and Crowdy 1971). At higher ligand concentrations, such as those used in phytoextraction, injury to root membranes occurred and this, together with the flush of solubilized metal, was the apparent cause of the ultimate plant death (Vassil et al. 1998). Meighan et al. (2011) exposed mature

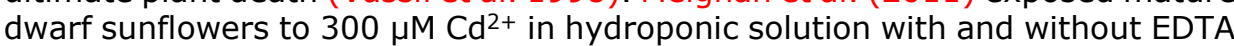
at $900 \mu \mathrm{M}$. In the absence of EDTA, $93 \%$ of the Cd loosely adsorbed onto the roots. EDTA addition reduced $\mathrm{Cd}$ removal from solution to a mere $10 \%$. However, all of these $\mathrm{Cd}$ was transported to the leaves with no noticeable damage to the plants after a week-long exposure.

It should be noted that experiments on ligand-enhanced metal uptake by plants in soils are often done at ligand concentrations that exceed those used in hydroponic studies. For example, Luo et al. (2005) showed that at the end of a 14 days uptake period, EDTA and EDDS at $5 \mathrm{mM} \mathrm{kg} \mathrm{kg}^{-1}$ soil significantly impaired root growth of corn and white beans. The respective shoot growth reduction was $60 \%$ and $52 \%$ when compared to the control corn plants, and by $76 \%$ and $61 \%$ when compared to the control beans. The presence of the ligands also caused chlorosis and necrosis in the leaves. Under the experimental conditions, the effective concentration of organic ligands in the soil solution (at $274 \mathrm{~g}$ water per $\mathrm{kg}$ soil) was approximately $20 \mathrm{mM}$. In this study, the authors did not attempt to distinguish between the behavior of the organic ligands or of the investigated metals $(\mathrm{Cu}, \mathrm{Pb}, \mathrm{Zn}$, and $\mathrm{Cd})$.

So far as Cd-removal is concerned, limited hyperaccumulators of Cd viz., Thalapsi caerulensis, Pannycress, Arabidopsis halleri have been identified as hyperaccumulators (Vassilev et al. 2002). The use of high biomass plants offers an efficient avenue for soil rehabilitation and stabilization (Danh et al. 2009; French et al. 2006; Shen et al. 2002). The Eucalyptus genus is very attractive for soil rehabilitation because of the extremely wide range of environment that its more than 500 species occupy (King et al. 2008). Traditionally, Eucalyptus is used to dry out water-logged soil because of its extremely high transpiration rates. This chapter describe the study to test the suitability for Cdphytoextraction of Eucalyptus camaldulensis, a salinity and drought resistant tree which is a deep-rooting, fast growing and accumulating high biomass. Hydroponically grown, acclimated E. camaldulensis stem-cuttings grew normally in the presence of 0.05 and $0.1 \mathrm{mM} \mathrm{Pb}$, while accumulating $\mathrm{Pb}$ in the roots (6600-26,200 mg kg-1) and shoots (190-550 mg kg-1) (Waranusantigul et al. 2011). This and other related Eucalyptus species are capable of thriving under extreme saline and drought conditions while maintaining high transpiration rates and removing substantial amounts of nutrients and trace elements under effluent irrigation and biosolids application (Fine et al. 2006; Mani et al. 2012; Myers et al. 1999; Singh and Bhati 2003). One of the benefits of using Eucalyptus in phytoremediation is the low risk of metals entering the food chain (King et al. 2008; Waranusantigul et al. 2011). Relatively, a little attention is paid to the potential use of Eucalypti in metal phytoextraction and phytostabilization, and to our knowledge, no studies on Cd-phytoextraction by $E$. camaldulensis in the presence of organic ligands are documented. The objectives of the study are to investigate (i) cadmium uptake by the roots and translocation to the canopy of mature E. camaldulensis saplings, and (ii) the effect of EDTA and EDDS on the plants and on Cd uptake and translocation. 


\subsection{MATERIALS AND METHODS}

Two controlled experiments were carried out in a temperature-adjusted greenhouse at the Volcani Center, Israel, with E. camaldulensis plants grown in hydroponic nutrient solution ( $\mathrm{SOL}$ ) system. The mean daily temperature during the experiments was $28^{\circ} \mathrm{C}$ (range: $22-38^{\circ} \mathrm{C}$ ). The organic ligands used were EDTA (disodium salt dehydrate; $\mathrm{C}_{10} \mathrm{H}_{14} \mathrm{~N}_{2} \mathrm{O}_{8} .2 \mathrm{Na} ; 372.24 \mathrm{~g} \mathrm{~mol}^{-1}$; SigmaAldrich) and S, S-EDDS (tri-sodium salt solution; $\mathrm{C}_{10} \mathrm{H}_{13} \mathrm{~N}_{2} \mathrm{O}_{8} \cdot 3 \mathrm{Na} ; 358.19 \mathrm{~g}$ $\mathrm{mol}^{-1} ; 30 \%$ in water; Sigma-Aldrich). All other chemicals used were of analytical grade.

\subsubsection{SOL-1 CADMIUM UPTAKE STUDY}

Eucalyptus camaldulensis was seeded in vermiculite in $10 \mathrm{~L}$ containers. Saplings at approximately $15 \mathrm{~cm}$ stem height were selected for the uptake experiment. They were transferred to $10 \mathrm{~L}$ buckets containing one-quarter strength modified Hoagland nutrient solution (Hoagland and Arnon 1950). The Hoagland solution provides every nutrient necessary for plant growth and is appropriate for the growth of a large variety of plant species. The nutrient solution was modified by adding the $\mathrm{Fe}^{2+}$ in the sulfate salt form (Tandy et al. $2006 \mathrm{~b}$ ), and by fortifying all solutions with $1 \mathrm{mg} \mathrm{\textrm {L } ^ { - 1 }}$ boron (as boric acid) and increasing the sulfate concentration to $3 \mathrm{mM}\left(\right.$ as $\left.\mathrm{K}_{2} \mathrm{SO}_{4}\right)$. Boron was added because the boron concentration in the Hoagland solution is much below concentrations that occur under field condition when using controlled deficit irrigation (CDI) with tap water. CDI should be used in phytoextraction in order to prevent solubilized metals from leaching below the root zone. Sulfate was fortified to supply the plant with enough sulphur for the synthesis of $\mathrm{SH}$ containing, metal binding peptides (Barazani et al. 2004).

The buckets were covered with a plastic lid to minimize evaporation, and the solution was stirred and aerated by bubbling oil-free air at approximately 10 $\mathrm{mL} \min ^{-1} \mathrm{~L}^{-1}$, using aquarium stones (Hewitt 1966). The saplings were held upright by placing them through a hole in the bucket lid and held in place by wrapping the part of stem passing through the hole with polystyrene. The plants were grown and acclimated for 2 months while replacing the growth solution once a week before the start of the $\mathrm{Cd}$ uptake experiment. Mineral nitrogen species and phosphate in the solution media were monitored colorimetrically with a Lachat autoanalyzer (Milwaukee, WI, USA).

At the onset of the experiment, $\mathrm{Cd}$ was added to the solution at $0.5 \mathrm{mg} \mathrm{L}^{-1}$ $\left(4.5 \mu \mathrm{M}\right.$ as nitrate salt; $\left.\mathrm{Cd}\left(\mathrm{NO}_{3}\right)_{2} \cdot 4 \mathrm{H}_{2} \mathrm{O}\right)$ in combination with either EDTA or EDDS at $0.1,1.0$, and $5.0 \mathrm{mM}$ concentrations. Control treatments were either without a ligand or without $\mathrm{Cd}$ and without both. The solutions were changed every 3-4 days, were analyzed for $\mathrm{Cd}$ and their $\mathrm{pH}$ determined. The $\mathrm{pH}$ was maintained at 6.5-7.5, and only the $5 \mathrm{mM}$ ligand treatments needed adjustment (which was done with $0.1 \mathrm{M} \mathrm{NaOH}$ ). Cd uptake was measured during a 30 days period. In the 3-4 day period between changing solutions, $\mathrm{Cd}$ concentrations in the absence of a ligand sharply declined, while in the presence of a ligand, the concentration of Cd decreased by no more than $25 \%$. Treatments were run in 4 replicates. Cadmium concentrations in solution media was checked using AA spectrometry (PerkinElmer AAnalyst 800). 


\subsubsection{SOL-2 CADMIUM UPTAKE STUDY}

The setup described above was repeated, except that 3 months old saplings which were purchased from a commercial nursery were used. The canopy and roots of each plant were drastically trimmed, and the remaining roots were thoroughly rinsed with running water before the plants were transferred to the buckets. The plants were acclimated for 3 months before the onset of the experiment, and by then a new root system and canopy developed (Figure 2.1). A Shefer 7-3-7 fertilizer solution concentrate (ICL Fertilizers, Haifa, Israel) was used at final $\mathrm{N}\left(40 \%\right.$ as $\left.\mathrm{NH}_{4}\right)-\mathrm{P}-\mathrm{K}$ concentrations of $170-32-140$ $\mathrm{mg} \mathrm{L}^{-1}$, respectively, and with Fe (with $4 \mu \mathrm{M}$ EDTA), Mn, Zn, Cu and Mo at 215, $127,64,9.3,7 \mu \mathrm{g} \mathrm{L}^{-1}$ final concentration, respectively. Boron and sulfate were supplemented as in the first experiment. The growing solution was prepared in tap water. A drip irrigation system, with the emitters attached to the bottom of the buckets, was used to compensate for transpiration losses and to refresh the solution by displacing approximately $10-20 \%$ of the solution volume each day. A proportional dosing pump (MixRite, Nahsholim, Israel) was used to inject the fertilizer into the irrigation line. The water replacement regime here was adapted to the much larger plant size than in the first study.
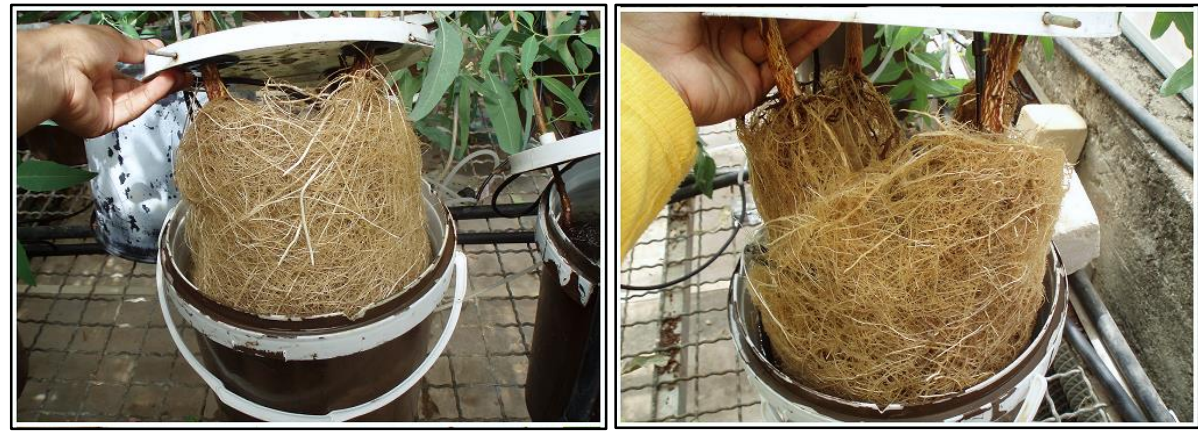

Figure 2.1: Developed new root system (white fibrous roots) and canopy of E. camaldulensis used in the solution culture experiments.

Following the acclimation period, the best saplings (by size and appearance) were selected for the uptake experiment. Each plant was weighed after tapping off the roots as much excess water as possible. The average initial fresh weight of the plants was $1.7 \mathrm{~kg} \mathrm{plant}^{-1}$. This was repeated at the end of the Cd uptake experiment and the ratio between the fresh weights was recorded. Pairs of plants were placed in the buckets; 3 buckets per control and 2 per treatment (Figure 2.2). The nutrient solution was the same as in the acclimation period.

The growth solutions were amended with EDTA or EDDS at $0.1,1$ and $5 \mathrm{mM}$ concentrations and with $\mathrm{Cd}$ (as nitrate salt) at $10 \mathrm{mg} \mathrm{L}^{-1}(89 \mu \mathrm{M})$. Herein, Cd concentration was raised from 0.5 to $10 \mathrm{mg} \mathrm{L}^{-1}$, as in the first study, it was noted that cadmium at $0.5 \mathrm{mg} \mathrm{L}^{-1}$ had no effect on the overall plant growth. Three types of control treatments were applied: media without an organic ligand, media without Cd, and media without either. Tap water was added daily to compensate for transpiration losses and the solutions were replaced every 3-4 days. The solutions were brought to the original volume before being 
replaced and they were sampled both before and after changing. The $\mathrm{pH}$ was adjusted as described above. The duration of the uptake test was 1 month.

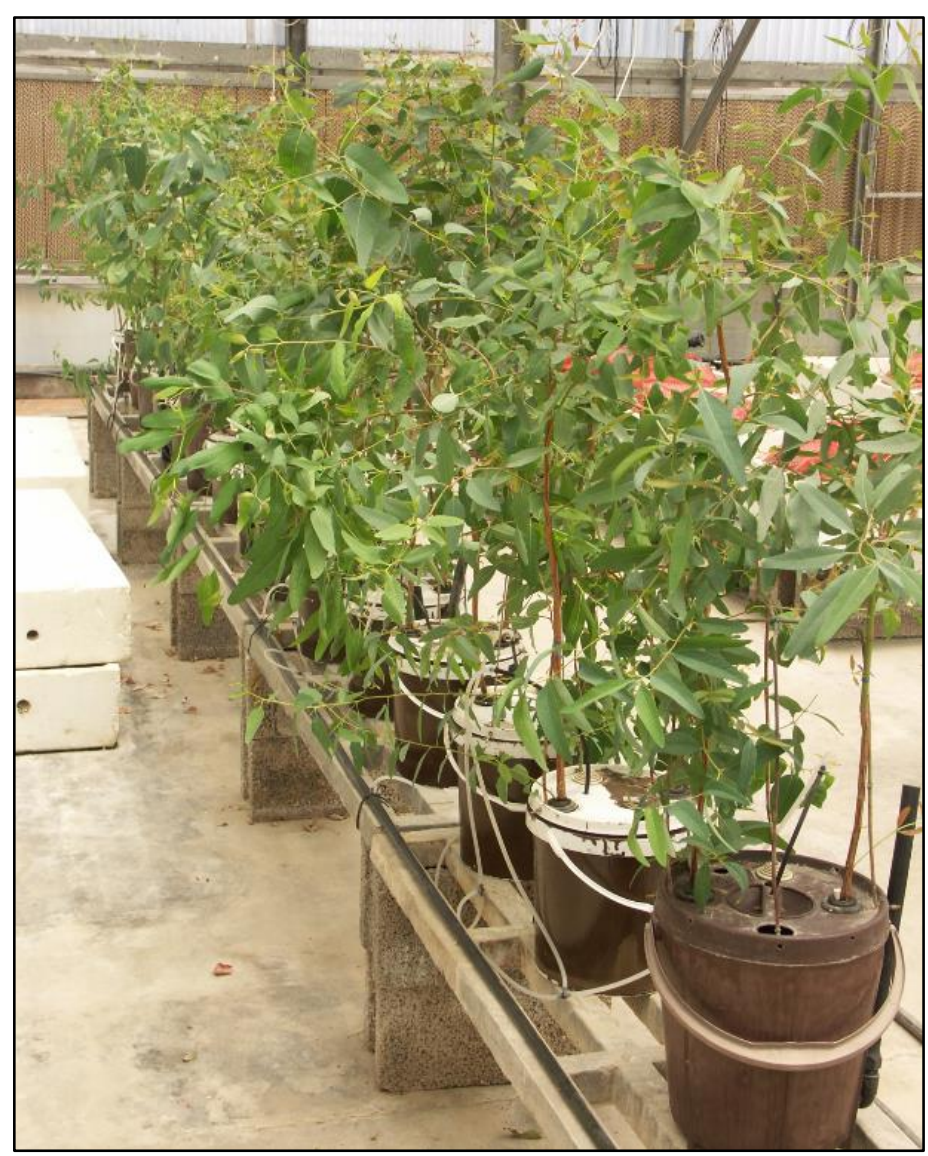

Figure 2.2: General view of assembly for hydroponic study using Eucalyptus camaldulensis (SOL-2 study)

\subsubsection{SAMPLE PREPARATION AND CHEMICAL ANALYSIS}

Whole plants were weighed at the beginning and end of the uptake experiments, and each plant was then dissected into roots (cutting at the root neck), stem (including twigs) and leaves. The roots were soaked in $0.01 \mathrm{M}$ $\mathrm{H}_{2} \mathrm{SO}_{4}$ for $30 \mathrm{sec}$ after excision and then washed in deionized water. Plant material was dried at $70{ }^{\circ} \mathrm{C}$ for 3 days, milled using steel blade grinder, and one half gram samples were digested in $4 \mathrm{~mL}$ boiling concentrated $\mathrm{HNO}_{3}$ on a hot block (Huang and Schulte 1985). Oxygen peroxide was not added to the digests, and the digestion continued at $90{ }^{\circ} \mathrm{C}$ until complete clearing of the digests (usually within 2 days). Occasionally, selected samples were spiked by adding a standard elemental solution. Following dilutions with double distilled water, the digests were analyzed for elemental composition using ICP-AES [ICP-AES "Arcos", SOP (Side-On-Plasma), Spectro Ltd, Kleve, Germany]. 


\subsubsection{CadmiUm binding to ROOT tISSUE}

\section{EXTENDED ACID WASHING}

A set of $9 \mathrm{E}$. camaldulensis pair saplings were grown in buckets (10-L capacity) and treated with $10 \mathrm{mg} \mathrm{L}^{-1} \mathrm{Cd}$ in the same way as was done in the SOL-2 experiment. At the end of a month-long uptake period, the plants were excised as above, and the root systems were each thoroughly washed with tap water followed with deionized water, and then soaked for 10 minutes in $0.01 \mathrm{M}$ $\mathrm{H}_{2} \mathrm{SO}_{4}$. The acid wash solution was analyzed for $\mathrm{Cd}$ by $\mathrm{AA}$ spectrometry (PerkinElmer AAnalyst 800). The roots were dried, acid-digested and analyzed for chemical composition by ICP-AES as described above (as described in the section 2.2.3).

\section{CADMIUM SORPTION ON GROUND ROOT TISSUE}

Cadmium adsorption to Eucalyptus camaldulensis root tissue was examined using roots of saplings from the no $\mathrm{Cd}$ and no ligand control treatment in the SOL-2 experiment. Dried roots were milled to pass a $1 \mathrm{~mm}$ sieve, and stored in a desiccator. An adsorption test was performed at $25^{\circ} \mathrm{C}$ as follows: $1.0 \mathrm{~g}$ root tissue samples were placed in $50 \mathrm{~mL}$ centrifuge tubes, $20 \mathrm{~mL}$ Cd solution (as nitrate salt) at $\mathrm{pH} 7.0$ was added at $0,0.5,1.0,5.0,10$, and $50 \mathrm{mg} \mathrm{L}^{-1}$ concentrations, with or without EDTA or EDDS, each at $0.1 \mathrm{mM}$ concentration. All solutions were prepared in double distilled water. The tubes were shaken for a week on a horizontal shaker, with each treatment run in triplicate. The tubes were then centrifuged at $6500 \mathrm{rpm}$ for 10 minute, and the supernatant was filtered through a syringe-mounted, $0.45 \mu \mathrm{m}$ nylon filter. The filtrates were acidified (with $\mathrm{HNO}_{3}$ ) and analyzed for Cd content, using the above mentioned Perkin Elmer AA spectrometer.

\subsubsection{TRANSLOCATION AND ACCUMULATION FACTORS AND STATISTICAL ANALYSIS}

An accumulation factor (AF) was calculated which describes Cd accumulation in a plant part (root or shoot) relative to the metal concentration in the solution medium (Singh et al. 2010). Hence, AF is the ratio of concentration of the metal in a plant organ to the concentration in the solution medium. Similarly, a translocation factor (TF) delineates the translocation of a metal from the roots into the shoot, where TF is the ratio of concentration of a metal in the shoot to the concentration in the roots. A completely randomized design was applied in the experiments. Statistical analyses were performed with JMP 7.0 software and MS Excel spreadsheet 2007 (SAS 2005).

\subsection{RESULTS AND DISCUSSION}

\subsubsection{EFFECT OF THE ADDITION OF ORGANIC LIGANDS AND CADMIUM ON THE GROWTH OF E. CAMALDULENSIS SAPLINGS}

The dry weight of the leaves, stems and roots of the $E$. camaldulensis saplings were not adversely affected during a month contact with $0.5 \mathrm{mM} \mathrm{Cd}$ in the solution culture (SOL-1 study; Figure 2.3). In this experiment, the weights of 
the plants exposed to $\mathrm{Cd}$ and organic ligand were compared to those of the control plants. At the end of the experiment the average (and standard deviation) of the dry weight of the control plants (no Cd or ligand present) was 9.9 ( \pm 1.8$)$ grams. The weight of the plant parts at each organic ligand concentration was not significantly different in the presence or absence of Cd, and the effect of the two ligands was virtually the same. Hence, all the results for all the ligand concentrations were pooled together thus improving the statistical significance of the results.
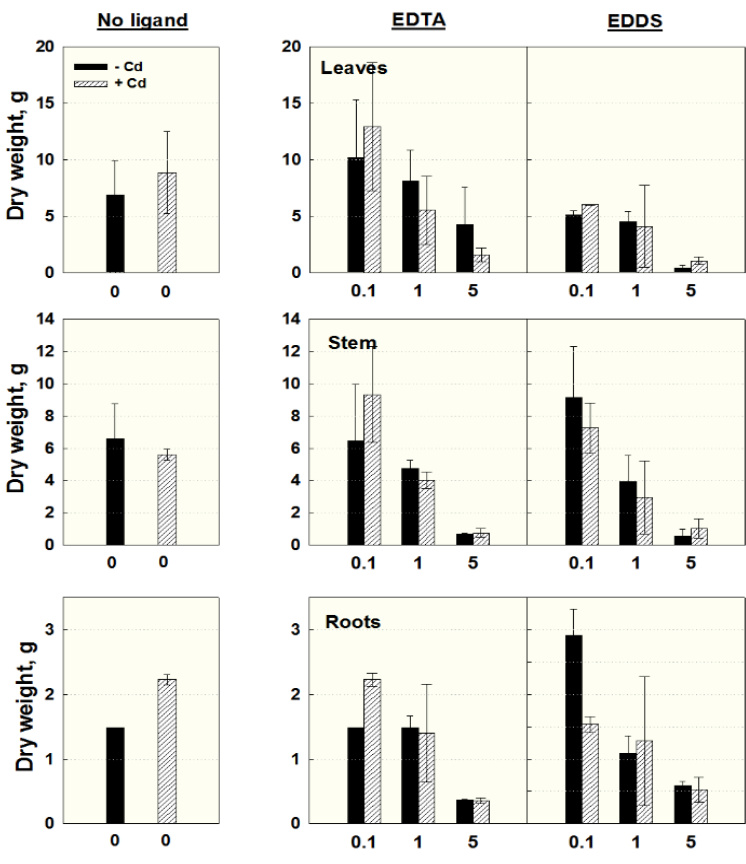

Ligand concentration $(\mathrm{mM})$

Figure 2.3: Dry weight of parts of $E$. camaldulensis grown in a nutrient solution with or without organic ligands (EDTA or S,S-EDDS), and with or without $0.5 \mathrm{mg} \mathrm{Cd} \mathrm{L}^{-1}$ (SOL-1 experiment).

The data presented in Figure 2.4 demonstrates that the $0.1 \mathrm{mM}$ ligand concentration enhanced growth, and that this effect was most pronounced and statistically significant in the leaves. The enhancement of growth by the 0.1 $\mathrm{mM}$ ligands was not related to alleviation of $\mathrm{Cd}$ stress, unlike the suggestion by Tandy et al. (2006b) for $\mathrm{Cu}, \mathrm{Zn}$, and $\mathrm{Pb}$ (at $125 \mu \mathrm{M}$ each) in the presence of EDDS (at $0.5 \mathrm{mM}$ ) in a sunflower uptake experiment. At the $1 \mathrm{mM}$ ligand concentration there was some growth retardation of all three plant parts (this retardation being weakly statistically significant; $p=0.09$ ), compared with the growth increase in the no-ligand treatment. Yet, hydroponically grown sunflower showed no reduction in shoot and root biomass in the presence of $0.5 \mathrm{mM}$ EDDS in solution (Tandy et al. 2006b). This could perhaps be due to the short exposure ( 6 days) of the plants to the ligand in that study. At $5 \mathrm{mM}$ concentration, a highly significant $(p<0.001)$ growth retardation of all three plant parts was observed (Figure 2.5). 

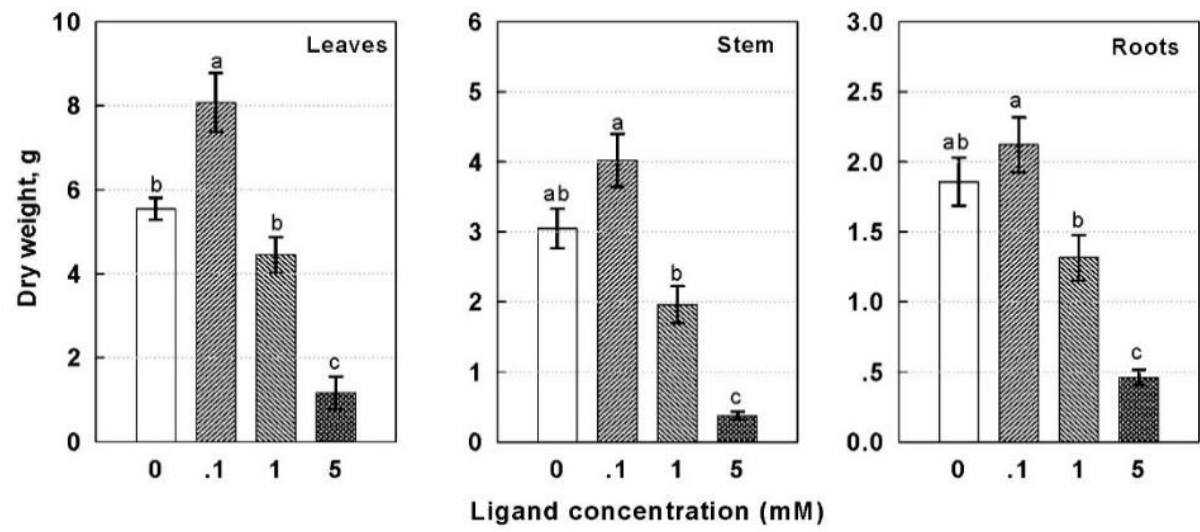

Figure 2.4: Dry weight of parts of $E$. camaldulensis saplings grown in buckets in a nutrient solution with or without EDTA or S,S-EDDS (SOL-1 experiment).

The data for the two ligands were pooled together, and the data for the saplings exposed to $C d$ and for those not exposed to it were pooled together

as well. The columns are the means \pm one standard error of the mean. Within each organ, levels not designated by the same letter are significantly different at $\alpha=0.05$ according to Tukey HSD.

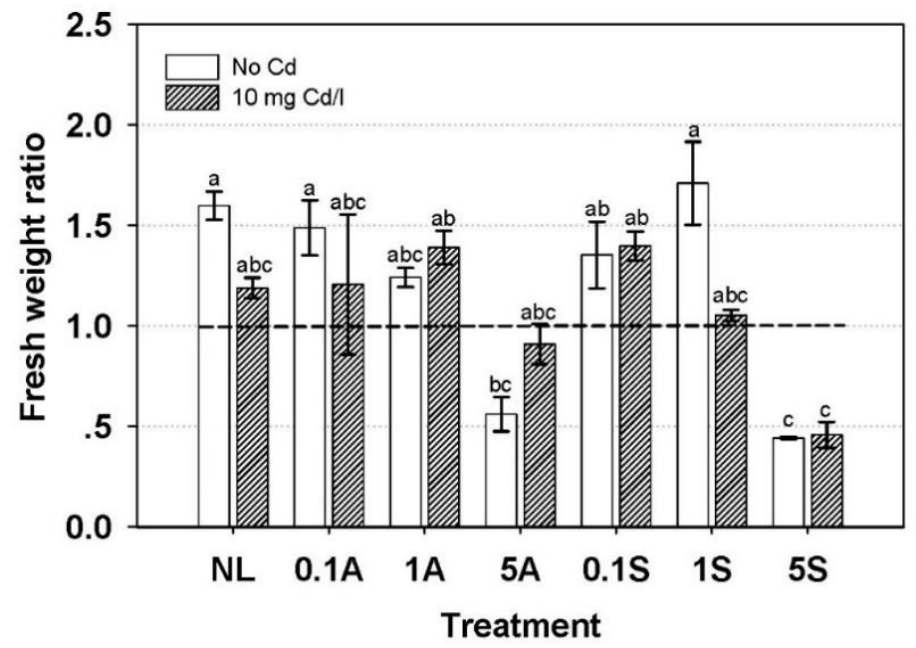

Figure 2.5: Relative fresh weight ratio (final plant weight divided by its initial weight) in whole $E$. camaldulensis saplings grown for one month in buckets in a nutrient solution (SOL-2 experiment) with EDTA (A) or S,S-EDDS (S) or

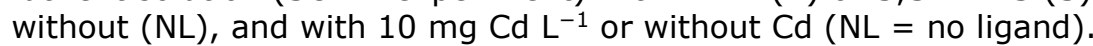
The format and statistical analysis are as in Figure 2.4.

The SOL-2 experiment differed from the first in two major aspects: the plants were larger, averaging $1.7 \mathrm{~kg}$ per plant (i.e., approximately 2 orders of magnitude larger), and the $\mathrm{Cd}$ concentration was $10 \mathrm{mg} \mathrm{L}^{-1}(89 \mu \mathrm{M})$ rather 
than $0.5 \mathrm{mg} \mathrm{L}^{-1}$. Another difference was that whole plants were weighed before the onset and at the culmination of the 1 month $\mathrm{Cd}$ uptake period. The concentrations of the organic ligands were the same in both experiments, and these were applied either with $\mathrm{Cd}$ or without. It can be seen from Figure 2.5 that at $10 \mathrm{mg} \mathrm{Cd} \mathrm{L} \mathrm{m}^{-1}$ in the absence of the ligand significantly $(p=0.009)$ reduced plant growth from a $60 \%$ fresh weight increase in the control (without Cd) to only $19 \%$ weight increase in the presence of Cd (Figure 2.5; NL treatments). In a hydroponic study, Liu et al. (2008a) showed that exposing Thlaspi ferganense (a non-hyperaccumulator species) for 3 weeks to even 0.1 mg Cd L ${ }^{-1}$ decreased plant growth, whereas the growth of Thlaspi caerulescens (a hyperaccumulator species) shows tolerance to the $5.5 \mathrm{mg} \mathrm{Cd} \mathrm{L}^{-1}$. Cadmium, $\mathrm{Cr}(\mathrm{VI})$, and $\mathrm{Cu}$ at $20 \mathrm{mg} \mathrm{L}^{-1}$ (each in agar-based medium; 15 days of uptake) inhibited growth, yet were tolerated by Convolvulus arvensis saplings; however $40 \mathrm{mg} \mathrm{Cd} \mathrm{L^{-1 }}$ was lethal while the saplings still survived at $80 \mathrm{mg} \mathrm{L}^{-1}$ for each of the two other ion species tested (Gardea-Torresdey et al. 2004).

At the two lower ligand concentrations $(0.1$ and $1 \mathrm{mM})$ there was no consistent effect of the ligands or Cd on growth, and the growth stimulating effect of the ligands at $0.1 \mathrm{mM}$ concentration observed in the SOL-1 experiment did not occurred in the SOL-2 experiment. This difference between the two experiments could perhaps be due to the relative maturity of the saplings used in the SOL-2 experiment and to the improvement of the nutritional status by the inclusion of micronutrients in the solution media. However again, the organic ligands at $5 \mathrm{mM}$ concentration were deleterious to plant growth (significant at $p=0.003$ ); the plants actually lost weight by root decay and shedding off of leaves. This held true with $\mathrm{Cd}$ present in the solution and without $\mathrm{Cd}$. Plant biomass reduction, with visible necrosis and chlorosis was observed at higher rates of EDTA or EDDS application in various studies (Evangelou et al. 2007a; Kos et al. 2003; Luo et al. 2006; Meers et al. 2005).

Both $\mathrm{Cd}$ and each of the organic ligands had the potential to reduce plant growth. Yet, the effect of their combined presence at the two lower ligand concentrations ( $\leq 1 \mathrm{mM}$ ) was not additive (Figure 2.5 ). At any rate, the organic ligands did not alleviate the deleterious effect of $\mathrm{Cd}$ on growth as reported elsewhere (Tandy et al. 2006b). The more intense growth (compared with the initial weight) at $1 \mathrm{mM}$ EDTA + Cd (average $\pm \mathrm{SEm}=39 \% \pm 10$, where SEm is the standard error of mean], than at $1 \mathrm{mM}$ EDDS $+\mathrm{Cd}(5 \% \pm 3 ; p=0.086]$, might suggest that the stronger binding of Cd by EDTA [Cd-EDTA, stability constant $\log \mathrm{K}_{\mathrm{s}}=16.36$; Martell et al. (2001)] reduced free Cd concentration more than EDDS [Cd-EDDS, log $\mathrm{K}_{\mathrm{s}}=11.42-12.70$; Martell et al. (2001)].

\subsubsection{CADMIUM UPTAKE AND TRANSLOCATION IN E. CAMALDULENSIS SAPLINGS}

Below are discussed Cd uptake and distribution in the roots, stem and leaves of $E$. camaldulensis saplings grown in solution cultures with either $0.5 \mathrm{mg} \mathrm{Cd}$ $\mathrm{L}^{-1}$ or $10 \mathrm{mg} \mathrm{Cd} \mathrm{L}^{-1}$ (Figure 2.6a, b and Table 2.1). With Cd addition in the absence of organic ligands in the solution, the roots were the main sink for $\mathrm{Cd}$, with concentrations of 360 and $5,340 \mathrm{mg} \mathrm{kg}^{-1}$, respectively. 


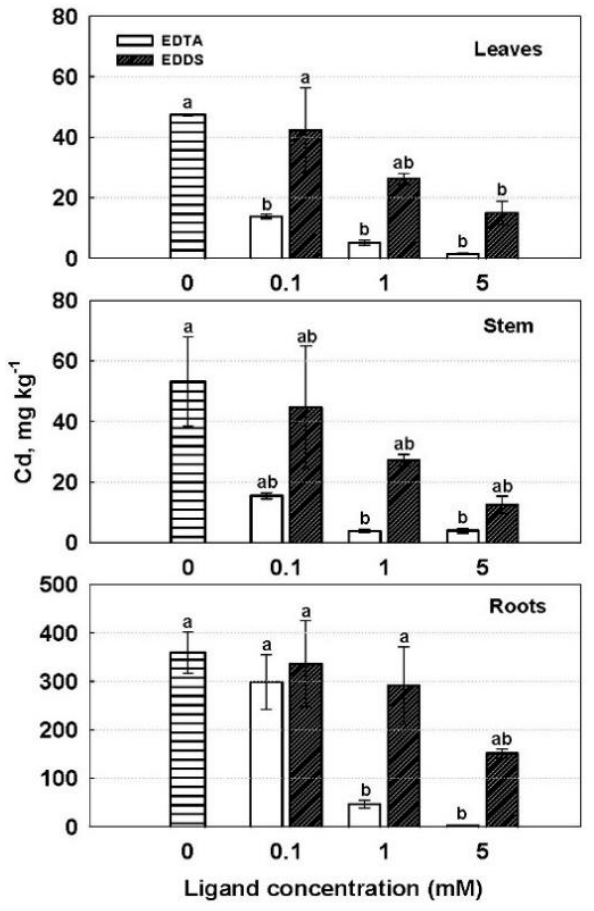

(a)
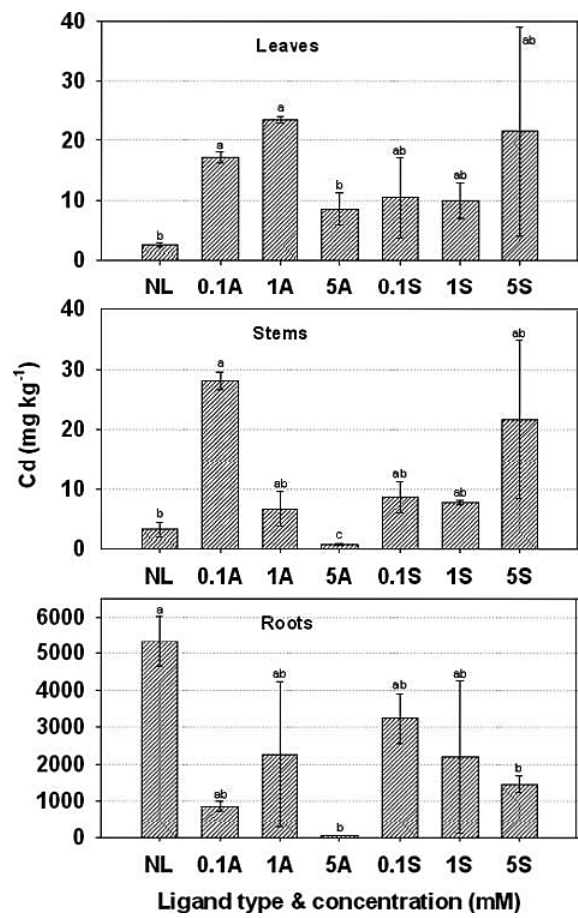

(b)

Figure 2.6: (a) Cadmium concentration in parts of $E$. camaldulensis saplings grown in buckets in a nutrient solution with $0.5 \mathrm{mg} \mathrm{Cd} \mathrm{L}^{-1}$ (SOL-1

experiment) as affected by the presence of an organic ligand (EDTA or S,SEDDS) at various concentrations (b) Cadmium concentration in parts of $E$. camaldulensis saplings grown in buckets in a nutrient solution with $10 \mathrm{mg} C d$ $\mathrm{L}^{-1}$ (SOL-2 experiment) as affected by the presence of an EDTA (A) or S,S$\operatorname{EDDS}(\mathrm{S})$ at various concentrations $(\mathrm{NL}=$ no ligand).

The format and statistical analysis are as in Figure 2.4.

These concentrations represent accumulation factors $>700$ and $>500$ over the concentrations in the solution. Such high accumulation was enabled both by the tendency of plants to sequester $\mathrm{Cd}$ (and other transition metals) in their roots (Reichman et al. 2006), and by the frequent refreshment of the nutrient solutions. Cadmium immobilization in roots is brought about by mechanisms such as chelation by thiol-containing peptides (such as phytochelatins and metallothionins; PCs and MTs), compartmentalization in the cell vacuoles, and adsorption to the cell walls (Cobbett and Goldsbrough 2002; Mendoza-Cózatl et al. 2008; Nocito et al. 2011). While it is commonly accepted that adsorption to the root cell walls accounts for almost all Cd binding in roots (Meighan et al. 2011), in the current study, this contribution of adsorption was diminished, but perhaps not completely eliminated, by acid washing of the roots prior to their drying. Note that the treatment solutions of the SOL-2 experiment containing $10 \mathrm{mg} \mathrm{Cd} \mathrm{L}^{-1}$ contained also $4 \mu \mathrm{M}$ EDTA and the micronutrients of the Hoagland solution. Neither the micronutrients nor the EDTA at this low concentration seemed to inhibit the high uptake and immobilization of $\mathrm{Cd}$ in the roots. 
Table 2.1: Content of selected elements (in $\mathrm{mg} \mathrm{kg}^{-1}$ )* of E. camaldulensis saplings grown in hydroponics with $10 \mathrm{mg}$ Cd $\mathrm{L}^{-1}$ and without $\mathrm{Cd}$. The values are averages $( \pm$ SEM) of 3 replicates (without $C d$ ) or 2 replicates (with Cd).

\begin{tabular}{|c|c|c|c|c|c|c|}
\hline \multirow{2}{*}{ Elements } & \multicolumn{2}{|c|}{ Roots } & \multicolumn{2}{|c|}{ Stems } & \multicolumn{2}{|c|}{ Leaves } \\
\hline & No Cd & Cd & No Cd & Cd & No Cd & Cd \\
\hline$B$ & $111( \pm 28)$ & $146( \pm 21)$ & $15( \pm 2)^{b}$ & $22( \pm 1)^{a}$ & $79( \pm 9)^{b}$ & $111( \pm 6)^{b}$ \\
\hline $\mathrm{Ca}$ & $19150( \pm 3760)$ & $32700( \pm 5500)$ & $11780( \pm 2280)$ & $5580( \pm 200)$ & $12200( \pm 850)$ & $9050( \pm 1080)$ \\
\hline $\mathrm{K}$ & $11520( \pm 1070)$ & $8720( \pm 550)$ & $14870( \pm 1270)$ & $13030( \pm 520)$ & $21070( \pm 2600)^{a}$ & $12760( \pm 1220)^{b}$ \\
\hline $\mathrm{Mg}$ & $3280( \pm 170)$ & $3340( \pm 550)$ & $1220( \pm 150)$ & $840( \pm 110)$ & $2960( \pm 130)$ & $2690( \pm 210)$ \\
\hline $\mathrm{Mn}$ & $330( \pm 140)$ & $360( \pm 50)$ & $70( \pm 8)^{a}$ & $30( \pm 1)^{b}$ & $270( \pm 10)^{a}$ & $120( \pm 10)^{b}$ \\
\hline $\mathrm{Na}$ & $24730( \pm 12850)$ & $25680( \pm 5960)$ & $3410( \pm 1210)$ & $2570( \pm 700)$ & $2370( \pm 1062)$ & $6260( \pm 1056)$ \\
\hline$P$ & $8960( \pm 2090)$ & $13510( \pm 1840)$ & $3920( \pm 880)$ & $2520( \pm 340)$ & $4370( \pm 930)$ & $1930( \pm 370)$ \\
\hline $\mathrm{S}$ & $3100( \pm 210)$ & $6310( \pm 1460)$ & $790( \pm 50)$ & $790( \pm 70)$ & $2530( \pm 180)$ & $2320( \pm 170)$ \\
\hline $\mathrm{Cd}$ & $6.0( \pm 0.7)^{b}$ & $5340( \pm 680)^{a}$ & $0.24( \pm 0.09)$ & $3.22( \pm 1.20)$ & $0.18( \pm 0.03)^{b}$ & $2.55( \pm 0.35)^{a}$ \\
\hline Co & $0.17( \pm \pm 0.03)^{b}$ & $0.58( \pm 0.08)^{a}$ & $0.03( \pm 0.02)$ & $0.02( \pm 0.03)$ & $0.08( \pm 0.04)$ & $0.06( \pm 0.02)$ \\
\hline $\mathrm{Cr}$ & $6.0( \pm 0.1)$ & $6.3( \pm 0.6)$ & $0.7( \pm 0.1)$ & $0.8( \pm 0.4)$ & $1.0( \pm 0.3)$ & $0.8( \pm 0.1)$ \\
\hline $\mathrm{Cu}$ & $30( \pm 2)^{b}$ & $76( \pm 10)^{a}$ & $8.7( \pm 0.7)^{a}$ & $2.9( \pm 0.45)^{b}$ & $6.4( \pm 0.4)^{a}$ & $3.6( \pm 0.7)^{b}$ \\
\hline $\mathrm{Fe}$ & $1863( \pm 184)$ & $1804( \pm 161)$ & $38( \pm 8)$ & $30( \pm 12)$ & $106( \pm 15)$ & $100( \pm 17)$ \\
\hline Mo & $11( \pm 2)^{b}$ & $19( \pm 2)^{a}$ & $0.53( \pm 0.13)^{a}$ & $0.15( \pm 0.04)^{b}$ & $2.66( \pm 0.31)^{a}$ & $0.84( \pm 0.13)^{b}$ \\
\hline $\mathrm{Ni}$ & $0.79( \pm 0.08)$ & $0.94( \pm 0.12)$ & $0.19( \pm 0.05)$ & $0.39( \pm 0.23)$ & $0.40( \pm 0.05)$ & $0.34( \pm 0.03)$ \\
\hline $\mathrm{Zn}$ & $118( \pm 25)^{b}$ & $368( \pm 27)^{a}$ & $48( \pm 7)^{a}$ & $21( \pm 2)^{b}$ & $62( \pm 10)$ & $43( \pm 6)$ \\
\hline
\end{tabular}

*Values within each organ designated by different letters are statistically significantly different. 
Cadmium concentrations in the stems and leaves of the saplings grown in the

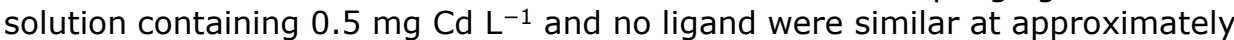
$50 \mathrm{mg} \mathrm{kg}-1$, nearly an order of magnitude less than the concentrations in the roots $(T F \approx 0.14$; Figure $2.6 a$ ). The corresponding concentration in the plants grown in the $10 \mathrm{mg} \mathrm{Cd} \mathrm{L}^{-1}$ solution were only around $3 \mathrm{mg} \mathrm{kg}^{-1},>3$ orders of magnitude less than in the roots $\left(T F \approx 5 * 10^{-4}\right.$; Figure $\left.2.6 \mathrm{~b}\right)$. One possible explanation for the lower Cd concentrations in the shoots at the higher $\mathrm{Cd}$ concentration in solution, despite the one order of magnitude higher $\mathrm{Cd}$ concentration in the roots in the SOL-2 experiment, may be the inclusion of the essential trace elements in the nutrient solution and their interference with Cd translocation (Chaney et al. 2000). At any rate, despite the injury caused to the plants (as is evident from the growth reduction; Figure 2.5, NL treatments) apoplastic Cd translocation did not occur when chelants were not present in the growth medium.

\subsubsection{UPTAKE OF CADMIUM AND OTHER TRACE ELEMENTS AS AFFECTED BY THE CONCENTRATION OF CADMIUM AND ORGANIC LIGANDS IN THE GROWTH MEDIUM}

At $0.5 \mathrm{mg} \mathrm{L}^{-1} \mathrm{Cd}$ concentration in the solution medium, EDTA at 1 and $5 \mathrm{mM}$ concentrations (but not at $0.1 \mathrm{mM})$, substantially $(p=0.001)$ reduced the concentration of $\mathrm{Cd}$ in the roots (Figure 2.6a). The S,S-EDDS was less effective, and even at $5 \mathrm{mM}, \mathrm{Cd}$ concentration in the roots was only moderately different than in the no-ligand control (Figure 2.6a). In comparison to EDTA, the rootCd concentrations were respectively $1.13,6.30$ and 85.17 times higher with EDDS at $0.1,1$ and $5 \mathrm{mM}$ concentration. The root-Cd AF was $\approx 300$ at $5 \mathrm{mM}$ EDDS (compared with $\mathrm{AF}=4$ at $5 \mathrm{mM}$ EDTA). At $10 \mathrm{mg} \mathrm{Cd} \mathrm{L}^{-1}$ in solution, the general trends in $\mathrm{Cd}$ concentration in the roots were much the same (Figure 2.6b). Both EDTA and EDDS substantially reduced $\mathrm{Cd}$ concentration in the roots, however EDTA was more effective, significantly reducing Cd concentration even at the lower ligand concentration (the respective $p$ values at $0.1,1$ and $5 \mathrm{mM}$ were $0.002,>0.05$, and $<0.001$ ). The effect of the EDDS in reducing $\mathrm{Cd}$ root concentration was statistically significant only at the $5 \mathrm{mM}$ concentration $(p<0.002$; Figure 2.6b).

The effect of the organic ligands on $\mathrm{Cd}$ concentration in the shoots was consistent with their effect on the roots, albeit that the concentrations were 12 orders of magnitude lower. At $0.5 \mathrm{mg} \mathrm{Cd} \mathrm{L}^{-1}, 0.1$, and $1 \mathrm{mM}$ EDDS reduced $\mathrm{Cd}$ concentrations in the stem and leaves relatively slightly, however at $5 \mathrm{mM}$ the reduction of $\mathrm{Cd}$ content in the leaves became significant (Figure 2.6a). A significant reduction did occur in the presence of EDTA at all tested concentrations (Figure 2.6a). At $10 \mathrm{mg} \mathrm{L}^{-1} \mathrm{Cd}$, both EDTA and EDDS increased $\mathrm{Cd}$ translocation into the shoots. The effect of EDTA on the concentration of Cd in the stem and leaves displayed a bell-shaped form; at $0.1 \mathrm{mM}$ it significantly $(p<0.001)$ increased the Cd concentration in the stem from 3 to $28 \mathrm{mg} \mathrm{kg}^{-1}$, and $\mathrm{Cd}$ concentration in the leaves from 3 to $17 \mathrm{mg} \mathrm{kg}^{-1}$. At $1 \mathrm{mM}$ EDTA the Cd concentration in the leaves rose to $23 \mathrm{mg} \mathrm{kg}^{-1}(p<0.001)$ (Figure 2.6b). EDDS addition to the $10 \mathrm{mg} \mathrm{L}^{-1} \mathrm{Cd}$ solution increased $\mathrm{Cd}$ concentrations in the shoot to a lesser extent (Figure 2.6b). The higher efficacy of EDTA in enhancing $\mathrm{Cd}$ translocation seem to arise from the $>5.5$ orders of magnitude higher Ks of its complex with $\mathrm{Cd}$, and the fact that translocation of the metal takes place 
predominantly in the complexed form (Nowack et al. 2006). As mentioned above, at the $5 \mathrm{mM}$ ligand concentration the plants were severely injured. Thus, it seems that at $10 \mathrm{mg} \mathrm{L}^{-1} \mathrm{Cd}$ concentration, the addition of a ligand increased $\mathrm{Cd}$ translocation into the shoots and, at the higher concentrations, retarded the growth of the plants.

An increased abundance of thiol-containing peptides in the root cells associated with Cd uptake (Stolt et al. 2003) might explain the enhanced accumulation of essential microelements in the Eucalyptus roots (Table 2.1). Exposure of chives (Allium schoenoprasum) to a Hoagland medium containing $50 \mu \mathrm{M}$ or $250 \mu \mathrm{M}$ Cd for 28 days, simultaneously increased the content in the leaves of the metal (to up to $0.2 \%$ and $0.5 \%$ of the dry weight) and of what the authors defined as SH-containing compounds (Barazani et al. 2004). Accordingly, the exposure

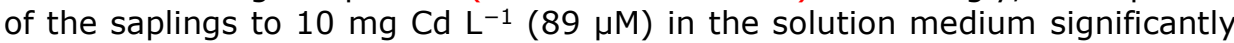
increased the concentration in the roots of $\mathrm{Zn}, \mathrm{Cu}, \mathrm{Mo}$, and $\mathrm{Co}$ in addition to that of $\mathrm{Cd}$ (Table 2.1). The rather complex effect of $\mathrm{Cd}$ addition on the metabolism of the plant is indicated, for example, by the fact that exposure of Brassica napus to Cd almost eliminated iron in the xylem and phloem sap, yet the concentrations of other essential trace elements did not change (MendozaCózatl et al. 2008).

The concentrations of $\mathrm{Zn}, \mathrm{Cu}, \mathrm{Mo}$ as well as of $\mathrm{Ba}, \mathrm{K}, \mathrm{Mn}$, and $\mathrm{Sr}$ were significantly lower in the stems and/or leaves of the $\mathrm{Cd}$ treated plants (Table 2.1), although the enhanced accumulation in the roots of the latter four elements was not statistically significant. Other elements displayed lower concentrations in the shoots of the Cd-treated plants but this was not statistically significant (Table 2.1). Boron was the only element tested that had a significantly higher concentrations in the stem and leaves of the Cd-treated saplings. Because $\mathrm{B}$ uptake at neutral $\mathrm{pH}$ is passive and transpiration dependent, these higher concentrations could simply result from the decreased growth rate under the $\mathrm{Cd}$ treatment and the resulting higher proportion of older leaves (Figure 2.5).

\subsubsection{CADMIUM BINDING TO ROOT TISSUE}

A laboratory adsorption study was conducted to estimate the extent of Cd binding to the root cell walls and of the ligands' interference with the binding. At Cd concentrations of 4.5-445 $\mu \mathrm{M}\left(0.5-50 \mathrm{mg} \mathrm{L}^{-1}\right)$ and in the absence of ligands, virtually all of the Cd adsorbed onto the dry root material (Figure 2.7). It was not possible to test $\mathrm{Cd}$ adsorption at higher $\mathrm{Cd}$ concentrations because it would have precipitated under the conditions of the test. Addition of $0.1 \mathrm{mM}$ EDTA to the reaction mixture reduced Cd adsorption by $40-60 \%$ at $\mathrm{Cd}$ concentrations not much larger than $0.1 \mathrm{mM}$. However, $0.1 \mathrm{mM}$ EDDS had practically no effect on Cd adsorption (Figure 2.7). The difference between the two organic ligands derives, most likely, from the difference in the stability constant of their complexes with Cd. At $445 \mu \mathrm{M}$ Cd, the EDTA in solution (100 $\mu \mathrm{M})$ bound at most root material, and hence the observed increase in the fraction of the Cd adsorbed (Figure 2.7). 
The above results are in accordance with our observations (Figure 2.6a, b) that EDTA, and to a lesser extent EDDS, reduced the Cd content of the Eucalyptus roots. Yet, these results cannot explain most of the measured reduction in $\mathrm{Cd}$ content in the roots upon ligand addition. This is so, because even after a 10 minute root washing in a $0.01 \mathrm{M} \mathrm{H}_{2} \mathrm{SO}_{4}$ solution, $75 \%( \pm 4)$ of the $3,500( \pm 34)$ $\mathrm{mg} \mathrm{Cd} \mathrm{kg} \mathrm{kg}^{-1}$ (averages and SEM of 9 plant pairs) was retained by the roots. This indicates that most of the metal was taken up into the roots rather than being adsorbed at its surface. Similar results were also reported for sunflower by Meighan et al. (2011). Hence, the reduction in uptake by the root cells brought about by the addition of a ligand was the major reason for the reduction of $\mathrm{Cd}$ content in the roots. At higher ligand concentrations, the fraction of $\mathrm{Cd}$ bound to the ligand will increase, leaving less free $\mathrm{Cd}$ for the uptake by the roots. In our experimental setup (maximum $\mathrm{Cd}$ concentration of $89 \mu \mathrm{M}$ ) an EDTA concentration higher than $0.1 \mathrm{mM}$ was sufficient to drastically reduce $\mathrm{Cd}$ content in the roots. This is because almost all the $\mathrm{Cd}$ in solution was already complexed and thus much less available for uptake. This might not have been the case with EDDS, and concentrations an order of magnitude higher was necessary to significantly reduce root $\mathrm{Cd}$ content in the roots (Figure 2.6a, b).
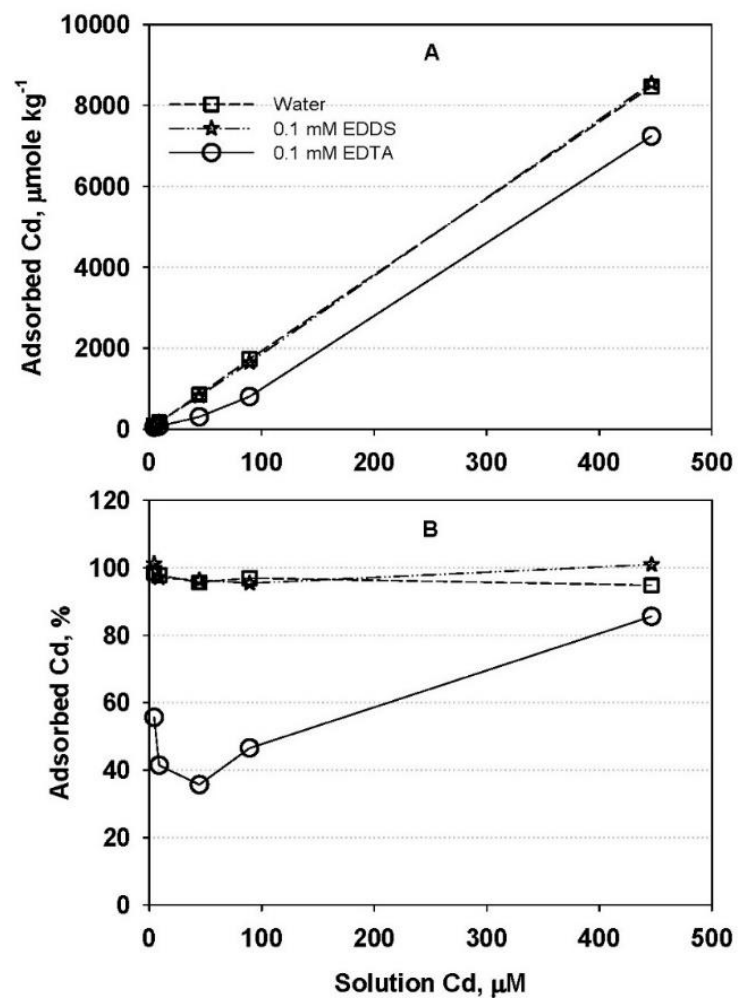

Figure 2.7: Cd adsorption to $E$. camaldulensis ground dry root tissue as affected by a $0.1 \mathrm{mM}$ concentration of either EDTA or S,S-EDDS. (A) Amount of $\mathrm{Cd}$ adsorbed vs. Cd concentration in solution (B) percent of amount of Cd added that adsorbed onto the root tissue. 


\subsection{CONCLUSION}

Eucalyptus camaldulensis was examined for its suitability for phytoremediation of Cd-polluted soils by growing saplings in solution media. These saplings were tested for (i) the effect of Cd and of EDTA and S,S-EDDS on their vitality, (ii) uptake of $\mathrm{Cd}$ and translocation into the shoot, and (iii) the effect of the chelants on the uptake and translocation of $\mathrm{Cd}$. It was shown that (i) exposure to $\mathrm{Cd}$ at $0.5 \mathrm{mg} \mathrm{L}^{-1}$ for 1 month had no effect on the growth of the saplings, and exposure to $10 \mathrm{mg} \mathrm{L}^{-1}$ reduced the weight increase of the saplings from approximately $60 \%$ in the Cd-free solution to $19 \%$ (ii) EDTA and EDDS seem not to negatively affect plant growth at $0.1 \mathrm{mM}$ concentration, perhaps even to the contrary. However, at $1 \mathrm{mM}$ concentration, some growth reduction did occur, and at $5 \mathrm{mM}$ the chelants were lethal (iii) Almost all of the Cd taken up by the plants remained in the roots, amounting to 360 and 5,300 mg Cd kg-1 at 0.5 and $10 \mathrm{mg} \mathrm{Cd} \mathrm{L}^{-1}$, with shoot concentration of approximately 50 and 3 $\mathrm{mg} \mathrm{kg}^{-1}$, all respectively. The respective root/shoot TFs were $\approx 0.15$ and $<10^{-3}$. The higher loading of $\mathrm{Cd}$ in the shoot at the lower concentration of $\mathrm{Cd}$ in solution probably resulted from a lower content of the metal-binding peptides, phytochelatins and metallothionins (PCs and MTs), in the root cells. This also explains why at $10 \mathrm{mg} \mathrm{Cd} \mathrm{L}^{-1}$ significantly more $\mathrm{Co}, \mathrm{Cu}, \mathrm{Mo}$, and $\mathrm{Zn}$ was intercepted in the plant roots than in the absence of $\mathrm{Cd}$, and concurrently the concentration in the shoot of these and other elements $(\mathrm{Mn}, \mathrm{Ba})$ were significantly lower in the Cd-treated plants. (iv) The addition of the chelants to the growth solution drastically reduced the $\mathrm{Cd}$ load in the roots by competing over the metal ions with the root binding sites, and impeding the membrane crossing of Cd. EDTA was more effective than EDDS in this respect due to the $>5.5$ orders of magnitude higher stability constant of its complex with Cd. Cadmium translocation into the shoot at $10 \mathrm{mg} \mathrm{Cd} \mathrm{L}^{-1}$ was enhanced by EDTA (concentrations in shoot parts increased 9 folds as compared to those in the absence of the ligand) and to a lesser extent by EDDS. The results of the present study suggest that $E$. camaldulensis might be suitable for phytostabilization of sites polluted by metals. But, it is less suitable for phytoextraction of metals from heavily contaminated soils or sediments. In addition, the results demonstrate that E. camaldulensis may be successfully used for phytoextraction of metals from soils that are contaminated at environmental concentrations, with the assistance of properly applied chelating agents. EDTA was shown to be much more efficient in enhancing $\mathrm{Cd}$ translocation than S,S-EDDS. 


\title{
CHAPTER 3 : CheLATE-ENHANCED METAL UPTAKE BY EUCALYPTUS TREES UNDER CONTROLLED DEFICIT IRRIGATION - A LYSIMETER STUDY ${ }^{1}$
}

\begin{abstract}
We tested the hypothesis that controlled deficit irrigation (CDI) of the fast growing, salinity resistant Eucalyptus camaldulensis tree with timely EDTA application can enhance sediment clean-up while minimizing leaching of metal complexes. Lysimeters (of 220 Liters capacity) containing a sand plus metalpolluted sludge mixture. Established saplings were irrigated with tap or desalinized (RO) water with/without 4-times daily addition of EDTA, EDDS and citric acid. In the second season (2008/09) the chelates were added at $2 \mathrm{mM}$ for $\approx 70$ summer days. Diagnostic leaves and soil solution compositions were regularly monitored, the latter by applying prescribed leaching at an overall leaching percentage of $\approx 0.4 \%$. While the three chelants solubilized sludge metals in batch extraction, EDDS often being the more efficient chelant, EDTA only was effective in the soil system. Leachate and leaves peak average concentrations in EDTA treatment vs. the control treatments were: Cd: 200 $\mathrm{mg} \mathrm{L}^{-1}$ vs. 1.0 and 67 vs. $21 \mathrm{mg} \mathrm{kg}^{-1}$; Cu: 90 vs. $1.5 \mathrm{mg} \mathrm{L}^{-1}$ and 17 vs. 3.0 mg kg-1; Ni: $60 \mathrm{mg} \mathrm{L}^{-1}$ vs. 14 and 20 vs. $6.0 \mathrm{mg} \mathrm{kg}^{-1} ; \mathrm{Pb}:>44$ vs. $0.1 \mathrm{mg} \mathrm{L}^{-1}$ and 9.0 vs. $1.0 \mathrm{mg} \mathrm{kg}^{-1}$; and $\mathrm{Zn}$ : 650 vs. $4.0 \mathrm{mg} \mathrm{L}^{-1}$ and 200 vs. $70 \mathrm{mg} \mathrm{kg}^{-1}$, all respectively. Peak average leachate EDTA concentration was $>60 \mathrm{mM}$, yet acclimating soil microflora gradually degraded most all the EDTA. In incubation study, EDDS and EDTA half-lives in acclimated lysimeter media were 5-11 days and $\geq 27$ days, respectively. It suggests that sustainable phytoextraction of heavy metals is feasible under careful CDI with EDTA (yet not with biodegradable chelants) augmentation at low doses. Despite that the eucalypt was highly salinity (and EDTA) resistant, CDI using RO water further reduces soil solution salinity, thus increasing the usefulness of this remediation technique.
\end{abstract}

\footnotetext{
${ }^{1}$ This chapter is based on following paper:

Pinchas Fine, Paresh H. Rathod*, Anna Beriozkin and Amir Hass (2014). Chelantenhanced heavy metal uptake by Eucalyptus trees under controlled deficit irrigation. Science of the Total Environment, 493: 995-1005.

DOI: $10.1016 /$ j.scitotenv.2014.06.085 (*shared first authorship).
} 


\subsection{INTRODUCTION}

In-situ phytoremediation of polluted soils and sediments is considered an economical and ecologically sustainable cleaning option for low to medium metal-contaminated sites (Cooper et al. 1999; Salt et al. 1998). Successful phytoextraction of heavy metals necessitates metal solubilization, uptake by plant roots and translocation and accumulation in aboveground biomass for subsequent off site removal, a process often assisted by organic chelants (Mench et al. 2010b). EDTA is by far the most commonly used chelating agent in phytoremediation (Blaylock et al. 1997; Huang et al. 1997; Saifullah et al. 2009). Plant uptake and translocation of the solubilized metals are believed to occur mostly by transport of the EDTA-metal complex in the apoplastic pathway (Nowack et al. 2006; Tandy et al. 2006b).

Despite EDTA's ability to enhance metal solubility and uptake by plant, it is gradually being phased out in favour of more transient, readily biodegradable phytoextraction agents (TPAs; triphenylamines) that may effectively enhance accumulation in the plant without resulting in the introduction of a persistent chelant and chelant-metal complexes to the environment (Nowack et al. 2006; Parra et al. 2008). Efficacy of several naturally occurring TPAs, including organic acids (acetic, ascorbic, citric, malic, oxalic, and succinic acids), and degradable amino polycarboxylic acids (including EDDS and NTA) was evaluated over the years as a replacement for EDTA (Han et al. 2005; Parra et al. 2008). While some studies, especially with respect to replacing EDTA with EDDS, are often reported in phytoextraction literature (Alkorta et al. 2004; Grčman et al. 2003; Shen et al. 2002); (Meers et al. 2005; Mench et al. 2010b), other reports still emphasize EDTA superiority over TPAs (Karczewska et al. 2011; Wu et al. 2004).

Some approaches to limit metal and EDTA leaching from the treated root zone include split applications (Barócsi et al. 2003; Shen et al. 2002; Wenzel et al. 2003) or chelant encapsulation in slow-release formulas ( Li et al. 2005; Xie et al. 2012). Another approach is to arrest water and solutes migration in the soil profile by irrigating at rates below the potential evapotranspiration, namely by applying controlled deficit irrigation (CDI) (Bolan et al. 2011; Chen et al. 2004; Fine et al. 2006; Meers et al. 2005). The use of plants of high evapotranspiration demand that perform well under elevated salinity offers possibly efficient avenue to sustain CDI for the purpose of delaying transport and limiting leaching of solutes from the root zone. Eucalyptus camaldulensis is a deep-rooting, fast growing, high biomass producing forest tree, and some varieties are more salinity and drought resistant (Marcar et al. 2002).

E. camaldulensis was found to maintain high transpiration rates and to remove substantial amounts of nutrients and trace elements from soils treated with effluent and biosolids under high salinity levels (Fine et al. 2006; Fine and Hass 2007; Fine et al. 2002; Mani et al. 2012; Myers et al. 1999; Singh and Bhati 2003). Fine et al. (2006, 2007) tested a CDI regime for E. camaldulensis in gravimetric lysimeters as a means to minimize leaching of nutrients, dissolved organic matter, heavy metals and enteric bacteria from wastewater effluent. Two year old trees transpired nearly $60 \mathrm{~L} \mathrm{day}^{-1}$ tree $^{-1}$ under CDI in midsummer at soil solution salinities nearing $50 \mathrm{dS} \mathrm{m}^{-1}$. Under these conditions, 
the soil-tree system captured virtually all of the applied nitrogen and most of the phosphorus and trace and heavy elements (Fine et al. 2006; Hass et al. 2011).

Although use of EDTA is gradually decreasing because of its environmental persistence and possible blocking of metal uptake by viable plants, it is still by far more preferred over TPAs for soil and sediment rehabilitation purposes. In a lysimeter study, we tested the following series of hypotheses: (i) $E$. camaldulensis can efficiently remove and translocate solubilized metals from a continually salinizing soil solution; (ii) frequent application of EDTA, EDDS and citric acid by fertigation increases metal solubility in polluted soil media; (iii) careful CDI can capture solubilized metal complexes within the root zone and limit their leaching, (iv) chelant application can be timed to (a) solubilize metals and enhance their plant uptake and translocation during summer, and (b) allow the biodegradation of the metal-complexes before winter leaching occurs thus releasing the metals for plant uptake and adsorption onto the soil matrix.

\subsection{MATERIALS AND METHODS}

\subsubsection{ChELANTS}

The chelants used in laboratory experiments were of analytical grade. EDTA (disodium salt dihydrate; E5134 Sigma), citric acid $\left(\mathrm{H}_{3} \mathrm{C}_{6} \mathrm{H}_{5} \mathrm{O}_{7} ; 818707\right.$ Merck), and S,S-EDDS (trisodium salt solution; $\approx 35 \%$ in $\mathrm{H}_{2} \mathrm{O} ; 92698$ Aldrich). Same EDTA and citric acid were also used in the lysimeter study, however the EDDS was at Octaquest ${ }^{\circledR}$ E30 (Innospec, Cheshire, UK; S,S-EDDS at $\approx 30 \%$ in water in $25 \mathrm{~kg}$ containers). Standards for HPLC determinations used the 92698 Aldrich EDDS and EDS Sigma-Aldrich anhydrous EDTA.

\subsubsection{BATCH EXTRACTION STUDY - METAL DISSOLUTION FROM SLUDGE}

A metal-rich sewage sludge was used in the study which is of a mixed domestic-industrial origin from an air-force base (Tel-Nof, Israel). Selected properties of the sludge are provided in Table 3.1. The potential dissolution capacity of EDTA, EDDS and citric acid for $\mathrm{Cd}, \mathrm{Cu}, \mathrm{Cr}, \mathrm{Fe}, \mathrm{Mg}, \mathrm{Ni}, \mathrm{Pb}$, and $\mathrm{Zn}$ present in the sludge was tested using a parallel batch extraction procedure. The concentrations of EDTA and EDDS were $0.1,0.5$ and $1 \mathrm{mM}$, and citric acid was tested also at up to $20 \mathrm{mM}$. A sample of $0.5 \mathrm{~g}$ sludge was placed in $50 \mathrm{~mL}$ polycarbonate centrifuge tubes and $20 \mathrm{~mL}$ extraction solution was added. The solutions were pre-adjusted to $\mathrm{pH} 6.5$, and the $\mathrm{pH}$ was checked after 2 hours shaking and corrected if necessary to 6-7 (using dilute solution of either $\mathrm{NH}_{4} \mathrm{OH}$ or $\mathrm{HCl}$ ). All treatments were triplicated. The tubes were reciprocally shaken for 24 hours and for a week at $25^{\circ} \mathrm{C}$. Tubes were then centrifuged at $10000 \mathrm{rpm}$ for $10 \mathrm{~min}$ and the eluent was filtered through a syringe-mounted $0.45 \mu \mathrm{m}$ nylon filter. The filtrates were acidified and stored for elemental analysis using ICP-AES ("Arcos", Side-On-Plasma, Spectro Ltd., Kleve, Germany). The elemental composition of the sludge and the sand-sludge mixtures was determined using the method described in the section 2.2.3 in chapter 2. The $\mathrm{pH}$ and electrical conductivity were determined in the centrifuged supernatant of $1: 5$ solid:RO water slurries that were shaken 1 hour on a reciprocal shaker. 
Table 3.1: Composition of the sludge and quartz sand-sludge mixture (sludge: average of 5 grab samples; mixture: average of samples from 24 lysimeters)

\begin{tabular}{|c|c|c|}
\hline Chemical parameters & Sludge & Sand-sludge mixture \\
\hline $\mathrm{pH}\left(1: 5\right.$ water; dS m $\left.{ }^{-1}\right)$ & 6.97 & 7.05 \\
\hline EC ( $1: 5$ water; dS m $\left.{ }^{-1}\right)$ & 0.80 & 2.6 \\
\hline Organic carbon $\left(\mathrm{g} \mathrm{kg}^{-1}\right)$ & 273.0 & 22 \\
\hline Calcium (Ca; $\mathrm{g} \mathrm{kg}^{-1}$ ) & 32.6 & - \\
\hline Magnesium (Mg; $\mathrm{g} \mathrm{kg}^{-1}$ ) & 7.0 & - \\
\hline Nitrogen $\left(\mathrm{N} ; \mathrm{g} \mathrm{kg}^{-1}\right)$ & 27.1 & - \\
\hline Phosphorus $\left(\mathrm{P} ; \mathrm{g} \mathrm{kg}^{-1}\right)$ & 9.8 & - \\
\hline Potash (K; $\left.\mathrm{g} \mathrm{kg}^{-1}\right)$ & 3.2 & - \\
\hline Iron $\left(\mathrm{Fe} ; \mathrm{g} \mathrm{kg}^{-1}\right)$ & 31.6 & 4.9 \\
\hline Cadmium (Cd; mg kg ${ }^{-1}$ ) & 640 & 52 \\
\hline Chromium ( $\mathrm{Cr} ; \mathrm{mg} \mathrm{kg}^{-1}$ ) & 1475 & 170 \\
\hline Copper (Cu; mg kg $\left.{ }^{-1}\right)$ & 555 & 38 \\
\hline Manganese $\left(\mathrm{Mn} ; \mathrm{mg} \mathrm{kg}^{-1}\right)$ & 200 & 50 \\
\hline Nickel $\left(\mathrm{Ni} ; \mathrm{mg} \mathrm{kg}^{-1}\right)$ & 221 & 14 \\
\hline Lead ( $\mathrm{Pb} ; \mathrm{mg} \mathrm{kg}^{-1}$ ) & 290 & 22 \\
\hline Zinc (Zn; mg kg $\left.{ }^{-1}\right)$ & 2700 & 210 \\
\hline
\end{tabular}

\subsubsection{LYSIMETER STUDY}

\section{LYSIMETER CONSTRUCTION AND MAINTENANCE}

Data is presented in this chapter from a lysimeter system up-scaled through batch, hydroponic (10 L buckets; 3 months old $E$. camaldulensis trees; +/- 10 $\mathrm{mg} \mathrm{L}^{-1} \mathrm{Cd} ;+/-0.5-5 \mathrm{mM}$ EDTA or EDDS) studies described in chapter 2 . The lysimeter setup comprised of twenty four $220 \mathrm{~L}$ cylindrical steel drums $(0.87$ $\mathrm{m}$ deep, $57.1 \mathrm{~cm}$ inner diameter, $0.26 \mathrm{~m}^{2}$ surface area) each fitted with a polyethylene container insert (Pachmas Packaging, Ein-Hahoresh, Israel). A drainage device ( $5 \mathrm{~cm}$ long, $20 \mathrm{~mm}$ inner diameter) was fitted through the bottoms of drum and insert. The drums were placed on iron frames ( $3 \mathrm{~m}$ long, $0.6 \mathrm{~m}$ wide, and $0.6 \mathrm{~m}$ high) in groups of three (Figure 3.1). A geotechnical fabric was laid at the bottom of each container covered by a $5 \mathrm{~cm}$ layer of 3 $\mathrm{mm}$ plastic beads. The same fabric was placed on top of the beads, covered by a $10 \mathrm{~cm}$ layer of quartz dune sand (mostly $0.2-0.25 \mathrm{~mm}$ particle size).

The Tel-Nof sludge was crushed to pass a $5 \mathrm{~mm}$ screen and it was mixed with the sand using a portable $155 \mathrm{~L}$ cement mixer at a 2:1 sand: sludge volumetric ratio (12:1 weight ratio). The lysimeters were packed with $150 \mathrm{~L}$ sand-sludge mixture to the depth of $60 \mathrm{~cm}$. Each mixture was sampled for elemental analysis. Five month old $E$. camaldulensis saplings (leafless, trimmed at $50 \mathrm{~cm}$ long, $\approx 1 \mathrm{~cm}$ in diameter) were planted in May 2006, with one plant per lysimeter. The lysimeters were fertigated 2-4 times daily with tap water that was supplemented with fertilizer solution ("Raviv 7-3-7"; ICL Fertilizers, Haifa, Israel) at final $\mathrm{N}\left(40 \%\right.$ as $\left.\mathrm{NH}_{4}\right)-\mathrm{P}-\mathrm{K}$ concentrations of $83-16-70 \mathrm{mg} \mathrm{L}^{-1}$, 
respectively. Potassium sulphate $\left(\mathrm{K}_{2} \mathrm{SO}_{4}\right)$ and boric acid were added at final concentrations of 2 and $0.05 \mathrm{mM}$, respectively. Stock solutions were prepared at 100 -times the final concentrations and water-powered proportional dosing pumps (MixRite, Nahsholim, Israel) were used for their injection into the irrigation line at a $1 \%$ ratio. The chelants were similarly applied (as per the treatments described below). Irrigation was computer controlled using two $8 \mathrm{~L}$ $\mathrm{hr}^{-1}$ surface drippers per lysimeter (Figure 3.1D).

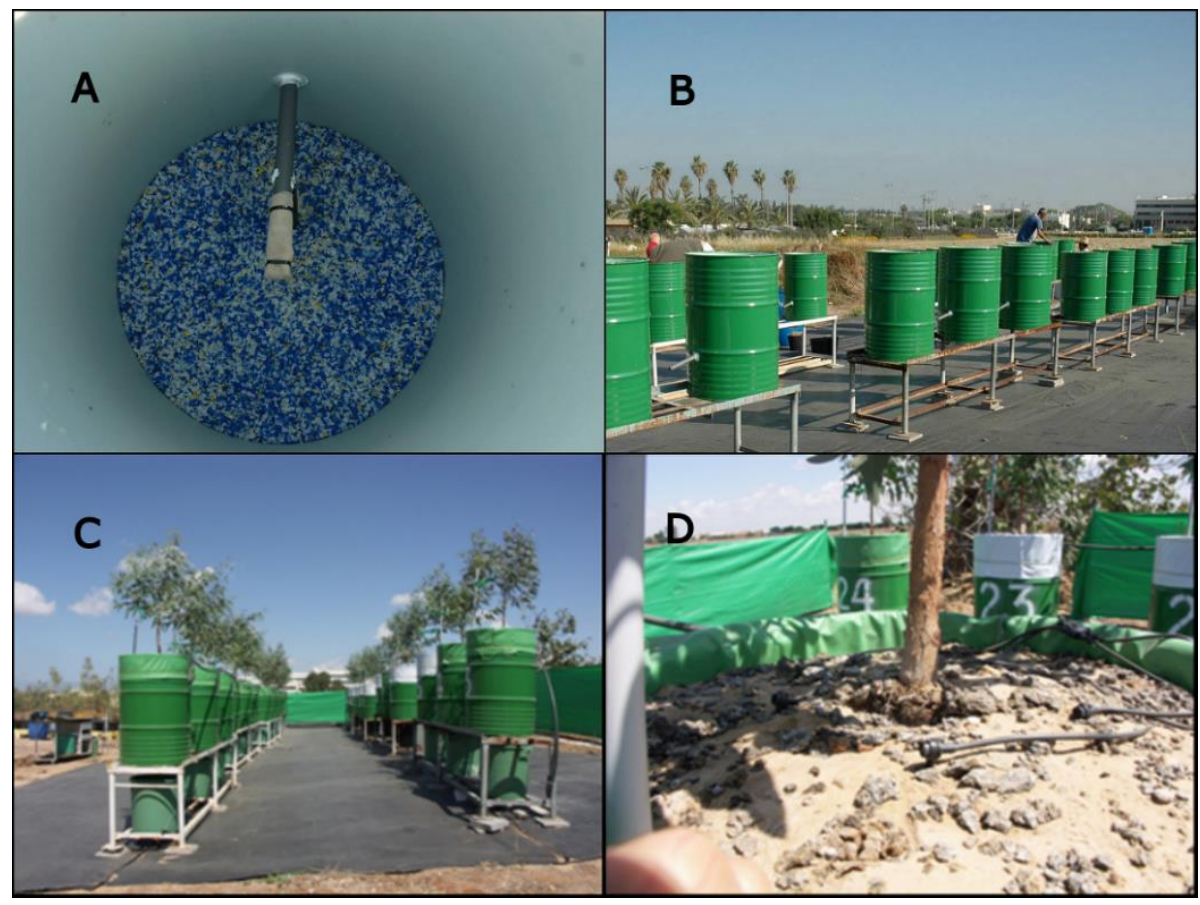

Figure 3.1: General view of lysimeter experimental setup

(A) Small plastic beads cover the bottom of the container at $5 \mathrm{~cm}$ layer. The tubing shown in the picture lies on between the sand layer below and the sand-sludge layer above. It is used to withdraw solution samples by applying low vacuum (B) a general view of the lysimeters prior to packing and planting

(C) a view of the lysimeters 4 months after planning $E$. camaldulensis, in mid-Sept 2006 (D) a closer view of sand-sludge mixture and the base of tree with fertigation system

\section{Controlled DEFICIT IRRIGATION}

Irrigation was conducted to compensate for evapotranspiration without leaching. Water doses were 10-25 and at 0-10 L lysimeter $^{-1}$ day $^{-1}$, respectively in the summer and winter periods. Most leaching events during the irrigation period were prescribed, for the purpose of soil solution monitoring. The first prescribed leaching campaign was on the last day of chelants fertigation. Spontaneous leaching had also occurred occasionally and these leachates were sampled for analysis. The number of leaching campaigns in both 2007-08 and 2008-09 periods was 10-12, and the respective leachate volume averages 
( \pm standard error) were $2.3( \pm 0.2)$ and $4.1( \pm 0.3)$ litters lysimeter ${ }^{-1}$ per event. In 2007-08, the dry season lasted from May through December, with significant rains occurring only in Apr 2008. The average leaching percentage for the period May 1, 2007-Apr 1, 2008 was $<2 \%$ of the overall amount of water applied. Rain leaching in Apr 2008 was at an average 64 L lysimeter $^{-1}(\approx 2.5$ times the $25 \mathrm{~L}$ content at water holding capacity). Tap water fertigation (without chelates in all the lysimeters) restarted on May 1, 2008 until June 8, when the treatments started and lasted until mid-Sept 2008. Fertigation under CDI and leachate monitoring continued for another year. The 2008-09 winter was very dry ( $\approx 70 \%$ of the average precipitation) with little effective rains. The overall average leaching percentage in the period mid-June 2008 to Sept 2009 was $0.4 \%$.

\section{TREATMENTS}

One year after planting, the lysimeters were randomly assigned to six treatments, each with four replicates (Table 3.2). The effect of the following variables on tree metal uptake was tested: (i) type of chelant: $\mathrm{Na}_{2}$ EDTA, $\mathrm{Na}_{3} \mathrm{EDDS}$, and a mixture of the two, (ii) concentration of the chelants: $0,0.1$ and $0.5 \mathrm{mM}$. The chelant mixture was composed of $0.05 \mathrm{mM}$ concentrations of EDTA and EDDS. The application of the chelants began on May 1, 2007 and ceased on Sept 11, 2007, when the first leaching campaign was conducted. Soil solution was sampled by intentionally causing leaching (prescribed leaching) at approximately once a month thereafter (e.g., dates of data points in Figure 3.3).

In the summer of 2008 the following variables were tested: (i) type of chelant: citric acid, $\mathrm{Na}_{2}$ EDTA, $\mathrm{Na}_{3}$ EDDS (all at $2 \mathrm{mM}$ concentration), a mixture of EDTA and EDDS (each at $1 \mathrm{mM}$ ), and a control without chelant addition, (ii) type of irrigation water: tap vs. RO water (reverse osmosis at EC $<10 \mu \mathrm{S} \mathrm{cm}{ }^{-1}$; 4LPM by Saggiv.co.il, Israel). The citric acid and the chelant mix treatments were in the RO water only (Table 3.2). The shift to $2 \mathrm{mM}$ concentration was because soil metal dissolution in all the first season treatments was unnoticeable (data not shown), and the use of RO was in an attempt to avoid the CDI derived rapid soil solution salination. The 8 treatments were triplicated. The application of the chelants was from June 6, 2008 until Aug 18, 2008, when the first leaching campaign of that season was conducted. Prescribed leaching under CDI continued until mid-Sep 2009 at approximately one month intervals (dates in Figure 3.3b).

Note that the lysimeter treatment allocation in 2008 and in 2007 was not always the same (Table 3.2). The main change was by raising the concentration of a chelants from 0.1 and $0.5 \mathrm{mM}$ to $2 \mathrm{mM}$. We assumed that the shift to a higher concentration minimized carryover effects especially as no change in soil metal content had occurred in the first season in any part of the soil profile (data not shown). In addition, a $2 \mathrm{mM}$ citric acid treatment was added in 2008 by shifting 3 lysimeters from the [0.05 mM EDTA + $0.05 \mathrm{mM}$ EDDS] mixture, and two $0.1 \mathrm{mM}$ EDDS lysimeters were altered to no-chelant controls. This too seemed sound for the reason mentioned above, which was especially true in the case of stepping into the former EDDS treatments (section 3.3.5). 
Table 3.2: Treatments and allocation of lysimeters to treatments in 2007-08 and in 2008-09 year.

\begin{tabular}{|c|c|c|c|c|}
\hline \multirow{2}{*}{$\begin{array}{l}\text { Lysi- } \\
\text { meter\# }\end{array}$} & \multicolumn{2}{|l|}{ Year 2007-08 } & \multicolumn{2}{|l|}{ Year 2008-09 } \\
\hline & Chelant & Water & Chelant & Water \\
\hline 6 & None & Tap & None & RO \\
\hline 7 & None & Tap & None & RO \\
\hline 18 & None & Tap & None & RO \\
\hline 19 & None & Tap & None & Tap \\
\hline 1 & $0.1 \mathrm{mM}$ (EDTA \& EDDS) & Tap & $2 \mathrm{mM}$ (EDTA \& EDDS) & RO \\
\hline 8 & $0.1 \mathrm{mM}$ (EDTA \& EDDS) & Tap & 2 mM Citric acid & RO \\
\hline 17 & $0.1 \mathrm{mM}$ (EDTA \& EDDS) & Tap & 2 mM Citric acid & RO \\
\hline 24 & $0.1 \mathrm{mM}$ (EDTA \& EDDS) & Tap & 2 mM Citric acid & RO \\
\hline 2 & $0.1 \mathrm{mM}$ EDDS & Tap & $2 \mathrm{mM}$ EDDS & RO \\
\hline 3 & $0.1 \mathrm{mM}$ EDDS & Tap & None & Tap \\
\hline 4 & $0.1 \mathrm{mM}$ EDDS & Tap & None & Tap \\
\hline 5 & $0.1 \mathrm{mM}$ EDDS & Tap & $2 \mathrm{mM}$ EDDS & RO \\
\hline 20 & $0.1 \mathrm{mM}$ EDTA & Tap & 2 mM EDTA & RO \\
\hline 21 & $0.1 \mathrm{mM}$ EDTA & Tap & 2 mM EDTA & RO \\
\hline 22 & $0.1 \mathrm{mM}$ EDTA & Tap & $2 \mathrm{mM}$ (EDTA \& EDDS) & RO \\
\hline 23 & $0.1 \mathrm{mM}$ EDTA & Tap & $2 \mathrm{mM}$ (EDTA \& EDDS) & RO \\
\hline 9 & $0.5 \mathrm{mM}$ EDDS & Tap & $2 \mathrm{mM}$ EDDS & RO \\
\hline 10 & $0.5 \mathrm{mM}$ EDDS & Tap & $2 \mathrm{mM}$ EDDS & Tap \\
\hline 11 & $0.5 \mathrm{mM}$ EDDS & Tap & $2 \mathrm{mM}$ EDDS & Tap \\
\hline 12 & $0.5 \mathrm{mM}$ EDDS & Tap & $2 \mathrm{mM}$ EDDS & Tap \\
\hline 13 & $0.5 \mathrm{mM}$ EDTA & Tap & 2 mM EDTA & Tap \\
\hline 14 & $0.5 \mathrm{mM}$ EDTA & Tap & $2 \mathrm{mM}$ EDTA & Tap \\
\hline 15 & $0.5 \mathrm{mM}$ EDTA & Tap & 2 mM EDTA & Tap \\
\hline 16 & $0.5 \mathrm{mM}$ EDTA & Tap & 2 mM EDTA & RO \\
\hline
\end{tabular}

\section{LEACHATE COLLECTION, SAMPLING AND ANALYSIS}

Leachate was collected into a $10 \mathrm{~L}$ plastic bag attached to the lysimeter drainage outlet. Collection under confined atmosphere prevented degasification and $\mathrm{pH}$ changes, and possible co-precipitation of carbonates and heavy metals (Fine et al. 2002). Leaching was prescribed and achieved by gradually increasing the irrigation head until leachate started to emerge. Then the irrigation was stopped (usually for 1 day) to allow for transpiration to reduce soil water content and restore the deficit irrigation regime. The bags were weighed for leachate volume and the leachates were sampled. Leachate $\mathrm{pH}$ and electrical conductivity (EC) were measured immediately after sampling, and the leachate was further subdivided for the determination of: (i) organic (OC) and inorganic (IC) carbon (TOC-VCPN, Shimadzu [Suzhou] Instruments Manufacturing Co., Ltd., China), (ii) $\mathrm{NO}_{3}, \mathrm{NH}_{4}$ and $\mathrm{PO}_{4}$ (Lachat QuikChem 8500 Series 2 FIA automated ion-analyzer, Hach Loveland, CO), (iii) elemental composition using ICP-AES, and (iv) EDTA and EDDS by HPLC (Shimadzu LC10AT VP liquid chromatograph; UV detector set at $258 \mathrm{~nm}$ ) after complexation with $\mathrm{Fe}^{+3}$ (Henneken et al. 1995; Tandy et al. 2006b; Xie et al. 2010). As measurements were set at $<1 \mathrm{mM}$ chelant, diluting concentrated samples also solved the problem of peak suppression caused by higher ionic strengths (Henneken et al. 1995). All the subsamples were kept at $4{ }^{\circ} \mathrm{C}$ until measurement and those for ICP were slightly pre-acidified with nitric acid. 


\section{Plant sampling and analyses}

Young fully expanded leaves were sampled for metal analysis (sampling dates in 2008-09, see Table 3.5; results for 2007-08 are not reported) for metal analysis (Campion and Scholes 2007), taking approximately 50 leaves from the upper half of each canopy. The exception to this was that mature leaves were sampled at the beginning of the metal uptake experiment (June 6,2008 ) to have a snapshot of the metal loading of the leaves. The leaves were washed by immersion in $0.01 \mathrm{M} \mathrm{HCl}$ for 30 seconds, and then washed in tap and in deionized water. The total elemental composition of leaves were analyzed using ICP-AES following chemical digestion as described in the section 2.2.3 of chapter 2. Trees' height and diameter (at $20 \mathrm{~cm}$ above the ground) were measured in Apr 2008, and in Nov 2009, the trees (8 tap- and 15 RO-water irrigated) were cut and weighed.

\section{INCUBATION STUDY - TEST OF EDTA AND EDDS DEGRADABILITY}

An incubation study was conducted to assess metal solubilization and EDTA and EDDS degradation capacity of lysimeter media. Four treatment media were tested: (i) Fresh mixture - the original dry sand-biosolids mixtures that were stored and sealed in plastic containers immediately after mixing in May 2006, (ii) Control sand-sludge media - from the chelant-free treatment that was under CDI with tap water (Table 3.2), (iii) EDTA treated media - from lysimeter that was under CDI with tap water and EDTA addition, (iv) EDDS treated media - from lysimeter under CDI with tap water and EDDS addition. The medium for the first treatment was composed of $50 \mathrm{~g}$ samples from each of the 24 original stored sand-biosolids mixtures used in the lysimeter construction. The incubation media in treatments ii-iv were from the $0-15 \mathrm{~cm}$ layer of the lysimeter, sampled in Feb 2009. Each of the triplicate samples per treatment was used as a replicate in the incubation study (they were not mixed).

Ten gram samples were placed in $50 \mathrm{~mL}$ polycarbonate centrifuge tubes, and wetted by adding $2.5 \mathrm{~mL}$ RO water, containing $10 \mathrm{mM}$ of EDTA or EDDS. The centrifuge tubes were loosely covered and incubated in a moist-air incubator at $30^{\circ} \mathrm{C}$ temperature. Moisture content was monitored by weighing the tubes and replenished with RO water as needed. Triplicate tubes/treatment were sacrificed following $0,3,7,14,30$, and 85 days of incubation. The soil solution volume was adjusted to $20 \mathrm{~mL}$ with RO water, and the tubes were reciprocally shaken for 2 hrs. The tubes were then centrifuged at $6000 \mathrm{rpm}$ for $10 \mathrm{~min}$ and the eluent was filtered using a syringe-mounted $0.45 \mu \mathrm{m}$ nylon filter. The filtrates were slightly acidified and stored at $4^{\circ} \mathrm{C}$ temperature for chelant (using HPLC as described above) and metal determinations.

\subsubsection{STATISTICAL ANALYSIS}

A complete randomized experimental design was used in the lysimeter study. Statistical analyses, including analysis of variance, paired t-test and TukeyKramer HSD multiple range test, were performed using JMP 10 software (SAS 2012). 


\subsection{RESULTS AND DISCUSSION}

\subsubsection{BATCH EXTRACTION STUDY: METAL DISSOLUTION FROM TEL-NOF SLUDGE BY CITRIC ACID, EDDS AND EDTA}

Evidently, at the lower chelant concentrations, citric acid was not very effective (Figure 3.2). EDTA was more effective than EDDS in solubilizing Cd (305 and $432 \mathrm{mg} \mathrm{kg} \mathrm{kg}^{-1}$ following 1 and 7 days extraction; $52 \%$ and $73 \%$ of the amount in the sludge, all respectively), $\mathrm{Pb}$ (26 and $60 \mathrm{mg} \mathrm{kg} \mathrm{kg}^{-1} ; 8$ and $19 \%$, all respectively), and $\mathrm{Mn}$ to a lesser extent (up to $15 \%$; Figure 3.2 ), while EDDS was more effective in solubilizing $\mathrm{Cu}\left(214\right.$ and $319 \mathrm{mg} \mathrm{kg}^{-1} ; 34$ and $50 \%$, all respectively) and $\mathrm{Ni}$ (90 and $110 \mathrm{mg} \mathrm{kg}^{-1} ; 40$ and $49 \%$, all respectively). Zinc was substantially equally solubilized by both EDTA and EDDS already after the 1 day extraction ( $1155 \mathrm{mg} \mathrm{kg}^{-1}, \approx 48 \%$ dissolution; Figure 3.2). However, only small fractions of the $\mathrm{Fe}$ and $\mathrm{Cr}$ (not more than $0.2 \%$ and $3 \%$ of their, respective contents) were solubilized with either EDTA or EDDS, and EDDS was more effective with respect to Fe, solubilizing up to $800 \mathrm{mg} \mathrm{kg}^{-1}$ (Figure 3.2).

While, the contact time had a rather small effect on the extent of metal solubilization, chelant concentration was important as was demonstrated for citric acid. The extent of solubilization of all the 8 metals increased in direct proportion to the citric acid concentration. Even the more resistant metals, $\mathrm{Cr}$ and $\mathrm{Fe}$, were solubilized at increasing proportions (up to $6 \%$ and $10 \%$, respectively at 7 day extraction in 20 mM citric acid; Figure 3.2).

The efficacy of the chelants in solubilizing the sludge metals can be expressed also in terms of the molar ratio between the amount of the chelant in solution and the sum of the amounts of the major 8 metals extracted. Their net amount was calculated by subtracting the amounts extracted in the blank (water) from the amount extracted with a chelant (Table 3.3). The weak metal binding capacity of citric acid was reflected by the high ligand:metal molar ratio (719), while both EDTA and EDDS displayed molar ratios of 1 to 2 as was expected from the high formation constant of the metal ion complexes due to their multi-dentate binding (Fine et al. 2013; Parra et al. 2008).

\subsubsection{SALINITY BUILD-UP IN THE LYSIMETERS' SOIL PROFILE UNDER CDI}

The salinity of the leachate (as EC; $\mathrm{dS} \mathrm{m}^{-1}$ ) of all the tap water irrigated treatments (with and without chelant) over the two years study period was usually between 20 and $40 \mathrm{dS} \mathrm{m}^{-1}$ (Figure 3.3). The winter rains in 2007-08, (which in 2008 started only in April) reduced the EC to $10.7 \mathrm{dS} \mathrm{m}^{-1}$ (average of April data of all the 6 treatments; Figure 3.3a). Chelant application under CDI was resumed on June 6, 2008 with two water types: tap and RO, with the first leaching event on Aug 18, 2008. Under tap water irrigation, the leachateEC increased to approximately $30-40 \mathrm{dS} \mathrm{m}^{-1}$ (Figure 3.3b and Table 3.4). The corresponding average $\mathrm{Cl}^{-}$and $\mathrm{Na}^{+}$concentrations were 220-270 mM and 220$360 \mathrm{mM}$ (Table 3.4), approximately $40-50 \%$ and $50-75 \%$ of that of sea water, respectively. Under irrigation with RO water (in the No chelant amended control treatments), the leachate EC for the period June 2008-November 2009 decreased somewhat (average $\mathrm{EC}=7.6 \mathrm{dS} \mathrm{m}^{-1}$; Figure 3.3b). However, the corresponding average EC of the leachate from the EDTA or EDDS treatments 
in RO water increased to $30 \mathrm{dS} \mathrm{m}-1$ (Figure 3.3b). Yet, while the leachate $\mathrm{Cl}^{-}$ concentrations were relatively low (the corresponding average being $22 \mathrm{mM}$; Table 3.4 treatments 4,6 and 8 ), $\mathrm{Na}^{+}$concentrations were almost 3 times as much ( $80 \mathrm{mM}$ in average; Table 3.4 treatments 4,6 and 8 ). This additional $\mathrm{Na}^{+}$was from the sodium contained within the chelant formulations.

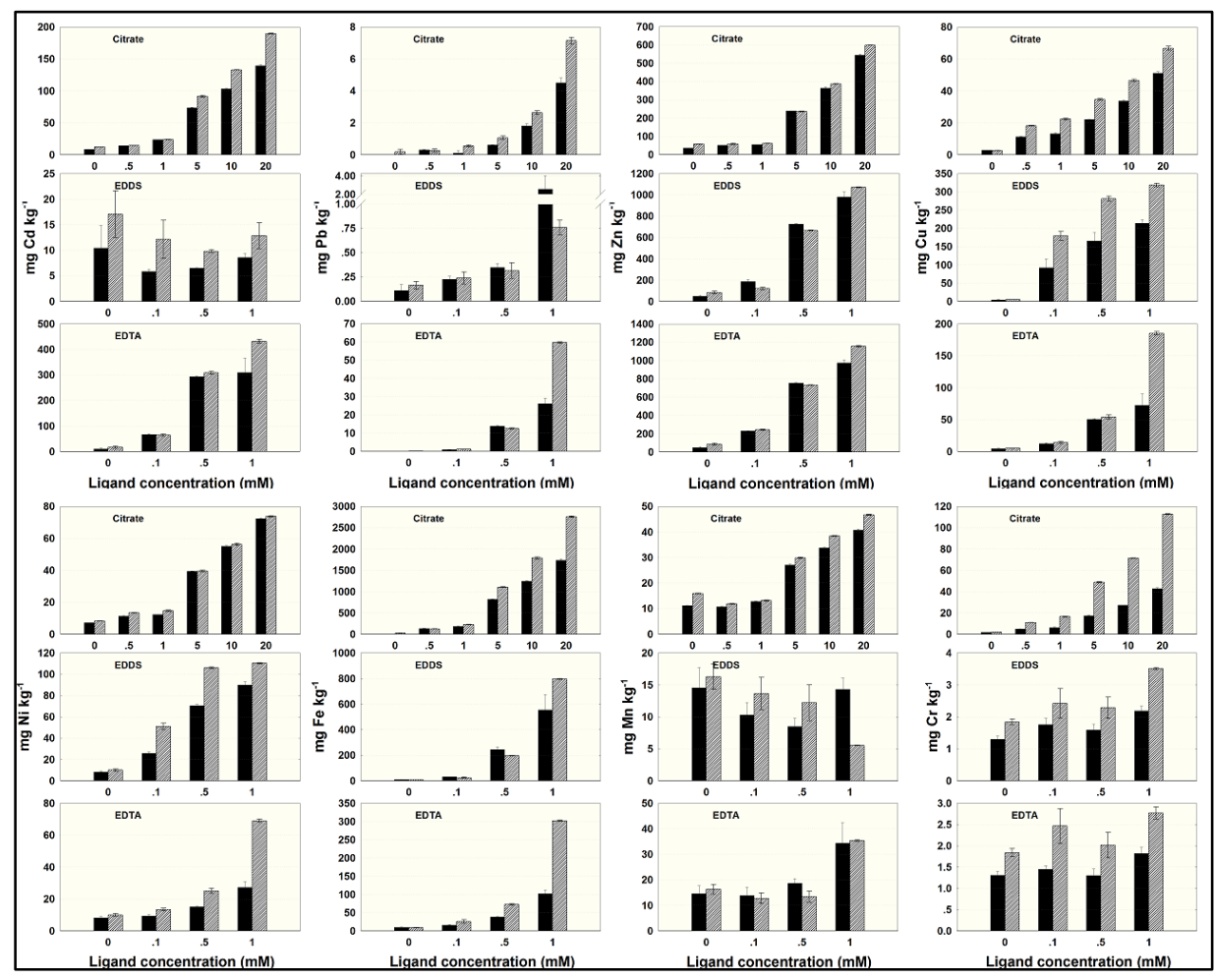

Figure 3.2: Dissolution of metals by chelates in batch extraction as affected chelate type (EDTA, EDDS, and citric acid), chelate concentration and time (black columns: 1 day; gray coloured columns: 7 weeks). The data are averages ( $\pm \mathrm{SE}$; error bars).

Table 3.3: The molar ratio between the amount chelant in the solution and the sum total of the 8 metals extracted

\begin{tabular}{|c|c|c|c|c|c|c|}
\hline \multirow{2}{*}{$\begin{array}{c}\text { Chelant } \\
(\mathbf{m} M)\end{array}$} & \multicolumn{2}{|c|}{ Citric acid } & \multicolumn{2}{c|}{ EDTA } & \multicolumn{2}{c|}{ EDDS } \\
\cline { 2 - 7 } & 1 day & 7 days & 1 day & 7 days & 1 day & 7 days \\
\hline 0.1 & - & - & 1.2 & 1.2 & 1.0 & 1.0 \\
0.5 & 7.3 & 9.4 & 1.4 & 1.4 & 1.1 & 1.1 \\
1 & 10.3 & 9.4 & 2.0 & 1.3 & 1.4 & 1.1 \\
5 & 10.2 & 8.1 & - & - & - & - \\
10 & 13.3 & 9.8 & - & - & - & - \\
20 & 18.6 & 12.6 & - & - & - & - \\
Average & 10.9 & - & 1.4 & - & 1.1 & - \\
\hline
\end{tabular}




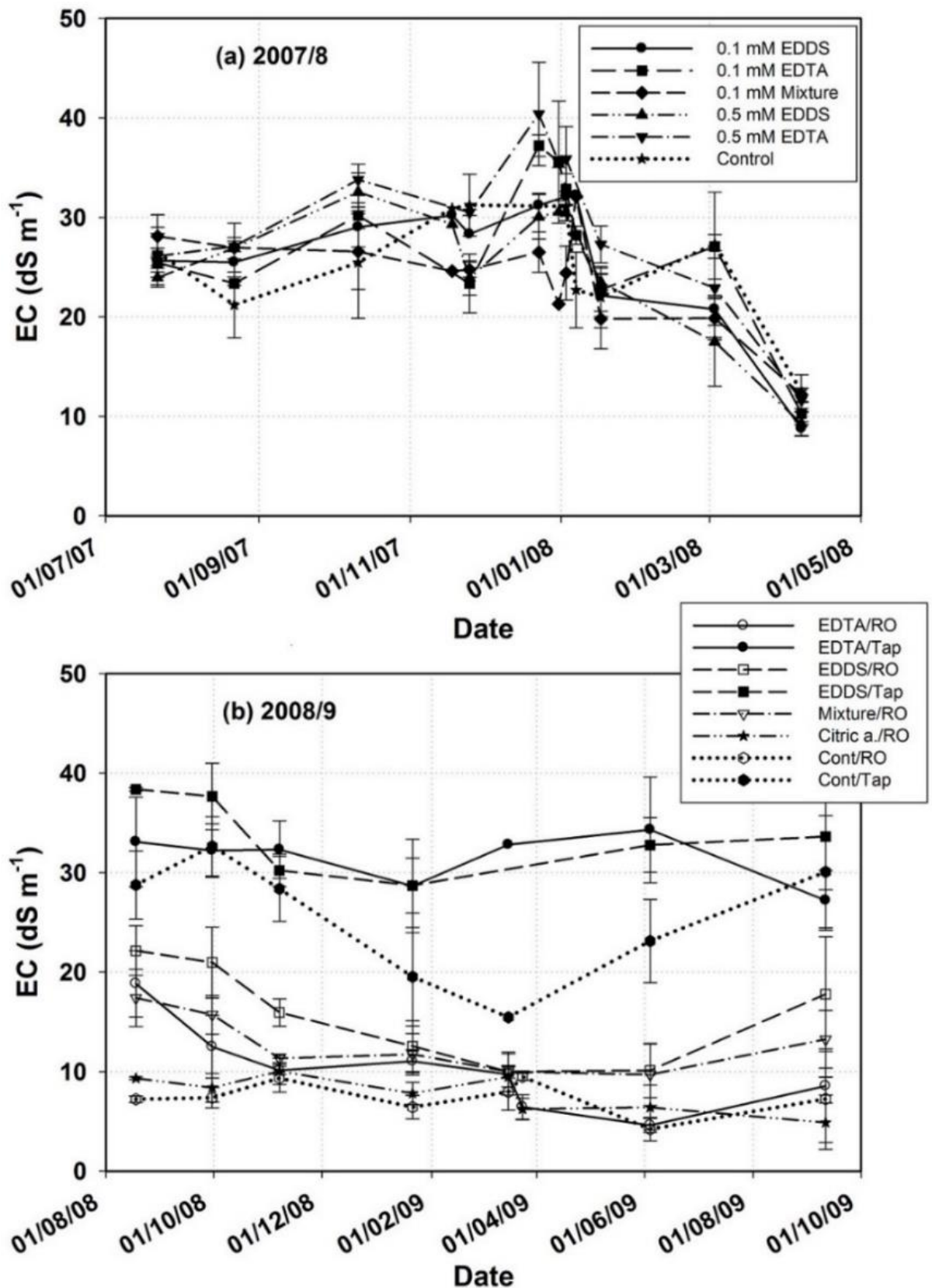

Figure 3.3: Electrical conductivity (EC) of the leachates from the lysimeters in (a) 2007-08 and (b) 2008-09 treatment periods.

Data points are average ( \pm SE of 3 replicates; error bars). 
Table 3.4: Average concentrations (in $\mathrm{mg} \mathrm{L}^{-1}$ ) of constituents in the leachates from the lysimeters

\begin{tabular}{|c|c|c|c|c|c|c|c|c|c|}
\hline Element & $\begin{array}{c}\text { Cont./ } \\
\text { RO }\end{array}$ & $\begin{array}{c}\text { Cont./ } \\
\text { Tap }\end{array}$ & $\begin{array}{c}\text { Citric/ } \\
\text { tap }\end{array}$ & $\begin{array}{c}\text { EDDS/ } \\
\text { RO }\end{array}$ & $\begin{array}{c}\text { EDDS/ } \\
\text { tap }\end{array}$ & $\begin{array}{c}\text { EDTA/ } \\
\text { RO }\end{array}$ & $\begin{array}{l}\text { EDTA/ } \\
\text { Tap }\end{array}$ & $\begin{array}{c}\text { Mix/ } \\
\text { RO }\end{array}$ & $\boldsymbol{p}^{*}$ \\
\hline \multicolumn{10}{|c|}{ First leaching period (18 Aug and 30 Sept 2008) } \\
\hline $\begin{array}{c}\mathrm{Cl} \\
\mathrm{Na} \\
\mathrm{EC} \\
\mathrm{OC} \\
\text { Chelant } \\
\mathrm{pH} \\
\mathrm{Cd} \\
\mathrm{Pb} \\
\mathrm{Zn} \\
\mathrm{Cu} \\
\mathrm{Ni} \\
\mathrm{Fe} \\
\mathrm{Mn} \\
\mathrm{Cr}\end{array}$ & $\begin{array}{c}1008^{b} \\
1027^{d} \\
7^{c} \\
416^{d} \\
- \\
7.35^{a b c} \\
3.1^{b} \\
0.10^{b} \\
5.9^{b} \\
0.1^{b} \\
8^{c} \\
2.1^{c} \\
0.7^{c} \\
0.06^{d}\end{array}$ & $\begin{array}{c}10792^{a} \\
5247^{c} \\
31^{a} \\
2539^{b c d} \\
- \\
6.82^{c} \\
11.7^{b} \\
0.11^{b} \\
22.9^{b} \\
0.1^{b} \\
21^{b c} \\
1.5^{c} \\
1.3^{c} \\
0.06^{d}\end{array}$ & $\begin{array}{c}1203^{b} \\
1480^{d} \\
8^{c} \\
340^{d} \\
- \\
6.89^{b c} \\
0.8^{b} \\
0.10^{b} \\
2.3^{b} \\
0.1^{b} \\
5^{c} \\
1.7^{c} \\
0.5^{c} \\
0.05^{d}\end{array}$ & $\begin{array}{c}1682^{b} \\
5820^{b c} \\
22^{b} \\
724^{c d} \\
\mathrm{BDL}^{\#} \\
7.42^{a b} \\
1.5^{b} \\
0.08^{b} \\
6.5^{b} \\
2.8^{b} \\
22^{b c} \\
2^{c} \\
1^{c} \\
2.8^{b c}\end{array}$ & $\begin{array}{c}9217^{a} \\
8232^{a} \\
38^{a} \\
640^{c d} \\
\mathrm{BDL} \\
7.61^{a} \\
2.3^{b} \\
0.09^{b} \\
7^{b} \\
1.3^{b} \\
15^{c} \\
2.1^{c} \\
0.5^{c} \\
1.7^{c d}\end{array}$ & $\begin{array}{c}1700^{b} \\
4224^{c} \\
16^{b c} \\
6305^{a} \\
61^{a} \\
7.20^{a b c} \\
183^{a} \\
49^{a} \\
659^{a} \\
93^{a} \\
60^{a} \\
337^{b} \\
60^{a b} \\
3^{a b}\end{array}$ & $\begin{array}{c}9167^{a} \\
7049^{a b} \\
33^{a} \\
5664^{a b} \\
44^{a b} \\
7.23^{a b c} \\
214^{a} \\
49^{a} \\
659^{a} \\
93^{a} \\
60^{a} \\
337^{b} \\
60^{a b} \\
3^{a b}\end{array}$ & $\begin{array}{c}2083^{b} \\
5138^{c} \\
18^{b} \\
4077^{a b c} \\
24^{b} \\
7.40^{a b} \\
222^{a} \\
33^{a} \\
670^{a} \\
80^{a} \\
74^{a} \\
206^{b c} \\
36^{b c} \\
3^{b c}\end{array}$ & $\begin{array}{c}<0.0001 \\
<0.0001 \\
<0.0001 \\
<0.0001 \\
0.014 \\
<0.001 \\
<0.0001 \\
<0.0001 \\
<0.0001 \\
<0.0001 \\
<0.0001 \\
<0.0001 \\
<0.0001 \\
<0.0001\end{array}$ \\
\hline \multicolumn{10}{|c|}{ Second leaching period (Oct 2008 to Nov 2009) } \\
\hline $\begin{array}{c}\mathrm{Cl} \\
\mathrm{Na} \\
\mathrm{EC} \\
\mathrm{OC} \\
\text { Chelant } \\
\mathrm{pH} \\
\mathrm{Cd} \\
\mathrm{Pb} \\
\mathrm{Zn} \\
\mathrm{Cu} \\
\mathrm{Ni} \\
\mathrm{Fe} \\
\mathrm{Mn} \\
\mathrm{Cr}\end{array}$ & $\begin{array}{c}653^{b} \\
594^{f} \\
7.7^{c} \\
223^{c} \\
- \\
7.50^{a} \\
0.15^{b} \\
0.10^{b} \\
0.4^{b} \\
0.001^{b} \\
2.8^{c} \\
0.04^{b} \\
0.2^{b} \\
0.005^{b}\end{array}$ & $\begin{array}{c}6542^{a} \\
3014^{b c} \\
24.6^{b} \\
269^{c} \\
- \\
6.96^{b} \\
0.90^{b} \\
0.004^{b} \\
1.6^{b} \\
0.010^{b} \\
5.9^{b c} \\
0.24^{b} \\
0.7^{b} \\
0.009^{b}\end{array}$ & $\begin{array}{c}693^{b} \\
661^{\mathrm{ef}} \\
7.6^{c} \\
181^{c} \\
- \\
7.15^{a b} \\
0.10^{b} \\
0.002^{b} \\
0.3^{b} \\
0.001^{b} \\
1.5^{c} \\
0.53^{b} \\
0.2^{b} \\
0.005^{b}\end{array}$ & $\begin{array}{c}840^{b} \\
2032^{c d} \\
12.6^{c} \\
320^{b c} \\
- \\
7.1^{a b} \\
0.13^{b} \\
\text { BDL } \\
0.9^{b} \\
0.174^{b} \\
4.9^{b c} \\
0.17^{b} \\
0.5^{b} \\
0.9^{a}\end{array}$ & $\begin{array}{c}4413^{a} \\
32.0^{a} \\
300^{c} \\
- \\
7.08^{a b} \\
0.44^{b} \\
0.001^{b} \\
0.9^{b} \\
0.081^{b} \\
4.8^{b c} \\
0.41^{b} \\
0.8^{b} \\
0.4^{a b}\end{array}$ & $\begin{array}{c}452^{b} \\
1379^{d e f} \\
8.4^{c} \\
783^{a b} \\
8^{a b} \\
7.36^{a b} \\
36^{a} \\
5^{a} \\
117^{a} \\
14^{a} \\
14^{a b} \\
63^{a} \\
11^{a} \\
1.1^{a}\end{array}$ & $\begin{array}{c}8361^{a} \\
4354^{a b} \\
31.4^{a} \\
943^{a} \\
13^{a} \\
7.06^{b} \\
38^{a} \\
5^{a} \\
119^{a} \\
13^{a} \\
21^{a} \\
28^{a b} \\
5^{a} \\
1^{a}\end{array}$ & $\begin{array}{c}1080^{b} \\
2018^{c d e} \\
11.8^{c} \\
502^{a b c} \\
4^{b} \\
7.35^{a b} \\
21^{a b} \\
0.5^{a b} \\
88^{a} \\
3^{a b} \\
22^{a} \\
1^{b} \\
2^{b} \\
0.7^{a b}\end{array}$ & $\begin{aligned} &< 0.0001 \\
&< 0.0001 \\
&<0.0001 \\
&<0.0001 \\
&<0.05 \\
& 0.001 \\
&<0.0001 \\
&<0.0001 \\
&<0.0001 \\
&<0.0001 \\
&<0.0001 \\
&<0.0001 \\
&<0.001 \\
&<0.0001\end{aligned}$ \\
\hline
\end{tabular}

${ }^{*}$ Statistically significant difference between elemental concentrations in leachates first passed ANOVA and those found significantly different at $p<0.05$ were subject to the Tukey-Kramer HSD multiple range test $(\alpha<0.05)$. Significantly different values are followed by a different letter.

${ }^{\#} B D L=$ below detection limit

\subsubsection{GROWTH OF E. CAMALDULENSIS UNDER INCREASING SALINITY AND CHELANTS CONCENTRATIONS}

The growth of $E$. camaldulensis trees was recorded by measuring trunk diameter (at $20 \mathrm{~cm}$ above ground level) and height, at planting, 6, 17 and 22 months after planting (Figure 3.4). The average trunk diameter and height of the trees in Apr 2008 were $8.6 \mathrm{~cm}$ and $3.35 \mathrm{~m}$, respectively, not significantly different among the treatments. Up till this time, all grew under CDI with tap water, and the soil solution salinities were high throughout (Figure 3.3). The average weights of the trees in Nov 2009 was $22 \pm 1 \mathrm{~kg} \mathrm{tree}^{-1}$, the tap was ( 8 lysimeters) and RO water (15 lysimeters) irrigated trees not being statistically significantly different. Furthermore, the weight of the trees in the RO water irrigated, control treatment was not statistically significantly different from that of the tap water +2 mM EDTA treatment. 


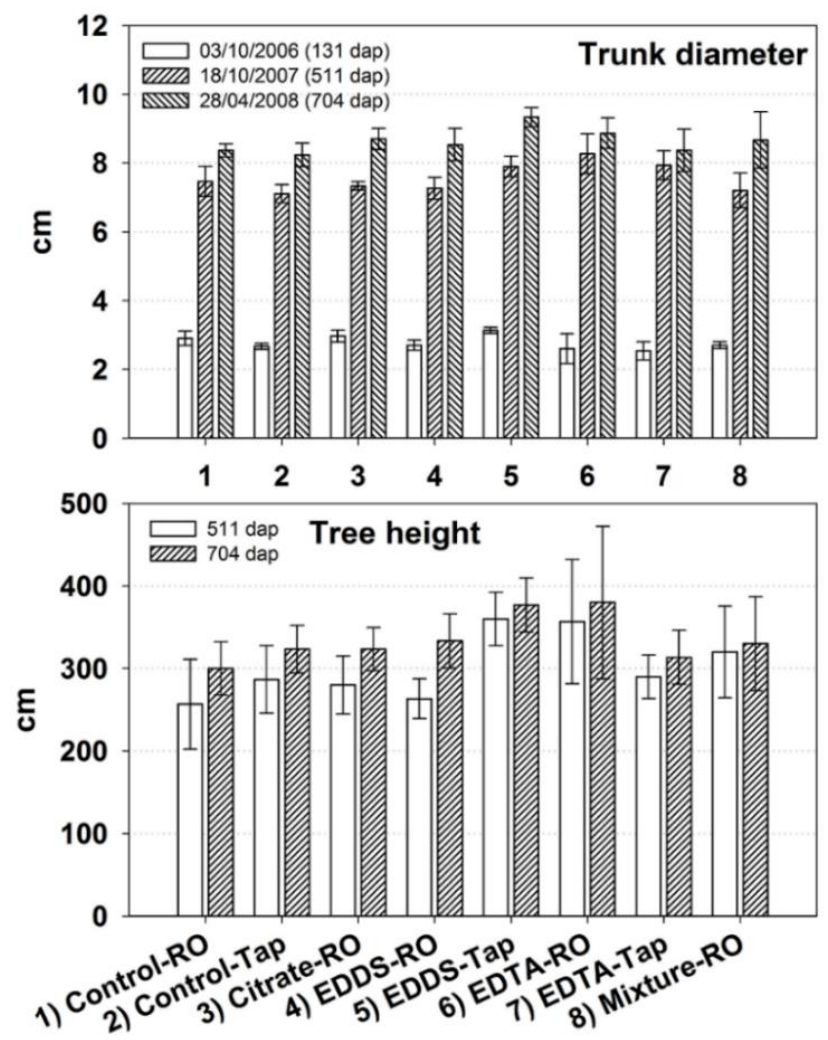

Figure 3.4: E. camaldulensis trunk diameter and the height at 6,17 , and 22 months after planting of tree in the lysimeters under chelate fertigation with tap and RO water

E. camaldulensis is not a typical salinity resistant species (Myers et al. 1999). Fine et al. (2006); Fine et al. (2002) observed that upon shifting $E$. camaldulensis irrigation regime from $20 \%$ leaching fraction to CDI, the trees immediate response was substantially reduced transpiration rates. Marcar et al. (2002) tested E. camaldulensis resistance to salinity. Seedlings from 15 seed sources in Australia were grown for 2 months in sand-filled pots under salinities of up to $150 \mathrm{mM} \mathrm{NaCl}$. After 2 months of treatmet, the seedlings from different sources differed significantly in height and shoot dry weight, and at the higher salinity shoot dry weight decreased by 43 to $82 \%$ depending on the seedling sources. Shoot height was not affected by the salinity. Hence, the growth similarity found here between the treatments is rather peculiar considering the range of salinities gained (average ECs of 7-38 $\mathrm{dS} \mathrm{m}^{-1}$ ) and the contents of salinity components in the leachates $\left(\mathrm{Na}^{+}\right.$and $\mathrm{Cl}^{-} ; 48-356 \mathrm{mM}$ and $30-270 \mathrm{mM}$ ).

The average EDTA concentrations in the lysimeter soil solution during the 5 months period after the cessation of chelates application in 2008 was 24-61 $\mathrm{mM}$ (described hereunder in section 3.3.4; Table 3.4), which was decreased averaging at $4-13 \mathrm{mM}$ in the next 9 months periods (Table 3.4). This is 
noteworthy since when tested in solution growth media, EDTA and EDDS were detrimental to mature $E$. camaldulensis mature saplings already at $1 \mathrm{mM}$ and they were lethal at $5 \mathrm{mM}$ [as discussed at section 2.3.1 of chapter 2; Tandy et al. (2006b)]. In a soil uptake study, Luo et al. (2005) also showed that at the end of a 14 days period, EDTA and EDDS at $5 \mathrm{mM} \mathrm{kg}^{-1}$ soil (assumed $20 \mathrm{mM}$ soil solution concentration) significantly impaired root growth of corn and white beans. The growth reduction of the shoots exceeded $50 \%$ compared to the control plants, and the chelates also caused chlorosis and necrosis in the leaves.

With the average leachate concentration of the more recalcitrant EDTA $>60$ $\mathrm{mM}$, peaking at $100 \mathrm{mM}$ (described hereunder in section 3.3.4) could be expected to injure the Eucalyptus roots and reduce tree growth (as observed in hydroponic studies; chapter 2), the contrary actually happened with lysimeter study. This inconsistency probably emanates from the differences in the composition of the solution media (Henneken et al. 1995). In the lysimeter soil solution, di- and tri-valent cationic species could exploit the complexation capacity of the EDTA for most all the time, and this was probably also assisted by the gradual addition of the chelant. Yet, this was probably not the case in the pure solution medium (chapter 2: hydroponic studies) and in the pot experiment (Luo et al. 2005). In addition, the root system of E. camaldulensis trees is vast, thus even if some parts of it have been damaged (e.g., at the soil top) this does not necessarily hamper tree growth and longevity. Also, while small pots and solution media are uniform, the soil solution composition in the 220 L lysimeters is variegate, especially down the soil profile. It should also be noted that some damage to root integrity is considered necessary for the apoplastic route of EDTA-metal complex uptake and translocation (Hernández-Allica et al. 2006; Leštan et al. 2008a; Tandy et al. 2006b; Tanton and Crowdy 1971).

\subsubsection{FATE OF EDTA AND EDDS IN THE SOIL ENVIRONMENT}

\section{INCUBATION STUDY: EDTA AND EDDS BIODEGRADATION}

The biodegradability of the chelants in the lysimeter media and the effect of former exposure of the soil to the chelants were tested by adding either EDDS or EDTA to four types of lysimeter media and incubating them for 85 days. The chelates were added at $10 \mathrm{mM}$ and their average ( $\pm \mathrm{SE})$ recovery at time zero was $8.65( \pm 0.07) \mathrm{mM}$ (Figure 3.5$)$. EDDS decayed rapidly in the soil samples taken from the EDTA-treated and control lysimeters, reaching $\approx 70-80 \%$ reduction within 7-14 days, with an approximately 5 days half-life in the EDTA soil and 11 days in the control soil (Figure 3.5a), similar to the 3.8-7.5 days 'effective half-life' inferred by Meers et al. (2005) from the rates of dissipation of solubilized heavy metals. The asymptotic-like behavior thereafter reflects the rapid degradation and near-complete depletion of EDDS in the sandbiosolid mixes. Added EDDS recoveries in the original, fresh sand-biosolid mixture and in the soil taken from the EDDS-treated lysimeters were rather high, approximately 70 and 50\%, respectively. Interestingly, EDDS biodegradation in soil from the EDTA-treated lysimeters was very effective, while it only slowly decayed in the soil from the EDDS-treated lysimeters. 
The degradation of EDTA was considerably slower than that of EDDS, with $\approx 65 \%$ removal within 85 days in the soil from the EDTA-treated lysimeters (a half-life of $\approx 27$ days); $35 \%$ in soil from the control lysimeters; and $20 \%$ removal in the original fresh mixture and in the soil from the EDDS-treated lysimeters (Figure 3.5). Meers et al. (2005) calculated an 'effective' average half-life for EDTA applied at $\leq 3.6 \mathrm{mM} \mathrm{kg}^{-1}$ of 43 days. At double this load, no EDTA degradation was observed. The fact that the extent of EDDS degradation in soil from the control lysimeters was greater than in the soil from the EDDStreated lysimeters suggests that degradation of EDDS does not require highly specified microbial communities (Bucheli-Witschel and Egli 2001). In any event, the removal of the diagnostic HPLC band of the chelates does not necessarily mean that they were completely mineralized (Yuan and VanBriesen 2008).
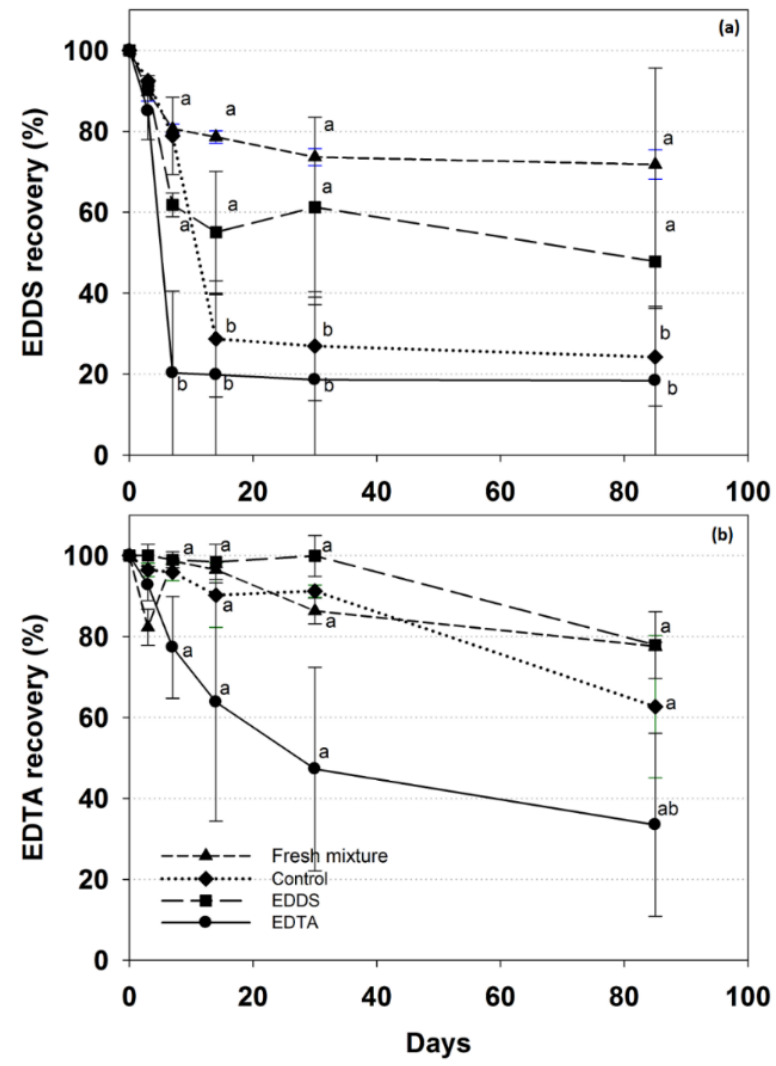

Figure 3.5: Recovery of EDTA and EDDS during their incubation in four types of lysimeter media.

Data points are averages ( \pm SE; error bars) of three replicates, and those connected by same letters are statistically non-significant according to Tukey-Kramer HSD multiple range test at $\alpha=0.05$. 


\section{Chelates concentrations in Lysimeter leachates}

Applied at a $2 \mathrm{mM}$ concentration during the 2008 season, the overall amount of chelants added per lysimeter was 4.4 moles. The expected concentration in the soil solution, assuming uniform dilution in the $\approx 25 \mathrm{~L}$ soil solution volume, would be approximately $175 \mathrm{mM}$. The actual average ( $\pm \mathrm{SE}$ ) concentration of EDTA in the leachates at the first two leaching events from the 9 EDTA-treated lysimeters (from the three EDTA-containing treatments) was $44( \pm 5) \mathrm{mM}$, peaking at $100 \mathrm{mM}$ (Table 3.4; Figure 3.6). The average EDTA concentration in the leachates during the later period was 4-13 mM (Figure 3.6). The decrease in EDTA in the leachate was attributed to biodegradation rather than to dilution and leaching. The supporting evidence comes from the incongruence between the patterns of change of the EC and of the EDTA concentrations in the EDTA/RO water treatments where all the salinity was inherent from the former season and no new salinity was introduced. While, the EC decreased slowly during the first 4 months after the cessation of chelant application (Figure 3.3b), the leachate EDTA concentrations decreased more rapidly (Figure 3.6). Hence, we conclude that under CDI, EDTA had accumulated in the soil solution and that it slowly degraded during and after its application.

Unlike EDTA, EDDS was completely absent in the leachates from its three corresponding treatments (citrate measurement was not attempted). This was also reflected in the dissolved organic carbon (DOC) concentrations in the leachates, which were very high in the case of the EDTA treatments, yet were considerably lower and rather similar in the leachates of the EDDS, citric acid and control treatments (Figure 3.7). The pooled average concentrations of the later treatments did not differ significantly in the first leaching period (ranging from 300 to $2500 \mathrm{mg} \mathrm{L}^{-1}$; Table 3.4), or in the subsequent period (averaging 180-300 $\mathrm{mg} \mathrm{L}^{-1}$; Table 3.4). We conclude that EDDS and citric acid degraded while migrating in the soil profile, probably already close to the soil surface.

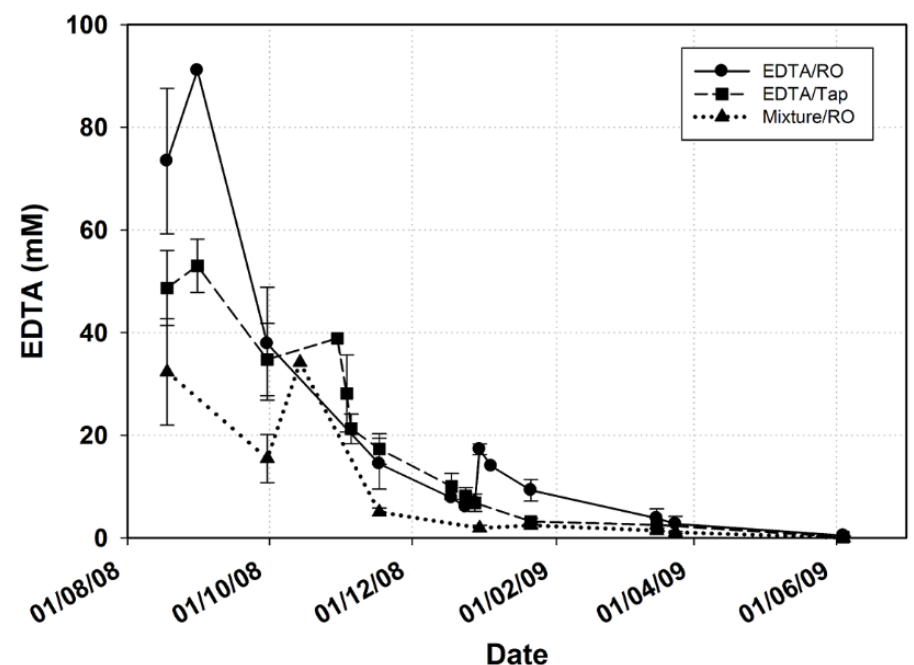

Figure 3.6: Concentration of EDTA in the 2008-09 leachates from lysimeters in the 3 treatments that received EDTA.

Data points are averages of triplicates ( $\pm S E$; error bars). 


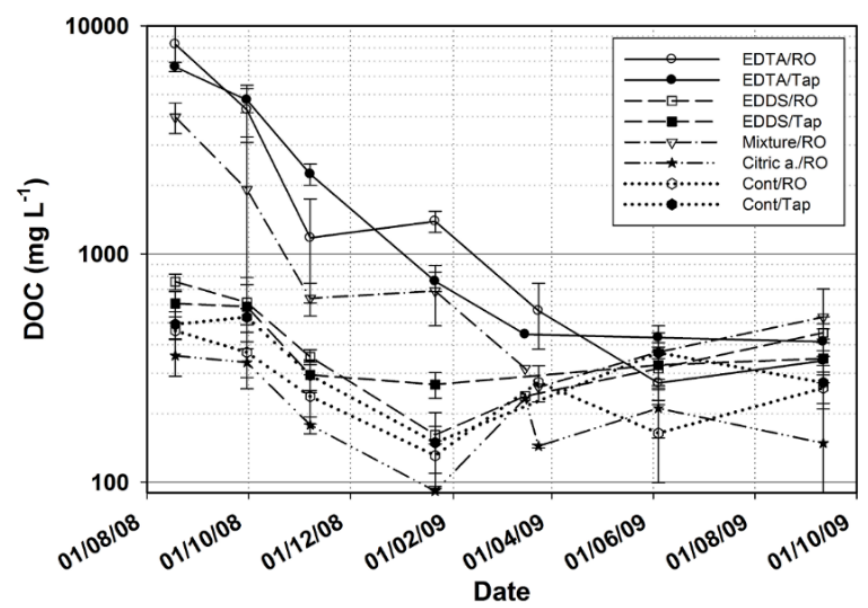

Figure 3.7: Concentration of dissolved organic carbon (DOC) in the 2008-09 leachates from the lysimeters in all 8 treatments.

Data points are averages of triplicates ( $\pm \mathrm{SE}$; error bars).

\subsubsection{CHELANT-ENHANCED HEAVY METAL SOLUBILIZATION}

\section{HeAVY METAL CONCENTRATIONS IN LYSimeter LEACHATES}

Eight heavy metals were monitored in the lysimeter study: $\mathrm{Cd}, \mathrm{Cu}, \mathrm{Cr}, \mathrm{Fe}, \mathrm{Mn}$, $\mathrm{Ni}, \mathrm{Pb}$, and $\mathrm{Zn}$, and all displayed similar leaching patterns as is illustrated in detail for $\mathrm{Cd}$ (Figure 3.8). Cadmium concentration in the leachates between July 2007 and Apr 2008 in the chelant-free control did not exceed $10 \mu \mathrm{g} \mathrm{L}^{-1}$ throughout this period (Figure 3.8a). Average Cd concentrations for the 0.1 $\mathrm{mM}$ and $0.5 \mathrm{mM}$ EDDS treatments were 0.02 and $0.28 \mathrm{mg} \mathrm{L}^{-1}$, with the 0.5 $\mathrm{mM}$ treatment peaking at $1.5 \mathrm{mg} \mathrm{Cd} \mathrm{L}^{-1}$ (Figure 3.8a). EDTA for both the 0.1 $\mathrm{mM}$ and $0.5 \mathrm{mM}$ treatments increased peak (and average) Cd leachate concentrations to $22(16)$ and $36(23) \mathrm{mg} \mathrm{L}^{-1}$, respectively (Figure $3.8 \mathrm{a}$ ) and the corresponding values in the $0.1 \mathrm{mM}$ EDDS-EDTA mixture were $11(10) \mathrm{mg}$ $\mathrm{L}^{-1}$ (Figure 3.8a), which we attribute almost solely to the $0.05 \mathrm{mM}$ EDTA component. By Apr 2008, average Cd concentrations decreased to $0.34,1.42$ and $0.35 \mathrm{mg} \mathrm{L}^{-1}$, in the $0.1,0.5 \mathrm{mM}$ EDTA treatments and the EDDS-EDTA mixture, respectively (Figure 3.8a). As reasoned of EDTA, also the decrease in $\mathrm{Cd}$ leachate concentrations was probably not due to mere dilution and leaching but rather to immobilization probably via plant uptake, adsorption and reprecipitation.

In 2008-09, CDI was run using tap and RO water with EDTA, EDDS, citric acid and EDTA-EDDS mixture applications (Table 3.2). As mentioned that winter was dry and non-prescribed leaching was rare. Cadmium concentrations in leachate during the 15 month period after the cessation of chelant applications are presented in Figure 3.8b. Table 3.4 also presents data for other solution components including $\mathrm{pH}, \mathrm{EC}, \mathrm{Cl}^{-}$, chelates and metals. Two sets of averages are given for each component: one for the first two leaching events (Aug 18 and Sept 30, 2008), and the other for the following 13-months period (Oct 2008-Nov 2009). 
Cadmium concentrations in the leachates from the chelant-free control lysimeters in 2008 were considerably higher than in the previous year (Figure 3.8). The average $\mathrm{Cd}$ concentration for the first two leaching events was 3.1 and $11.7 \mathrm{mg} \mathrm{L}^{-1}$ in the RO and tap water controls, respectively (Table 3.4), with a peak average concentration as high as $32 \mathrm{mg} \mathrm{L}^{-1}$ (Figure $3.8 \mathrm{~b}$ ). Cd concentrations in the subsequent leachates (Oct 2008-Nov 2009) decreased by $1-2$ orders of magnitude, averaging 0.15 and $0.90 \mathrm{mg} \mathrm{Cd} \mathrm{L}^{-1}$ under RO and tap water, respectively (Table 3.4); which was consistently higher than in the previous year. Application of citric acid (in RO water) and of EDDS (tap and RO water) did not solubilize more $\mathrm{Cd}$ than did the water alone (Figure 3.8b and Table 3.4). However, $\mathrm{Cd}$ concentrations in the leachate from the EDTA treatments exceeded $200 \mathrm{mg} \mathrm{L}^{-1}$ during the first month after the cessation of chelant application, and remained $>10 \mathrm{mg} \mathrm{L}^{-1}$ and $>1.0 \mathrm{mg} \mathrm{L}^{-1}$ respectively for 6 and 8 months thereafter (Figure 3.8b). Higher metal solubility in EDTA compared with the other treatments probably resulted from EDTA that still resided in the soil solution (Figure 3.8a; Table 3.4). Similar results were obtained in all three EDTA-containing treatments (Table 3.4).

It is noteworthy that $\mathrm{Cd}$ concentrations in the tap water irrigated chelant-free control treatment were significantly higher than in the RO water counterpart (Table $3.4 ; p<0.05$ in the first period and $p<0.001$ in the second period; all pairwise t-tests). This could result from expected lower metal adsorption at the significantly lower $\mathrm{pH}$ under tap than $\mathrm{RO}$ water irrigation $[p=0.0012$ and 0.034 in the first and second periods, respectively; all pairwise t-tests (Comte et al. 2006; Hass and Fine 2010)], and from Cd complexation by $\mathrm{Cl}^{-}$at the 10 times greater $\mathrm{Cl}^{-}$concentrations [Table 3.4; Hahne and Kroontje (1973); Weggler et al. (2004)]. This however could also be related to soluble Cd that resided in the soil from the former year in 2 (of the 3) lysimeters (\#3 and \#4; Table 3.2) that were shifted from the $0.1 \mathrm{mM}$ EDDS treatment (Figure 3.8). Still, such enhancement did not occur in the citric acid treatment despite that all the 3 lysimeters in this treatment were shifted from an even more solubilization intensive treatment (Table 3.2; Figure 3.8).

The concentrations of the other metals that were monitored in the lysimeter leachates are presented in Table 3.4. Their leaching pattern was similar to that of Cd. Thus, while EDTA treatments (EDTA-RO, EDTA-tap, and EDTA-EDDS mixture) effectively solubilized the metal of concern, raising their concentrations by 1-2 orders of magnitude over that in the control treatments, the application of EDDS and citric acid was virtually ineffective in solubilizing the metals. EDDS and citrate inefficiency was despite their constant 4 times daily application at $2 \mathrm{mM}$ concentration for $>2$ summer months in year 2008 (and EDDS application in the former summer). This contradicted the EDDS's metal solubilizing capacity revealed in batch extraction study which was often superior to EDTA [e.g., with respect to $\mathrm{Cu}, \mathrm{Zn}, \mathrm{Ni}$, Fe; Figure 3.2; (Meers et al. 2005)]. This seeming discrepancy between the laboratory and lysimeter results was probably due to accelerated EDDS (and citrate) biodegradation in the soil environment. Accelerated EDDS biodegradation may help explains the lack of metal solubilization and accumulation in the tree canopies, and the complete absence of EDDS in the leachates. Meers et al. (2005); Meers et al. (2008); Meers et al. (2010) recommended that because of the high degradability of TPAs, their mobilization of heavy metals in calcareous soils can be achieved 
only at dosages 10-100 times higher than that of synthetic chelants, and that additions should only be made just prior to the harvest. Average peak EDTA concentration in soil pore water was $>60 \mathrm{mM}$ (a 30 -fold concentration factor over the irrigation water; Figure 3.6, Table 3.4). It was reported that at such concentration no biodegradation will occur (Bucheli-Witschel and Egli 2001; Henneken et al. 1995), however the EDTA did degrade, as was deduced from the rate of its disappearance which was faster than the rate of EC reduction in the RO-water treatments (Figure 3.3b). We further suggested that EDTA biodegradation capacity will gradually enhance in EDTA-treated soils.
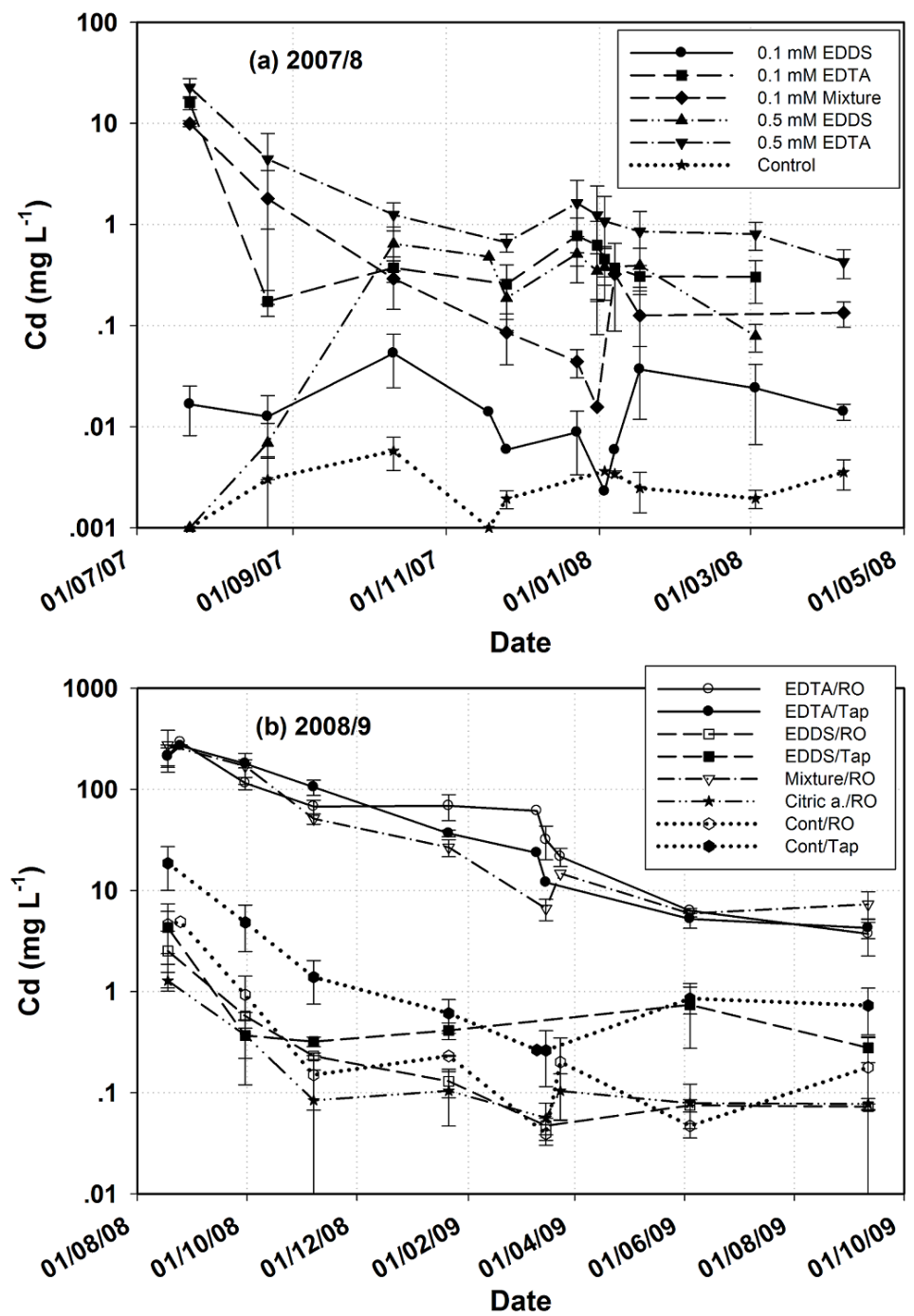

Figure 3.8: The concentration of $\mathrm{Cd}$ in the leachates from the lysimeters in the 2007-08 season (a) and the 2008-09 season (b).

Data points are averages of triplicates ( $\pm S E$; error bars). 
The average $\mathrm{Cl}^{-}$leachate concentrations in the 2007 and 2008 control-tap water treatment were 190 and $308 \mathrm{mM}$, respectively. Inasmuch as these concentrations were above the threshold for the formation of $\mathrm{CdCl}^{+}$and $\mathrm{CdCl}_{2}$ complexes $\left[\approx 60 \mathrm{mM} \mathrm{Cl}^{-}\right.$at pH 8.5; (Hahne and Kroontje 1973)], because they were not so much different, it does not seem that $\mathrm{Cl}^{-}$had a major role in increasing $\mathrm{Cd}$ solubility in 2008. Fe and $\mathrm{Mn}$ leachate concentrations were lower in 2007 than in the 2008 tap-water control treatment, being $0.04 \mathrm{vs} .0 .67 \mathrm{mg}$ $\mathrm{L}^{-1}(p<0.05)$ and 0.23 vs. $0.91 \mathrm{mg} \mathrm{L}^{-1}(p<0.01)$, respectively. This may suggest some oxy-hydroxide dissolution, however the redox potential has not decreased enough to cause nitrate reduction (data not shown) which means that the release of heavy metals that were associated with the oxy-hydroxides could not be substantial (Hass and Fine 2010). However, it cannot be ruled out that all these three mechanisms had some role in increasing the concentration of Cd (and other metals) in the control-tap water treatment in 2008 compared with 2007.

\section{HEAVY METAL SOLUBILIZATION DURING INCUBATION WITH EDTA AND EDDS}

Metal concentrations were measured in an incubation study which measured EDTA and EDDS degradability. Metal solubility depends on properties of soil medium, the nature of chelate-metal interactions, and the duration of the incubation. This was demonstrated with respect to $\mathrm{Cd}$ and $\mathrm{Cu}$ (Figure 3.9). The solubility of both $\mathrm{Cd}$ and $\mathrm{Cu}$ after an 85 day incubation period was much higher in the original sand-sludge mixture than in the soils which were obtained from the lysimeters after $\approx 2.5$ years of treatment. This is in agreement with the persistence of the chelants in these mixtures (Figure 3.9). As Cd was extracted better in EDTA and $\mathrm{Cu}$ in EDDS (Figure 3.2; Figure 3.9), biodegradation affected $\mathrm{Cu}$ solubilization more than $\mathrm{Cd}$. In the fresh mixture, where both EDDS and EDTA did not degrade, more metal extraction occurred after 85 days than after 3 days; Cd by EDTA and Cu by EDDS (and to some extent also by EDTA). However, in the other treatments, where the chelants did degrade (Figure 3.5), 85 day incubation yielded less metal solubilization than 3 days, and this was most evident in the soil samples from the EDTA-treated lysimeters (Figure 3.9). It should be noted again that the soil from the EDDS-treated lysimeters displayed rather similar $\mathrm{Cu}$ solubilization rates at 3 and 85 day incubation, which reflects the lesser extent of EDDS degradability in this treatment compared with the chelant-free CDI treatment (Figure 3.5). 

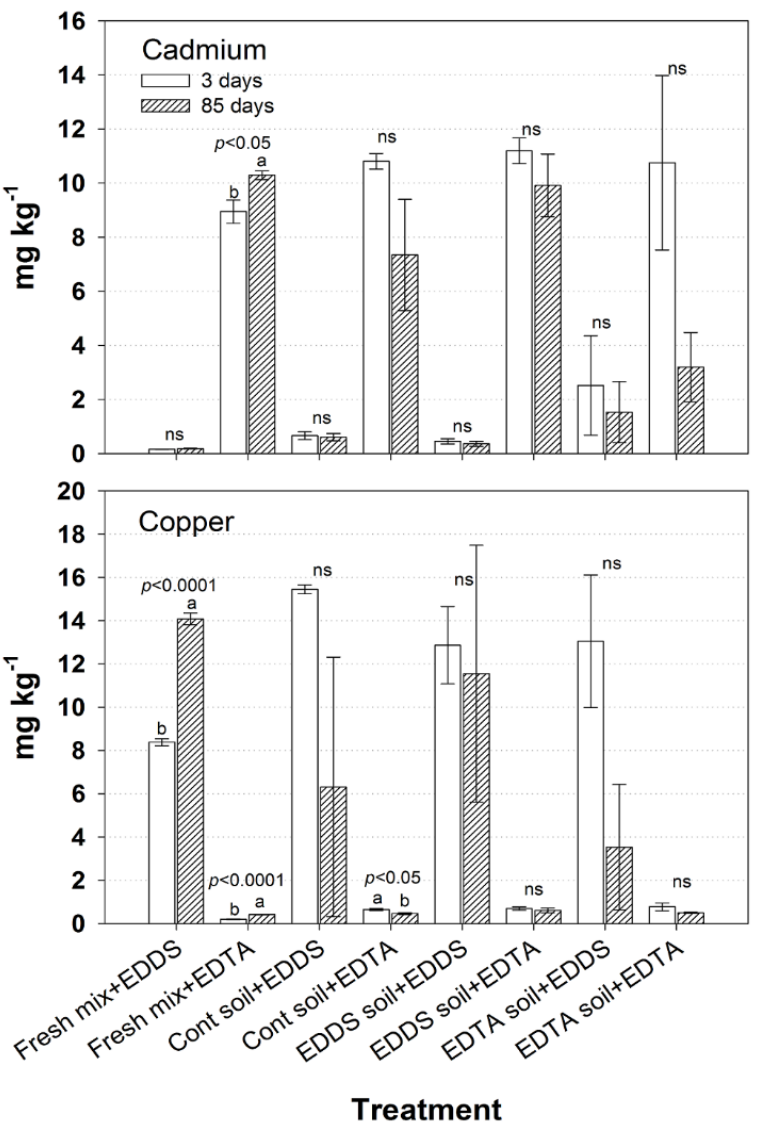

Figure 3.9: Cadmium and Cu solubilization after 3 and 85 days of EDTA and EDDS incubation in four types of lysimeter media.

Data points are averages ( \pm SE) of three replicates, and those connected by same letter are statistically non-significant accordingly to ANOVA test.

\subsubsection{HEAVY METAL CONTENT IN EUCALYPTUS LEAVES: 2008-09 TRIAL}

The leaves were sampled five times starting on June 6,2008 , before the onset of ligand application; on Aug 20, immediately after the cessation of ligand application; in mid-Oct 2008; and in Jan and Oct 2009. The concentrations of $\mathrm{Cd}, \mathrm{Pb}, \mathrm{Zn}, \mathrm{Ni}, \mathrm{Cu}$ and $\mathrm{Cr}$ increased in the leaves of the trees that were under CDI with the addition of EDTA in the irrigation water (Table 3.5). This was true for all 3 treatments that had EDTA, including at $1 \mathrm{mM}$ (in the mixture), which was half the regular concentration. Metal concentrations before chelant application (June 6, 2008) and 14 months after its cessation (Oct 10, 2009) were usually low. The addition of EDDS was completely ineffective in enhancing the uptake of $\mathrm{Cd}, \mathrm{Pb}$ and $\mathrm{Zn}$, but it did somewhat increase the uptake of $\mathrm{Cu}$ (non-significant compared with the chelant-free control treatment; Table 3.5) and $\mathrm{Cr}$. Iron and $\mathrm{Mn}$ concentrations in the leaves were not affected by any of the chelants (Table 3.5). The addition of citric acid also had no effect on the concentration of the metals in the leaves (Table 3.5). 
Table 3.5: Average concentrations (in $\mathrm{mg} \mathrm{kg}^{-1}$ ) of elements in diagnostic leaves of $E$. camaldulensis during the second trial (2008-09)

\begin{tabular}{|c|c|c|c|c|c|c|c|c|c|c|}
\hline & Date & $\begin{array}{c}\text { All } \\
\text { Avg. }\end{array}$ & $\begin{array}{c}\text { Cont./ } \\
\text { RO }\end{array}$ & $\begin{array}{c}\text { Cont./ } \\
\text { Tap }\end{array}$ & $\begin{array}{c}\text { Citric/ } \\
\text { RO }\end{array}$ & $\begin{array}{c}\text { EDDS/ } \\
\text { RO }\end{array}$ & $\begin{array}{c}\text { EDDS/ } \\
\text { Tap }\end{array}$ & $\begin{array}{l}\text { EDTA/ } \\
\text { RO }\end{array}$ & $\begin{array}{c}\text { EDTA/ } \\
\text { Tap }\end{array}$ & $\begin{array}{l}\text { Mix/ } \\
\text { RO }\end{array}$ \\
\hline Cd & $\begin{array}{l}06-06-08 \\
20-08-08 \\
13-10-08 \\
22-01-09 \\
10-10-09\end{array}$ & $\begin{array}{c}17^{b} \\
44^{a} \\
28^{a b} \\
43^{a} \\
10\end{array}$ & $\begin{array}{c}14^{\alpha \beta ; b} \\
30^{\gamma ; a} \\
15^{b} \\
22^{\beta \gamma ; a b} \\
14^{b}\end{array}$ & $\begin{array}{c}15^{\alpha \beta ; b c} \\
36^{\beta \gamma ; a} \\
24^{b c} \\
30^{\alpha \beta \gamma} a b \\
10^{c}\end{array}$ & $\begin{array}{c}7^{\beta ; b} \\
23^{\gamma ; a} \\
9^{b} \\
15^{\gamma ; a b} \\
9^{b}\end{array}$ & $\begin{array}{c}9^{\beta} \\
23^{\gamma} \\
9 \\
17^{\gamma} \\
6\end{array}$ & $\begin{array}{c}10^{\beta} \\
32^{\beta \gamma} \\
11 \\
19^{\gamma} \\
13\end{array}$ & $\begin{array}{c}31^{\alpha ; b} \\
77^{\alpha \beta ; a} \\
48^{a b} \\
85^{\alpha ; a} \\
12^{b}\end{array}$ & $\begin{array}{c}18^{\alpha \beta ; b c} \\
55^{\alpha \beta \gamma ; a b} \\
50^{a b} \\
69^{\alpha \beta \gamma ; a} \\
6^{c}\end{array}$ & $\begin{array}{c}29^{\alpha} \\
80^{\alpha} \\
54 \\
84^{\alpha \beta} \\
7\end{array}$ \\
\hline Pb & $\begin{array}{l}06-06-08 \\
20-08-08 \\
13-10-08 \\
22-01-09\end{array}$ & $\begin{array}{l}1.3^{b} \\
4.5^{a b} \\
3.7^{a b} \\
5.2^{a}\end{array}$ & $\begin{array}{c}1.1^{\alpha \beta ; a b} \\
1.5^{\beta ; a} \\
0.3^{\beta ; b} \\
1.3^{\beta ; a}\end{array}$ & $\begin{array}{c}0.7^{\beta ; a b} \\
1.7^{\beta ; a} \\
0.1^{\beta ; b} \\
2^{\beta ; a}\end{array}$ & $\begin{array}{c}1.2^{\alpha \beta} \\
1.3^{\beta} \\
0.3^{\beta} \\
1^{\beta}\end{array}$ & $\begin{array}{c}0.8^{\beta} \\
1.8^{\beta} \\
1^{\beta} \\
1^{\beta}\end{array}$ & $\begin{array}{c}0.8^{\beta} \\
1.9^{\beta} \\
0.8^{\beta} \\
1^{\beta}\end{array}$ & $\begin{array}{c}2.2^{\alpha ; b} \\
10.2^{\alpha ; a} \\
10.2^{\alpha ; a} \\
15^{\alpha ; a}\end{array}$ & $\begin{array}{l}1.4^{\alpha \beta ; b} \\
7.9^{\alpha ; a} \\
8.4^{\alpha ; a} \\
10^{\alpha ; a}\end{array}$ & $\begin{array}{l}2.1^{\alpha} \\
9.8^{\alpha} \\
8.3^{\alpha} \\
10^{\alpha}\end{array}$ \\
\hline Zn & $\begin{array}{l}06-06-08 \\
20-08-08 \\
13-10-08 \\
22-01-09 \\
10-10-09\end{array}$ & $\begin{array}{c}63^{b c} \\
105^{a b} \\
105^{a b} \\
132^{a} \\
50^{c}\end{array}$ & $\begin{array}{c}64 \\
84^{\alpha \beta} \\
91 \\
94 \\
82^{\gamma}\end{array}$ & $\begin{array}{l}53 \\
66^{\beta} \\
58 \\
64 \\
36^{\beta}\end{array}$ & $\begin{array}{c}42 \\
53^{\beta} \\
50 \\
64 \\
50^{\alpha \beta}\end{array}$ & $\begin{array}{l}72 \\
64^{\beta} \\
47 \\
62 \\
37^{\beta}\end{array}$ & $\begin{array}{l}51 \\
69^{\beta} \\
48 \\
56 \\
43^{\beta}\end{array}$ & $\begin{array}{c}75^{b} \\
172^{\alpha \beta ; a} \\
185^{a} \\
258^{a} \\
68^{\alpha \beta ; b}\end{array}$ & $\begin{array}{c}56^{b c} \\
127^{\alpha \beta} ; a b \\
165^{a} \\
197^{a} \\
31^{\beta ; c}\end{array}$ & $\begin{array}{c}88 \\
205^{\alpha} \\
193 \\
261 \\
52^{\alpha \beta}\end{array}$ \\
\hline $\mathrm{Cu}$ & $\begin{array}{l}06-06-08 \\
20-08-08 \\
13-10-08 \\
22-01-09 \\
10-10-09\end{array}$ & $\begin{array}{l}6^{a b} \\
7^{a b} \\
12^{a} \\
7^{a b} \\
4^{a}\end{array}$ & $\begin{array}{l}3.2^{\beta} \\
3.2^{\beta} \\
5.1 \\
2.9^{\beta} \\
4.1^{\beta \gamma}\end{array}$ & $\begin{array}{c}3.7^{\beta ; a} \\
1.9^{\beta ; b} \\
2.9^{a b} \\
1.8^{\beta \gamma} ; b \\
1.8^{\beta \gamma ; b}\end{array}$ & $\begin{array}{c}2.8^{\beta ; a b} \\
1.6^{\beta ; c} \\
3.1^{a} \\
1.7^{\beta ; b c} \\
2^{\beta \gamma ; a b c}\end{array}$ & $\begin{array}{c}11.8^{\alpha ; a} \\
9.4^{\alpha \beta ; a b} \\
8.9^{a b} \\
5.9^{\beta ; a b} \\
3.8^{\beta \gamma ; b}\end{array}$ & $\begin{array}{c}5^{\beta ; a} \\
5.6^{\alpha \beta ; a} \\
4.5^{a b} \\
2.5^{\beta ; a b} \\
1.2^{\gamma ; b}\end{array}$ & $\begin{array}{c}4.9^{\beta ; c} \\
11.8^{\alpha \beta ; b c} \\
22.1^{a} \\
19.7^{\alpha ; a b} \\
8.5^{\alpha ; c}\end{array}$ & $\begin{array}{c}3.7^{\beta} \\
8.9^{\alpha \beta} \\
39.1 \\
10.5^{\alpha \beta} \\
2.3^{\beta \gamma}\end{array}$ & $\begin{array}{c}10.9^{\alpha} \\
14.9^{\alpha} \\
13.8 \\
11.4^{\alpha \beta} \\
5^{\beta}\end{array}$ \\
\hline $\mathbf{N i}$ & $\begin{array}{l}06-06-08 \\
20-08-08 \\
13-10-08 \\
22-01-09 \\
10-10-09\end{array}$ & $\begin{array}{c}4^{c} \\
13^{a b} \\
10^{b} \\
16^{a} \\
4^{c}\end{array}$ & $\begin{array}{c}3^{c} \\
8^{a b} \\
7^{\beta ; a b c} \\
9^{\beta ; a} \\
4.2^{\alpha ; b c}\end{array}$ & $\begin{array}{c}3 \\
10 \\
5^{\beta} \\
7^{\beta} \\
1.5^{\alpha}\end{array}$ & $\begin{array}{c}3^{b} \\
9^{a} \\
4^{\beta ; a b} \\
8^{\beta ; a b} \\
2.5^{\alpha ; b}\end{array}$ & $\begin{array}{c}7^{a b} \\
17^{a} \\
10^{a \beta ; a b} \\
19 a^{\beta ; a} \\
3.4^{\alpha ; b}\end{array}$ & $\begin{array}{c}4 \\
12 \\
5^{\beta} \\
9^{\beta} \\
1.7^{\alpha}\end{array}$ & $\begin{array}{c}4^{b} \\
18^{a} \\
15^{\alpha \beta ; a} \\
23^{\alpha \beta ; a} \\
6.7^{\alpha ; b}\end{array}$ & $\begin{array}{c}3^{b} \\
1^{a b} \\
13^{\alpha \beta ; a} \\
19^{\alpha \beta ; a} \\
2.9^{\alpha ; b}\end{array}$ & $\begin{array}{c}6^{b} \\
22^{a b} \\
21^{\alpha ; a b} \\
34^{\alpha ; a} \\
5.9^{\alpha ; b}\end{array}$ \\
\hline
\end{tabular}

Statistically significant differences between elemental concentrations in the leaves first passed ANOVA and those found significantly different at $p<0.05$ were subject to the Tukey-Kramer HSD multiple range test (at $\alpha<0.05$ ). Significantly different values are followed by a different letter. Each element was tested for the effect of the treatment within each date (values in rows; statistical significance designated in Greek letters) for the effect of time within each treatment (values in columns; statistical significance designated in common letters).

Presented here are the metal concentrations in the leaves. Three types of data are shown for each metal: first, the average concentration of the chelant-free control treatments, each value is the average of 30 measurements ( 2 water types, 3 lysimeters/each, 5 dates). Second, the data for the three EDTA treatments wherein only the 3 median dates (Aug 20, 2008-Jan 22, 2009) were considered. Two values are presented: the average of the 27 measurements ( 3 treatments, 3 lysimeters/each, 3 dates), and the largest of the 9 averages (Table 3.5). The average concentrations in the leaves are as follows: Cd increased from an average of $21 \mathrm{mg} \mathrm{kg}{ }^{-1}$ in the control treatments to $57 \mathrm{mg}$ $\mathrm{kg}^{-1}$, and the highest average concentration was $85 \mathrm{mg} \mathrm{kg}^{-1}$. The average lead concentrations in leaves were $1.1 \mathrm{mg} \mathrm{kg}{ }^{-1}$ (control), $8.2 \mathrm{mg} \mathrm{kg}^{-1}$ (overall EDTA) and $15 \mathrm{mg} \mathrm{kg}^{-1}$ (max EDTA of the 9 averages); the respective averages for $\mathrm{Zn}$ were 70,165 and $260 \mathrm{mg} \mathrm{kg}^{-1}$; Cu: $3.1,14.3$ and $39 \mathrm{mg} \mathrm{kg}^{-1}$; Ni: 5.8, 15.8 and $34 \mathrm{mg} \mathrm{kg}^{-1}$; and $\mathrm{Cr}: 1.1,2.1$ and $3.2 \mathrm{mg} \mathrm{kg}^{-1}$. The return to low metal concentrations previously observed in leaves that were sampled on October 2009 (Table 3.5) was concurrent with the complete depletion of EDTA in the soil solution (Figure 3.6). These leaves must have been young enough not to have been exposed to the prior higher metal concentrations in the soil solution. 


\subsection{CONCLUSION}

Eucalyptus camaldulensis, the model tree tested in this study, is very well suited for the rehabilitation and stabilization of metal polluted soils using CDI coupled with EDTA application. This fast growing, deep rooting tree responded to the gradual soil solution salination and increasing concentration EDTA-metal complexes by increasing metal concentrations in the leaves. Most leaching of the metal-EDTA complexes was prevented, thus only minute amounts were allowed to escape below the 'root zone'. Acclimated soil microflora degraded the metal-EDTA complexes prior to possible uncontrolled winter leaching, releasing the metals for plant uptake, adsorption onto the soil matrix and reprecipitation. At $10 \mathrm{mM}$ EDTA concentration in the incubated soil solution, the half-life of the chelant was 27 days. This biodegradation capacity was established over 20 months of a nearly continual EDTA presence in the soil. Even at concentrations well above $60 \mathrm{mM}$, most of the EDTA had eventually biodegraded as was inferred from the discrepancy between the relatively constant $\mathrm{Cl}$-concentrations in the $\mathrm{RO}$-water treatments on the one hand, and the declining concentrations of EDTA on the other. We further suggest that using CDI with RO-water can potentially solve the problem of soil salinization, thus widening the scope of CDI application in soil rehabilitation operations.

The data presented here is not in accord with postulates that "massive and persistent solubilization by field application of EDTA is neither a feasible nor sustainable approach" (Meers et al. 2008), and that use of 'persistent' chelantassisted phytoextraction is unlikely to lead to any sort of promising solution and that it should be abandoned (Evangelou et al. 2007a). These seem not to have considered circumstances that enable a tightly controlled leaching regime under repeated, yet incremental, application of phytoremediation agents for metal solubilization and translocation. Hence, while acclimated soil microflora degrade 'persistent' agents such as EDTA over time, 'transient' agents may be much too short lived for long-term in-situ operations. 
This page intentionally left blank 


\title{
CHAPTER 4 : PROXIMAL SPECTRAL SENSING OF METAL-CONTAMINATED SOILS - A TECHNOLOGY REVIEW ${ }^{1}$
}

\begin{abstract}
Assessment of soil contamination and its long-term monitoring are necessary to evaluate the effectiveness of phytoremediation systems. Spectral sensingbased monitoring methods promise obvious benefits compared to field-based methods: lower cost, faster data acquisition and better spatio-temporal monitoring. This chapter reviews the theoretical basis whereby proximal spectral sensing of soil and vegetation could be used to monitor phytoremediation of metal-contaminated soils, and the eventual up-scaling to imaging sensing. Both laboratory and field spectroscopy have been applied to sense heavy metals in soils indirectly via their intercorrelations with soil constituents, and also through metal-induced vegetation stress. In soil, most predictions are based on intercorrelations of metals with spectrally-active soil constituents, viz., Fe-oxides, organic carbon, and clays. Spectral variations in metal-stressed plants is particularly associated with changes in chlorophyll, other pigments, and cell structure, all of which can be investigated by vegetation indices and red edge position shifts. Key shortcomings in obtaining satisfactory calibration for monitoring the metals in soils or metal-related plant stress include: reduced prediction accuracy compared to chemical methods, complexity of spectra, no unique spectral features associated with metalrelated plant stresses, and transfer of calibrations from laboratory to field to regional scale. Nonetheless, spectral sensing promises to be a time saving, non-destructive and cost-effective option for long-term monitoring especially over large phytoremediation areas, and it is well-suited to phytoremediation networks where monitoring is an integral part.
\end{abstract}

${ }^{1}$ This chapter is based on following paper:

Paresh H. Rathod, David G. Rossiter, Marleen F. Noomen and Freek D. van der Meer (2013). Proximal spectral sensing to monitor phytoremediation of metal-contaminated soils. International Journal of Phytoremediation, 15 (5): 405-426.

DOI: $10.1080 / 15226514.2012 .702805$. 


\subsection{INTRODUCTION}

The term "phytoremediation' refers to a non-destructive method to remove contaminants such as heavy metals from soils by means of vegetation (Salt et al. 1998). This approach, especially phytoextraction and phytostabilization, has gained popularity compared to soil cleaning for both financial and environmental reasons. Phytoremediation, like any remedial system, requires regular monitoring to determine progress towards its objectives (ITRC 2009). This is especially true for phytoextraction system, since it would take decades to decontaminate a site, and also for the phytostabilization system, wherein contaminants are left in place, hence long-term monitoring is essential to make sure that stabilizing conditions maintained in the future (USEPA 2000). To ensure that phytoremediation proceeds quickly and at the lowest cost possible, it is necessary confirm that plants are healthy, actively growing and taking up the contaminant from soils. Monitoring can also be continued after cleanup in order to determine the effect of phytoremediation on the eco-system. Monitoring implies an extensive and repeated measurement, so that measurement techniques must be fast, inexpensive, and sensitive enough to distinguish real change in status from system noise.

\subsubsection{CURRENT PRACTICE IN PHYTOREMEDIATION MONITORING}

The US-DOE (2000) has categorized phytoremediation monitoring into: (i) performance monitoring - to determine the effectiveness of phytoremediation process to meet standard regulatory limits, (ii) risk monitoring - to assure that bioaccumulation of metals in plant or metal stabilization in soil root-zone does not cause human health or ecological risk, and (iii) optimization monitoring to manage agronomic practices for optimal plant growth rate to facilitate the optimal metal removal from site (i.e., biomass yields $\times$ plant metal concentration), and for optimal root growth, its lateral extension to phytostabilize the metals in root-zone.

Performance monitoring is requisite to determine success of phytoremediation in reaching regulatory limits and is the prime objective of most monitoring programs. The performance determination involves the calculation of mass balance of contaminant and/or its degradation product in soil-plant system. Phytoremediation efficiency can be also evaluated on the basis of net metalremoval from soil i.e., bio-concentration factor, translocation index, metal extraction ratio (McGrath and Zhao 2003; Mertens et al. 2005) and restoration time required to achieve cleanup goal (ITRC 2009). Moreover, performance monitoring must take into account the particular mechanism of phytoremediation approach (McLinn 2001) listed in the Table 1.2 of chapter 1. There is, yet no conceptual monitoring framework and well-established performance criteria for phytoremediation system that allow practitioners to monitor remediation in a consistent way. The only documents available are: an introduction of phytoremediation (USEPA 2000) and recent revised technical and regulatory guidance for phytotechnology (ITRC 2009). However, determination of several parameters, such as geo-chemical analyses, mass balance of contaminants in soil and measurement of plant growth parameters (both physical and biochemical; survivability) as well as stress response, are useful for assessing performance of phytoremediation program. 
Risk monitoring of remediation system is again as important as performance monitoring to assure that bioaccumulation of contaminants in plants does not cause human health or ecological risk. This involves identification of potentially contaminated media, release and exposure pathways, and potential receptors. While, optimization monitoring must goes with performance monitoring to managing soil fertility, irrigation and other agronomic practices for optimal plant growth and contaminant removal. Most monitoring criteria in phytoremediation system are remain as same as in any other remediation system (McLinn 2001). Table 1.3 in chapter 1 lists common monitored parameters. This list is not all-inclusive, and is vary with the individual phytoremediation system (USEPA 2000).

Standard monitoring technique requires destructive samplings of soil and plant for chemical analyses in the laboratory to determine their metal concentration and their spatial distribution. Field methods for assessing plant stress may use sap flow loggers to measure plant water use, photosynthetically active radiation sensors, dendrometers for measuring plant growth, or leaf area and root measurement systems (section 1.4 of chapter 1 ). These conventional methods are relatively expensive, and besides unfeasible for continual monitoring the larger contaminated sites (McCarty and Reeves 2006; Ortega and Santibáñez 2007; Wu et al. 2005b). This motivates the search for fast, inexpensive techniques that can be applied to many samples and repetitive measurements. An obvious candidate is remote sensing, which may cover larger areas at low cost and high temporal resolution (Dematte et al. 2009; Nanni and Dematte 2006). Remote sensing is routinely used to assess agricultural conditions, and could also be used at phytoremediation sites (Burckhard 1998, 1999). Furthermore, remotely-sensed data can easily be integrated into Geographic Information System (GIS) for analyses such as spatial autocorrelation or trend analysis and spatial correlation with predictive or explanatory factors, and might be used to produce maps of phytoremediation sites.

\subsubsection{Potential of REMOte SENSING for monitoring PHYTOREMEDIATION}

Remote sensing is generic term refers to any technique that senses without touching the target, either close (laboratory), medium (field), or far (air or space). A wide variety of sensors are available at all scales (laboratory, field, aerial, and satellite) with countless applications (Borengasser et al. 2007; Navalgund et al. 2007). Measurements by sensors must be calibrated with direct measurements of the property of interest. A further step is to determine the physical basis for any observed relation. This can be direct, i.e., the target property affects the sensor, or indirect, i.e., some other part the of system affects the sensors and this part is affected by the target property. In context of phytoremediation of metal-contaminated soils we can distinguish (i) direct measurements of targets, for example heavy metals in soils; (ii) indirect measurements via other soil properties; (iii) direct measurements of targets in plants; and (iv) indirect measurements via plant properties, e.g., metal induced stress response. With added spatial and temporal components, many advanced remote sensing techniques have potential in assessing the conditions at metal-contaminated site and providing significant information to the 
remediation programs. Of the many available remote sensing systems, visible and near-infrared (Vis-NIR; 350-1100 nm), shortwave-infrared (SWIR; 1100$2500 \mathrm{~nm}$ ) and mid-infrared (MIR; 2500-25000 nm) reflectance spectroscopy, have been most used to assess soil properties (Cécillon et al. 2009; Du and Zhou 2009; Stenberg et al. 2010) and plant conditions (Font et al. 2007).

It is useful to distinguish proximal sensing (also called 'near sensing') from far remote sensing. Proximal sensing is close enough to the target (either in field or laboratory) that the sensor records a single spectrum of the target, generally considered as single "pure" object (Viscarra Rossel et al. 2010). Common illumination is tungsten halogen-bulb radiation (in the laboratory) and direct solar radiation (in the field). Common instruments used in the field or laboratory to measure the Vis-IR spectra are Analytical Spectral Devices Inc. FieldSpec portable spectroradiometer, Spectra Vista Corporation's GER series spectroradiometer, etc. While, far remote sensing for constituents or status generally uses hyperspectral images, also termed imaging spectroscopy, where the image sensor collects data from airborne or satellite platforms with an area-array detector which integrates over a larger area. The aim of this chapter is to review applications of proximal spectral sensing for monitoring soil metal-contamination and relevant plant health status in order to evaluate its suitability as technique for monitoring phytoremediation sites. Hereunder, sections 4.2 and 4.3 summarize the infrared spectroscopic studies, respectively on monitoring soil metal-contamination and changes in plant spectral properties due to phyto-accumulation of metals or toxic effects of elevated concentration of metals in root-zone. The chapter ends with challenges and ideas of possible up-scaling of proximal sensing techniques to hyperspectral imaging spectroscopy for phytoremediation monitoring.

\subsection{NEAR/PROXIMAL SPECTRAL SENSING FOR ASSESSING METAL CONTAMINATION IN SOILS}

Proximal soil sensing has gained much attention among soil scientist for measuring a wide range of soil constituents, notably organic carbon, plant nutrients and soil minerals, as well as soil functions such as workability (Viscarra Rossel et al. 2010). This technique is able to collect in-situ spectral data in the Vis-IR regions from close by, or within the soils using hand-held and/or field-based sensors. These sensors are of active or passive; invasive (direct sensor-to-soil contact) or non-invasive (measuring soil above the surface). However, there no much literature available on proximal sensing of heavy metals, most likely because they are difficult to directly sense (see below) with these systems.

Infrared spectroscopy is sensitive to both organic and inorganic constituents of soil and is based on vibrations of the bonds within molecules, when stimulated with Vis-NIR radiation. Visible radiation $(350-780 \mathrm{~nm}$ ) is primarily associated with iron-containing minerals, e.g., hematite and goethite (Sherman and Waite 1985), and with organic matter (Daniel et al. 2004). Near- and shortwaveinfrared radiation (780-2500 $\mathrm{nm}$ ) is mostly absorbed by water, soil organic matter (Song and $\mathrm{He} 2005$ ), and by ions of transition metals (Fe, $\mathrm{Ni}, \mathrm{Cr}$, Co, $\mathrm{Cu})$ due to electronic processes (Holze 2004; Hunt 1977). Infrared 
spectroscopy combined with statistical data-reduction and regression techniques (Xu et al. 2008), has been used for soil characterization and quantitative prediction of various physico-chemical constituents of soil, for examples Fe-oxides (Nanni and Dematte 2006; Scheinost et al. 1998), organic matter, organic and inorganic carbon (Morgan et al. 2009; Reeves III 2010), and clays (Van Der Meer 1999; Waiser et al. 2007). Moreover, several soil environmental concerns, such as salinity (Farifteh et al. 2008), hydrocarbon contamination (Chakraborty and Weindorf 2010; Van der Meer et al. 2002) have also been investigated using infrared spectroscopy. The feasibility of VisIR spectroscopy for monitoring metal-contaminated soils has been of research interest since it was first reported by Malley and Williams (1997). An important distinction is between direct methods, where metal contamination affects the spectrum directly, and indirect methods, where metals either affect some other soil constituent that affects the spectrum, or where metals are correlated with some other constituents. We consider these indirect methods in turn.

\subsubsection{DIRECT PREDICTION OF HEAVY METALS IN SOIL}

Direct quantitative prediction of heavy metals using soil Vis-IR spectroscopy is, in general, not possible since most metallic ions are spectrally featureless in Vis-IR regions. However, transition elements such as $\mathrm{Ni}, \mathrm{Cu}, \mathrm{Co}$ and $\mathrm{Cr}$ with an unfilled ' $d$ ' shell, can exhibit absorption features due to crystal field effects (Burns 1993; Clark 1999a). For example, Wu et al. (2007) modelled absorption feature of transition metals ( $\mathrm{Ni}, \mathrm{Cr}$ and $\mathrm{Cu}$ ) using reflectance spectra of artificially contaminated soil samples. Metals could not be detected directly at concentration $<1000 \mathrm{mg} \mathrm{kg}^{-1}$, but $\mathrm{Cr}$ and $\mathrm{Cu}$ exhibited absorption features (610 and $830 \mathrm{~nm}$ ) at concentrations $>4000 \mathrm{mg} \mathrm{kg}{ }^{-1}$. Such high soil contamination occurs only near some mining or industrial areas. On contaminated agricultural soils having moderate to low, diffuse contamination, direct prediction of heavy metals with their absorption features seems impossible. Since many phytoremediation sites are of this type (e.g., contaminated floodplains), indirect methods must be used.

\subsubsection{INDIRECT PREDICTION OF HEAVY METALS IN SOIL}

The sorption of metals in soils is mainly due to oxides of $\mathrm{Fe}$ and $\mathrm{Al}$, clay minerals and organic matter. Therefore, indirect prediction of metallic ions via their intercorrelations with these spectrally active soil constituents has been well investigated. A problem with this approach is: determining what proportion of these natural constituents has sorbed metal cations. In general this is solved by knowing that a site is contaminated, from a field study or historical knowledge, and then assessing the level of contaminant by correlated constituent. Using this indirect approach in assessing metals in phytoremediation system has the additional difficulty that the concentration of predictor constituents is not expected to vary as a result of metal being removed or stabilized from the system by plants. However, the basic principle involves the metal cation $\left(\mathrm{M}^{2+}\right)$ binding onto the hydroxylated sites $(R O H$; where $R=\mathrm{Al}, \mathrm{Fe}, \mathrm{Mn}, \mathrm{Si}$; $R \mathrm{OH}+\mathrm{M}^{2+}=R \mathrm{O}-\mathrm{M}^{+}+\mathrm{H}^{+}$) on a surface, such as clays and metal oxides. In heavily contaminated soils, the extent of $R \mathrm{OH}$ sites may decrease, with a consequent increase in $R O$, and these changes may cause variation in soil reflectance spectral features. Various prediction mechanisms have been proposed based on such metal-binding reactions and metal's 
associations with spectrally active soil constituents. The most common tool used for the indirect predictions were by chemometric approaches, such as partial least square regression (PLSR), principal component regression (PCR), multiple linear regression (MLR), artificial neural networks (ANN), etc., which develops calibration models (Beebe et al. 1998). This calibration mostly involves spectral pre-processing (viz., derivatives, continuum removal, multiplicative scatter correction, etc.; to deal with scattering effect and outliers), model selection and validation.

\subsubsection{PREDICTIONS BASED ON IRON OXIDES AND CLAYS}

Most Fe-oxide in soils and sediments, e.g., goethite $(\alpha-\mathrm{FeOOH})$, exhibit absorption bands in the Vis-NIR (Torrent and Barrón 2002), while clay minerals have absorption features in the SWIR and MIR regions due to $\mathrm{OH}, \mathrm{H}_{2} \mathrm{O}$, and $\mathrm{CO}_{3}$ overtones and combination vibrations (Clark 1999a). Variation in spectral absorption features near $500 \mathrm{~nm}$ and $2200 \mathrm{~nm}$ are associated with FeO and hydroxyl lattice on mineral surface, respectively (Ben-Dor et al. 1999).

Kemper and Sommer (2002) showed that Vis-NIR wavelengths used for predicting metals in soil polluted by a mining accident could be attributed to the absorption features of Fe-oxides and clays minerals. This is as expected, since soil samples were taken from floodplains of the Agrio and Guadiamar rivers (Spain), which were contaminated by pyritic sludge due to Aznalcóllar Mine accident. Authors obtained the best coefficients of determination $\left(R^{2}\right)$ $>0.80$ by MLR and ANN, between predicted and chemically-analyzed concentrations for $\mathrm{As}, \mathrm{Pb}, \mathrm{Hg}$ and $\mathrm{Sb}$, whereas predictions of $\mathrm{Cd}, \mathrm{Zn}$ and $\mathrm{Cu}$ were poor. This can be attributed to their different geo-chemical behaviour in soils, e.g., solubility and precipitation. While, other element were could be strongly adsorbed by pyritic sludge. Contrary to the above findings, Xia et al. (2007) found significant exponential relationship between Cd concentration in sediment of Changjiang (Yangtze, China) river and spectral proxies of Feoxides (first derivatives of absorption at 560-760 nm), clay minerals (first derivatives at $1410,1910,2300 \mathrm{~nm})$ and organic matter $(400-530 \mathrm{~nm})$. In this study, about $70 \%$ of total Cd was presented in exchangeable and reducible forms, to be associated with Fe- and Mn-oxides and clay minerals and allows their predictions using soil reflectance.

Choe et al. (2008) correlated the metal concentrations in gold mining areas (SE Spain; concentration of $\mathrm{Pb}, \mathrm{Zn}$, As were ranged from 96-18811, 61-728, $62-826 \mathrm{mg} \mathrm{kg}^{-1}$, respectively) to the variation in spectral absorption features of the hydroxyl lattice on surface of clays and oxides due to metal complexation. Results showed significant correlations between $\mathrm{Pb}$ and the absorption ratio of 610 to $500 \mathrm{~nm}, \mathrm{Zn}$ and absorption area at $2200 \mathrm{~nm}$, and As and the asymmetry of absorption at $2200 \mathrm{~nm}$. Stepwise linear multiple regression using all three spectral features was much stronger $\left(R^{2}=0.84\right)$, and it showed a weak relationship for $\mathrm{Zn}$ and $\mathrm{Pb}$. However, for the multiple linear regression using enter method, superior predictions for $\mathrm{Zn}, \mathrm{Pb}$ and $\mathrm{As}$ were reported with $\mathrm{R}^{2}=0.59,0.61$ and 0.87 , respectively. In another study, authors reported similar results for $\mathrm{As}, \mathrm{Cu}$, and $\mathrm{Pb}$ concentration in areas around an Au-Ag mine in Republic of Korea (Choe et al. 2009). Both these reports as well as of Kemper and Sommer (2002) were studied the soils from mining regions, 
where heavy metal contamination is very high, and were of highly correlated to each other and to absorption features of Fe and Fe-oxides.

Comparably, for metal-contaminated agricultural soils in Nanjing areas (China), Wu et al. (2005b) showed similar results that the most important wavelengths for metal prediction, were attributed to absorption features of Feoxides and clays i.e., at 520, 900 and 2000-2200 nm, respectively related to the goethite, $\mathrm{Fe}^{3+}$ or $\mathrm{Fe}^{2+}$ and clays absorption. However, regression coefficients in later two regions were lower, indicates a weak absorption capability of other Fe-oxides and clay minerals than goethite. A satisfactory prediction was obtained for studied metals, with correlation coefficients of predicted vs. measured, were above 0.87 for $\mathrm{Ni}$ and $\mathrm{Cr}$, and varies from 0.65 0.81 for $\mathrm{Cu}, \mathrm{Hg}, \mathrm{Pb}, \mathrm{Zn}$ and As. Likewise, in another study on assessing $\mathrm{Hg}$ concentration in soils of same region, authors found that the wavelengths 496 and $2210 \mathrm{~nm}$ used for $\mathrm{Hg}$ prediction, were attributed to absorption features of goethite and clay minerals, respectively (Wu et al. 2005a). Authors worked out prediction capability of reflectance spectra to classify $\mathrm{Hg}$ contamination classes, and found that classification accuracy for low contamination was satisfactory; however for the highly contaminated classes, it was low. Therefore, authors suggested for considering the various chemical $\mathrm{Hg}$-binding forms to improve prediction accuracy. Contributing to above studies, Wu et al. (2007) showed that the major prediction mechanism of certain metals was based on their correlation with total Fe i.e., active and residual Fe. Authors supported this by combing statistical methods and chemical sequential extraction, wherein inclusion in PLSR models of residual fractions of metals strengthens the prediction. The results showed the highest prediction accuracy for $\mathrm{Ni}, \mathrm{Cr}, \mathrm{Co}$, and the lowest for $\mathrm{Cd}$. The poorer prediction of $\mathrm{Cd}$ was explained by its higher exchangeable and lower residual fractions. It does show that the correlated constituent alone is not sufficient to predict the metal with high accuracy. This however requires a detailed chemical analysis to get best celebration models. It is also an argument that the residual fraction has no direct environmental impact because is too strongly fixed to soil. Nonetheless, recent works of Ji et al. (2010), Ren et al. (2009) and Wu et al. (2011) demonstrated the potential of Vis-IR spectroscopy for monitoring of heavy metal $(\mathrm{Ni}, \mathrm{Cr}, \mathrm{Cu}, \mathrm{Co})$ in agricultural soils by spectral features via Fe-based indirect prediction. However, prediction for Cd was found least, in agrees with other researchers' findings (Kemper and Sommer 2002; Wu et al. 2007).

\subsubsection{PREDICTIONS BASED ON ORGANIC MATTER OR ORGANIC CARBON}

In contrast to above results, many studies conclude that metal sorption by soil organic matter (SOM), often reported as soil organic carbon (SOC) is the major mechanism to predict heavy metal by Vis-IR spectroscopy. An association of metals with soil SOM is well described (Kabata-Pendias and Pendias 2001). SOM has distinct spectral fingerprints in the Vis-IR regions due to various chemical bonds such as $\mathrm{C}-\mathrm{H}, \mathrm{C}-\mathrm{C}, \mathrm{C}=\mathrm{C}, \mathrm{C}-\mathrm{N}$, and $\mathrm{O}-\mathrm{H}$ (He et al. 2009; Ludwig and Khanna 2001). Again, the question is how the researcher can determine whether the detected SOM is contaminated or not. As with the association with inorganic constituents, studies are mostly of known contaminated sites, and have been used to assess contaminated levels at one point in time, not for monitoring. Same is true for other indirect parameters like clays or Fe-oxides. 
Malley and Williams (1997) were the first to report the prediction of heavy metal concentrations in fresh-water sediments by infrared spectroscopy (1000$2500 \mathrm{~nm}$ ) on the basis of their association with OM. They obtained good predictive relations between NIR-predicted and chemically-analyzed metal concentration: $\mathrm{R}^{2}>0.90$ for $\mathrm{Cu}, \mathrm{Zn}, \mathrm{Mn} ; 0.80-0.90$ for $\mathrm{Pb}, \mathrm{Ni}, \mathrm{Fe} ; 0.61$ for $\mathrm{Cd}$. The poorer prediction for $\mathrm{Cd}$ was attributed to its association with inorganic soil constituents and its shorter residence time in the sediments, since it was experimentally elevated several years before sampling. Similarly, Kooistra et al. (2001) used absorption features of OM (2000-2500 nm) in PLSR models to assess $\mathrm{Cd}$ and $\mathrm{Zn}$ contaminated areas in the floodplains of river Rhine (Netherlands). Moros et al. (2008); Moros et al. (2009) also used a similar wavelength range, in their case 2241-2598 nm, in PLSR models for screening several metals in estuarine sediments. For instance, PLSR models well predicted the contents of $\mathrm{As}, \mathrm{Pb}$ and $\mathrm{Cd}$, while $\mathrm{Co}$ and Ni were poorly predicted due to their inorganic forms in the sediments. Vohland et al. (2009) showed that a spectroscopic assessment of trace metals in German floodplain soil by means of active SOC as major predictor is feasible, however, the PLSR accuracies for $\mathrm{Zn}, \mathrm{Pb}, \mathrm{Cu}$ prediction were low $\left(\mathrm{R}^{2}=0.56-0.71\right)$. Similarly, the spectral region of $400-530 \mathrm{~nm}$, absorption at $630 \mathrm{~nm}$, and absorption ratio of $624 / 564 \mathrm{~nm}$ were found to be dominant spectral proxies of OM/SOC, respectively for prediction of total $\mathrm{Cd}$ in river sediments (Xia et al. 2007), for $\mathrm{Cd}$ in agricultural soils in the Changjiang river delta (Ji et al. 2010), and Pb, $\mathrm{Cu}, \mathrm{Zn}$ in soils (Liu et al. 2011b). Recently, Zheng et al. (2011) found that prediction of As in soil having lower OM content was better $\left(R^{2}=0.69\right)$ than that in soils with of higher OM. Pandit et al. (2010) observed that SOM masks the spectral signatures, so that most significantly correlated spectral bands i.e. 800 and $1300 \mathrm{~nm}$ to soil $\mathrm{Pb}$ did not result in highly accurate prediction.

\subsubsection{PREDICTIONS USING MID-INFRARED SPECTRA}

It has been found that NIR-based calibrations underestimated certain inorganic forms of heavy metal e.g., dust-borne heavy metals in heavily polluted arable soil and in forest soil organic layers close to industrial emissions (Chodak et al. 2007; Siebielec et al. 2004). Instead, mid-infrared reflectance spectroscopy has been reported more promising (Janik et al. 1998), since the MIR regions contain more wavelengths associated to the vibrations of fundamental organic bonds (e.g., $\mathrm{C}-\mathrm{H}, \mathrm{O}-\mathrm{H}, \mathrm{C}=\mathrm{O}, \mathrm{C}-\mathrm{O}-\mathrm{C}, \mathrm{N}-\mathrm{H}$, etc.) and also to the inorganic components e.g., phosphate and carbonate in the soils (Siebielec et al. 2004). In this study, prediction of $\mathrm{Cd}, \mathrm{Cu}, \mathrm{Ni}$, and $\mathrm{Zn}$ based on MIR-calibrations gave better results, with $\mathrm{R}^{2}=0.94,0.80,0.99$ and 0.96 , respectively. Dupuy and Douay (2001) showed that MIR spectral bands centred at $5848 \mathrm{~nm}$ (1710 $\left.\mathrm{cm}^{-1}\right)$ and 5917-5988 nm (1690-1670 $\left.\mathrm{cm}^{-1}\right)$ vary with $\mathrm{Pb}$ concentration, which seems to be preferentially complexed by functional groups such as, phenolic hydroxyls or carboxylic groups present in organic matter (Logan et al. 1997). MIR spectroscopy substantially outperformed NIR for prediction of metal contents in ex-situ soils (Wu et al. 2010b), where a PLSR calibration model for 8 elements had satisfactory $\mathrm{R}^{2}$ values ( $\mathrm{Ni}>0.80>\mathrm{Cr}, \mathrm{Cu}, \mathrm{Zn}, \mathrm{Pb}, \mathrm{Hg}>0.60$ $>$ As, Cd) when applied to validation set. However, Bray et al. (2009) and Moros et al. (2009) preferred reflectance spectroscopy in Vis-IR over MIR, since it may be used in-situ for providing real-time diagnostic screening. 


\subsubsection{CHALLENGES TO INDIRECT PREDICTION MODELS}

As discussed above, metals can indirectly be assessed by soil reflectance via surrogate calibration using regression modeling, which largely involves the metal's correlation with certain soil constituents. Variation in results obtained in the reported studies, as summarized in Table 4.1, is possibly justified by many factors like: soil sampling, chemical analytical procedure, selection of spectral features, regression methods, sample size, etc. Key shortcomings in estimating soil metals by spectral sensing in comparison with classic chemical methods are: the reduced accuracy of prediction, it does sense only the surface soils and in-situ subsurface sensing is difficult, model calibrations greatly depend on the quality of chemical reference data. Most studies discussed above were done in laboratory with small-medium sample set (Table 4.1), where conditions are more feasible, less environmental interference than in the field. Even so, prediction accuracy of lab-based calibration may be influenced by analytical or subsampling errors. Additionally, usage of different spectrometers might leads to the variations in result i.e., instrumental errors, and this needed to be corrected by spectral standardization using common internal standard (e.g., sand) and protocol to correct the spectra from any spectrometers (Pimstein et al. 2011). In-situ spectral measurement also involves spectral complication due to soil roughness, soil moisture, sun zenith, low signal-tonoise, vegetative cover, etc. However, these shortcomings do not imply that calibrations from one soil dataset would be irrelevant to another. A comparative study is needed to validate a calibration model (i.e. developed using soil dataset from in-situ multi-metal contaminated site e.g., river floodplain) for an independent soil dataset belongs to areas of single metal contamination with specific source. It is feasible to apply such locally-calibrated model to larger regions having broad range of metal content and similar soil types for preliminary monitoring of contaminants (Wu et al. 2011). Many scientists advocated for a soil spectral library concept (Cécillon et al. 2009; Du and Zhou 2009; Slonecker et al. 2010) that might be useful in this direction. Moreover, further study is also needed for comparison of errors for chemical analysis and spectral sensing.

A reliable and robust indirect prediction is challenging as soil predictive properties, especially SOM, SOC, clay contents, Fe-oxides, and other hydroxides were varied distinctly from one study to another. This is not surprising that in-situ metal-contaminated sites, such as abandoned mines, have extreme variations in all these properties and so, does alter the soil reflectance. But it maybe not the same for agricultural or anthropogenic metalcontamination, as it has been shown in study of Pandit et al. (2010) that little $\mathrm{SOM}$ needed to retain soil $\mathrm{Pb}$, and consequently an increase in SOM would not retain any more $\mathrm{Pb}$. Interactions between soil constituents and metal sorption are largely controlled by soil $\mathrm{pH}$, ionic strength, ligand ions, nature and species of metallic ions present, etc. (Naidu et al. 1998). A clear relationship between soil texture and accuracy of predictions was observed by Siebielec et al. (2004) for all studied metals except Fe. Predictions of metals were inaccurate in soils having clay content less than $70-80 \mathrm{~g} \mathrm{~kg}^{-1}$. Organic matter itself changes in quality as it decomposes and passes through various humus forms; this strongly influences soil reflectance (Ben-Dor and Banin 1995). Moreover, complexation of metals to organic fractions is variable and depends on size 
fractions (Ducaroir and Lamy 1995; Parat et al. 2002). A metal binding to OM is usually attributed to humic substances enriched with functional groups, such as carboxyl and hydroxyl, which serve as electron donors; accordingly, variations in soil spectral feature will occur due to humus type, irrespective of metal complexation. In soil with multi-metal contaminations, it is possible that while SOM has little relation to one metal, it does affect other metals as reported by Pandit et al. (2010) in case of Pb deposition in soil. However, these authors succeed in predicting soil Pb by PLSR modeling $\left(R^{2}=0.95\right)$ using a full Vis-IR spectrum data. The sorption of metals by Fe-oxides, especially depends on soil $\mathrm{pH}$ and presence of humic substances, and accordingly the order of binding of metals onto the surface differs with these (Kabata-Pendias and Pendias 2001). Soil constitutes, those associated with metals, do not change in their concentration due to phytoremediation, but their geo-chemical behavior or associations might change with the progress of phytoremediation, particularly when soil amendments or chelating agents used to enhance metal extraction or stabilization, and this should be addressed appropriately

\subsection{Proximal SPECTRAL SENSING FOR MONITORING VEGETATION IN PHYTOREMEDIATION SYSTEMS}

For successful phytoremediation, another key consideration is that the system must function for decades to meet an acceptable limit of contaminants in soils, i.e. chemically reactive pool of metals. Hence, the survivability and growth rate of plants, exposed to metal load, needs to be monitored closely and periodically. To this respect, monitoring of variations in plant spectral characteristics in Vis-IR regions due to direct effects of metal phytoextraction and/or indirect toxic effects of metal in soil rhizosphere, as in case of phytodegradation and phytostabilization, could provide measure of plant health status before any stress-related damage occurs. Spectral characteristics of leaf are mainly governed by its cellular structure, water content, biochemical composition, and pigments content (Guyot et al. 1992). Excessive concentrations of heavy metals (both essential and non-essential elements) in soils and their plant uptake adversely affect plant growth causing metabolic disturbance (Maksymiec 2007; Prasad 2004) and/or ultra-structural changes in tissues (Kabata-Pendias and Pendias 2001) that distinctly influences the spectral characteristic of the plant (Figure 4.1). In general, metal-induced stress causes a decrease in chlorophyll content (Zengin and Munzuroglu 2005), changes in leaf internal structure (Slaton et al. 2001), and these directly or indirectly alter the reflectance of Vis-IR radiation, (Horler et al. 1980; Milton et al. 1989; Schwaller et al. 1983).

In recent years, several papers have explored the concept of vegetation stress as bio-indicators of soil contamination using Vis-IR reflectance spectroscopy. For example, Noomen et al. (2008) studied spectral changes in leaves of maize and wheat plants as a result of soil hydrocarbons-contamination; Font et al. (2004); Font et al. (2002); Font et al. (2005) monitored heavy metals in plant samples of Indian mustard, amaranth and rice; Woodhouse et al. (1994) detected $\mathrm{Zn}$ and $\mathrm{Cu}$-induced stress in wheat and lettuce, and Rosso et al. (2005) showed that visible reflectance of pickle weed leaves closely followed the changes in pigment concentration due to $\mathrm{Cd}$ treatments. 
Table 4.1: Summary of indirect predictions of heavy metal through soil reflectance spectra

\begin{tabular}{|c|c|c|c|c|c|}
\hline $\begin{array}{l}\text { *Heavy } \\
\text { Metals }\end{array}$ & $\begin{array}{l}\text { Concentration } \\
\text { range in soils } \\
\left(\mathrm{mg} \mathrm{kg} \mathrm{k}^{-1}\right)\end{array}$ & $\begin{array}{l}\text { Regression statistics } \\
\text { (technique) }\end{array}$ & $\begin{array}{l}\text { Type of spectra or } \\
\text { absorption features used }\end{array}$ & $\begin{array}{c}\text { Sample size } \\
(\#) ; \text { Sampling } \\
\text { site }\end{array}$ & Reference \\
\hline $\mathrm{Zn}$ & - & $R^{2}=0.92(P L S R)$ & $\begin{array}{l}\text { Reflectance spectra at } 1100-2498 \\
\text { nm }\end{array}$ & $\begin{array}{l}\text { 169; River } \\
\text { sediments }\end{array}$ & $\begin{array}{l}\text { Malley and Williams } \\
\text { (1997) }\end{array}$ \\
\hline $\mathrm{Zn}$ & - & $R^{2}=0.92(P L S R)$ & VNIR soil reflectance spectra & $\begin{array}{l}\text { 69; Floodplain } \\
\text { soils }\end{array}$ & Kooistra et al. (2001) \\
\hline $\begin{array}{l}\mathrm{Hg} \\
\mathrm{Pb}\end{array}$ & $\begin{array}{l}0.01-0.29 \\
8-221 \\
\end{array}$ & $\begin{array}{l}\mathrm{R}^{2}=0.96(\mathrm{MLR}), 0.93(\mathrm{ANN}) \\
\mathrm{R}^{2}=0.95(\mathrm{MLR}), 0.94(\text { ANN })\end{array}$ & $2^{\text {nd }}$ Derivatives of $700-1400 \mathrm{~nm}$ & 214; Mining & \begin{tabular}{|l|} 
Kemper and Sommer \\
$(2002)$
\end{tabular} \\
\hline $\begin{array}{l}\mathrm{Ni} \\
\mathrm{Zn} \\
\mathrm{Pb}\end{array}$ & $\begin{array}{c}13.3 \text { (mean) } \\
14-4500 \\
18-6530\end{array}$ & $\begin{array}{l}R^{2}=0.99(P L S R) \\
R^{2}=0.96(P L S R) \\
R^{2}=0.94(\text { PLSR) }\end{array}$ & $\begin{array}{l}\text { All predictions using mid-infrared } \\
\text { spectra; Mean and variance, MSC }\end{array}$ & 70; Agril. soils & Siebielec et al. (2004) \\
\hline $\mathrm{Ni}$ & $10.6-57.5$ & $R^{2}=0.93(P L S R)$ & Reduced spectra at $128 \mathrm{~nm}$ interval & $\begin{array}{l}120 ; \text { Suburban } \\
\text { soils }\end{array}$ & Wu et al. (2005a) \\
\hline $\mathrm{Hg}$ & $0.04-1.26$ & $R=0.84(P C R)$ & $\begin{array}{l}1^{\text {st }} \text { Derivatives spectra at } 1000- \\
2500 \mathrm{~nm}\end{array}$ & $\begin{array}{l}105 ; \text { Agril. } \\
\text { soils, delta }\end{array}$ & Wu et al. (2005b) \\
\hline $\mathrm{Cr}$ & $60.8-104.0$ & $R^{2}=0.85(P L S R)$ & $1^{\text {st }}$ Derivatives reflectance spectra & $\begin{array}{l}\text { 61; Agril. soils, } \\
\text { delta }\end{array}$ & Wu et al. (2007) \\
\hline $\mathrm{Cd}$ & $0.17-1.57$ & $\begin{array}{l}\mathrm{R}=0.76 \text { (Univariate } \\
\text { regression) }\end{array}$ & Normalized reflectance at $578 \mathrm{~nm}$ & $\begin{array}{l}\text { 69; River } \\
\text { sediments }\end{array}$ & Xia et al. (2007) \\
\hline As & $62.3-826.9$ & $R^{2}=0.84(S M L R), 0.87(E M L R)$ & Adsorption area at $2200 \mathrm{~nm}$; Log & $\begin{array}{l}\text { 49; } \mathrm{Au}-\mathrm{Ag} \\
\text { mining }\end{array}$ & Choe et al. (2008) \\
\hline
\end{tabular}


Table 4.1: Summary of indirect predictions of heavy metal through soil reflectance spectra (Continued)

\begin{tabular}{|c|c|c|c|c|c|}
\hline $\begin{array}{l}* \text { Heavy } \\
\text { Metals }\end{array}$ & $\begin{array}{l}\text { Concentration } \\
\text { range in soils } \\
\left(\mathrm{mg} \mathrm{kg}^{-1}\right)\end{array}$ & $\begin{array}{c}\text { Regression statistics } \\
\text { (technique) }\end{array}$ & $\begin{array}{c}\text { Type of spectra or } \\
\text { absorption features used }\end{array}$ & $\begin{array}{c}\text { Sample size } \\
(\#) ; \text { Sampling } \\
\text { site }\end{array}$ & Reference \\
\hline $\mathrm{Cu}$ & $21.9-252.6$ & $\begin{array}{l}\mathrm{R}^{2}=0.72(\mathrm{SMLR}), 0.81 \\
(\mathrm{EMLR})\end{array}$ & Ratio of $1344 / 778 \mathrm{~nm}, 610 / 500 \mathrm{~nm}$ & $\begin{array}{l}\text { 22; Au-Ag } \\
\text { mining }\end{array}$ & Choe et al. (2009) \\
\hline As & $0.6-220$ & $\begin{array}{l}\mathrm{R}=0.91(\mathrm{PLSR}) \\
\mathrm{R}=0.88 \text { (PLSR) }\end{array}$ & $\begin{array}{l}\text { NIR, } 1067-2598 \mathrm{~nm} ; \text { MSC } \\
\text { MIR, 5567-7168,8833-16666 nm }\end{array}$ & $\begin{array}{l}117 \text {; River } \\
\text { sediments }\end{array}$ & Moros et al. (2009) \\
\hline As & $19.3-403.7$ & $R^{2}=0.61(P L S R)$ & $1^{\text {st }}$ Derivatives reflectance spectra & $\begin{array}{l}\text { 33; Agril. soils } \\
\text { at mines }\end{array}$ & Ren et al. (2009) \\
\hline $\mathrm{Pb}$ & $150-600$ & Accuracy $=75.9 \%(\mathrm{OLR})$ & $\begin{array}{l}\text { Reflectance spectra at } 2500-25000 \\
\text { nm }\end{array}$ & $\begin{array}{l}489 ; \text { Urban } \\
\text { soils }\end{array}$ & Bray et al. (2009) \\
\hline $\mathrm{Zn}$ & $40-1322$ & $\mathrm{R}^{2}=0.84(\mathrm{PLSR})$ & MSC reflectance spectra & $\begin{array}{l}109 ; \text { Floodplain } \\
\text { soils }\end{array}$ & Vohland et al. (2009) \\
\hline $\mathrm{Cr}$ & $31.0-108.9$ & $\begin{array}{l}\mathrm{R}=0.76 \text { (Univariate } \\
\text { regression) }\end{array}$ & Reflectance at $2376 \mathrm{~nm}$ & $\begin{array}{l}122 ; \text { Agril. } \\
\text { soils, delta }\end{array}$ & ji et al. (2010) \\
\hline $\mathrm{Pb}$ & $187-412$ & $\mathrm{R}^{2}=0.69$ (Linear regression) & Reflectance at $800 \mathrm{~nm}$ & $\begin{array}{l}\text { 8; Along } \\
\text { military park }\end{array}$ & Pandit et al. (2010) \\
\hline $\begin{array}{l}\mathrm{Cu} \\
\mathrm{Pb}\end{array}$ & $1.6-332.1$ & $\begin{array}{l}\mathrm{R}=0.89 \text { (Linear regression) } \\
\mathrm{R}=0.81 \text { (Linear regression) }\end{array}$ & $\begin{array}{l}1^{\text {st }} \text { Derivatives spectral ratio of } \\
624 / 564\end{array}$ & $\begin{array}{l}\text { 30; Floodplain } \\
\text { soils }\end{array}$ & Liu et al. (2011b) \\
\hline $\mathrm{Cr}, \mathrm{Ni}$ & - & $\mathrm{R}^{2}=0.93,0.91$ (MARS) & S-G smoothed reflectance spectra & 120; Agril. soils & Wu et al. (2011) \\
\hline
\end{tabular}

*details are of those metals, for which prediction/calibration statistics were higher. For further information refer given references.

(Abbreviation/symbol: $R^{2}=$ coefficient of determination, $R=$ correlation coefficient, $M L R=$ multiple linear regression, EMLR = Enter $M L R$, $A N N=$ artificial neural networks, PLRS = partial least square regression, PCR = principal component regression, MARS = multiplicative

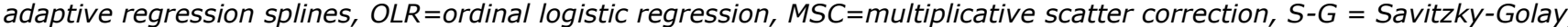


Burckhard (1998, 1999) and Su et al. (2007) advocated that Vis-IR spectroscopy can also be deployed at phytoremediation sites for monitoring plant physiological status and metal bio-accumulation. For many years, spectral sensing of vegetation in Vis-IR regions has been utilized in identification or classification of metal-contaminated soils using concept of rededge and variety of vegetation spectral indices (Kooistra et al. 2003; Kooistra et al. 2004). These have also great potential in monitoring phytoremediation, such as monitoring the variation in relative concentration of metals in soil and stress effects in plants attributed to effects of metal-phytoextraction or phytostabilization.

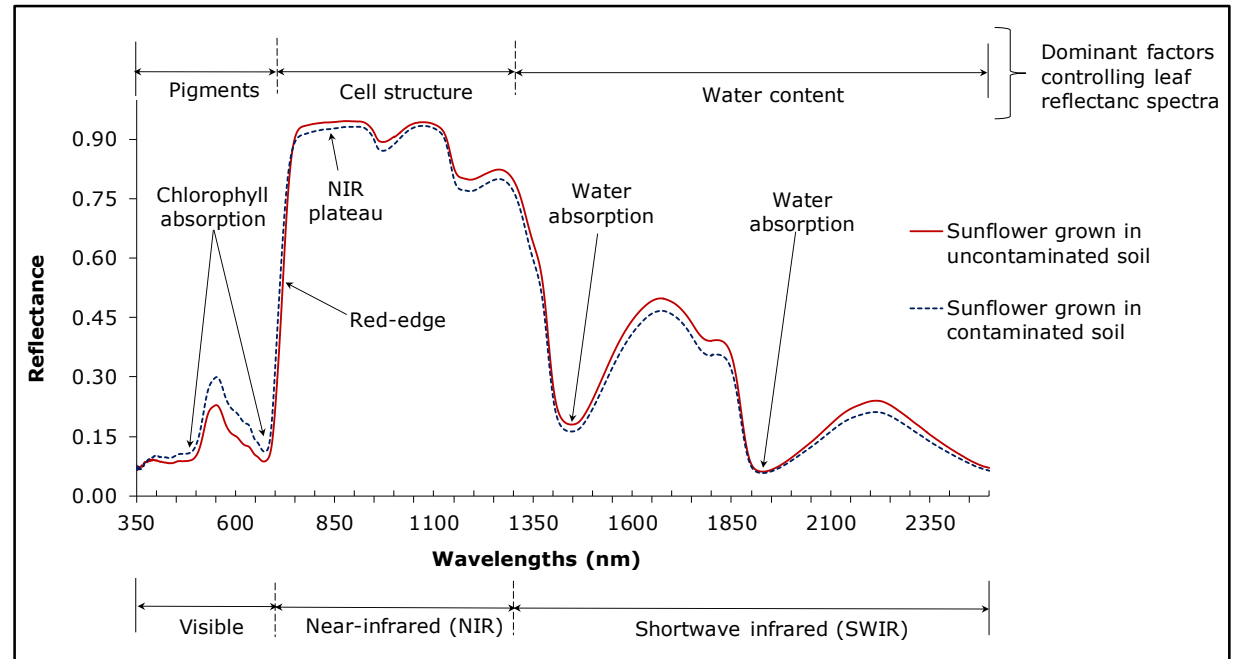

Figure 4.1: Changes in Visible infrared reflectance spectra of sunflower leaves due to metal-induced stress.

(Figure re-drawn from http:// rst.gsfc.nasa.gov/ using unpublished data).

\subsubsection{RED-EDGE POSITION RELEVANT TO METAL AND METAL-INDUCED STRESS}

The typical reflectance spectrum of healthy vegetation is characterized by an absorption of blue and red light caused by chlorophyll, respectively at around 450 and $680 \mathrm{~nm}$, and a rapid rise to a spectral peak around $780 \mathrm{~nm}$ due to reflection of NIR radiation by internal leaf mesophyll tissues (Figure 4.1). The red edge position (REP) that is the wavelength at maximum slope of the reflection curve between red (670-680 nm) and NIR (760-780 nm), has been studied as an indication of plant chlorophyll status. Many definitions and techniques are available in literature for computing the REP (Cho and Skidmore 2006; Dawson and Curran 1998; Guyot and Baret 1988; Pu et al. 2003). 'Red shift' and 'blue shift' are two important features of REP for spectral analysis (Horler et al. 1983). Red shift i.e. shift of REP towards longer wavelengths, is generally thought to be caused by an increase in chlorophyll concentration. A 'blue shift' (shift towards shorter wavelengths around $680 \mathrm{~nm}$ ) is associated with a decrease in chlorophyll content, and this has been observed in several studies on spectral changes due to high soil metal-contamination (Cheng et al. 
2008; Collins et al. 1983; Götze et al. 2010; Slonecker et al. 2010). For metalcontaminated floodplains (concentrations of $\mathrm{Pb}, \mathrm{Cd}, \mathrm{Zn}$ and $\mathrm{Cu}$ were respectively $70-490,6.6-7.3,170-1450,30-130 \mathrm{mg} \mathrm{kg}^{-1}$ ) of river Waal in the Netherlands, Clevers et al. (2004) observed a significant negative correlation between the REP of reflectance of grass species (Poa annua and Lolium perene) and $\mathrm{Pb}$ in soils $\left(\mathrm{R}^{2}=0.64\right)$. These findings were further confirmed by Kooistra et al. (2004) who found significant $R^{2}$ values (0.43-0.61 for $\mathrm{Zn}, \mathrm{Cd}, \mathrm{Cu}, \mathrm{Pb}$ ) between REP of grass species and measured metals in soils in floodplain along the river Waal.

Dunagan et al. (2007) found blue shift of REP in spectra of field mustard grown in $\mathrm{Hg}$-spiked and contaminated soils during early and pre-mature growth stages, and this was consistent with reduction in chlorophyll content due to $\mathrm{Hg}$ toxicity. Similar results of REP shift for cabbage leaf spectra have been reported by Cheng et al. (2008) and Liu et al. (2008b) respectively with an increased $\mathrm{Zn}$ and $\mathrm{Cu}$ pollution in soil $\left(\mathrm{R}^{2} \geq 0.95\right)$. Studies by Ren et al. (2010); Ren et al. (2008) proved that the REP shift has potential for estimation of $\mathrm{Pb}$ concentration in rice plant at early tillering stage. In these studies, REP of rice crop exposed to $2.5 \mathrm{mg} \mathrm{kg} \mathrm{g}^{-1}$ of $\mathrm{Pb}$ shifted towards shorter wavelength by 22 $\mathrm{nm}$ on $30^{\text {th }}$ day after sowing. Yang et al. (2008) also noted $19 \mathrm{~nm}$ blue shift of REP in spectrum of China sumac plant in $\mathrm{Cu}$ mining area with respect to plant spectra from non-mining area. However, this blue-shift of REP also investigated to be associated with stresses due to nutrient deficiencies, which imply that shift of REP alone does not characterize metal-specific plant stresses. This demands to look over combinatory changes in spectral parameters that unique to each kind of metal-related plant stress.

\subsubsection{VEGETATION INDICES RELEVANT TO METALS AND METAL-INDUCED STRESS}

Vegetation indices are mathematical calculations, generally ratios or linear combinations, of two or more spectral wavelengths to amplify vegetation spectral signal by minimizing background effects. Well-studied indices to discriminate stressed plants are the Normalized Difference Vegetation Index (NDVI) and the Ratio Vegetation Index (RVI). A high value of such indices indicates high chlorophyll content and healthy plant status (Schowengerdt 2007). Ren et al. (2010) observed a significant correlation between metals concentration in paddy leaves and NDVI values with $r=-0.76,-0.68,-0.76$, respectively for $\mathrm{Cu}$ and $\mathrm{NDVI}_{(660,870)} ; \mathrm{Zn}$ and $\mathrm{NDVI}_{(510,870)} ; \mathrm{Pb}$ and $\mathrm{NDVI}_{(510,810)}$. Gallagher et al. (2008) also demonstrated that NDVI and red/green wavelength ratio indices can be useful in detecting metal-induced stress in hardwood assemblages (Betula populifolia) on urban brownfields. For field mustard grown in Hg-spiked soils, Dunagan et al. (2007) reported significantly lower RVI $\left(R_{750 / 700}\right)$ and NDVI $\left[\left(R_{750}-R_{690}\right) /\left(R_{750}+R_{690}\right)\right]$ values than control plants at early to mid-growth stages. Yang et al. (2008) studied several indices of spectral data of three plants (china sumac, sweet wormwood herb and sword fern) of copper and tin mining areas. For all studied plants, the index $R_{725 / 675}$ was highly correlated to $\mathrm{Cu}, \mathrm{Mn}, \mathrm{Pb}$ and $\mathrm{Zn}$ concentrations in soil. However, Schuerger et al. (2003) concluded that NDVI and RVI $\left(R_{750 / 700}\right)$ could not differentiate between plant stress induced either by deficient or toxic $(25,50$, and $100 \mathrm{mg} \mathrm{L}^{-1}$ ) levels of zinc. 
Kooistra et al. (2003) showed that reflectance of ryegrass (Lolium perenne) can be used to predict elevated Zn contamination levels in the soil of floodplain of rivers Rhine and Meuse (Netherlands) using several vegetation indices (Table 4.2) and regression models, wherein a simple linear regression model using index MSAVI2 performed best as compared to multivariate PLSR model. In another study, Kooistra et al. (2004) obtained satisfactory relationships between concentration of $\mathrm{Ni}, \mathrm{Cd}, \mathrm{Cu}, \mathrm{Zn}$ and $\mathrm{Pb}$ in river floodplain and spectral reflectance of grass species (Poa annua and Lolium perenne; in range of 400$1350 \mathrm{~nm}$ ) with $\mathrm{R}^{2}$ ranged from 0.50 to 0.73 for DVI (Difference Vegetation Index) using PLSR model. However, the obtained relationship is species dependent as authors observed lower $R^{2}(0.17-0.22)$ and higher crossvalidation errors for herbaceous vegetation (Urtica dioica, Cirsium arvensis and Rumex acetosa). This is probably due to differences in morphology, metal tolerance of plants and time of data collection (Bork et al. 1999). Furthermore, studies of Götze et al. (2010) and Panigada et al. (2010) shown that pigment indices such as NPCI and PRI (Table 4.2) were highly correlated to metal related plant stress, and this could be due to influenced plant metabolism by metal stress (Curran et al. 2001). Liu et al. (2010b) developed regression models using continuum removal normalized band depth values at wavelengths $537,667,747 \mathrm{~nm}$ to estimate metals in grass via changes in chlorophyll concentrations. Estimated $\mathrm{Cu}$ and $\mathrm{Pb}$ were significantly correlated to the measured values ( $r=0.89$ and 0.87 , respectively). Recently, Liu et al. (2010a); Liu et al. (2011a) concluded that spectral indices sensitive to chlorophyll (e.g., NDVI, MTVI, MCARI, OSAVI; Table 4.2) using a back propagation and dynamic neural network model were accurate in predicting heavy metals in paddy.

It is evident that most studied vegetation indices use spectral wavelengths in vicinity of red-edge region, which is sensitive to changes in chlorophyll and other pigments. However, red-edge based indices cannot differentiate the changes due to metal accumulation/toxicity from other stresses, since loss of chlorophyll is a general symptom of many biological and physiological stresses in plants (Carter 1993; Chapin III 1991; Schuerger et al. 2003; Sridhar et al. 2007a, 2007b). In other words, these indices can characterize only stressed plants irrespective of specific metal stress. Instead, the infrared regions have been considered in several studies for metal detection, since this region is particularly influenced by structural variations in leaf internal architecture. Excessive metal accumulation is known to affect leaf internal/cell structure, and chloroplast ultrastructure, for example changes in leaf structure of Indian mustard due to Zn, Cd phytoextraction (Sridhar et al. 2005) decreases number of mesophyll cells in several plant species have been observed due to metal toxicity (Chmielewska and Chwil 2005; Küpper et al. 2000).

With this perspective, in studies on phytoextraction of $\mathrm{Cd}, \mathrm{Zn}$ (by barley) and As, $\mathrm{Cr}$ (by Chinese brake fern), Sridhar et al. (2007a, 2007b) considered wavelength range $800-1300 \mathrm{~nm}$ for spectral analysis, as this region is sensitive to leaf structural changes due to phyto-accumulation of metals. They found that a ratio index $R_{1110 / 810}$ was sensitive to foliar structural changes in metal accumulators. 
Table 4.2: Vegetation indices* studied for heavy metals induced plant stress

\begin{tabular}{|c|c|c|}
\hline Vegetation Indices & Equation ( $R$ denotes reflectance; NIR=Near-infrared) & Reference \\
\hline Difference Vegetation Index (DVI) & $\left(R_{N I R}-R_{r e d}\right)$ & \multirow{7}{*}{$\begin{array}{l}\text { Where, } \\
\text { NIR=760-900 nm } \\
\text { red=630-690 nm } \\
\text { Davidson and } \\
\text { Csillag (2001); } \\
\text { Kooistra et al. } \\
(2003)\end{array}$} \\
\hline Ratio Vegetation Index (RVI) & $R_{\text {NIR }} \div R_{\text {red }}$ & \\
\hline Ratio Difference Vegetation Index (RDVI) & $\left(R_{N I R}-R_{r e d}\right) \div\left(R_{N I R}+R_{r e d}\right)^{1 / 2}$ & \\
\hline Soil Adjusted Vegetation Index (SAVI) & $\left(R_{N I R}-R_{r e d}\right)(1+L) \div\left(R_{N I R}+R_{r e d}+L\right) ;$ where $L=0.5$ & \\
\hline Modified SAVI second (MSAVI2) & $2 \times R_{N I R}+1-\left[\left(2 \times R_{N I R}+1\right)^{2}-8\left(R_{N I R}-R_{r e d}\right)\right]^{1 / 2}$ & \\
\hline $\begin{array}{l}\text { Infrared Percentage Vegetation Index } \\
\text { (IPVI) }\end{array}$ & $\left(R_{N I R}\right) \div\left(R_{N I R}+R_{\text {red }}\right)$ & \\
\hline Modified Simple Ratio (MSR) & {$\left[\left(R_{\text {NIR }} \div R_{\text {red }}\right)-1\right] \div\left[\left(R_{\text {NIR }} \div R_{\text {red }}\right)+1\right]^{1 / 2}$} & \\
\hline NDVI & $\left(R_{800}-R_{670}\right) \div\left(R_{800}+R_{670}\right)$ & \multirow{4}{*}{ Liu et al. (2010a) } \\
\hline Optimized SAVI (OSAVI) & {$\left[(1+0.5) \times\left(R_{800}-R_{670}\right)\right] \div\left(R_{800}+R_{670}+0.5\right)$} & \\
\hline $\begin{array}{l}\text { Modified Chlorophyll Absorption Ratio } \\
\text { Index (MCARI) }\end{array}$ & {$\left[\left(R_{700}-R_{670}\right)-0.2 \times\left(R_{700}-R_{670}\right)\right] \times\left\{\left(R_{700} \div R_{670}\right)\right.$} & \\
\hline Modified Triangle Vegetation Index (MTVI) & $1.5 \times\left[1.2 \times\left(R_{712}-R_{550}\right)-2.1 \times\left(R_{670}-R_{550}\right)\right]$ & \\
\hline Photochemical Reflectance Index (PRI) & $\left(R_{531}-R_{570}\right) \div\left(R_{531}+R_{570}\right)$ & \multirow{2}{*}{$\begin{array}{l}\text { Panigada et al. } \\
(2010)\end{array}$} \\
\hline Chlorophyll Index (CI) & $\left(R_{750}-R_{705}\right) \div\left(R_{750}-R_{705}\right)$ & \\
\hline $\begin{array}{l}\text { Normalized Pigment Chlorophyll Index } \\
\text { (NPCI) }\end{array}$ & $\left(R_{680}-R_{430}\right) \div\left(R_{680}-R_{430}\right)$ & $\begin{array}{l}\text { Peñuelas and } \\
\text { Filella (1998) }\end{array}$ \\
\hline
\end{tabular}

*Refer article of Zarco-Tejada et al. (2004) for further details of modified vegetation indices 
The ratio index significantly correlated $(* p<0.05, * * p<0.01)$ with $\mathrm{Cr}$ content in shoot $\left(r=0.59^{*}\right)$ and roots $(r=0.84 * *)$; so did NDVI values with $\mathrm{Cr}$ shoot $\left(r=0.53^{*}\right)$ and roots $\left(r=0.77^{* *}\right)$. Contrary, NDVI shows better correlation with As content in shoot and roots compared to ratio index, but cannot distinguished $\mathrm{Cr}$-treated plants from As-treated and control plants, as so ratio index did. However, the ratio index was not sensitive to $\mathrm{Cd}$ and As in leaves, which attributed to the fewer leaf structural changes in Cd- and As-treated plants. These results are in good agreement with study of (Bandaru et al. 2010), wherein changes in spinach leaf reflectance around 1048, 1098, and $1080 \mathrm{~nm}$ were strongly correlated with leaf As concentration and structural parameters viz., leaf thickness, mean ratio of palisade mesophyll to spongy mesophyll, mean leaf air space ratio, and mean mesophyll surface area. Regression analysis using optimum NIR bands and its ratio index (i.e., $R_{1048 / 1021}$ ) show great potential for predicting As in spinach leaf, with $\mathrm{R}^{2}=0.69$ and 0.59, respectively. For predicting As in two Pteris fern species, Slonecker et al. (2009) used NIR and SWIR wavelengths 998, 1448, 1644, $2184 \mathrm{~nm}$ and 956, 1174, 1888, 2140, $2331 \mathrm{~nm}$ respectively for Pteris multifida and Pteris cretica mayii. Wavelengths at 1448, 2140 and 2331 were likely to be related with leaf chemistry and chemical absorption i.e. lignin and cellulose. First derivative model for both fern showed the best $R^{2}$, respectively 0.59 and 0.75 . It was also showed by Götze et al. (2010) that band depth of continuum removal at $1730 \mathrm{~nm}\left(\mathrm{CR}_{1730}\right.$; which thought to be sensitive to lignin or protein production as influenced by metal accumulation) is a potential indicator for metal stress detection. These results imply that combinations of red-edge indices and spectral ratio index in infrared region, were more feasible for monitoring physiological status of plant during process of phytoremediation of metal contaminants (Sridhar et al. 2007a, 2007b).

\subsection{Challenges AND FUtURE PROSPECTS}

Although, the potential of proximal spectral sensing techniques for assessing properties of soils and plants are recognized, the practical application of these techniques has not been studied for monitoring soil remediation program. The most important reasons are: First, the direct quantification of metals in soil is not possible since most metallic ions, except that of transition elements, are spectrally inactive within Vis-IR regions. Second, spectral characteristics of metal-contaminated soil have been mainly studied in the laboratory or field, and so, no generalized prediction mechanisms can be obtained with such studies. The main difficulties in producing satisfactory predictions for metals in soil, as discussed in section 4.2.6, are compositional diversity of soils and presence of various metallic ions-complexes in soil. Third, the potential of imaging spectroscopy, i.e. remotely sensed data from either airborne or satellite platforms, for monitoring of full-scale phytoremediation site is yet to be studied. For an emerging field of phytoremediation, the imaging spectroscopy has great value over proximal sensing since it can assess the metal-contaminated sites before (which provides spatial overview of metalcontamination), during (for optimization and performance monitoring of phytoremediation via assessing plant's status), and after (for risk monitoring) the setting-up of phytoremediation system. Research prospect is availability of many imaging sensors, such as Airborne Visible Infrared Imaging Spectrometer, Compact High Resolution Imaging Spectrometer, HyMap series 
of airborne hyperspectral scanners, Hyperion, etc., could allow monitoring of soils as well as plants. Absorption features of Fe-oxides, which associated to the metals, are broad, and this can be determined with multispectral bands using above sensors (Wu et al. 2011). On other hand, imaging spectroscopy is complicated due to mixed pixels, lower spectral resolution, low signal-tonoise ratio, atmospheric attenuation, etc. Despite all these, several studies have shown that imaging spectroscopy can be a promising tool for assessing metal-contaminated soils - both directly (Chevrel et al. 2003; Choe et al. 2008; Kemper and Sommer 2003; Lehmann and Gläßer 2005; Wu et al. 2011), and indirectly through monitoring stressed vegetation (Boluda et al. 1993; Lehmann and Gläßer 2005; Lyalko et al. 1996; Reusen et al. 2003; Shafri et al. 2006; Splajt et al. 2003; Zhang 2010). European MINEO projects (http://www2.brgm.fr/mineo/) have employed remote sensed data to assist with the monitoring of mine waste areas.

Fourth, most remote sensing methods for vegetation monitoring are only capable of monitoring relatively severe plant stress (US-DOE 2000). In particular, quantification (i.e. identification of stressor) of metal-induced plant stress with spectral sensing has not yet been studied. From phytoremediation point of view, where aim is metal removal or stabilization, it is important to study the changes in plant spectral properties with changes in concentration of metal in soil due to remediation process. There are many other techniques are available for detecting early signs of natural as well metal related stress, for instance chlorophyll fluorescence spectroscopy or imaging (Colls and Hall 2004; Zarco-Tejada et al. 2009) and thermal infra-red reflectance/emission spectroscopy to monitor plant surface temperature (Suresh et al. 1989); these can deliver complementary information. In general, most effects of metalinduced stress (specifically toxicity) on plant physiology resembles with plantstress caused by others stressors. Further research is therefore needed to distinguish metal-induced stress from natural stress and to delineate speciesspecific spectral responses of metal-stress. This should be done considering the sources and nature of metal contamination, for a realistic plant monitoring in phytoremediation. However, phytoremediation clean-up approach offers a good match with studying field deployment of remote sensing techniques, as phytoremediation involves the use of homogeneous plant species, and thus complication due to signatures from multiple-species may be eliminated.

\subsection{CONCLUSION}

This chapter shows that remote sensing techniques, particularly proximal spectral sensing at laboratory and field scales, appear to be a promising and inexpensive alternative for assessing metal contamination in field soils. Indirect spectroscopic assessment of heavy metals in contaminated soil is possible on the basis of metals' intercorrelations with spectrally active soil constituents. As an interrelationship exits between soils, vegetation and metal contamination, there is a potential of spectral sensing for the optimizing phytoremediation system through plant health monitoring. However, field sampling and laboratory measurements, mostly chemical analyses of plants and soil, are stil mandatory for model calibration and validation. Field-based proximal spectral sensing has proved to be promising for monitoring phytoremediation process; the application of far remote sensing remains challenging research area. 


\title{
CHAPTER 5 : FEASIBILITY STUDY OF VISIBLE AND NEAR INFRARED REFLECTANCE SPECTROSCOPY FOR ASSESSING METALS IN SOIL ${ }^{1}$
}

\begin{abstract}
Visible and near infrared reflectance (VNIR; 350-2500 nm) spectroscopy have greatly been used in soils, especially for studying variability in spectrally active soil components (e.g., organic carbon, clays, and Fe/Al-oxides) based on their diagnostic spectral features. In recent years, this technique have also been applied to assess soil metallic-ions. In this research, the feasibility of VNIR spectroscopy for determination of soil metals was investigated with two soil data sets: (i) artificially metal-spiked, and (ii) in-situ metal-contaminated soils. Results showed that reflectance spectra of neither metal-spiked soils with $\mathrm{Cd}$, As and $\mathrm{Pb}$ even at their higher concentrations of 20,900 , and $1200 \mathrm{mg} \mathrm{kg}^{-1}$, respectively nor in-situ metal-contaminated soils (with concentrations of 30 $\mathrm{mg} \mathrm{Cd}, 3019 \mathrm{mg}$ As and $5725 \mathrm{mg} \mathrm{Pb} \mathrm{kg}{ }^{-1}$ soil), showed any recognized absorption peaks that correspond to soil metal-concentrations. We observed variations in reflectance intensity for in-situ metal-contaminated soils only, showing higher reflectance across the entire spectrum for strongly and lower for less metal-contaminated soils. A significant correlation was found between surface soil metals' concentrations and continuum removed spectra; while soil metals were also found significantly associated with soil organic matter and total Fe. A partial least square regression with cross-validation approach produced an acceptable prediction of metals $\left(R^{2}=0.58-0.94\right)$ for both soil data sets, metal-spiked and in-situ metal-contaminated soils. However, high values of root mean square error ruled out practical application of the achieved prediction models.
\end{abstract}

\footnotetext{
${ }^{1}$ This chapter is based on following paper:

Paresh H. Rathod, Freek D. Van der Meer, Ingo Müller and Boudewijn de Smeth (2016). Analysis of visible and near infrared spectral reflectance for assessing metals in soil. Environmental Monitoring and Assessment, 188 (10): article no. 558.

DOI: $10.1007 / \mathrm{s} 10661-016-5568-9$.
} 


\subsection{INTRODUCTION}

Visible and near infrared reflectance (VNIR) spectroscopy principally is used to describe materials based on their spectral reflectance in wavelengths from $350-2500 \mathrm{~nm}$. Back in 1970-80s, a systematic study of the "spectral reflectance of American soils" by Condit (1970; and reference therein) and another study of "Characteristic variations in reflectance of surface soils" by Stoner and Baumgardner (1981), encouraged soil researchers for exploring soil reflectance spectra within the VNIR and mid-infrared domains to characterize soils and monitor the changes in soils quality. Characteristic soil spectral reflectance signatures are owed to electronic transitions of atoms (e.g., iron containing soil minerals) and vibrational stretching and/or bending of structural groups of atoms (e.g., hydroxyl- and $\mathrm{H}_{2} \mathrm{O}$-bearing minerals (Dalal and Henry 1986). Prominent absorption features at $\sim 1400$ and $\sim 1900 \mathrm{~nm}$ due to bound and unbound water are typical for soil reflectance that is correspondingly due to the overtone of $\mathrm{OH}$ stretches and the combination of $\mathrm{H}-\mathrm{O}-\mathrm{H}$ bend with the $\mathrm{OH}$ stretches (van der Meer 2002). Therefore, it is relatively possible to sense certain soil constitutes like soil moisture, organic carbon/matter, nitrogen, carbonates, Fe-oxides, and clays using VNIR spectroscopy via specific calibration modeling concept (Adamchuk et al. 2004; Ben-Dor and Banin 1990, 1995; Brown et al. 2006; Fidencio et al. 2002; Ji et al. 2002; Knadel et al. 2011; Nanni and Dematte 2006; Reeves 2002; Scheinost et al. 1998; Scheinost and Schwertmann 1999; Shao and He 2011; Volkan Bilgili et al. 2010).

With the advent of hyperspectral sensing, portable field spectroradiometer and particularly data mining and chemometric tools, the reflectance spectroscopy has been taken up strongly by soil scientists to study soil properties. Several comprehensive review articles of recent years (Ben-Dor et al. 2009; Cécillon et al. 2009; Du and Zhou 2009; Reeves III 2010; Stenberg and Rossel 2010; Stenberg et al. 2010) on the applications of infrared reflectance spectroscopy and hyperspectral sensing (together with air/satellite borne imaging spectroscopy) for the assessment and/or monitoring soil properties confirmed the interests of soil scientists towards these novel techniques. These studies straightforwardly advocated the VNIR reflectance spectroscopy as a comparatively rapid, non-destructive, inexpensive method compared to classical geochemical analyses; besides it could also take into account the soil's spatio-temporal variability. In this view, reflectance spectroscopy has been postulated as a promising tool for efficient detection and monitoring of soil contaminants, principally heavy/trace metals (Al Maliki et al. 2012; Horta et al. 2015; Schwartz et al. 2011; Shi et al. 2014). Inorganic elements such as potassium, phosphorus and most metallic ions, are generally spectrally inactive (Malley and Williams 1997), hence they do not exhibit any distinctive absorption features within VNIR spectral domains (Schwartz et al. 2011; Wu et al. 2005a). However, research literature available so far on use of reflectance spectroscopy to assess the metal-contaminated soils, have all assumed interrelationship between metallic elements and certain spectrally active soil constituents, and that so-called "surrogate or indirect" correlations could be the way of predicting metals in soils (Shenk et al. 2001; Vohland et al. 2009; Wu et al. 2010a). Thus, heavy metals' associations with organic carbon/matter, clay minerals, and Fe-oxides have been explored to detect soil- 
metals using reflectance spectroscopy. A detailed literature review on this aspect can be found in section 4.2 of chapter 4 .

The systematic study by Wu et al. (2010a) strongly supports the hypothesis of "surrogate" correlation for trace metals. According to this study, soil parameters can be categorized into primary soil parameters (e.g., soil moisture; which displayed characteristic absorption features within VNIR regions), secondary soil parameters (e.g., soil organic carbon/matter; that also causes only overall changes in the VNIR spectrum), and tertiary soil parameters (e.g., trace metals; those are spectrally featureless, and their presence in soil does not cause any distinct spectral features at any part of VNIR spectrum). Consequently, trace metals, being tertiary soil parameters, can be assessed through soil VNIR spectra since they are associated one way or another with primary or secondary soil parameters.

In this context, present study is based on following questions: (i) How great concentration of heavy metal can exhibit absorption features on the soil spectral curves? (ii) Which spectrally active soil constituents would be the most valid mechanism to quantify heavy metals in soils? The final objective was to explore the practicability of VNIR reflectance spectroscopy for the assessment of metal-contaminated soils for artificially and in-situ elevated metal-contaminated soils.

\subsection{MATERIALS AND METHODS}

\subsubsection{ARTIFICIALLY METAL-CONTAMINATED SOILS}

We utilized metal-spiked soil samples from barley and sunflower experiments wherein we simulated metal-contamination by spiking the $\mathrm{Cd}, \mathrm{Pb}$ and $\mathrm{As}$ metalsalts into sandy soil substrate (see Table 6.2 in chapter 6 and Table 7.2 in chapter 7). Total 80 soil samples (52 from barley and 28 from sunflower studies) were collected after metal-spiking, and before the barley crop seeding and sunflower seedling transplanting. Table 5.1 provides detail of all the metalspiked soils utilized for this study.

\subsubsection{IN-SITU METAL-CONTAMINATED SOILS}

Soils from arable and grassland from the region of Freiberg and Leipzig in the State of Saxony (Germany) were selected for this study. This region is located in district of Mittelsachsen (Middle Saxony) in the centre of German federal State of Saxony, and is characterized by centuries of mining and metallurgical ore-processing from medieval times to the middle of last century, which led to extended arsenic and other heavy metal accumulation in the soil. Geomorphologically it is situated on the Northern edge of the Erzgebirge (Ore Mountains), a mountain range between Germany and the Czech Republic. Compared to the Saxon background values (LfULG 2015) of arsenic, lead and cadmium for soil developed from Gneiss rocks $\left(61,160\right.$, and $0.41 \mathrm{mg} \mathrm{kg}^{-1}$, respectively), the concentration in soils of the Freiberg region is far higher reaching i.e., $168-4621,649-5239$ and $4.7-8.3 \mathrm{mg} \mathrm{kg}^{-1}$, respectively (IBA 2010) due to both natural geochemical mineralization and anthropogenic enhancement via ore mining and processing. The Saxon State Agency for 
Environment, Agriculture and Geology runs soil monitoring program (Bodendauerbeobachtungsflächen des Freistaates Sachsen - BDF) since year 1995. There are in total 55 BDF sites in Saxony chosen on soil type, geographic location and contamination levels (Figure 5.1). Out of 55 BDF sites, eight sites were selected for soil samplings on basis of varying levels of metal contamination. Details of selected sites and their soil physico-chemical properties are respectively given in Table 5.2 and Table 5.3. From these 8 sites, we collected altogether 40 surface-soil $(0-20 \mathrm{~cm} ; 5$ samples randomly from each site) and 40 subsurface-soil $(20-30 \mathrm{~cm})$ samples. Soil samples were filled in polythene bags and transported for soil analysis to the geo-chemical laboratory at ITC, Enschede, Netherlands. At the laboratory, samples were oven dried and crushed to pass through $2 \mathrm{~mm}$ sieve prior to use for spectral reflectance and geo-chemical measurements. We also used total 36 representative soil samples from another 36 BDF sites for measuring their reflectance spectra. The chemical data of those 36 soil samples were provided by Saxon State Agency for Environment, Agriculture and Geology (LfULG 2015).

Table 5.1: Details of artificially metal-spiked soil samples obtained from Barley and Sunflower studies

\begin{tabular}{|c|c|c|}
\hline Study with & $\begin{array}{l}\text { Metal spiking and } \\
\text { concentrations }\left(\mathrm{mg} \mathrm{kg}^{-1}\right)\end{array}$ & \# of samples \\
\hline $\begin{array}{l}\text { Barley } \\
\text { Sunflower }\end{array}$ & $\begin{array}{l}\text { Control (no metal spiking) } \\
\text { Control (no metal spiking) }\end{array}$ & $\begin{array}{l}4 \\
4\end{array}$ \\
\hline Barley & $\mathrm{Cd}_{1}$ : Cd spiking at 1 & 4 \\
\hline Barley & $\mathrm{Cd}_{2}$ : Cd spiking at 5 & 4 \\
\hline Barley & $\mathrm{Cd}_{3}: \mathrm{Cd}$ spiking at 10 & 4 \\
\hline Sunflower & $\mathrm{Cd}_{3}: \mathrm{Cd}$ spiking at 10 & 4 \\
\hline Sunflower & $\mathrm{Cd}_{4}: \mathrm{Cd}$ spiking at 20 & 4 \\
\hline Barley & $\mathrm{Pb}_{1}: \mathrm{Pb}$ spiking at 25 & 4 \\
\hline Barley & $\mathrm{Pb}_{2}: \mathrm{Pb}$ spiking at 75 & 4 \\
\hline Barley & $\mathrm{Pb}_{3}: \mathrm{Pb}$ spiking at 150 & 4 \\
\hline Sunflower & $\mathrm{Pb}_{4}: \mathrm{Pb}$ spiking at 1200 & 4 \\
\hline Barley & $A s_{1}$ : As spiking at 5 & 4 \\
\hline Barley & $\mathrm{As}_{2}$ : As spiking at 50 & 4 \\
\hline Barley & $\mathrm{As}_{3}$ : As spiking at 100 & 4 \\
\hline Sunflower & $\mathrm{As}_{3}$ : As spiking at 100 & 4 \\
\hline Sunflower & $\mathrm{As}_{4}$ : As spiking at 900 & 4 \\
\hline Barley & $\mathrm{Mix}_{1}: 1 \mathrm{Cd}+25 \mathrm{~Pb}+5 \mathrm{As}$ & 4 \\
\hline Barley & $\mathrm{Mix}_{2}: 5 \mathrm{Cd}+75 \mathrm{~Pb}+50 \mathrm{As}$ & 4 \\
\hline Barley & $\operatorname{Mix}_{3}: 10 \mathrm{Cd}+150 \mathrm{~Pb}+100 \mathrm{As}$ & 4 \\
\hline Sunflower & $\mathrm{Mix}_{4}: 20 \mathrm{Cd}+1200 \mathrm{~Pb}+900 \mathrm{As}$ & 4 \\
\hline
\end{tabular}




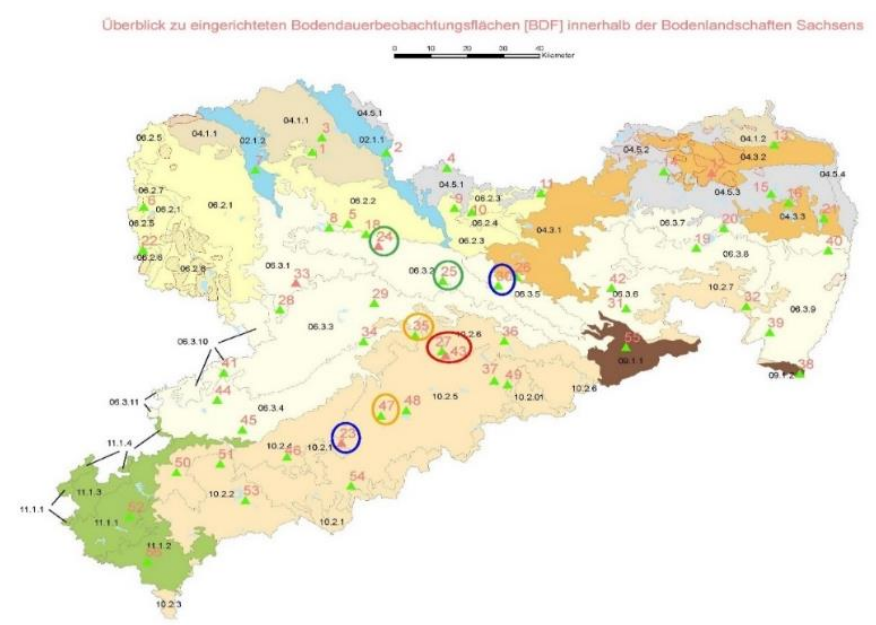

Figure 5.1: Location of permanent soil monitoring sites (BDF) sites in the State of Saxony, Germany. Source: http://www.umwelt.sachsen.de/

Table 5.2: Details of selected BDF sites for soil samplings

\begin{tabular}{|l|l|}
\hline Metal-contamination level & Site No. (Place), Land use pattern \\
\hline Severe contamination & BDF-27 (Neuhilbersdorf), Grassland and Floodplain \\
Moderate-high contamination & BDF-43 (Hilbersdorf), Grassland \\
& BDF-23 (Ehrenfriedersdorf), Arable land \\
LDF-30 (Niederwartha), Grassland and Floodplain & BDF-35 (Großschirma), Arable land \\
No contamination & BDF-47 (Börnichen), Arable land \\
& BDF-24 (Schmorren), Arable land \\
& BDF-25 (Krögis), Arable land
\end{tabular}

Table 5.3: Physico-chemical characteristics ${ }^{1,2}$ of soil at selected BDF sites

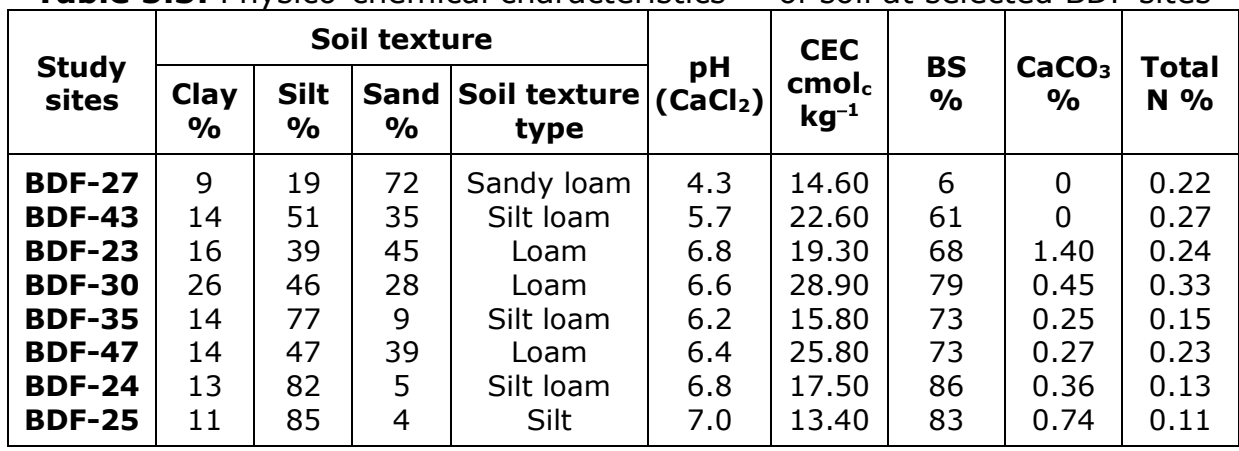

BS = Base Saturation, CEC = Cation Exchange Capacity

${ }^{1}$ Values are of top soils (0-20 cm soil depth); ${ }^{2}$ Source: LfULG (2015) 


\subsubsection{SOIL CHEMICAL ANALYSES}

Total heavy metal concentrations in soils from 8 selected BDF sites were determined using wet acid digestion method at geo-chemical laboratory at ITC. One gram of oven-dried sample was digested with $4 \mathrm{~mL}$ concentrated $\mathrm{HNO}_{3}$ on hot water bath at $80-90{ }^{\circ} \mathrm{C}$ temperature for about 8 hours (USEPA 1996, 1998). After cooling, digested solution was diluted with $10 \mathrm{~mL}$ of demineralized water and was then analyzed for heavy metals using ICP. Standard soil reference material was also digested to check recovery of heavy metal with above digestion procedure. Soil organic matter was determined by ashing a $2.5 \mathrm{~g}$ of sample at $400^{\circ} \mathrm{C}$ for $2-3$ hours in a muffle furnace. The loss by weight of the sample during ignition is calculated as the organic matter.

Soil samples from barley and sunflower experiments were analyzed for their total metal contents at Institute of General Ecology, TU Dresden (Tharandt, Germany) by digesting $500 \mathrm{mg}$ air-dried soil samples in $5 \mathrm{~mL}$ concentrated $\mathrm{HNO}_{3}$ in pressurized microwave accelerated reaction system (CEM Mars5 microwave digestion system; Matthews, USA) for 30-40 minutes (USEPA 1996, 1998). The digested substrate was then diluted with $10 \mathrm{~mL}$ deionized water and analyzed for total $\mathrm{Cd}, \mathrm{Pb}$ and $\mathrm{As}$ using inductively coupled plasma-mass spectrometry (ICPMS X-series instrument, Thermo Fisher Scientific GmbH, Bremen, Germany). Standard reference soil samples were digested for recovery test. Precision for all standards was better than 5\%. All chemical used in metal analysis were of analytical grade.

\subsubsection{SPECTRAL MEASUREMENTS AND TRANSFORMATIONS}

ASD FieldSpec portable spectroradiometer (350-2500 $\mathrm{nm}$ at $1 \mathrm{~nm}$ resolution; ASD, Inc., Boulder, CO) was used to measure soil reflectance spectra. Aluminium cup ( $5 \mathrm{~cm}$ diameter $\times 1.5 \mathrm{~cm}$ height) was used for placing soil sample for spectral measurements (Figure 5.2). Spectral measurement was done using ASD contact probe (designed for contact spectral measurements; having $10 \mathrm{~mm}$ spot size and halogen bulb as internal light source) fixed on burette stand and attached by fibre optic cable to an ASD FieldSpec portable spectroradiometer (Figure 5.2). For each soil sample, 5 spectra were collected in order to capture maximum variance on the soil surface, which were then averaged to obtain a single reflectance spectrum for each soil sample. Reflectance spectra were calibrated against a white Spectralon panel face, and this step was repeated at every 5 sample's spectral measurements to verify instrumental drift during the spectral analysis.

Soil reflectance spectra were corrected for ASD jump (drift correction; additive) using AS-toolbox package (Dorigo et al. 2006) add-in installed in ENVI+IDL version 4.3. Continuum removal (CR) analysis and First derivative (FD) calculation was done on corrected spectra with 5-point moving average to intensify spectral features. The wavelengths regions ranges from 350-449 and 2451-2500 nm possess low signal-to-noise ratio, hence they were excluded from further spectral processing. 

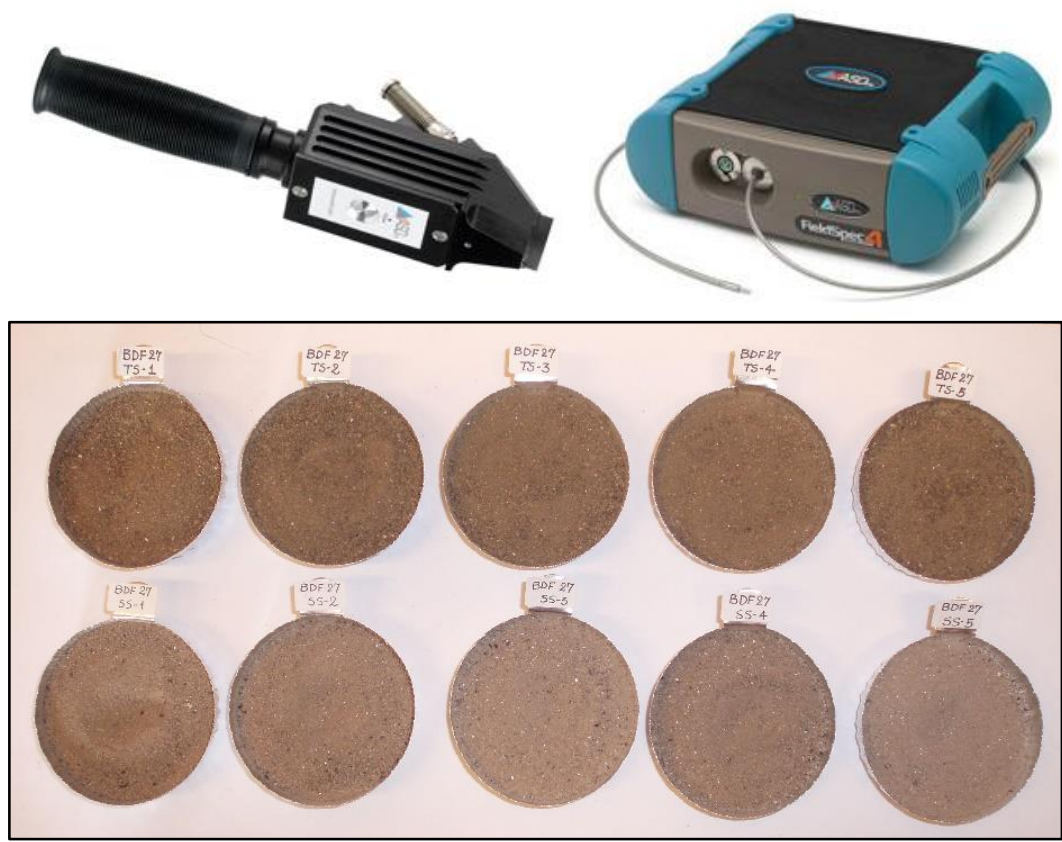

Figure 5.2: ASD FieldSpec spectroradiometer, ASD's standard contact probe and aluminium cup filled with BDF soils for spectral measurements

\subsubsection{STATISTICAL ANALYSES}

Statistical analyses of chemical and spectral data were performed in MS Excel spreadsheets 2007 with XLSTAT 2009.1.02 add-ins and reported at $\alpha=0.05$ significance level. The relationship between soil-metal concentration and spectral data was modeled using regression analysis, leave-one-out cross validation techniques (PLSR, partial least square regression and MLR, multiple linear regression; in Unscrambler 9.7, CAMO ASA, Norway). Values of coefficient of determination $\left(R^{2}\right)$ between measured and predicted value and root mean square error (RMSE) were used to examine the relationship found.

\subsection{RESULTS AND DISCUSSION}

\subsubsection{STATISTICS OF SOIL PROPERTIES AND METALS}

Table 5.4 summarizes the mean value (of $n=5$ ) of soil variables in both surface and subsurface soils sampled from eight selected BDF sites. All the eight BDF sites were selected for soil sampling on basis of varying degree of metalcontamination. Amongst the eight sites, BDF-27 and -43 showed high As-, $\mathrm{Pb}$ and Cd-concentration (2494 mg As, $5268 \mathrm{mg} \mathrm{Pb}$, and $27 \mathrm{mg} \mathrm{Cd} \mathrm{kg}^{-1}$ dry soils of BDF-27; $1138 \mathrm{mg} \mathrm{As}, 1947 \mathrm{mg} \mathrm{Pb}$ and $17.8 \mathrm{mg} \mathrm{Cd} \mathrm{kg}-1$ dry soils of BDF43). Source of metal contamination at BDF-43 (Hilbersdorf, grassland) is mainly due to mining (abandoned), and emissions from larger smelter smokestack about $1 \mathrm{~km}$ away at Muldenhütten. BDF-27 (Neuhilbersdorf, floodplain of River Frieberger Mülde) is mainly characterized by stream 
sediments from Muldenhütten smelter about $2 \mathrm{~km}$ upstream. At this site, the surface soil layer $(\sim 40 \mathrm{~cm})$ is of coarse sand and sub soil is of fine sand, as a result of frequent floods. All other selected sites were moderately to low metalcontaminated.

Statistics of soil variables in entire data sets of surface and subsurface soils and Pearson's correlation coefficients between them are presented in Table 5.5. The concentration of $\mathrm{Pb}$ in the campaigned sites was relatively high (ranges from 28.6 - 5726 and 15.8 - $4727 \mathrm{mg} \mathrm{kg}^{-1}$, respectively in surface and subsurface soils), followed by As concentration (2.07 - 3019 and 3.64 $1121 \mathrm{mg} \mathrm{kg}{ }^{-1}$, respectively in surface- and subsurface-soil). Significant correlations existed among measured soil variables, but on a moderate level with total Fe and OM (Table 5.5). Total Fe and organic matter in surface soils to some extent correlated with surface soil-As, $-\mathrm{Pb},-\mathrm{Cd}$ and $-\mathrm{Zn}$ (respectively $0.40,0.45,0.35$, and 0.44 with Total Fe; $0.36,0.33,0.24$, and 0.87 with OM). These correlations are different from those observed with subsurface soil samples (Table 5.5), where no significant correlation found between total Fe, $\mathrm{OM}$ and soil-As, - $\mathrm{Pb}$, and -Cd, except significant correlation of soil-Cd with total Fe (0.38), and could be attributed to the Cd mobility and complexation into the soils.

Table 5.4: Metals' concentration and other physico-chemicals properties of surface and subsurface soils of eight BDF sites

\begin{tabular}{|c|c|c|c|c|c|c|c|}
\hline \multirow{2}{*}{ Sites\# } & \multicolumn{5}{|c|}{$\begin{array}{l}\text { Metal concentration }\left(\mathrm{mg} \mathrm{kg}^{-1}\right) \\
\text { Mean of } n=5 \text { samples }\end{array}$} & \multirow{2}{*}{$\begin{array}{l}\text { Total } \\
\text { Fe }(\%)\end{array}$} & \multirow{2}{*}{$\begin{array}{c}\text { OM } \\
(\%)\end{array}$} \\
\hline & $\begin{array}{l}\text { Total } \\
\text { As }\end{array}$ & $\begin{array}{l}\text { Total } \\
\text { Pb }\end{array}$ & $\begin{array}{l}\text { Total } \\
\text { Cd }\end{array}$ & $\begin{array}{l}\text { Total } \\
\text { Zn }\end{array}$ & $\begin{array}{l}\text { Total } \\
\text { Ni }\end{array}$ & & \\
\hline \multicolumn{8}{|c|}{ Surface soils } \\
\hline $\begin{array}{l}\text { BDF-27 } \\
\text { BDF-43 } \\
\text { BDF-23 } \\
\text { BDF-30 } \\
\text { BDF-35 } \\
\text { BDF-47 } \\
\text { BDF-24 } \\
\text { BDF-25 }\end{array}$ & $\begin{array}{c}2494.4 \\
1138.2 \\
147.57 \\
75.80 \\
14.98 \\
74.61 \\
3.79 \\
3.51\end{array}$ & $\begin{array}{c}5268.1 \\
1947.2 \\
89.41 \\
131.27 \\
78.35 \\
93.61 \\
143.86 \\
36.49\end{array}$ & $\begin{array}{c}26.92 \\
17.84 \\
1.50 \\
0.95 \\
3.71 \\
3.02 \\
3.96 \\
3.32\end{array}$ & $\begin{array}{c}1901.9 \\
584.2 \\
202.70 \\
514.41 \\
84.47 \\
119.75 \\
46.47 \\
47.97\end{array}$ & $\begin{array}{l}28.16 \\
22.93 \\
25.59 \\
39.50 \\
11.11 \\
18.58 \\
11.96 \\
11.17\end{array}$ & $\begin{array}{l}2.81 \\
1.97 \\
2.12 \\
2.11 \\
2.81 \\
2.26 \\
1.99 \\
2.35\end{array}$ & $\begin{array}{l}8.83 \\
7.23 \\
8.83 \\
9.63 \\
5.05 \\
8.30 \\
3.85 \\
3.64\end{array}$ \\
\hline \multicolumn{8}{|c|}{ Subsurface soils } \\
\hline $\begin{array}{l}\text { BDF-27 } \\
\text { BDF-43 } \\
\text { BDF-23 } \\
\text { BDF-30 } \\
\text { BDF-35 } \\
\text { BDF-47 } \\
\text { BDF-24 } \\
\text { BDF-25 }\end{array}$ & $\begin{array}{c}453.9 \\
787.4 \\
90.76 \\
82.75 \\
10.49 \\
48.95 \\
7.37 \\
5.04\end{array}$ & $\begin{array}{c}4164.2 \\
448.05 \\
25.67 \\
180.55 \\
40.87 \\
22.66 \\
31.50 \\
19.33\end{array}$ & $\begin{array}{c}17.59 \\
3.47 \\
1.05 \\
3.10 \\
3.83 \\
2.34 \\
4.70 \\
4.21\end{array}$ & $\begin{array}{c}2082.4 \\
566.60 \\
198.62 \\
715.02 \\
52.18 \\
63.63 \\
46.05 \\
42.01\end{array}$ & $\begin{array}{l}32.90 \\
39.06 \\
17.19 \\
46.14 \\
11.48 \\
14.21 \\
12.63 \\
13.95\end{array}$ & $\begin{array}{l}2.15 \\
3.24 \\
4.34 \\
2.26 \\
3.22 \\
2.33 \\
2.11 \\
2.90\end{array}$ & $\begin{array}{l}5.63 \\
3.91 \\
5.09 \\
8.33 \\
3.13 \\
4.88 \\
3.30 \\
2.63\end{array}$ \\
\hline
\end{tabular}


Table 5.5: Metals' concentration and organic matter content of surface and subsurface soils sampled from eight BDF sites ( $n=40$ each for surface- and subsurface-soils)

\begin{tabular}{|c|c|c|c|c|c|c|c|}
\hline \multirow[b]{2}{*}{ Statistics } & \multicolumn{5}{|c|}{ Metal concentration $\left(\mathrm{mg} \mathrm{kg}^{-1}\right)$} & \multirow{2}{*}{$\begin{array}{c}\text { Total } \\
\text { Fe } \\
(\%) \\
\end{array}$} & \multirow{2}{*}{$\begin{array}{c}\text { OM } \\
(\%)\end{array}$} \\
\hline & $\begin{array}{l}\text { Total } \\
\text { As }\end{array}$ & $\begin{array}{c}\text { Total } \\
\text { Pb }\end{array}$ & $\begin{array}{c}\text { Total } \\
\text { Cd }\end{array}$ & $\begin{array}{c}\text { Total } \\
\text { Zn }\end{array}$ & $\begin{array}{c}\text { Total } \\
\mathrm{Ni}\end{array}$ & & \\
\hline \multicolumn{8}{|c|}{ Surface soils } \\
\hline $\begin{array}{l}\text { Mean } \\
\text { Minimum } \\
\text { Maximum } \\
\text { Median } \\
\text { STDev } \\
\text { Skewness }\end{array}$ & \begin{tabular}{|l|}
494.11 \\
2.07 \\
3019.08 \\
75.51 \\
857.02 \\
1.82
\end{tabular} & \begin{tabular}{|l|}
973.53 \\
28.60 \\
5725.99 \\
93.40 \\
1760.05 \\
1.90
\end{tabular} & \begin{tabular}{|l|}
7.65 \\
0.70 \\
31.13 \\
3.68 \\
9.04 \\
1.44
\end{tabular} & \begin{tabular}{|l|}
437.73 \\
45.70 \\
2136.43 \\
158.64 \\
596.38 \\
1.91
\end{tabular} & $\begin{array}{l}21.12 \\
10.25 \\
42.28 \\
20.27 \\
9.56 \\
0.64\end{array}$ & \begin{tabular}{|l|}
2.30 \\
1.77 \\
2.88 \\
2.19 \\
0.33 \\
0.63
\end{tabular} & \begin{tabular}{|l|}
6.92 \\
3.62 \\
9.86 \\
7.73 \\
2.29 \\
-0.35
\end{tabular} \\
\hline $\begin{array}{l}\text { Pearson's 'r' } \\
\text { Total As } \\
\text { Total Pb } \\
\text { Total Cd } \\
\text { Total Zn } \\
\text { Total Ni } \\
\text { Total Fe } \\
\text { OM (\%) }\end{array}$ & $\begin{array}{l}1.00 \\
0.99 * * \\
0.94 * * \\
0.94 * * \\
0.34 * \\
0.40 * \\
0.36 *\end{array}$ & $\begin{array}{l}--- \\
1.00 \\
0.95 * * \\
0.96 * * \\
0.31 \\
0.45 * * \\
0.33 *\end{array}$ & $\begin{array}{l}--- \\
--- \\
1.00 \\
0.88^{* *} \\
0.20 \\
0.35 * \\
0.24\end{array}$ & $\begin{array}{l}--- \\
--- \\
--- \\
1.00 \\
0.51 * * \\
0.44 * * \\
0.50 * *\end{array}$ & $\begin{array}{l}--- \\
--- \\
--- \\
--- \\
1.00 \\
-0.15 \\
0.87 * *\end{array}$ & $\begin{array}{l}--- \\
--- \\
-- \\
--- \\
-- \\
1.00 \\
-0.03\end{array}$ & $\begin{array}{l}--- \\
--- \\
--- \\
--- \\
--- \\
-- \\
1.00\end{array}$ \\
\hline \multicolumn{8}{|c|}{ Subsurface soils } \\
\hline $\begin{array}{l}\text { Mean } \\
\text { Minimum } \\
\text { Maximum } \\
\text { Median } \\
\text { STDev } \\
\text { Skewness }\end{array}$ & \begin{tabular}{|l|}
185.85 \\
3.64 \\
1121.38 \\
65.67 \\
280.76 \\
1.76
\end{tabular} & \begin{tabular}{|l|}
616.60 \\
15.84 \\
4727.06 \\
32.91 \\
1377.11 \\
2.35
\end{tabular} & \begin{tabular}{|l|}
5.04 \\
0.95 \\
26.06 \\
3.77 \\
5.49 \\
2.81
\end{tabular} & \begin{tabular}{|l|}
470.82 \\
41.25 \\
2325.08 \\
131.51 \\
670.29 \\
1.86
\end{tabular} & \begin{tabular}{|l|}
23.45 \\
1.27 \\
60.45 \\
14.92 \\
14.37 \\
0.92
\end{tabular} & \begin{tabular}{|l|}
2.82 \\
1.94 \\
4.41 \\
2.53 \\
0.74 \\
0.92
\end{tabular} & $\begin{array}{l}4.61 \\
2.52 \\
8.47 \\
4.40 \\
1.75 \\
0.99\end{array}$ \\
\hline $\begin{array}{l}\text { Pearson's 'r' } \\
\text { Total As } \\
\text { Total Pb } \\
\text { Total Cd } \\
\text { Total Zn } \\
\text { Total Ni } \\
\text { Total Fe } \\
\text { OM (\%) }\end{array}$ & $\begin{array}{l}1.00 \\
0.48 * * \\
0.39 * \\
0.54 * * \\
0.53 * * \\
0.07 \\
0.07\end{array}$ & $\begin{array}{l}--- \\
1.00 \\
0.91 * * \\
0.95 * * \\
0.31 \\
-0.33 \\
0.25\end{array}$ & $\begin{array}{l}--- \\
--- \\
1.00 \\
0.85 * * \\
0.25 \\
-0.38 * \\
0.16\end{array}$ & $\begin{array}{l}--- \\
--- \\
-- \\
1.00 \\
0.58 * * \\
-0.32 * \\
0.48 * *\end{array}$ & $\begin{array}{l}--- \\
--- \\
--- \\
-- \\
1.00 \\
-0.18 \\
0.66 * *\end{array}$ & $\begin{array}{l}--- \\
--- \\
--- \\
-- \\
-- \\
1.00 \\
-0.22\end{array}$ & $\begin{array}{l}--- \\
--- \\
--- \\
--- \\
--- \\
-- \\
1.00\end{array}$ \\
\hline
\end{tabular}

STDev $=$ Standard deviation; OM = Organic Matter; *Correlation is significant at the $\alpha=0.05$ level; **Correlation is significant at the $\alpha=0.01$ level

In another soil data set (of acquired soil samples; $n=36$ ), soil metal variables have narrow ranges (Table 5.6), i.e., $\mathrm{As}, \mathrm{Pb}$, and $\mathrm{Cd}$ respectively ranges from 1.6 to 55.0 (mean=11.2), 4.9 to 34.4 (mean=34.4), and 0.1 to $10 \mathrm{mg} \mathrm{kg}^{-1}$ (mean $=0.5 \mathrm{mg} \mathrm{kg}^{-1}$ ) of dry soils. In general, soil metals exhibited a strong positive correlation with organic carbon, yielding highest coefficient ( $r$ ) of 0.95 for soil-Pb, followed by 0.84 for soil-Zn and 0.62 for soil-As. Similarly, significant $(p<0.01)$ correlations were found between clay fraction and Fe $(0.79), \mathrm{Cr}(\mathrm{r}=0.77)$, and $\mathrm{Ni}(\mathrm{r}=0.59)$; between total $\mathrm{Fe}$ and $\mathrm{Ni}(0.86), \mathrm{Cr}$ $(r=0.80)$, and $Z n(r=0.59)$. Metal-spiked soil samples of barley and sunflower studies are combined together in a data set of artificially metal-contaminated soils $(n=80)$, and summary statistics of measured metals of 80 soil samples are presented in Table 5.7. 
Table 5.6: Descriptive statistics for metals' concentration and other physicochemicals properties of soils from BDF sites $(n=36)$

\begin{tabular}{|c|c|c|c|c|c|c|c|c|c|}
\hline \multirow{2}{*}{ Statistics } & \multicolumn{6}{|c|}{ Metal concentration" ${ }^{\#}\left(\mathrm{mg} \mathrm{kg}^{-1}\right)$} & \multirow{2}{*}{$\begin{array}{l}\text { Total } \\
\text { Fe \% }\end{array}$} & \multirow{2}{*}{$\begin{array}{l}\text { OC } \\
\%\end{array}$} & \multirow{2}{*}{$\begin{array}{c}\text { Clay } \\
\%\end{array}$} \\
\hline & As & $\mathbf{P b}$ & Cd & Zn & $\mathbf{C r}$ & $\mathbf{N i}$ & & & \\
\hline Mean & 11.18 & 34.41 & 0.50 & 64.07 & 22.39 & 14.97 & 1.98 & 1.99 & 12.55 \\
\hline Minimum & 1.60 & 4.90 & 0.10 & 4.60 & 2.90 & 2.00 & 0.19 & 0.85 & 0.20 \\
\hline Maximum & 55.00 & 120.00 & 10.00 & 370.00 & 74.00 & 68.00 & 7.50 & 11.80 & 24.80 \\
\hline Median & 7.20 & 25.50 & 0.17 & 42.00 & 21.00 & 8.90 & 1.49 & 1.66 & 13.05 \\
\hline STDev & 11.55 & 23.55 & 1.64 & 66.14 & 15.27 & 16.61 & 1.80 & 1.80 & 6.04 \\
\hline Skewness & 2.56 & 2.10 & 5.92 & 3.10 & 1.22 & 1.89 & 1.76 & 4.85 & 0.09 \\
\hline
\end{tabular}

Pearson's correlation coefficient ' $r$ '

\begin{tabular}{|l|l|l|l|l|l|l|l|l|l|}
\hline As & 1.00 & -- & --- & --- & --- & --- & --- & --- & --- \\
$\mathbf{P b}$ & $0.88^{* *}$ & 1.00 & --- & --- & --- & --- & --- & --- & --- \\
$\mathbf{C d}$ & $0.55^{* *}$ & 0.36 & 1.00 & --- & --- & --- & --- & --- & --- \\
$\mathbf{Z n}$ & $0.66 * *$ & $0.55 * *$ & $0.84 * *$ & 1.00 & -- & --- & --- & --- & --- \\
$\mathbf{C r}$ & 0.27 & 0.30 & 0.20 & $0.59 * *$ & 1.00 & --- & --- & --- & --- \\
$\mathbf{N i}$ & 0.33 & 0.27 & $0.43 * *$ & $0.77 * *$ & $0.87 * *$ & 1.00 & --- & --- & --- \\
$\mathbf{F e} \%$ & 0.29 & 0.32 & 0.12 & $0.59 * *$ & $0.80 * *$ & $0.86 * *$ & 1.00 & --- & --- \\
OC \% & $0.62 * *$ & $0.43 * *$ & $0.95 * *$ & $0.84 * *$ & 0.25 & $0.49 * *$ & 0.21 & 1.00 & --- \\
Clay \% & 0.22 & 0.31 & -0.10 & 0.33 & $0.77 * *$ & $0.59 * *$ & $0.79 * *$ & -0.05 & 1.00 \\
\hline
\end{tabular}

\#Aqua regia concentration (DIN-EN-13657 2003); STDev = Standard deviation; OC = organic carbon; **Correlation is significant at the $\alpha=0.01$ level

Table 5.7: Descriptive statistics for $\mathrm{As}, \mathrm{Pb}$, and $\mathrm{Cd}$ concentration in metalspiked soil samples of barley and sunflower studies $(n=80)$

\begin{tabular}{|c|c|c|c|c|c|}
\hline \multirow[b]{2}{*}{ Statistics } & \multicolumn{5}{|c|}{ Metal concentration ( $\mathbf{m g ~} \mathbf{k g}^{-1}$ ) } \\
\hline & Total As & Total Pb & Total Cd & Total Zn & $\begin{array}{c}\text { Total Fe } \\
(\%)\end{array}$ \\
\hline Mean & 115.97 & 206.85 & 4.70 & 62.26 & 0.40 \\
\hline Minimum & 2.58 & 11.73 & 0.00 & 40.75 & 0.18 \\
\hline Maximum & 1040.48 & 1854.68 & 23.83 & 108.78 & 0.56 \\
\hline Median & 5.44 & 28.03 & 0.43 & 60.38 & 0.40 \\
\hline STDev & 281.53 & 467.86 & 7.15 & 10.14 & 0.06 \\
\hline Skewness & 2.71 & 2.77 & 1.60 & 1.73 & -0.23 \\
\hline \multicolumn{6}{|l|}{ Pearson's 'r' } \\
\hline Total As & 1.00 & --- & --- & --- & --- \\
\hline Total Pb & $0.48 * *$ & 1.00 & --- & --- & --- \\
\hline Total Cd & $0.32 * *$ & $0.34 * *$ & 1.00 & --- & --- \\
\hline Total Zn & 0.18 & $0.23 * *$ & $0.25 * *$ & 1.00 & --- \\
\hline Total Fe (\%) & -0.01 & 0.22 & $0.39 * *$ & $0.39 * *$ & 1.00 \\
\hline
\end{tabular}

STDev $=$ Standard deviation; ${ }^{* *}$ Correlation is significant at the $\alpha=0.01$ level 


\subsubsection{SOIL SPECTRAL REFLECTANCE FEATURES}

\section{Artificially metal-spiked soils}

We measured reflectance spectra of metal-spiked soils that were utilized for barley and sunflower experiments. Figure 5.3a-d displays mean reflectance spectra of soils spiked with $\mathrm{Cd}, \mathrm{Pb}, \mathrm{As}$ and their metal-mixture at various concentrations and Figure 5.4 shows continuum removed (CR) spectra of soils spiking with metals at their higher concentrations. The shape of the reflectance curves, in general, are perceived identical for all metal-spiked soils for the tested concentrations, with lower reflectance in visible and increasing reflectance in the infrared regions as it be well-defined in the literature (Stenberg and Rossel 2010; Stenberg et al. 2010). Excluding the characteristic spectral features at $\sim 1400, \sim 1900$ and $\sim 2200 \mathrm{~nm}$, no other distinct absorption peaks can be seen due to metal-spiking to soil. The absorption peaks at $\sim 1400$, $\sim 1900$ and $\sim 2200 \mathrm{~nm}$ are known to associate with molecular water, overtone of $\mathrm{OH}$ stretch and combination of vibrations fundamentals of $\mathrm{OH}$ groups in interlayer lattice (Clark 1999b; Stenberg and Rossel 2010; Stenberg et al. 2010). In CR spectra (Figure 5.4), it can be seen that some weaker absorption peaks occurred at $\sim 495, \sim 1160$, and $\sim 1780 \mathrm{~nm}$, which are mainly related to vibrations frequencies of $\mathrm{H}_{2} \mathrm{O}$ molecules. The results of no apparent absorption features due to metal-spiking are obvious as soil substrate used in the barley and sunflower studies was sandy in texture with low soil organic carbon and total iron, i.e., $1.4-1.6 \%$ and $0.62-0.71 \%$, respectively (

Table 6.1), that are known to bind metallic ions. Even with clay soils, Horta et al. (2015) didn't observe any influences of elevated concentration of $\mathrm{Pb}$ up to $16000 \mathrm{mg} \mathrm{kg}^{-1}$ on NIR absorption spectra of soil having low organic carbon.

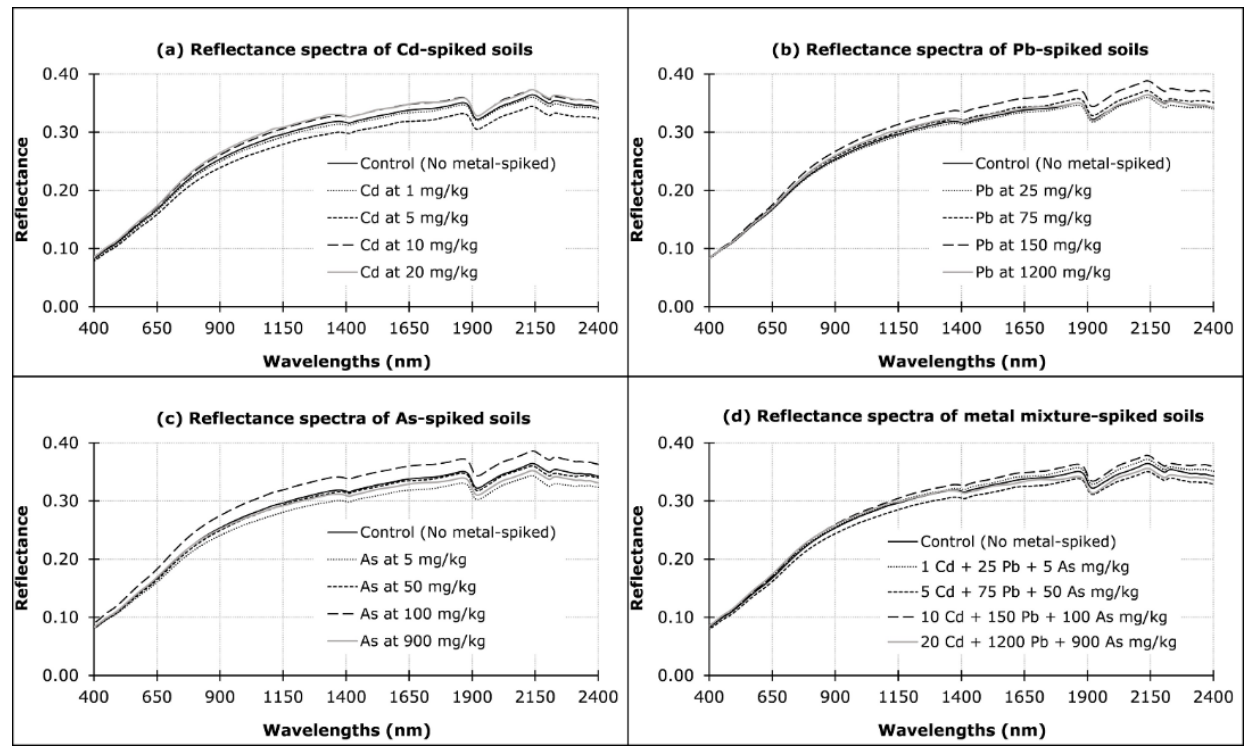

Figure 5.3: Reflectance spectra of (a) $\mathrm{Cd},(b) \mathrm{Pb},(c)$ As, and (d) metal mixture spiked soils at various concentrations 
Similar trend is also seen in the correlation analysis between the CR spectral values and concentrations of $\mathrm{Cd}, \mathrm{Pb}, \mathrm{As}$ and $\mathrm{Fe}$. The correlations are significant at certain wavelengths within the absorption feature regions, however on a weaker scale (Figure 5.5). These results are in accordance with the study of Wu et al. (2010a), who also did not find diagnostic absorption features for freshly spiked silt loam and sandy loam soils with $\mathrm{Cu}$ and $\mathrm{Zn}$ at various levels ranging from 0 to $32000 \mathrm{mg} \mathrm{kg}{ }^{-1}$. The metallic elements that exist in inorganic forms, as it be likely in our study with sandy soil substrate, cannot be detected using reflectance spectroscopy (Chodak et al. 2007; Siebielec et al. 2004).

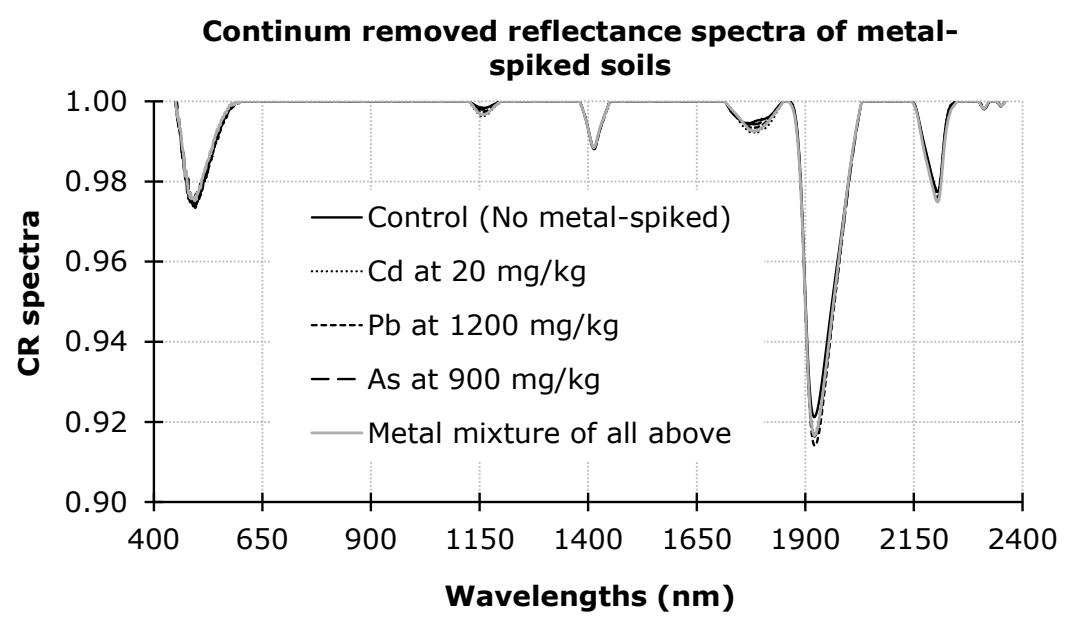

Figure 5.4: Continuum removed reflectance spectra of soil spiked with $\mathrm{Cd}$ at $20, \mathrm{~Pb}$ at $1200, \mathrm{As}$ at $900 \mathrm{mg} \mathrm{kg}^{-1}$ and their metal-mixture.

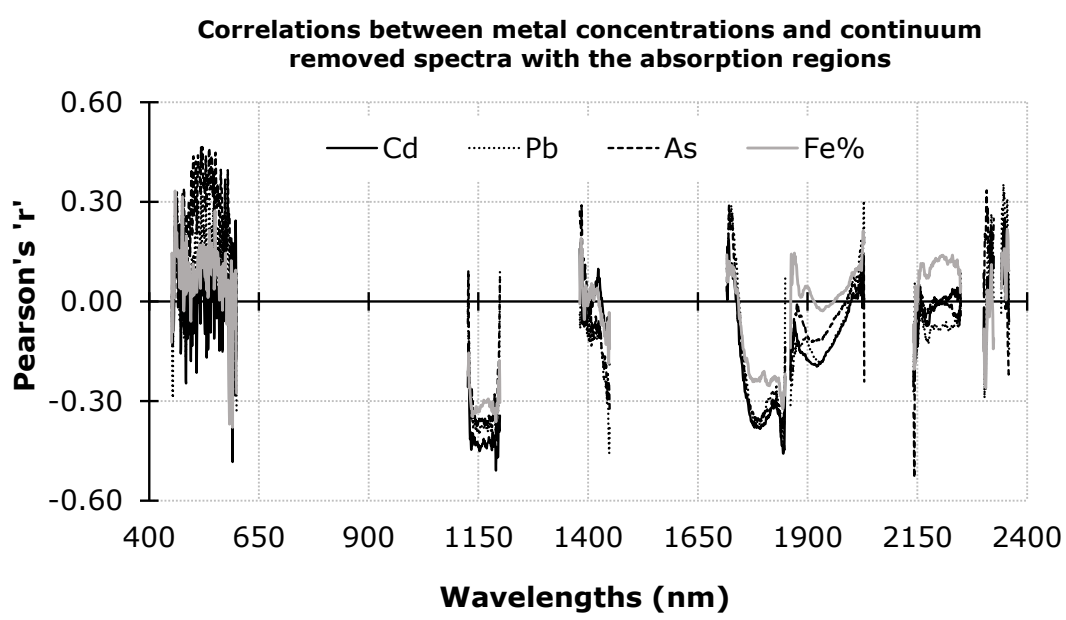

Figure 5.5: Pearson's correlations between continuum removed reflectance spectra (within the 450-600, 1100-1200, 1380-1450, 1715-1850, 18602030, 2140-2250 and 2300-2375 nm) and the concentrations of $\mathrm{Cd}, \mathrm{Pb}, \mathrm{As}$ and $\mathrm{Fe}$ in metal-spiked soils. 


\section{In-situ metal-contaminated soils}

Figure 5.6a-d shows raw reflectance (instrumental jump-corrected) and $C R$ reflectance spectra of surface and subsurface soils sampled from eight BDF sites. Similar to spectra obtained with metal-spiked soils, these spectral curves of in-situ metal-contaminated soils also followed the same basic shape, containing three major absorption features at $\sim 1400, \sim 1900$, and $\sim 2200 \mathrm{~nm}$ wavelengths. For all eight sites, the reflectance increased from the surface to the subsurface soils, and it might be a result of comparatively low organic matter and high iron contents at lower soil depths [Galvão et al. (2008); Table 5.4].

Typically, relatively lower spectral reflectance across the whole spectrum obtained with the higher metal-contaminated surface and subsurface soils (i.e., BDF-27, BDF-43, BDF-23, and BDF-30; Figure 5.6a-d). Primarily, we may relate these spectral changes between tested soils to the variations in the soil texture, organic matter, and to the extent of adsorbed metallic ions on these soil constituents (Table 5.4). However, it is important to note that the reflectance increases in the order of: BDF-27 (2494 mg As, $5268 \mathrm{mg} \mathrm{Pb}, 27$ mg Cd kg ${ }^{-1}$ ) <BDF-30<BDF-23<BDF-43<BDF-47<BDF-24 <BDF-35<BDF-25 (3.5 mg As, $36.5 \mathrm{mg} \mathrm{Pb}, 3.3 \mathrm{mg} \mathrm{Cd} \mathrm{kg}{ }^{-1}$ ), that only coincide with extreme and least metal contamination to the reflectance spectra. This observation strongly support the work of $\mathrm{Wu}$ et al. (2010a) who reported that metalliferous peat soils containing elevated amount of $\mathrm{Zn}\left(155-9082 \mathrm{mg} \mathrm{kg}^{-1}\right)$ and $\mathrm{Cd}(1.48-14.9$ $\mathrm{mg} \mathrm{kg}-1$ ) shown inconsistent pattern among the near infrared reflectance spectra of soils. The CR spectra (Figure 5.6c-d) amplified few other absorption peaks at $\sim 490 \mathrm{~nm}$ [known to occur due to iron-oxide goethite; Stenberg and Rossel (2010); Stenberg et al. (2010)], $895 \mathrm{~nm}$ [related to iron-oxides such as haematite and goethite; Summers et al. (2011)], 1160 nm [organic matter, C=O; Shonk et al. (1991)], $1780 \mathrm{~nm}$ [soil organic carbon, mineral N, salts; Bellon-Maurel and McBratney (2011); Du and Zhou (2009); Farifteh et al. (2008); Morra et al. (1991)] and 2350 nm [illite, muscovite, biotite; Clark $(1999 b)]$.

Pearson correlation analysis of calculated absorption band depths (at each wavelengths within the considered CR absorption features i.e., 450-600, 1100$1200,1380-1450,1715-1850,1860-2030,2140-2250$ and 2300-2375 nm) and soil variable (total metal, Fe and OM concentration) shows significant associations (Figure 5.7a-d). Particularly, surface soil concentrations of As, Cd, and $\mathrm{Pb}$ are correlated significantly with $\mathrm{CR}$ band depths corresponding to the absorption feature at wavelength 594, 990-991, 1185, 1447-1448, 1843$1844,1865,2237$, and 2301-2307 nm (Table 5.8). Correspondingly, we may assigned these absorption features to the spectral signatures of organic matter [570-700 nm; Galvdo et al. (1997)], amine [(N-H; $1000 \mathrm{~nm}$; Stenberg and Rossel (2010)], C=O in organic matter [1160 nm; Shonk et al. (1991)], carbonates [1449 nm, $1865 \mathrm{~nm}, 2300 \mathrm{~nm}$; Stenberg and Rossel (2010)], Fe ${ }^{3+}$ rich minerals [2235, $2233 \mathrm{~nm}$; Murphy et al. (2015)]. These could be explained by significant correlation of CR band depths with soil Fe and OM contents, but they displays relatively poor associations (Table 5.8). 
Chapter 4

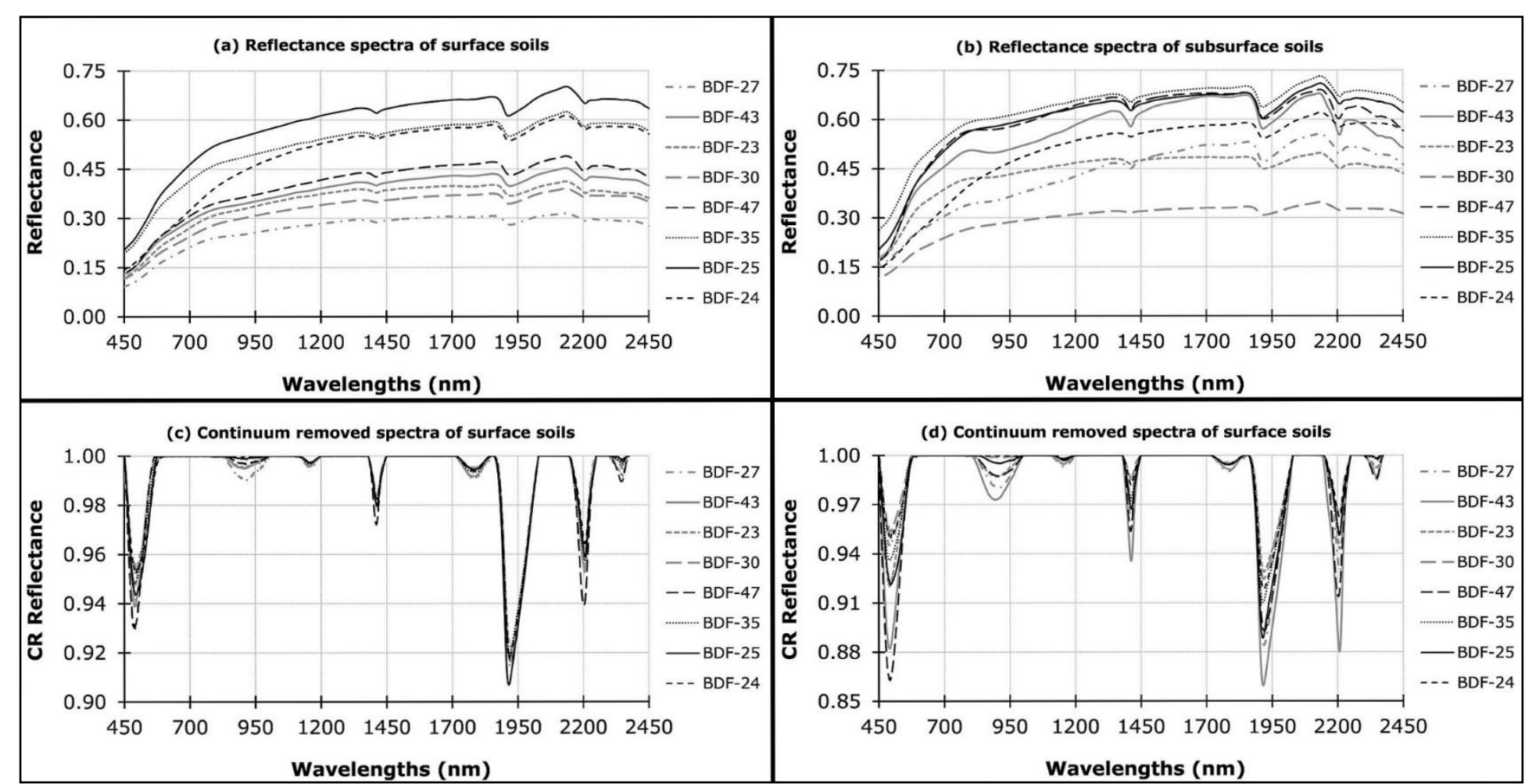

Figure 5.6: Reflectance $(a, b)$ and continuum removed reflectance $(c, d)$ spectra of surface soils sampled from eight insitu metal-contaminated BDF sites. 

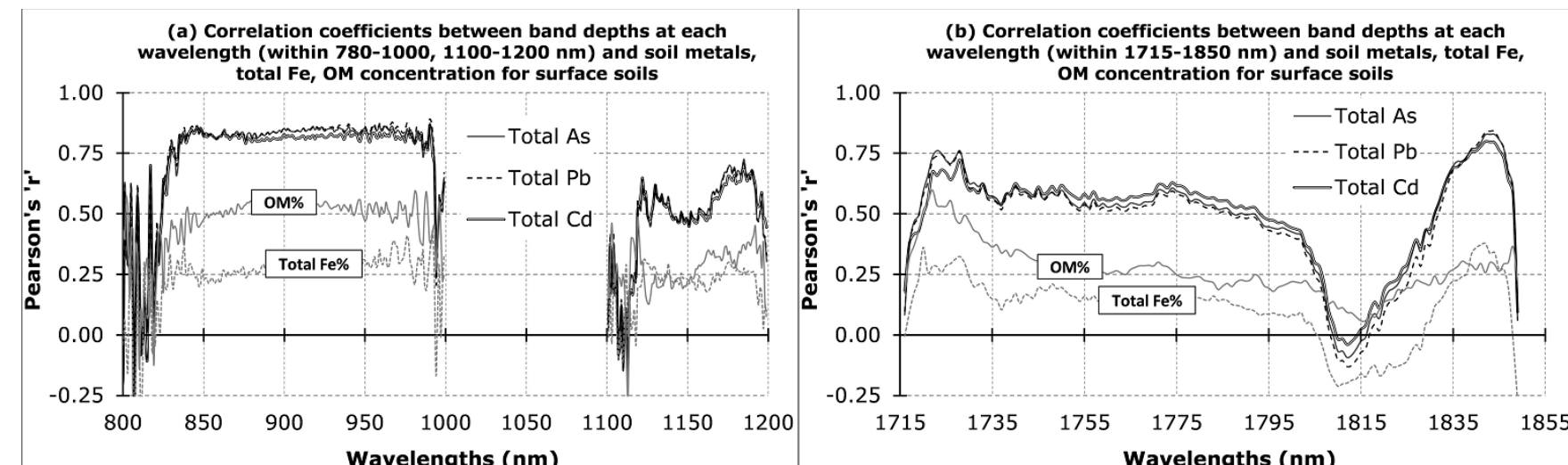

(c) Correlation coefficients between band depths at each
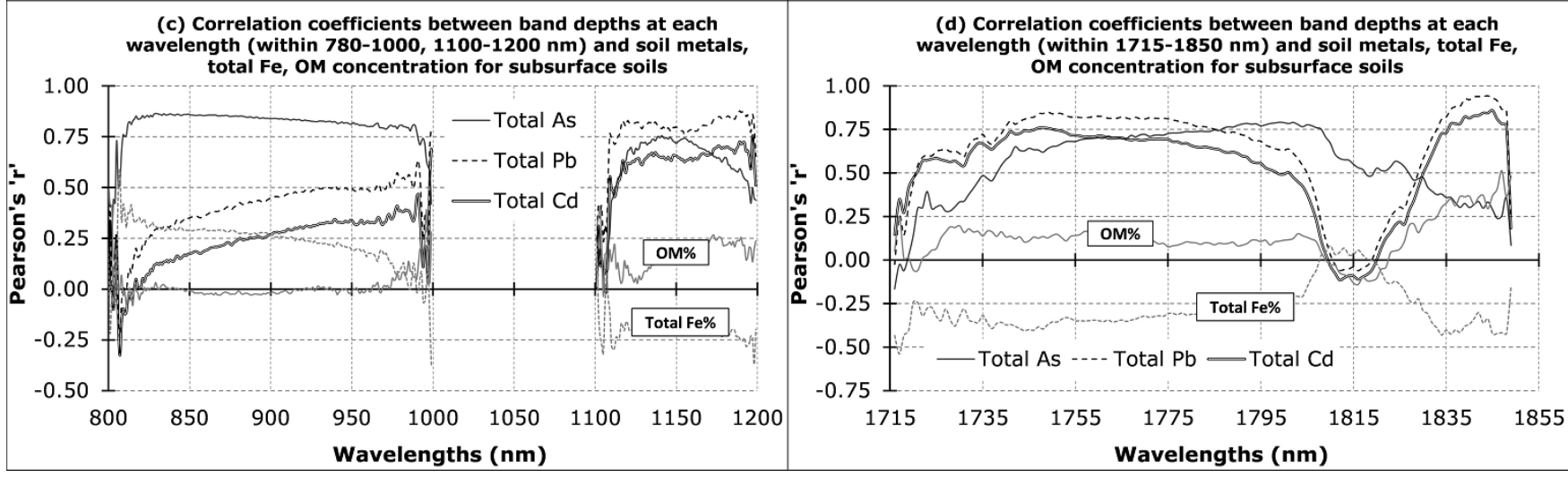

Figure 5.7: Pearson's correlation coefficients between the CR absorption features within 780-1000, 1100-1200, 1715-

$1850 \mathrm{~nm}$ and metal, total Fe and OM concentration in surface $(a, b)$ and subsurface (c, d) soils of eight BDF sites 
Table 5.8: Pearson correlation coefficients* between continuum removed spectral band depths within the considered absorption domains and soil variables of the surface-soil samples

\begin{tabular}{|c|c|c|c|c|c|c|c|c|}
\hline $\begin{array}{c}\text { Edges } \\
(\mathrm{nm}) \text { of } \\
\text { CR spectra }\end{array}$ & $\begin{array}{l}\text { Total } \\
\text { As }\end{array}$ & $\begin{array}{c}\text { Total } \\
\text { Pb }\end{array}$ & $\begin{array}{c}\text { Total } \\
\text { Cd }\end{array}$ & $\begin{array}{c}\text { Total } \\
\text { Zn }\end{array}$ & $\begin{array}{c}\text { Total } \\
\mathrm{Ni}\end{array}$ & $\begin{array}{c}\text { Total } \\
\mathbf{C u}\end{array}$ & $\begin{array}{l}\text { Total } \\
\text { Fe }\end{array}$ & OM \\
\hline \multicolumn{9}{|c|}{ Surface-soil samples } \\
\hline $450-600$ & $\begin{array}{l}0.56 \\
(594)\end{array}$ & $\begin{array}{l}0.60 \\
(594)\end{array}$ & $\begin{array}{l}0.54 \\
(594)\end{array}$ & $\begin{array}{l}0.66 \\
(594)\end{array}$ & $\begin{array}{l}0.68 \\
(587)\end{array}$ & 0.62 & $\begin{array}{l}-0.60 \\
(454)\end{array}$ & $\begin{array}{l}0.69 \\
(461)\end{array}$ \\
\hline $780-1100$ & $\begin{array}{l}0.87 \\
(990)\end{array}$ & $\begin{array}{l}0.89 \\
(990)\end{array}$ & $\begin{array}{l}0.86 \\
(990)\end{array}$ & $\begin{array}{l}0.89 \\
(982)\end{array}$ & $\begin{array}{l}0.70 \\
(802)\end{array}$ & $\begin{array}{l}0.87 \\
(991)\end{array}$ & $\begin{array}{l}0.43 \\
(992)\end{array}$ & $\begin{array}{l}0.60 \\
(981)\end{array}$ \\
\hline $1115-1200$ & $\begin{array}{l}0.73 \\
(1185)\end{array}$ & 0.72 & 0.68 & 0.70 & 0.40 & 0.68 & 0.31 & 0.48 \\
\hline $1380-1450$ & 0.55 & $\begin{array}{l}(1185) \\
0.55\end{array}$ & $\begin{array}{l}(1183) \\
0.53\end{array}$ & 0.50 & $\begin{array}{l}(1110) \\
-0.51\end{array}$ & $\begin{array}{l}(118 \\
0.55\end{array}$ & $\begin{array}{l}(1123) \\
-0.28\end{array}$ & $\begin{array}{l}(1119) \\
-0.49\end{array}$ \\
\hline & $(1447)$ & $(1448)$ & $(1449)$ & $(1448)$ & $(1433)$ & $(1448)$ & $(1386)$ & $(1434)$ \\
\hline $1715-1850$ & $\begin{array}{l}0.83 \\
(1843)\end{array}$ & $\begin{array}{l}0.84 \\
(1843)\end{array}$ & $\begin{array}{l}0.80 \\
(1842)\end{array}$ & $\begin{array}{l}0.81 \\
(1844)\end{array}$ & $\begin{array}{l}0.40 \\
(1724)\end{array}$ & $\begin{array}{l}0.81 \\
(1844)\end{array}$ & $\begin{array}{l}0.38 \\
(1842)\end{array}$ & $\begin{array}{l}0.60 \\
(1722)\end{array}$ \\
\hline $1860-2030$ & $\begin{array}{l}0.58 \\
(1865)\end{array}$ & $\begin{array}{l}0.60 \\
(1865)\end{array}$ & $\begin{array}{l}0.59 \\
(1865)\end{array}$ & $\begin{array}{l}-0.58 \\
(2016)\end{array}$ & $\begin{array}{l}-0.39 \\
(2022)\end{array}$ & $\begin{array}{l}-0.56 \\
(2016)\end{array}$ & $\begin{array}{l}0.36 \\
(1865)\end{array}$ & $\begin{array}{l}-0.57 \\
(1880)\end{array}$ \\
\hline $2140-2250$ & -0.76 & -0.75 & -0.69 & -0.80 & -0.65 & -0.72 & -0.28 & -0.68 \\
\hline & $(2237)$ & $(2237)$ & $(2237)$ & $(2237)$ & $(2243)$ & $(2237)$ & $(2145)$ & $(2245)$ \\
\hline $2300-$ & $\begin{array}{l}0.44 \\
(2307)\end{array}$ & $\begin{array}{l}0.41 \\
(2301)\end{array}$ & $\begin{array}{l}0.30 \\
(2301)\end{array}$ & $\begin{array}{l}0.48 \\
(2307)\end{array}$ & $\begin{array}{l}0.65 \\
(2312)\end{array}$ & $\begin{array}{l}0.48 \\
(2301)\end{array}$ & $\begin{array}{l}0.20 \\
(2370)\end{array}$ & $\begin{array}{l}0.79 \\
(2313)\end{array}$ \\
\hline \multicolumn{9}{|c|}{ Subsurface-soil samples } \\
\hline & $\begin{array}{l}-0.40 \\
(582)\end{array}$ & $\begin{array}{l}0.45 \\
(590)\end{array}$ & $\begin{array}{l}0.47 \\
(591)\end{array}$ & $\begin{array}{l}-0.38 \\
(452)\end{array}$ & $\begin{array}{l}-0.40 \\
(564)\end{array}$ & $\begin{array}{l}0.45 \\
(590)\end{array}$ & $\begin{array}{l}-0.51 \\
(589)\end{array}$ & $\begin{array}{l}-0.48 \\
(552)\end{array}$ \\
\hline $780-1$ & $\begin{array}{l}0.86 \\
(829)\end{array}$ & $\begin{array}{l}0.80 \\
(999)\end{array}$ & $\begin{array}{l}0.69 \\
(999)\end{array}$ & $\begin{array}{l}0.78 \\
(999)\end{array}$ & $\begin{array}{l}0.67 \\
(796)\end{array}$ & $\begin{array}{l}0.80 \\
(999)\end{array}$ & $\begin{array}{l}0.59 \\
(807)\end{array}$ & $\begin{array}{l}0.65 \\
(796)\end{array}$ \\
\hline $1115-1200$ & $\begin{array}{l}0.76 \\
(1141)\end{array}$ & $\begin{array}{l}0.88 \\
(1189)\end{array}$ & $\begin{array}{l}0.75 \\
(1197)\end{array}$ & $\begin{array}{l}0.90 \\
(1189)\end{array}$ & $\begin{array}{l}0.61 \\
(1161)\end{array}$ & $\begin{array}{l}0.88 \\
(1189)\end{array}$ & $\begin{array}{l}-0.37 \\
(1198)\end{array}$ & $\begin{array}{l}0.40 \\
(1103)\end{array}$ \\
\hline 138 & $\begin{array}{l}0.83 \\
(1381)\end{array}$ & $\begin{array}{l}0.38 \\
(1448)\end{array}$ & $\begin{array}{l}0.29 \\
(1448)\end{array}$ & $\begin{array}{l}0.26 \\
(1448)\end{array}$ & $\begin{array}{l}0.35 \\
(1382)\end{array}$ & $\begin{array}{l}0.23 \\
(1448)\end{array}$ & $\begin{array}{l}0.20 \\
(1385)\end{array}$ & $\begin{array}{l}-0.55 \\
(1449)\end{array}$ \\
\hline $1715-$ & $\begin{array}{l}0.79 \\
(1799)\end{array}$ & $\begin{array}{l}0.94 \\
(1844)\end{array}$ & $\begin{array}{l}0.86 \\
(1845)\end{array}$ & $\begin{array}{l}0.92 \\
(1843)\end{array}$ & $\begin{array}{l}0.57 \\
(1806)\end{array}$ & $\begin{array}{l}0.96 \\
(1843)\end{array}$ & $\begin{array}{l}-0.54 \\
(1717)\end{array}$ & $\begin{array}{l}0.51 \\
(1847)\end{array}$ \\
\hline $1860-2030$ & 0.72 & 0.64 & 0.55 & 0.54 & 0.42 & 0.55 & -0.36 & -0.49 \\
\hline & & & $(1866)$ & $(1866)$ & & & $(1863)$ & $(1881)$ \\
\hline & $\begin{array}{l}0.83 \\
(2159)\end{array}$ & $\begin{array}{l}-0.45 \\
(2245)\end{array}$ & $\begin{array}{l}-0.50 \\
(2246)\end{array}$ & $\begin{array}{l}-0.46 \\
(2245)\end{array}$ & $\begin{array}{l}0.51 \\
(2147)\end{array}$ & $\begin{array}{l}-0.54 \\
(2245)\end{array}$ & $\begin{array}{l}0.41 \\
(2239)\end{array}$ & $\begin{array}{l}-0.48 \\
(2244)\end{array}$ \\
\hline $2300-2375$ & $\begin{array}{l}0.77 \\
(2368)\end{array}$ & $\begin{array}{l}0.61 \\
(2370)\end{array}$ & $\begin{array}{l}0.42 \\
(2370)\end{array}$ & $\begin{array}{l}0.59 \\
(2370)\end{array}$ & $\begin{array}{l}0.47 \\
(2302)\end{array}$ & $\begin{array}{l}0.55 \\
(2374)\end{array}$ & $\begin{array}{l}-0.43 \\
(2302)\end{array}$ & $\begin{array}{l}0.72 \\
(2302)\end{array}$ \\
\hline
\end{tabular}

*Here, we reported the highest correlation coefficient value (absolute) between CR band depths and soil variables; Value given in the parenthesis is the wavelength $(\mathrm{nm})$ with which stated the highest ' $r$ ' value is found significant at $\alpha=0.05$ level of significance.

To confirm whether the observed reflectance variations among soils due to soil metal concentrations or not, the difference between the values of CR absorption band depth of least metal-contaminated soils (i.e. BDF-25; Table 5.4 ) and the rest of the soils are calculated. It is evident from Figure $5.8 a-b$ that with respect to the BDF-25 soils, the soils with moderate to elevated metal concentrations didn't show any observable spectral pattern that we can relate them to the metallic ions concentrations. The only notable differences observed within 780-1110 nm, in order of decreasing the band depths as BDF-27>BDF- 
$30>$ BDF-43>BDF-23>BDF-47>BDF-35>BDF-24 (Figure 5.8a), is to some extent follow the decreasing order of total metal concentration in surface soils: BDF-27>BDF-43>BDF-23>BDF-30>BDF-47>BDF-35>BDF-24 (Table 5.4). Other $\mathrm{CR}$ absorption features didn't display any specific pattern that would match with the amount of metal concentrations in the tested soils (Figure 5.8ab). Correspondingly, reflectance spectra of all the acquired 36 soil samples from other BDF sites (data not presented) were quite similar and exhibited the same features that were found with the soils from selected eight BDF sites (Figure 5.6). The only difference observed was the changes in the reflectance intensity, are likely the result of different types of soils, and varying amounts of other spectrally active soil constituents such as OC, clays, and Fe-oxides

\subsubsection{PREDiction of SOIL Metals}

Metal accumulation in the soils primarily occurs through adsorption mechanism, wherein inorganic and organic colloids such as clays, metal oxides, hydroxides and organic matter provide important edges for the metal adsorption (Bradl 2004). Consequently, the intercorrelations between spectrally featureless metallic ions and those spectrally active soil constituents have been explored in many studies for predicting metals using reflectance spectroscopy and chemometric (Horta et al. 2015; Rathod et al. 2013; Schwartz et al. 2011; Shi et al. 2014; and references therein). As discussed in above section, we didn't distinguish absorption features that we can assign directly to the metal concentrations in soil, but simultaneously significant correlations (i) between spectrally active soil variables and featureless heavy metals (Table 5.5, Table 5.6, Table 5.7); and (ii) between both these soil variables and spectral responses (Figure 5.5, Figure 5.7, Table 5.8), might be a useful approach to predict soil metal contamination. Hereafter, using spectral responses (raw, first derivatives and CR reflectance spectra), the partial least square regressions were run to predict soil metals. Full calibrated and crossvalidated prediction results for the tested soil data set are shown in Table 5.9, Table 5.10 and Table 5.11. Generally, for all the soil variables including metals and data set (except acquired 36 BDF soils) studied, the leave-one-out crossvalidation analysis showed good results of coefficients of determination $\left(R^{2}\right)$. For metal-spiked soils, the PLS1 regression (i.e., calibrating only one Y-variable at a time) using significant FD spectra (X-variable) generated best coefficient of determination for soil-As $\left(R^{2}=0.941\right.$; Figure $\left.5.9 a\right)$, soil-Pb $\left(R^{2}=0.943\right.$; Figure $5.9 b)$ and soil-Cd $\left(R^{2}=0.792\right.$; Figure 5.9c). But, the achieved higher root mean square error of cross validation $\left(\mathrm{RMSE}_{\mathrm{val}}, 94.50,158.03\right.$, and 3.586 respectively for soil-As, $-\mathrm{Pb}$ and -Cd prediction; Table 5.9 and Figure $5.9 \mathrm{a}-\mathrm{C}$ ) ruled out the prediction performance of shown PLSR models. The raw and CR reflectance spectra also found good predictors for tested soil variables in terms of high $\mathrm{R}^{2}$ values only.

Similar PLSR cross-validation results were also found for data set of selected BDF surface and subsurface soils ( $n=40$ each), here the PLS2 regression (i.e., several $\mathrm{Y}$-variables are modelled simultaneously; considers the correlations between $Y$-variables) using raw, FD and CR reflectance spectra have achieved optimum cross-validation $\mathrm{R}^{2}$ between measured and predicted soil metals (Table 5.9 and Table 5.10; Figure 5.9d-f), but consistent higher values of error term indicates inaccuracy of model to predict the responses. The error term 
RMSE designates the absolute fit of the model to the data that is how close the observed data are to the model's predicated values (Yeniay and Goktas 2002). In the same way, Al Maliki et al. (2014) also achieved less accurate PLS regression models with high RMSE values of 350-474 for soil-Pb prediction, and authors attributed this poor model accuracy to the method of Pb-spiking and to the soil texture of sandy loam. According to this, the prediction of soil$\mathrm{Pb}$ concentration decreased with an increase in the clay particles in soils. However in our study even with good amount of sand fractions in the tested soil samples (Table 5.3, Table 5.6), we found prediction models with high error terms.

(a) Band depth difference between least metal-contaminated soils and elevated metal-contaminated soils within CR absorption features; For surface soils

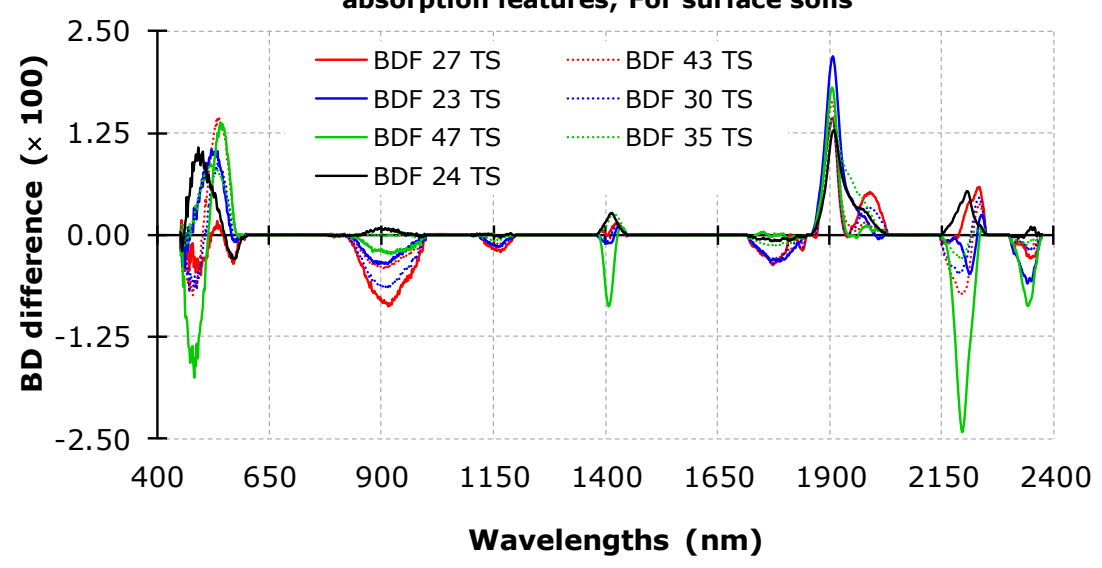

(b) Band depth difference between least metal-contaminated soils and elevated metal-contaminated soils within CR absorption features; For subsurface soils

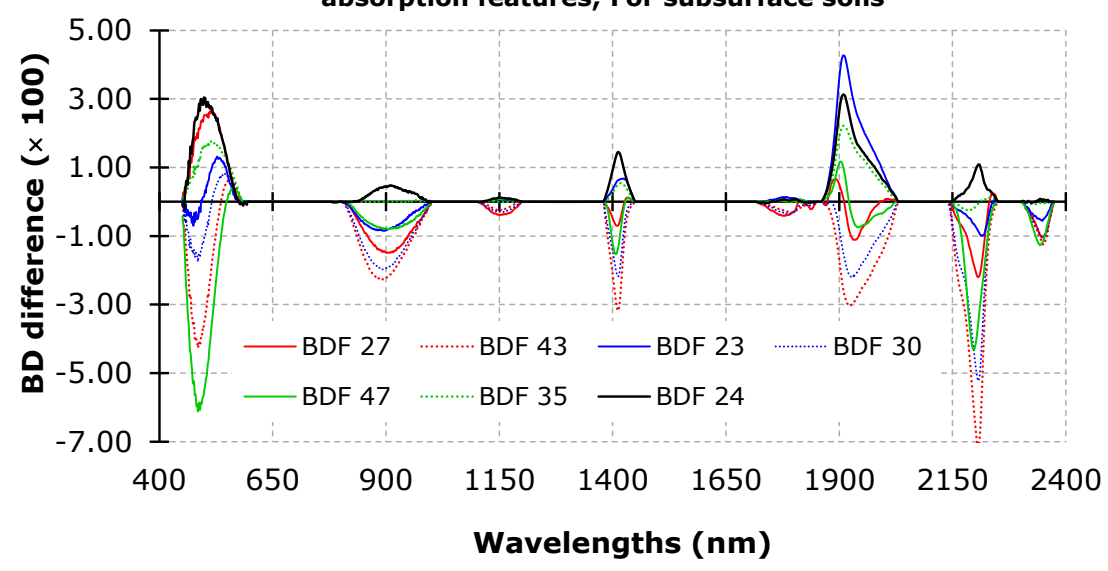

Figure 5.8: CR band depth difference between least metal-contaminated soils (i.e., BDF-25) and elevated metal-contaminated soils within CR absorption features for (a) surface soil and (b) subsurface soils 
Yet, the trend of PLS regression coefficient curves achieved for the tested soil metals in metal-spiked soils and selected eight BDF soils is relatively identical to the curves of soil organic matter that support the probability of surrogate correlations for the prediction on optically inactive soil elements. Another reason is that statistical distributions of the measured heavy metals concentration were skewed. For the data set of acquired 36 BDF soils, in spite of good correlation between soil metals with OC\% (Table 5.6), we find far less accurate regression models for soil metal predictions (data not presented). The inferior PLS results could be explained by heterogeneous soil samples with varying soil textures, soil properties, and more specifically an absence of generic relationship between metallic ions with other soil constituents such as clays, Fe and OC.

Contrary to the present results of regression analysis, several research studies (Al Maliki et al. 2014; Liu et al. 2011b; Malley and Williams 1997; Pandit et al. 2010; Ren et al. 2009; Wang et al. 2014; Wu et al. 2011; Wu et al. 2005a; Wu et al. 2005b; Xia et al. 2007) achieved satisfactory results for PLS prediction of soil metals. In present study, we only measured soil OC/OM and three metals without due respect to other soil active components (clays, Fe/Aloxides, carbonates, etc.), which are known to have interactions with the heavy metals (Bradl 2004). With these views and prevalent inconsistent results of prediction models in literature, more focused research is needed to prove the basis of surrogate correlations assumption for the determination of soil metal using visible near infrared reflectance spectroscopy.

Besides, as shown in the Table 5.10 and Table 5.11, we observed best fit PLS regression for soil organic matter using both raw reflectance between 450 $1000 \mathrm{~nm}$ ( $R^{2}$ of 0.926 and 0.955 ; RMSE of 0.628 and 0.373 , respectively for surface and subsurface soils) and FD spectra between $450-2400 \mathrm{~nm}\left(\mathrm{R}^{2}\right.$ of 0.933 and 0.948 ; RMSE of 0.599 and 0.402 , respectively for surface and subsurface soils). Likewise models for soil total Fe concentrations were obtained using raw reflectance spectra between $450-1000 \mathrm{~nm}$, which yields relatively higher $R^{2}$ of 0.726 and 0.763 ; lower RMSE of 0.172 and 0.373 for surface and subsurface soils, respectively (Table 5.10, Table 5.11). Based on these cross-validation results, reflectance spectroscopy could be feasible to predict soil OM efficiently, which was similar to the results obtained in several studies (Aïchi et al. 2009; Ladoni et al. 2010 and references within). 
Table 5.9: Best fit PLSR models for estimation of soil-metal concentration using metal-spiked soils data set, expressed in terms of coefficients of determination $\left(R^{2}\right)$ and root mean square error (RMSE) of calibration, cal and cross-validation, val models

\begin{tabular}{|c|c|c|c|c|}
\hline Particulars of regression models & $\begin{array}{l}\mathbf{R}^{2} \\
\text { cal. }\end{array}$ & $\begin{array}{l}\mathbf{R}^{2} \\
\text { val. }\end{array}$ & $\begin{array}{l}\text { RMSE } \\
\text { cal. }\end{array}$ & $\begin{array}{l}\text { RMSE } \\
\text { val. }\end{array}$ \\
\hline \multicolumn{5}{|c|}{ Soil-As concentration; As- and metal mixture-spiked soils $(n=35)$} \\
\hline $\begin{array}{l}\text { First derivatives of reflectance spectra }(450-2400 \\
\text { nm); Significant wavelengths }{ }^{a} ; \text { PC\# } 3\end{array}$ & 0.96 & 0.94 & 73.75 & 94.50 \\
\hline $\begin{array}{l}\text { First derivatives of reflectance spectra }(450-2400 \\
\mathrm{nm}) ; \mathrm{PC} \# 6\end{array}$ & 0.99 & 0.71 & 38.45 & 210.28 \\
\hline Raw reflectance spectra (450-2400 nm); PC\# 5 & 0.86 & 0.67 & 144.11 & 225.33 \\
\hline Continuum removed absorption features*; PC\# 4 & 0.76 & 0.53 & 186.54 & 266.70 \\
\hline \multicolumn{5}{|c|}{ Soil-Pb concentration; $\mathrm{Pb}-$ and metal mixture-spiked soils $(\mathrm{n}=32)$} \\
\hline $\begin{array}{l}\text { First derivatives of reflectance spectra (450- } \\
2400 \mathrm{~nm}) ; \text { Significant wavelengths }{ }^{b} ; \text { PC\# } 5\end{array}$ & 0.98 & 0.94 & 92.69 & 158.03 \\
\hline Continuum removed absorption features*; PC\# 7 & 0.97 & 0.88 & 99.89 & 229.20 \\
\hline $\begin{array}{l}\text { First derivatives of reflectance spectra (450-2400 } \\
\text { nm); PC\# } 5\end{array}$ & 0.98 & 0.87 & 81.07 & 244.20 \\
\hline Raw reflectance spectra (450-2400 nm); PC\# 4 & 0.86 & 0.80 & 240.90 & 300.95 \\
\hline \multicolumn{5}{|c|}{ Soil-Cd concentration; Cd- and metal mixture-spiked soils $(n=36)$} \\
\hline $\begin{array}{l}\text { First derivatives of reflectance spectra (450-2400 } \\
\text { nm); Significant wavelengthsc; PC\# } 2\end{array}$ & 0.82 & 0.79 & 3.21 & 3.59 \\
\hline $\begin{array}{l}\text { First derivatives of reflectance spectra (450-2400 } \\
\mathrm{nm}) ; \mathrm{PC} \# 4\end{array}$ & 0.91 & 0.74 & 2.29 & 4.04 \\
\hline Continuum removed absorption features*; PC\# 5 & 0.84 & 0.68 & 3.08 & 4.47 \\
\hline Raw reflectance spectra $(450-2400 \mathrm{~nm}) ;$ PC\# 2 & 0.57 & 0.52 & 4.99 & 5.43 \\
\hline
\end{tabular}

*Continuum removal transformations applied for absorption features between 450-600, $1100-1200,1380-1450,1715-1850,1860-2030,2140-2250$ and 2300-2375 nm wavelengths. 
Table 5.10: Best fit PLSR models for estimation of soil-metal concentration using eight BDF surface soils data set $(n=40)$, expressed in terms of coefficients of determination $\left(R^{2}\right)$ and root mean square error (RMSE) of calibration, cal and cross-validation, val models

\begin{tabular}{|c|c|c|c|c|}
\hline Particulars of regression models & $\begin{array}{l}\mathbf{R}^{2} \\
\text { cal. }\end{array}$ & \begin{tabular}{|l}
$\mathbf{R}^{2}$ \\
val.
\end{tabular} & $\begin{array}{l}\text { RMSE } \\
\text { cal. }\end{array}$ & $\begin{array}{l}\text { RMSE } \\
\text { val. }\end{array}$ \\
\hline \multicolumn{5}{|c|}{ Raw reflectance spectra $(450-1000 \mathrm{~nm}) ;$ PC\# 8} \\
\hline Total As (mg kg-1) & 0.93 & 0.81 & 220.56 & 378.99 \\
\hline Total Pb (mg kg-1) & 0.95 & 0.86 & 398.41 & 668.40 \\
\hline Total Cd (mg kg-1) & 0.95 & 0.86 & 1.96 & 3.37 \\
\hline Total Zn (mg kg-1) & 0.96 & 0.91 & 119.17 & 179.81 \\
\hline Total Ni (mg kg-1) & 0.93 & 0.90 & 2.408 & 3.131 \\
\hline Total Cu (mg kg-1) & 0.92 & 0.86 & 61.67 & 84.74 \\
\hline Total Fe (\%) & 0.82 & 0.73 & 0.14 & 0.17 \\
\hline Organic matter (\%) & 0.97 & 0.93 & 0.41 & 0.63 \\
\hline \multicolumn{5}{|c|}{ First derivatives of reflectance spectra $(450-2400 \mathrm{~nm})$; PC\# 6} \\
\hline Total As (mg kg-1) & 0.96 & 0.82 & 165.39 & 372.19 \\
\hline Total $\mathrm{Pb}\left(\mathrm{mg} \mathrm{kg}^{-1}\right)$ & 0.97 & 0.83 & 320.19 & 739.63 \\
\hline Total Cd $\left(\mathrm{mg} \mathrm{kg}^{-1}\right)$ & 0.91 & 0.73 & 2.62 & 4.77 \\
\hline Total Zn (mg kg-1) & 0.93 & 0.84 & 150.94 & 240.19 \\
\hline Total $\mathrm{Ni}\left(\mathrm{mg} \mathrm{kg}^{-1}\right)$ & 0.90 & 0.86 & 2.92 & 3.62 \\
\hline Total Cu (mg kg-1) & 0.87 & 0.79 & 73.69 & 101.83 \\
\hline Total Fe (\%) & 0.40 & 0.17 & 0.25 & 0.30 \\
\hline Organic matter $(\%)$ & 0.96 & 0.93 & 0.46 & 0.60 \\
\hline \multicolumn{5}{|c|}{ Continuum removed reflectance spectra $(450-2400 \mathrm{~nm})$; PC\# 3} \\
\hline Total As (mg kg-1) & 0.91 & 0.85 & 253.48 & 345.41 \\
\hline Total $\mathrm{Pb}\left(\mathrm{mg} \mathrm{kg}^{-1}\right)$ & 0.92 & 0.87 & 505.63 & 655.98 \\
\hline Total Cd (mg kg-1) & 0.82 & 0.79 & 3.83 & 4.22 \\
\hline Total Zn (mg kg-1) & 0.86 & 0.81 & 221.81 & 265.07 \\
\hline Total Cu (mg kg-1) & 0.84 & 0.76 & 88.04 & 112.70 \\
\hline
\end{tabular}


Table 5.11: Best fit PLSR models for estimation of soil-metal concentration using eight BDF subsurface soils data set $(n=40)$, expressed in terms of coefficients of determination $\left(R^{2}\right)$ and root mean square error (RMSE) of calibration, cal and cross-validation, val models

\begin{tabular}{|c|c|c|c|c|}
\hline Particulars of regression models & \begin{tabular}{|l|}
$\mathbf{R}^{2}$ \\
cal.
\end{tabular} & \begin{tabular}{|l|}
$\mathbf{R}^{2}$ \\
val.
\end{tabular} & $\begin{array}{l}\text { RMSE } \\
\text { cal. }\end{array}$ & $\begin{array}{l}\text { RMSE } \\
\text { val. }\end{array}$ \\
\hline \multicolumn{5}{|c|}{ Raw reflectance spectra $(450-1000 \mathrm{~nm}) ;$ PC\# 8} \\
\hline Total As (mg kg-1) & 0.91 & 0.82 & 82.67 & 119.92 \\
\hline Total Pb (mg kg-1) & 0.84 & 0.74 & 543.96 & 713.22 \\
\hline Total Cd (mg kg-1) & 0.75 & 0.58 & 2.70 & 3.60 \\
\hline Total Zn (mg kg-1) & 0.95 & 0.91 & 149.27 & 207.44 \\
\hline Total $\mathrm{Ni}\left(\mathrm{mg} \mathrm{kg}^{-1}\right)$ & 0.84 & 0.77 & 5.68 & 7.01 \\
\hline Total Cu (mg kg-1) & 0.95 & 0.90 & 34.46 & 48.43 \\
\hline Total Fe (\%) & 0.84 & 0.76 & 0.28 & 0.37 \\
\hline Organic matter $(\%)$ & 0.97 & 0.96 & 0.30 & 0.37 \\
\hline \multicolumn{5}{|c|}{ First derivatives of reflectance spectra $(450-2400 \mathrm{~nm}) ;$ PC\# 6} \\
\hline Total As (mg kg-1) & 0.84 & 0.76 & 109.71 & 136.80 \\
\hline Total $\mathrm{Pb}\left(\mathrm{mg} \mathrm{kg}^{-1}\right)$ & 0.98 & 0.95 & 213.63 & 310.72 \\
\hline Total Cd $\left(\mathrm{mg} \mathrm{kg}^{-1}\right)$ & 0.77 & 0.62 & 2.61 & 3.42 \\
\hline Total Zn $\left(\mathrm{mg} \mathrm{kg}^{-1}\right)$ & 0.96 & 0.94 & 125.26 & 163.68 \\
\hline Total Ni (mg kg-1) & 0.77 & 0.69 & 6.80 & 8.06 \\
\hline Total Cu (mg kg-1) & 0.98 & 0.97 & 20.70 & 27.78 \\
\hline Total Fe (\%) & 0.84 & 0.78 & 0.29 & 0.35 \\
\hline Organic matter $(\%)$ & 0.96 & 0.95 & 0.35 & 0.40 \\
\hline \multicolumn{5}{|c|}{ Continuum removed reflectance spectra $(450-2400 \mathrm{~nm}) ;$ PC\# 3} \\
\hline Total As (mg kg-1) & 0.85 & 0.68 & 109.12 & 161.26 \\
\hline Total Pb (mg kg-1) & 0.99 & 0.98 & 140.31 & 210.42 \\
\hline Total Cd $\left(\mathrm{mg} \mathrm{kg}^{-1}\right)$ & 0.87 & 0.76 & 1.93 & 2.69 \\
\hline Total Zn (mg kg $\left.{ }^{-1}\right)$ & 0.98 & 0.94 & 104.38 & 170.09 \\
\hline Total $\mathrm{Ni}\left(\mathrm{mg} \mathrm{kg}^{-1}\right)$ & 0.66 & 0.41 & 8.25 & 11.20 \\
\hline Total Cu (mg kg-1) & 0.98 & 0.96 & 19.56 & 31.65 \\
\hline Total Fe (\%) & 0.86 & 0.77 & 0.28 & 0.36 \\
\hline Organic matter (\%) & 0.70 & 0.53 & 0.94 & 1.24 \\
\hline
\end{tabular}




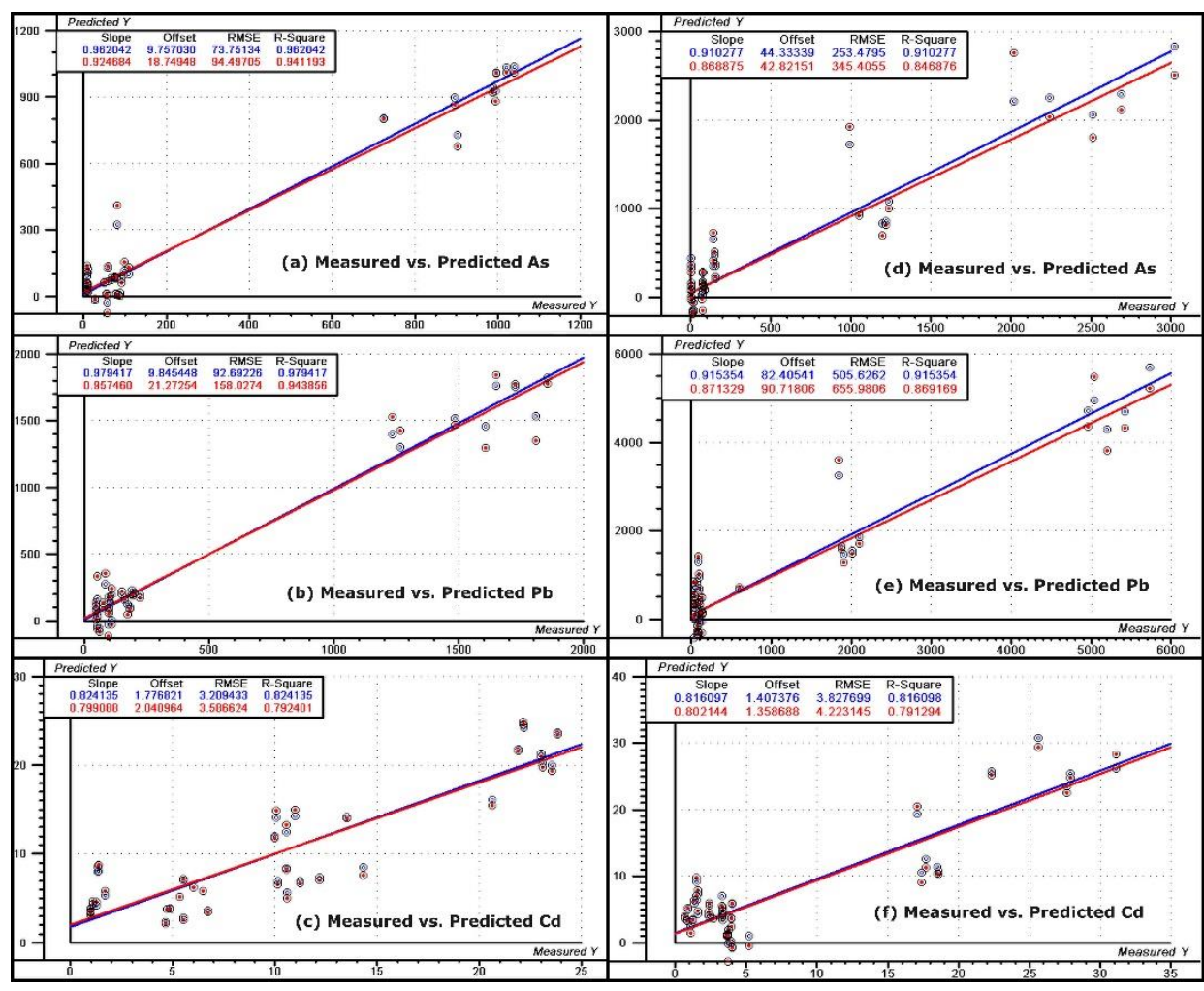

Figure 5.9 Scatter plot of measured vs. predicted metal concentration ( $\mathrm{mg}$ $\mathrm{kg}^{-1}$ ) using PLS1 regression model $(a, b, c)$ with significant first derivatives of reflectance spectra of metal-spiked soil, $(d, e)$ with CR spectra of selected BDF surface soils, and (f) with reflectance spectra in $450-1000 \mathrm{~nm}$ region of selected BDF surface soils.

Blue and red colour respectively represents the result of calibration and validation models

\subsection{SUMMARY AND CONCLUSION}

In this study, we tried to deliver an experimental confirmation to the observations made in the literature regarding practicability of soil reflectance spectroscopy for the prediction of soil metallic ions. Therefore, we measured visible and near infrared reflectance spectra of metal-contaminated soils (artificially and in-situ metal-contaminated soils) in the laboratory, and studied their direct and/or indirect influences on soil spectral response. Results of spectral analysis showed that reflectance spectra (within 450-2400 nm) of soil spiked either with separately by cadmium, arsenic and lead at 20,900, and $1200 \mathrm{mg} \mathrm{kg}^{-1}$ concentration, or with their metal-mixture didn't exhibit any sort of distinct spectral absorption features, that we can relate back to the soilmetal concentrations. With increasing magnitude of in-situ metalcontaminated soils, we only found relatively lower and higher reflectance across the entire spectrum for correspondingly extreme and lower metal- 
contaminated soils (in both surface and subsurface samples). For the rest of in-situ metal-contaminated soils, disorderly patterns of reflectance spectra were observed. Continuum removed spectra show a few more absorption peaks other than characteristic water and organic matter peaks, but they are associated with spectrally active soil constituents.

Finally, based on observed correlations between soil variables and spectral responses, we examined regression models using raw, FD and CR spectra to predict soil variables. The cross-validation leaving-one out approach yielded acceptable $\mathrm{R}^{2}$ for tested soil variables of both metal-spiked and in-situ metalcontaminated soil data sets, but higher cross validation root mean square error, obtained specifically for soil-metals prediction, suggested inadequacy of the PLS models to predict soil-metals. The results of this study, are in agreement with the recent articles of Baveye and Laba (2015a, 2015b), in which a discussion is presented on the practical use of VNIR spectroscopy to monitor soil metal-contamination. The authors suggested to switch to another possible measurement technique for at least monitoring of heavy metals, which fundamentally cannot be observed via VNIR reflectance spectroscopy. To some extent, from the achieved successful PLS regression models for estimation of soil OM content in this study, we may say that the reflectance spectroscopy could be feasible to assess soil OM content for large-scale soil monitoring program. 


\title{
CHAPTER 6 : SPECTRAL CHANGES IN THE LEAVES OF BARLEY PLANT DUE TO PHYTOREMEDIATION OF METALS - RESULTS FROM A POT STUDY ${ }^{1}$
}

\begin{abstract}
A study of changes in leaf spectra due to metal-phytoaccumulation could be a non-destructive tool for monitoring plant health status during process of phytoremediation. With this objective, barley plants were seeded in pot having $10 \mathrm{~kg}$ soil treated with three levels of each cadmium, lead, arsenic, and their multi-metals in a controlled condition. Reflectance spectra $(350-2500 \mathrm{~nm})$ of leaves were collected using portable ASD spectroradiometer, and respective leaves sample were analyzed for total metal contents. Chemical analyses shows that phytoaccumulation of metals were found in the order of root >straw zleaves > grains, showing no translocation of metal loadings from root to shoot. Metal phytoaccumulation increased with the level increment. There were lesser $\mathrm{Cd}$ and almost no $\mathrm{Pb}$-accumulation in the leaves in multi-metals treatment. As-phytoaccumulation under single and multi-metal treatments remained same, and As $>50 \mathrm{mg} \mathrm{kg}^{-1}$ observed to be phytotoxic to the barley.

Results of hyperspectral data shows that spectra in the visible and shortwave infrared regions considerably influenced by As only, in both single and multimetals treatments. Vegetation indices (NDVI, SR705, LCI, REIP, NDWI, NDWI_MIR, MSI, LWVI2) and band depth analysis at selected wavelengths proved to be good indicators for monitoring As-induced stress in the barley. Shifting of REIP (first order derivative spectra) toward the shorter wavelengths i.e., 'blue-shift' occurred with higher levels of As and multi-metals treatments. Regression models (PLSR and MLR) constructed from selected wavelengths located in the chlorophyll and water absorption regions, vegetation indices, and band depths at selected wavelength shows the potential use of hyperspectral data to monitor the plant health status and to estimate plant leaf-metal concentration grown in metal-contaminated soil for the phytoremediation purpose.
\end{abstract}

\footnotetext{
${ }^{1}$ This chapter is based on following paper:

Paresh H. Rathod, Carsten Brackhage, Freek D. Van der Meer, Ingo Müller, Marleen F. Noomen, David G. Rossiter and Gert E. Dudel (2015). Spectral changes in the leaves of barley plant due to phytoremediation of metals - results from a pot study. European Journal of Remote Sensing, 48: 283-302.

DOI : $10.5721 /$ EuJRS20154816
} 


\subsection{INTRODUCTION}

Heavy metals (e.g., $\mathrm{Cd}, \mathrm{Pb}, \mathrm{As}, \mathrm{Ni}, \mathrm{Cr}$, etc.) are known to be persistent in the environments, and the anthropogenic activities such as mining, ore processing, smelter's emission, industrial effluents/wastes disposal are progressively alleviated the metals' concentrations in the soil and river sediments. Unlike organic contaminants, metals cannot be degraded biologically and hence, require either immobilization or removal. Phytoremediation (i.e., utilizing of plants to remediate contaminated soils; also termed as phytotechnology) has been put forward as green-clean technique. With long-term plant-based remediation approach, the continuous monitoring of metal bio-accumulation and plant health status is foremost requirement (US-DOE 2000). This can be done by measuring plants growth parameters and stress response to the metals.

Adverse effects of excessive concentration of soil-metals on plant growth are well documented (Kabata-Pendias and Pendias 2001; Prasad 2004). They inhibits chlorophyll biosynthesis, decrease the total chlorophyll in higher plants, and are known to substitute the central Mg-ion in the chlorophyll molecules, resulting in a breakdown of photosynthesis. Structural and ultra-structural changes in vegetative tissues are also common effects of metal-stresses (Barceló and Poschenrieder 2004). Such metal-induced physiological and biochemical stresses in vegetation subsequently influence the vegetation reflectance spectra especially in visible $(400-700 \mathrm{~nm})$, near-infrared (NIR, 700-1300 nm) spectrum domains, and shortwave infrared (SWIR, >1300 nm) spectrum domains. A healthy vegetation shows bimodal reflectance pattern characterized by strong absorption of blue ( 450) and red ( 680) wavelengths by chlorophyll pigments, and strong reflectance of NIR wavelengths (700-1300 $\mathrm{nm}$ ) due to scattering of light by leaf mesophyll tissues. The spectral reflectance (in SWIR regions at $\sim 1400$ and $\sim 1900 \mathrm{~nm}$ ) also influences by water content.

Researchers have studied these spectral changes to relate them with phytoaccumulation of metals (Clevers and Kooistra 2003; Clevers et al. 2004; Dunagan et al. 2007; Horler et al. 1980; Kooistra et al. 2004; Schuerger et al. 2003; Sridhar et al. 2007a, 2007b; Su et al. 2007). Most studies used various vegetation indices (ratios or linear combinations of two or more spectral wavelengths [Bannari et al., 1995]) and red-edge position (a sharp transition between red and NIR wavelengths; positively related to chlorophyll concentration; [Horler et al., 1983; Dawson and Curran, 1998]) as an indication of plant stress.

To this context, studying the spectral characteristics of plant (which mainly governed by pigment contents, cellular structure, water content) is found to be useful in rapid diagnosing metal-induced vegetation stress before any stress-related damage occurs (Carter and Knapp 2001; Horler et al. 1980). Such study could provide a theoretical basis for remote sensing monitoring of metal-contaminated site. The aim of this chapter is to examine the changes in spectral reflectance of barley grown into various metal-spiked soils, thus to monitor the plant health and to estimate metal-bioaccumulation for optimizing phytoremediation system. 


\subsection{MATERIALS AND METHODS}

\subsubsection{EXPERIMENTAL SET-UP}

A pot experiment with artificially contaminated soil was carried out in glasschambers at a test facility (Figure 6.1) of Institute of General Ecology, TU Dresden in Tharandt, Germany from May-Aug 2011. The study with metalspiked into one type of soil has an advantage of constant soil conditions than those of in-situ contaminated soils. Furthermore, metal concentrations in soil solution in metal-spiked soil are larger (i.e., more metal-bioavailability, so to study the spectral changes in leaves upon bio-accumulation) than in real contaminated soils at similar total metal concentration (Mertens and Smolder 2010). Barley (Hordeum vulgare L.; cV. KWS Bambina E) was used as a test crop and seeds were obtained from Lochow, Bergen. Barley is a common crop in Saxony region, and even more commonly grown on contaminated agricultural sites due to its robustness and tolerance to the soil-metals. Yet, low translocation of $\mathrm{Cd}$ and other metals from soils to the barley grain makes it even more promising on metal-contaminated sites.

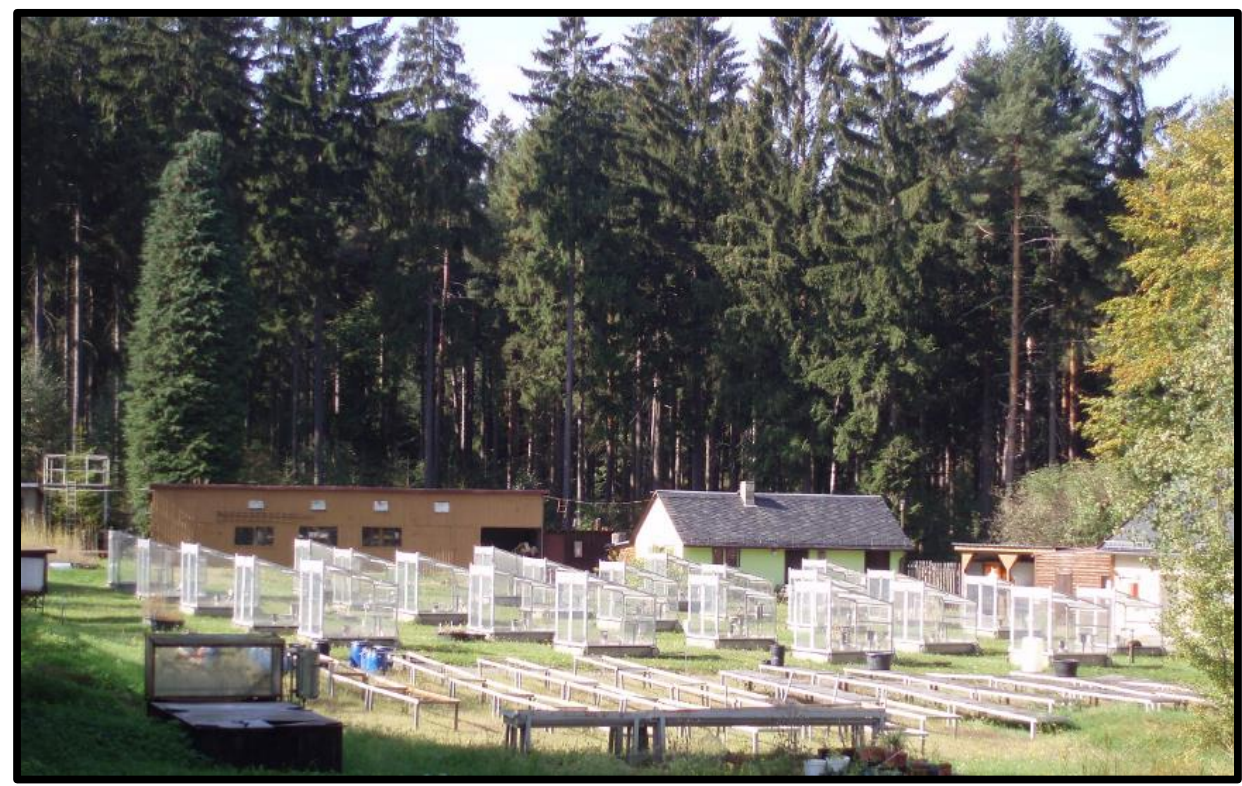

Figure 6.1: Glass-chambers at Ökologisches Prüffeld, TU Dresden, Tharandt

Bulk of uncontaminated soil substrate was brought from permanent monitoring site of Saxon State at Melptiz to the test facility at Tharandt. Bulk of soil was sieved through $0.5 \mathrm{~cm}$ using mechanical sieve. Soil at Melptiz was sandy ( $82 \%$ sand, $13 \%$ silt, and $5 \%$ clay) in texture, with medium cation exchange capacity ( $9.0 \mathrm{cmol}_{\mathrm{c}} \mathrm{kg}^{-1}$ top soil), $18-46 \%$ base saturation, $5.3-5.6 \mathrm{pH}$, and moderatelow water retention capacity (13-18\%). Physico-chemical characteristics of soil substrate are given in

Table 6.1 
Table 6.1: Physico-chemical characteristics of soil substrate used for phytoextraction pot study

\begin{tabular}{|c|c|c|c|c|c|}
\hline $\begin{array}{l}\text { Particle size; } \\
\text { Physico- } \\
\text { chemical } \\
\text { properties }\end{array}$ & Value & $\begin{array}{l}\text { Major- } \\
\text { nutrients } \\
\text { content* }\end{array}$ & Value & $\begin{array}{l}\text { Metallic-ions } \\
\text { content* }\end{array}$ & Value \\
\hline $\begin{array}{l}\text { Sand }(\%) \\
\text { Silt }(\%) \\
\text { Clay }(\%) \\
\text { BD }\left(\mathrm{g} \mathrm{cm}^{-3}\right) \\
\text { WHC }(\%) \\
\text { pH }\left(\mathrm{CaCl}_{2}\right) \\
\text { SOC }(\%) \\
\mathrm{HC}(\%)\end{array}$ & $\begin{array}{l}82.0 \\
13 \\
5 \\
1.4-1.6 \\
13-18 \\
5.3-5.6 \\
1.4-1.6 \\
1.9-2.8\end{array}$ & $\begin{array}{l}\text { Total N }(\%) \\
\text { Total P }\left(\mu g^{-1}\right) \\
\text { Total K }(\%)\end{array}$ & $\begin{array}{l}0.12 \\
550 \\
0.13\end{array}$ & $\begin{array}{l}\mathrm{Fe}(\%) \\
\left.\mathrm{Zn}(\mu \mathrm{g} \mathrm{g})^{-1}\right) \\
\mathrm{Mn}\left(\mu \mathrm{g} \mathrm{g}^{-1}\right) \\
\mathrm{Cu}\left(\mu \mathrm{g} \mathrm{g}^{-1}\right) \\
\mathrm{Ni}\left(\mu \mathrm{g} \mathrm{g}^{-1}\right) \\
\mathrm{Cr}\left(\mu \mathrm{g} \mathrm{g}^{-1}\right) \\
\mathrm{As}\left(\mathrm{mg} \mathrm{kg}^{-1}\right)^{*} \\
\mathrm{Cd}\left(\mathrm{mg} \mathrm{kg}^{-1}\right)^{*} \\
\mathrm{~Pb}\left(\mathrm{mg} \mathrm{kg}^{-1}\right)^{*}\end{array}$ & $\begin{array}{l}0.62-0.71 \\
26 \\
200 \\
6 \\
2.60 \\
7.30 \\
- \\
- \\
-\end{array}$ \\
\hline
\end{tabular}

$B D=$ Bulk density; $W H C=$ Water holding capacity; SOC = Soil organic carbon; $H C=$ Humus content; *Aqua regia extraction; *See Table 6.2 for $A s, C d$, and Pb metal content in soil substrate used for barley study.

\section{TREATMENT DETAILS}

Soil contamination was simulated by spiking salt of three metals viz., cadmium as $\mathrm{Cd}\left(\mathrm{NO}_{3}\right)_{2} \cdot 4 \mathrm{H}_{2} \mathrm{O}$, lead as $\mathrm{Pb}\left(\mathrm{NO}_{3}\right)_{2}$, and arsenic as $\mathrm{As}_{2} \mathrm{O}_{3}$ individually each at 3 different levels and also in mixture at their respective levels (Table 6.2). These metals were studied because they are the ubiquitous contaminants in agricultural soils in Saxony region (IBA 2010). Spike solutions of $\mathrm{Cd}$ and $\mathrm{Pb}$ were prepared by sequential dilutions of $\mathrm{Cd}\left(\mathrm{NO}_{3}\right)_{2} \cdot 4 \mathrm{H}_{2} \mathrm{O}$ and $\mathrm{Pb}\left(\mathrm{NO}_{3}\right)_{2}$ in deionized water, while $\mathrm{As}_{2} \mathrm{O}_{3}$ dissolved in a $\mathrm{NaOH}$-solution adjusted to near neutral $\mathrm{pH}$ value. The prepared metal-spike solutions were then added to the respective bulk of soil of the treatments (i.e., $40 \mathrm{~kg}$ soil for 4 replicate pots for each treatment; $13 \times 4=52$ plastic pots were prepared for 13 treatments set). The spiked soils were mixed homogenously, and kept for two wettingdrying cycles for 10-12 days to equilibrate metal spiking. Each $40 \mathrm{~kg}$ metalspiked soil was then divided on weight basis $\left(10 \mathrm{~kg} \mathrm{pot}^{-1}\right)$ into pot, and pots were thereafter randomized between four glass-chambers i.e., 13 pots per glass-chamber (Figure 6.2). Initial soil sample was collected from each pot before sowing barley seed for the analysis of total metals. Pre-concentration of metals in soil is given in Table 6.2.

Sowing of barley (at 30 seeds pot ${ }^{-1}$ ) was done on $18 \mathrm{Apr} 2011$. Recommended rate of major-nutrients $(\mathrm{N}, \mathrm{P}, \mathrm{K}, \mathrm{Ca}$, and $\mathrm{Mg}$ ) was given after compensating nitrate-nitrogen added through spiking of nitrate-salts as in case of $\mathrm{Cd}$ and $\mathrm{Pb}$ treatments. Nutrient solution of $\mathrm{N}, \mathrm{P}$, and $\mathrm{K}$ was prepared using analytical grade chemical respectively $\mathrm{NH}_{4} \mathrm{NO}_{3}, \mathrm{~K}_{2} \mathrm{HPO}_{4}$ and $\mathrm{KCl}$. Plants were irrigated daily with 200-300 ml deionized water to field capacity. Barley was harvested completely in second week of Sept, 2011. 


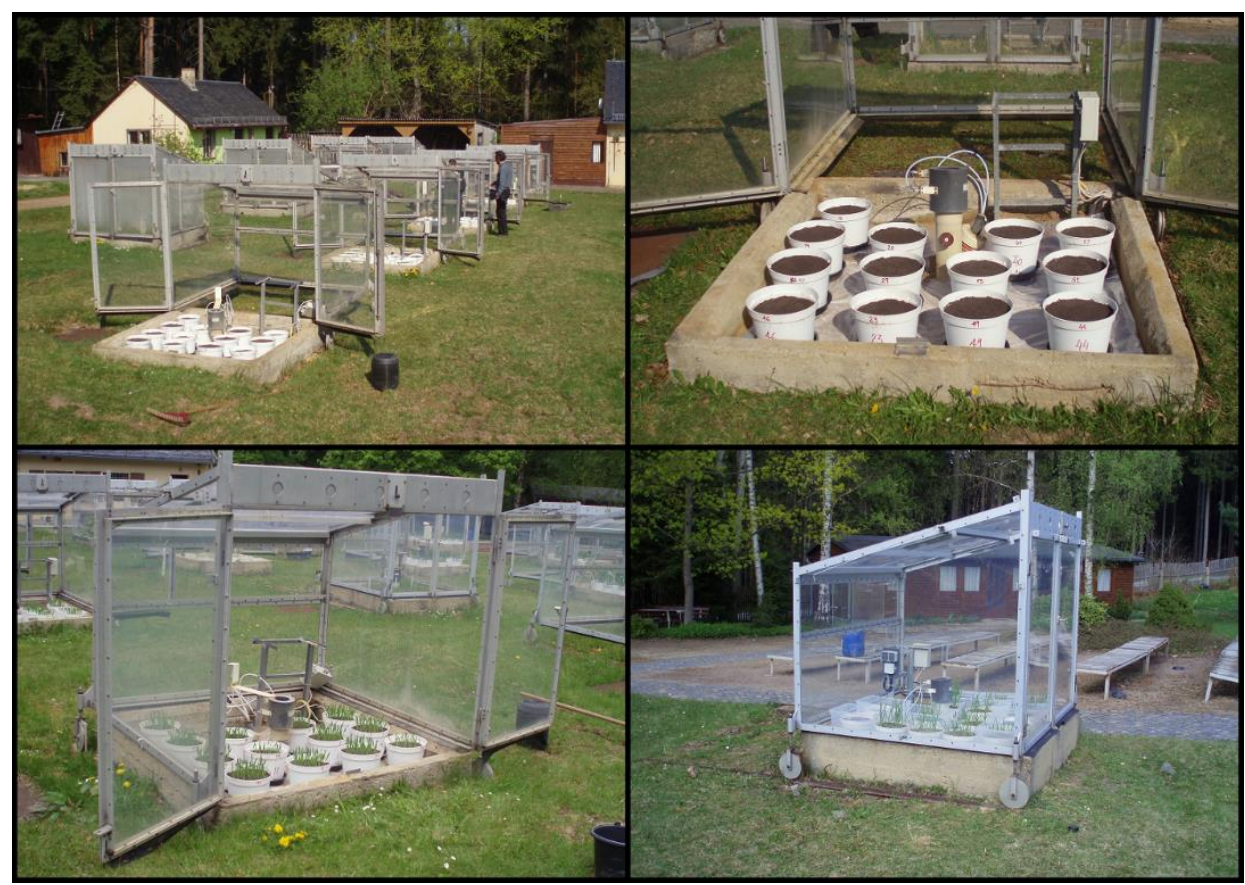

Figure 6.2: General view of experimental set-up in glass-chambers.

13 metal-treated pots were accommodated into 4-chamber each, total 52 metal-treated pots. Glass-chamber is with a provision to circulate fresh and clean air to provide a controlled condition for barley growth.

\subsubsection{SPECTRAL REFLECTANCE MEASUREMENT OF LEAVES}

Total four spectral reflectance measurements done on 20 May, 22 July, 24 Aug and 5+6 Sept 2011. For measuring leaf spectra, 4-5 plants from each pot were cut at $\sim 2.5 \mathrm{~cm}$ above soil using steel scissor. Immediately, leaf reflectance spectra was measured in a laboratory with ASD FieldSpec portable spectroradiometer (350-2500 $\mathrm{nm}$ at resolution of $1 \mathrm{~nm}$; ASD, Inc., Boulder, CO) using a plant probe leaf-clip assembly fitted with an internal halogen light. The reflectance spectra were measured by holding barley 2-3 leaves (alongside without overlapping) into leaf clip holder. Leaf-clip assembly has got two-sided rotating head: a black panel face for reflectance and a white for transmittance measurement. Reflectance spectra were calibrated against a white Spectralon panel face.

Individual spectral measurement for barley leaves was averaged ( $n=4-5$ plants) by treatment to reduce variations, and raw spectra were corrected for ASD jump (drift correction; additive) using AS-toolbox package add-in (Dorigo et al. 2006) installed in ENVI+IDL version 4.3. First derivative (FD) calculation was done on corrected spectra with 5-point moving average to intensify spectral features. Several VIs have been developed (Zarco-Tejada et al. 2001) and in this study, VIs relevant to the metal-induced plant stress, particularly in chlorophyll and water absorption regions, were computed: chlorophyll indices NDVI, LCI, SR705, REIP, and water stress indices NDWI, NDWI_MIR, 
MSI, LWVI2 (Table 6.3). Continuum removal (CR) was applied to jump corrected spectra which normalizes the reflectance spectra by applying convex hull and amplifies the individual absorption features (Clark and Roush 1984). Difference in band depth (BD) between control and metal-treatments were compared. Band depth at particular wavelength was statistically compared for each absorption regions (Table 6.3).

\subsubsection{BIOMETRIC MEASUREMENTS AND CHEMICAL ANALYSES}

Plant stand (\#plants pot ${ }^{-1}$ ) was recorded on 1 month after sowing. Whereas, plant height, other growth parameters such dry weight of plant parts (i.e., leaves, straw, and spike grain) were measured at the time of each spectral measurements and at harvest. The biometric data measured at each interval + at harvest were then sum-up with respect to the treatments and averaged over the 4 replicates.

At each spectral measurement, the plant samples were dried at $80{ }^{\circ} \mathrm{C}$ for 24 hrs and milled. Similarly, at harvest, each plant was separated into leaves, roots (cutting at the root neck; roots samples were thoroughly washed twice with deionized water), straw (stem; tillers), and spike grains. For analyzing total metal content from plant samples, $250 \mathrm{mg}$ of milled sample was digested with $5 \mathrm{~mL}$ concentrated $\mathrm{HNO}_{3}$ in Teflon tubes in pressurized microwave accelerated reaction system for 30-40 minutes. The digested substrate was then diluted with $10 \mathrm{~mL}$ deionized water and analyzed for total $\mathrm{Cd}, \mathrm{Pb}$ and $\mathrm{As}$ using inductively coupled plasma-atomic emission spectrometry (ICP-AES). Similarly, initial soil samples were also analyzed for total metal by digesting $500 \mathrm{mg}$ air-dried soil samples in $5 \mathrm{~mL}$ concentrated $\mathrm{HNO}_{3}$. Standard reference soil and plant samples were digested for recovery test. Precision for all standards was better than $5 \%$. All chemical used in metal analysis were of analytical grade.

\subsubsection{STATISTICAL ANALYSIS}

Statistical analyses of chemical and spectral data were performed in MS Excel spreadsheets with XLSTAT 2009.1.02 add-ins and reported at $\alpha=0.05$ level of significance. Means and standard errors ( \pm SE) were computed for all data. Data were statistically tested for significant effects through analysis of variance (ANOVA) and Post hoc Tukey HSD test was done to compare the treatment mean.

As an initial spectral data analyses, correlation coefficient (Pearson's 'r') was computed between spectral variables (i.e., corrected spectra, VIs, BDs of CR spectra) and leaf-metal concentration for each treatment. Regression models (PLSR, partial least square regression and MLR, multiple linear regression; Unscrambler 9.7, CAMO ASA, Norway) for predicting leaf-metal concentration from spectral data were computed by leave-one-out cross validation technique. Coefficient of determination $\left(R^{2}\right)$ between measured and predicted value and RMSE value were used to examine the relationship found. 
Table 6.2: Treatment details, initial pre-concentration of metals in soil*, and biometric parameters of barley grown with metal-spiked soil

\begin{tabular}{|c|c|c|c|c|c|c|}
\hline \multirow{2}{*}{$\begin{array}{l}\text { Details of metal- } \\
\text { spiking treatments }\end{array}$} & \multicolumn{3}{|c|}{$\begin{array}{l}\text { Pre-concentration of metals** } \\
\text { in soils }\left(\mathrm{mg} \mathrm{kg}^{-1}\right)\end{array}$} & \multirow{2}{*}{$\begin{array}{l}\text { Plant stand } \\
\text { (\# per pot) } \\
\text { at } 31 \text { DAS }^{\$}\end{array}$} & \multirow{2}{*}{$\begin{array}{c}\text { Plant height } \\
\text { (cm) at } 31 \\
\text { DAS }^{\S}\end{array}$} & \multirow{2}{*}{$\begin{array}{c}\text { Total dry } \\
\text { biomass } \\
\text { weight }(g)\end{array}$} \\
\hline & Cadmium & Lead & Arsenic & & & \\
\hline Control: No metal & $0.0( \pm 0.0)$ & $24.0( \pm 0.70)$ & $3.8( \pm 0.31)$ & $32.5^{a}( \pm 1.20)$ & $25.7^{b c}( \pm 0.50)$ & $43.7^{b}( \pm 4.14)$ \\
\hline $\mathbf{C d}_{\mathbf{1}}: 1 \mathrm{mg} \mathrm{kg}^{-1}$ & $1.2( \pm 0.11)$ & - & - & $29.8^{a b}( \pm 1.10)$ & $26.9^{a b}( \pm 0.28)$ & $42.4^{b}( \pm 4.91)$ \\
\hline $\mathbf{C d}_{\mathbf{2}}: 5 \mathrm{mg} \mathrm{kg}^{-1}$ & $5.4( \pm 0.28)$ & - & - & $27.5^{b}( \pm 0.50)$ & $28.7^{a b}( \pm 1.79)$ & $38.0^{b}( \pm 4.82)$ \\
\hline $\mathbf{C d}_{3}: 10 \mathrm{mg} \mathrm{kg}^{-1}$ & $11.1( \pm 1.79)$ & - & - & $28.0^{a b}( \pm 0.40)$ & $28.0^{a b}( \pm 1.13)$ & $43.2^{b}( \pm 3.24)$ \\
\hline $\mathbf{P b}_{\mathbf{1}}: 25 \mathrm{mg} \mathrm{kg}^{-1}$ & - & $51.0( \pm 3$ & - & $27.8^{a b}( \pm 1.10)$ & $28.4^{a b}( \pm 0.52)$ & $48.7^{b}( \pm 3.85)$ \\
\hline $\mathbf{P b}_{\mathbf{2}}: 75 \mathrm{mg} \mathrm{kg}^{-1}$ & - & $103.2( \pm 2.99)$ & - & $25.0^{b}( \pm 0.70)$ & $28.3^{a b}( \pm 1.31)$ & $38.4^{b c}( \pm 4.02)$ \\
\hline $\mathbf{P b}_{3}: 150 \mathrm{mg} \mathrm{kg}^{-1}$ & - & $180.0( \pm 7.52)$ & - & $28.3^{a b}( \pm 0.50)$ & $32.3^{a}( \pm 0.80)$ & $33.8^{b}( \pm 1.65)$ \\
\hline $\mathbf{A s}_{\mathbf{1}}: 5 \mathrm{mg} \mathrm{kg}-1$ & - & - & $8.9( \pm 0.50)$ & $27.8^{a b}( \pm 1.25)$ & $25.3^{b c}( \pm 1.72)$ & $48.8^{b}( \pm 1.45)$ \\
\hline As: $: 50 \mathrm{mg} \mathrm{kg}^{-1}$ & - & - & $47.1( \pm 6.76)$ & $25.5^{b}( \pm 0.65)$ & $20.6^{c d}( \pm 1.19)$ & $9.7^{a}( \pm 1.25)$ \\
\hline $\mathbf{A s}_{3}: 100 \mathrm{mg} \mathrm{kg}^{-1}$ & - & - & $76.1( \pm 3.29)$ & $28.3^{a b}( \pm 0.75)$ & $19.9^{c d}( \pm 1.36)$ & $3.9^{a}( \pm 1.13)$ \\
\hline $\mathbf{M i x}_{1}: \mathrm{Cd}_{1}+\mathrm{Pb}_{1}+\mathrm{As}_{1}$ & $1.2( \pm 0.15)$ & $55.4( \pm 6.09)$ & $8.9( \pm 0.27)$ & $27.0^{b}( \pm 0.80)$ & $27.6^{a b}( \pm 1.32)$ & $41.8^{c}( \pm 4.69)$ \\
\hline $\operatorname{Mix}_{2}: \mathrm{Cd}_{2}+\mathrm{Pb}_{2}+\mathrm{As}_{2}$ & $5.5( \pm 0.46)$ & $94.3( \pm 4.53)$ & $57.4( \pm 1.04)$ & $26.0^{b}( \pm 1.50)$ & $19.0^{d}( \pm 1.56)$ & $4.7^{a}( \pm 1.24)$ \\
\hline $\operatorname{Mix}_{3}: \mathrm{Cd}_{3}+\mathrm{Pb}_{3}+\mathrm{As}_{3}$ & $11.0( \pm 0.47)$ & $194.0( \pm 10.3)$ & $88.6( \pm 3.75)$ & $25.8^{b}( \pm 1.25)$ & $15.0^{d}( \pm 1.33)$ & $3.0^{a}( \pm 1.32)$ \\
\hline
\end{tabular}

*Aqua regia extraction; **values represent mean ( $\pm S E$ ) of 4 replicates. In each column values not connected by same letter are not significantly different at $\alpha=0.05$ according to Post hoc Tukey HSD test; ${ }^{\boldsymbol{s}}$ DAS $=$ Days after sowing; ${ }^{\mathbf{c}}$ Total dry biomass includes dry weight of straw + leaves + spikes + grains at each spectral measurement and at harvest, were then sum-up with respect to each treatment and averaged over the 4 replicates. 
Table 6.3: Vegetation indices calculation and absorption regions for which continuum removal was applied in present study

\begin{tabular}{|c|c|c|}
\hline \multicolumn{3}{|l|}{ Vegetation Indices } \\
\hline Chlorophyll indices & Calculation & Reference \\
\hline $\begin{array}{l}\text { Normalized Difference } \\
\text { Vegetation Index (NDVI) }\end{array}$ & $\left(R_{864}-R_{671}\right) /\left(R_{864}+R_{671}\right)$ & $\begin{array}{l}\text { Rouse Jr et al. } \\
(1974)\end{array}$ \\
\hline $\begin{array}{l}\text { Leaf Chlorophyll Index } \\
\text { (LCI) }\end{array}$ & $\left(R_{850}-R_{710}\right) /\left(R_{850}+R_{710}\right)$ & - \\
\hline Chlorophyll Index SR705 & $R_{750} / R_{705}$ & $\begin{array}{l}\text { Sims and Gamon } \\
(2002)\end{array}$ \\
\hline $\begin{array}{l}\text { Red Edge Inflection Point } \\
\text { (REIP) - Savitzky Golay } \\
\text { Filter } 1^{\text {st }} \text { order }\end{array}$ & - & $\begin{array}{l}\text { Cho and } \\
\text { Skidmore (2006) }\end{array}$ \\
\hline \multicolumn{3}{|l|}{ Water stress indices } \\
\hline $\begin{array}{l}\text { Normalized Difference } \\
\text { Water Index (NDWI) }\end{array}$ & $\left(R_{864}-R_{1245}\right) /\left(R_{864}+R_{1245}\right)$ & Gao (1996) \\
\hline $\begin{array}{l}\text { NDWI - Mid Infrared } \\
(\text { NDWI_MIR) }\end{array}$ & $\left(R_{864}-R_{2161}\right) /\left(R_{864}+R_{2161}\right)$ & - \\
\hline $\begin{array}{l}\text { Moisture Stress Index } \\
\text { (MSI) }\end{array}$ & $R_{850} / R_{1680}$ & $\begin{array}{l}\text { Hunt Jr and Rock } \\
(1989)\end{array}$ \\
\hline $\begin{array}{l}\text { Leaf Water Vegetation } \\
\text { Index (LWVI2) }\end{array}$ & $\left(R_{1094}-R_{1205}\right) /\left(R_{1094}+R_{1205}\right)$ & $\begin{array}{l}\text { Galvão et al. } \\
(2005)\end{array}$ \\
\hline \multicolumn{3}{|c|}{ Wavelengths between which the continuum removal applied } \\
\hline $\begin{array}{l}\text { Location of absorption } \\
\text { features }\end{array}$ & \multicolumn{2}{|c|}{$\begin{array}{l}\text { Wavelength }(\mathrm{nm}) \text { at which Band Depth } \\
\text { computed }\end{array}$} \\
\hline $415-545 \mathrm{~nm}$ & \multicolumn{2}{|l|}{495} \\
\hline $545-750 \mathrm{~nm}$ & \multicolumn{2}{|l|}{680} \\
\hline $900-1060 \mathrm{~nm}$ & \multicolumn{2}{|l|}{970} \\
\hline $1120-1275 \mathrm{~nm}$ & \multicolumn{2}{|l|}{1165} \\
\hline $1370-1570 \mathrm{~nm}$ & \multicolumn{2}{|l|}{1435} \\
\hline $1740-1825 \mathrm{~nm}$ & \multicolumn{2}{|l|}{1780} \\
\hline $1825-2170 \mathrm{~nm}$ & \multicolumn{2}{|l|}{1925} \\
\hline
\end{tabular}




\subsection{RESULTS AND DISCUSSION}

\subsubsection{EFFECT OF METALS ON BARLEY GROWTH}

Barley plant was sown on $18 \mathrm{Apr} 2011$, and plant growth was recorded by measuring plant stand (1 month after sowing), plant height (1 month after sowing and at harvest), and dry weights of plant parts at each spectral measurement and at harvest. The result presented in Table 6.2 shows that treatments $\mathrm{As}_{2}, \mathrm{As}_{3}, \mathrm{Mix}_{2}$, and $\mathrm{Mix}_{3}$ caused significant $(p<0.05)$ reduction in plant stand (by $13-20 \%$ reduction), plant height at 1 month (by $25-42 \%$ ), and total dry biomass weight (by 78-93\%) compared to untreated barley plants (Figure 6.5). The inorganic arsenic species (i.e., arsenite, As-III; arsenate, AsV) are generally phytotoxic (Kabata-Pendias and Pendias 2001) and found to reduce biomass and yield significantly at higher concentration (CarbonellBarrachina et al. 1997). Present result is in consistent with study of Jiang and Singh (1994) wherein author reported reduction in barley yield due to $50 \mathrm{mg}$ As $\mathrm{kg}^{-1}$ soil. Barley is As-sensitive crop and phytotoxicity depends on As concentration in the rooting medium (Shaibur et al. 2008). For As-sensitive plant, soil concentration of $5 \mathrm{mg} \mathrm{As} \mathrm{kg} \mathrm{mg}^{-1}$ is toxic, while $50 \mathrm{mg} \mathrm{As} \mathrm{kg} \mathrm{m}^{-1}$ could reduce growth by $50 \%$ (Lepp 1981). The As-phytotoxicity to barley is also expected because of sandy soil substrate used in present study ( $82 \%$ sand) and according to (Sheppard 1992), inorganic-As is 5-times more toxic in sandy soils (thresholds $40 \mathrm{mg} \mathrm{kg}^{-1}$ ) than in clayey soils (thresholds $200 \mathrm{mg} \mathrm{kg}^{-1}$ ).

In contrast, barley grew steadily in $\mathrm{Cd}$ and $\mathrm{Pb}$-spiked soils and no significant growth reduction was observed compared (Figure 6.3) to untreated plants. This might be a result of relatively low concentration of $\mathrm{Cd}(1,5$, and $10 \mathrm{mg}$ $\left.\mathrm{kg}^{-1}\right)$ and $\mathrm{Pb}\left(25,50\right.$, and $\left.150 \mathrm{mg} \mathrm{kg}^{-1}\right)$. Barley cultivars are reported to have greater degree of tolerance to high $\mathrm{Cd}$ and $\mathrm{Pb}$ concentration in soils (Pirselová 2011; Vassilev 2003). Conversely, low concentration of metal could have growth promoting effects (Nyitrai et al. 2003). Furthermore, no effect of Cd and $\mathrm{Pb}$ on barley growth is obvious as a fact of $\mathrm{NO}_{3}$-metal salts spiking, which supplied $\mathrm{NO}_{3}{ }^{-}$ions (readily available $\mathrm{N}$ ) at early stage of barley growth and thus aided to alleviate an immediate $\mathrm{Cd}$ - and $\mathrm{Pb}$-phytotoxic effects. According to Berry (1924), $\mathrm{Pb}\left(\mathrm{NO}_{3}\right)_{2}$-salt at certain low concentration could have manurial properties and stimulating effect. It implies that metal-induced stress varies with genotype of same species (Metwally et al. 2005), and also with soilmetal concentration and physico-chemical properties of metal-salts (Vassilev and Yordanov 1997).

\subsubsection{Metal acCUMULATION IN THE PLANT ABOVE GROUND PARTS}

Results of chemical analyses for $\mathrm{Cd}, \mathrm{Pb}$ and As concentration in the barley leaves at different intervals are summarized in Table 6.4 and the metal's distribution in root, the leaves (average of 4 intervals + at harvest), straw and grain of barley are shown in Figure 6.4. The amount of all three metals in plant parts increased with increasing levels of metal treatment, and was found significant $(p<0.05)$. The average (of all intervals) concentrations of metal in the leaves are: 6.16 and $3.09 \mathrm{mg} \mathrm{Cd} ; 5.26$ and $0.74 \mathrm{mg} \mathrm{Pb} ; 18.65$ and 20.08 $\mathrm{mg} \mathrm{As} \mathrm{kg}^{-1}$, respectively for higher level of single (i.e., $\mathrm{Cd}_{3}, \mathrm{~Pb}_{3}, \mathrm{As}_{3}$ ) and multimetals $\left(\mathrm{Mix}_{3}\right)$ treatment. 


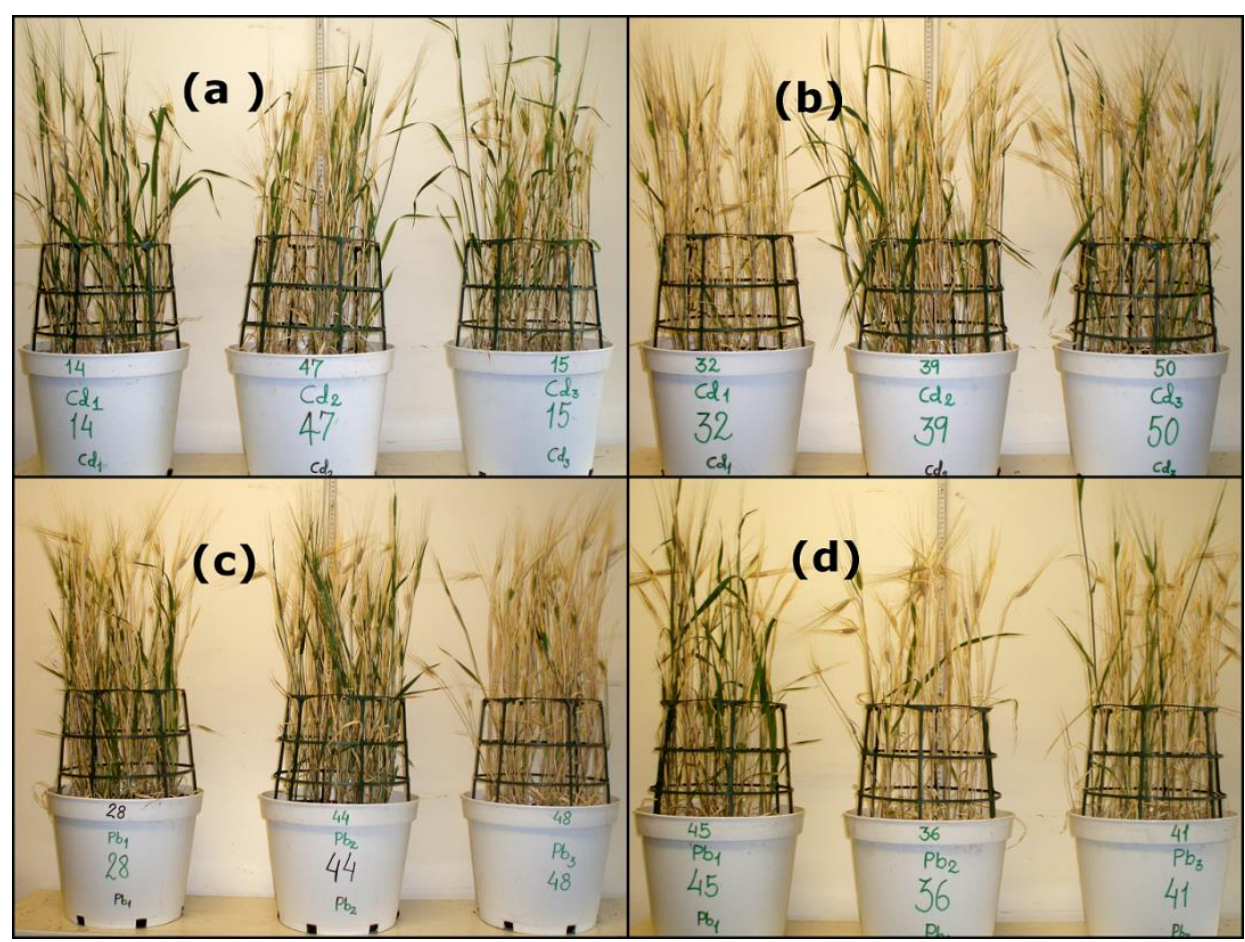

Figure 6.3: Growth of barley plants (at $~ 3.5$ months after sowing) in cadmium ( $a, b)$ and lead ( $c, d)$ spiked soils, showing no-different between levels of treatment.

For all three metals, noticeable difference in metals' accumulation in different plant parts was observed, with preferentially higher metal accumulated in roots, followed by straw plus leaves, and while grains contained much lower concentration of metal, i.e., the metal content was in the order of: roots >straw $\geq$ leaves $>$ grains (Figure 6.4 and Table 6.4). Of the total metal accumulation in plant, $\approx 94 \% \mathrm{~Pb}, \approx 82 \% \mathrm{Cd}$, and $\approx 64 \%$ As were concentrated in roots only, advocates an existence of different metal sequestration mechanism, which hampered the metal translocation from root to the above-ground plant parts. Several studies (Guo et al. 2007; Karimi et al. 2013; Žaltauskaitè and Šliumpaitè 2013) had confirmed hyper-accumulation of Cd into barley roots, could partly be explained by the Cd-loading into cell vacuole as non-active form and immobilization by cell wall (Vassilev et al. 2002). Phytoaccumulation of Pb into above-ground plant parts is principally rare due to low solubility of most $\mathrm{Pb}$-compounds, and ready precipitation of $\mathrm{Pb}$ by sulphate and phosphate at root system (Dushenkov et al. 1995; McGrath et al. 2002). Arsenic translocation from root to shoot is as well rare phenomenon in most terrestrial plant species, except certain hyper-accumulators species of Brake ferns, Pteris vittata (Banejad and Olyaie 2011; McGrath et al. 2002). 
Table 6.4: Metal concentration (in $\mathrm{mg} \mathrm{kg}^{-1}$; dry weight basis)* in leaves of barley

\begin{tabular}{|c|c|c|c|c|c|c|}
\hline \multirow{2}{*}{ 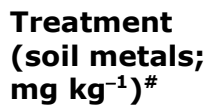 } & \multicolumn{6}{|c|}{ Cd concentration at different intervals (days after sowing) } \\
\hline & 31 & 65 & 92 & 126 & At harvest & AVERAGE \\
\hline $\begin{array}{l}\text { Control (0.001) } \\
\mathrm{Cd}_{1(1.15)} \\
\mathrm{Cd}_{2(2.39)} \\
\mathrm{Cd}_{3(11.11)} \\
\operatorname{Mix}_{1(1.24)} \\
\operatorname{Mix}_{2(5.45)} \\
\operatorname{Mix}_{3(11.00)} \\
\end{array}$ & $\begin{array}{l}0.07^{c}( \pm 0.01) \\
0.50^{c}( \pm 0.04) \\
2.28^{b}( \pm 0.46) \\
4.20^{a}( \pm 0.35) \\
0.62^{c}( \pm 0.12) \\
2.07^{b}( \pm 0.22) \\
2.72^{b}( \pm 0.19) \\
\end{array}$ & $\begin{array}{l}0.06^{e}( \pm 0.01) \\
0.95^{d}( \pm 0.31) \\
3.11^{b}( \pm 0.31) \\
3.90^{a}( \pm 0.46) \\
0.60^{d e}( \pm 0.06) \\
2.00^{c}( \pm 0.12) \\
3.53^{a b}( \pm 0.18)\end{array}$ & $\begin{array}{l}0.17^{d}( \pm 0.03) \\
1.14^{c d}( \pm 0.20) \\
3.78^{b}( \pm 0.50) \\
5.78^{a}( \pm 1.20) \\
1.42^{c}( \pm 0.32) \\
2.11^{c}( \pm 0.20) \\
2.29^{b c}( \pm 0.50)\end{array}$ & $\begin{array}{l}0.18^{b}( \pm 0.02) \\
0.93^{b}( \pm 0.13) \\
5.01^{a}( \pm 1.54) \\
5.98^{a}( \pm 0.55) \\
1.00^{b}( \pm 0.23) \\
4.76^{a}( \pm 0.40) \\
4.71^{a}( \pm 0.00)\end{array}$ & $\begin{array}{l}0.15^{e}( \pm 0.02) \\
1.21^{d}( \pm 0.21) \\
4.78^{b}( \pm 0.34) \\
7.32^{a}( \pm 0.35) \\
1.04^{d}( \pm 0.06) \\
2.20^{c}( \pm 0.37) \\
3.98^{b}( \pm 0.53)\end{array}$ & $\begin{array}{c}0.38^{c}( \pm 0.01) \\
1.07^{b c}( \pm 0.04) \\
4.31^{a}( \pm 0.83) \\
5.60^{a}( \pm 0.47) \\
0.99^{b c}( \pm 0.10) \\
2.40^{b}( \pm 0.16) \\
2.44^{b}( \pm 0.15)\end{array}$ \\
\hline $\operatorname{Mix}_{3}(11.00)$ & \multicolumn{6}{|c|}{ Pb concentration at different intervals (days after sowing) } \\
\hline $\begin{array}{l}\text { Control (23.96) } \\
\mathrm{Pb}_{1(50.96)} \\
\mathrm{Pb}_{2}(103.22) \\
\mathrm{Pb}_{3}(179.96) \\
\mathrm{MiX}_{1}(55.40) \\
\mathrm{MiX}_{2}(94.25) \\
\operatorname{Mix}_{3}(194.06) \\
\end{array}$ & $\begin{array}{l}0.27^{d}( \pm 0.02) \\
0.78^{c}( \pm 0.28) \\
2.80^{d}( \pm 0.40) \\
5.73^{a}( \pm 0.14) \\
0.56^{c d}( \pm 0.09) \\
0.51^{c d}( \pm 0.14) \\
0.64^{c d}( \pm 0.08)\end{array}$ & $\begin{array}{l}0.24^{c}( \pm 0.03) \\
0.93^{c}( \pm 0.03) \\
3.25^{b}( \pm 0.53) \\
7.12^{a}( \pm 0.95) \\
0.56^{c}( \pm 0.06) \\
0.45^{c}( \pm 0.04) \\
0.66^{c}( \pm 0.18)\end{array}$ & $\begin{array}{l}0.25^{b}( \pm 0.03) \\
0.53^{b}( \pm 0.04) \\
1.45^{b}( \pm 0.22) \\
4.33^{a}( \pm 1.70) \\
0.33^{b}( \pm 0.09) \\
0.31^{b}( \pm 0.08) \\
0.27^{b}( \pm 0.11)\end{array}$ & $\begin{array}{l}0.23^{c}( \pm 0.02) \\
0.51^{c}( \pm 0.10) \\
2.07^{b}( \pm 0.37) \\
3.46^{a}( \pm 0.74) \\
0.47^{c}( \pm 0.07) \\
0.40^{c}( \pm 0.05) \\
0.65^{b c}( \pm 0.00)\end{array}$ & $\begin{array}{l}0.41^{c}( \pm 0.05) \\
1.05^{c}( \pm 0.06) \\
3.17^{b}( \pm 0.19) \\
7.51^{a}( \pm 0.55) \\
0.88^{c}( \pm 0.05) \\
0.47^{c}( \pm 0.17) \\
0.94^{c}( \pm 0.26)\end{array}$ & $\begin{array}{l}0.32^{c}( \pm 0.03) \\
0.69^{c}( \pm 0.09) \\
2.25^{b}( \pm 0.20) \\
5.26^{a}( \pm 0.49) \\
0.52^{c}( \pm 0.04) \\
0.46^{c}( \pm 0.10) \\
0.74^{c}( \pm 0.08)\end{array}$ \\
\hline $\operatorname{Mix}_{3}(194.06)$ & \multicolumn{6}{|c|}{ As concentration at different intervals (days after sowing) } \\
\hline $\begin{array}{l}\text { Control (3.81) } \\
\mathrm{As}_{1}(8.90) \\
\mathrm{As}_{2}(47.14) \\
\mathrm{As}_{3}(76.09) \\
\mathrm{Mix}_{1}(8.94) \\
\operatorname{Mix}_{2}(57.38) \\
\operatorname{Mix}_{3}(88.59)\end{array}$ & $\begin{array}{c}0.02 \mathrm{e}( \pm 0.002) \\
4.80^{d}( \pm 0.14) \\
18.71^{b}( \pm 1.96) \\
22.48^{a}( \pm 0.32) \\
3.09^{d}( \pm 0.32) \\
14.08^{c}( \pm 0.90) \\
12.50^{c}( \pm 0.48)\end{array}$ & $\begin{array}{c}0.02 \mathrm{e}( \pm 0.002) \\
5.18^{d}( \pm 0.38) \\
22.80^{b}( \pm 2.71) \\
27.75^{a}( \pm 1.04) \\
5.58^{d}( \pm 0.86) \\
15.67^{b}( \pm 1.11) \\
18.82^{b}( \pm 1.67)\end{array}$ & $\begin{array}{c}0.03^{c}( \pm 0.004) \\
0.67^{c}( \pm 0.62) \\
13.48^{a b}( \pm 2.17) \\
20.71^{a b}( \pm 0.48) \\
0.83^{c}( \pm 0.75) \\
25.75^{a}( \pm 4.85) \\
19.27^{a b}( \pm 0.44)\end{array}$ & $\begin{array}{c}0.04^{b}( \pm 0.001) \\
2.11^{b}( \pm 0.23) \\
20.61^{a}( \pm 4.45) \\
17.32^{a}( \pm 4.74) \\
1.71^{b}( \pm 0.21) \\
15.30^{a}( \pm 2.82) \\
22.15^{a}( \pm 0.00)\end{array}$ & $\begin{array}{l}0.10^{c}( \pm 0.06) \\
4.63^{c}( \pm 0.24) \\
2.49^{a b}( \pm 1.80) \\
31.67^{a}( \pm 7.59) \\
4.69^{c}( \pm 15.34) \\
15.34^{c}( \pm 3.84) \\
30.49^{a}( \pm 4.25)\end{array}$ & $\begin{array}{c}0.02^{b}( \pm 0.00) \\
2.92^{b}( \pm 0.27) \\
19.02^{a}( \pm 1.26) \\
24.03^{a}( \pm 3.14) \\
2.49^{b}( \pm 0.34) \\
18.01^{a}( \pm 1.27) \\
20.34^{a}( \pm 0.64)\end{array}$ \\
\hline
\end{tabular}

*The values represent averages $\pm S E$ of $n=4$ replicates (of metal-spiking) and $n=28$ replicates (of control).

In each column values not connected by same letter are significantly different at $\alpha=0.05$ according to Post hoc Tukey HSD test.

\#Pre-concentration of metal in soils in respective treatments. 

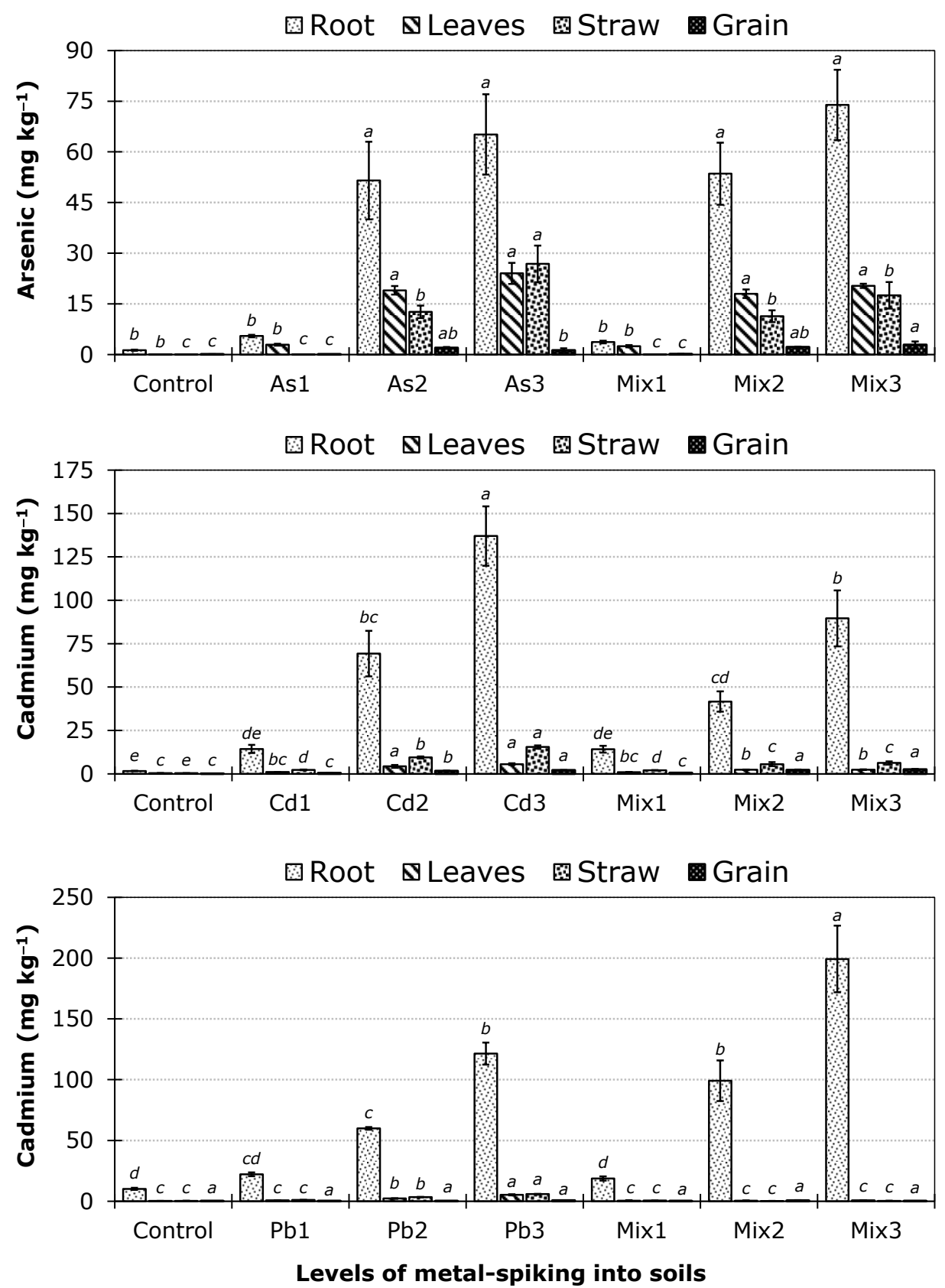

Figure 6.4: Cadmium, lead and arsenic concentration (in $\mathrm{mg} \mathrm{kg}^{-1}$; dry weight basis) in roots, leaves*, straw and grains of barley.

Error bars are values of $\pm \mathrm{SE}$. The column not connected by same letter are significantly different at $\alpha=0.05$ according to Post hoc Tukey HSD test.

*Average value of all measurements done on 31, 65, 92, 126 days after sowing, and at harvest. 
For all three metals, it is important to note that metal concentrations in leaves, straw, and grains under the multi-metal treatments were significantly lower than the respective levels of single-metal treatments (Figure 6.4 and Table 6.4 ). This result noticeably pronounced for $\mathrm{Pb}$ content in leaves, straw, and grains. Contrary, the $\mathrm{Pb}$ in roots was statistically higher in multi-metal treatments than that of respective levels of single $\mathrm{Pb}$ treatments, indicating that root uptake of $\mathrm{Pb}$ could be alleviated in combination of either $\mathrm{Cd}$ or As, but barley was inefficient in translocation of these root loads of $\mathrm{Pb}$ into the above-ground parts. However, the multi-metal treatment (Mix 2 and $\mathrm{Mix}_{3}$; Figure 6.4) significantly hampered the $\mathrm{Cd}$ accumulation in the all plant parts than the single $\mathrm{Cd}$ treatments $\left(\mathrm{Cd}_{2}\right.$ and $\mathrm{Cd}_{3}$; Figure 6.4$)$, this apparently due to antagonism of either $\mathrm{As}$ or $\mathrm{Pb}$ with $\mathrm{Cd}$ build-up by the plant tissues. This finding is consistent with the report of Sun et al. (2008), in which high concentration of As had negative effect on Cd uptake by the Solanum nigrum plant.

Above results confirmed that the tested cultivar of barley could capable to concentrate more than one metals into the roots (i.e., co-accumulation), and had tolerance mechanism towards $\mathrm{Pb}$ and $\mathrm{Cd}$ by restricting their entry into the shoots, specifically in the $\mathrm{Mix}_{1}$ and Mix 2 treatments. As-toxicity was apparent in the $\mathrm{Mix}_{3}$ treatment (as same in the $A s_{3}$ treatment; Figure 6.5), which disturbs plant functioning, and thereby the uptake mechanism of other metals.

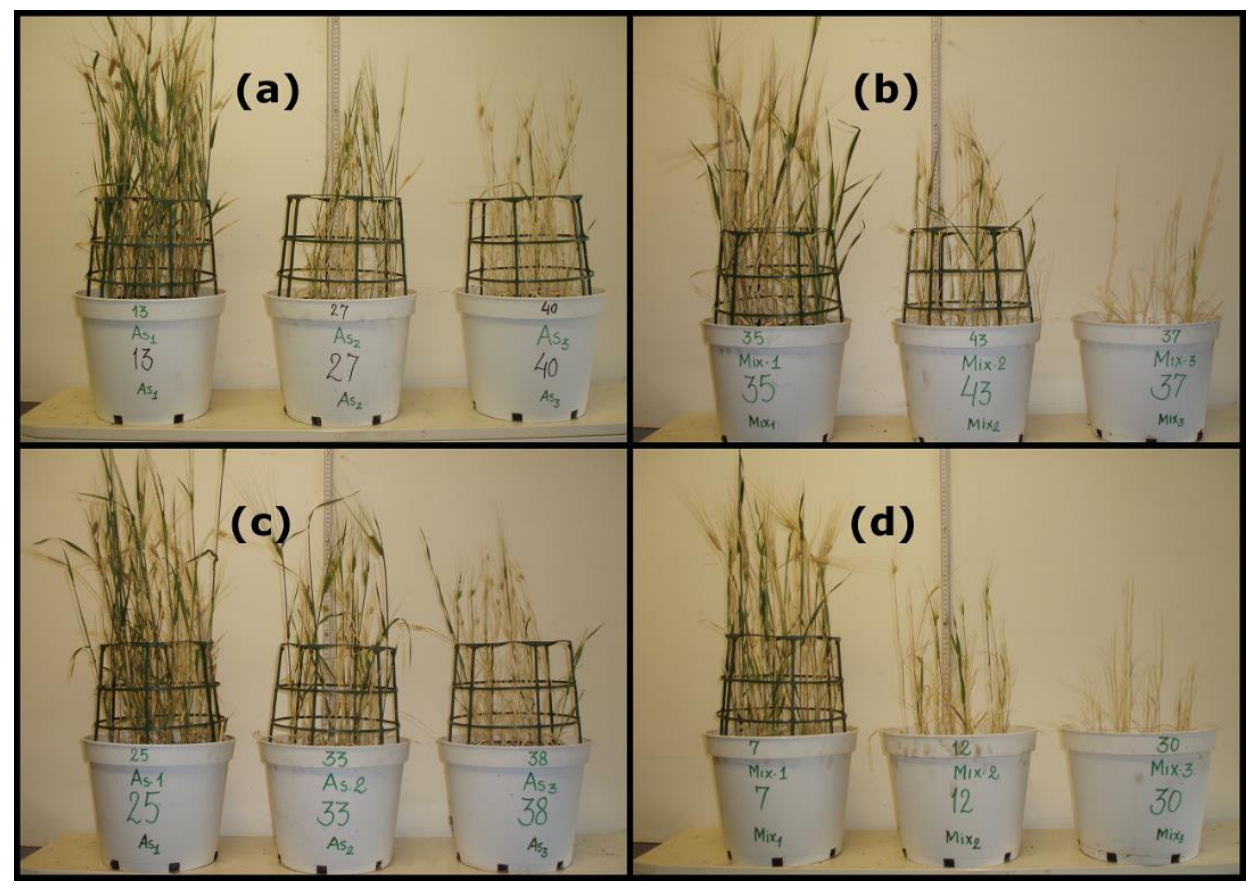

Figure 6.5: Barley growth (at 3.5 months after sowing) in arsenic (a, c) and multi-metals $(b, d)$ treatments, showing intensified As-phytotoxic effects on barley growth 


\subsubsection{SPECTRAL REFLECTANCE ANALYSIS}

\section{Cadmium and Lead treatment}

At first, the mean spectra of leaves for each treatments were studied and analyzed visually. The spectral changes due to $\mathrm{Cd}$ and $\mathrm{Pb}$ (except $\mathrm{Cd}_{3}$ and $\mathrm{Pb}_{3}$ ) do not show visible difference; spectra are nearly indistinguishable from the untreated plant, and the shape of these curve is consistent over the time (Figure 6.6a-f).

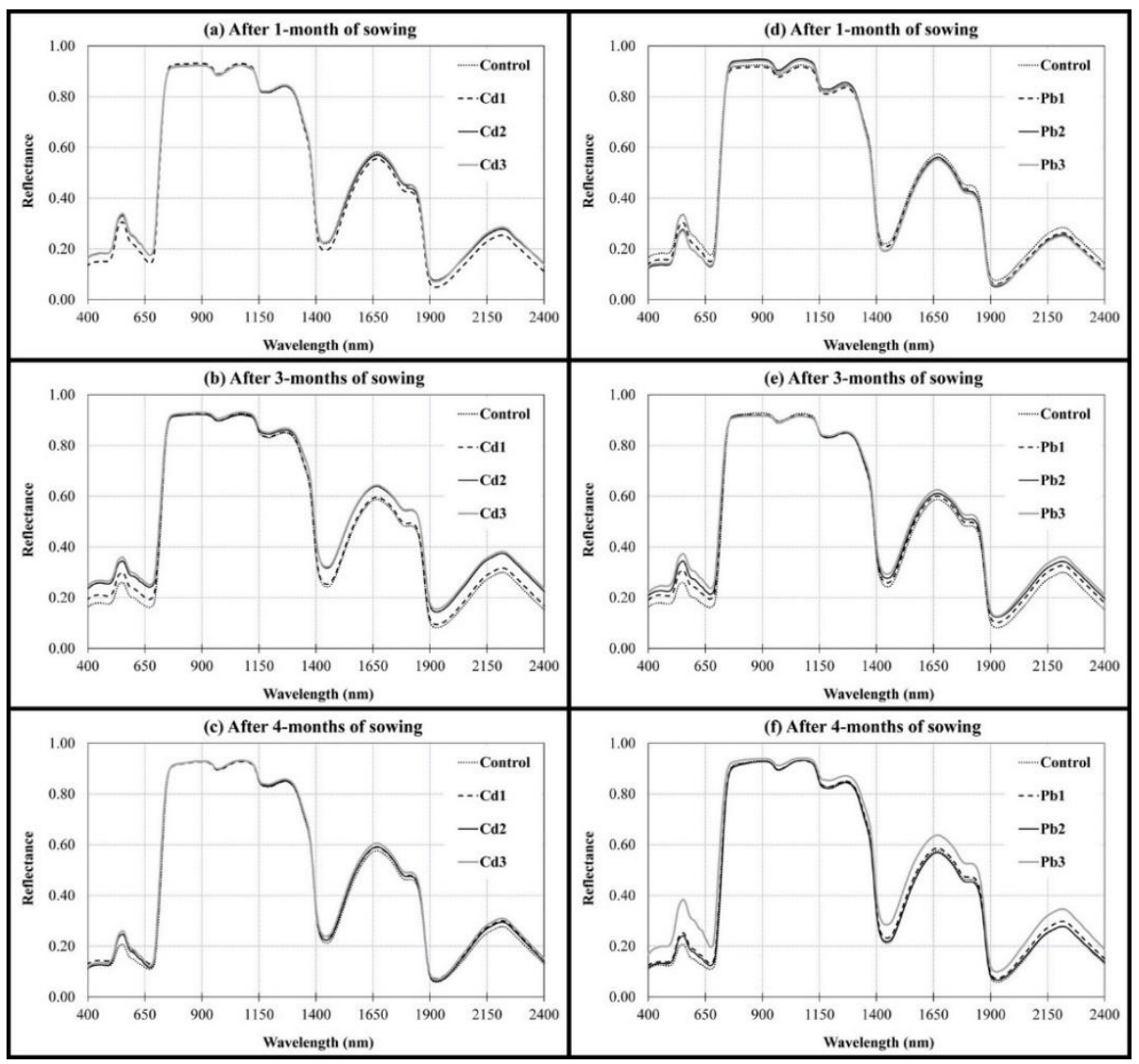

Figure 6.6: Reflectance of barley leaves for three levels of cadmium (a, b, c) and lead $(d, e, f)$ treatments in comparison to untreated control spectra at 1 , 3 and 4 months.

This might be as a result of $\mathrm{NO}_{3}$-metal salt spiking, which could favoured the chlorophyll biosynthesis, and hence spectra were not much deviated from the control spectra, rather relatively a deepen absorption features at $\sim 495$ and $\sim 680 \mathrm{~nm}$ were noted in case of $\mathrm{Pb}_{3}$ at 1 month compared to control spectra (Figure 6.9a). Non-significant Pearson's correlation between leaf-Cd, Pb content and leaf spectra was noticed in both single and multi-metals treatment except for 1 month of sowing (Figure 6.7a-b). On 1 month, significant negative 
correlation was noted between leaf- $\mathrm{Pb}$ (in Pb-treatment) and 513-645 nm ( $r=$ -0.58 to $-0.72 ; p=0.007), 691-721 \mathrm{~nm}(-0.58$ to $-0.73 ; p=0.008)$.
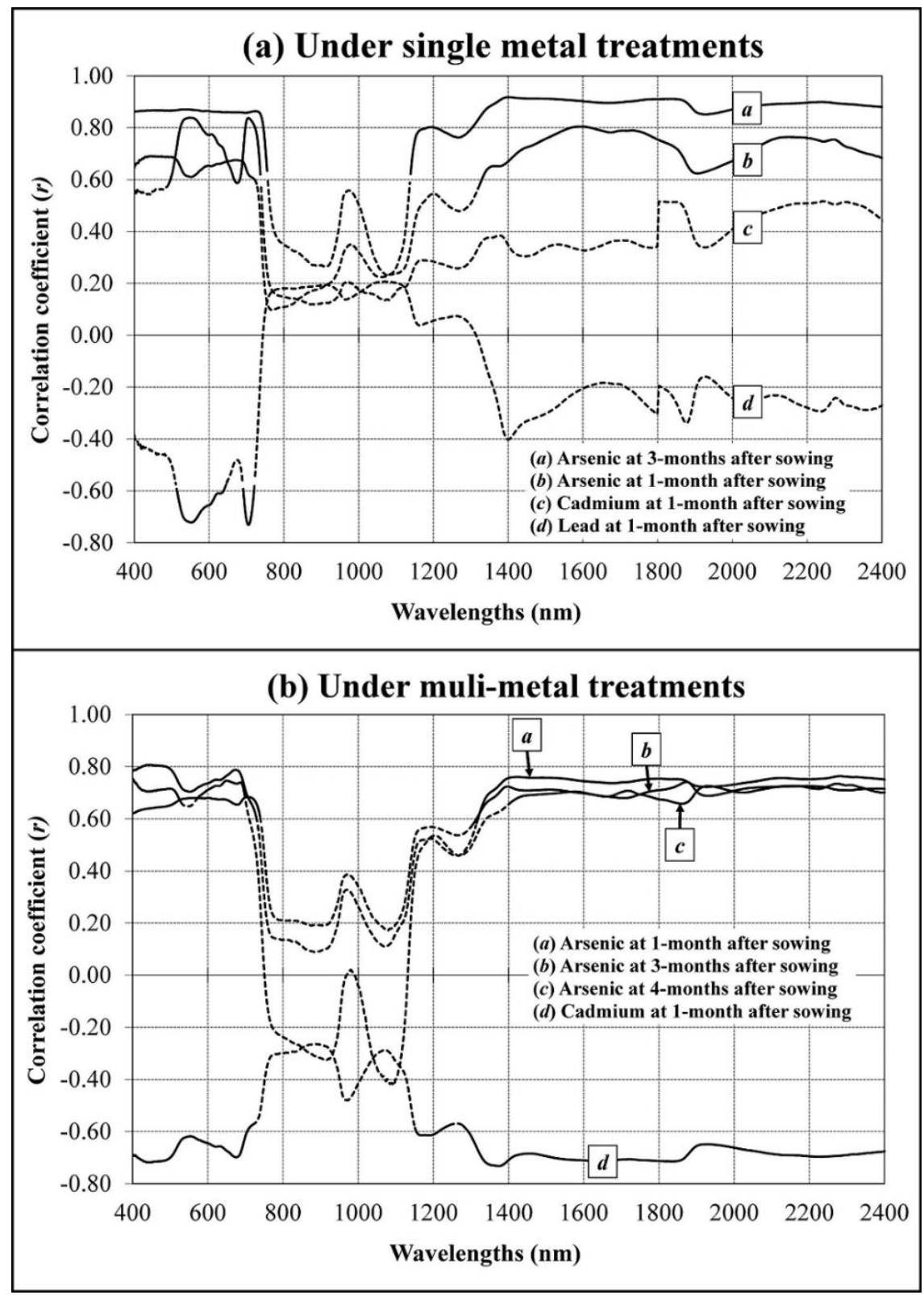

Figure 6.7: Pearson's correlation ( $r$ ) of the leaf-metal concentration and leaf reflectance spectra under (a) single metal and (b) multi-metals treatments.

Solid line $(-)$ represents significant correlation between wavelength and metal concentration at $\alpha=0.05$ level of significance and Dotted line (----) represents non-significant correlations. 
This could be either due to of straight effect of $\mathrm{Pb}\left(\mathrm{NO}_{3}\right)_{2}$-salt spiking into soil or relatively low level of $\mathrm{Pb}$ that itself stimulates photosynthetic machineries and pigment biosynthesis (Nyitrai et al. 2003), causing increased absorption at these wavelengths. Whereas, leaf-Cd in Cd-treatments was positively correlated ( $r=0.58$ to $0.84 ; p=0.001$ ) at wavelengths from $491-737 \mathrm{~nm}$, with the highest coefficient $(r)$ values were found at wavelengths from $545-553 \mathrm{~nm}$. In contrast, correlograms between leaf-Cd in multi-metal treatments and wavelengths from 351-717, 1151-1241, and >1279 nm shows significant negative relationship, with the highest $r$ values of $-0.72(p=0.008)$ and -0.73 $(p=0.007)$ at 443 and $1369-1377 \mathrm{~nm}$, respectively.

\section{ARSENIC AND MULTI-METALS TREATMENT}

In contrast to $\mathrm{Cd}$ - and $\mathrm{Pb}$-treatments, barley grown in As- and multi-metals spiked soils had increased reflectance in visible and SWIR regions, while small changes occurred in NIR compared to control spectra.

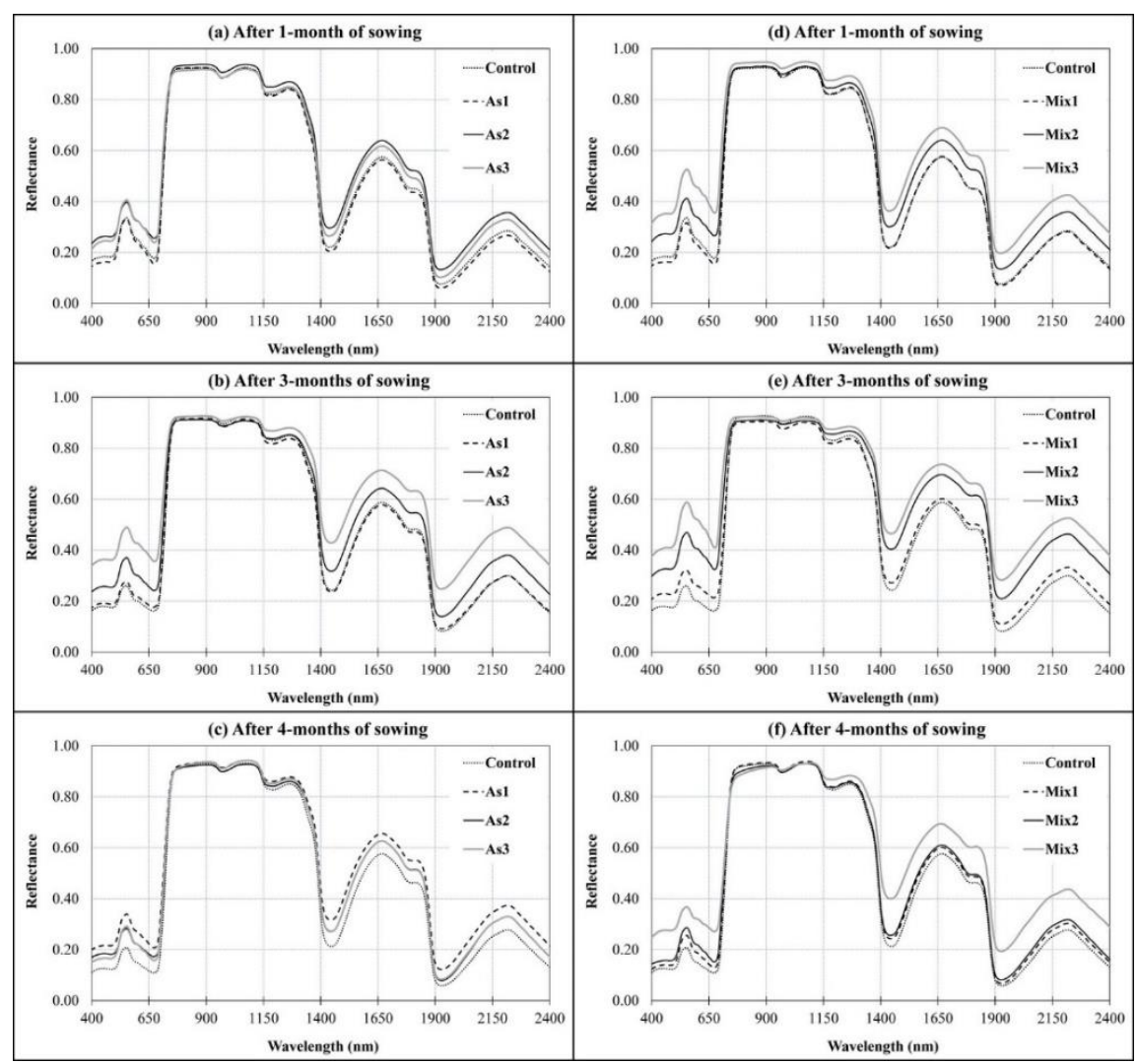

Figure 6.8: Reflectance of barley leaves for three levels of arsenic ( $a, b, c)$ and multi-metals $(d, e, f)$ treatments in comparison to untreated control spectra at 1,3 and 4 months.

As it can be seen in Figure 6.8a-f and Figure 6.9a-c, spectral change was clear with the highest level of treatment over control spectra, and spectral amplitude 
in visible and SWIR regions was prominent with $\mathrm{As}_{3}$ and $\mathrm{Mix}_{3}$ treatments at 1 and 3 months. Reflectance difference between treated and untreated plant is significant $(p<0.0001)$ in the visible and SWIR regions with the greatest difference observed at $\sim 700-715 \mathrm{~nm}$ for $\mathrm{As}_{3}$ and $\mathrm{Mix}_{3}$ treatments (Figure $6.9 \mathrm{~d}$ f). Other potential changes due to metal treatment includes absorption features around 970, 1160, 1430, and $1920 \mathrm{~nm}$, are likely related to leaf water stress.
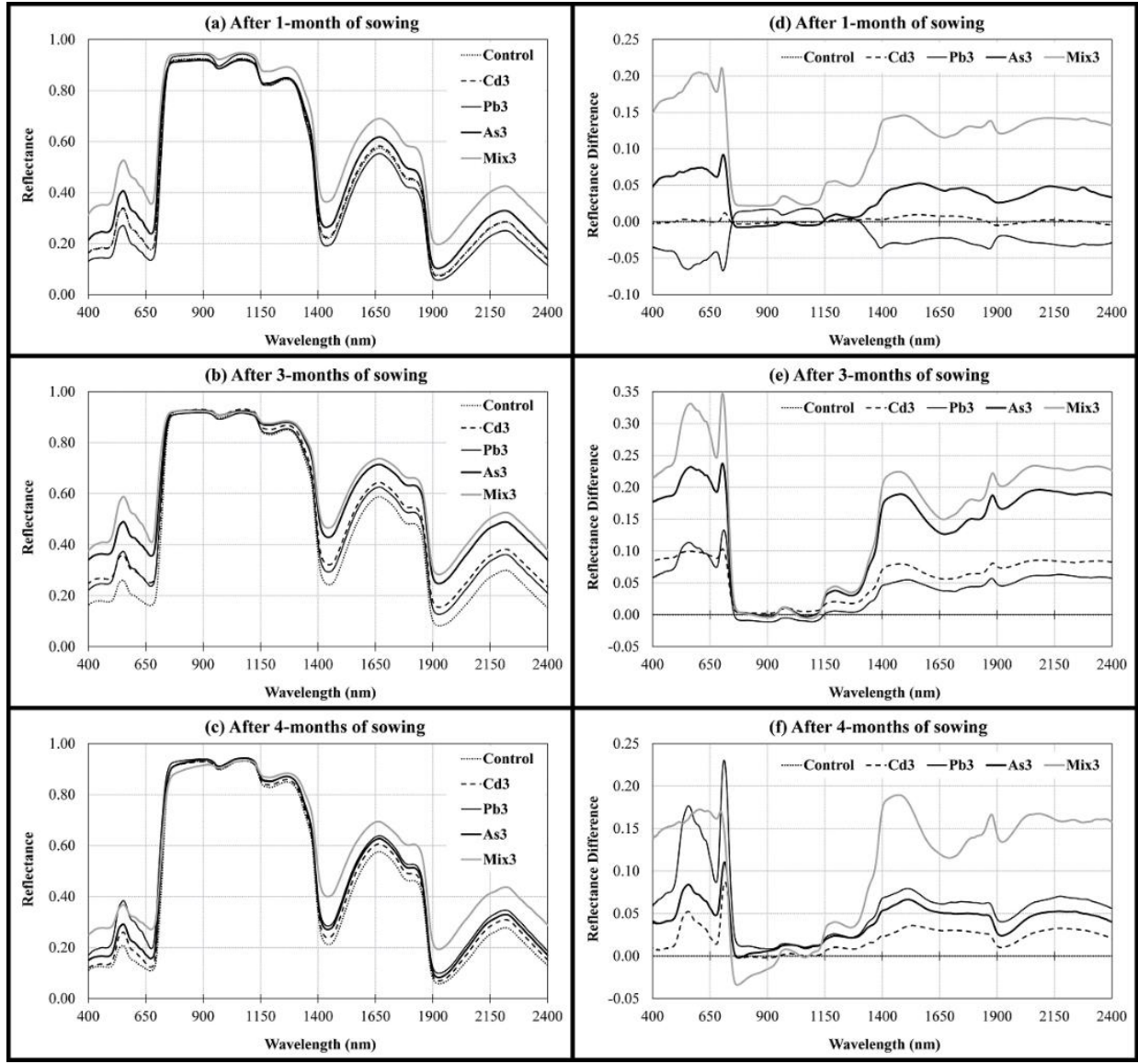

Figure 6.9: Reflectance spectra of barley leaves ( $a, b, c)$ and differences in reflectance values between treated and untreated plants $(d, e, f)$ for control and higher level of treatments at 1,3 , and 4 months.

Derivative spectra were also computed to provide a more subtle analysis. First derivative spectra between 475 and $775 \mathrm{~nm}$ for $\mathrm{As}_{3}$ and Mix $\mathrm{M}_{3}$ treatments are shown in Figure 6.10a-b. The magnitude of the derivative peaks decrease with increasing level of metal stress and demonstrate a shift towards shorter wavelengths i.e., blue-shift for $\mathrm{As}_{3}$ and $\mathrm{Mix}_{3}$ treatments. Moreover, doublepeaks feature at $\sim 700$ and $\sim 725 \mathrm{~nm}$ (Figure 6.10a-b) observed in first derivative spectra respectively attributed to the chlorophyll absorption and light scattering by leaves tissues (Horler et al. 1983). 


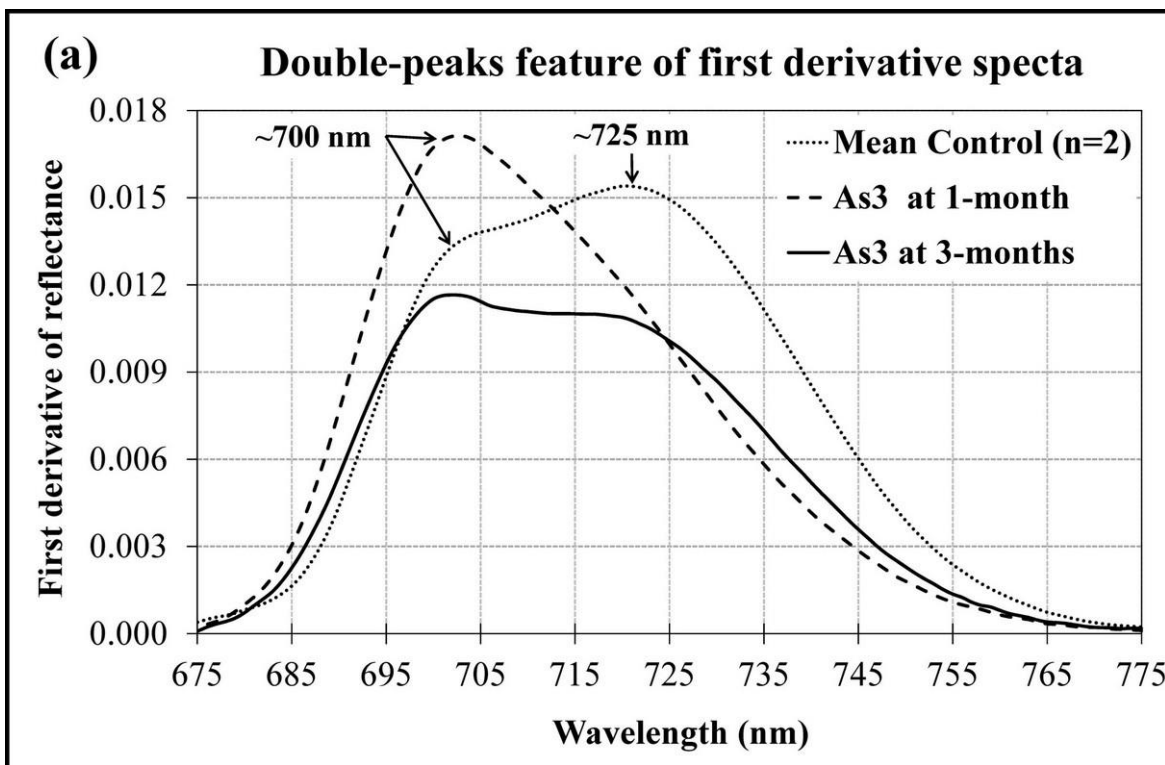

(b) Double-peaks feature of first derivative specta

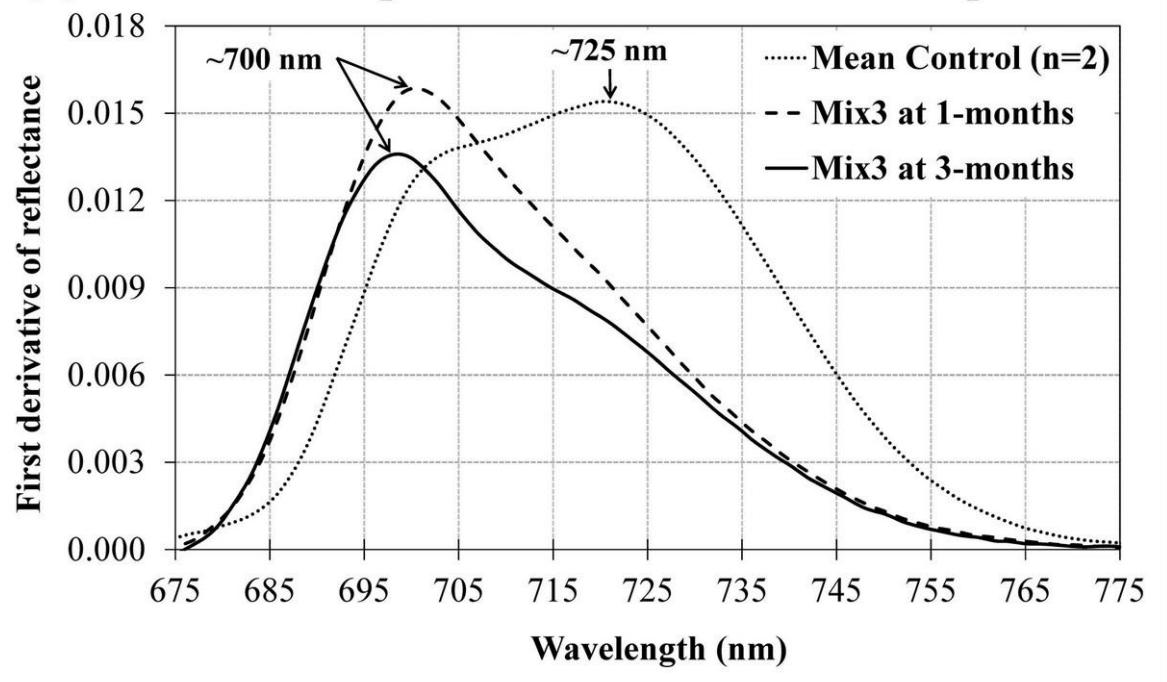

Figure 6.10: First derivatives of leaf reflectance $(475-775 \mathrm{~nm})$ for higher level of arsenic (a) and multi-metals (b) at 1 and 3 months

The double-peak feature has been identified by several researchers (Smith et al. 2004 and references therein), and it has a definite significance to the stressed vegetation with second peak(s) of derivative spectra being less apparent (or absent) in the stressed vegetation. In present study, it is evident that the magnitude of second peak of first derivative spectra at $\sim 725 \mathrm{~nm}$ decreased with stress progressed (as at 3 months, second peak disappeared 
in Mix $_{3}$ treatment; Figure 6.10b). However, Zarco-Tejada et al. (2003) relate such double-peak(s) feature to the chlorophyll fluorescence.

Pearson's correlation analyses also showed that leaf-As had strong positive correlation with reflectance in visible and SWIR regions (Figure 6.7). On 1 month, wavelengths 351-727 and >1325 nm were significantly correlated with leaf-As content, with the highest $r$ values of $0.69 \quad(p=0.013)$ and 0.80 $(p=0.002)$ respectively at $443-473$ and $1585-1603 \mathrm{~nm}$ for single-metal treatments; $r$ values are of $0.81(p=0.002)$ and $0.76(p=0.004)$ respectively at 443-449 and 2275-2289 nm for multi-metals treatments. Similarly, on 3months, significant and the highest correlation coefficient values $(r=0.87$; $p=0.0005$ and $0.92 ; p<0.0001$ ) were obtained for leaf-As with wavelengths at 531-537 and 1399-1403 nm, respectively.

The present results of As-stress induced spectral changes in visible regions can be linked to the fact of reduction in chlorophyll due to As-phytotoxicity. Previous works have shown that high arsenic damages the photosynthetic machinery and pigment biosynthesis (Garg and Singla 2011; Peñuelas and Filella 1998; Sanal et al. 2014), which leading to a decrease in light absorption and henceforth increases spectral reflectance in visible region (Bandaru et al. 2010; Milton et al. 1989; Slonecker et al. 2009). This phenomenon is welldocumented and used to monitor vegetation stress (Horler et al. 1980). Small variations in the NIR region (750-1300 nm) in arsenic and multi-metal treatments could be due to a decrease in the leaf water upon bioaccumulation of phytotoxic metal, particularly arsenic, in the plant parts (Table 6.4 and Figure 6.4). This spectral change is similar to the results of Sridhar et al. (2007b) who found variations in leaf NRI reflectance in barley treated with cadmium and zinc.

\subsubsection{VEGETATION INDICES AND CONTINUUM REMOVAL SPECTRA}

\section{ChLorophyll AND WATER STRESS INDices}

In present study, looking at the effect of metals especially on chlorophyll and water absorption features (Figure 6.6-5.9), indices related to them were computed (Table 6.3) to distinguish metal-treated plant from untreated plant. The trends of these spectral indices for all the treatments are presented in Figure 6.11a-h. Cadmium and lead treated barley showed non-significant changes in the indices from control plant at 1 and 3 months, without observing any significant $(p<0.05)$ correlation of indices with leaf-Cd and $-\mathrm{Pb}$ concentration were observed. The probable reasons of non-significant result, as discussed in section 5.3.1, are: (i) relatively low concentration of $\mathrm{Cd}$ and $\mathrm{Pb}$-spiking into soil, (ii) higher degree of tolerance of barley towards $\mathrm{Cd}$ and $\mathrm{Pb}$ toxicity, and (iii) positive effect of $\mathrm{NO}_{3}^{-}$ions from applied metallic-salt solution to soil. Sridhar et al. (2007b) reported that Cd at $1 \mathrm{mM}\left(112 \mathrm{mg} \mathrm{kg}^{-1}\right)$ and 10 $\mathrm{mM}\left(1120 \mathrm{mg} \mathrm{kg}^{-1}\right.$ ) concentration (respectively 10- and 100-times higher Cd concentration than the $\mathrm{Cd}$ applied in present study) had phytotoxic effect on barley and such Cd-induced stress was revealed by NDVI analysis. 


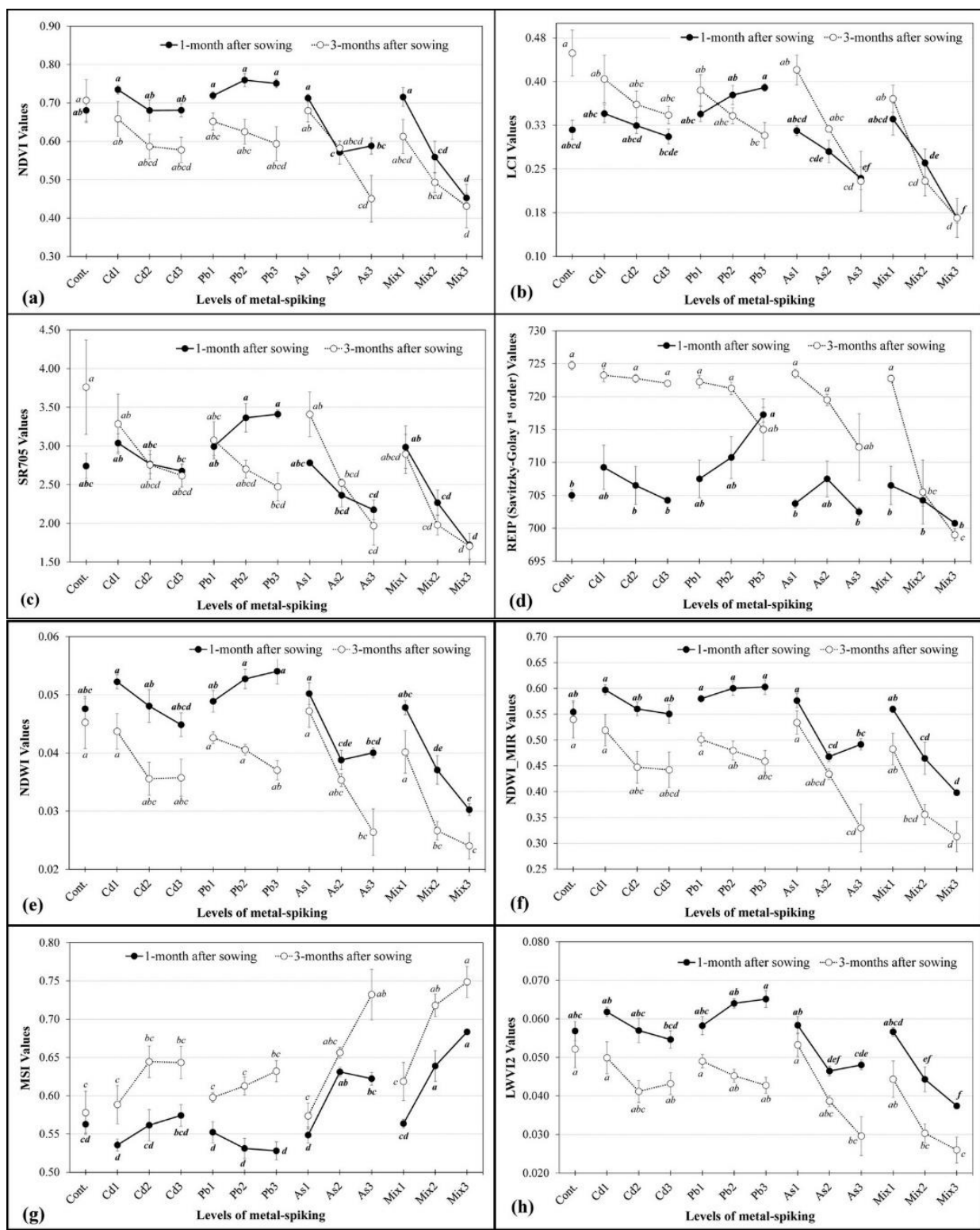

Figure 6.11: Comparison between values of chlorophyll indices (a-d) and water indices (e-h) for different metal treatments.

Error bar is value of \pm SEm of 4 replicates. The markers not connected with same letter are significantly different at $\alpha=0.05$ according to Post hoc Tukey HSD test.

Arsenic and multi-metals $\left(\mathrm{As}_{2}, \mathrm{As}_{3}, \mathrm{Mix} 2\right.$, and $\left.\mathrm{Mix}_{3}\right)$ treated plants, in contrast, can statistically be distinguished from untreated plants. For NDVI, SR705 and LCI on 1 month, least values were obtained with $\operatorname{Mix}_{3}(0.45,1.72$ and 0.17 , respectively) and they differed significantly ( $p \leq 0.0001-0.0003)$ differed from control treatment. Consistently, also on 3 months, a significant $(p<0.0001)$ 
decrease in the indices value was observed in Mix $_{3}$ treatment (NDVI, 0.43; SR705, 1.71; LCI, 0.17) followed by $\mathrm{Mix}_{2}$ and $\mathrm{As}_{3}$ treatments. These results clearly shows the metal-induced stress caused by reduction in chlorophyll absorption (Figure 6.9a-c) with increased As-accumulation in plant parts (Table 6.4 and Figure 6.4). It is confirmed by significant negative correlation between chlorophyll indices and leaf-As for multi-metal treatments $(r=-0.81,-0.75$, -0.70 on 1 month and $r=-0.68,-0.72,-0.71$ on 3 months, respectively for NDVI, SR705, LCI). For As-treatment, similar to Mix-treatments, significant negative association between leaf-As and chlorophyll indices on 3 months was observed ( $r=-0.86,-0.86,-0.81$ respectively for NDVI, SR705, LCI). Unusually, no significant correlation of chlorophyll indices with leaf-Cd and $-\mathrm{Pb}$ was observed in Mix-treatments. Results revealed that in comparison to either control or $\mathrm{Cd}$ or $\mathrm{Pb}$ treatments, chlorophyll indices are highly indicative of metal-induced stress in barley for As- and Mix-treatments. Moreover, stress caused by higher levels of As- and Mix-treatments had more impact than lower levels $\left(A s_{1}, A s_{2}, M_{i x}\right.$, and Mix 2$)$. A decrease in the values of chlorophyll indices could be the indirect effects of As-bioaccumulation, specifically into the roots, that decrease photosynthetic pigment content, influence chloroplast membrane structure and disturb the functions of integral photosynthetic process (Appenroth 2010; Garg and Singla 2011 and references therein).

In many studies (Clevers and Kooistra 2003; Horler et al. 1980; Horler et al. 1983), researchers have focused on the red-edge feature (red-edge inflection points; REIP) characterized by incline between red and NIR wavelengths. The REIPs (Savitzky-Golay Filer 1st order derivative and smoothing technique; Savitzky and Golay 1964) were derived for each treatments (Figure 6.11d). No significant changes occurred in the REIPs on 1 month except $\mathrm{Pb}_{3}$ treatment $(717 \mathrm{~nm}$; red-shift by $12 \mathrm{~nm})$. The red-shift of REIP towards longer wavelength in $\mathrm{Pb}_{3}$ treatment is confirming the broadening of chlorophyll absorption feature around $680 \mathrm{~nm}$ (Figure 6.9a) and the probable causes of this stimulatory effects are discussed in sections 5.3.1 and 5.3.3. On 3 months, REIPs for Mix 2 $(705 \mathrm{~nm})$ and $\operatorname{Mix}_{3}(699 \mathrm{~nm})$ significantly differed from control plant $(724 \mathrm{~nm})$, and it shows shifting respectively by $19 \mathrm{~nm}$ and $25 \mathrm{~nm}$ with reference to control. The blue-shift of REIP strongly linked to the inhibition of chlorophyll biosynthesis due to As-induced stress, as confirmed with significant negative correlation ( $r=-0.63 ; p=0.027)$ between REIP and leaf-As. Arsenic bioaccumulation in plant leaves caused changes in visible and NIR spectra (Bandaru et al. 2010) and similar blue-shift result due to metal-induced stress have been reported by Clevers et al. (2004); Dunagan et al. (2007); Liu et al. (2008c); Milton et al. (1989); Ren et al. (2010).

The water index uses reflectance in the NIR (light scattering) and SWIR (water absorption feature) regions to monitor water-stress conditions in vegetation. Alike chlorophyll indices, Mix ${ }_{3}$-treated barley showed significant $(p<0.0001)$ differences in values of water indices from the control plant on 1 and 3 months (Figure 6.11e-h). Treatment Mix $2, \mathrm{As}_{2}$, and $\mathrm{As}_{3}$ were also differed statistically $(p<0.05)$ from the control. Barley grown in multi-metals spiked soil had started to show significant changes in the water indices on 1 month onwards. In Mixtreatments, merely leaf-As concentration had significant correlation with studied water indices, NDWI, NDWI_MIR, MSI, and LWVI2 $(r=-0.81,-0.80$, 0.81 , and -0.83 on 1 month and $r=-0.74,-0.75,0.73$, and -0.73 on 3 
months; respectively). This shows that As-accumulation in plant parts, particularly into roots, is solely responsible for indirect inhibition of root growth and enzymatic activities (Sanal et al. 2014) and ultimate consequences are the water stress and disturbed nutrients absorbance (Appenroth 2010).

\section{CONTINUUM REMOVED SPECTRA AND BAND DEPTHS}

Continuum removal (CR) analysis of particular spectral absorption features is one of the popular normalization technique to amplify variation in the reflectance spectra from a common baseline (Kokaly and Clark 1999). In this study, continuum removal (using ENIV-IDL version 4.3) was applied to seven absorption features and band depth (BD) at each and selected wavelength in the absorption features (Table 6.3) were calculated by subtracting the CR reflectance from 1 . The $\mathrm{Cd}$ and $\mathrm{Pb}$-treated plants at 1 month had the deeper BDs at each wavelength within all absorption features compared to untreated plants, and as a result, a negative difference (i.e., larger band depths than the control) was observed between untreated and $\mathrm{Cd}$ - and $\mathrm{Pb}$-treated plants (Figure 6.12). Whereas, on 3-months, patterns changed (i.e., shallower BDs for $\mathrm{Cd}$ - and $\mathrm{Pb}$ - treated plants than control), and hence positive difference observed (Figure 6.12).

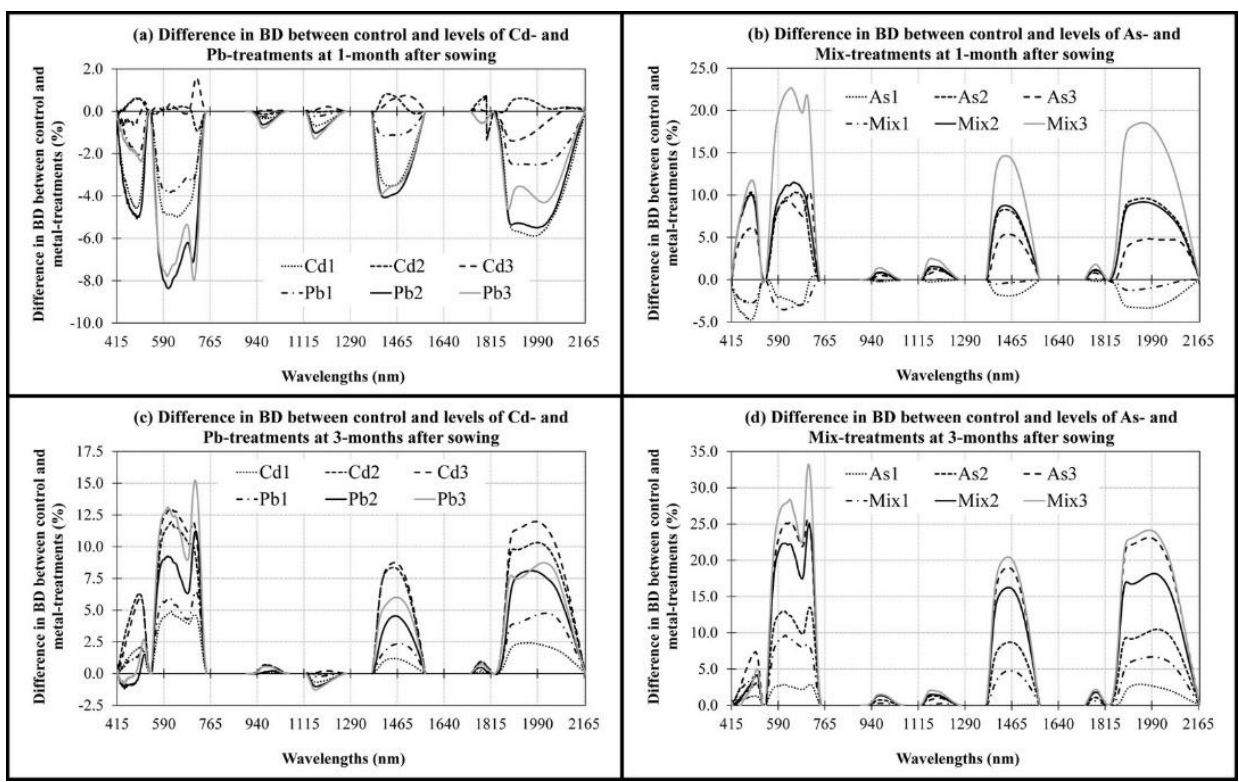

Figure 6.12: Difference (\%) in band depth values between control and levels of metal-treatments on 1 and 3 months after sowing.

A positive difference refers to the larger band depth in the control treatment than the metal-treatments at given wavelengths. 


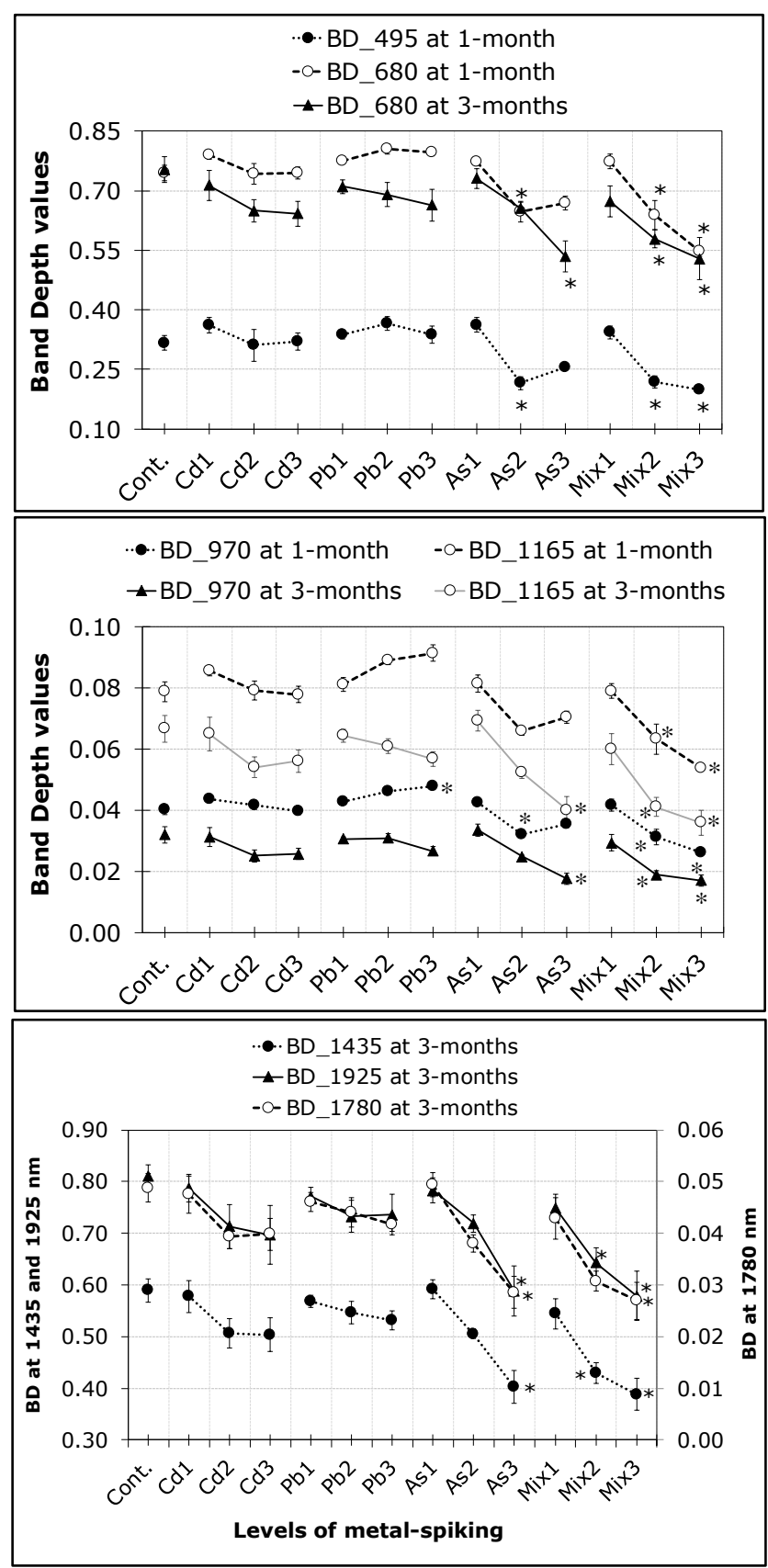

Figure 6.13: Band depth at selected wavelength for different treatments. Error bars are values of \pm SE of 4 replicates. The markers with asterisk $(*)$ are significantly differed from control treatment at $\alpha=0.05$ according to Post hoc Tukey HSD test. 
A negative difference in BDs at 1 month infers that irrespective of levels, Cdand $\mathrm{Pb}$-spiking into soil had no phytotoxic effects on the growth of barley, but certainly barley growth was enhanced (Table 6.2), and so it causes strong absorption at each wavelength. However, non-significant variation was observed between control and $\mathrm{Cd}$ - and $\mathrm{Pb}$-treatments for $\mathrm{BD}$ at selected wavelengths at 495, 680, 970, 1165, 1435, 1780, and $1925 \mathrm{~nm}$ (Figure 6.13). According to Boyd et al. (2006); Curran (1989), absorption features in visible region (at 495 and $680 \mathrm{~nm}$ ) can be attributable to chlorophyll, $970 \mathrm{~nm}$ to the water, at $1165 \mathrm{~nm}$ to the biochemical of lignin, $1435 \mathrm{~nm}$ to the water or nitrogen, $1780 \mathrm{~nm}$ to cellulose or lignin, and $1925 \mathrm{~nm}$ to the cellulose or water.

This was not the case, however, for As- and multi-metals treated plants, which had shallowest BDs relative to the control on 1 and 3 months except low levels of treatments on 1-month (Figure $6.13 \mathrm{~b}, \mathrm{~d}$ ). It is evident from the figures that the greatest positive difference (relative to the control) was observed with Mix $_{3}$ treatment at each wavelengths in all absorption region, predominantly in the red region (550-740 $\mathrm{nm}$ ) and water absorption regions (1380-1550, 1850$2140 \mathrm{~nm}$ ). Over the time, the value of BDs at each wavelengths show greater distinction from control (Figure 6.13a-d). Statistical analysis of BDs at selected wavelengths showed that the highest $\left(\mathrm{Mix}_{3}\right)$ and intermediate $\left(\mathrm{Mix}_{2}\right)$ level of multi-metals treatment had caused significant decrease in the BD at that wavelengths compared to the control. Consequently, BDs at selected wavelength showed significant negative correlation with only leaf-As concentration in multi-metal treatments $(r=-0.75$ to $-0.92, p<0.05)$, demonstrating phytotoxic effects of As-stress on barley. In plant, As is mainly accumulated in the root system $\left(\sim 75 \mathrm{mg} \mathrm{kg}^{-1}\right.$ in barley root for Mix $\mathrm{M}_{3}$ treatment, Figure 6.4), which causes physiological changes including chlorophyll reduction and water imbalance in the plant tissues (Garg and Singla 2011). Results of continuum removal analysis agrees with finding of Noomen et al. (2006) who noted reduction in band depths in the chlorophyll and water absorption regions in the continuum removed spectra of maize plants treated with various hydrocarbon gases.

\subsubsection{REGRESSION ANALYSIS}

Prediction model for leaf-metal concentration from leaf-spectra, was one of the aim of present study and it could be a monitoring tool for phytoremediation process. The PLSR technique is widely used to build prediction model (Carrascal et al. 2009). Since it is evident from correlation result (Figure 6.7) that only leaf-As (in both As- and Mix-treatments) had significant association with leaf spectra, the PLSR and MLR analysis was run using significantly correlated spectral features, explanatory variables and leaf-As concentration, dependent/response variables. Table 6.5 summarizes the set of spectral regions that yielded the best $R^{2}$ (close to 1 ) and RMSE (the lowest) for the prediction of leaf-As concentration. 
Table 6.5: Best fit PLSR and MLR models for estimation of leaf-As concentration in barley for As- and Mix-treatments set $(n=19-22)$ on 1 and 3 months after sowing, expressed in terms of coefficients of determination $\left(R^{2}\right)$ and root mean square error (RMSE) of calibration, cal and cross-validation, val models

\begin{tabular}{|c|c|c|c|c|c|}
\hline \multicolumn{2}{|r|}{ Spectral regions selected for regression models } & $\begin{array}{c}\mathbf{R}^{2} \\
\text { cal. }\end{array}$ & $\begin{array}{c}\mathbf{R}^{2} \\
\text { val. }\end{array}$ & $\begin{array}{c}\text { RMSE } \\
\text { cal. }\end{array}$ & $\begin{array}{c}\text { RMSE } \\
\text { val. }\end{array}$ \\
\hline Sr & \multicolumn{5}{|c|}{ For As- and Mix-treatment set ( $n=22 ;$ on 1 -month after sowing) } \\
\hline 1 & Spectra of $415-2170 \mathrm{~nm} ; \mathrm{PC} \# 10$ & 0.99 & 0.91 & 0.81 & 2.28 \\
\hline 2 & Mean normalized spectra of $415-2170 \mathrm{~nm}$; PC\#10 & 0.99 & 0.94 & 0.64 & 1.93 \\
\hline 3 & *Spectra ranges as of CRR abs features; PC\#10 & 0.99 & 0.92 & 0.80 & 2.13 \\
\hline 4 & $* *$ Abs at $415-750,1370-1570,1825-2170 \mathrm{~nm} ; \mathrm{PC} \# 7$ & 0.98 & 0.95 & 0.95 & 1.66 \\
\hline 5 & Spectra of $1370-1570 \mathrm{~nm} ;$ PC\#6 & 0.95 & 0.90 & 1.64 & 2.39 \\
\hline 6 & Spectra of $1825-2170 \mathrm{~nm} ; \mathrm{PC} \# 5$ & 0.92 & 0.86 & 2.02 & 2.60 \\
\hline 7 & Spectra of $1370-1570$ and $1825-2170 \mathrm{~nm} ; \mathrm{PC} \# 7$ & 0.94 & 0.88 & 1.72 & 2.70 \\
\hline 8 & CR spectra of $1370-1570$ and $1825-2170 \mathrm{~nm}$; PC\#6 & 0.97 & 0.93 & 1.27 & 2.00 \\
\hline 9 & MLR with a & 0.99 & & 0.60 & 2.50 \\
\hline 10 & $970 \mathrm{~nm}$ & 0.99 & 0.94 & & 1.86 \\
\hline \multirow[t]{2}{*}{11} & MLR without LCI, REIP, BDs at $680,970,1435 \mathrm{~nm}(n=21)$ & 0.99 & 0.97 & 0.59 & 1.28 \\
\hline & \multicolumn{5}{|c|}{ For As- and Mix-treatment set ( $n=19 ;$ on 3-months after sowing) } \\
\hline 12 & spectra of $1370-1570,1825-2170 \mathrm{~nm} ;$ PC\#5 & 0.95 & 0.90 & 2.50 & 3.62 \\
\hline 13 & Spectra of $1370-1570 \mathrm{~nm} ; \mathrm{PC} \# 7$ & 0.97 & 0.89 & 1.99 & 3.89 \\
\hline 14 & Spectra of $1825-2170 \mathrm{~nm}$; PC\#5 & 0.91 & 0.84 & 3.21 & 4.63 \\
\hline 15 & FD spectra of $415-2170 \mathrm{~nm} ; \mathrm{PC} \# 5$ & 0.91 & 0.83 & 2.31 & 4.81 \\
\hline 16 & FD spectra of $1370-1570,1825-2170 \mathrm{~nm} ; \mathrm{PC} 6$ & 0.98 & 0.88 & 1.61 & 3.92 \\
\hline 17 & MLR with NDWI, MSI and BDs at $680,1435,1925$ & 0.96 & 0.93 & 2.03 & 2.89 \\
\hline 18 & MLR with all calculated BDs & 0.96 & 0.90 & 2.13 & 3.47 \\
\hline 19 & MLR with BDs at $495,680,1165,1435,1780,1925 \mathrm{~nm}$ & 0.96 & 0.90 & 2.16 & 3.35 \\
\hline 20 & MLR with NDVI, LCI, REIP, NDWI, NDWI_MIR, MSI & 0.96 & 0.88 & 2.20 & 3.74 \\
\hline
\end{tabular}

$P C=$ principal component; $F D=$ first derivatives, no. of smoothing points $5 ; C R=$ continuum removed; *Spectral range from: 415-750, 900-1060, 1120-1275, 1370-1570, 1740-2170 nm; $* *$ Selected significant wavelengths: 528-563, 627-634, 637-638, 705-719, 1392-1403, 1487-1505, 1867-1893, 1938-1970, 1999-2006, 2073-2170 nm; ***Selected significant wavelengths: 1370$1391,1473-1476,1561-1570,1846-1897,1948-1976 \mathrm{~nm}$

On 1-month, the best model for leaf-As estimation was obtained with significant spectra (selected through Marten's uncertainty significance testing implemented in Unscrambler 9.7; see Table 6.5 foot-note) from 415-750, $1370-1570,1825-2170 \mathrm{~nm}$ range, which yielded $\mathrm{R}^{2}, 0.98$ and 0.95 and RMSE, 0.95 and 1.66, respectively for calibration and cross-validation (Table 6.5; Figure 6.14a). The cross-validation results showed that this PLS model with PC\# 7 explained $95.22 \%$ variance of response variable (leaf-As). The PLSR models using mean normalized spectra from $415-2170 \mathrm{~nm}$ also showed best result with $\mathrm{R}^{2}, 0.94$ and $\mathrm{RMSE}, 1.93$ for cross-validation (Table 6.5; Figure 6.14b), wherein PC\# 10 explained $93.70 \%$ variance in leaf-As. Results revealed that PLS regression involving chlorophyll and water absorption wavelengths appeared to be relatively the best predictors of leaf-As, particularly when including spectra from visible $(415-750 \mathrm{~nm})$ and/or SWIR (1370-1570 and 1825-2170 nm) regions. Alike, on 3-months, the best model obtained using significant wavelengths of water absorption regions (i.e., 13701570, $1825-2170 \mathrm{~nm}$ ), with $\mathrm{R}^{2}, 0.90$ and RMSE, 3.62 for cross-validation (Table 6.5; Figure 6.14c). However, raw and FD of water absorption spectra, 
also gave relatively good results with cross-validation $\mathrm{R}^{2}, 0.89$ and 0.88 and RMSE, 3.89 and 3.92, respectively (Table 6.5; Figure 6.14d). Other best fit models for leaf-As estimation on 1 and 3 months can been seen in Table 6.5. However, the selection of wavelengths for obtaining best fit model were inconsistent.

Multiple linear regression (MLR) model, done with Unscrambler 9.7, for estimating leaf-As using the VIs and BDs showed good results. On 1 month, the model using all VIs and BDs yielded $\mathrm{R}^{2}, 0.89$ and RMSE, 2.50 for crossvalidation (Table 6.5; Figure 6.15a). The MLR model showed the best $R^{2}(0.97)$ and RMSE (1.28) for cross-validation upon excluding non-significant variable viz., LIC, REIP, and BDs at 680, 970, $1435 \mathrm{~nm}$ (Figure 6.15b). Similarly on 3 months, MLR using NDWI, MSI, and BD at $680,1435,1925 \mathrm{~nm}$ is to be the best predictors ( $R^{2}, 0.93$ and RMSE, 2.89 for cross-validation; Figure $6.15 \mathrm{c}$ ) for leaf-As estimation.

PLS regression models, in general, shows that the best spectral regions for barley leaf-As estimation in the present study positioned in chlorophyll and/or water absorption regions of spectrum, which were highly influenced either directly or indirectly by As-toxicity as can be seen from the results presented in previous sections. Similarly, MLR models, which typically include VIs and BDs based on wavelengths in visible and SWIR regions of spectrum, also present good results. Results of both regression analyses were similar to those reported by Bandaru et al. (2010); Hong et al. (2010); Slonecker et al. (2009) According to them, regression results in present study put forward the possibility of using visible and SWIR reflectance to predict leaf-As concentration in barley grown with As- and Mix-treatments. 
Chapter 6

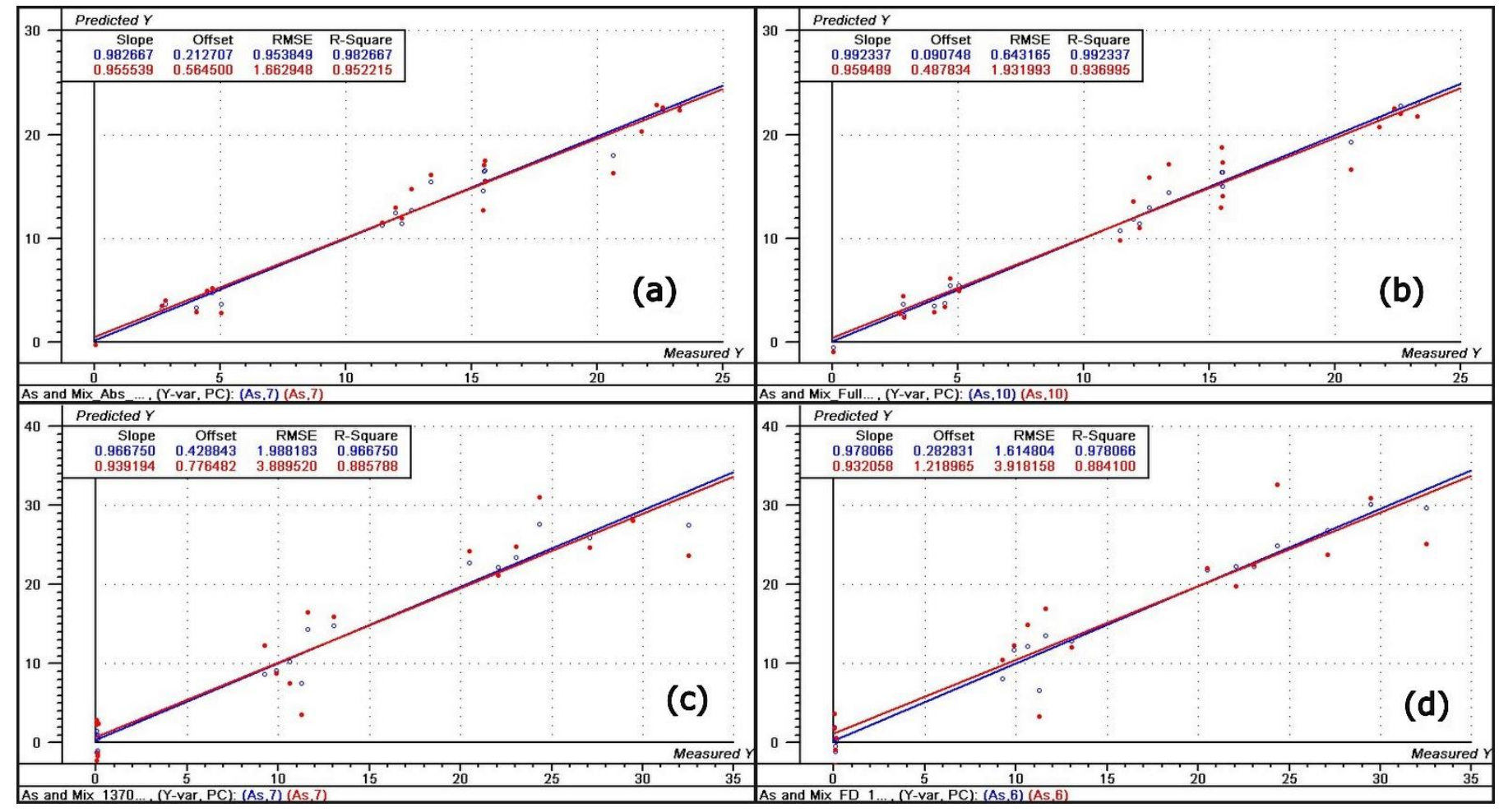

Figure 6.14: PLSR scatter plots of measured leaf-As vs. predicted leaf-As concentration ( $\left.\mathrm{mg} \mathrm{kg}^{-1}\right)$ at 1 -month for (a) selected significant wavelengths* from absorption features at 425-750, 1370-2170 nm; PC\#7, (b) mean normalized spectra of 415-2170 nm; PC\#10, (c) selected significant wavelengths* from absorption features at 1370-1570, 1875-2170 nm; PC\#5 and (d) first derivative spectra of 1370 $1570,1875-2170 \mathrm{~nm} ;$ PC\#6.

Red line is calibration and blue one is validation results. *See foot-note at Table 6.5 for details of selected wavelengths. 
Chapter 6

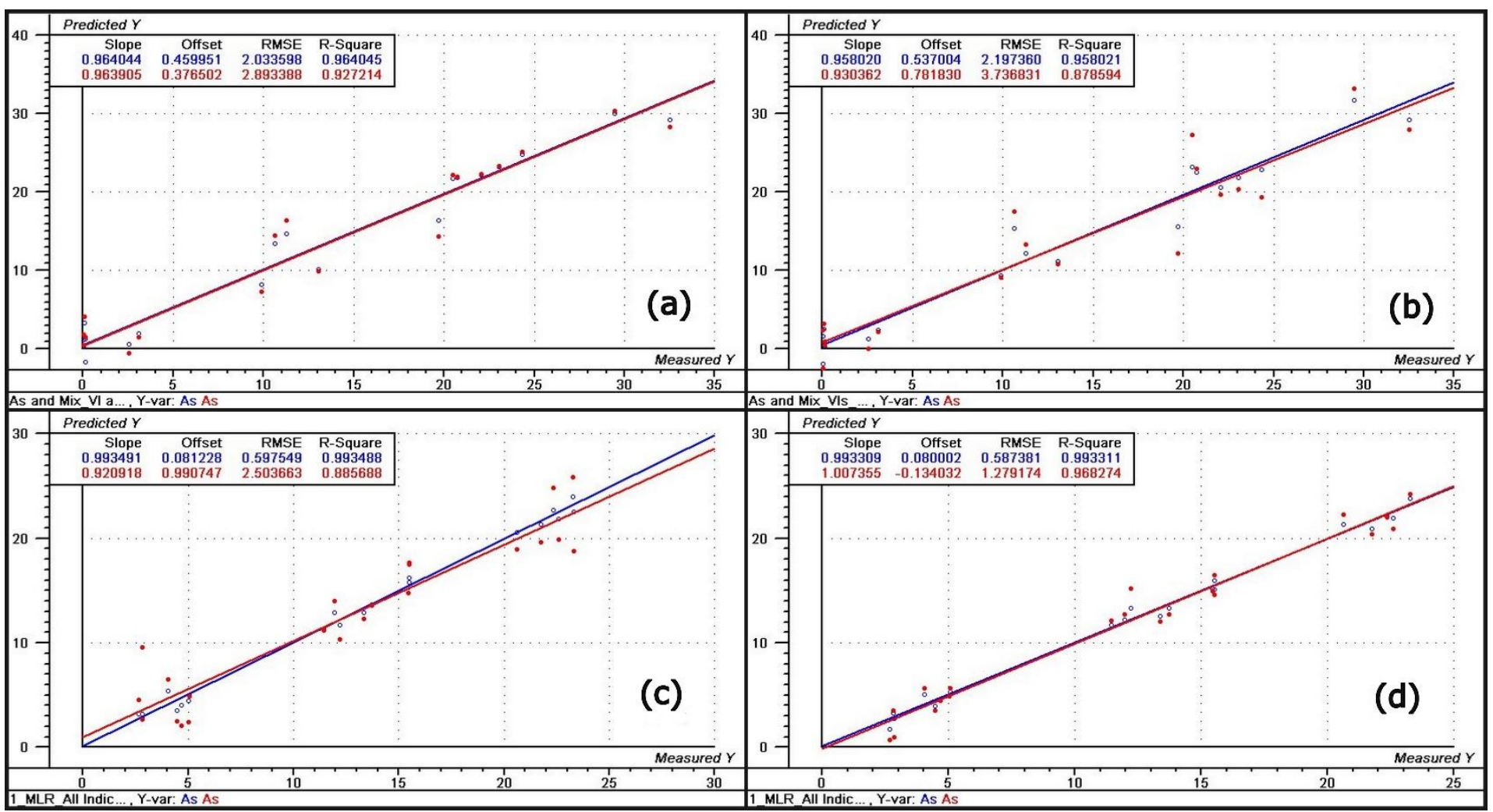

Figure 6.15: MLR scatter plots of measured leaf-As vs. predicted leaf-As concentration $\left(\mathrm{mg} \mathrm{kg}^{-1}\right)$ at 1 month for (a) all calculated VIs and BDs, (b) VIs and BDs excluding LIC, REIP and BDs at 680,970, $1435 \mathrm{~nm}(n=21)$ (c) VIs, NDWI, MSI and BDs at 680, 1435,1925 nm (d) VIs, NDVI, LCI, REIP, NDWI, NDWI_MIR, and MSI. 


\subsection{CONCLUSION}

The aim of the study was to evaluate the spectral changes in the leaves of barley plant due to phytoextraction of metals, and to use reflectance spectra to estimate leaf-As concentration. The key results of the study can be summarized as follows:

- The higher level of As (i.e., $100 \mathrm{mg} \mathrm{kg}^{-1}$ ) and multi-metals (10 mg Cd + $150 \mathrm{mg} \mathrm{Pb}+100 \mathrm{mg} \mathrm{As} \mathrm{kg}{ }^{-1}$ ) spiking into soil caused significant reduction in plant stand, plant height and dry biomass of the plant. The phytotoxic effect of arsenic (in both, single and multi-metals treatments) on barley plant was noticeable than control, $\mathrm{Cd}$ - and Pb-treatments.

- The phytoaccumulation of studied metals into barley plant parts followed the order of: root >straw $\geq$ leaves > grains. The high metal loadings into roots has definitely direct or indirect impacts on plant growth parameters.

- Least amount of spectral variations were observed in $\mathrm{Cd}$ and $\mathrm{Pb}$ treatments. Contrary, arsenic and multi-metal treatments caused significant changes in the barley leaf-spectra of barley in the chlorophyll and water absorption regions of spectrum, which can effectively be used to monitor plant stress due to phytoremediation process. It is important to note that for multimetal treatment, only leaf-As concentration was found significantly correlation with leaf-spectra, signifying the phytotoxic effects of arsenic on barley plant grown in multi-metal treatments.

- Results on VIs and BDs analyses show that the As- and Mix-treated plant can be discriminated from untreated plant, and could be the potential indicators of plant stress caused by As-accumulation in barley parts, mostly into the roots. For instance, $\mathrm{Mix}_{2}$ and $\mathrm{Mix}_{3}$ treatments on 3-months showed blue-shift (linked to the As-stress) of REIP respectively by 19 and $25 \mathrm{~nm}$. Similarly, BDs at selected wavelength decreased significantly for As- and multi-metals relative to control treatment, demonstrating the phytotoxic effects of As-stress on barley.

- Finally, results of PLSR and MLR empirical models advocate the possibility of using hyperspectral data, VIs and BDs to estimate leaf-As concentration in barley. On 1-month, the PLSR model of significant spectra from the regions of chlorophyll (415-750 nm) and water absorption (1370-1570, 1825-2170 nm) generated $\mathrm{R}^{2}, 0.952$ for cross-validation. Alike, MLR model involving VIs NDVI, SR705, NDWI, NDWI_MIR, LWVI2 and BDs at 495, $1165,1780,1925 \mathrm{~nm}$ also yield the best $\bar{R}^{2}, 0.968$ and RMSE, 1.279 for cross-validation.

In summary, the use of hyperspectral reflectance data, as well as studied VIs and BDs appears to have potentials for assessing metal-induced stress (particularly, As-stress in this study) and for monitoring the phytoextraction of arsenic into above-ground parts of barley. For $\mathrm{Cd}$ and $\mathrm{Pb}$-metal, further studies is recommended with higher concentration and with metal-salt other than Nitrate-salt, may give distinct spectral signatures to be used for monitoring phytoextraction process. 
This page intentionally left blank 


\title{
CHAPTER 7 : SPECTRAL RESPONSE OF SUNFLOWER, WHEAT AND RYEGRASS TO METAL- CONTAMINATED SOILS ${ }^{1}$
}

\begin{abstract}
The aim of this study was to examine phytoaccumulation of trace elements $(\mathrm{Cd}, \mathrm{Pb}$ and $\mathrm{As})$ in sunflower, winter wheat and perennial ryegrass grown in metal-contaminated soil substrates monitored via changes in leaf spectral reflectance. Sunflower mutant (M5 mutant line 38/R4-R6/15-35-190-04-M5) plants were grown in spiked and natural metal-contaminated potted soils. Winter wheat and ryegrass were grown likewise in pots to study As-uptake under two moisture regimes in combination with $\mathrm{N}$ - and P-fertilization treatments. Chemical analyses confirmed the phytoextraction capability of sunflower mutant plant for tested metals in general, but stunted growth of plant was observed in soil spiked at $900 \mathrm{mg} \mathrm{As} \mathrm{kg}^{-1}$; and to less extent in both in-situ metal-contaminated soil substrates. Results of spectral reflectance were promising and aligned with metal concentration in leaves. The spectral changes were quite noticeable and showed increased visible and decreased NIR reflectance for sunflower grown in soil spiked with $900 \mathrm{mg} \mathrm{As} \mathrm{kg}^{-1}$, and in both in-situ metal-contaminated soils. These changes also involved a blue-shift feature of red-edge position in the first derivatives spectra, studied vegetation indices, continuum removed spectra and band depths. Correlograms of leafmetal concentration and reflectance values show highest degrees of overall correlation for visible and water-sensitive wavelengths. Partial least square and multiple linear regression statistical models (cross-validated) respectively based on Savitzky-Golay filter $1^{\text {st }}$ order derivative spectra and combination of spectral feature such as VIs and BDs yielded good prediction of leaf-metal concentrations. Leaf spectral analyses of wheat and ryegrass also showed a characteristic spectral variation due to the moisture regimes, soil types, and the tested levels of nitrogen and phosphorus fertilization.
\end{abstract}

${ }^{1}$ This chapter is based on following paper:

Paresh H. Rathod, Carsten Brackhage, Ingo Müller, Rolf Herzig, Freek D. Van der Meer and Marleen F. Noomen (2016). Assessing metal-induced changes in the visible and near infrared spectral reflectance of leaves - A pot study with sunflower (Helianthus annuus L.). Submitted to Journal of Indian Society of Remote Sensing (Under review) 


\subsection{INTRODUCTION}

Worldwide, the metal-contamination to the arable lands is a prominent issue and in particular, the soils adjacent to industrial and mining regions are more prone to be contaminated with several toxic metallic ions (Kabata-Pendias and Pendias 2001; Martin 2012). In the Europe and the US, $>100,000$ hectares of soils are contaminated by heavy metal (Liedekerke et al. 2014; Mulligan et al. 2001; USEPA 2012). Looking at the environmental consequences associated with metal-contaminated sites, an immediate site-remediation has become an important task. Many physico-chemical methods have been materialized for remediating metal-contaminated sites, and phytoremediation (i.e., cleaningup process that employs various types of plants to remove, transfer, or stabilize metals in the soil) is amongst the most emphasized eco-friendly and inexpensive method (Cundy et al. 2016; Mench et al. 2010a; Pilon-Smits 2005; Vangronsveld et al. 2009). However, like any remediation system, phytoremediation does have shortcomings: (i) there are only few recognized hyperaccumulators i.e., exceptional plant species, which tolerate as well as accumulate large amounts of metals into plant parts when growing on heavily metal-contaminated soils (Prasad and Freitas 2003), (ii) usually, it takes long time (>10 years) to clean up hazardous contaminated sites when focusing on total concentrations, and (iii) prolonged exposure to the elevated soil-metal concentration causes severe environmental stress to plants, even to hyperaccumulators (Prasad 2004). Cundy et al. (2015) defined a number of site-based indicators to identify a kind of implementation window, e.g. large areas, where contamination may cause concern but is not at strongly elevated level, where biological soil functionality and ecosystem service is required, where there is a need to restore marginal land to produce non-food crops and where there are some budgetary or deployment constraints regarding other remediation options. Although phytoremediation can provide strong benefits in terms of risk management, deployment costs and sustainability for a range of site problems, however, awareness and take up in remediation practice is low, at least in a European context (Cundy et al. 2016; Onwubuya et al. 2009). The barriers to wider adoption of gentle remediation options (GRO), especially in Europe, arise both from the nature of GRO as remediation techniques, and market and stakeholder perceptions of uncertainties over whether these methods can achieve effective risk management in the long term.

Such long-term and plant based clean-up processes, therefore require a technique that can remotely monitor the soil-plant system, and aid in assessing the contamination level in soil and plant. Monitoring spectral reflectance of vegetation growing in metal-contaminated soil could be the one approach to optimize the phytoremediation system (Sridhar et al. 2007a, 2007b). Spectral reflectance signatures from plant in the visible, near-infrared, and short-wave infrared regions have been widely documented to assess the contaminants (see chapter 4, section 4.3). A healthy plant has a minimum spectral reflectance in the visible wavelengths resulting from the pigments in leaves, while maximum reflectance in the near infrared due to light scattering by internal structures of leaves. Accordingly, stressed plant can be monitored by significantly lower reflectance in the infrared, higher reflectance in visible wavelengths, and through various vegetation indices calculations (Blackburn 2007; Liew et al. 2008). 
Unlike some essential metals ( $\mathrm{Mn}, \mathrm{Fe}, \mathrm{Cu}$ and $\mathrm{Zn}$ ) for plant metabolism, certain metals such as $\mathrm{Cd}, \mathrm{Pb}$, and $\mathrm{As}$ are toxic to the plant even at rather low concentrations (Cuypers et al. 2009; Prasad 2004). They influence pigment synthesis, structural and ultrastructural changes in plant tissue, and these alterations can be revealed by the spectral signatures (Barceló and Poschenrieder 2004; Clevers and Kooistra 2003; Clevers et al. 2004; Dunagan et al. 2007; Kooistra et al. 2004; Schuerger et al. 2003; Sridhar et al. 2007a; Su et al. 2007). With these view, the present study was taken to assess the metal-induced plant stress using spectral reflectance in 350-2500 nm domains, so to monitor the metal accumulation into the plant.

In contrast to the study described in chapter 6 , this study was carried out with different plant species (i.e., sunflower mutants, wheat and ryegrass), and with elevated metal-contaminated soil substrates. Sunflower, with moderate metalaccumulation and high biomass production, is a potential candidate for phytoremediation (Adesodun et al. 2010; Herzig et al. 2014; Nehnevajova et al. 2005).

This chapter presents the results of leaf spectral reflectance response (in 350$2500 \mathrm{~nm}$ ) of sunflower, wheat and ryegrass grown in the different metalcontaminated soils.

\subsection{MATERIALS AND METHODS}

\subsubsection{Sunflower (Helianthus anNUUS) - Pot EXPERImental SET-UP}

A pot experiment was setup in glass-chambers with filtered air circulation and controlled temperature at a test facility (Prüffeld) of Institute of General Ecology, TU Dresden in Tharandt, Germany from July-Nov 2011. Three different soil substrates from permanent soil monitoring sites of Saxon state were used: (i) $S_{1}$ : uncontaminated soil substrate from Melpitz, (ii) $S_{2}$ : heavily contaminated grassland soils from Hilbersdorf, and (iii) $\mathrm{S}_{3}$ : severely contaminated floodplains soils from Neuhilbersdorf. Source of metal contamination both at Hilbersdorf and Neuhilbersdorf is mainly due to abandoned Artisanal mining, and emission from a larger ore processing about 1-2 km away at Muldenhütten. Neuhilbersdorf as a floodplain site is additionally affected by stream sediments from the Freiberger Mulde River directly after passing Muldenhütten smelter area. Top soils from these sites were collected and sieved through $0.5 \mathrm{~cm}$ using horizontal mechanical sieve. Physico-chemical properties of soils are given in Table 7.1.

Using the uncontaminated soil substrate from Melptiz $\left(S_{1}\right)$, in addition metalcontamination was simulated by spiking three metal-salts viz., cadmium as $\mathrm{Cd}\left(\mathrm{NO}_{3}\right)_{2} \cdot 4 \mathrm{H}_{2} \mathrm{O}$, lead as $\mathrm{Pb}\left(\mathrm{NO}_{3}\right)_{2}$, and arsenic as $\mathrm{As}_{2} \mathrm{O}_{3}$, individually each at different levels and also in mixture at their higher levels (treatment details in Table 7.2). Herein, metal concentrations were raised to higher levels ( $\mathrm{Cd}-10$ and $20 \mathrm{mg} \mathrm{kg}$; $\mathrm{Pb}-1200 \mathrm{mg} \mathrm{kg}{ }^{-1}$, and $\mathrm{As}-100$ and $900 \mathrm{mg} \mathrm{kg}{ }^{-1}$ ) to simulate severe metal-contamination in soils. Spike solutions of $\mathrm{Cd}$ and $\mathrm{Pb}$ were prepared by sequential dilutions of $\mathrm{Cd}\left(\mathrm{NO}_{3}\right)_{2} \cdot 4 \mathrm{H}_{2} \mathrm{O}$ and $\mathrm{Pb}\left(\mathrm{NO}_{3}\right)_{2}$ in deionized water, while $\mathrm{As}_{2} \mathrm{O}_{3}$ was dissolved in a $\mathrm{NaOH}$-solution, and was 
adjusted to near neutral $\mathrm{pH}$. The prepared metal-spike solutions were then added to the respective bulk of soil of treatments (i.e., $40 \mathrm{~kg}$ soil for 4 replicate pots for each treatment; $9 \times 4=36$ pots were prepared for 9 treatment sets). The spiked soil was mixed homogenously, and kept for two wetting-drying cycles for 10-12 days to equilibrate metal spiking. Each $40 \mathrm{~kg}$ metal-spiked soil was then divided on weight basis $\left(10 \mathrm{~kg} \mathrm{pot}^{-1}\right)$, and pots were thereafter randomized between four glass-chambers (Figure 7.1). Initial soil sample was collected from each pot before transplanting sunflower seedlings for the analysis of total metals. Pre-concentration of metals in soil is given in Table 7.2.

Table 7.1: Physico-chemical characteristics ${ }^{1}$ of soil substrate used in sunflower study

\begin{tabular}{|c|c|c|c|c|c|}
\hline \multirow[b]{2}{*}{ Soil properties } & \multicolumn{3}{|c|}{ Soils used in Sunflower study ${ }^{2}$} & \multicolumn{2}{|c|}{$\begin{array}{l}\text { Soils used in Wheat and } \\
\text { Ryegrass study }\end{array}$} \\
\hline & $\begin{array}{l}\text { S1: } \\
\text { Melptiz } \\
\text { soil }\end{array}$ & $\begin{array}{l}\text { S2: } \\
\text { Hilbers- } \\
\text { dorf soil }\end{array}$ & $\begin{array}{l}\text { S3: } \\
\text { Neuhilbers } \\
\text {-dorf soil }\end{array}$ & $\begin{array}{l}\text { S } 1: \\
\text { Colditz } \\
\text { Sandy soil }\end{array}$ & $\begin{array}{l}S_{2}: \\
\text { Schopfheim } \\
\text { Loamy soil }\end{array}$ \\
\hline $\begin{array}{l}\text { Sand (\%) } \\
\text { Silt (\%) } \\
\text { Clay }(\%)\end{array}$ & $\begin{array}{l}82 \\
13 \\
5\end{array}$ & $\begin{array}{l}72 \\
19 \\
9\end{array}$ & $\begin{array}{l}72 \\
19 \\
20\end{array}$ & $\begin{array}{l}93.7 \\
1.3 \\
4.9\end{array}$ & \begin{tabular}{|l|}
53.7 \\
7.7 \\
38.5
\end{tabular} \\
\hline $\begin{array}{l}\mathrm{BD}\left(\mathrm{g} \mathrm{cm}^{-3}\right) \\
\text { pH }\left(\mathrm{CaCl}_{2}\right) \\
\text { SOC }(\%) \\
\text { HC }(\%) \\
\text { BS }(\%) \\
\text { CEC }\left(\mathrm{cmol}_{\mathrm{c}} \mathrm{kg}^{-1}\right)\end{array}$ & $\begin{array}{l}1.4-1.6 \\
5.3-5.6 \\
1.1-1.6 \\
1.9-2.8 \\
18-46 \\
5-9\end{array}$ & $\begin{array}{l}1.4-1.5 \\
5.4-5.7 \\
2.4-7.7 \\
4.2-4.6 \\
47-66 \\
21.5-22.9\end{array}$ & $\begin{array}{l}1.3-1.4 \\
4.3-6.5 \\
2.5-4.8 \\
4.3-8.2 \\
30-49 \\
13.6-14.6\end{array}$ & $\begin{array}{l}- \\
5.3 \\
2.2 \\
- \\
- \\
5.4\end{array}$ & $\begin{array}{l}- \\
6.0 \\
3.2 \\
- \\
- \\
29.4\end{array}$ \\
\hline $\begin{array}{l}\text { Total N (\%) } \\
\text { Fe }(\%) \\
\text { Zn }\left(\mathrm{mg} \mathrm{kg}^{-1}\right) \\
\mathrm{Mn}\left(\mathrm{mg} \mathrm{kg}^{-1}\right) \\
\mathrm{Cu}\left(\mathrm{mg} \mathrm{kg}^{-1}\right)\end{array}$ & $\begin{array}{l}0.08-0.12 \\
0.62-0.71 \\
61.5 \\
239.1 \\
6.9\end{array}$ & \begin{tabular}{|l}
$0.22-0.27$ \\
3.1 \\
633.4 \\
1656.4 \\
75.0
\end{tabular} & $\begin{array}{l}0.11-0.22 \\
4.9 \\
1892.1 \\
1945.7 \\
638.2\end{array}$ & $\begin{array}{l}0.11 \\
1.9 \\
244 \\
3.3 \\
47.4\end{array}$ & $\begin{array}{l}0.35 \\
5.9 \\
58 \\
4.1 \\
14.9\end{array}$ \\
\hline $\begin{array}{l}\mathrm{Cr}\left(\mathrm{mg} \mathrm{kg}^{-1}\right) \\
\mathrm{Ni}\left(\mathrm{mg} \mathrm{kg}^{-1}\right) \\
\mathrm{Co}\left(\mathrm{mg} \mathrm{kg}^{-1}\right) \\
\text { As }\left(\mathrm{mg} \mathrm{kg}^{-1}\right)^{*} \\
\mathrm{Cd}\left(\mathrm{mg} \mathrm{kg}^{-1}\right)^{*} \\
\mathrm{~Pb}\left(\mathrm{mg} \mathrm{kg}^{-1}\right)^{*}\end{array}$ & $\begin{array}{l}7.3 \\
2.6 \\
1.7 \\
- \\
- \\
-\end{array}$ & $\begin{array}{l}33.0 \\
21.0 \\
9.7 \\
- \\
- \\
-\end{array}$ & $\begin{array}{l}25.0 \\
31.0 \\
16.0 \\
- \\
- \\
-\end{array}$ & $\begin{array}{l}- \\
- \\
- \\
26.5 \\
- \\
-\end{array}$ & $\begin{array}{l}- \\
- \\
- \\
163.9 \\
- \\
-\end{array}$ \\
\hline
\end{tabular}

$B D=$ bulk density, $B S=$ Base Saturation, CEC = Cation Exchange Capacity, SOC = Soil organic carbon, $H C=$ Humus content. ${ }^{1}$ Values are of top soils $(0-20 \mathrm{~cm}$ soil depth); ${ }^{1}$ Values are of top soils (0-20 cm soil depth); ${ }^{2}$ Source: LfULG (2015); ${ }^{3}$ Source: Brackhage et al. (2014). *See Table 7.2 for As, Cd, and Pb metal content in soil substrate used for sunflower study.

Sunflower (Helianthus annuus) was used as a test crop and seeds of $5^{\text {th }}$ generation mutant inbred line (M5 mutant line 38/R4-R6/15-35-190-04-M5) were obtained from Phytotech Foundation (PT-F), Bern, Switzerland. This inbred line was developed with in mutagenesis and in-vitro breeding with improved metal-phytoextraction and metal tolerance (Herzig et al. 2014; Nehnevajova et al. 2009a). Sunflower seedlings were prepared in May-June 
2011, and a month-old seedlings ( 2 seedling pot ${ }^{-1}$ ) were transplanted into pot on 25-26 July 2011. Recommended rate of major-nutrients (N, P, K, Ca, and $\mathrm{Mg}$ ) was added into pot-soils. Nutrients were added into metal-spiked soils by compensating nitrate-nitrogen supply through spiking of nitrate-salts as in case of $\mathrm{Cd}$ and $\mathrm{Pb}$ treatments. $\mathrm{N}, \mathrm{P}$ and $\mathrm{K}$ solution was prepared respectively from analytical grade chemical $\mathrm{NH}_{4} \mathrm{NO}_{3}, \mathrm{~K}_{2} \mathrm{HPO}_{4}$ and $\mathrm{KCl}$. Plants were irrigated daily with $500 \mathrm{ml}$ deionized water.

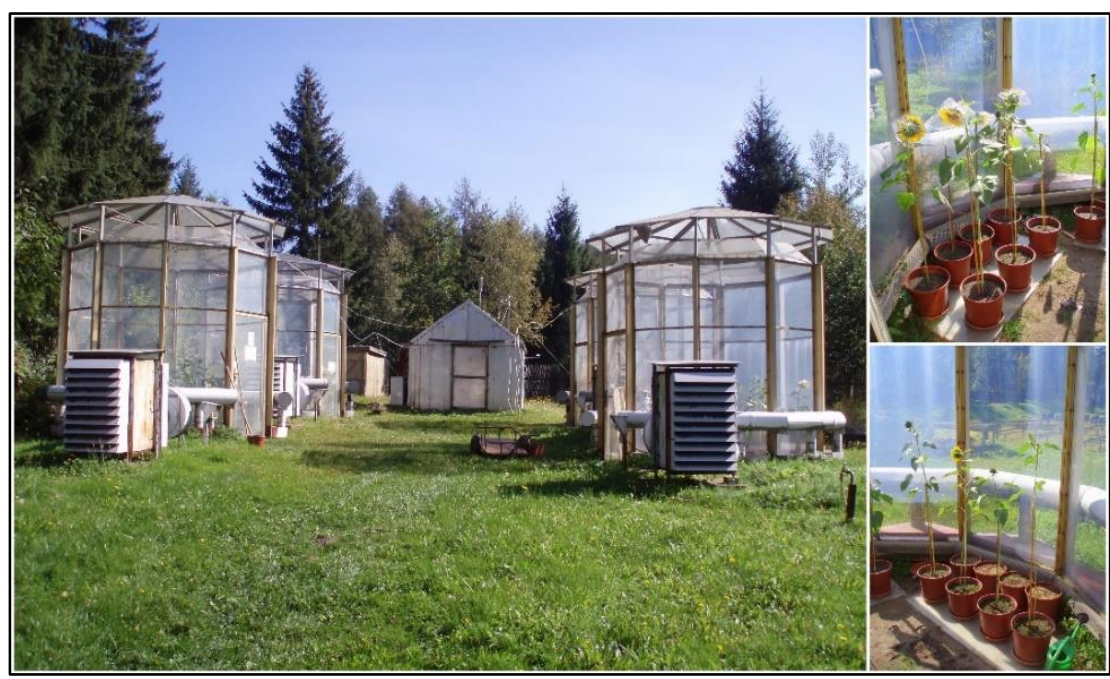

Figure 7.1: Glass-chambers with facility of filtered air circulation and temperature control, and view of pot-grown sunflowers in them.

Table 7.2: Treatment details and metal concentration after metal-spiking to uncontaminated soils before planting

\begin{tabular}{|c|c|c|c|}
\hline \multirow{2}{*}{$\begin{array}{l}\text { Details of metal-spiking } \\
\text { treatments }\end{array}$} & \multicolumn{3}{|c|}{$\begin{array}{l}\text { Pre-concentration of metals* in soils } \\
\text { (in } \mathrm{mg} \mathrm{kg}^{-1} \text { ) }\end{array}$} \\
\hline & Cadmium & Lead & Arsenic \\
\hline Metal-spiking to $S_{1}$-soil & & & \\
\hline 1. $S_{1}$-Control: No spiking & $0.4( \pm 0.01)$ & $27.3( \pm 1.98)$ & $4.9( \pm 0.23)$ \\
\hline 2. $\mathrm{S}_{1}-\mathrm{Cd}_{1}: 10 \mathrm{mg} \mathrm{kg}^{-1}$ & $10.5( \pm 0.19)$ & --- & --- \\
\hline 3. $\mathrm{S}_{1}-\mathrm{Cd}_{2}: 20 \mathrm{mg} \mathrm{kg}^{-1}$ & $23.1( \pm 0.43)$ & --- & --- \\
\hline 4. $\mathrm{S}_{1}-\mathrm{Pb}_{1}: 1200 \mathrm{mg} \mathrm{kg}^{-1}$ & --- & $1478( \pm 138.7)$ & --- \\
\hline 5. $\mathrm{S}_{1}-\mathrm{As}_{1}: 100 \mathrm{mg} \mathrm{kg}^{-1}$ & --- & --- & $94.7( \pm 5.72)$ \\
\hline 6. $\mathrm{S}_{1}-\mathrm{As}_{2}: 900 \mathrm{mg} \mathrm{kg}^{-1}$ & --- & --- & $910( \pm 66.8)$ \\
\hline 7. $\mathrm{S}_{1}$-Mix & $22.0( \pm 0.50)$ & $1677( \pm 77.1)$ & $980( \pm 30.3)$ \\
\hline 8. $\mathbf{S}_{\mathbf{2}}$ soil & $17.9( \pm 0.10)$ & $2175( \pm 48.6)$ & $1167( \pm 11.5)$ \\
\hline 9. $\mathbf{S}_{3}$ soil & $16.6( \pm 0.94)$ & $5815( \pm 378.9)$ & $2949( \pm 205.7)$ \\
\hline
\end{tabular}

$\mathrm{S}_{1}$-Mix is metal-mixture containing $20 \mathrm{Cd}+1200 \mathrm{~Pb}+900 \mathrm{As} ; \mathrm{mg} \mathrm{kg}^{-1}$.

$S_{2}$ and $S_{3}$ soils are respectively metal-contaminated grassland and floodplain soils.

*Aqua regia extraction; values represent mean ( $\pm S E)$ of 4 replicates. 


\subsubsection{WHEAT AND RYEGRASS - ARSENIC UPTAKE STUDY}

These experiments were originally setup by Carsten Brackhage and his team (at Institute of General Ecology and Environmental Protection, Technische Universität Dresden, Tharandt, Germany) to evaluate As-uptake and translocation under periodically flooded conditions mimicking heavy rainfall events combined with different $\mathrm{P}$ - and $\mathrm{N}$-fertilization regimes on different soil types. Detailed experimental design for wheat study is described in the research article authored by Brackhage et al. (2014). Treatments detail for both the study is given in Table 7.3.

Soil at Colditz and Schopfheim is respectively sandy and loamy in texture. The sandy soil in Colditz is periodically flooded (on average once a year), while loamy soils in Schopfheim is influenced by near surface but changing groundwater levels. Characteristics of the soils are given in Table 7.1. The soils were sieved $(<10 \mathrm{~mm})$, homogenized and then placed in $13 \mathrm{~L}$ white polyethylene vessels for use in experiments.

In the wheat and ryegrass studies, two different moisture treatments were simulated for each soils: (i) $70 \%$, kept at $60-80 \%$ field capacity throughout the experiment, and (ii) $100 \%$, kept at $80-100 \%$ field capacity and being periodically flooded. Soils were flooded with deionized water maintaining a near soil surface water level. In wheat study only, as second factor P-fertilization (as $\mathrm{KH}_{2} \mathrm{PO}_{4}$ or $\mathrm{K}_{2} \mathrm{HPO}_{4}$ ) and $\mathrm{N}$-fertilization (as $\mathrm{NO}_{3} \mathrm{NH}_{4}$ ) was added each at two levels: $\mathrm{P}_{0}-0.32 \mathrm{mM} \mathrm{P} \mathrm{kg}{ }^{-1}, \mathrm{P}_{1}-3.2 \mathrm{mM} \mathrm{P} \mathrm{kg}{ }^{-1}, \mathrm{~N}_{0}-5.6 \mathrm{mM} \mathrm{N} \mathrm{kg}^{-1}$ and $\mathrm{N}_{1}$ - $56 \mathrm{mM} \mathrm{N} \mathrm{kg}^{-1}$. K-fertilization (as $\mathrm{KCl}$ ) was added proportionally giving 3.1 $\mathrm{mM} \mathrm{K} \mathrm{kg}{ }^{-1}$ in all pots. Additionally, to the all pots $\mathrm{Ca}\left(0.37 \mathrm{mM} \mathrm{kg}^{-1}\right.$ added as $\left.\mathrm{CaCl}_{2}\right)$, and $\mathrm{Mg}\left(0.61 \mathrm{mM} \mathrm{kg}{ }^{-1}\right.$ added as $\left.\mathrm{MgSO}_{4}\right)$ were added. A common dose of $\mathrm{N}$ - and $\mathrm{P}$-fertilizers were added (i.e., $0.32 \mathrm{mM} \mathrm{P} \mathrm{kg}^{-1}$ and $5.6 \mathrm{mM} \mathrm{N} \mathrm{kg}^{-1}$ ) to ryegrass grown pots. Each pot was fertilized by irrigating an appropriate solution beginning of April (start of the growing season) and again beginning of May.

An initial 22 seeds of wheat (Triticum aestivum L.; cv. 'Akteur' (winter wheat; etched with Arena C, Bayer Crop Science AG, Germany) were sown per vessel in late autumn 2010. After germination, pots were kept outside in a sand bed during winter, and in early spring they were placed in greenhouses with filtered air and temperature control (mimicking outside values). At this time, the number of seedlings was reduced to 16 per pot. The experiment was terminated in July 2011. Ryegrass seeds were broadcasted into the pots in mid-May 2011.

\subsubsection{SPECTRAL REFLECTANCE MEASUREMENT OF LEAVES}

For sunflower experiment, total four spectral measurements were done on: 26 Aug, 13 Sept, 26 Sept, and 27 Oct 2011. For wheat, one measurement on 12 May 2011, while for ryegrass experiment, two spectral measurements were taken before $2^{\text {nd }}$ foliage cut during 18-27 July and final cut during 5-15 Sept 2011 
Table 7.3: Treatment* details of wheat and ryegrass experiments

\begin{tabular}{|c|c|c|c|}
\hline Crop & $\begin{array}{c}\text { Soil } \\
\text { Substrate }\end{array}$ & $\begin{array}{c}\text { P- and N- } \\
\text { fertilization }\end{array}$ & $\begin{array}{c}\text { \% Field } \\
\text { Capacity (FC) }\end{array}$ \\
\hline \multirow{3}{*}{$\begin{array}{c}\text { Wheat } \\
\text { (Triticum }\end{array}$} & $\mathbf{S}_{\mathbf{1}}$ : Colditz & $\mathrm{P}_{0} \mathrm{~N}_{0}$ & 70 \\
aestivum L.) & (Sandy soil) & $\mathrm{P}_{0} \mathrm{~N}_{1}$ & 70 \\
\cline { 2 - 4 } & $\mathrm{P}_{1} \mathrm{~N}_{0}$ & 100 \\
& $\mathbf{S}_{\mathbf{2}}$ : Schopfheim & $\mathrm{P}_{1} \mathrm{~N}_{1}$ & 100 \\
\hline \multirow{3}{*}{$\begin{array}{c}\text { Ryegrass } \\
\text { (Lolium }\end{array}$} & (Loamy soil) & $\mathrm{P}_{0} \mathrm{~N}_{0}$ & 70 \\
perenne L.) & $\mathrm{P}_{0} \mathrm{~N}_{1}$ & 70 \\
\cline { 2 - 4 } & $\mathrm{P}_{1} \mathrm{~N}_{0}$ & 100 \\
& (Sandy soil) & $\mathrm{P}_{1} \mathrm{~N}_{1}$ & 100 \\
\hline S: Schopfheim & $\mathrm{P}_{0} \mathrm{~N}_{0}$ & 70 \\
& (Loamy soil) & $\mathrm{P}_{0} \mathrm{~N}_{0}$ & 100 \\
\hline
\end{tabular}

${ }^{*}$ All treatment replicated 5 times. Hence there were 8 treatments $\times 5$ replicates $=40$ pots for wheat study and 6 treatments $\times 5$ replicates $=30$ pots for ryegrass study. $P_{0}: 0.32 \mathrm{mMP} \mathrm{kg}{ }^{-1}, P_{1}: 3.2 \mathrm{mM} P \mathrm{~kg}^{-1}, \mathrm{~N}_{0}: 5.6 \mathrm{mM} \mathrm{N} \mathrm{kg}{ }^{-1}$ and $\mathrm{N}_{1}: 56.0 \mathrm{mM} \mathrm{N} \mathrm{kg}^{-1}$.

For sunflower leaf spectral measurement, 2-3 leaves were dissected from each pot using steel scissor, and immediately reflectance spectra were measured in a laboratory. The leaf spectral measurement of wheat and ryegrass was done on uncut leaves and 3-4 measurements were taken from each pot, and then averaged per pot. ASD FieldSpec portable spectroradiometer (350-2500 nm at resolution of $1 \mathrm{~nm}$; ASD, Inc., Boulder, CO) was used to collect reflectance spectra using a plant probe leaf-clip assembly fitted with an internal halogen light. The reflectance spectra were measured by holding sunflower leaf (in case of wheat and ryegrass 3-5 leaves, side-by-side without leaf overlapping) into leaf clip holder. Leaf-clip assembly has got two-sided rotating head: a black panel face for reflectance and a white for transmittance measurement. Reflectance spectra were calibrated against a white Spectralon panel face. The use of the leaf clip and contact probe reduces interferences, such as atmospheric disturbances, and unstable light. The leaf clip was repositioned on the same leaf/leaves between each scan to 3-5 different locations, to minimize measurement inaccuracy and to acquire the natural variations in metalinduced stress.

Individual spectral measurement was averaged by treatment to reduce variation and spectra were corrected for ASD jump (drift correction; additive) using AS-toolbox package (Dorigo et al. 2006) add-in installed in ENVI+IDL version 4.3. First derivative (FD) calculation was done on corrected spectra with 5-point moving average to intensify spectral features. Several VIs relevant to the metal-induced plant stress, particularly in chlorophyll and water absorption regions, were computed (same as of in the barley study): chlorophyll indices NDVI, LCI, SR705, REIP and water stress indices NDWI, NDWI_MIR, MSI, LWVI2 (see Table 6.3 of chapter 6). Continuum removal (CR) was applied to corrected spectra which normalizes the reflectance spectra by 
applying convex hull and amplifies the individual absorption feature (Clark and Roush 1984). Difference in BDs between control and metal-treatment was statistically compared for each absorption region and at specific wavelength (see Table 6.3 of chapter 5).

\subsubsection{Chemical analyses}

At each spectral measurement, the sampled leaves were dried at $80{ }^{\circ} \mathrm{C}$ for 24 hrs and milled. At harvest, root samples were collected, and were thoroughly washed twice with deionized water. For analyzing total metal content, $250 \mathrm{mg}$ of milled sample was digested with $5 \mathrm{~mL}$ concentrated $\mathrm{HNO}_{3}$ in Teflon tubes in pressurized microwave accelerated reaction system (CEM Mars5 microwave digestion system; Matthews, USA) for 30-40 min. Wheat and rye grass leaves samples were mineralized using $3 \mathrm{~mL} \mathrm{HNO}_{3}$ and 2-mL $\mathrm{H}_{2} \mathrm{O}_{2}$. The digested substrate was then diluted with $10 \mathrm{~mL}$ deionized water and analyzed for total $\mathrm{Cd}, \mathrm{Pb}$ and $\mathrm{As}$ using inductively coupled plasma-atomic emission spectrometry (ICPMS X-series instrument, Thermo Fisher Scientific $\mathrm{GmbH}$, Bremen, Germany). Similarly, initial soil samples also analyzed for total metal content by digesting $500 \mathrm{mg}$ air-dried soil in $5 \mathrm{~mL} \mathrm{HNO}_{3}$. Standard reference soil and plant samples (GBW7604, poplar leaves, office of CRM's, China) were also digested for recovery test. Precision for all standards were better than $95 \%$. All chemical used in chemical analysis were of analytical grade.

\subsubsection{STATISTICAL ANALYSES}

Statistical analyses of spectral and chemical data were performed in MS Excel spreadsheets 2007 with XLSTAT 2009.1.02 add-ins and reported at $\alpha=0.05$ significance level. Mean and standard error $( \pm S E)$ were computed for all data. Data were statistically tested for significant effects through analysis of variance and Post hoc Tukey HSD test was done to compare the treatment mean. Correlation coefficients (Pearson's ' $r$ ') were computed between spectral variables (i.e., corrected spectra, VIs, BDs of CR spectra) and leaf-metal content for each treatment. The relationship between leaf-metal concentration and spectral features (i.e., correlated spectral wavelength regions, VIs and BDs values) was modeled using regression analysis, leave-one-out cross validation techniques (PLSR, partial least square regression and MLR, multiple linear regression; in Unscrambler 9.7, CAMO ASA, Norway). Values of coefficient of determination $\left(R^{2}\right)$ between measured and predicted value and root mean square error (RMSE) were used to examine the relationship found.

\subsection{RESULTS AND DISCUSSION}

\section{(A) SUNFLOWER STUDY}

\subsubsection{Metal phytoaccumulation}

Table 7.4 and Figure 7.2 respectively show the $\mathrm{Cd}, \mathrm{Pb}$, and As concentrations in leaves and roots from sunflower grown in three metal-contaminated soils. Overall, the metal concentration of root was higher than that of leaves, and was increased as the amount of spiked-metal increased over growing time. Leaf- and root-Cd concentration (mean values; Figure 7.2 ) at $10 \mathrm{mg} \mathrm{Cd} \mathrm{kg}{ }^{-1}$ 
soil were respectively 26.3 and $37.7 \mathrm{mg} \mathrm{kg}^{-1}$, and these values increased by 1.5-2.0 times at $20 \mathrm{mg} \mathrm{Cd} \mathrm{kg}^{-1}$ spiking to the soil substrate, i.e., 54.7 and 61.0 $\mathrm{mg} \mathrm{kg}^{-1}$ (Figure 7.2). As seen in Table 7.4 and Figure 7.2, most of the $\mathrm{Pb}$ were concentrated in roots $\left(1970.5 \mathrm{mg} \mathrm{kg}^{-1}\right.$ ), and only little amount translocated into leaves $\left(69.1 \mathrm{mg} \mathrm{kg}^{-1}\right.$ ). Minimal leaf-Pb concentration could be attributed to the plant's restricted translocation mechanism, the low-solubility of most $\mathrm{Pb}$-species, and precipitation of $\mathrm{Pb}$ by sulphate and phosphate at root system (Dushenkov et al. 1995; McGrath et al. 2002).

Generally, As concentration is low in plants (Matschullat 2000). Conversely, sunflower accumulated greater amount of As from the soils. Root-As was 7.5-

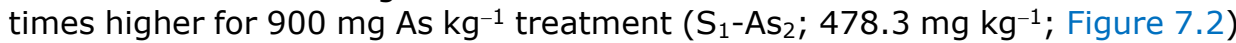
than at $100 \mathrm{mg} \mathrm{kg}{ }^{-1}\left(S_{1}-A s_{1}\right)$ level. For $S_{1}-A s_{1}$, despite of significantly higher root-As concentration (Figure 7.2), it was not moved into leaves as observed in case of $\mathrm{S}_{1}-\mathrm{As}_{2}$. Contrary, plant showed high As-accumulation in leaves at

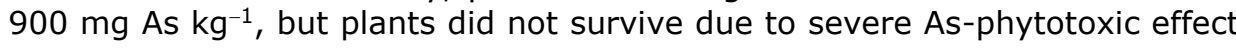
(Figure 7.3A-C).

Table 7.4: Metal concentration ( $\mathrm{mg} \mathrm{kg}^{-1}$; dry wt. basis)* in sunflower leaves

\begin{tabular}{|c|c|c|c|c|}
\hline \multirow{2}{*}{$\begin{array}{l}\text { Treat. } \\
(\text { metals; } \\
\left.\text { mg kg }^{-1}\right)^{\#}\end{array}$} & \multicolumn{4}{|c|}{ Cd concentration at different intervals (days after sowing) } \\
\hline & 30 & 45 & 60 & 90 \\
\hline S ${ }_{1}$-Contr & $0.88( \pm 0.15)^{a}$ & $1.03( \pm 0.21)^{a}$ & $1.3( \pm 0.20)^{a}$ & $1.17( \pm 0.52)^{a}$ \\
\hline $\mathrm{S}_{1}-\mathrm{Cd}_{1}$ & $23.1( \pm 2.42)^{b}$ & $22.5( \pm 1.81)^{b c}$ & $27.7( \pm 1.50)^{b}$ & $32.1( \pm 3.12)^{b}$ \\
\hline $\mathrm{S}_{1}-\mathrm{Cd}_{2}$ & $45.6( \pm 5.87)^{c}$ & $55.4( \pm 7.17)^{d}$ & $58.3( \pm 6.52)^{d}$ & $59.6( \pm 5.76)^{c}$ \\
\hline $\mathrm{S}_{1}-\mathrm{Mix}$ & $31.2( \pm 2.88)^{b}$ & $0.5( \pm 0.17)^{a}$ & --- & $0.7( \pm 0.29)^{a}$ \\
\hline $\mathrm{S}_{2}$ & $28.5( \pm 3.73)^{b}$ & $40.4( \pm 2.74)^{c d}$ & $51.3( \pm 1.58)^{d}$ & $56.3( \pm 3.29)^{c}$ \\
\hline \multirow[t]{2}{*}{$\mathrm{S}_{3}$} & $3.4( \pm 1.02)^{a}$ & $18.9( \pm 6.47)^{b}$ & $10.9( \pm 1.51)^{b}$ & $24.4( \pm 5.05)^{b}$ \\
\hline & \multicolumn{4}{|c|}{ Pb concentration at different intervals (days after sowing) } \\
\hline $\mathrm{S}_{1}$-Contr & $1.10( \pm 0.14)^{a}$ & $0.40( \pm 0.06)^{a}$ & $0.25( \pm 0.04)^{a}$ & $0.04( \pm 0.03)^{a}$ \\
\hline $\mathrm{S}_{1}-\mathrm{Pb}_{1}$ & $82.2( \pm 12.5)^{b}$ & $90.8( \pm 8.61)^{c}$ & $66.1( \pm 4.78)^{b}$ & $37.2( \pm 3.04)^{c}$ \\
\hline $\mathrm{S}_{1}-\mathrm{Mix}$ & $4.8( \pm 1.14)^{a}$ & $1.3( \pm 0.27)^{a b}$ & --- & $1.4( \pm 0.43)^{a}$ \\
\hline $\mathrm{S}_{2}$ & $3.6( \pm 0.35)^{a}$ & $3.3( \pm 0.59)^{a b}$ & $3.5( \pm 0.18)^{a}$ & $3.7( \pm 0.64)^{a}$ \\
\hline \multirow[t]{2}{*}{$\mathrm{S}_{3}$} & $1.3( \pm 0.33)^{a}$ & $24.2( \pm 12.3)^{b}$ & $4.5( \pm 2.34)^{a}$ & $15.4( \pm 3.36)^{b}$ \\
\hline & \multicolumn{4}{|c|}{ As concentration at different intervals (days after sowing) } \\
\hline $\mathrm{S}_{1}$-Contr & $1.37( \pm 0.29)^{a}$ & $0.25( \pm 0.15)^{a}$ & $0.14( \pm 0.06)^{a}$ & $0.025( \pm 0.16)^{a}$ \\
\hline $\mathrm{S}_{1}-\mathrm{A} \mathrm{S}_{1}$ & $61.7( \pm 11.04)^{b}$ & $89.8( \pm 14.7)^{b c}$ & $60.7( \pm 9.1)^{b}$ & $49.79( \pm 6.95)^{b}$ \\
\hline $\mathrm{S}_{1}-\mathrm{As} 2$ & $429.5( \pm 0.00)^{d}$ & $490.5( \pm 34.4)^{e}$ & --- & --- \\
\hline $\mathrm{S}_{1}-\mathrm{Mix}$ & $156.9( \pm 9.97)^{c}$ & $157.6( \pm 50.5)^{c d}$ & --- & $385.7( \pm 37.3)^{d}$ \\
\hline $\mathrm{S}_{2}$ & $154.5( \pm 16.36)^{c}$ & $214.3( \pm 25.2)^{d}$ & $149.0( \pm 24.7)^{c}$ & $110.9( \pm 17.40)^{c}$ \\
\hline $\mathrm{S}_{3}$ & $1.97( \pm 1.10)^{a}$ & $7.5( \pm 2.50)^{a b}$ & $26.03( \pm 1.30)^{a}$ & $4.4( \pm 1.26)^{a}$ \\
\hline
\end{tabular}

${ }^{\#} \boldsymbol{S}_{1}$ : Uncontaminated soils and $S_{1}-C d_{1}, S_{1}-C d_{2}, S_{1}-A s_{1}, S_{1}-A s_{2}, S_{1}-P b_{1}, S_{1}-$ Mix are metalsalt spiking treatments into $S_{1}$ soil. $\boldsymbol{S}_{2}:$ moderately metal-contaminated soils. $\boldsymbol{S}_{3}$ : Severely metal-contaminated soils. Dash line (---) indicates either leaves were not sampled or plant not survived due to high metal-toxicity. *The values represent averages \pm SEm of $n=4$ replicates (of metal-spiking) and $n=16,20$ and 16 replicates (of respective control in case of $C d, P b$, and $A s$ ). In each column values not connected by same letter are significantly different at $a=0.05$ according to Post hoc Tukey HSD test. 

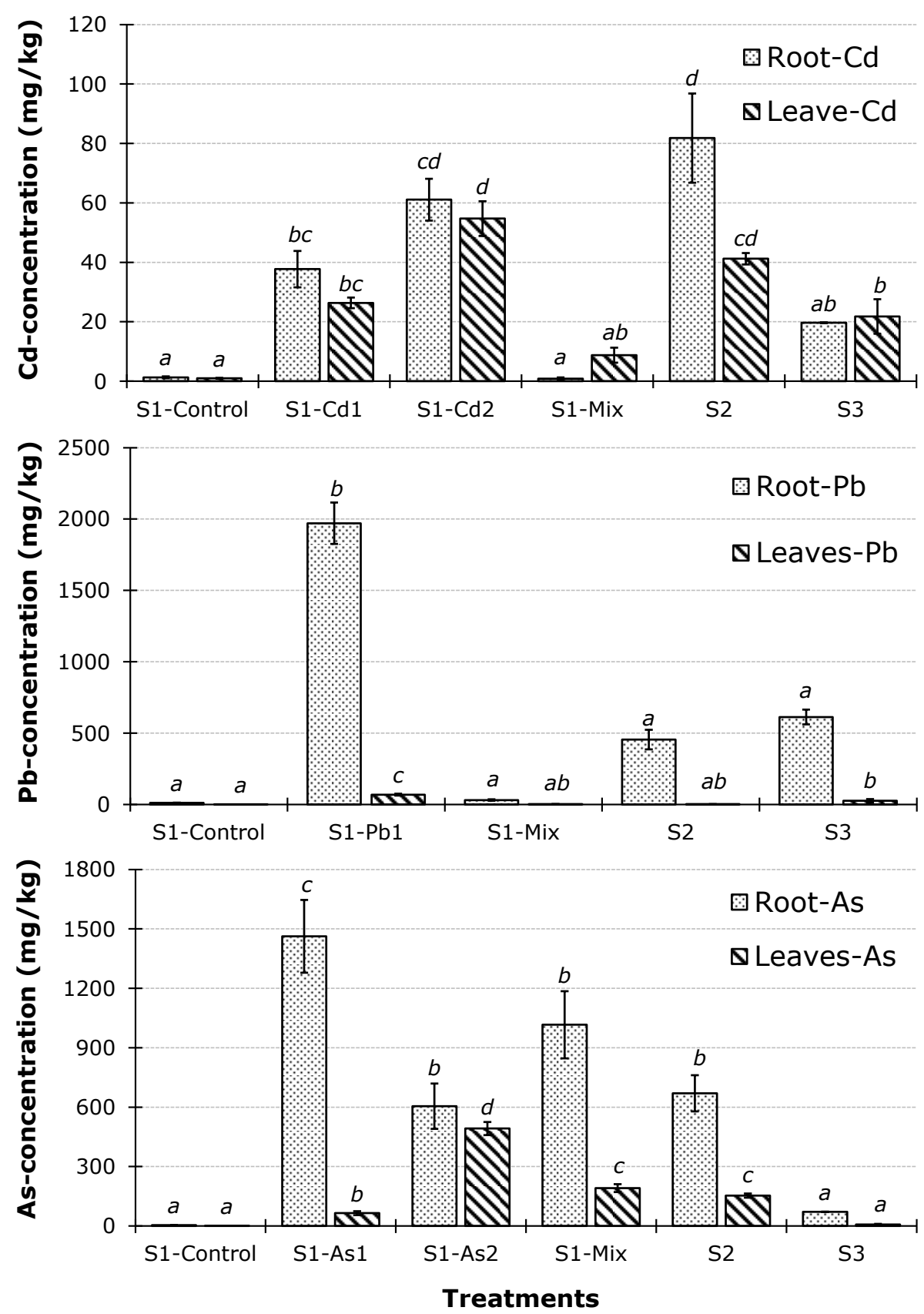

Figure 7.2: Cadmium, lead and arsenic concentration (in $\mathrm{mg} \mathrm{kg}^{-1}$; dry weight basis) in roots and leaves (mean of all sampling dates) of sunflower. Error bars are values of \pm SE. The column not connected by same letter are significantly different at $\alpha=0.05$ according to Post hoc Tukey HSD test. See foot-note at Table 7.4 for treatment detail. 


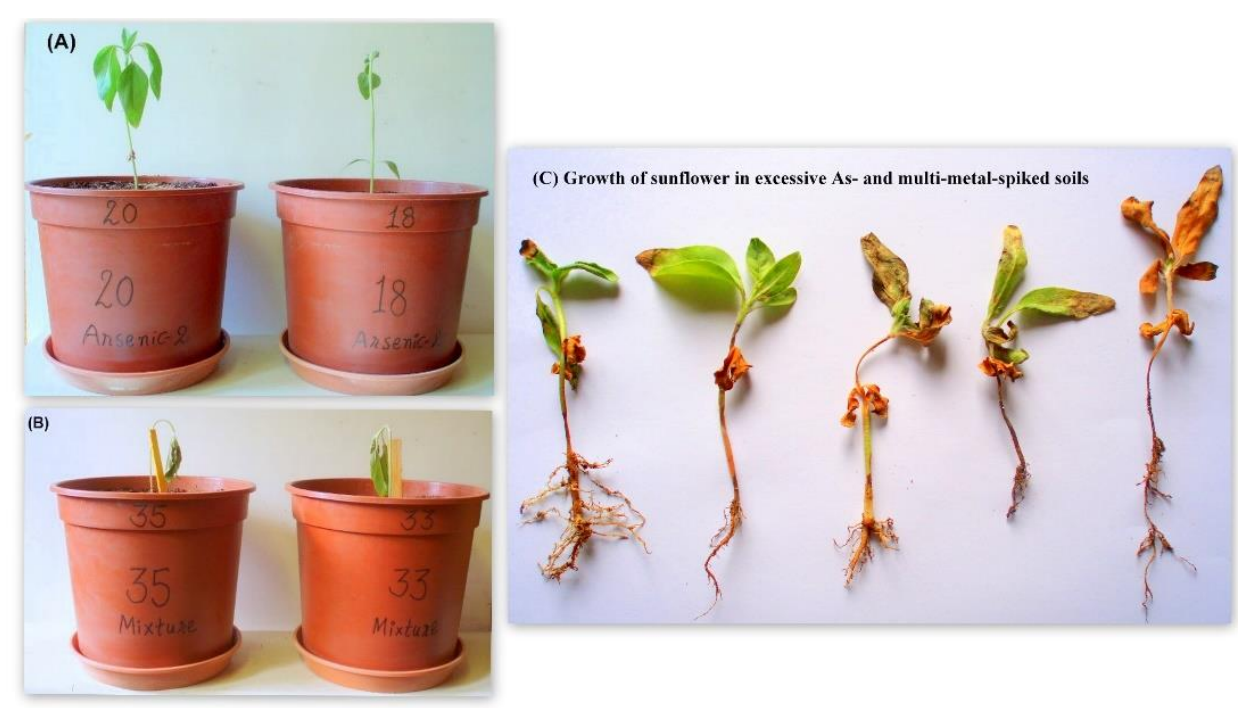

Figure 7.3: Sunflower growth into (A) $S_{1}-A s_{2}$ and (B) $S_{1}-$ Mix soil at 30 days after seedling transplantation. (C) The sunflower plants were not survived under the condition of extreme higher concentration of As $\left(900 \mathrm{mg} \mathrm{kg}^{-1}\right)$ and metal-mixture $\left(20 \mathrm{mg} \mathrm{Cd}+1200 \mathrm{mg}+\mathrm{Pb}\right.$ and $\left.900 \mathrm{mg} \mathrm{kg}^{-1}\right)$. Plants were also stunted in in-situ metal-contaminated floodplain soils.

Exposure to trivalent-As (Arsenite) causes plant-stress including growth reduction and plant death (Garg and Singla 2011; Kabata-Pendias and Pendias $2001)$. Added to this, As-spiking to the sandy soil substrate $\left(S_{1}\right)$ used in present study explained the severe phytotoxicity to the plant (Sheppard 1992). For $\mathrm{S}_{1}$-Mix treatment $\left(20 \mathrm{mg} \mathrm{Cd}+1200 \mathrm{mg}+\mathrm{Pb}\right.$ and $900 \mathrm{mg} \mathrm{kg}^{-1}$ ), minimum $\mathrm{Cd}$ and $\mathrm{Pb}$ concentrations in leaves and root were noticed (Figure 7.2), i.e. mean values in leaves: $\mathrm{Cd}, 8.7 ; \mathrm{Pb}, 2.3 \mathrm{mg} \mathrm{kg}^{-1}$ and root: $\mathrm{Cd}, 0.8 ; \mathrm{Pb}, 32.3$ $\mathrm{mg} \mathrm{kg}{ }^{-1}$. Relatively, As in leaves $\left(191.2 \mathrm{mg} \mathrm{kg}^{-1}\right.$ ) and root $\left(1015.9 \mathrm{mg} \mathrm{kg}^{-1}\right.$ ) for $S_{1}$-Mix was found significantly higher, which probably disturbs plant functioning, and thereby hampered the accumulation of other metals into plants. Moreover, for $S_{1}-M i x$, the translocation of As into leaves was found minimal compared to $S_{1}-A s_{2}$ spiking, a possible explanation could be the multimetal interaction within soils, which either inhibited the accumulation or complexation of As (III) with thiols, possibly sequestration into root vacuoles, which restricted the translocation from root to leaves.

Phytoaccumulation of metals was significantly different between soils used in the study. Between the three soils used $\left(S_{1}-\right.$ Mix, $S_{2}$, and $S_{3}$ ), a significantly higher $\mathrm{Cd}$ concentration in root and leaves (respectively, 81.8 and $41.2 \mathrm{mg}$ $\mathrm{kg}^{-1}$ ) was found with $\mathrm{S}_{2}$-soil compared to the $\mathrm{S}_{1}$-uncontaminated control soil. Higher $\mathrm{Pb}$ and $\mathrm{As}$ concentrations in leaves and root were observed respectively with $S_{3}$-soil and $S_{1}$-Mix soil compared to $S_{1}$-control (Figure 7.2). The $S_{2}$ and $S_{3}-$ soil substrate is respectively sandy loam and sandy clay loam in texture with high soil organic carbon and humus content (Table 7.1), which might have enhanced $\mathrm{Cd}$ and $\mathrm{Pb}$ bioavailability through organically-bound species at the plant root. 
Sunflower mutant lines ( $3^{\text {rd }}$ and $4^{\text {th }}$ generation) have positively been assessed for their improved metal phytoaccumulation and tolerance in Europe (Kidd et al. 2015; and references within). Present results of metal concentration confirmed that sunflower could accumulate $\mathrm{Cd}$, As and transport them to above-ground parts, however such correlation was not observed in the case of $\mathrm{Pb}$, which is almost immobile within soils and confined only to root tissues in present study. High metal concentration in root suggesting sunflower's defence or tolerance mechanism to avoid metal-toxicity at certain levels. Generally, the mechanisms of metal-ion tolerance involve the exclusion of the metal-ion from uptake or translocation to the shoots, and immobilization of the metal in the cell wall to protect sensitive structures in the cytoplasm.

\subsubsection{LEAF SPECTRAL REFLECTANCE}

The leaf reflectance measured at 30,45, 60 and 90 days of sunflower growth and showed a similar pattern over the growth for most treatments. $\mathrm{S}_{1}$-Mix and $\mathrm{S}_{3}$ however showed spectral variations between spectral measurements at 30 and 45 days (Figure $7.4 a-b$ ), which was also visible by eye.

In response to $\mathrm{Cd}$-spiking into $\mathrm{S}_{1}$-soil, slight spectral changes in sunflower leaves were observed compared to control spectra (Figure 7.5a-b). Leaf reflectance spectra from $\mathrm{S}_{1}-\mathrm{Cd}_{2}$ spiked pot varied from control plant spectra especially in chlorophyll absorption regions ( 490-675 $\mathrm{nm})$, as can be seen in the first derivatives spectra (Figure $7.5 \mathrm{c}-\mathrm{d}$ ), and also in the water absorption regions at around 950, 1150, 1400 and $1900 \mathrm{~nm}$ (Figure 7.5c-d). Cadmium is known to interfere with uptake of other essential nutrients [(Prasad 2004); we also found decreased leaf-Fe and -P concentration for Cd-treated plant compared to control; data not shown], to inhibit chlorophyll synthesis, and to alter water balance in tissues (Maria et al. 2013); these stress induced changes in chlorophyll and water content, altogether provides a most generic spectral response in VNIR and water-absorption bands (Kancheva and Borisova 2010; Peñuelas and Filella 1998). Slight spectral changes in visible and at the rededge wavelengths were observed from $\mathrm{S}_{1}-\mathrm{Pb}$ treated sunflower compared to untreated plant spectra (Figure 7.5a-d).

The changes in visible wavelengths were noticeable and showed a larger increase in reflectance for As-treated plant leaves compared to rest of the treatments. An increased reflectance in visible regions and decreased reflectance in NIR regions were substantial in case of $S_{1}-A s_{2}$ treatment at 30 days of sunflower growth (Figure 7.5a). A clear difference can be seen in the first derivatives spectra at visible wavelengths Figure $7.5 \mathrm{c}$ ), wherein red-edge shift to the shorter wavelength was clearly visible, indicating severe As-stress at $900 \mathrm{mg} \mathrm{kg}^{-1}$ to the plant (Figure 7.5a, c). Metal-induced plant stress results in leaf chlorophyll loss that usually cause reduction of the absorption band in red and a red-edge shift to shorter wavelengths (Horler et al. 1983), is consistent with present result. Similar result has been reported in other studies of sunflower exposed to metal contamination (de Gandy 2010).

For metal-mixture spiking $\left(\mathrm{S}_{1}-\mathrm{Mix}\right)$ and in-situ metal-contaminated soils $\left(\mathrm{S}_{2}\right.$ and $S_{3}$ ), substantial changes in the leaf reflectance were found mainly in the red-edge, NIR and water absorption regions of spectrum at 45 days of plant 
growth, especially with sunflower grown in $\mathrm{S}_{3}$-soil (Figure $7.6 \mathrm{a}-\mathrm{b}$ ), which was severely contaminated with $\mathrm{Pb}$ and As-metals (Table 7.2). Similar spectral changes also found with $\mathrm{S}_{1}$-Mix treatment, whereas moderate spectral changes observed with sunflower plant in $\mathrm{S}_{2}$-soil compared to the control plant spectra. These spectral change with natural metal-contaminated soils illustrates metals' additive toxic effects upon their higher accumulation into plant parts (Table 7.4, Figure 7.2). At higher concentration, arsenic interferes with plant metabolic processes and can inhibit growth, often leading to the plant death (Garg and Singla 2011).

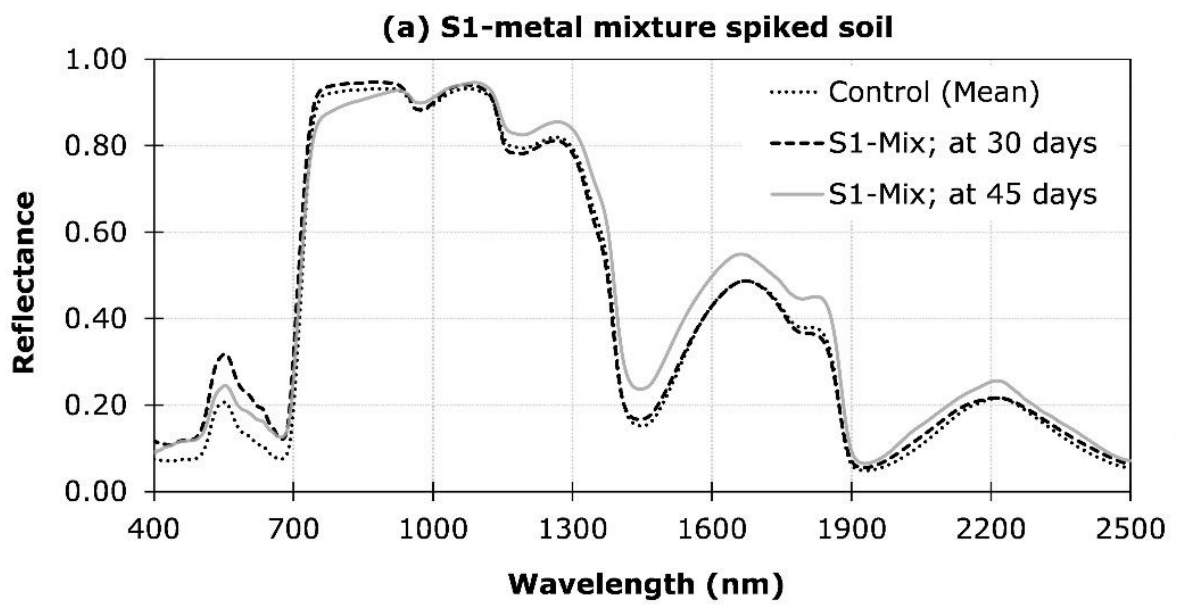

(b) S3-contaminated floodplain soil

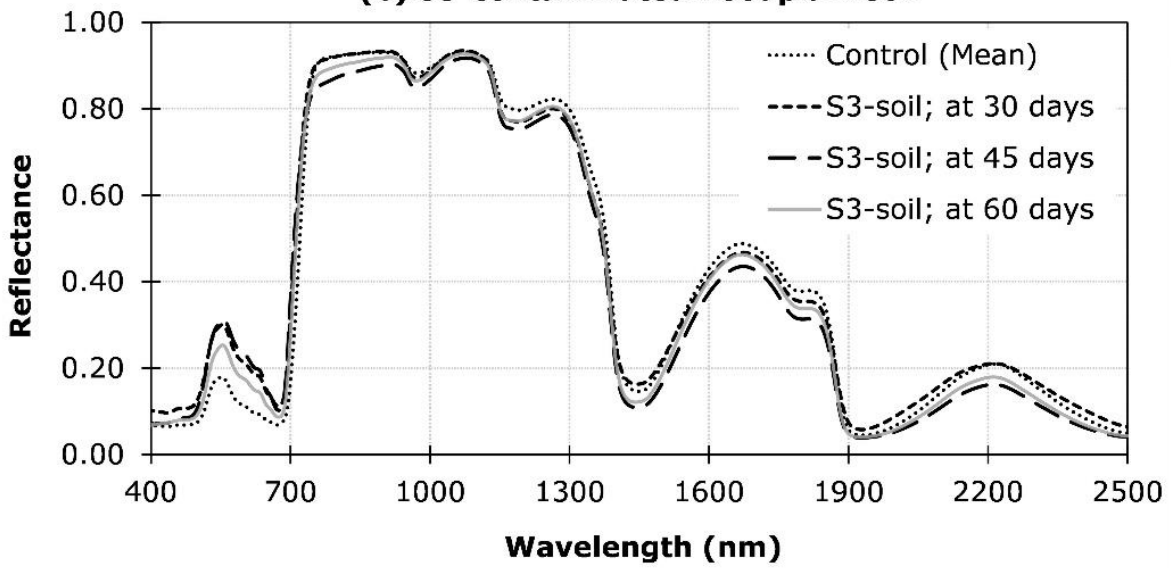

Figure 7.4: Reflectance spectra of (a) $S_{1}$-Mix and (b) $S_{3}$-contaminated floodplain soil treatments at different spectral measurement intervals. 


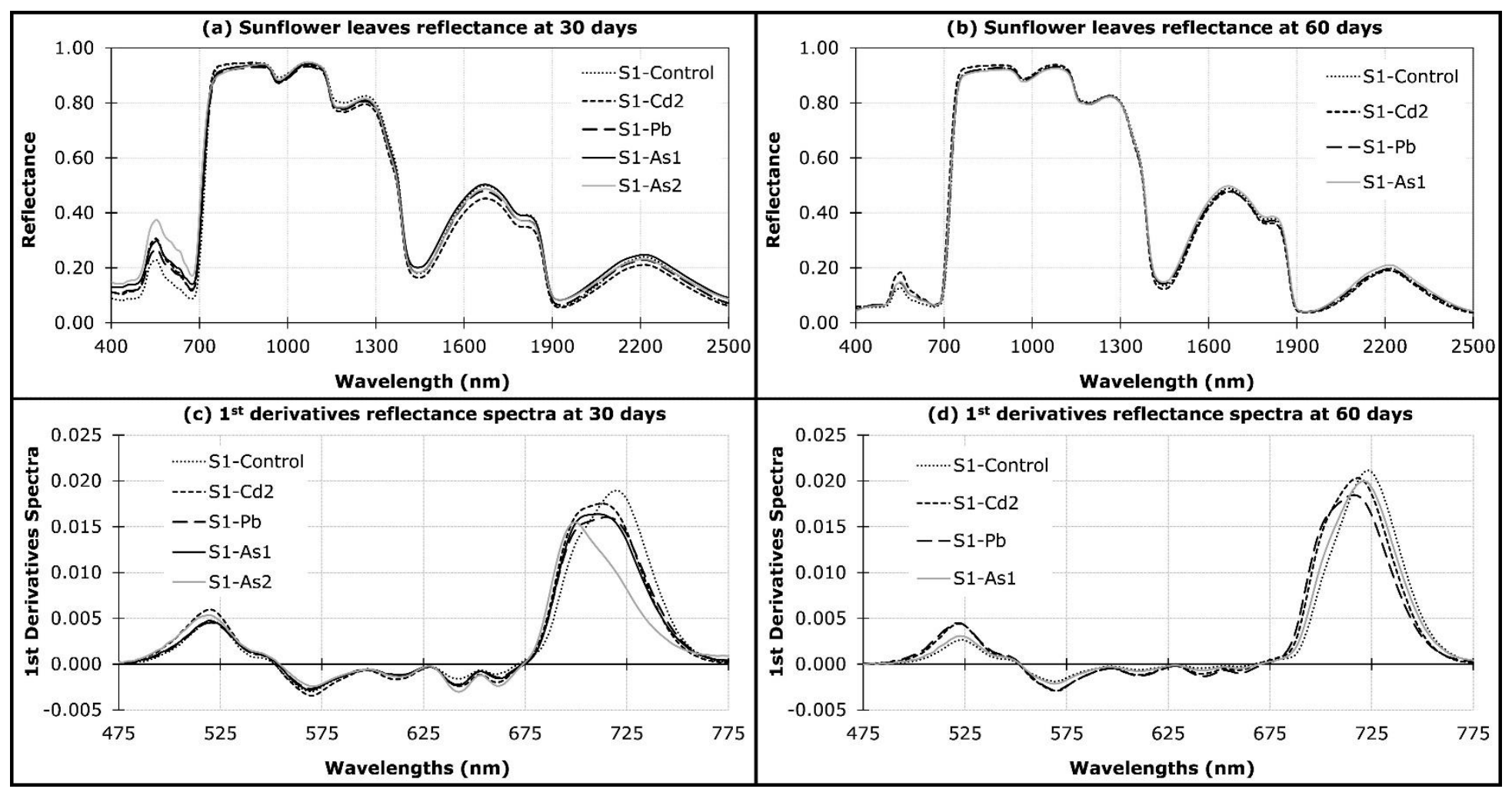

Figure 7.5: Reflectance spectra $(a, b)$ and their first derivatives reflectance spectra (c, d) of leaves of sunflower grown in metal-spiked soils at 30 and 60 days of growth. 
(a) Sunflower leaves reflectance at $\mathbf{4 5}$ days

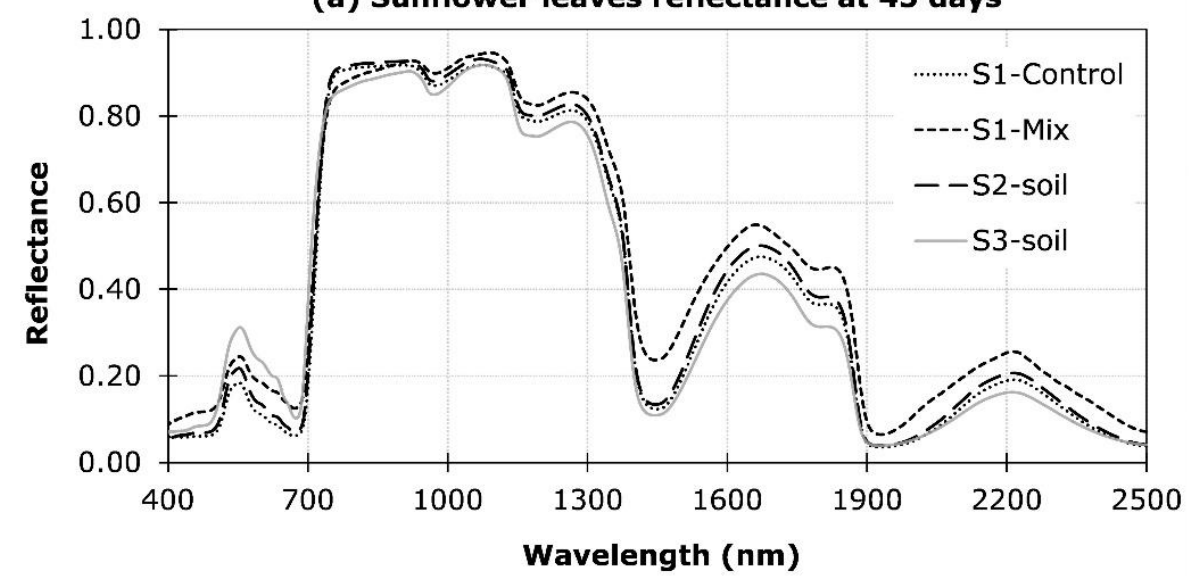

(b) $1^{\text {st }}$ derivatives reflectance spectra at 45 days

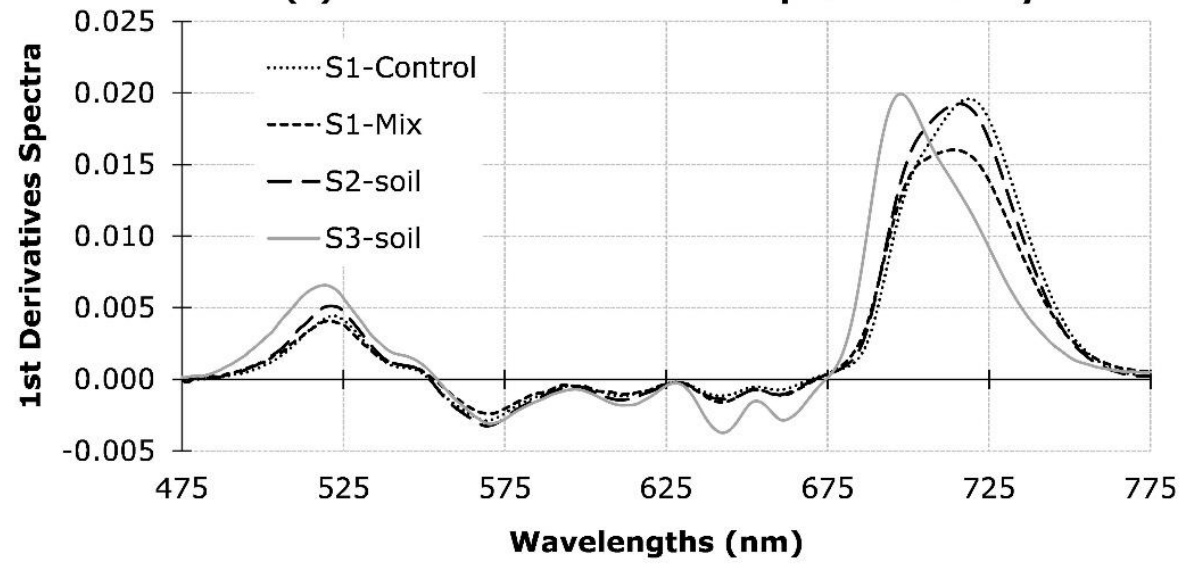

Figure 7.6: Leaf reflectance spectra (a) and first derivatives reflectance spectra (a) from sunflower grown in metal mixture-spiked soils and in-situ metal-contaminated soils at 45 days of plant growth.

Pearson's correlation coefficients between reflectance spectra and leaf-metal concentration were computed for all observations within the respective treatment set. The correlograms of leaf-metal content and reflectance across the entire spectrum show the highest degree of overall correlation for visible and water absorption regions of the spectrum (Figure 7.7a-c). Generally on 30 and 45 days, for $\mathrm{S}_{1}-\mathrm{Cd}$ treatment set, $\sim 470-750 \mathrm{~nm}(r=0.58$ to 0.76$)$, and for $\mathrm{S}_{1}-\mathrm{Pb}$ treatment set, $\sim 415-690 \mathrm{~nm}(r=0.72$ to 0.94$)$ wavelengths showed significant $(p<0.05)$ positive correlation respectively with leaf-Cd and $-\mathrm{Pb}$ metal concentration (Figure 7.7a-c).

While, NIR and water absorption wavelengths showed significant negative correlations, i.e., on 30 days, wavelengths $950-1006 \mathrm{~nm}(r=-0.58$ to -0.65$)$, 1127-1908 ( $r=-0.58$ to -0.73$)$ with leaf-Cd; 744-955 nm $(r=-0.71$ to - 
0.94 ) with leaf-Pb. On 45 days, $1389-1438$ and 1866-1893 nm wavelengths yield negative correlation ( $r=-0.58$ to -0.65$)$ with leaf-Cd. In case of-metal mixture $\left(S_{1}-\right.$ Mix $)$ spiked and in-situ contaminated soils $\left(S_{2}\right.$ and $S_{3}$ soils) treatment sets on 30 days, reflectance in visible regions showed significant positive correlation with leaf-metal concentrations (Figure 7.7c), i.e., 400700 ( $r=0.50$ to 0.88 ) for leaf-Cd, $\sim 451-690$ ( $r=0.50$ to 0.55 ) for leaf-Pb, $\sim 450-690$ ( $r=0.50$ to 0.69 ) for leaf-As concentration.

The observed positive correlation for visible wavelengths at the initial growth periods might be associated with reduction in chlorophyll as a manifestation of metallic-ion toxicity. Such VNIR spectral variations in sunflower leaves due to mineral deficiencies and metal-toxicity have been reported in other studies (Mariotti et al. 1996; Peñuelas et al. 1994), are in agreement with our results. With respect to spiked metal concentration and background levels in soils, these elements are known phytotoxins (Azevedo et al. 2005; Gallego et al. 1996; Imran et al. 2015; Kabata-Pendias and Pendias 2001; Raba et al. 2005) that may have caused damage to chlorophyll and leaf structure of the sunflower plant.
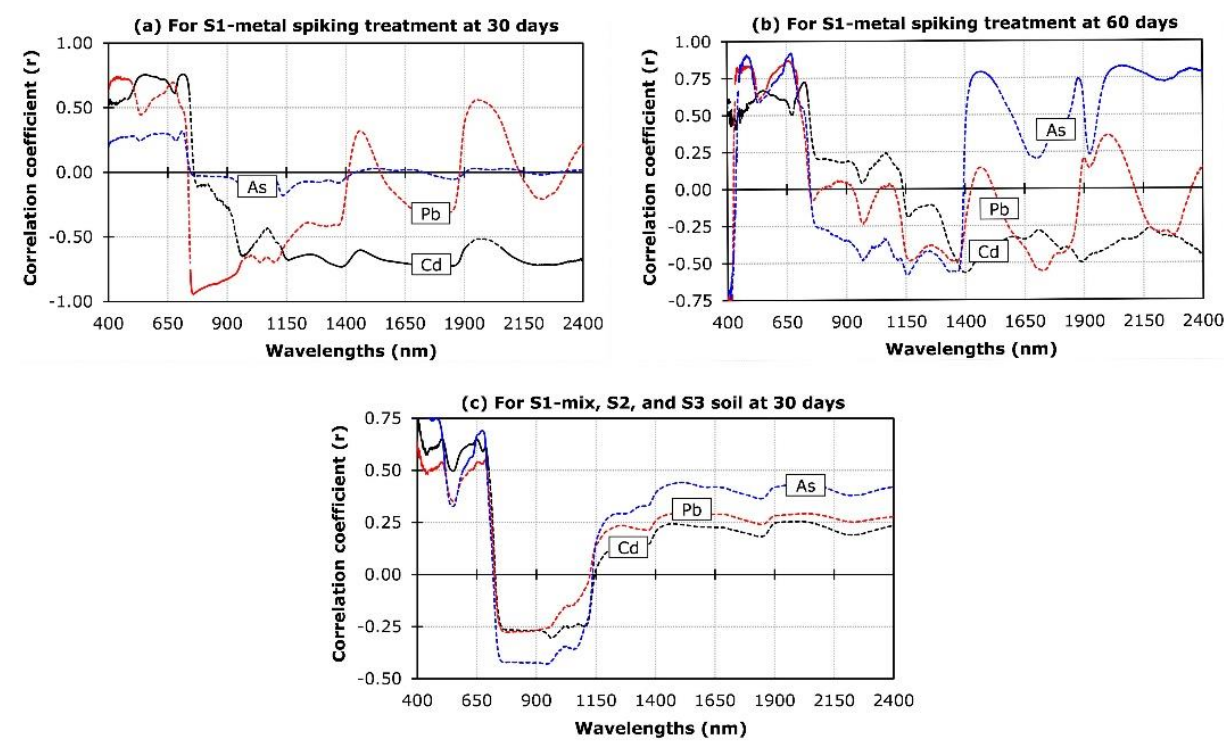

Figure 7.7: Pearson's correlation ( $r$ ) of reflectance spectra against leaf-metal concentration for $(\mathrm{a}, \mathrm{b}) \mathrm{S}_{1}-\mathrm{Cd},-\mathrm{Pb}$, and -As spiking treatments at 30 and 60 days and (c) for $S_{1}$-metal mixture, $S_{2}$, and $S_{3}$ treatments at 30 days. Solid line $(-)$ represents significant correlation between wavelength and metal concentration at $\alpha=0.05$ level and dotted line (----) represents nonsignificant correlations. 


\subsubsection{VEGETATION INDICES AND CONTINUUM REMOVED SPECTRA}

Vegetation indices related to chlorophyll and water absorption features are calculated to monitor the plant stress caused by soil-metal contamination (Table 6.3 of chapter 6 ). Generally, the Cd-spiking to $\mathrm{S}_{1}$-soils showed nonsignificant changes in the calculated indices compared to indices obtained from untreated plant spectra (Figure 7.8). Treatment $\mathrm{S}_{1}-\mathrm{Pb}_{1}$ showed significant decrease in SR705 index compared to control treatment at 30 days, i.e. 2.853 against 4.064. However, $\mathrm{S}_{1}-\mathrm{Pb}_{1}$ show no significant difference in other calculated indices from control plants. The REIPs (Savitzky-Golay Filter $1^{\text {st }}$ order derivative and smoothing technique) also decreased (i.e., shifted towards blue wavelengths) for $\mathrm{Cd}$ - and Pb-spiking, but was found nonsignificant with respect to control REIPs.

As seen in Figure 7.8 , the arsenic and metal-mixture spiking to $\mathrm{S}_{1}$-soils can statistically be distinguished from untreated plants. On 30 days of sowing, the least values of NDVI, LCI, and SR705 obtained with As-spiking at $900 \mathrm{mg} \mathrm{kg}$ to $S_{1}$-soils $(0.685,0.268$, and 2.110 respectively) followed by multi-metal spiking to $\mathrm{S}_{1}$-soils $(0.726,0.310$, and 2.565 respectively), are significantly differed from untreated plant $(0.832,0.440$, and 4.064 respectively). The REIPs are also significantly different from untreated plants for $S_{1}-A s_{2}$ and $S_{1}$ Mix treatments, a blue-shift (toward shorter wavelengths) by 20 and $13 \mathrm{~nm}$ respectively observed. However, these indices for As-spiking at $100 \mathrm{mg} \mathrm{kg}^{-1}$ to $\mathrm{S}_{1}$-soils significantly on par with indices from untreated plant, indicated that

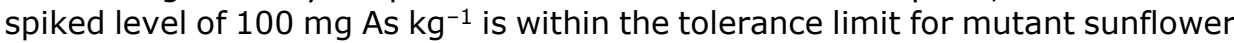
plant, and did not cause plant stress. Similarly, plants grown in in-situ contaminated floodplains soils $\left(\mathrm{S}_{3}\right.$-soil) can be differentiated using NDVI, LCI and, SR705 indices, since these values are significantly lower than those of control treatment on 30, 45 and 60 days (Figure 7.8). Moreover, REIPs for $\mathrm{S}_{3}-$ soil treatment shows significant blue shift by 14,21 , and $18 \mathrm{~nm}$ comparative to the control REIP on 30,45, and 60 days, respectively. A decrease in the values of chlorophyll indices and blue shift of REIPs with $\mathrm{S}_{1}-\mathrm{As}_{2}, \mathrm{~S}_{1}$-Mix and $\mathrm{S}_{3^{-}}$ soil could be due to indirect effects of metal-accumulation in plant parts, specifically into roots (Figure 7.2) on photosynthetic activities and chlorophyll synthesis, which altogether lead to changed plant spectral reflectance. Present results are in agreement with several studies that have demonstrated the blueshift of REIPs and effectiveness of different chlorophyll indices for the delineation of metal-induced stress related variations ( $\mathrm{Li}$ et al. 2015; Milton et al. 1989; Slonecker et al. 2009; Sridhar et al. 2007a; Sridhar et al. 2014).

Water indices (NDWI, NDWI_MIR, MSI, and LWVI2) are found to be lower for metal-spiking treatments (except $\mathrm{S}_{1}-\mathrm{As}_{2}$; wherein plants died at 30 days) as well as for $\mathrm{S}_{2^{-}}$and $\mathrm{S}_{3}$-soils than the control treatment, but the differences found statistically non-significant. This might be owed to either an efficient metal tolerance mechanism of $M_{5}$ sunflower mutants towards stress, particularly drought-stress, or a well-development root-growth, that can lead to improved access to water, minerals and toxic metal as well (Nehnevajova et al. 2009b; Schwitzguébel et al. 2008). Hence, least spectral variations observed in domains of water absorption regions for moderately metal-spiked or contaminated soils. 

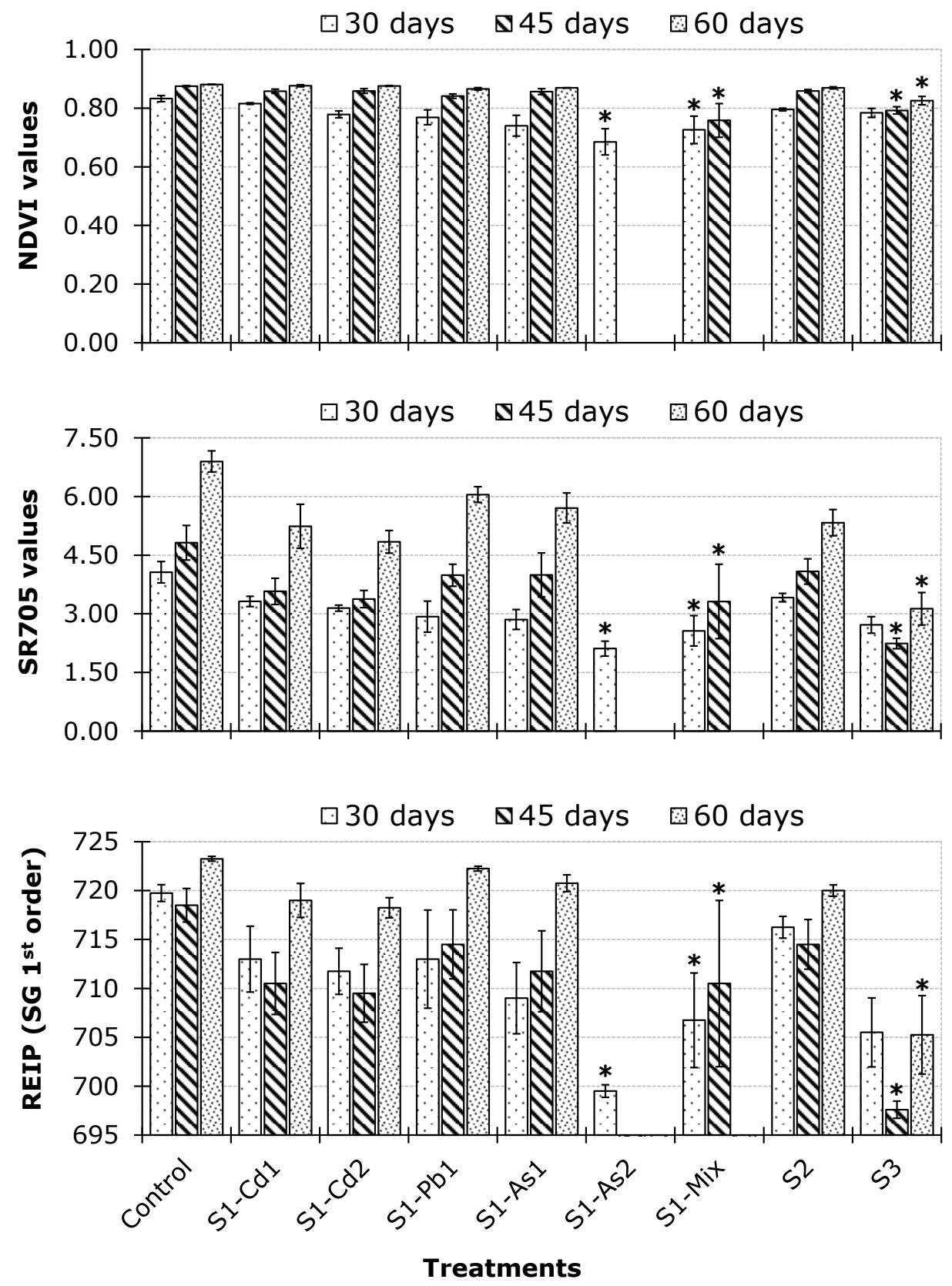

Figure 7.8: Changes in chlorophyll vegetation indices (NDVI and SR705) and REIP (SG $1^{\text {st }}$ order) for different metal contamination treatments.

Error bars are values of \pm SEm of 3-4 replicates. The columns with asterisk $\left(^{*}\right)$ are significantly differed from control treatment at $\alpha=0.05$ according to Post hoc Tukey HSD test. 
Continuum removal (CR; in ENVI-IDL version 4.3) technique was applied, and absorption features around 495, 680, 970, 1165, 1435, 1780, and $1925 \mathrm{~nm}$ were recognized by visual analyses and by considering typical absorption features noted in the literature (Boyd et al. 2006; Curran 1989). Band depths $(B D s=1-C R$ reflectance spectra) at selected bands in each absorption features were calculated. The absorption features in visible region (at 495 and $680 \mathrm{~nm}$ ) can be associated to chlorophyll, $970 \mathrm{~nm}$ to the water, at $1165 \mathrm{~nm}$ to the biochemical of lignin, $1435 \mathrm{~nm}$ to the water or nitrogen, $1780 \mathrm{~nm}$ to cellulose or lignin, and $1925 \mathrm{~nm}$ to the cellulose or water.

(a) CR reflectance spectra; at $\mathbf{3 0}$ days

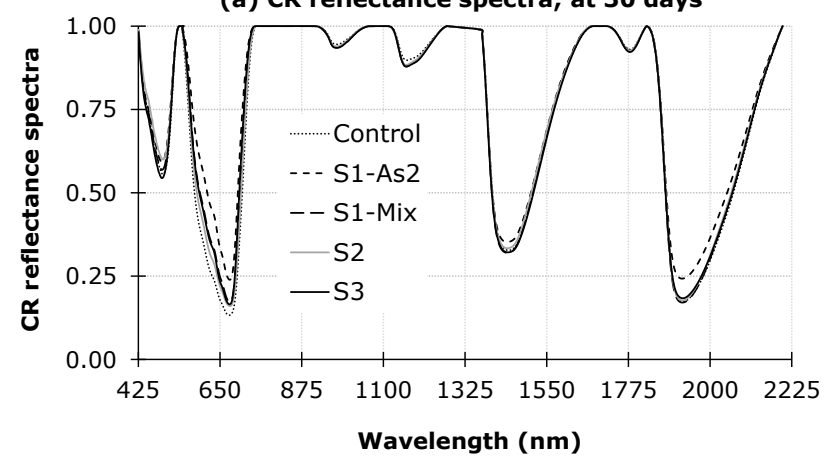

(b) CR reflectance spectra; at 45 days

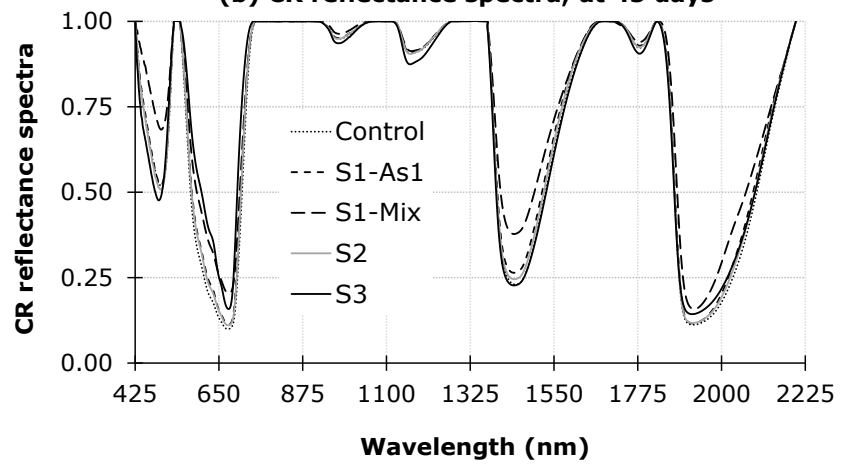

Figure 7.9: Continuum removed spectra of control and metal-contamination treatments at (a) 30 and (b) 45 days of plant growth.

The CR spectra and BDs difference between control and metal-contamination treatments at 30 and 45 days are shown respectively in Figure 7.9a-b and Figure 7.10a-b. Generally, spectra of control plants had the deepest BDs in considered absorption regions. The BDs for plant grown in $\mathrm{Cd}$ - and $\mathrm{Pb}$-spiked soils were same as observed for control plants. The lowest BDs and greatest positive BDs difference relative to control (i.e., shallower BDs than control) noted for $\mathrm{S}_{1}-\mathrm{As}_{2}, \mathrm{~S}_{1}-\mathrm{Mix}$, and $\mathrm{S}_{3}$ treatments, most prominent in red-edge (550$750 \mathrm{~nm}$ ) and water absorption (1371-1675, 1850-2250 nm) regions. This demonstrates phytotoxic effects of metals on sunflower plant and significant changes in leaf spectral reflectance. Absorption features in red-edge region is strongly governed by foliar pigment concentration which characteristically 
decreases due to abiotic stress. While, absorption features within 1371-1675 and 1850-2250 nm wavelengths related to the biochemical of water, nitrogen, lignin and cellulose (Boyd et al. 2006; Curran 1989; Curran et al. 2001; Huber et al. 2008), and there might be selective depletion of these biochemicals due to phytoaccumulation of toxic metals into plant parts, and it can be revealed through spectral changes (Götze et al. 2010).

(a) At 30 days after sowing

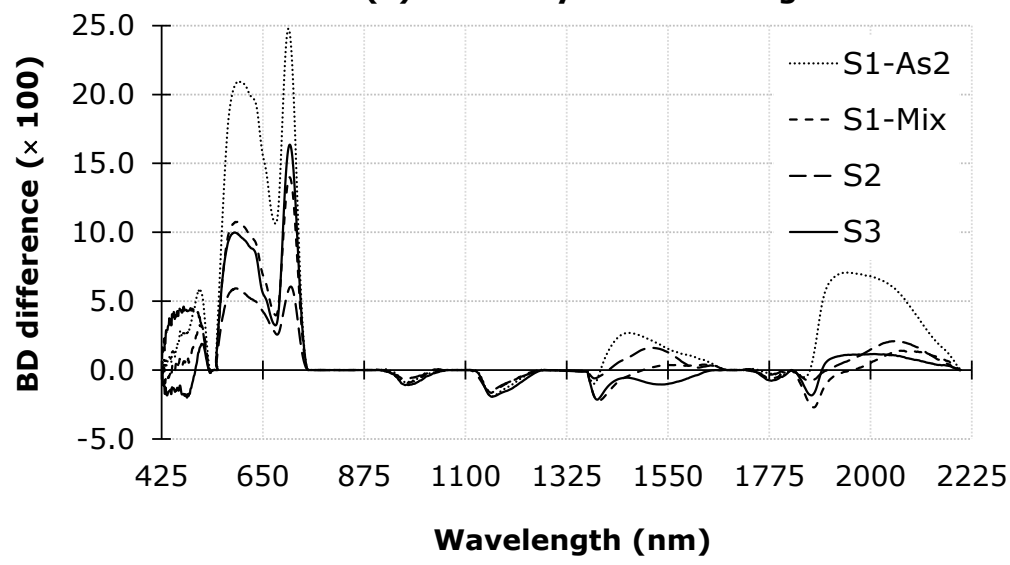

(b) At 45 days after sowing

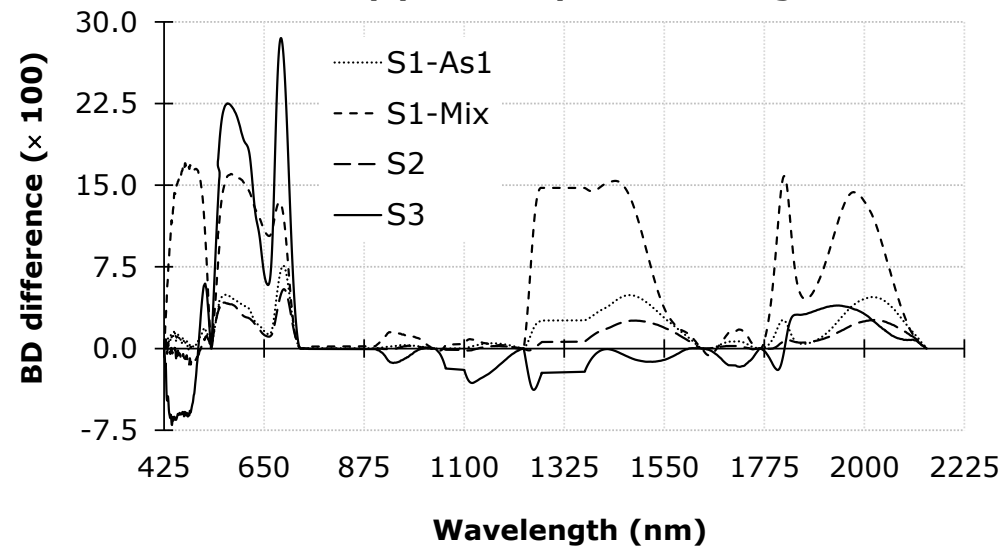

Figure 7.10: Band depth difference between control and metalcontamination treatments at (a) 30 and (b) 45 days.

Positive difference indicates greater absorption (or deeper band depths) in control than metal-contaminated soils. Treatments $S_{1}-A S_{2}$ and $S_{3}$ causes the largest differences.

Correlation results reported in Table 7.5 indicate a significant effect of metalspiking to $S_{1}$-soil on sunflower leaf spectral properties related with chlorophyll absorption, while no other treatments were found to be statistically significant. Leaf-Cd and -As concentration are strongly correlated with LCI $(r=-0.707$; $p=0.0001$ and $r=-0.544 ; p=0.013)$, while lead-Pb correlated with PRI $(r=-$ 
$0.710 ; p=0.002)$. Leaf-As also showed an inverse relationship with band depth at $680 \mathrm{~nm}(r=0.465 ; p=0.039)$, that is associated with chlorophyll absorption (Buschmann and Nagel 1993; Curran et al. 1992; Gitelson and Merzlyak 1996).

Table 7.5: Correlation coefficient $(r)$ of leaf-metal concentration to vegetation indices and band depths at selected wavelengths within the CR absorption regions

\begin{tabular}{|c|c|c|c|c|c|c|}
\hline \multirow{2}{*}{ VIs and BDs } & \multicolumn{2}{|c|}{$\begin{array}{c}\text { Leaf-Cd } \\
\text { concentration* }\end{array}$} & \multicolumn{2}{c|}{$\begin{array}{c}\text { Leaf-Pb } \\
\text { concentration* }\end{array}$} & \multicolumn{2}{c|}{$\begin{array}{c}\text { Leaf-As } \\
\text { concentration* }\end{array}$} \\
\cline { 2 - 6 } & $\begin{array}{c}\text { Pearson } \\
\boldsymbol{r}\end{array}$ & $\boldsymbol{p}$-values & $\begin{array}{c}\text { Pearson } \\
\boldsymbol{r}\end{array}$ & $\boldsymbol{p}$-values & $\begin{array}{c}\text { Pearson } \\
\boldsymbol{r}\end{array}$ & $\boldsymbol{p}$-values \\
\hline NDVI & -0.281 & 0.183 & -0.506 & 0.046 & -0.433 & 0.056 \\
LCI & -0.707 & 0.0001 & -0.418 & 0.107 & -0.544 & 0.013 \\
SR705 & -0.630 & 0.001 & -0.465 & 0.069 & -0.368 & 0.110 \\
PRI* & -0.445 & 0.029 & -0.710 & 0.002 & -0.366 & 0.112 \\
REIP & -0.626 & 0.001 & -0.345 & 0.190 & -0.422 & 0.064 \\
NDWI & 0.447 & 0.029 & -0.122 & 0.653 & 0.114 & 0.634 \\
NDWI_MIR & 0.414 & 0.044 & -0.163 & 0.546 & -0.055 & 0.819 \\
MSI & -0.645 & 0.001 & 0.284 & 0.286 & -0.049 & 0.837 \\
BD_495 & 0.452 & 0.027 & -0.544 & 0.003 & -0.375 & 0.104 \\
BD_680 & -0.248 & 0.242 & -0.328 & 0.215 & -0.465 & 0.039 \\
BD_970 & 0.431 & 0.035 & 0.025 & 0.927 & 0.254 & 0.279 \\
BD_1165 & 0.500 & 0.013 & 0.167 & 0.538 & 0.214 & 0.366 \\
BD_1780 & 0.497 & 0.014 & -0.236 & 0.378 & -0.339 & 0.144 \\
\hline
\end{tabular}

*PRI = Photochemical Reflectance Index; [(R529 - R569) $\div\left(R_{529}-R_{569}\right) ;$ Sims and Gamon, 2002]

\subsubsection{REGRESSION ANALYSIS}

Partial least square regression (PLSR) analysis was performed to relate leafmetal concentration to the leaf reflectance spectra (raw and first derivatives). The PLS regression reduces the large number of measured collinear spectral variables to a few non-correlated latent variables or factors (Abdi 2003). The factors represent the relevant information in the measured leaf spectral reflectance and are used to predict the dependent variable, herein leaf-metal concentration. We also tested MLR built upon the vegetation indices and BDs values at selected wavelengths within the absorption features. Due to small sample size, each treatment dataset collected on 30 and 45 days was combined to improve the statistical significance of the models.

Table 7.6 depicts the cross-validated calibration values of $\mathrm{R}^{2}$ and RMSE using PLSR and MLR analysis. The scatter plots of measured versus predicted leafmetal concentration ( $\mathrm{mg} \mathrm{kg}^{-1}$ ) are shown in Figure 7.11, Figure 7.12, and Figure 7.13. The final models, which were selected by high $\mathrm{R}^{2}$ and low root mean squared error (RMSE) values of cross-validated analysis in each dataset, included different spectral wavelengths data.

We found the PLSR using raw reflectance spectra to be inferior to PLSR models based on Savitzky-Golay filter $1^{\text {st }}$ order derivative spectra. A combination of vegetation indices, as well as BDs within selected absorption features also proved to be good predictors of leaf-metal variability. The important wavelengths with significant regression coefficient were selected for PLSR modeling according to Martens' uncertainty test (Westad and Marten 2000) 
performed with cross-validation, and those wavelengths are mostly centred around chlorophyll absorption, red-edge, near infra-red and water-absorption regions.

For the leaf-Cd estimation, the best PLSR model based on significant FD spectral wavelengths (i.e., 607-10, 1067, 1332-33, 1338-45 nm) obtained in the combined datasets of control, $S_{1}-C d$ treatments $(n=19)$ that yielded $R^{2}$ 0.913 , and RMSE, 6.251 for validation model (

Table 7.6 and Figure 7.11). Good predictive model for leaf-Cd estimation $\left(R^{2}\right.$ 0.913 , and RMSE, 6.251) similarly also obtained for control, $\mathrm{S}_{1}-\mathrm{Mix}, \mathrm{S}_{2}$, and $\mathrm{S}_{3}$ treatment dataset $(n=25)$ using significant FD spectra. Relatively inferior predictions of leaf-Cd was achieved with MLR models based on all VIs and BDs $\left(R^{2}, 0.600\right.$, and $\left.R M S E, 13.924\right)$ for control and $S_{1}$-Cd treatments dataset. Likely, the PLSR and MLR models respectively based on significant FD spectral wavelengths (within the 400-2200 nm) and all VIs, BDs showed robust assessment of leaf-Pb ( $\mathrm{R}^{2}, 0.946$ and 0.989 , and RMSE, 11.295 and 4.579; validation model) for control and $\mathrm{S}_{1}-\mathrm{Pb}$ treatment dataset (Figure $7.12 \mathrm{a}$ and Figure $7.13 \mathrm{~b}$ ). The models for leaf-Pb estimation found inferior for control, $\mathrm{S}_{1}$ Mix, $S_{2}$, and $S_{3}$ treatment dataset.

For estimation of leaf-As concentration, only visible spectral region (400-800 $\mathrm{nm}$ ) was found to be particularly suitable, and the cross-validation performance further improved using most significant wavelengths within visible region (

Table 7.6). The best fit model of leaf-As estimation was obtained with $R^{2}, 0.962$ and RMSE, 8.027 for control, $\mathrm{S}_{1}$-As treatment dataset $(n=18$; Figure 7.12a). Similarly, for dataset of control, $S_{1}-M i x, S_{2}$, and $S_{3}$ treatments $(n=28)$, the best fit model of leaf-As estimation was obtained with $\mathrm{R}^{2}, 0.825$, and RMSE, 35.062 (Figure 7.12c). The MLR calibration model based on all calculated VIs also yielded good prediction results ( $R^{2}, 0.890$ and $R M S E, 15.573$; Figure $\left.7.13 c\right)$ of leaf-As for control, $S_{1}$-As treatment dataset $(n=18)$.

For all PLSR analysis, the FD wavelengths with significant regression coefficient (i.e., relationship between predictor wavelengths and response variable leafmetal concentration; important wavelengths are given at footnote at

Table 7.6) used in the models are associated with chlorophyll absorption, rededge position, and water absorption regions of spectrum. This finding is coherent with observed vegetation spectral pattern due to soil metalcontamination, and it has been also studied by Bandaru et al. (2010); Hong et al. (2010); Slonecker et al. (2009) for different test crops and soil metalcontamination. 
Table 7.6: Best fit PLSR and MLR models for estimation of sunflower leafmetal concentration.

\begin{tabular}{|c|c|c|c|c|c|}
\hline \multicolumn{2}{|c|}{ Regression models } & $\begin{array}{c}\mathbf{R}^{2} \\
\text { cal. }\end{array}$ & $\begin{array}{c}\mathbf{R}^{2} \\
\text { val. }\end{array}$ & $\begin{array}{c}\text { RMSE } \\
\text { cal. }\end{array}$ & $\begin{array}{l}\text { RMSE } \\
\text { val. }\end{array}$ \\
\hline \multicolumn{6}{|c|}{ For the prediction of Leaf-Cd concentration } \\
\hline 1. & $\begin{array}{l}\text { PLSR_FD full spectra }(400-2200 \mathrm{~nm}) \text {; for } \\
\text { Control, } \mathrm{S}_{1}-\text { Cd dataset, } \mathrm{n}=19 ; \mathrm{PC} \# 4\end{array}$ & 0.848 & 0.660 & 7.816 & 12.336 \\
\hline 2. & $\begin{array}{l}\text { PLSR_FD significant WLA; for Control, } \mathrm{S}_{1}-\mathrm{Cd} \\
\text { dataset, } \mathrm{n}=19, \mathrm{PC} \# 3\end{array}$ & 0.934 & 0.913 & 5.125 & 6.251 \\
\hline 3. & $\begin{array}{l}\text { PLSR_FD significant } W^{B} \text {; for Control, } S_{1}-\text { Mix, } \\
S_{2}, S_{3} \text { dataset, } n=25, P C \# 3\end{array}$ & 0.906 & 0.856 & 4.702 & 6.073 \\
\hline 4. & $\begin{array}{l}\text { MLR with selected VIs and BDs }{ }^{c} \text {; for Control, } \\
\mathrm{S}_{1}-\mathrm{Cd} \text { dataset, } \mathrm{n}=22\end{array}$ & 0.899 & 0.600 & 6.977 & 13.924 \\
\hline \multicolumn{6}{|c|}{ For the prediction of Leaf-Pb concentration } \\
\hline 5. & $\begin{array}{l}\text { PLSR_FD significant } W^{D} \text {; for Control, } \mathrm{S}_{1}-\mathrm{Pb} \\
\text { dataset, } \mathrm{n}=15 ; \mathrm{PC} \# 5\end{array}$ & 0.977 & 0.946 & 6.866 & 11.295 \\
\hline 6. & $\begin{array}{l}\text { MLR with all VIs and BDs at } 495,970,1780 \\
\mathrm{~nm} \text {; for Control, } \mathrm{S}_{1}-\mathrm{Pd} \text { dataset, } \mathrm{n}=15\end{array}$ & 0.999 & 0.989 & 0.379 & 4.579 \\
\hline \multicolumn{6}{|c|}{ For the prediction of Leaf-As concentration } \\
\hline 7. & $\begin{array}{l}\text { PLSR_FD spectra (400-800 nm); for Control, } \\
\mathrm{S}_{1} \text {-As dataset, } \mathrm{n}=20 ; \mathrm{PC} \# 7\end{array}$ & 0.981 & 0.641 & 5.123 & 24.042 \\
\hline 8. & $\begin{array}{l}\text { PLSR_FD significant WLE within } 400-800 \mathrm{~nm} \text {; } \\
\text { for Control, } \mathrm{S}_{1} \text {-As dataset, } \mathrm{n}=18 ; \mathrm{PC} \# 4\end{array}$ & 0.979 & 0.962 & 5.585 & 8.027 \\
\hline 9. & $\begin{array}{l}\text { PLSR_FD significant } \mathrm{WL}^{\mathrm{F}} \text { within } 400-800 \mathrm{~nm} ; \\
\text { for Control, } \mathrm{S}_{1}-\mathrm{Mix}, \mathrm{S}_{2}, \mathrm{~S}_{3} \text { dataset, } \mathrm{n}=28 ; \mathrm{PC} 7\end{array}$ & 0.995 & 0.825 & 17.115 & 35.062 \\
\hline 10. & $\begin{array}{l}\text { MLR with all VIs; for Control, } S_{1} \text {-As dataset, } \\
n=17\end{array}$ & 0.977 & 0.890 & 7.108 & 15.573 \\
\hline
\end{tabular}

Model is expressed in terms of coefficients of determination $\left(\mathrm{R}^{2}\right)$ and root mean square error (RMSE) of calibration, cal and cross-validation, val models.

ASignificant FD wavelengths are: $607-10,1067,1332-33,1338-45 \mathrm{~nm}$;

BSignificant $F D$ wavelengths are: 470, 476-77, 780, 979-81, 1078, 1172-76, 1182-83, 1193-96, 1202-04, 1372, 1438-39, 1790-93 nm;

cSelected VIs and BDs are: NDVI, LCI, SR705, PRI, NDWI, NDWI_MIR, BD_495, and BD_1165;

${ }^{D}$ Most significant $F D$ wavelengths are within the chlorophyll absorption, red-edge, near infra-red and water-absorption regions;

ESingificant FD wavelengths are: $411,426,432,535-40,545,677-79 \mathrm{~nm}$

FSignificant FD wavelengths are: 410-11, 417-20, 421, 425-26, 434, 465-66, 473-74, 476-77, 481, 488-92, 499, 587-88, 695-695 $\mathrm{nm}$. 

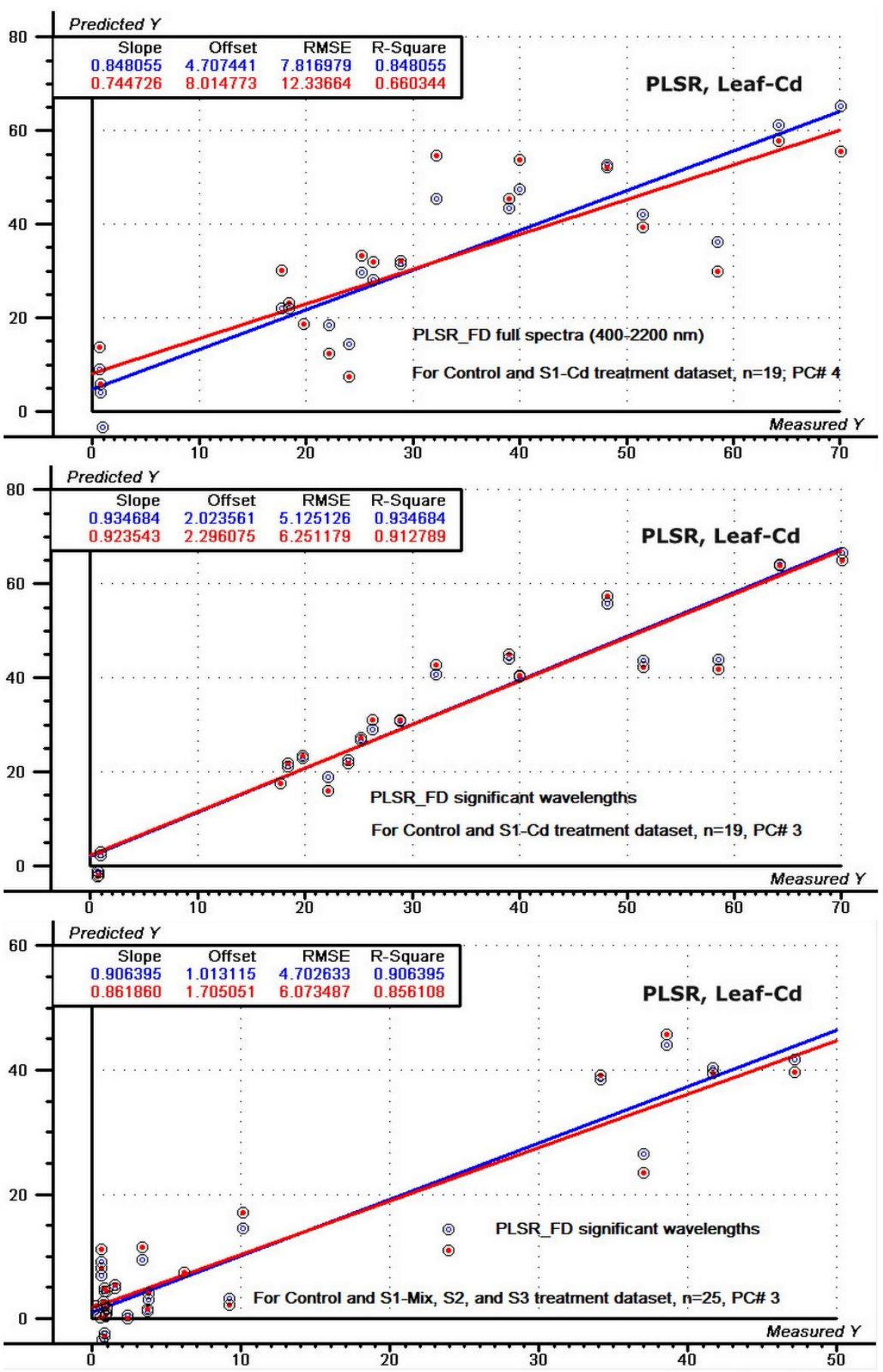

Figure 7.11: Scatter plot of measured versus predicted leaf-Cd concentration using PLSR calibration models. Blue and red colour respectively represents the result of calibration and validation models. 

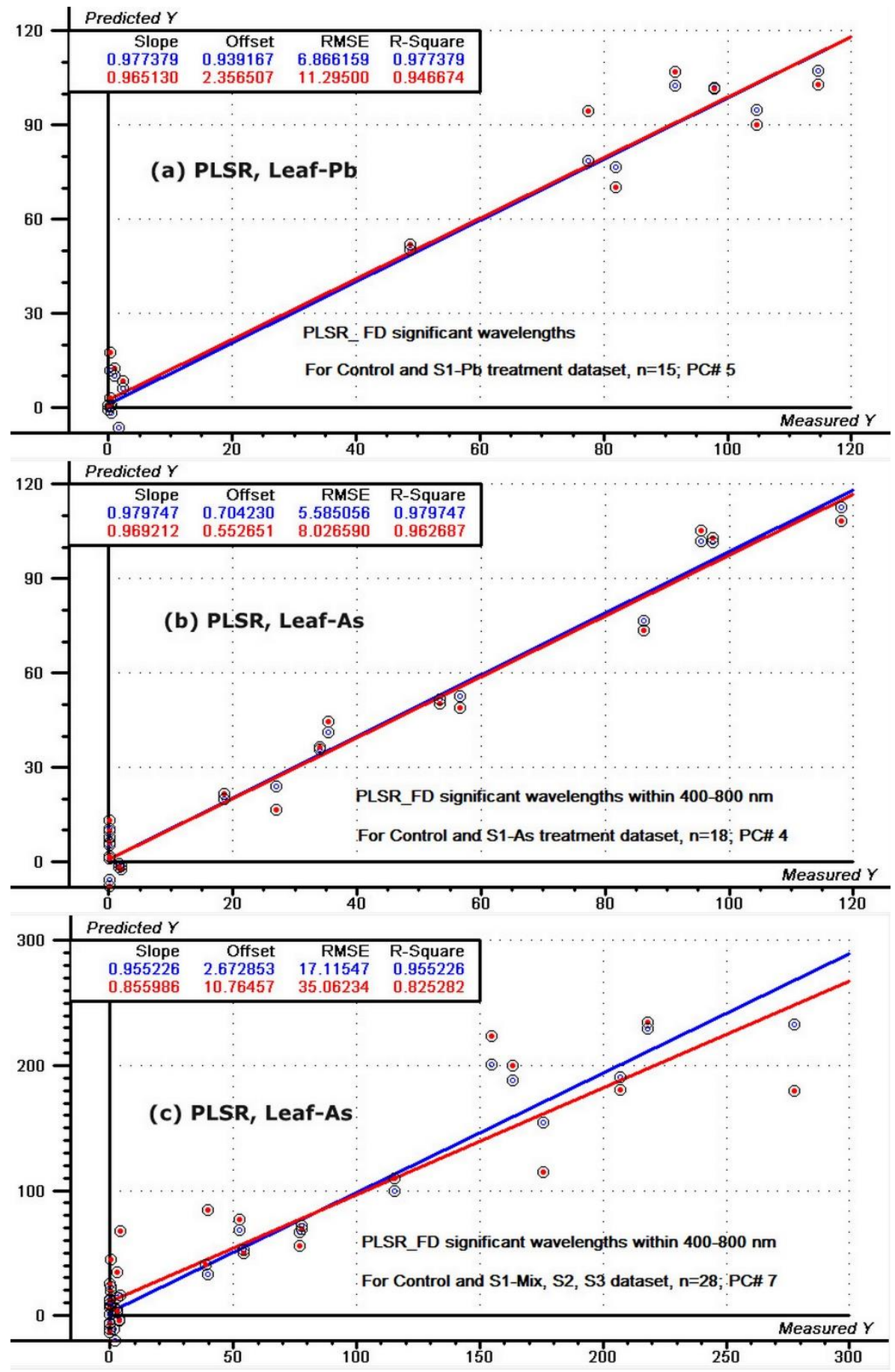

Figure 7.12: Scatter plot of measured versus (a) predicted leaf-Pb $(b, c)$ leaf-As concentration using PLSR calibration models. 

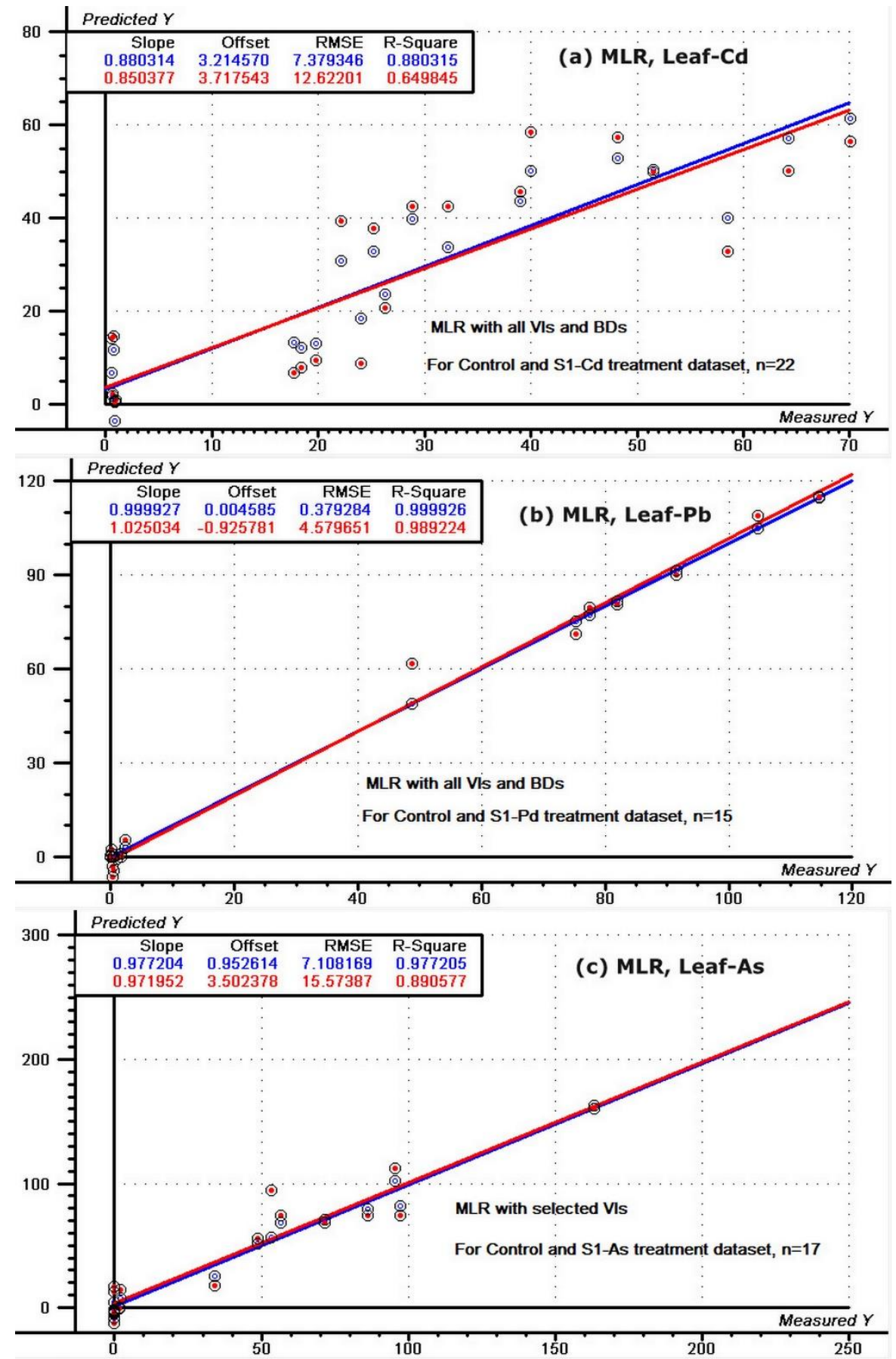

Figure 7.13: Scatter plot of measured versus (a) predicted leaf- $\mathrm{Pb},(\mathrm{b})$ predicted leaf- $\mathrm{Pb}$, and (c) predicted leaf-As concentration using MLR calibration models. 


\section{(B) WHEAT AND RYEGRASS AS-UPTAKE STUDY}

In this chapter, we only report the spectral changes in wheat and ryegrass leaves due to given treatments. Results on arsenic uptake and distribution in winter wheat (Triticum aestivum L.) with two different moisture regimes and NP fertilization have been reported by Brackhage et al. (2014). Authors observed that the arsenic uptake might be enhanced by P-fertilization with changing reducing conditions, and this counteracts with $\mathrm{N}$-fertilization. In the wheat plant at harvest in loamy soils from Schopfheim, the total As concentration follows the order of root>leaves>stem>grains, while the distribution is different on the sandy soil from Colditz (Figure 7.14a-b). Similarly for ryegrass study, arsenic concentration into shoot at harvest found higher with $100 \%$ moisture regimes in sandy soils, while no significant variations were observed between two moisture conditions in loamy soil (Figure 7.15a-b).

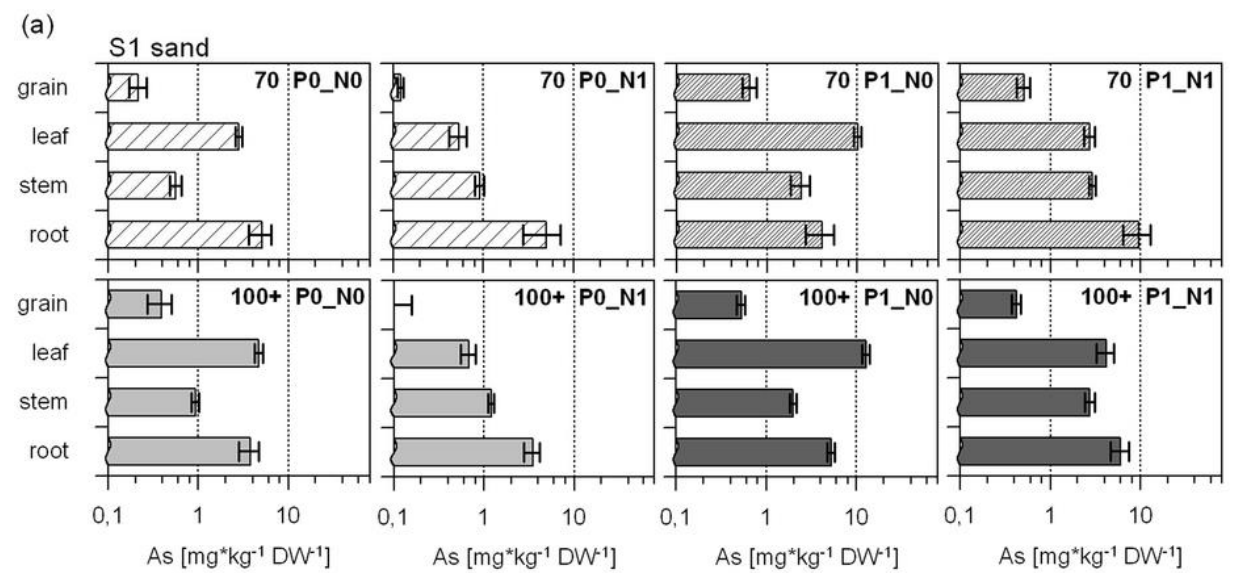

(b)

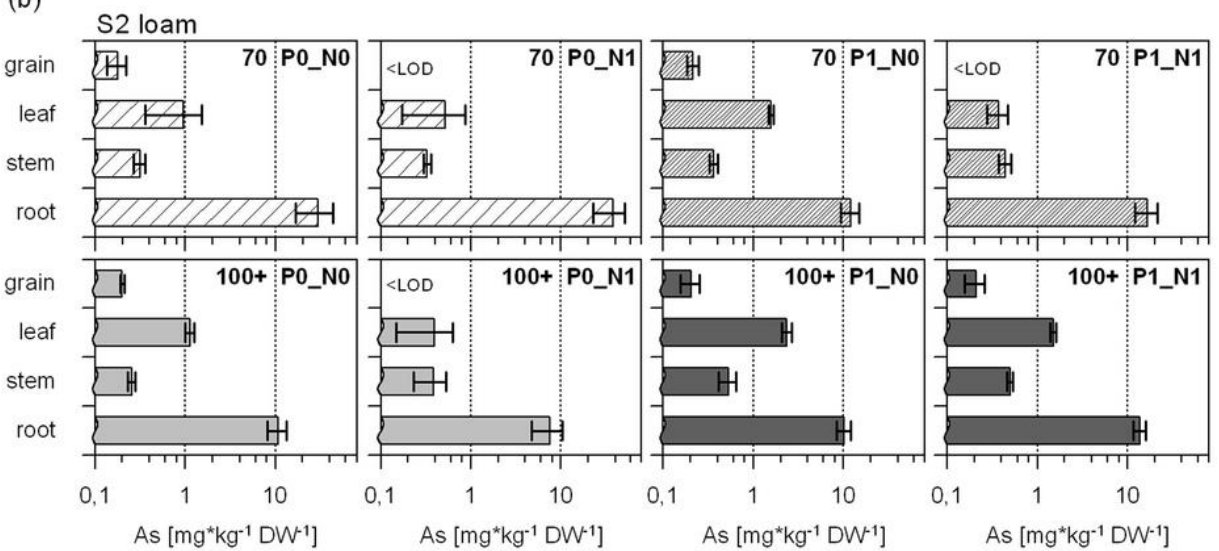

Figure 7.14: Total As concentrations in different plant parts of Triticum aestivum on the sandy soil $\mathrm{S}_{1}$ (a) and on the loamy soil $\mathrm{S}_{2}$ (b) with moisture treatment $(70 \% ; 100 \%)$, P-treatment $\left(\mathrm{P}_{0} ; \mathrm{P}_{1}\right)$ and $\mathrm{N}$-treatment $\left(\mathrm{N}_{0} ; \mathrm{N}_{1}\right)$. (Mean with $\pm S D ; n=5$ ). [Source: Brackhage et al. (2014)] 


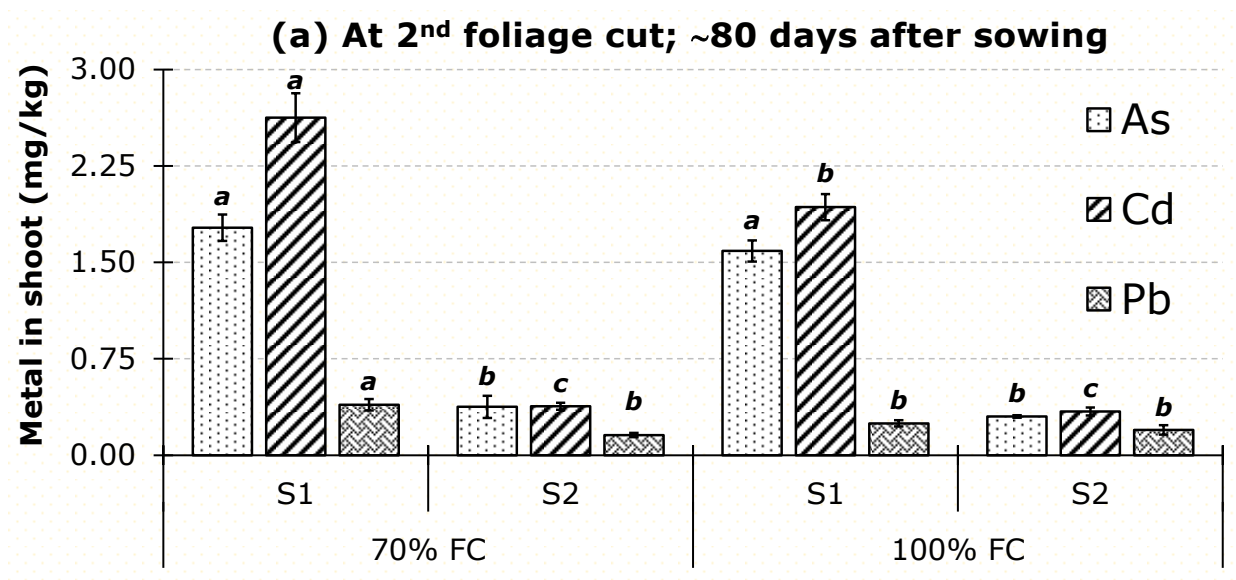

Treatments (two soils with $70 \%$ and $100 \%$ FC condition)

(b) At harvest; 120 days after sowing

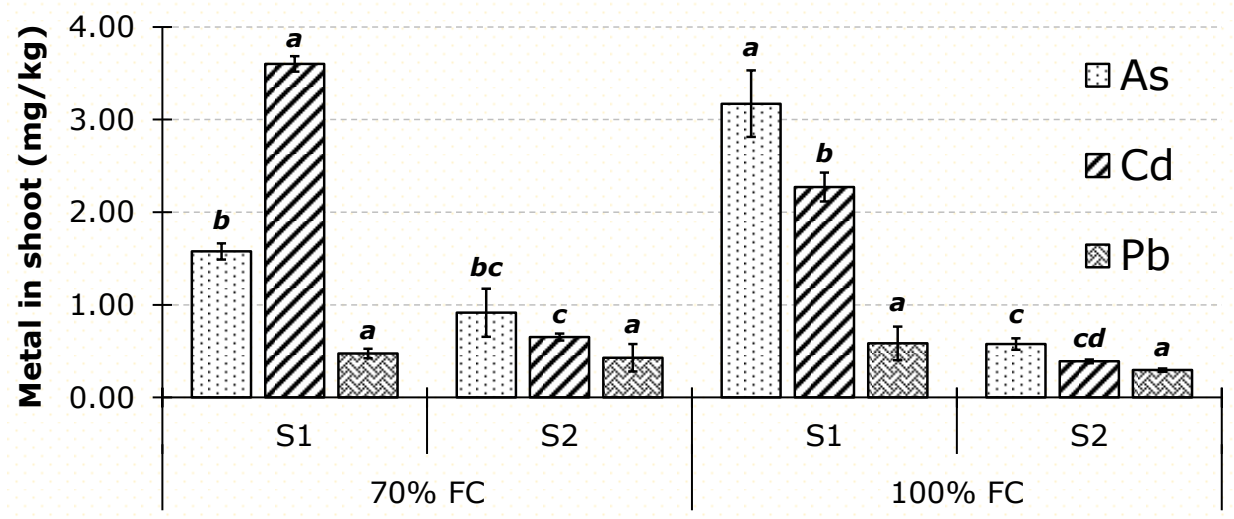

Treatments (two soils with $\mathbf{7 0} \%$ and $\mathbf{1 0 0} \%$ FC condition)

Figure 7.15: Arsenic, cadmium and lead concentration in shoot of ryegrass grown in two different soils with $70 \%$ and $100 \%$ field capacity moisture treatments at $\sim 80$ and $\sim 120$ days after sowing.

The values are the average of 5 replicates. Error bars are values of \pm SEm $(n=5$ replicates). Columns not connected with same letters are significantly differred at $\alpha=0.05$ level of significant.

\subsubsection{LEAF SPECTRAL REFLECTANCE AND VEGETATION INDICES}

As it been concluded by Brackhage et al. (2014) that phosphate and nitrate counteract for the As-mobilization in soil and subsequent uptake into wheat plant, and the changing redox conditions in soil may accelerate plant As uptake from the soil. Higher As concentration in leaves was found especially with high $\mathrm{P}$ fertilization under periodic flooding (Figure 7.14), contrary $\mathrm{N}$-fertilization resulted into much lower leaf-As concentration both under different $\mathrm{P}$ fertilization and moisture treatments. With these findings, we hereunder 
studied the spectral reflectance of wheat leaves (Figure 7.16, Figure 7.17) measured in May 2011, during which soils had been periodically flooded, and of ryegrass (Figure 7.19) measured at two different dates.

\section{Wheat leaves reflectance spectra}

Irrespective to $\mathrm{P}_{0} \mathrm{~N}_{0}$ and $\mathrm{P}_{0} \mathrm{~N}_{1}$ fertilizer levels added to $\mathrm{S}_{1}$ soils, there were no noticeable changes in the spectral pattern observed under $70 \%$ and $100 \%$ moisture regimes (Figure 7.16a). However, the reflectance varies with $\mathrm{N}$ application, as seen higher reflectance values in NIR and SWIR regions and lower values in visible spectrum, which explain the healthy plant growth under accelerated $\mathrm{N}$ application at $56 \mathrm{mM} \mathrm{N} \mathrm{kg}^{-1}$ and low $\mathrm{P}$ application at $0.32 \mathrm{mM} \mathrm{P}$ $\mathrm{kg}^{-1}$ soils. With same treatment set $\left(\mathrm{P}_{0} \mathrm{~N}_{0}, \mathrm{P}_{0} \mathrm{~N}_{1}\right.$ with $70 \%$ and $\left.100 \% \mathrm{FC}\right)$, the spectral variations were apparent and different with loamy soil $\left(\mathrm{S}_{2}\right)$, as a lower reflectance at $\sim 650 \mathrm{~nm}, \sim 1400 \mathrm{~nm}$ and $\sim 1900 \mathrm{~nm}$ was observed especially with high $\mathrm{N}$ application plus $70 \%$ moisture (Figure $7.17 \mathrm{a}$ ), whereas slight variations were found between $\mathrm{N}$ levels under $100 \%$ moisture regime. For loamy soil, higher leaf reflectance values in visible regions under both moisture regimes with low $\mathrm{N}$ application, indicating an excess moisture-induced plant stress under reduced conditions, could be due to high clay content in tested loamy soil. These spectral variations were also observed when first derivatives of reflectance within red-edge wavelengths were calculated (Figure 7.17b, Figure 7.17d).

Unlike higher arsenic concentration in wheat leaves as was reported from sandy soil with high $\mathrm{P}$ and low N fertilization under 100\% FC (Figure 7.14), the leaves exhibited relatively higher light absorption at around chlorophyll, NIR, and water bands (Figure 7.16c, Figure 7.16d); this could be related to the mobilization of phosphate under reducing condition and their positive nutritional influence over plant growth. Wheat grown in loamy soil showed relatively higher leaf-reflectance in visible and water absorption that could be a plant stress signature due to high P-fertilization (with both $\mathrm{N}$ levels) under reduced condition. Probable reason could be an alleviated As uptake into plant leaves due to P-fertilization, as it reported by Brackhage et al. (2014). However, no variation was found in the location of red-edge position peaks in first derivatives which shows that whatsoever spectral changes observed in this study could only be direct effects of NP fertilization and moisture regimes. For the calculated REIPs (SG $1^{\text {st }}$ order; Figure 7.18) of reflectance spectra of wheat, irrespective to the moisture and P-fertilization to sandy soil, wheat grew with low $\mathrm{N}$-fertilizer had significantly least REIP (721 nm; $p=0.0003)$ than high $\mathrm{N}$-fertilizer $(726 \mathrm{~nm})$. Similarly, the a significant interaction effect for REIPs between $\mathrm{N}$ - and P-addition confirmed the findings of Brackhage et al. (2014) that the $\mathrm{N}$-fertilization lowered the leave-As concentration in all treatments, which revealed from a typical REIPs at around $\sim 725 \mathrm{~nm}$ in all treatments consisting high $\mathrm{N}$-addition (Figure 7.18). 

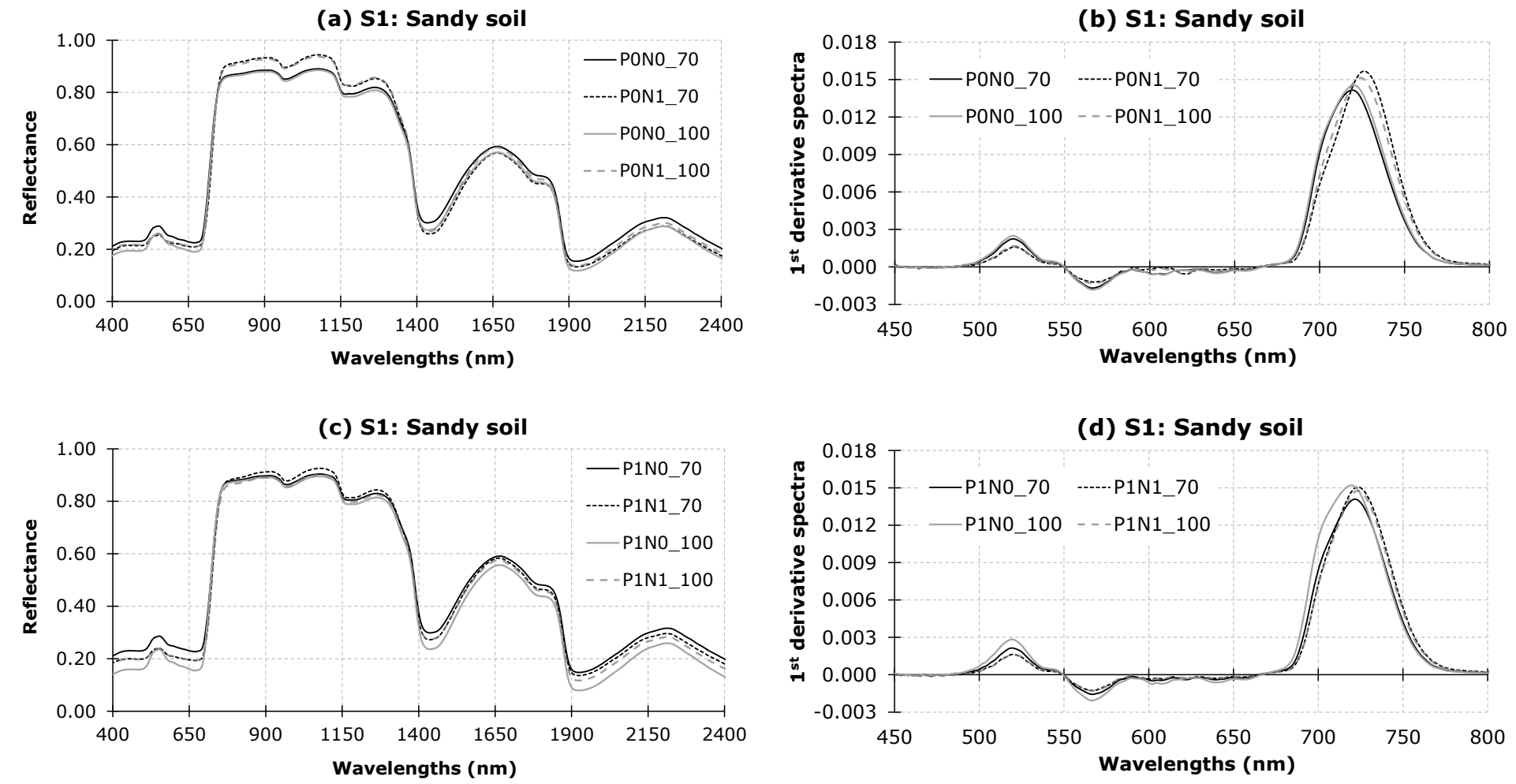

Figure 7.16: Leaf reflectance $(a, c)$ and first derivatives reflectance spectra $(b, d)$ from wheat grown in sandy soil, $S_{1}$ with moisture treatment $(70 \%, 100 \% \mathrm{FC})$, P-treatment $\left(\mathrm{P}_{0}, \mathrm{P}_{1}\right)$ and $\mathrm{N}$-treatment $\left(\mathrm{N}_{0}, \mathrm{~N}_{1}\right)$. 

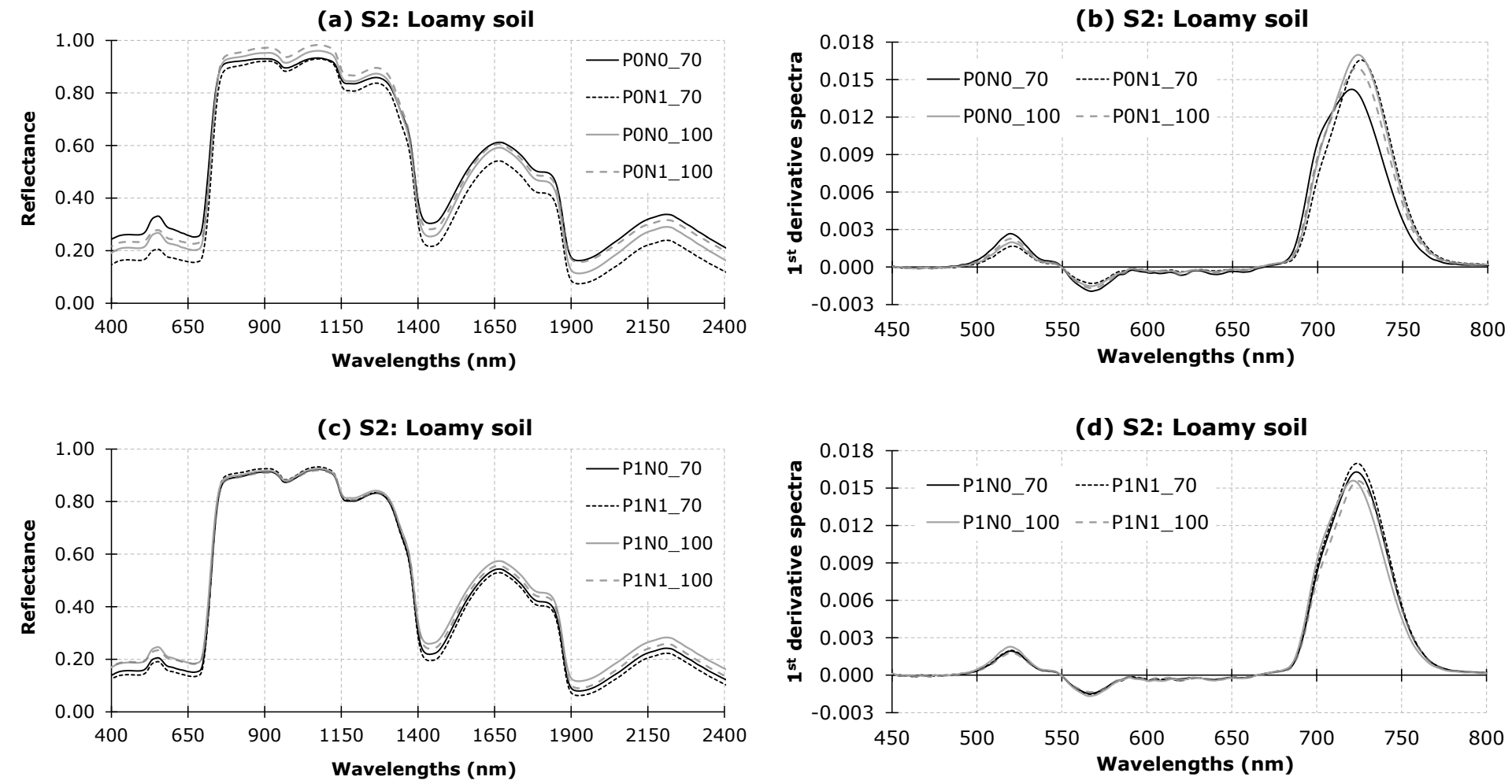

Figure 7.17: Leaf reflectance $(a, c)$ and first derivatives reflectance spectra $(b, d)$ from wheat grown in loamy soil, $S_{2}$ with moisture treatment $(70 \%, 100 \% \mathrm{FC})$, P-treatment $\left(\mathrm{P}_{0}, \mathrm{P}_{1}\right)$ and $\mathrm{N}$-treatment $\left(\mathrm{N}_{0}, \mathrm{~N}_{1}\right)$. 


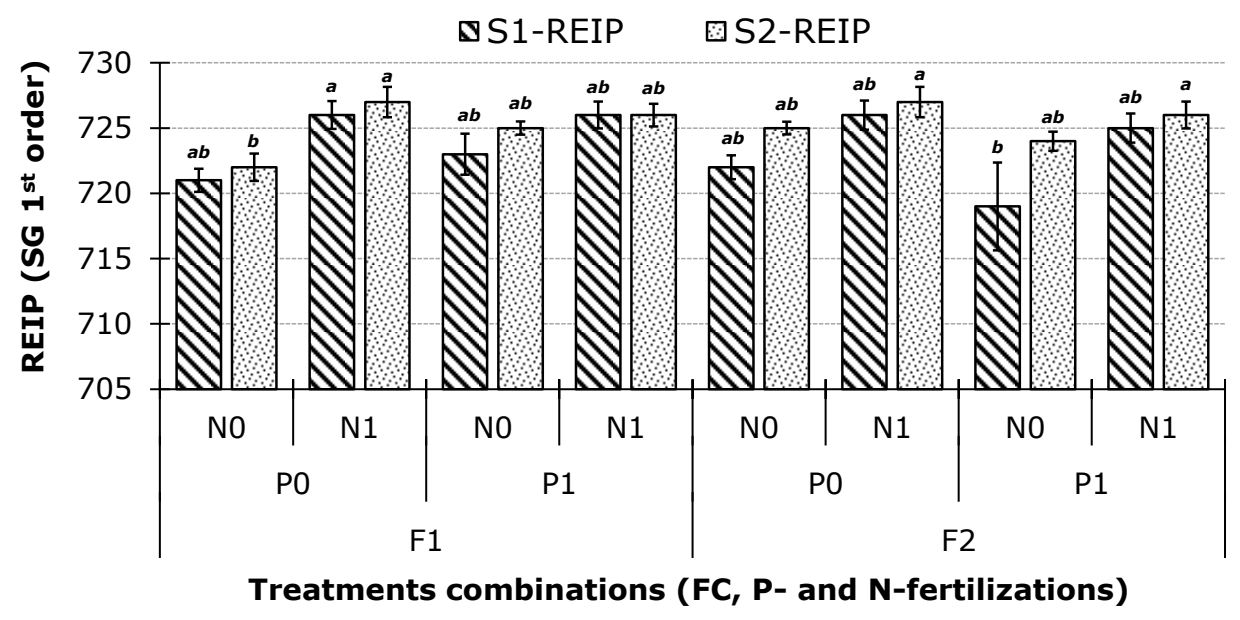

Figure 7.18: REIPs (SG $1^{\text {st }}$ order) for treatments combinations of $F C, P$ - and $\mathrm{N}$-fertilizations given to wheat grown in $\mathrm{S}_{1}$-sandy and $\mathrm{S}_{2}$-loamy soils.

Error bars are values of $\pm \mathrm{SEm}$ of 5 replicates. The columns with different letters are significantly differed from each other at $\alpha=0.05$ according to Post hoc Tukey HSD test.

\section{Ryegrass reflectance spectra}

Figure 7.19a-b shows the spectral signatures of ryegrass grown in two different soils each with two moisture regimes. At second foliage cut, ryegrass grown in sandy soils $+70 \% \mathrm{FC}$ had higher reflectance values over entire spectrum than ryegrass in loamy soil $+70 \%$ FC (Figure 7.19a). Higher red reflectance (at $\sim 650 \mathrm{~nm}$ ) of ryegrass in sandy soils can be related to the higher shoot-As and -Cd concentration, which may have a negative effect on chlorophyll synthesis (Horler et al. 1980; Horler et al. 1983). Conversely, a higher NIR reflectance values signifies healthy growth state, could be due to favourable moisture regime that to have positive effects on leaf morphology and biomass. At later stage of plant growth ( 120 days after sowing), no distinct leaves spectral differences can be seen between two soils each with 70\% FC (Figure 7.19b).

Nearly identical spectra were observed in both the tested soils with $100 \%$ and $70 \%$ FC at $\sim 80$ days (Figure $7.19 a$ ). Whereas, at $\sim 120$ days, when two soils each with $100 \%$ FC compared, ryegrass from sandy soils had lower reflectance in NIR and water-sensitive wavelengths ( 940-970 nm) regions than those of ryegrass from loamy soils. This could be effects of alleviated metal-uptake into shoot under reduced soil condition especially in sandy soils (Figure 7.15b). This would not be a case in loamy soils with a higher organic matter, which aided As-fixation in soils, and thus have lower mobilization potential (Brackhage et al. 2014). Hence, even with high As-contamination level in loamy soils, ryegrass showed higher NIR reflectance. 

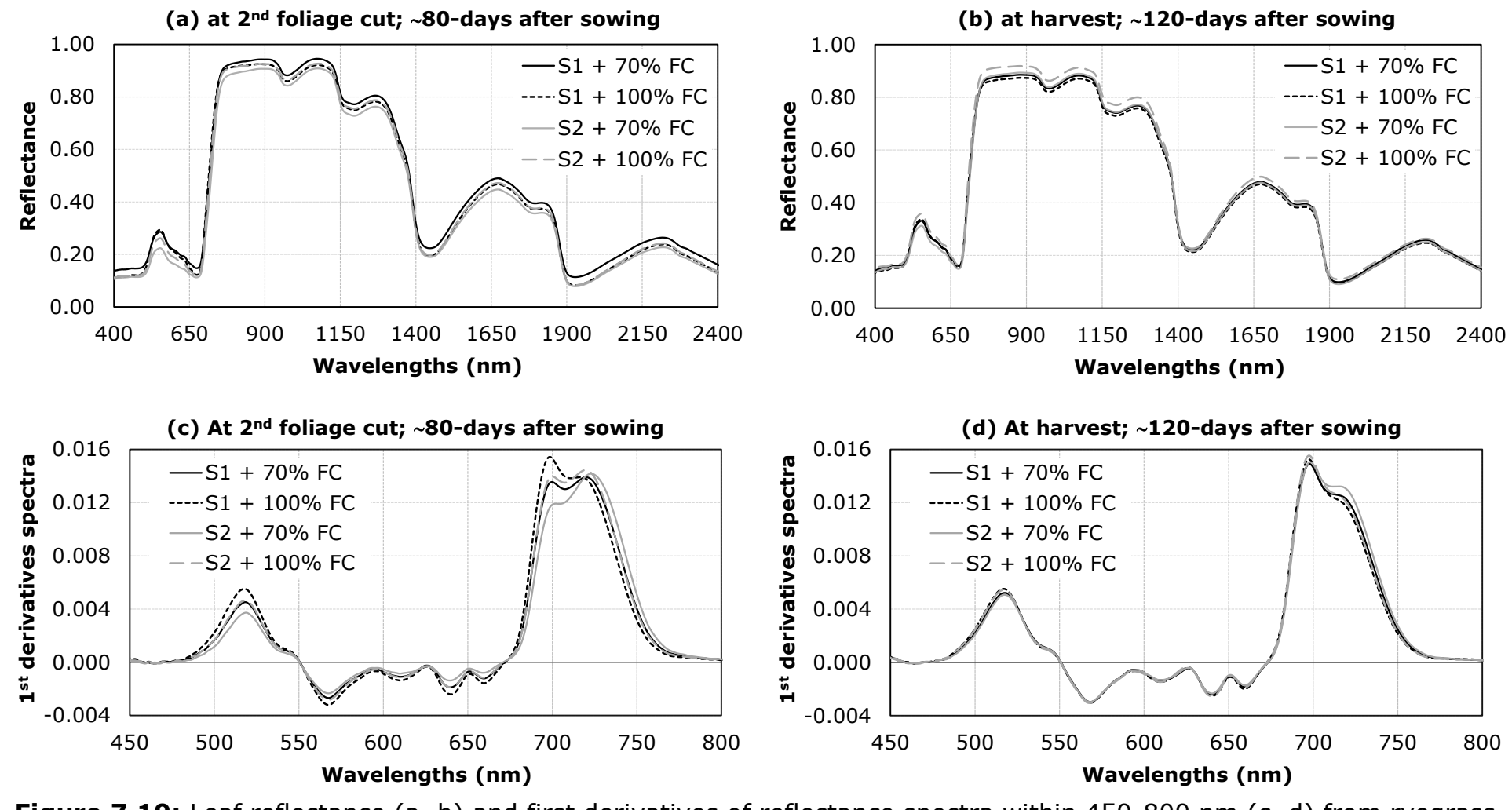

Figure 7.19: Leaf reflectance $(a, b)$ and first derivatives of reflectance spectra within 450-800 $\mathrm{nm}(\mathrm{c}, \mathrm{d})$ from ryegrass grown in two different soils with two moisture treatment $(70 \%, 100 \%$ FC) at $\sim 80$ - and $\sim 120$-days after sowing 
The lower reflectance in NIR and water-sensitive wavelengths become apparent in the first derivatives of reflectance, where the red-edge position varies with the soil types and moisture regimes (Figure $7.19 \mathrm{c}-\mathrm{d}$ ). The red-edge position is often considered as good indicator to discriminate stressed and unstressed vegetation. We observed double-peaks features (at $\sim 700$ and $\sim 725$ $\mathrm{nm}$ ) in the first derivative of reflectance spectra, as it had been reported by several researchers (Clevers et al. 2004; Smith et al. 2004). Literature has shown that red-edge peak positioned near $700 \mathrm{~nm}$ signifies stressed condition, while peak near $725 \mathrm{~nm}$ represents unstressed plant growth (Boochs et al. 1990; Horler et al. 1980; Lamb et al. 2002). The amplitude of red-edge position peak at $\sim 700 \mathrm{~nm}$ increased while peak at $\sim 725 \mathrm{~nm}$ is less evident under high moisture regimes in both the soils (Figure 7.19c-d). Further, REIPs (SavitzkyGolay Filter $1^{\text {st }}$ order derivative and smoothing technique) were calculated, and it is evident from Figure 7.20 that on $\sim 80$ days after sowing, ryegrass grown in sandy soil $+100 \%$ FC had a significantly lower REIP (704.6 nm; $p=0.004)$ that showed a blue-shift by $20.6 \mathrm{~nm}$ compared to ryegrass grown in loamy soils $+70 \%$ FC $(725.2 \mathrm{~nm})$. On $\sim 120$ days, ryegrass from all treatments showed the REIPs values centred at $\sim 700 \mathrm{~nm}$ (Figure 7.20), and a probable reason for this is the elevated concentration of metals in the plant that may have caused damage to chlorophyll and leaf structure plant, as it been evident in many research studies ( Li et al. 2015; Milton et al. 1989; Ren et al. 2008; Slonecker et al. 2009).

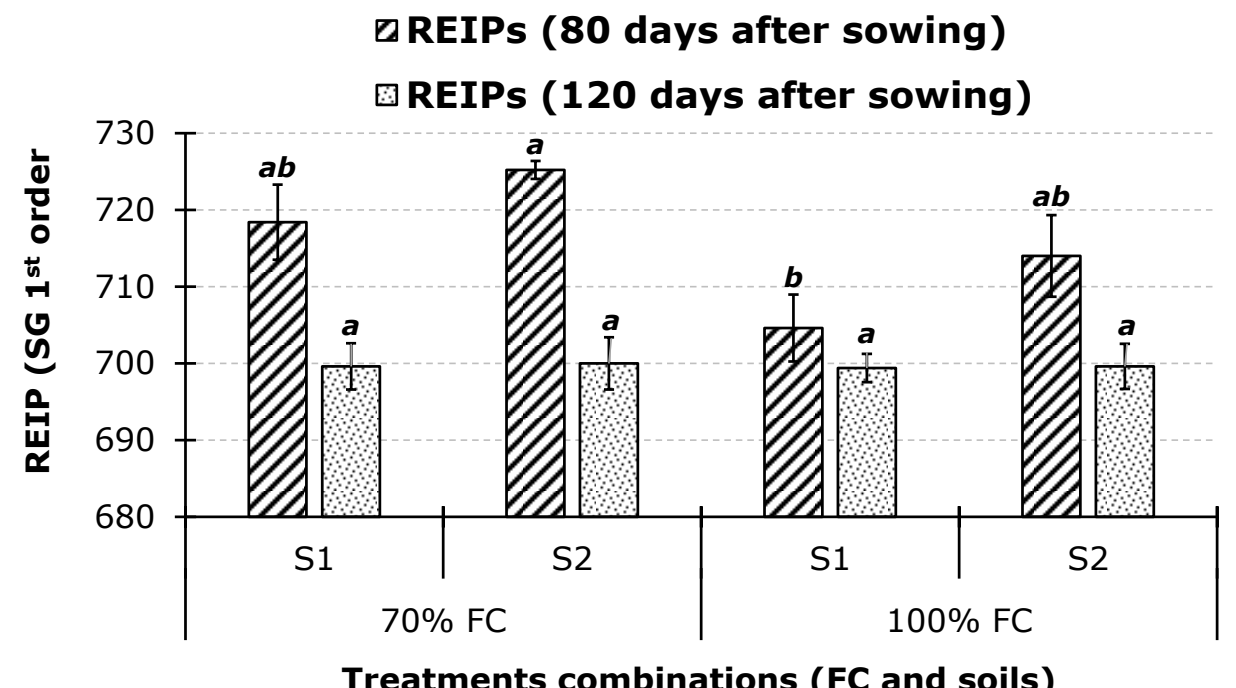

Figure 7.20: REIPS (SG $1^{\text {st }}$ order) for two moisture treatments given to ryegrass grown in $S_{1}$-sandy and $S_{2}$-loamy soils at $\sim 80$ and $\sim 120$ days.

Error bars are values of \pm SEm of 5 replicates. The columns with different letters are significantly differed from each other at $\alpha=0.05$ according to Post hoc Tukey HSD test. 


\subsection{SUMMARY AND CONCLUSION}

In present study, we tested mutant sunflower cultivar for its phytoextraction capability and concurrently studied the spectral variations in the leaves due to metal phytoextraction from metal-spiked and natural metal-contaminated soils. We also studied the changes in reflectance spectra of winter wheat and perennial ryegrass grown in two different soils, supplied with different combination of NP fertilization and moisture treatments.

Phytoextraction of studied metals ( $\mathrm{Cd}, \mathrm{Pb}, \mathrm{As})$ into sunflower revealed that the metals were confined into roots (maximum $\mathrm{Pb}$ followed by $\mathrm{As}$ and $\mathrm{Cd}$ ), and their amounts in plants were increased with level of metal-spiking treatment (for instance, with Cd-levels). Sunflower mutant observed to concentrate greater amount of As into leaves from As-spiked soils at $900 \mathrm{mg} \mathrm{kg}^{-1}$ level, but spiking of this much amount either in single $\left(S_{1}-A s_{2}\right)$ or in metal-mixture $\left(S_{1}\right.$ Mix) was found to be lethal to sunflower. Yet, such effect was found relatively less with natural metal contaminated soils owned to their loamy soil texture with high organic carbon and humus content. Amongst three soil substrates used ( $S_{1}-$ Mix, $S_{2}$ and $S_{3}$ soils), Cd-phytoextraction into roots and leaves was maximum with $\mathrm{S}_{2}$-grassland contaminated soil, whereas maximum $\mathrm{As}$ - and $\mathrm{Pb}$ phytoextraction were found respectively with $\mathrm{S}_{3}$-floodplain contaminated soil and metal mixture spiked $S_{1}$-soil. The results showed that the sunflower mutant could be a good candidate for the phytoremediation of metalcontaminated soil.

An elevated concentration of soil-metals caused stress in sunflower plants, and to this context, another objective was to monitor metal-induced stress via leaf spectral signatures. Overall, leaf-reflectance obtained from sunflower grown in metal-contaminated soils were varied in chlorophyll absorption and NIR domains of spectrum, and it shows the highest degree of overall correlation with leaf-metal concentration. Sunflower grown in metal-spiked $S_{1}$ soil (i.e., $S_{1}-A S_{2}$ and $S_{1}-$ Mix) and in natural metal-contaminated $S_{2}$ and $S_{3}$ soils might possibly be examined at early growth stages through chlorophyll vegetation indices NDVI, LCI, SR705 and REIP, as of these indices were found significantly different from the control values. Shifting of red-edge inflection points by $\sim 20$ $\mathrm{nm}$ toward blue wavelength is evident of metal-induced plant stress. Similarly, first derivatives of reflectance, continuum removed absorption features and band depth values were found to be a promising spectral analysis approach in monitoring plant health during phytoremediation process. Regardless of the kind and amount of stressors, the changes in spectral properties are mainly linked to an alteration in chlorophyll concentration, water balance and/or leaf morphology. Thus, if the specific stressor is known (metal-induced stress, for example, in present sunflower study), the measurement of spectral properties are useful for monitoring early metal-toxicity in plant, but it could be challenging to distinguish them among individual metal-induced plant stress. Multivariate regression approaches confirmed that obtained PLSR and MRL models respectively based on first derivative spectral reflectance and spectral feature likes VIs and BDs could provide good estimation of the leaf-metal variation. 
The reflectance spectra of wheat showed non-significant spectral variations between two moisture regimes, whilst the spectral variations were noticed in ryegrass reflectance. Ryegrass grown-up in sandy soil plus $100 \%$ field capacity had lower reflectance in NIR and water-sensitive regions at $\sim 120$ days after sowing, which could be a results of higher metal-uptake into shoot under reduced soil condition. However, such spectral variations did not occur in ryegrass in loamy soil, owing to restricted metal mobilization in soil. For wheat study, the variations in reflectance spectra are mostly attributed to $\mathrm{N}$ - and $\mathrm{P}$ fertilization treatments, and it also seemed to differ between two soil substrates. Phosphorus added at $3.2 \mathrm{mM} \mathrm{kg}^{-1}$ to loamy soil under $100 \%$ field capacity caused relatively higher visible and lower NIR reflectance of wheat leaves; this can be linked to higher leaf-As concentration that is apparent with $\mathrm{P}$-fertilization plus reduced soil condition.

Present results of sunflower, wheat and ryegrass study demonstrate that it is feasible to use plant spectral reflectance for monitoring of physiological stress caused by metal contaminants during the process of phytoextraction. As the spectral variations have been observed at the leaf level under stable illuminated source in the laboratory, they have to be further verified at the canopy level and on the metal-contaminated sites for extending the applications of hyperspectral remote sensing. 


\section{CHAPTER 8 : SYNTHESIS}

The studies presented in this dissertation are deliberating the two different but very relevant aspects: (i) phytoremediation strategies by tree, and (ii) proximal spectral sensing of metal-contaminated soils and phytoremediating plant species. The general conclusion from the studies of phytoremediation by tree is that fast growing Eucalyptus camaldulensis tree species could be efficient in phytoremediation (especially for phytoextraction and/or phytostabilization strategies) of Cd-polluted soil substrates. The conclusion from the studies of proximal spectral sensing of vegetation (barley and sunflower mutants tested here) and soil is that plant reflectance spectroscopy hold potential to assess plant stress induced due to phytoaccumulation of metals, while the quantification of soil-metals using soils reflectance spectra was found unfeasible for tested metals and soil data sets. More specific conclusion related to the aims of the dissertation, are divided into following subsections:

\subsection{Phytoremediation of Cadmium-Polluted solls BY TREES}

\subsubsection{CADMIUM-UPTAKE BY THE TREES: HYDROPONIC STUDIES}

Successful phytoextraction of metals from contaminated soils involves metals' solubilization in soil, uptake into the plant roots and translocation into the canopy. Regarding the use of plants to rehabilitate metal-polluted soils, hydroponic study can provide first estimate on (i) extent of uptake and translocation of metal of interest within a target plant, (ii) the role of organic chelates in the uptake and translocation, and (iii) the possible effects of metals and organic chelates on the test plants (Tandy et al. 2006b). With these views, the second chapter is concerned with hydroponic studies concentrating on Cd-phytoextraction by Eucalyptus camaldulensis tree species. Here, we tested the uptake of $\mathrm{Cd}$ by young and mature $E$. camaldulensis saplings at $\mathrm{Cd}$ concentrations of 4.5 and $89 \mu \mathrm{M}\left(0.5\right.$ and $\left.10 \mathrm{mg} \mathrm{L}^{-1}\right)$. This was done both in absence and presence of two organic ligands, the rather recalcitrant EDTA and its biodegradable analogue S,S-EDDS. During the uptake trails that lasted a month, the growth rate of the $E$. camaldulensis saplings was not affected at lower $\mathrm{Cd}$ concentration of $0.5 \mathrm{mg} \mathrm{L}^{-1}$, but it decreased from a $60 \%$ weight increase in the control (No Cd-addition in solution) to only a $19 \%$ increase with

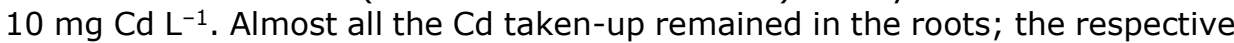
concentrations in the root at 0.5 and $10 \mathrm{mg} \mathrm{Cd} \mathrm{L}^{-1}$ concentration in solution were $360 \mathrm{mg}$ and $5300 \mathrm{mg} \mathrm{Cd} \mathrm{kg}$, correspondingly 1 and 3 orders of magnitude larger in the roots than in the shoots. The extent of $\mathrm{Cd}$ translocation to the shoots was larger (the Cd concentration in the shoots being 10-20 time higher) at lower $\mathrm{Cd}$ concentration in solution than at the higher concentration. This could have resulted from retarded xylem loading due to damage to the transfer cells or to enhanced metal loading and binding within the root cells' 
vacuoles involving also metal binding peptides, phytochelatins and metallothionins.

The addition of EDTA and EDDS drastically reduced Cd loading in the root cells. This was considerably more pronounced with EDTA than with EDDS, which is explained by the $>5.5$ order of magnitude larger stability constant of the EDTA than of the EDDS complex with Cd. Interestingly, 0.1 and $1 \mathrm{mM}$ EDTA (and to some extent also EDDS) increased loading of $\mathrm{Cd}$ in solution tested. This increase is probably related to apoplastic uptake and translocation routes (Vassil et al. 1998). Two organic ligands used did not differ qualitatively in their influence on the growth of Eucalyptus saplings. At $0.1 \mathrm{mM}$, no or positive effect on growth was observed, but at $1 \mathrm{mM}$ concentration negative effects on growth occurred (albeit not statistically significant compared with the control). The organic ligands were found lethal to the plants at $5 \mathrm{mM}$ concentration. Without an organic ligand in the solution, the plants immobilized soluble $\mathrm{Cd}$ in their roots but did not translocate it into shoot, and with EDTA or EDDS added uptake has been drastically reduced, leaving almost all the $\mathrm{Cd}$ in solution. However, at $10 \mathrm{mg} \mathrm{Cd} \mathrm{L}^{-1}$ concentration in solution, the $\mathrm{Cd}$ translocation in the canopy increased by 9 -folds by EDTA and to a lesser extent by EDDS also.

Briefly, we conclude that the Eucalyptus camaldulensis is less suitable for phytoextraction of soils or sediments that are heavily contaminated by metals. However, this plant is adaptable for site stabilization (phytostabilization) due to high accumulation of pollutant in the roots. Moreover, for remediation of low-moderately metal-contaminated soils, E. camaldulensis could be the candidate for phytoextraction of metals, in an organic ligand assisted strategy, wherein EDTA was found relatively efficient in enhancing Cd translocation into shoots.

\subsubsection{CHELANT-ENHANCED METAL UPTAKE BY EUCALYPTUS TREES - A LYSIMETER STUDY}

Traditional phytoremediation uses discrete applications of organic ligand culminated by crop harvest, often leaving solubilized metal complexes to migrate in the pore water (Salt et al. 1998). Owing to the rather recalcitrant nature of EDTA and its rising concentrations in the environment, environmental agencies are in pursuit for degradable ligands adequate for 'assisted' phytoremediation of metal polluted soils. Currently, the naturally occurring EDDS is the favourable candidate, often comparable to EDTA in reported phytoextraction results (Leštan et al. 2008b; Luo et al. 2006; Meers et al. 2005). In the third chapter, a different approach was tested, which relies on application of three chelants (EDTA, EDDS, and citric acid or citrate) by fertigation under control deficit irrigation (CDI) of the fast growing and salinity resistant $E$. camaldulensis trees that possess extensive canopy and root system. The CDI arrests down-profile water migration, and extends the chelants and metals residence time within the root zone. This was tested in 220-L lysimeters packed with sand mixed with metals-polluted biosolids. One year old trees were brought under CDI with tap or RO water for two growing seasons. EDTA, EDDS and citric acid fertigation at $2 \mathrm{mM}$ started in each May for 2.5-3.5 months, and prescribed soil leaching and sampling of tree leaves started thereafter. 
While all 3 chelants solubilized the metals in batch extraction (EDDS often being superior), in the lysimeter simulated soil system, EDDS and citrate were futile due to rapid biodegradation. EDTA greatly increased metal concentrations in the soil solution and Eucalyptus leaves, thus $\mathrm{Pb}$ and $\mathrm{Cd}$ concentrations were: 60 and $200 \mathrm{mg} \mathrm{L}^{-1}$ in soil solution and 10 and $67 \mathrm{mg} \mathrm{kg}^{-1}$ in leaves, all respectively. Average weight of the 3.5 years old Eucalyptus trees was 22 $\mathrm{kg} /$ tree with no significant difference between RO and tap water treatments despite the salinization of CDI-derived soil solution (respective average ECs of 8 and $38 \mathrm{dS} \mathrm{m}^{-1}$ ) and EDTA accumulation (average $>60 \mathrm{mM}$ ). The study suggests that sustainable phytostabilization and phytoextraction of heavy metals are achievable under CDI with EDTA augmentation at lower dose. The $\mathrm{CDI}$ with RO water further widened the scope of this remediation technique.

\subsection{PROXIMAL SPECTRAL SENSING OF CONTAMINATED SOILS AND METAL-INDUCED PLANT STRESS}

This section includes set of chapters exclusively dedicated to the proximal spectral sensing (here, laboratory-based hyperspectral sensing) of metalcontaminated soils and of plants grown for phytoextraction of toxic metals. We aimed to explore suitability of in-situ reflectance spectroscopy for monitoring phytoremediation process, and further to investigate the physico-chemical mechanism that allows estimation of toxic metals in soil-plant system through spectral signatures from plant and/or soil.

\subsubsection{PROXIMAL SPECTRAL SENSING AS TOOL fOR PHYTOREMEDIATION MONITORING}

A phytoremediation system principally depend on the assessment of extent of soil contamination (i.e., spatial variability and concentrations of various contaminants). Once a phytoremediation system is deployed at such sites, it performance has to be monitored on a frequent and regular basis by measuring general plant/tree health and overall soil conditions, i.e., metal-induced plant stress, mass balance of targeted metals or its degrading products in soil-waterplant systems. Furthermore, to determine risk (if any) associated with an installed phytoremediation system, a post-monitoring is equally mandatory on a regular basis. The standard assessment procedures for soil and plant parameters generally turn out to be expensive and time-consuming, particularly when considering long-term monitoring of soil-plant system over larger areas. Proximal spectral sensing within visible and near infrared (VNIR; 350-2500 nm) domains has been recognized as a relatively quicker and nondestructive method. The VNIR reflectance spectroscopy could largely estimate soil constituents and plant health status grown on metal-contaminated soils with a greater spatio-temporal feature, and could provide near real-time results.

In view of above theme, the fourth chapter presented a literature review on proximal spectral sensing techniques for soil and plant monitoring, and so to evaluate the phytoremediation system. The objective of this review chapter is to present a technology review on the suitability of laboratory and/or fieldscaled reflectance spectroscopy as tool for monitoring plant-based soil remediation program. The key shortcomings in the practical utilization of this 
technique in soil remediation program is particularly discussed. Though the soil-borne metals (except transition metal viz., $\mathrm{Ni}, \mathrm{Cr}, \mathrm{Co}, \mathrm{Fe}, \mathrm{Cu}, \mathrm{Mn}$ ) cannot be sensed directly through VNIR reflectance spectroscopy, according to research studies reviewed in the fourth chapter, their measurement might be possible on the basis of metals' correlations with spectrally active soil constituents (such as organic matter, clays, and Fe/Al oxides) using statistical modeling tools. In similar manner, it is evident from the reviewed literature, the plant reflectance spectroscopy can certainly be utilized for optimization of phytoremediation system by monitoring physiological status of tree/plant that explicitly grown to phytoextract or phytostabilize soil-metals.

These have been evaluated by relating the spectral features of plant leaves or canopy (for example, vegetation indices related to chlorophyll and water absorption features, and shifting of red-edge position) to the concentration of metals in plants and/or soils. In the following text the three experimental studies in achieving the set objectives are briefly discussed and highlights on the main findings given.

\subsubsection{VNIR REFLECTANCE SPECTROSCOPY FOR ASSESSMENT OF SOIL- METALS - A FEASIBILITY STUDY}

In the fifth chapter, we tried a set of questions concerning estimation of soilmetals using reflectance spectroscopy in visible and near infrared domains: (i) Can we estimate heavy metal contents directly or indirectly using soil spectral data? (ii) How great concentration of heavy metal is needed to exhibit its inherent absorption features on the soil spectral curves? (iii) Which spectrally active soil constituents (such as organic matter, Fe-oxides and clays) would be the most valid mechanism to indirectly quantify heavy metals in soil?

These questions had been attempted in many studies, and there are inconsistent results available in the literatures, with most studies supported the theory of "surrogate or indirect correlations" and according to this theory, the spectrally inactive heavy metals can be detected via their intercorrelations with other spectrally active soil constituents. Here, we investigated in-situ soil VNIR reflectance spectra of artificially metal-spiked and in-situ metalcontaminated soils to evaluate their feasibility and mechanisms for estimating heavy metals.

Reflectance spectra of metal-spiked soils were nearly uniform, and no other typical features (apart from characteristics features 1400, 1900 and 2200 $\mathrm{nm}$ wavelengths) were observed in response to metal-spiking to the soils even at higher concentration of $20 \mathrm{mg} \mathrm{Cd}, 1200 \mathrm{mg} \mathrm{Pb}$ and $900 \mathrm{mg} \mathrm{As} \mathrm{kg}^{-1}$, and with metal-mixture as well. This also interprets as poor correlation between concentration of soil-metal and continuum removed reflectance values. In this study, metal salts were spiked into sandy soils having low organic carbon, and hence from the obtained inconsistent soil spectral responses, we may infer that inorganic metallic ions do not exhibit any direct characteristic spectral feature within VNIR regions.

In in-situ metal-contaminated soil, we observed certain degree of spectral variations in terms of reflectance intensity for soils having extreme and least 
metal contamination that respectively presented a lower and higher VNIR spectral reflectance. Here, the surface concentrations of $\mathrm{As}, \mathrm{Cd}$, and $\mathrm{Pb}$ were significantly associated with CR band depth values at those wavelengths which are the recognized spectral proxies of spectrally active soil ingredients. Moreover, the difference of $\mathrm{CR}$ band depths at each wavelengths (within the edges of $450-600,1100-1200,1380-1450,1715-1850,1860-2030,2140-$ 2250 and $2300-2375 \mathrm{~nm}$ ) between least metal-contaminated soil and rest of soils, didn't give out any coherent pattern to which we can relate the background level of metal-contamination. However, considering an obtained significant intercorrelations of metals with organic carbon, total Fe and clays, the soil VNIR spectral data (as raw, first derivatives and CR reflectance) were regressed (partial least square method) against soil metal concentrations, which yielded an acceptable coefficient of determination $\left(R^{2}\right)$ in a crossvalidation result for metal prediction. But, consistent higher value of an error term i.e., root mean square error, indicates inadequacy of obtained model.

The results presented in the fifth chapter contradict those studies wherein the VNIR reflectance spectroscopy was postulated as a promising tool for prediction of soil-metals via theory of "surrogate correlations". To some extent, we too found correlations amongst the tested soil variables, but it did not translate into best-fit prediction models that should have lower error term. In future, advance study would be needed with larger soil data with varying degree of natural metal contamination and also with different soils type and quality parameters.

\subsubsection{SPECTRAL RESPONSES OF VARIOUS PLANTS GROWN FOR PHYTOREMEDIATION OF METALS}

Understanding the spectral response of plants to the metal-induced stress at the leaf level represents the first step to identify characteristic spectral responses for the up-scaling it to the canopy and/or regional scale. Of several metals and metalloids, some metals such as $\mathrm{Cd}$, As, and $\mathrm{Pb}$ are neither essential nor beneficial to plants; they are rather toxic to most terrestrial plants once their excessive accumulation occurred in soil-plant system. Metal toxicity in plants involves biochemical and internal structural changes in the plants, which noticeably can alter spectral characteristics of plants (Barcelo et al. 1988; Horler et al. 1980). Specific spectral changes in plant (both at leaf or canopy level) due to metal-induced plant stress have been successfully obtained in several in-situ studies, as it be reviewed in the fourth chapter.

The sixth and seventh chapters documented results of two experiments respectively carried out with barley and sunflower mutants, grown in pots filled with artificially metal-contaminated soils and natural metal-contaminated soils (in sunflower study only). Both these studies examine the phytoaccumulation of toxic metals into plant's parts, and the use of reflectance spectroscopy as a tool for assessing the resultant plant stress, and to quantify metal concentrations in the leaves. Moreover, in the seventh chapter, we also reported the results of spectral measurements of winter wheat and ryegrass, which were grown in two different As-contaminated soils with an aim to study As-uptake under the influence of treatments of moisture regime and NP fertilization. 
The $\mathrm{Cd}$ - and Pb-treated barley plants show no noticeable difference in leafspectra from untreated plants. But, we detected an obvious effects of spiking of nitrate-metal salts: fairly reduced reflectance at chlorophyll bands $\sim 495$ and $\sim 680 \mathrm{~nm}$ for higher level of $10 \mathrm{mg} \mathrm{Cd}$ and $150 \mathrm{mg} \mathrm{Pb} \mathrm{kg}^{-1}$ were observed when compared to leaf spectra from untreated plants. However, during early growth stage, fairly increased reflectance at chlorophyll wavelengths and their positive correlation with leaf-metal concentration were observed for sunflower mutants those grown in soil spiked with $\mathrm{Cd}$ - and $\mathrm{Pb}$-nitrate salts at elevated levels of $20 \mathrm{mg}$ and $1200 \mathrm{~Pb} \mathrm{~kg}^{-1}$, respectively.

The results were promising for arsenic and metal-mixture treatments in both the studies. The chlorophyll and water absorption spectral domains were observed to be affected typically by the amount of arsenic at soil concentration of $150 \mathrm{mg} \mathrm{kg}^{-1}$ (tested in barley study) and $900 \mathrm{mg} \mathrm{kg}^{-1}$ (tested in sunflower study). Similar result of spectral changes were also observed with metalmixture treatment of $\mathrm{Cd}, \mathrm{Pb}$, and $\mathrm{As}$ at higher their levels, i.e., $10 \mathrm{mg} \mathrm{Cd}+$ $150 \mathrm{mg} \mathrm{Pb}+100 \mathrm{mg} \mathrm{As} \mathrm{kg}{ }^{-1}$ and $20 \mathrm{mg} \mathrm{Cd}+1200 \mathrm{mg} \mathrm{Pb}+900 \mathrm{mg} \mathrm{As} \mathrm{kg}{ }^{-1}$ which were tested respectively for barley and sunflower plants. Sunflower grown in natural metal-contaminated soils also presented similar spectral changes in visible and near infrared regions.

Several vegetation indices (within chlorophyll and water absorption domains; NDVI, LCI, SR705, PRI, REIP, NDWI, NDWI_MIR, MIS and band depth analysis of $\mathrm{CR}$ reflectance at 495, 680,970, 1165, $1780 \mathrm{~nm}$ ) that are known to be associated with abiotic plant stresses were examined to establish relationship between leaf-metal concentration and the spectral data from leaves. All these vegetation indices and $C R$ band depths values significantly distinguished the As- and metal mixture-treated plants from untreated plants, and they could be used as sensitive indicators to assess metal-induces plant stress, especially at phytoremediation sites where the plant growth conditions are to be optimized to ease metal phytoaccumulation.

Barley and sunflower grown in soils spiked with higher level of As (100 mg and $900 \mathrm{mg} \mathrm{kg}^{-1}$, respectively) and metal-mixtures (10 mg Cd $+150 \mathrm{mg} \mathrm{Pb}+100$

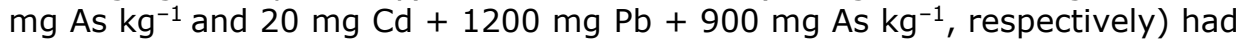
decreased values of chlorophyll indices, including blue-shift of REIPs by 19-25 $\mathrm{nm}$ when compared to values from respective control plants. Furthermore, the results of regression analysis to estimate the leaf-As concentration have revealed satisfactory cross-validated values of $\mathrm{R}^{2}$ and RMSE. Here, the spectral regions centred at chlorophyll, red-edge, and water absorption wavelengths were found important in obtaining the best-fit regression models.

In another experiment with winter wheat and ryegrass plants, leaves reflectance spectra were varied with the tested moisture regime $(70 \%$ and $100 \%$ field capacity) and NP fertilization treatments applied in two different soils. For loamy soils, treatment combination of high P- $\left(3.2 \mathrm{mM} \mathrm{kg}^{-1}\right)$ and low $\mathrm{N}$-fertilization ( $5.6 \mathrm{mM} \mathrm{kg}^{-1}$ ) under reduced condition of $100 \%$ FC improved As-uptake into wheat leaves, which explains as a relative increase in the red reflectance at $\sim 650 \mathrm{~nm}$ and at water absorption wavelengths. Wheat leafspectra showed typical REIPs at $\sim 725 \mathrm{~nm}$ for the treatments having higher $\mathrm{N}$ fertilization even so with high P-fertilization that found to accelerate the As- 
uptake into plant under reduced moisture regime that confirmed the theory of counteraction between readily available nitrogen and phosphorus for Asuptake into wheat plant.

By the same token, ryegrass grown with same sets of treatments have also shown the changes in the leaf reflectance spectra, where red-edge region varies significantly with the soil types and moisture regime tested. The doublepeaks feature in the first derivatives spectra, one at $\sim 700$ and another at $\sim 725$ $\mathrm{nm}$ wavelengths, was evident. Here, the peak at $\sim 725 \mathrm{~nm}$ was less evident for ryegrass grown at $100 \%$ FC condition, in both the tested soil type, which also translates as decreased REIP values compared to $70 \%$ FC condition.

\subsection{FUTURE PROSPECTS}

To verify the data obtained in the phytoremediation work with Eucalyptus tree, long-term studies should be performed, with larger lysimeters or in the field. While, further field- and canopy-scaled studies are needed to confirm the feasibility of proximal spectral sensing tool for monitoring phytoextraction of other trace metals using documented hyperaccumulating plant species. To evaluate the use of hyperspectral sensing in a large scale setting, a field-based or air-borne spectral sensing experiment on a full-fledged phytoremediation system is recommended. 
This page intentionally left blank 


\section{BIBLIOGRAPHY}

Abdi, H. (2003). Partial least square regression (PLS regression). Encyclopedia for research methods for the social sciences, 792-795.

Adamchuk, V. I., Hummel, J., Morgan, M., and Upadhyaya, S. (2004). On-the-go soil sensors for precision agriculture. Computers and electronics in agriculture, 44(1), 71 91.

Adesodun, J., Atayese, M., Agbaje, T. A., Osadiaye, B., Mafe, O. F., and Soretire, A. (2010). Phytoremediation Potentials of Sunflowers (Tithonia diversifolia and Helianthus annuus) for Metals in Soils Contaminated with Zinc and Lead Nitrates. Water, Air, and Soil Pollution, 207(1-4), 195-201.

Adriano, D. (2001). Trace elements in terrestrial environments: Biogeochemistry, bioavailability, and risks of metals: Springer Verlag.

Al Maliki, A., Bruce, D., and Owens, G. (2012). Capabilities of remote sensing hyperspectral images for the detection of lead contamination: a review. ISPRS annals of the photogrammetry, remote sensing and spatial information sciences. Melbourne, 55.

Al Maliki, A., Bruce, D., and Owens, G. (2014). Prediction of lead concentration in soil using reflectance spectroscopy. Environmental Technology \& Innovation, 1, 8-15.

Ali, H., Khan, E., and Sajad, M. A. (2013). Phytoremediation of heavy metals-Concepts and applications. Chemosphere, 91(7), 869-881.

Alkorta, I., Hernández-Allica, J., Becerril, J., Amezaga, I., Albizu, I., Onaindia, M., et al. (2004). Chelate-enhanced phytoremediation of soils polluted with heavy metals. Reviews in Environmental Science and Biotechnology, 3(1), 55-70.

Alloway, B. J. (2013). Sources of heavy metals and metalloids in soils. In B. J. Alloway (Ed.), Heavy metals in soils: Trace metals and metalloids in soils and their bioavailability (3rd ed., Environmental Pollution, Vol. 22): Springer Science \& Business Media.

Ansari, M. K. A., Shao, H.-B., Umar, S., Ahmad, A., Ansari, S. H., Iqbal, M., et al. (2013). Screening Indian Mustard Genotypes for Phytoremediating Arsenic-Contaminated Soils. CLEAN - Soil, Air, Water, 41(2), 195-201.

Appenroth, K.-J. (2010). Definition of "heavy metals" and their role in biological systems. In I. Sherameti, \& A. Varma (Eds.), Soil heavy metals, Soil Biology (Vol. 19, pp. 1929): Springer-Verlag Berlin Heilelber.

Azevedo, H., Pinto, C. G. G., and Santos, C. (2005). Cadmium effects in sunflower: nutritional imbalances in plants and calluses. Journal of Plant Nutrition, 28(12), 2221-2231.

Bandaru, V., Hansen, D. J., Codling, E. E., Daughtry, C. S., White-Hansen, S., and Green, C. E. (2010). Quantifying arsenic-induced morphological changes in spinach leaves: implications for remote sensing. International Journal of Remote Sensing, 31(15), 4163-4177.

Banejad, H., and Olyaie, E. (2011). Arsenic toxicity in the irrigation water-soil-plant system: A significant environmental problem. Journal of American Science, $7(1)$, $125-131$

Bannari, A., Morin, D., Bonn, F., and Huete, A. (1995). A review of vegetation indices. Remote Sensing Reviews, 13(1), 95-120.

Barazani, O., Dudai, N., Khadka, U., and Golan-Goldhirsh, A. (2004). Cadmium accumulation in Allium schoenoprasum L. grown in an aqueous medium. Chemosphere, 57(9), 1213-1218.

Barceló, J., and Poschenrieder, C. (2004). Structural and ultrastructural changes in heavy metal exposed plants. In M. N. V. Prasad (Ed.), Heavy metal stress in plants: from biomolecules to ecosystems (Vol. 2nd ed., pp. 223-248): Springer. 
Barcelo, J., Vazquez, M., and Poschenrieder, C. (1988). Cadmium-induced structural and ultrastructural changes in the vascular system of bush bean stems. Botanica Acta (Germany, FR).

Barócsi, A., Csintalan, Z., Kocsanyi, L., Dushenkov, S., Kuperberg, J., Kucharski, R., et al. (2003). Optimizing Phytoremediation of Heavy Metal-Contaminated Soil by Exploiting Plants Stress Adaptation. International journal of phytoremediation, 5(1), 13-23.

Baveye, P. C., and Laba, M. (2015a). Comment on "Potential of integrated field spectroscopy and spatial analysis for enhanced assessment of soil contamination: A prospective review" by Horta et al. Geoderma.

Baveye, P. C., and Laba, M. (2015b). Visible and near-infrared reflectance spectroscopy is of limited practical use to monitor soil contamination by heavy metals. Journal of Hazardous Materials, 285, 137-139.

Beebe, K. R., Pell, R. J., and Seasholtz, M. B. (1998). Chemometrics: a practical guide (Vol. 4). New York: Wiley-Interscience.

Bellon-Maurel, V., and McBratney, A. (2011). Near-infrared (NIR) and mid-infrared (MIR) spectroscopic techniques for assessing the amount of carbon stock in soils-Critical review and research perspectives. Soil Biology and Biochemistry, 43(7), 1398-1410.

Ben-Dor, E., and Banin, A. (1990). Near-infrared reflectance analysis of carbonate concentration in soils. Applied Spectroscopy, 44(6), 1064-1069.

Ben-Dor, E., and Banin, A. (1995). Near-infrared analysis as a rapid method to simultaneously evaluate several soil properties. Soil Science Society of America Journal, 59(2), 364-372.

Ben-Dor, E., Chabrillat, S., Dematte, J. A. M., Taylor, G. R., Hill, J., Whiting, M. L., et al. (2009). Using imaging spectroscopy to study soil properties. Remote Sensing of Environment, 113, S35 - S38.

Ben-Dor, E., Irons, J. R., and Epema, G. F. (1999). Soil reflectance. In A. N. Rencz (Ed.), In "Remote Sensing for the Earth Sciences: Manual of Remote Sensing" (A. N. Rencz, Ed.), Vol. 3, pp. 111-188. (3rd edn.). Wiley, New York. (pp. 111-188).

Berry, R. A. (1924). The manurial properties of lead nitrate. The Journal of Agricultural Science, 14(01), 58-65.

Blackburn, G. (2007). Hyperspectral remote sensing of plant pigments. Journal of Experimental Botany, 58(4), 855-867.

Blaylock, M., Salt, D., Dushenkov, S., Zakharova, O., Gussman, C., Kapulnik, Y., et al. (1997). Enhanced accumulation of $\mathrm{Pb}$ in Indian mustard by soil-applied chelating agents. Environmental Science and Technology, 31(3), 860-865.

Bolan, N. S., Park, J. H., Robinson, B., Naidu, R., and Huh, K. Y. (2011). Phytostabilization: A Green Approach to Contaminant Containment. Advances in Agronomy, 112, 145-204.

Boluda, R., Andreu, V., Gilabert, M., and Sobrino, P. (1993). Relation between reflectance of rice crop and indices of pollution by heavy metals in soils of Albufera Natural Park (Valencia, Spain). Soil technology, 6(4), 351-363.

Boochs, F., Kupfer, G., Dockter, K., and Kühbauch, W. (1990). Shape of the red edge as vitality indicator for plants. International Journal of Remote Sensing, 11(10), 17411753.

Borengasser, M., Hungate, W. S., and Watkins, R. L. (2007). Hyperspectral remote sensing: principles and applications. In Q. Weng (Ed.), Remote Sensing Applications. Indiana, USA: CRC Press, Taylor \& Fransic Group.

Bork, E. W., West, N. E., and Price, K. P. (1999). Calibration of broad-and narrow-band spectral variables for rangeland cover component quantification. International Journal of Remote Sensing, 20(18), 3641-3662.

Boyd, D., Entwistle, J., Flowers, A., Armitage, R., and Goldsmith, P. (2006). Remote sensing the radionuclide contaminated Belarusian landscape: a potential for imaging spectrometry? International Journal of Remote Sensing, 27(10), 1865-1874.

Brackhage, C., Huang, J.-H., Schaller, J., Elzinga, E. J., and Dudel, E. G. (2014). Readily available phosphorous and nitrogen counteract for arsenic uptake and distribution in wheat (Triticum aestivum L.). Scientific Reports, 4(4944), 1-7. 
Bradl, H. B. (2004). Adsorption of heavy metal ions on soils and soils constituents. Journal of Colloid and Interface Science, 277(1), 1-18.

Brandon, E. (2013). The Nature and Extent of Site Contamination. In Global Approaches to Site Contamination Law (1st ed., pp. 11-39): Springer Netherlands.

Bray, J. G. P., Rossel, R. V., and McBratney, A. B. (2009). Diagnostic screening of urban soil contaminants using diffuse reflectance spectroscopy. Australian Journal of Soil Research, 47(4), 433-442.

Briggs, G. G., Bromilow, R. H., and Evans, A. A. (1982). Relationships between lipophilicity and root uptake and translocation of non-ionised chemicals by barley. Pesticide Science, 13(5), 495-504.

Brown, D. J., Shepherd, K. D., Walsh, M. G., Dewayne Mays, M., and Reinsch, T. G. (2006). Global soil characterization with VNIR diffuse reflectance spectroscopy. Geoderma, 132(3-4), 273-290.

Bucheli-Witschel, M., and Egli, T. (2001). Environmental fate and microbial degradation of aminopolycarboxylic acids. FEMS Microbiology Reviews, 25(1),69-106.

Burckhard, S. R. (1998). Remote sensing tools for phytoremediation site assessment. In EPA Tech Trends newsletter (EPA 542-N-98-009).

Burckhard, S. R. (1999). Satellite sensing in assessment of phytoremediation field sites. In Soil \& Groundwater Cleanup Magazine (Vol. February/March issue).

Burns, R. G. (1993). Mineralogical applications of crystal field theory. 2nd edition (2nd Edition ed.): Cambridge University Press, Cambridge, UK.

Buschmann, C., and Nagel, E. (1993). In vivo spectroscopy and internal optics of leaves as basis for remote sensing of vegetation. International Journal of Remote Sensing, 14(4), 711-722.

Cai, Y., and Braids, O. C. (2002). Biogeochemistry of environmentally important trace elements: American Chemical Society Publications.

Campion, J., and Scholes, M. (2007). Diagnosing foliar nutrient dynamics of Eucalyptus grandis in KwaZulu-Natal, South Africa, using optimal element ratios and the diagnosis and recommendation integrated system (DRIS). Southern Hemisphere Forestry Journal, 69(3), 137-150.

Canada, G. o. (2012). Federal Contaminated Sites Inventory. Available at: http://www.tbs-sct.gc.ca/fcsi-rscf/home-accueil-eng.aspx.

Carbonell-Barrachina, A., Burlo, F., Burgos-Hernandez, A., Lopez, E., and Mataix, J. (1997). The influence of arsenite concentration on arsenic accumulation in tomato and bean plants Scientia Horticulturae, 71(3), 167-176.

Carman, E. P., and Crossman, T. L. (2001). Phytoremediation. In E. K. Nyer (Ed.), In Situ Treatment Technology (2nd ed.): CRC Press, Taylor \& Francis Group.

Carrascal, L. M., Galván, I., and Gordo, O. (2009). Partial least squares regression as an alternative to current regression methods used in ecology. Oikos, 118(5), 681-690.

Carter, G. A. (1993). Responses of leaf spectral reflectance to plant stress. American Journal of Botany, 80(3), 239-243.

Carter, G. A., and Knapp, A. K. (2001). Leaf optical properties in higher plants: linking spectral characteristics to stress and chlorophyll concentration. American Journal of Botany, 88(4), 677.

Cécillon, L., Barthès, B. G., Gomez, C., Ertlen, D., Genot, V., Hedde, M., et al. (2009). Assessment and monitoring of soil quality using near-infrared reflectance spectroscopy (NIRS). European Journal of Soil Science, 60(5), 770-784.

Chakraborty, S., and Weindorf, D. (2010). Rapid identification of oil-contaminated soils using visible near infrared diffuse reflectance spectroscopy. Journal of Environmental Quality, 39, 1378-1387.

Chaney, R. (1980). Health risks associated with toxic metals in municipal sludge. SludgeHealth Risks of Land Application, 59-83.

Chaney, R. L., Li, Y. M., Angle, J. S., Baker, A. J. M., Reeves, R. D., Brown, S. L., et al. (2000). Improving metal hyper-accumulator wild plants to develop commercial phytoextraction systems: Approaches and progress. In: Terry N, Banuelos GS, eds. Phytoremediation of Contaminated Soil and Water.Boca Raton, FL: CRC Press: 131160 . 
Chapin III, F. S. (1991). Integrated responses of plants to stress. BioScience, 41(1), 2936.

Chen, J., Chen, Y., Shi, Z.-Q., Su, Y., and Han, F. X. (2015). Phytoremediation to remove metals/metalloids from soils. In A. A. Ansari, S. S. Gill, R. Gill, G. R. Lanza, \& L. Newman (Eds.), Phytoremediation: Management of Environmental Contaminants (Vol. 2, pp. 297-304). Switzerland: Springer International Publishing.

Chen, Y., Shen, Z., and Li, X. (2004). The use of vetiver grass (Vetiveria zizanioides) in the phytoremediation of soils contaminated with heavy metals. Applied Geochemistry, 19(10), 1553-1565.

Cheng, Q., Tang, D., and Wu, X. Reflectance properties and physiological responses of bulrush in wetland parks to heavy metal contamination. In U. Michel, D. L. Civco, M. Ehlers; , \& H. J. Kaufmann (Eds.), Remote Sensing for Environmental Monitoring, GIS Applications, and Geology VIII, Proceedings Vol. 7110, 2008: Proceedings of SPIE.

Chevrel, S., Kuosmanen, V., Grösel, K., Marsh, S., Tukiainen, T., Schäffer, U., et al. (2003). Assessing and monitoring the environmental impact of mining activities in Europe using advanced Earth Observation techniques. Final Report MINEO Project, IST-1999-10337, May 2003.

Chmielewska, E. W., and Chwil, M. (2005). Lead induced histological and ultrastructural changes in the leaves of soybean (Glycine max ). Soil Science and Plant Nutrition, 51(2), 203-212.

Cho, M. A., and Skidmore, A. K. (2006). A new technique for extracting the red edge position from hyperspectral data: The linear extrapolation method. Remote Sensing of Environment, 101(2), 181-193.

Chodak, M., Nikli, M., and Beese, F. (2007). Near-infrared spectroscopy for analysis of chemical and microbiological properties of forest soil organic horizons in a heavymetal-polluted area. Biology and Fertility of Soils, 44(1), 171-180.

Choe, E., Kim, K. W., Bang, S., Yoon, I. H., and Lee, K. Y. (2009). Qualitative analysis and mapping of heavy metals in an abandoned $\mathrm{Au}-\mathrm{Ag}$ mine area using NIR spectroscopy. Environmental Geology, 58(3), 477-482.

Choe, E., Van der Meer, F., Van Ruitenbeek, F., Van der Werff, H., de Smeth, B., and Kim, K. W. (2008). Mapping of heavy metal pollution in stream sediments using combined geochemistry, field spectroscopy, and hyperspectral remote sensing: A case study of the Rodalquilar mining area, SE Spain. Remote Sensing of Environment, $112(7), 3222-3233$.

Clark, R. N. (Ed.). (1999a). Spectroscopy of rocks and minerals, and principles of spectroscopy (Vol. 3, Manual of remote sensing, volume 3, Remote sensing for the earth sciences): John Wiley \& Sons, New York.

Clark, R. N. (1999b). Spectroscopy of rocks and minerals, and principles of spectroscopy. In A. Rencz (Ed.), Remote Sensing for the Earth Sciences: Manual of Remote Sensing (3rd ed., pp. 3-58). New York, USA: John Wiley \& Sons

Clark, R. N., and Roush, T. L. (1984). Reflectance spectroscopy: Quantitative analysis techniques for remote sensing applications. Journal of Geophysical Research: Solid Earth, 89(B7), 6329-6340.

Clevers, J., and Kooistra, L. (2003). Assessment of heavy metal contamination in river floodplains by using the red-edge index. Presented at the 3rd EARSeL Workshop on Imaging Spectroscopy, Herrsching, 13-16 May 2003.

Clevers, J., Kooistra, L., and Salas, E. A. L. (2004). Study of heavy metal contamination in river floodplains using the red-edge position in spectroscopic data. International Journal of Remote Sensing, 25(19), 3883-3895.

Cobbett, C., and Goldsbrough, P. (2002). Phytochelatins and metallothioneins: roles in heavy metal detoxification and homeostasis. Annual Review of Plant Biology, 53(1), 159-182.

Collins, W., Chang, S. H., Raines, G. L., Canney, F., and Ashley, R. (1983). Airborne biogeophysical mapping of hidden mineral deposits. Economic Geology, 78(4), 737.

Colls, J. J., and Hall, D. P. (2004). Application of a chlorophyll fluorescence sensor to detect chelate-induced metal stress in Zea mays. Photosynthetica, 42(1), 139-145. 
Comte, S., Guibaud, G., and Baudu, M. (2006). Biosorption properties of extracellular polymeric substances (EPS) resulting from activated sludge according to their type: soluble or bound. Process Biochemistry (Amsterdam, Netherlands), 41(4), 815-823.

Condit, H. (1970). The spectral reflectance of American soils. Photogrammetric Engineering, 36(9), 955-966.

Conesa, H. M., Evangelou, M. W. H., Robinson, B. H., and Schulin, R. (2012). A Critical View of Current State of Phytotechnologies to Remediate Soils: Still a Promising Tool? The Scientific World Journal, 2012, 173829.

Cundy, A., Bardos, P., Puschenreiter, M., Witters, N., Mench, M., Bert, V., et al. (2015). Developing effective decision support for the application of "gentle" remediation options: The GREENLAND project. Remediation Journal, 25(3), 101-114.

Cundy, A., Bardos, R., Puschenreiter, M., Mench, M., Bert, V., Friesl-Hanl, W., et al. (2016). Brownfields to green fields: Realising wider benefits from practical contaminant phytomanagement strategies. Journal of environmental management.

Curran, P., Dungan, J., Macler, B., Plummer, S., and Peterson, D. (1992). Reflectance spectroscopy of fresh whole leaves for the estimation of chemical concentration. Remote Sensing of Environment, 39(2), 153-166.

Curran, P. J. (1989). Remote sensing of foliar chemistry. Remote Sensing of Environment, 30(3), 271-278.

Curran, P. J., Dungan, J. L., and Peterson, D. L. (2001). Estimating the foliar biochemical concentration of leaves with reflectance spectrometry: Testing the Kokaly and Clark methodologies. Remote Sensing of Environment, 76(3), 349-359.

Cuypers, A., Smeets, K., and Vangronsveld, J. (2009). Heavy metal stress in plants. Plant Stress Biology: From Genomics to Systems Biology, 139.

Dalal, R., and Henry, R. (1986). Simultaneous determination of moisture, organic carbon, and total nitrogen by near infrared reflectance spectrophotometry. Soil Science Society of America Journal, 50(1), 120-123.

Danh, L. T., Truong, P., Mammucari, R., Tran, T., and Foster, N. (2009). Vetiver grass, Vetiveria zizanioides: a choice plant for phytoremediation of heavy metals and organic wastes. International journal of phytoremediation, 11(8), 664-691.

Daniel, K. W., Tripathi, N. K., Honda, K., and Apisit, E. (2004). Analysis of VNIR 400$1100 \mathrm{~nm}$ spectral signatures for estimation of soil organic matter in tropical soils of Thailand. International Journal of Remote Sensing, 25(3), 643-652.

Dawson, T. P., and Curran, P. J. (1998). Technical note A new technique for interpolating the reflectance red edge position. International Journal of Remote Sensing, 19(11), 2133-2139.

de Gandy, Y. P. P. (2010). Spectral Reflectance as an Indicator of Foliar Concentrations of Arsenic in Common Sunflower (Helianthus Annuus). MS dissertation No. 1488735: Department of Chemistry, University of Texas-Pan American. .

Dematte, J., Fiorio, P., and Ben-Dor, E. (2009). Estimation of Soil Properties by Orbital and Laboratory Reflectance Means and its Relation with Soil Classification. The Open Remote Sensing Journal, 2(1), 12-23.

Dorigo, W., Bachmann, M., and Heldens, W. (2006). AS toolbox and processing of field spectra: Use's manual, Version 1.13. Wessling, Germany: German Aerospace Center (DLR), German Remote Sensing Data Center, Institute for Environment and Geoinformation Team Imaging Spectroscopy.

Du, C., and Zhou, J. (2009). Evaluation of soil fertility using infrared spectroscopy: a review. Environmental Chemistry Letters, 7(2), 97-113.

Duarte, B., Freitas, J., and Caçador, I. (2011). The role of organic acids in assisted phytoremediation processes of salt marsh sediments. Hydrobiologia, 1-9.

Ducaroir, J., and Lamy, I. (1995). Evidence of trace metal association with soil organic matter using particle size fractionation after physical dispersion treatment. Analyst, $120(3), 741-745$.

Dunagan, S. C., Gilmore, M. S., and Varekamp, J. C. (2007). Effects of mercury on visible/near-infrared reflectance spectra of mustard spinach plants (Brassica rapa P.). Environmental Pollution, 148(1), 301-311. 
Dupuy, N., and Douay, F. (2001). Infrared and chemometrics study of the interaction between heavy metals and organic matter in soils. Spectrochimica Acta Part A: Molecular and Biomolecular Spectroscopy, 57(5), 1037-1047.

Dushenkov, V., Kumar, P. N., Motto, H., and Raskin, I. (1995). Rhizofiltration: the use of plants to remove heavy metals from aqueous streams. Environmental Science and Technology, 29(5), 1239-1245.

Epstein, A. L., Gussman, C. D., Blaylock, M. J., Yermiyahu, U., Huang, J. W., Kapulnik, Y., et al. (1999). EDTA and Pb-EDTA accumulation in Brassica juncea grown in $\mathrm{Pb}$ amended soil. Plant and Soil, 208(1), 87-94.

Evangelou, M., Bauer, U., Ebel, M., and Schaeffer, A. (2007a). The influence of EDDS and EDTA on the uptake of heavy metals of $\mathrm{Cd}$ and $\mathrm{Cu}$ from soil with tobacco Nicotiana tabacum. Chemosphere, 68(2), 345-353.

Evangelou, M. W., and Deram, A. (2014). Phytomanagement: A Realistic Approach to Soil Remediating Phytotechnologies with New Challenges for Plant Science. Plant Science (Amsterdam, Netherlands), 2(4), 1023.

Evangelou, M. W., Ebel, M., and Schaeffer, A. (2007b). Chelate assisted phytoextraction of heavy metals from soil. Effect, mechanism, toxicity, and fate of chelating agents. Chemosphere, 68(6), 989-1003.

Farifteh, J., Van der Meer, F., Van der Meijde, M., and Atzberger, C. (2008). Spectral characteristics of salt-affected soils: A laboratory experiment. Geoderma, 145(3-4), 196-206.

Favas, P. J. C., Pratas, J., Varun, M., D'Souza, R., and Paul, M. S. (2014). Phytoremediation of Soils Contaminated with Metals and Metalloids at Mining Areas: Potential of Native Flora. In M. C. Hernandez-Soriano (Ed.), Environmental Risk Assessment of Soil Contamination (pp. 486-517): InTech.

Fidencio, P. H., Poppi, R. J., and de Andrade, J. C. (2002). Determination of organic matter in soils using radial basis function networks and near infrared spectroscopy. Analytica Chimica Acta, 453(1), 125-134.

Fine, P., Atzmon, N., Adani, F., and Hass, A. (2006). Disposal of sewage effluent and biosolids in eucalyptus plantations: a lysimeter simulation study. Soil and Water Pollution Monitoring, Protection and Remediation, 433-453.

Fine, P., and Hass, A. (2007). Role of organic matter in microbial transport during irrigation with sewage effluent. Journal of Environmental Quality, 36(4), 1050-1060.

Fine, P., Hassa, A., Prost, R., and Atzmon, N. (2002). Organic carbon leaching from effluent irrigated lysimeters as affected by residence time. Soil Science Society of America Journal, 66(5), 1531.

Fine, P., Rathod, P. H., Beriozkin, A., and Mingelgrin, U. (2013). Uptake of Cadmium by Hydroponically Grown, Mature Eucalyptus Camaldulensis Saplings and the Effect of Organic Ligands. International journal of phytoremediation, 15(6), 585-601.

Flechas, F., and Latady, M. (2003). Regulatory Evaluation and Acceptance Issues for Phytotechnology Projects. In Advances in Biochemical Engineering/Biotechnology (Vol. 78, pp. 171-185). Berlin Heidelberrg: Springer-Verlag.

Font, R., del Río-Celestino, M., and de Haro-Bailón, A. (2007). Near-infrared reflectance spectroscopy: methodology and potential for predicting trace elements in plants. In N. Willey (Ed.), Phytoremediation, Methods and Reviews (Vol. 23). Totowa, New Jersey: Humana Press Inc.

Font, R., del Río-Celestino, M., Vélez, D., Montoro, R., and de Haro-Bailón, A. (2004). Use of near-infrared spectroscopy for determining the total arsenic content in prostrate amaranth. Science of the Total Environment, 327(1-3), 93-104.

Font, R., Del Río, M., and De Haro, A. (2002). Use of near infrared spectroscopy to evaluate heavy metal content in Brassica juncea cultivated on the polluted soils of the Guadiamar River area. Fresenius Environmental Bulletin, 11(10), 777-781.

Font, R., Vélez, D., del Río-Celestino, M., de Haro-Bailón, A., and Montoro, R. (2005). Screening inorganic arsenic in rice by visible and near-infrared spectroscopy. Microchimica Acta, 151(3), 231-239. 
French, C. J., Dickinson, N. M., and Putwain, P. D. (2006). Woody biomass phytoremediation of contaminated brownfield land. Environmental Pollution, 141(3), 387-395.

Gallagher, F. J., Pechmann, I., Bogden, J. D., Grabosky, J., and Weis, P. (2008). Soil metal concentrations and productivity of Betula populifolia (gray birch) as measured by field spectrometry and incremental annual growth in an abandoned urban Brownfield in New Jersey. Environmental Pollution, 156(3), 699-706.

Gallego, S. M., Benavides, M. P., and Tomaro, M. L. (1996). Effect of heavy metal ion excess on sunflower leaves: evidence for involvement of oxidative stress. Plant Science (Amsterdam, Netherlands), 121, 151-159.

Galvão, L. S., Formaggio, A. R., Couto, E. G., and Roberts, D. A. (2008). Relationships between the mineralogical and chemical composition of tropical soils and topography from hyperspectral remote sensing data. ISPRS Journal of Photogrammetry and Remote Sensing, 63(2), 259-271.

Galvão, L. S., Formaggio, A. R., and Tisot, D. A. (2005). Discrimination of sugarcane varieties in Southeastern Brazil with EO-1 Hyperion data. Remote Sensing of Environment, 94(4), 523-534.

Galvdo, L. S., Vitorello, Í., and Formaggio, A. R. (1997). Relationships of spectral reflectance and color among surface and subsurface horizons of tropical soil profiles. Remote Sensing of Environment, 61(1), 24-33.

Gao, B. (1996). NDWI-a normalized difference water index for remote sensing of vegetation liquid water from space. Remote Sensing of Environment, 58(3), 257-266.

Gardea-Torresdey, J., Peralta-Videa, J., Montes, M., De la Rosa, G., and Corral-Diaz, B. (2004). Bioaccumulation of cadmium, chromium and copper by Convolvulus arvensis L.: impact on plant growth and uptake of nutritional elements. Bioresource Technology, 92(3), 229-235.

Garg, N., and Singla, P. (2011). Arsenic toxicity in crop plants: physiological effects and tolerance mechanisms. Environmental Chemistry Letters, 9(3), 303-321.

Gitelson, A. A., and Merzlyak, M. N. (1996). Signature analysis of leaf reflectance spectra: algorithm development for remote sensing of chlorophyll. Journal of Plant Physiology, 148(3), 494-500.

Godt, J., Scheidig, F., Grosse-Siestrup, C., Esche, V., Brandenburg, P., Reich, A., et al. (2006). The toxicity of cadmium and resulting hazards for human health. Journal of Occupational Medicine and Toxicology, 1(1), 22.

Götze, C., Jung, A., Merbach, I., Wennrich, R., and Gläßer, C. (2010). Spectrometric analyses in comparison to the physiological condition of heavy metal stressed floodplain vegetation in a standardised experiment. Central European Journal of Geosciences, 2(2), 132-137.

Grčman, H., Velikonja-Bolta, Š., Vodnik, D., Kos, B., and Leštan, D. (2001). EDTA enhanced heavy metal phytoextraction: metal accumulation, leaching and toxicity. Plant and Soil, 235(1), 105-114.

Grčman, H., Vodnik, D., Velikonja-Bolta, Š., and Leštan, D. (2003). Ethylenediaminedissuccinate as a new chelate for environmentally safe enhanced lead phytoextraction. Journal of Environmental Quality, 32(2), 500.

Guo, T. R., Zhang, G. P., and Zhang, Y. H. (2007). Physiological changes in barley plants under combined toxicity of aluminum, copper and cadmium. Colloids and Surfaces $B$ : Biointerfaces, 57(2), 182-188.

Guyot, G., and Baret, F. Utilisation de la haute resolution spectrale pour suivre l'etat des couverts vegetaux. In 4th Int. Coll. Spectral Signatures of Objects in Remote Sensing, Aussois, France, 1988 (Vol. ESA SP-287, pp. 279-286).

Guyot, G., Baret, F., and Jacquemoud, S. (1992). Imaging spectroscopy for vegetation studies. Imaging spectroscopy: fundamentals and prospective application, 145-165.

Hahne, H., and Kroontje, W. (1973). Significance of pH and chloride concentration on behavior of heavy metal pollutants: mercury (II), cadmium (II), zinc (II), and lead (II). Journal of Environmental Quality, 2(4), 444-450. 
Halvorson, A., and Lindsay, W. (1977). The critical $\mathrm{Zn}^{2+}$ concentration for corn and the nonabsorption of chelated zinc. Soil Science Society of America Journal, 41(3), 531534.

Han, F., Shan, X. Q., Zhang, J., Xie, Y. N., Pei, Z. G., Zhang, S. Z., et al. (2005). Organic acids promote the uptake of lanthanum by barley roots. New Phytologist, 165(2), 481-492.

Hass, A., and Fine, P. (2010). Sequential selective extraction procedures for the study of heavy metals in soils, sediments, and waste materials-a critical review. Critical Reviews in Environmental Science and Technology, 40(5), 365-399.

Hass, A., Mingelgrin, U., and Fine, P. (2011). Heavy metals in soils irrigated with wastewater. In G. J. Levy, F. Pinchas, \& B.-T. Asher (Eds.), Treated wastewater in agriculture: Use and impacts on the soil environment and crops (pp. 247-285).

He, T., Wang, J., Lin, Z., and Cheng, Y. (2009). Spectral features of soil organic matter. Geo-Spatial Information Science, 12(1), 33-40.

Henneken, L., Nörtemann, B., and Hempel, D. (1995). Influence of physiological conditions on EDTA degradation. Applied Microbiology and Biotechnology, 44(1-2), 190-197.

Hernández-Allica, J., Becerril, J., Zárate, O., and Garbisu, C. (2006). Assessment of the efficiency of a metal phytoextraction process with biological indicators of soil health. Plant and Soil, 281(1), 147-158.

Herzig, R., Nehnevajova, E., Pfistner, C., Schwitzguebel, J.-P., Ricci, A., and Keller, C. (2014). Fesibility of labile Zan phytoextraction using enhanced tobacco and sunflower: Results of fice and one-year field-scale experiments in Switzerland. International journal of phytoremediation, 16, 735-754.

Hewitt, E. J. (1966). Sand and water culture methods used in the study of plant nutrition. In Tech Communication No. 22. Commonwealth Agricultural Bureau of Horticulture and Plantation Crops. $p$ 430-451.

Hoagland, D. R., and Arnon, D. I. (1950). The water-culture method for growing plants without soil. Circular, Agricultural Experiment Station, University of California, Berkeley, CA 347(2nd edit).

Holze, R. (2004). Fundamentals and applications of near infrared spectroscopy in spectroelectrochemistry. Journal of Solid State Electrochemistry, 8(12), 982-997.

Hong, H., Feng-jie, Y., Guang-zhu, Z., and Yin-ming, L. Spectral Features and Regression Model of Mine Vegetation in the Press of Heavy Metal. In Second International Workshop on Education Technology and Computer Science, 2010 (pp. 57-59): IEEE.

Horler, D. N. H., Barber, J., and Barringer, A. R. (1980). Effects of heavy metals on the absorbance and reflectance spectra of plants. International Journal of Remote Sensing, 1, 121-136.

Horler, D. N. H., Dockray, M., and Barber, J. (1983). The red edge of plant leaf reflectance. International Journal of Remote Sensing, 4(2), 273-288.

Horta, A., Malone, B., Stockmann, U., Minasny, B., Bishop, T., McBratney, A., et al. (2015). Potential of integrated field spectroscopy and spatial analysis for enhanced assessment of soil contamination: A prospective review. Geoderma, 241, 180-209.

Huang, C. Y. L., and Schulte, E. (1985). Digestion of plant tissue for analysis by ICP emission spectroscopy. Communications in Soil Science and Plant Analysis, 16(9), 943-958.

Huang, J. W., Chen, J., Berti, W. R., and Cunningham, S. D. (1997). Phytoremediation of lead-contaminated soils: role of synthetic chelates in lead phytoextraction. Environmental Science and Technology, 31(3), 800-805.

Huber, S., Kneubuhler, M., Psomas, A., Itten, K., and Zimmermann, N. E. (2008). Estimating foliar biochemistry from hyperspectral data in mixed forest canopy. Forest Ecology and Management, 256, 491-501.

Hunt, G. R. (1977). Spectral signatures of particulate minerals in the visible and near infrared. Geophysics, 42(3), 501-513.

Hunt Jr, E. R., and Rock, B. N. (1989). Detection of changes in leaf water content using near-and middle-infrared reflectances. Remote Sensing of Environment, 30(1), 4354. 
IBA (2010). Biomass on contaminated land: Options of biomass crops on contaminated soil - Cultivation and utilization of biomass in the area of Freiberg / Saxony, under the EU project ReSource, international Building Exhibition (IBA) Fürst-Pückler-Land $\mathrm{GmbH}$, Großräschen, DE. CENTRAL EUROPE Project 1CE084P4 ReSOURCE. (pp. 1-8).

Imran, M. A., Sajid, Z. A., and Chaudhary, M. N. (2015). Arsenic (As) toxicity to germination and vegetation growht of sunflower (Helianthus annuus L.). Poland Journal of Environment Studies, 24(5), 1993-2002.

ITRC (2009). Phytotechnology Technical and Regulatory Guidance and Decision Trees, Revised. PHYTO-3. Washington, D.C.: Interstate Technology \& Regulatory Council, Phytotechnologies Team, Tech Reg Update. www.itrcweb.org.

Janik, L., Merry, R., and Skjemstad, J. (1998). Can mid infrared diffuse reflectance analysis replace soil extractions? Australian Journal of Experimental Agriculture, 38, 681-696.

Jankaite, A., and Vasarevičius, S. (2005). Remediation technologies for soils contaminated with heavy metals. Journal of Environmental Engineering and Landscape Management, 13(2), 109-113.

Ji, J., Balsam, W., Chen, J., and Liu, L. (2002). Rapid and quantitative measurement of hematite and goethite in the Chinese loess-paleosol sequence by diffuse reflectance spectroscopy. Clays and Clay Minerals, 50(2), 208-216.

Ji, J., Song , Y., Yuan, X., and Yang, Z. (2010). Diffuse reflectance spectroscopy study of heavy metals in agricultural soils of the Changjiang River Delta, China. Paper presented at the 19th World Congress of Soil Science, Soil Solutions for a Changing World, 1 - 6 August 2010, Brisbane, Australia,

Jiang, Q. Q., and Singh, B. R. (1994). Effect of different forms and sources of arsenic on crop yield and arsenic concentration. Water, Air, and Soil Pollution, 74(3-4), 321343.

Kabata-Pendias, A., and Pendias, H. (2001). Trace elements in soils and plants (3rd ed.): CRC Press LLC.

Kancheva, R., and Borisova, D. (2010). Spectral data for plant chlorophyll assessment. $7(3), 239-245$.

Karczewska, A., Orlow, K., Kabala, C., Szopka, K., and Galka, B. (2011). Effects of chelating compounds on mobilization and phytoextraction of copper and lead in contaminated soils. Communications in Soil Science and Plant Analysis, 42(12), 1379-1389.

Karimi, R., Solhi, S., Solhi, M., and Safe, A. (2013). Effects of Cd, Pb and Ni on growth and macronutrients in Hordeum vulgare L., and Brassica napus L. International Journal of Agronomy and Plant Production, 4(1), 76-81.

Kemper, T., and Sommer, S. (2002). Estimate of heavy metal contamination in soils after a mining accident using reflectance spectroscopy. Environmental Science and Technology, 36(12), 2742-2747.

Kemper, T., and Sommer, S. Mapping and monitoring of residual heavy metal contamination and acidification risk after the Aznalcóllar mining accident (Andalusia, Spain) using field and airborne hyperspectral data. In 3rd EARSeL Workshop on Imaging Spectroscopy, Herrsching, 2003 (pp. 333-343).

Kidd, P., Mench, M., Álvarez-López, V., Bert, V., Dimitriou, I., Friesl-Hanl, W., et al. (2015). Agronomic practices for improving gentle remediation of trace elementcontaminated soils. International journal of phytoremediation(just-accepted), 00-00.

King, D. J., Doronila, A. I., Feenstra, C., Baker, A. J., and Woodrow, I. E. (2008). Phytostabilisation of arsenical gold mine tailings using four Eucalyptus species: Growth, arsenic uptake and availability after five years. Science of the Total Environment, 406(1), 35-42.

Knadel, M., Thomsen, A., and Greve, M. H. (2011). Multisensor on-the-go mapping of soil organic carbon content. Soil Science Society of America Journal, 75(5), 17991806.

Kokaly, R., and Clark, R. (1999). Spectroscopic determination of leaf biochemistry using band-depth analysis of absorption features and stepwise multiple linear regression. Remote Sensing of Environment, 67(3), 267-287. 
Kooistra, L., Leuven, R., Wehrens, R., Nienhuis, P. H., and Buydens, L. M. C. (2003). A comparison of methods to relate grass reflectance to soil metal contamination. International Journal of Remote Sensing, 24(24), 4995-5010.

Kooistra, L., Salas, E. A. L., Clevers, J., Wehrens, R., Leuven, R., Nienhuis, P. H., et al. (2004). Exploring field vegetation reflectance as an indicator of soil contamination in river floodplains. Environmental Pollution, 127(2), 281-290.

Kooistra, L., Wehrens, R., Leuven, R., and Buydens, L. M. C. (2001). Possibilities of visible-near-infrared spectroscopy for the assessment of soil contamination in river floodplains. Analytica Chimica Acta, 446(1-2), 97-105.

Kos, B., Greman, H., and Lestan, D. (2003). Phytoextraction of lead, zinc and cadmium from soil by selected plants. Plant Soil and Environment, 49(12), 548-553.

Küpper, H., Lombi, E., Zhao, F. J., and McGrath, S. P. (2000). Cellular compartmentation of cadmium and zinc in relation to other elements in the hyperaccumulator Arabidopsis halleri. Planta, 212(1), 75-84.

Lai, K. C. K., Surampalli, R. Y., Tyagi, R. D., Lo, I., and Yan, S. (2007). Performance monitoring of remediation technologies for soil and groundwater contamination: Review. Practice Periodical of Hazardous, Toxic, and Radioactive Waste Management, 11(3), 132-157.

Lamb, D., Steyn-Ross, M., Schaare, P., Hanna, M., Silvester, W., and Steyn-Ross, A. (2002). Estimating leaf nitrogen concentration in ryegrass (Lolium spp.) pasture using the chlorophyll red-edge: theoretical modelling and experimental observations. International Journal of Remote Sensing, 23(18), 3619-3648.

Lasat, M. (2000). Phytoextraction of metals from contaminated soil: a review of plant/soil/metal interaction and assessment of pertinent agronomic issues. Journal of Hazardous Substance Research, 2(5), 1-25.

Lehmann, M., and Gläßer, C. High resolution multisensoral approach to determine high stressed vegetation in floodplains in the mulderegion (Germany) 2002/2003. In B. Zagajewski, M. Sobczak, \& M. Wrzesień (Eds.), 4th EARSeL Workshop on Imaging Spectroscopy. New quality in environmental studies., Warsaw University, Warsaw, Poland, 2005 (pp. 721-726).

Lepp, N. W. (1981). Effect of heavy metals pollution on plants. In N. W. Lepp (Ed.), Effects of trace metal on plant function (Vol. 1, pp. 299-342). London: Applied Science Publishers.

Leštan, D., Luo, C.-I., and Li, X.-d. (2008a). The use of chelating agents in the remediation of metal-contaminated soils: a review. Environmental Pollution, 153(1), 3-13.

Leštan, D., Luo, C., and Li, X. (2008b). The use of chelating agents in the remediation of metal-contaminated soils: a review. Environmental Pollution, 153(1), 3-13.

LfULG (2015). Materialien zum Bodenschutz: Boden-Dauerbeobachtungsprogramm des LfULG in Sachsen Standortcharakteristika (Materials for soil conservation: Soil monitoring program of the LfULG in Saxony), Sächsisches Landesamt für Umwelt, Landwirtschaft und Geologie (Saxon State Agency for Environment, Agriculture and Geology), Freiberg, Freistaates Sachsen, Germany.

Li, H., Wang, Q., Cui, Y., Dong, Y., and Christie, P. (2005). Slow release chelate enhancement of lead phytoextraction by corn (Zea mays L.) from contaminated soila preliminary study. Science of the Total Environment, 339(1), 179-187.

Li, X., Liu, X., Liu, M., Wang, C., and Xia, X. (2015). A hyperspectral index sensitive to subtle changes in the canopy chlorophyll content under arsenic stress. International Journal of Applied Earth Observation and Geoinformation, 36, 41-53.

Li, X., Ziadi, N., Bélanger, G., Cai, Z., and Xu, H. (2011). Cadmium accumulation in wheat grain as affected by mineral $\mathrm{N}$ fertilizer and soil characteristics. Canadian Journal of Soil Science, 91(4), 521-531.

Liedekerke, M. v., Prokop, G., Rabl-Berger, S., Kibblewhite, M., and Louwagie, G. (2014). Progress in the Management of Contaminated Sites in Europe (EUR 26376 - Joint Research Centre - Institute for Environment and Sustainability). (pp. 1-64 ). Luxembourg: Publications Office of the European Union. 
Liew, O., Chong, P., Li, B., and Asundi, A. (2008). Signature optical cues: emerging technologies for monitoring plant health. Sensors, 8, 3205-3239.

Liu, M., Liu, X., Li, M., Fang, M., and Chi, W. (2010a). Neural-network model for estimating leaf chlorophyll concentration in rice under stress from heavy metals using four spectral indices. Biosystems Engineering, 106(3), 223-233.

Liu, M., Liu, X., Wu, M., Li, L., and Xiu, L. (2011a). Integrating spectral indices with environmental parameters for estimating heavy metal concentrations in rice using a dynamic fuzzy neural-network model. Computers and Geosciences, 37(10), 16421652.

Liu, M., Yanai, J., Jiang, R., Zhang, F., McGrath, S., and Zhao, F. (2008a). Does cadmium play a physiological role in the hyperaccumulator Thlaspi caerulescens? Chemosphere, 71(7), 1276-1283.

Liu, S., Liu, X., Hou, J., Chi, G., and Cui, B. (2008b). Study on the spectral response of Brassica campestris L. leaf the copper pollution. Science in China Series E: Technolgical Sciences, 51(2), 202-208.

Liu, S., Liu, X., Hou, J., Chi, G., and Cui, B. (2008c). Study on the spectral response of Brassica campestris L. leaf to the copper pollution. Science in China Series E: Technological Sciences, 51(2), 202-208.

Liu, Y., Chen, H., Wu, G., and Wu, X. (2010b). Feasibility of estimating heavy metal concentrations in Phragmites australis using laboratory-based hyperspectral data-A case study along Le'an River, China. International Journal of Applied Earth Observation and Geoinformation, 12(Supplement 2), S166-S170.

Liu, Y., Li, W., Wu, G., and Xu, X. (2011b). Feasibility of estimating heavy metal contaminations in floodplain soils using laboratory-based hyperspectral data-A case study along Le'an River, China. Geo-Spatial Information Science, 14(1), 10-16.

Logan, E. M., Pulford, I. D., Cook, G. T., and Mackenzie, A. B. (1997). Complexation of $\mathrm{Cu}^{2+}$ and $\mathrm{Pb}^{2+}$ by peat and humic acid. European Journal of Soil Science, 48(4), 685696.

Ludwig, B., and Khanna, P. K. (2001). Use of near infrared spectroscopy to determine inorganic and organ carbon fractions in soil and litter. In R. Lal, J. M. Kimble, R. F. Follett, \& B. A. Stewert (Eds.), Assessment methods for soil carbon: CRC Press, Boca Raton, FL.

Luo, C., Shen, Z., and Li, X. (2005). Enhanced phytoextraction of $\mathrm{Cu}, \mathrm{Pb}, \mathrm{Zn}$ and $\mathrm{Cd}$ with EDTA and EDDS. Chemosphere, 59(1), 1-11.

Luo, C., Shen, Z., Li, X., and Baker, A. (2006). Enhanced phytoextraction of Pb and other metals from artificially contaminated soils through the combined application of EDTA and EDDS. Chemosphere, 63(10), 1773-1784.

Lyalko, V. I., Djary, V. Y., Hodorovsky, A. J., Woolfson, L. D., Shportjuk, Z. B., Gimel'farb, G. L., et al. (1996). Estimation of heavy metal and radionuclide contamination of soils and vegetation within the chernobyl danger zone using remote sensing data Paper presented at the International archives of photogrammetry and remote sensing, Vol. XXXI Part B7, Vienna,

Maksymiec, W. (2007). Signaling responses in plants to heavy metal stress. Acta Physiologiae Plantarum, 29(3), 177-187.

Malley, D. F., and Williams, P. C. (1997). Use of near-infrared reflectance spectroscopy in prediction of heavy metals in freshwater sediment by their association with organic matter. Environmental Science and Technology, 31(12), 3461-3467.

Mani, D., Sharma, B., Kumar, C., Pathak, N., and Balak, S. (2012). Phytoremediation potential of Helianthus annuus $\mathrm{L}$ in sewage-irrigated Indo-Gangetic alluvial soils. International journal of phytoremediation, 14(3), 235-246.

Marcar, N. E., Zohar, Y., Guo, J., and Crawford, D. F. (2002). Effect of $\mathrm{NaCl}$ and high pH on seedling growth of 15 Eucalyptus camaldulensis Dehnh. provenances. New forests, 23(3), 193-206.

Maria, S. D., Puschenreiter, M., and Rivelli, A. R. (2013). Cadmium accumulation and physiological response of sunflower plants to Cd during the vegetative growing cycle. Plant Soil Environment, , 59(6), 254-261. 
Mariotti, M., Ercoli, L., and Masoni, A. (1996). Spectral properties of iron-deficient corn and sunflower leaves. Remote Sensing of Environment, 58(3), 282-288.

Marmiroli, N., Marmiroli, M., and Maestri, E. (2006). Phytoremediation and phytotechnologies: A review for the present and the future. Soil and Water Pollution Monitoring, Protection and Remediation, 403-416.

Martell, A., Smith, R., and Motekaitis, R. (2001). NIST critical stability constants of metal complexes database. NIST Standard Reference Database, 6.

Martin, M. (2012). Biological monitoring of heavy metal pollution: land and air: Springer Science \& Business Media.

Matschullat, J. (2000). Arsenic in the geosphere-a review. Science of the Total Environment, 249(1), 297-312.

McCarty, G., and Reeves, J. (2006). Comparison of near infrared and mid infrared diffuse reflectance spectroscopy for field-scale measurement of soil fertility parameters. Soil Science, $171(2), 94$.

McGrath, S. P., and Zhao, F.-J. (2003). Phytoextraction of metals and metalloids from contaminated soils. Current Opinion in Biotechnology, 14(3), 277-282.

McGrath, S. P., Zhao, J., and Lombi, E. (2002). Phytoremediation of metals, metalloids, and radionuclides. In Advances in Agronomy (Vol. 75, pp. 1-56): Academic Press.

McLinn, E. Monitoring remediation with trembling leaves: assessing the effectiveness of a full-scale phytoremediation system. In 6th Annual International Symposium on InSite Bioremediation, June 4 - 7, San Diego, CA, 2001.

Meers, E., Ruttens, A., Hopgood, M., Samson, D., and Tack, F. (2005). Comparison of EDTA and EDDS as potential soil amendments for enhanced phytoextraction of heavy metals. Chemosphere, 58(8), 1011-1022.

Meers, E., Tack, F., Van Slycken, S., Ruttens, A., Vangronsveld, J., and Verloo, M. (2008). Chemically assisted phytoextraction: A review of potential soil amendments for increasing plant uptake of heavy metals. International journal of phytoremediation, 10(5), 390-414.

Meers, E., Van Slycken, S., Adriaensen, K., Ruttens, A., Vangronsveld, J., Du Laing, G., et al. (2010). The use of bio-energy crops (Zea mays) for 'phytoattenuation'of heavy metals on moderately contaminated soils: A field experiment. Chemosphere, 78(1), 35-41.

Meighan, M. M., Fenus, T., Karey, E., and MacNeil, J. (2011). The impact of EDTA on the rate of accumulation and root/shoot partitioning of cadmium in mature dwarf sunflowers. Chemosphere, 83(11), 1539-1545

Mench, M., Lepp, N., Bert, V., Schwitzguébel, J.-P., Gawronski, S. W., Schröder, P., et al. (2010a). Successes and limitations of phytotechnologies at field scale: outcomes, assessment and outlook from COST Action 859. Journal of Soils and Sediments, 10(6), 1039-1070.

Mench, M., Vangronsveld, J., Clijsters, H., Lepp, N., and Edwards, R. (2010b). In Situ Metal Immobilization and Phytostabilization of Contaminated Soils. Phytoremediation of contaminated soil and water, 323.

Mendoza-Cózatl, D. G., Butko, E., Springer, F., Torpey, J. W., Komives, E. A., Kehr, J., et al. (2008). Identification of high levels of phytochelatins, glutathione and cadmium in the phloem sap of Brassica napus. A role for thiol-peptides in the long-distance transport of cadmium and the effect of cadmium on iron translocation. The Plant Journal, 54(2), 249-259.

Mertens, J., Luyssaert, S., and Verheyen, K. (2005). Use and abuse of trace metal concentrations in plant tissue for biomonitoring and phytoextraction. Environmental Pollution, 138(1), 1-4.

Mertens, J., and Smolder, E. (2010). Heavy metals in soils: Trace Metals and Metalloids in Soils and their Bioavailability (Ed. Alloway, BJ) (Third ed.): Springer.

Metwally, A., Safronova, V. I., Belimov, A. A., and Dietz, K.-J. (2005). Genotypic variation of the response to cadmium toxicity in Pisum sativum L. Journal of Experimental Botany, 56(409), 167-178. 
Milton, N. M., Ager, C. M., Eiswerth, B. A., and Power, M. S. (1989). Arsenic-and selenium-induced changes in spectral reflectance and morphology of soybean plants. Remote Sensing of Environment, 30(3), 263-269.

Morgan, C. L. S., Waiser, T. H., Brown, D. J., and Hallmark, C. T. (2009). Simulated in situ characterization of soil organic and inorganic carbon with visible near-infrared diffuse reflectance spectroscopy. Geoderma, 151(3), 249-256.

Moros, J., Barciela-Alonso, M. C., Pazos-Capeáns, P., Bermejo-Barrera, P., PeñaVázquez, E., Garrigues, S., et al. (2008). Characterization of estuarine sediments by near infrared diffuse reflectance spectroscopy. Analytica Chimica Acta, 624(1), 113127.

Moros, J., de Vallejuelo, S. F. O., Gredilla, A., de Diego, A., Madariaga, J. M., Garrigues, S., et al. (2009). Use of reflectance infrared spectroscopy for monitoring the metal content of the estuarine sediments of the Nerbioi-Ibaizabal River (Metropolitan Bilbao, Bay of Biscay, Basque Country). Environmental Science and Technology, 43(24), 9314-9320.

Morra, M., Hall, M., and Freeborn, L. (1991). Carbon and nitrogen analysis of soil fractions using near-infrared reflectance spectroscopy. Soil Science Society of America Journal, 55(1), 288-291.

Mulligan, C., Yong, R., and Gibbs, B. (2001). Remediation technologies for metalcontaminated soils and groundwater: an evaluation. Engineering geology, 60(1), 193-207.

Murphy, R. J., Taylor, Z., Schneider, S., and Nieto, J. (2015). Mapping clay minerals in an open-pit mine using hyperspectral and LiDAR data. European Journal of Remote Sensing, 48, 511-526.

Myers, B. J., Bond, W. J., Benyon, R. G., Falkiner, R. A., Polglase, P. J., Smith, C. J., et al. (1999). Sustainable Effluent-Irrigated Plantations: An Australian Guideline. CSIRO Forestry and Forest Products, Canberra, 293 pp plus CD Rom.

Naidu, R., Sumner, M. E., and Harter, R. D. (1998). Sorption of heavy metals in strongly weathered soils: an overview. Environmental Geochemistry and Health, 20, 5-9.

Nanni, M. R., and Dematte, J. A. M. (2006). Spectral reflectance methodology in comparison to traditional soil analysis. Soil Science Society of America Journal, 70(2), 393.

Navalgund, R., Jayaraman, V., and Roy, P. (2007). Remote sensing applications: An overview. Current Science, 93(12), 1747-1766.

Nehnevajova, E., Herzig, R., Bourigault, C., Bangerter, S., and Schwitzguébel, J.-P. (2009a). Stability of enhanced yield and metal uptake by Sunflower mutants for improved phytoremediation. International journal of phytoremediation, 11(4), 329346.

Nehnevajova, E., Herzig, R., Federer, G., Erismann, K.-H., and Schwitzguébel, J.-P. (2005). Screening of sunflower cultivars for metal phytoextraction in a contaminated field prior to mutagenesis. International journal of phytoremediation, 7(4), 337-349.

Nehnevajova, E., Herzig, R., Schwitzguébel, J., and Schmülling, T. Sunflower mutants with improved growth and metal accumulation traits show a potential for soil decontamination. In Q. Y. Shu (Ed.), Induced Plant Mutations in the Genomics Era. Food and Agriculture Organization of the United Nations, Rome, 2009b (pp. 83-86).

Nocito, F. F., Lancilli, C., Dendena, B., Lucchini, G., and Sacchi, G. A. (2011). Cadmium retention in rice roots is influenced by cadmium availability, chelation and translocation. Plant, Cell and Environment.

Noomen, M. F., Skidmore, A. K., Van der Meer, F. D., and Prins, H. H. T. (2006). Continuum removed band depth analysis for detecting the effects of natural gas, methane and ethane on maize reflectance. Remote Sensing of Environment, 105(3), 262-270.

Noomen, M. F., Smith, K. L., Colls, J. J., Steven, M. D., Skidmore, A. K., and Van Der Meer, F. (2008). Hyperspectral indices for detecting changes in canopy reflectance as a result of underground natural gas leakage. International Journal of Remote Sensing, 29(20), 5987-6008. 
Nowack, B., Schulin, R., and Robinson, B. (2006). Critical assessment of chelantenhanced metal phytoextraction. Environmental Science and Technology, 40(17), 5225-5232.

Nyitrai, P., Bóka, K., Gáspár, L., Sárvári, É., Lenti, K., and Keresztes, Á. (2003). Characterization of the stimulating effect of low-dose stressors in maize and bean seedlings. Journal of Plant Physiology, 160(10), 1175-1183.

Onwubuya, K., Cundy, A., Puschenreiter, M., Kumpiene, J., Bone, B., Greaves, J., et al. (2009). Developing decision support tools for the selection of "gentle" remediation approaches. Science of the Total Environment, 407(24), 6132-6142.

Ortega, R., and Santibáñez, O. (2007). Determination of management zones in corn (Zea mays L.) based on soil fertility. Computers and electronics in agriculture, 58(1), 49-59.

Padmavathiamma, P. K., Ahmed, M., and Rahman, H. A. (2014). Phytoremediation-A sustainable approach for contaminant remediation in arid and semi-arid regions-a review. Emirates Journal of Food and Agriculture, 26(9), 757-772.

Pandit, C. M., Filippelli, G. M., and Li, L. (2010). Estimation of heavy-metal contamination in soil using reflectance spectroscopy and partial least-squares regression. International Journal of Remote Sensing, 31(15), 4111-4123.

Panigada, C., Colombo, R., Meroni, M., Rossini, M., Cogliati, S., Busetto, L., et al. (2010). Remote sensing of vegetation status using hyperspectral data. Paper presented at the Proc. 'Hyperspectral 2010 workshop', 17 - 19 March 2010, Frascati, Italy (ESA SP-683, May 2010),

Panwar, B., Kadar, I., Biro, B., Rajkai-Vegh, K., Ragalyi, P., Rekasi, M., et al. (2011). Phytoremediation: Enhanced cadmium (Cd) accumulation by organic manuring, EDTA and microbial inoculants (Azotobacter sp., Pseudomonas sp.) in Indian mustard (Brassica juncea L.). Acta Agronomica Hungarica, 59(2), 117-123.

Parat, C., Chaussod, R., Leveque, J., Dousset, S., and Andreux, F. (2002). The relationship between copper accumulated in vineyard calcareous soils and soil organic matter and iron. European Journal of Soil Science, 53(4), 663-670.

Parra, R., Ulery, A., Elless, M., and Blaylock, M. (2008). Transient phytoextraction agents: establishing criteria for the use of chelants in phytoextraction of recalcitrant metals. International journal of phytoremediation, 10(5), 415-429.

Peñuelas, J., and Filella, I. (1998). Visible and near-infrared reflectance techniques for diagnosing plant physiological status. Trends in Plant Science, 3(4), 151-156.

Peñuelas, J., Gamon, J. A., Fredeen, A. L., Merino, J., and Field, C. B. (1994). Reflectance indices associated with physiological changes in nitrogen- and water-limited sunflower leaves. Remote Sensing of Environment, 48, 135-146.

Pilon-Smits, E. (2005). Phytoremediation. Annual Review of Plant Biology, 56, 15-39.

Pimstein, A., Ben-Dor, E., and Notesco, G. (2011). Performance of three identical spectrometers in retrieving soil reflectance under laboratory conditions. Soil Science Society of America Journal, 75(2), 746-759.

Pirselová, B. (2011). Monitoring the sensitivity of selected crops to lead, cadmium and arsenic Journal of Stress Physiology \& Biochemistry, 7(4), 31-38.

Prasad, M. N. V. (2004). Heavy metal stress in plants: from molecules to ecosystems (2nd ed.): Springer and Jointly published with Narosa Publishing House, New Delhi, India.

Prasad, M. N. V., and Freitas, H. M. d. O. (2003). Metal hyperaccumulation in plants: Biodiversity prospecting for phytoremediation technology. Electronic Journal of Biotechnology, 6, 285-321.

Pu, R., Gong, P., Biging, G. S., and Larrieu, M. R. (2003). Extraction of red edge optical parameters from Hyperion data for estimation of forest leaf area index. Geoscience and Remote Sensing, IEEE Transactions on, 41(4), 916-921.

Pulford, I., and Watson, C. (2003). Phytoremediation of heavy metal-contaminated land by trees-a review. Environment International, 29(4), 529-540.

Raba, A., Henk, S., Meharg, A. A., and Feldmann, J. (2005). Uptake, translocation, tranformation of arsenate and arsenite in sunflower (Helianthus annuus): Formation 
of arsenic-phytocheletins complexes during exposure to high arsenic concentration. New Phytologist, 168, 551.

Rathod, P. H., Rossiter, D. G., Noomen, M. F., and Van der Meer, F. D. (2013). Proximal spectral sensing to monitor phytoremediation of metal-contaminated soils. International journal of phytoremediation, 15(5), 405-426.

Reeves III, J. B. (2010). Near-versus mid-infrared diffuse reflectance spectroscopy for soil analysis emphasizing carbon and laboratory versus on-site analysis: Where are we and what needs to be done? Geoderma, 158(1-2), 3-14.

Reeves, J. (2002). The potential of diffuse reflectance spectroscopy for the determination of carbon inventories in soils. Environmental Pollution, 116, S277-S284.

Reeves, R. D., and Baker, A. J. M. (2000). Metal-accumulating plants. In I. Raskin, \& B. D. Ensley (Eds.), Phytoremediation of toxic metals: using plants to clean up the environment (pp. 193-229). New York: John Wiley and Sons.

Reichman, S., Menzies, N., Asher, C., and Mulligan, D. (2006). Responses of four Australian tree species to toxic concentrations of copper in solution culture. Journal of Plant Nutrition, 29(6), 1127-1141.

Ren, H. Y., Zhuang, D. F., Pan, J. J., Shi, X. Z., Shi, R. H., and Wang, H. J. (2010). Study on canopy spectral characteristics of paddy polluted by heavy metals. Spectroscopy and Spectral Analysis, 30(2), 430-434.

Ren, H. Y., Zhuang, D. F., Pan, J. J., Shi, X. Z., and Wang, H. J. (2008). Hyper-spectral remote sensing to monitor vegetation stress. Journal of Soils and Sediments, 8(5), 323-326.

Ren, H. Y., Zhuang, D. F., Singh, A. N., Pan, J. J., Qiu, D. S., and Shi, R. H. (2009). Estimation of As and Cu contamination in agricultural soils around a mining area by reflectance spectroscopy: A case study. Pedosphere, 19(6), 719-726.

Reusen, I., Bertels, L., Debacker, S., Debruyn, W., Scheunders, P., Sterckx, S., et al. Detection of stressed vegetation for mapping heavy metal polluted soil. In $3 \mathrm{rd}$ EARSeL Workshop on Imaging Spectroscopy, May 13-16, Oberpfaffenhofen, 2003.

Rosso, P. H., Pushnik, J. C., Lay, M., and Ustin, S. L. (2005). Reflectance properties and physiological responses of Salicornia virginica to heavy metal and petroleum contamination. Environmental Pollution, 137(2), 241-252.

Rouse Jr, J., Haas, R., Schell, J., and Deering, D. (1974). Monitoring vegetation systems in the Great Plains with ERTS. NASA special publication, 351, 309.

Ryan, J., Pahren, H., and Lucas, J. (1982). Controlling cadmium in the human food chain: a review and rationale based on health effects. Environmental Research, 28(2), 251302.

Saifullah, Ghafoor, A., and Qadir, M. (2009). Lead phytoextraction by wheat in response to the EDTA application method. International journal of phytoremediation, 11(3), 268-282.

Salt, D. E., Smith, R. D., and Raskin, I. (1998). Phytoremediation. Annual Review of Plant Biology, 49(1), 643-668.

Sanal, F., Şeren, G., and Güner, U. (2014). Effects of arsenate and arsenite on germination and some physiological attributes of barley Hordeum vulgare L. Bulletin of Environmental Contamination and Toxixology, 92(4), 483-489.

SAS (2005). SAS user's guide: Statistics. Cary (NC): SAS Institute.

SAS (2012). JMP®10 Discovering JMP. Cary, NC: SAS Institute Inc.

Savitzky, A., and Golay, M. J. (1964). Smoothing and differentiation of data by simplified least squares procedures. Analytical Chemistry, 36(8), 1627-1639.

Scheinost, A. C., Chavernas, A., Barron, V., and Torrent, J. (1998). Use and limitations of second-derivative diffuse reflectance spectroscopy in the visible to near-infrared range to identify and quantity Fe oxide minerals in soils. Clays and Clay Minerals, 46(5), 528-536.

Scheinost, A. C., and Schwertmann, U. (1999). Color identification of iron oxides and hydroxysulfates: use and limitations. Soil Science Society of America Journal, 63(5), 1463-1471.

Schowengerdt, R. A. (2007). Remote sensing: models and methods for image processing. New York, USA: Academic Press. 
Schuerger, A. C., Capelle, G. A., Di Benedetto, J. A., Mao, C., Thai, C. N., Evans, M. D., et al. (2003). Comparison of two hyperspectral imaging and two laser-induced fluorescence instruments for the detection of zinc stress and chlorophyll concentration in bahia grass (Paspalum notatum Flugge.). Remote Sensing of Environment, 84(4), 572-588.

Schwaller, M. R., Schnetzer, C. C., and Marshall, P. E. (1983). The changes in leaf reflectance of sugar maple (Acer saccharum Marsh) seedlings in response to heavy metal stress. International Journal of Remote Sensing, 4, 93-100.

Schwartz, G., Eshel, G., and Ben-Dor, E. (2011). Reflectance spectroscopy as a tool for monitoring contaminated soils. Soil Contamination, 67-90.

Schwitzguébel, J. P., Nehnevajova, E., and Herzig, R. (2008). Sustainable approach to remove metals from contaminated soils: Improved phytoextraction by sunflower mutants. Paper presented at the 4th European Bioremediaiton conference. Retrived from: http://www.srcosmos.gr/srcosmos/showpub.aspx?aa=11394, Chania, Greece,

Shafri, H. Z. M., Salleh, M. A. M., and Ghiyamat, A. (2006). Hyperspectral remote sensing of vegetation using red edge position techniques. American Journal of Applied Sciences, 3(6), 1864-1871.

Shaibur, M. R., Kitajima, N., Sugawara, R., Kondo, T., Imamul Huq, S., and Kawai, S. (2008). Physiological and mineralogical properties of arsenic-induced chlorosis in barley seedlings grown hydroponically. Journal of Plant Nutrition, 31(2), 333-353.

Shao, Y., and He, Y. (2011). Nitrogen, phosphorus, and potassium prediction in soils, using infrared spectroscopy. Soil Research, 49(2), 166-172.

Sharma, P., and Pandey, S. (2014). Status of Phytoremediation in World Scenario. International Journal of Environmental Bioremediation \& Biodegradation, 2(4), 178191.

Shen, Z. G., Li, X. D., Wang, C. C., Chen, H. M., and Chua, H. (2002). Lead phytoextraction from contaminated soil with high-biomass plant species. J. Environ. Qual, 31(6), 1893-1900.

Shenk, J. S., Workman, J. J., and Westerhaus, M. O. (2001). Application of NIR spectroscopy to agricultural products. Practical Spectroscopy Series, 27, 419-474.

Sheppard, S. (1992). Summary of phytotoxic levels of soil arsenic. Water, Air, and Soil Pollution, 64(3-4), 539-550.

Sherman, D. M., and Waite, T. D. (1985). Electronic spectra of Fe oxides and oxyhydroxides in the near infrared to ultraviolet. American Minerologist, 70, 12621269.

Shi, T., Chen, Y., Liu, Y., and Wu, G. (2014). Visible and near-infrared reflectance spectroscopy-An alternative for monitoring soil contamination by heavy metals. Journal of Hazardous Materials, 265, 166-176.

Shonk, J., Gaultney, L., Schulze, D., and Van Scoyoc, G. (1991). Spectroscopic sensing of soil organic matter content. Transactions of the ASAE, 34(5), 1978-1984.

Siebielec, G., McCarty, G. W., Stuczynski, T. I., and Reeves III, J. B. (2004). Near-and mid-infrared diffuse reflectance spectroscopy for measuring soil metal content. Journal of Environmental Quality, 33(6), 2056.

Singh, G., and Bhati, M. (2003). Growth, biomass production, and nutrient composition of eucalyptus seedlings irrigated with municipal effluent in loamy sand soil of Indian desert. Journal of Plant Nutrition, 26(12), 2469-2488.

Singh, R., Singh, D. P., Kumar, N., Bhargava, S. K., and Barman, S. C. (2010). Accumulation and translocation of heavy metals in soil and plants from fly ash contaminated area. . Journal of Environmental Biology 31, 421-430.

Slaton, M. R., Raymond, H. J. E., and Smith, W. K. (2001). Estimating near-infrared leaf reflectance from leaf structural characteristics. American Journal of Botany, $88(2)$, 278-284

Slonecker, T., Fisher, G., Aiello, D., and Haack, B. (2010). Visible and infrared remote imaging of hazardous waste: a review. Remote Sensing, 2(11), 2474-2508.

Slonecker, T., Haack, B., and Price, S. (2009). Spectroscopic analysis of arsenic uptake in Pteris ferns. Remote Sensing, 1, 644-675. 
Smith, K., Steven, M., and Colls, J. (2004). Use of hyperspectral derivative ratios in the red-edge region to identify plant stress responses to gas leaks. Remote Sensing of Environment, 92(2), 207-217.

SoE (2011). Australia State of the Environment 2011. Independent report to the Australian Government Minister for Sustainability, Environment, Water, Population and Communities, Canberra. Retrieved from: http://www.environment.gov.au/science/soe/2011-report/5-land/3-pressures/3-3land-uses.

Song, $\mathrm{H}$., and $\mathrm{He}, \mathrm{Y}$. Evaluating soil organic matter with visible spectroscopy. In IMTC 2005 - Instrumentation and Measurement Technology Conference, Ottawa, Canada, 17-19 May 2005, 2005 (Vol. 2, pp. 1321-1324): IEEE.

Splajt, T., Ferrier, G., and Frostick, L. (2003). Monitoring of landfill leachate dispersion using reflectance spectroscopy and ground-penetrating radar. Environmental Science and Technology, 37(18), 4293-4298.

Sridhar, B. B., Diehl, S. V., Han, F. X., Monts, D. L., and Su, Y. (2005). Anatomical changes due to uptake and accumulation of $\mathrm{Zn}$ and $\mathrm{Cd}$ in Indian mustard (Brassica juncea). Environmental and Experimental Botany, 54(2), 131-141.

Sridhar, B. B., Han, F. X., Diehl, S. V., Monts, D. L., and Su, Y. (2007a). Monitoring the effects of arsenic and chromium accumulation in Chinese brake fern (Pteris vittata). International Journal of Remote Sensing, 28(5), 1055-1067.

Sridhar, B. B., Han, F. X., Diehl, S. V., Monts, D. L., and Su, Y. (2007b). Spectral reflectance and leaf internal structure changes of barley plants due to phytoextraction of zinc and cadmium. International Journal of Remote Sensing, 28(5), 1041-1054.

Sridhar, B. B., Witter, J. D., Wu, C., Spongberg, A. L., and Vincent, R. K. (2014). Effect of biosolids amendments on the metal and nutrient uptake and spectral characteristics of five vegetables plants. Water, Air, and Soil Pollution, 225(2092), 114.

Stenberg, B., and Rossel, R. V. (2010). Diffuse reflectance spectroscopy for highresolution soil sensing. In Proximal Soil Sensing (pp. 29-47): Springer.

Stenberg, B., Viscarra Rossel, R. A., Mouazen, A., and Wetterlind, J. (2010). Visible and near infrared spectroscopy in soil science. In L. S. Donald (Ed.), Advances in Agronomy (Vol. Volume 107, pp. 163-215): Academic Press.

Stephenson, C., and Black, C. R. (2014). One step forward, two steps back: the evolution of phytoremediation into commercial technologies. Bioscience Horizons, 7, hzu009.

Stolt, J., Sneller, F., Bryngelsson, T., Lundborg, T., and Schat, H. (2003). Phytochelatin and cadmium accumulation in wheat. Environmental and Experimental Botany, 49(1), 21-28.

Stoner, E. R., and Baumgardner, M. (1981). Characteristic variations in reflectance of surface soils. Soil Science Society of America Journal, 45(6), 1161-1165.

Su, Y., Sridhar, B. B. M., Han, F. X., Monts, D. L., and Diehl, S. V. (2007). Effect of bioaccumulation of $\mathrm{Cs}$ and $\mathrm{Sr}$ natural isotopes on foliar structure and plant spectral reflectance of Indian mustard (Brassica juncea). Water, Air and Soil Pollution, 180, 65-74.

Summers, D., Lewis, M., Ostendorf, B., and Chittleborough, D. (2011). Visible nearinfrared reflectance spectroscopy as a predictive indicator of soil properties. Ecological Indicators, 11(1), 123-131.

Sun, Y., Zhou, Q., and Diao, C. (2008). Effects of cadmium and arsenic on growth and metal accumulation of Cd-hyperaccumulator Solanum nigrum L. Bioresource Technology, 99(5), 1103-1110.

Suresh, R., Foy, C. D., Weidner, J. R., Schnetzler, C. S., and Schwaller, M. R. (1989). Effect of metal stress on the thermal infrared emission of soybeans: a greenhouse experiment. Possible utility in remote sensing. International Journal of Remote Sensing, 10(3), 557-563.

Tandy, S., Ammann, A., Schulin, R., and Nowack, B. (2006a). Biodegradation and speciation of residual SS-ethylenediaminedisuccinic acid (EDDS) in soil solution left after soil washing. Environmental Pollution, 142(2), 191-199. 
Tandy, S., Schulin, R., and Nowack, B. (2006b). The influence of EDDS on the uptake of heavy metals in hydroponically grown sunflowers. Chemosphere, 62(9), 1454-1463.

Tanton, T., and Crowdy, S. (1971). The distribution of lead chelate in the transpiration stream of higher plants. Pesticide Science, 2(5), 211-213.

Taylor, G. J., and Foy, C. D. (1985). Mechanisms of Aluminum tolerance in Triticum aestivum L. (Wheat). II. Differential $\mathrm{pH}$ induced by spring cultivars in nutrient solutions. American Journal of Botany, 72(5), 702-706.

Torrent, J., and Barrón, V. (2002). Diffuse reflectance spectroscopy of iron oxides. Encyclopedia of Surface and Colloid Science, 1438-1446.

US-DOE. Appendix D: Monitoring report. In Proceedings from the Workshop on Phytoremediation of Inorganic Contaminants, November 30 - December 2, 1999, Argonne National Laboratory, Chicago, Illinois, 2000: U.S. Department of Energy Subsurface Contaminants Focus Area.

USEPA (2000). Introduction to phytoremediation. (pp. 56): United State Environment Protection Agency: No. EPA/600/R-99/107, February 2000.

USEPA (2010). Phytotechnologies for site cleanup. 4th Fact Sheets on Ecological Revitalization developed by the U.S. Environmental Protection Agency (EPA). Available at www.epa.gov/tio/download/remed/phytotechnologies-factsheet.pdf.

USEPA (2012). United States Environmental Protection Agency, National priorities list. Available at http://www.epa.gov/superfund/sites/npl/.

Van Der Meer, F. (1999). Can we map swelling clays with remote sensing? International Journal of Applied Earth Observation and Geoinformation, 1(1), 27-35.

Van der Meer, F., Van Dijk, P., Van Der Werff, H., and Yang, H. (2002). Remote sensing and petroleum seepage: a review and case study. Terra Nova, 14(1), 1-17.

van der Meer, F. D. (2002). Basic physics of spectrometry. In F. D. van der Meer, \& S. M. De Jong (Eds.), Imaging Spectrometry (Vol. Volume 4 of the series Remote Sensing and Digital Image Processing pp. 3-16): Springer Netherlands.

Vangronsveld, J., Herzig, R., Weyens, N., Boulet, J., Adriaensen, K., Ruttens, A., et al. (2009). Phytoremediation of contaminated soils and groundwater: lessons from the field. Environmental Science and Pollution Research, 16(7), 765-794.

Vassil, A. D., Kapulnik, Y., Raskin, I., and Salt, D. E. (1998). The role of EDTA in lead transport and accumulation by Indian mustard. Plant Physiology, 117(2), 447-453.

Vassilev, A. (2003). Physiological and agroecological aspects of cadmium interactions with barley plants: an overview. Journal of Central European Agriculture, 4(1), 6576.

Vassilev, A., Vangronsveld, J., and Yordanov, I. (2002). Cadmium phytoextraction: present state, biological backgrounds and research needs. Bulgurian Journal of Plant Physiology, 28(3-4), 68-95.

Vassilev, A., and Yordanov, I. (1997). Reductive analysis of factors limiting growth of cadmium-treated plants: a review. Bulgarian Journal Plant Physiology, 23(3-4), 114133.

Viscarra Rossel, R. A., McBratney, A., and Minasny, B. (Eds.). (2010). Proximal Soil Sensing (1st ed.). Dordrecht Heidelberg London New York: Springer Verlag.

Vohland, M., Bossung, C., and Fründ, H. C. (2009). A spectroscopic approach to assess trace-heavy metal contents in contaminated floodplain soils via spectrally active soil components. Journal of Plant Nutrition and Soil Science, 172(2), 201-209.

Volkan Bilgili, A., Van Es, H. M., Akbas, F., Durak, A., and Hively, W. D. (2010). Visiblenear infrared reflectance spectroscopy for assessment of soil properties in a semiarid area of Turkey. Journal of Arid Environments, 74(2), 229-238.

Waiser, T. H. M., Brown, C. L. S., Hallmark, D. J., and Tom, C. (2007). In situ characterization of soil clay content with visible near-infrared diffuse reflectance spectroscopy. Soil Science Society of America Journal, 71(2), 389.

Wang, J., Cui, L., Gao, W., Shi, T., Chen, Y., and Gao, Y. (2014). Prediction of low heavy metal concentrations in agricultural soils using visible and near-infrared reflectance spectroscopy. Geoderma, 216, 1-9.

Waranusantigul, P., Lee, H., Kruatrachue, M., Pokethitiyook, P., and Auesukaree, C. (2011). Isolation and characterization of lead-tolerant Ochrobactrum intermedium 
and its role in enhancing lead accumulation by Eucalyptus camaldulensis. Chemosphere, 85(4), 584-590.

Weggler, K., McLaughlin, M. J., and Graham, R. D. (2004). Effect of chloride in soil solution on the plant availability of biosolid-borne cadmium. Journal of Environmental Quality, 33(2), 496-504.

Wenzel, W. W., Unterbrunner, R., Sommer, P., and Sacco, P. (2003). Chelate-assisted phytoextraction using canola (Brassica napus L.) in outdoors pot and lysimeter experiments. Plant and Soil, 249(1), 83-96.

Westad, F., and Marten, H. (2000). Variable selection in near infrared spectroscopy based on significance testing in partial least squares regression. Journal of Near Infrared Spectroscopy, 8(2), 117-124.

Woodhouse, R., Heeb, M., Berry, W., Hoshizaki, T., and Wood, M. (1994). Analysis of remote reflection spectroscopy to monitor plant health. Advances in Space Research, 14(11), 199-202.

Wu, C. Y., Jacobson, A. R., Laba, M., Kim, B., and Baveye, P. C. (2010a). Surrogate correlations and near-infrared diffuse reflectance sensing of trace metal content in soils. Water, Air, and Soil Pollution, 209(1-4), 377-390.

Wu, D. W., Wu, Y. Z., and Ma, H. R. (2010b). Study on the prediction of soil heavy metal elements content based on mid-infrared diffuse reflectance spectra. Guang Pu Xue Yu Guang Pu Fen Xi, 30 (6), 1498-1502.

Wu, L., Luo, Y., Xing, X., and Christie, P. (2004). EDTA-enhanced phytoremediation of heavy metal contaminated soil with Indian mustard and associated potential leaching risk. Agriculture, Ecosystems \& Environment, 102(3), 307-318.

Wu, Y., Chen, J., Ji, J., Gong, P., Liao, Q., Tian, Q., et al. (2007). A mechanism study of reflectance spectroscopy for investigating heavy metals in soils. Soil Science Society of America Journal, 71(3), 918-926.

Wu, Y., Zhang, X., Liao, Q., and Ji, J. (2011). Can contaminant elements in soils be assessed by remote sensing technology: A case study with simulated data. Soil Science, 176(4), 196-205.

Wu, Y. Z., Chen, J., Ji, J. F., Tian, Q. J., and Wu, X. M. (2005a). Feasibility of reflectance spectroscopy for the assessment of soil mercury contamination. Environmental Science and Technology, 39(3), 873-878.

Wu, Y. Z., Chen, J., Wu, X., Tian, Q., Ji, J., and Qin, Z. (2005b). Possibilities of reflectance spectroscopy for the assessment of contaminant elements in suburban soils. Applied Geochemistry, 20(6), 1051-1059.

Xia, X. Q., Mao, Y. Q., Ji, J. F., Ma, H. R., Chen, J., and Liao, Q. L. (2007). Reflectance spectroscopy study of Cd contamination in the sediments of the Changjiang River, China. Environmental Science and Technology, 41(10), 3449-3454.

Xie, C. Z., Healy, T., Robinson, P., and Stewart, K. (2010). Determination of EDTA in Dairy Wastewater and Adjacent Surface Water. Journal of Civil and Environmental Engineering, 2(1), 44-48.

Xie, Z., Wu, L., Chen, N., Liu, C., Zheng, Y., Xu, S., et al. (2012). Phytoextraction of Pb and $\mathrm{Cu}$ contaminated soil with maize and microencapsulated EDTA. International journal of phytoremediation, 14(8), 727-740.

Xu, L., Zhou, Y. P., Tang, L. J., Wu, H.-L., Jiang, J. H., Shen, G. L., et al. (2008). Ensemble preprocessing of near-infrared (NIR) spectra for multivariate calibration. Analytica Chimica Acta, 616, 138-143.

Yang, F., Li, N., Zhou, G., Song, C., and Li, Q. The spectral and image characteristics of vegetation in the presence of heavy metals in Southern China. In Remote Sensing for Environmental Monitoring, GIS Applications and Geology VIII. (Eds. Michel U, Civco DL, Ehlers M and Kaufmann HJ). Proceedings of the SPIE, Volume 7110, pp. 112., 2008.

Yao, Z., Li, J., Xie, H., and Yu, C. (2012). Review on remediation technologies of soil contaminated by heavy metals. Procedia Environmental Sciences, 16, 722-729.

Yeniay, O., and Goktas, A. (2002). A comparison of partial least squares regression with other prediction methods. Hacettepe Journal of Mathematics and Statistics, 31(99), 99-101. 
Yuan, Z., and VanBriesen, J. M. (2008). Bacterial growth yields on EDTA, NTA, and their biodegradation intermediates. Biodegradation, 19(1), 41-52.

Žaltauskaitè, J., and Šliumpaitè, I. (2013). Evaluation of Toxic Effects and Bioaccumulation of Cadmium and Copper in Spring Barley (Hordeum vulgare L.). Environmental Research, Engineering and Management, 64(2), 51-58.

Zarco-Tejada, P., Miller, J., Noland, T., Mohammed, G., and Sampson, P. (2001). Scaling-up and model inversion methods with narrowband optical indices for chlorophyll content estimation in closed forest canopies with hyperspectral data. IEEE Transactions on Geoscience and Remote Sensing, 39(7), 1491-1507.

Zarco-Tejada, P. J., Berjón, A., and Miller, J. R. Stress detection in crops with hyperspectral remote sensing and physical simulation models. In Proceedings of the Airborne Imaging Spectroscopy Workshop, 8 October 2004, Bruges, Belgium, 2004.

Zarco-Tejada, P. J., Berni, J. A. J., Suárez, L., Sepulcre-Cantó, G., Morales, F., and Miller, J. R. (2009). Imaging chlorophyll fluorescence with an airborne narrow-band multispectral camera for vegetation stress detection. Remote Sensing of Environment, 113(6), 1262-1275.

Zarco-Tejada, P. J., Pushnik, J., Dobrowski, S., and Ustin, S. (2003). Steady-state chlorophyll a fluorescence detection from canopy derivative reflectance and doublepeak red-edge effects. Remote Sensing of Environment, 84(2), 283-294.

Zengin, F. K., and Munzuroglu, O. (2005). Effects of some heavy metals on content of chlorophyll, proline and some antioxidant chemicals in bean (Phaseolus vulgaris L.) seedlings. Acta Biologica Cracoviensia Series Botanica, 47(2), 157-164.

Zhang, B. Hyperspectral remote sensing of vegetation growing condition and regional environment. In In: $2^{\text {nd }}$ Workshop on hyperspectral image and signal processing: Evolution in remote Sensing (WHISPERS), 14-16 June, Reykjavik, 2010 (pp. 1-4): IEEE.

Zhang, Y. (2014). Soil Quality in China - Policy Implications. Short Term Policy Brief 98. Europe China Research and Advice Network (ECRAN). Retrieved from: http://eeas.europa.eu/china/docs/index en.htm. (pp. 1-10).

Zheng, G. H., Zhou, S. L., and Wu, S. H. (2011). Prediction of As in soil with reflectance spectroscopy (article in Chinese). Guang Pu Xue Yu Guang Pu Fen Xi, 31(1), 173176. 


\section{SUMMARY}

An elevated concentration of certain toxic metals such as $\mathrm{Cd}, \mathrm{Pb}$, and $\mathrm{As}$ in arable soils either through natural or anthropogenic sources is undesirable, and is a global environmental issue (rather a serious problem!). Considering an extent of toxic metal contamination to the soil-water-air ecosystems, and their adverse consequences on living organisms (including human beings!), an efficient and all-inclusive remediation strategy for metal-contaminated sites is of prime necessity of today's industrialized environment. Compared to conventional "dig-and-dump" approach of soil remediation, phytoremediation (here, the phytoextraction) or phytostabilization are seeming an economical and ecologically sustainable alternative for remediation of metal-contaminated soils. In first part of the work, we tested phytoextraction and phytostabilization strategies by tree. Phytoextraction requires metal solubilization and their translocation from plant's root to shoot, while the phytostabilization seeks to arrest the leaching of metal-complexes by reducing migration of water in soils.

Aimed at the phytoextraction strategy, the potential adaptability of Eucalyptus camaldulensis for Cd-polluted sediments was tested in hydroponic studies in combination with organic ligands, EDTA and S,S-EDDS. Acclimated $E$. camaldulensis saplings were exposed to $\mathrm{Cd}$ at either 4.5 or $89 \mu \mathrm{M}$ for a month period with or without EDTA or EDDS at $0.1,1$ and $5 \mathrm{mM}$ concentrations. The growth of saplings at the higher Cd concentration decreased from a $60 \%$ weight increased in the control to a $19 \%$ increase. Most Cd taken up was immobilized in the roots. Furthermore, at $0.1 \mathrm{mM}$, the two organic ligands had no or positive effect on the growth of the saplings but this was reversed at 1 $\mathrm{mM}$, and became lethal at the $5 \mathrm{mM}$ concentration. A major conclusion for hydroponic studies is that the results do not support the assertion that $E$. camaldulensis, even with ligand addition, is suitable for cleanup of soil or sediment contaminated by metals (phytoextraction). This tree might however be suitable for site stabilization (phytostabilization) owing to the high accumulation of the pollutant in the roots.

Therefore aimed at phytostabilization, an agronomic scenario of control deficit irrigation (CDI) was tested in the 220-L lysimeters setup containing sand plus metal-polluted biosolids mixture for $E$. camaldulensis suitability as sink for heavy metals and for its resistance to combinations of metals, organic ligands and water deficit stresses. The CDI was applied in order to minimize leaching of ligands and ligand-metal complexes below root-zone. Established trees were irrigated with tap or desalinized (RO) water with and without 4-times daily addition of EDTA, EDDS and citric acid at $2 \mathrm{mM}$ concentrations. The results revealed that EDDS and citrate were found completely ineffective in enhancing metal solubility and plant uptake. EDTA increased metal concentration in soil solution as well as in the Eucalyptus leaves. Under the tap water CDI regime in lysimeter, the trees tolerated the salinity built-up to $>30 \mathrm{dS} \mathrm{m}^{-1}$, and shifting to RO water greatly reduced salinity. While in hydroponic studies, EDTA and EDDS were found toxic to tree saplings at $>1 \mathrm{mM}$ concentration, in the 
lysimeter soil solution EDTA reached at concentration of $>60 \mathrm{mM}$ without noticeable symptoms of any stress. In incubation study for testing fate of ligands in the lysimeter soil media, degradation of EDTA was found considerably slower (with half-life of 27 days) than that of EDDS having an approximately half-life of 5-11 days.

A metal-contaminated site going through treatment with phytotechnologies needs to be assessed for the performance and ecological risk of the treatment. A successful phytoremediation requires the cleaning of the soil to a level that complies with environmental regulations. Moreover, for a viable phytoremediation system, phytoremediating plants have to be monitored to confirm that they are healthy, actively growing and taking up and/or stabilizing the soil contaminants. In the second part of the work, we first test the feasibility of soil visible near infrared (VNIR) reflectance spectroscopy for the quantification of soil-borne metals from freshly metal-spiked and in-situ metalcontaminated soils. The visual examination of spectra revealed that there were no significant spectral responses observed in term of distinct absorption feature, neither for metal-spiked soil with $\mathrm{Cd}, \mathrm{Pb}$, and As at 20,1200, and 900 $\mathrm{mg} \mathrm{kg}^{-1}$, respectively nor for elevated natural metal-contaminated soil at 30 , 3019, and $5725 \mathrm{mg} \mathrm{kg}^{-1}$ concentrations, respectively. The only difference observed in spectra from extreme and lower metal-contaminated soil is the lower and higher VNIR reflectance, respectively. Moreover, for natural metalcontaminated soils, significant Pearson's correlations exist between metal concentration and continuum removed (CR) reflectance spectra; and between soil metals and other soil variables like total $\mathrm{Fe}$, clay and organic matter, and their intercorrelations could be the basis for indirect prediction of soil-metal using spectral absorption features. Consequently, spectral data (raw, first derivatives, and $\mathrm{CR}$ reflectance spectra) were utilized to build partial least square regression models, that generated an acceptable coefficient of determination $\left(R^{2}\right)$ for the cross-validated soil-metal prediction, but concurrently the higher value of root mean square error ruled out the achieved PLS models.

We further explored the VNIR reflectance spectroscopy as a tool for monitoring phytoremediation studies with potted plants, by means of changes in the leafspectral properties due to metal-induced plant stresses and finally, the quantification of leaf-metal concentration based on regression models using spectral features. Of several metals and metalloids, some metals such as Cd, $\mathrm{Pb}$, and $\mathrm{As}$ are neither essential nor beneficial to plants; they are rather toxic to most terrestrial plants once their excessive accumulation occurred in soilplant system. The metal toxicity in plants involves biochemical and internal structural changes in the plants, and it was assumed that metal-toxicity can noticeably alter spectral characteristics of plants. Aimed at obtaining specific spectral changes in plant (at leaf level) due to phytoaccumulation of metals, two experiments were performed: one experiment with barley plants, were exposed to the soils artificially contaminated with three levels of each $\mathrm{Cd}(1,5$ and $\left.10 \mathrm{mg} \mathrm{kg}^{-1}\right), \mathrm{Pb}\left(25,75\right.$ and $\left.150 \mathrm{mg} \mathrm{kg}^{-1}\right)$, As (5, 50 and $100 \mathrm{mg} \mathrm{kg}^{-1}$ ), and their respective metal mixtures. Another experiment with sunflower (M5 mutants with an improved metal-phytoextraction and tolerance), here we tested higher levels of $\mathrm{Cd}\left(10\right.$ and $\left.20 \mathrm{mg} \mathrm{kg}{ }^{-1}\right), \mathrm{Pb}\left(1200 \mathrm{mg} \mathrm{kg}^{-1}\right)$, As (100 and $\left.900 \mathrm{mg} \mathrm{kg}^{-1}\right)$ and their metal-mixture $(20 \mathrm{Cd}+1200 \mathrm{~Pb}+900 \mathrm{As} ; \mathrm{mg}$ 
$\mathrm{kg}^{-1}$ ). Moreover, two natural elevated metal-contaminated soil substrates were also included as treatments in the sunflower experiment to compare the effects of freshly metal-spiked soils and naturally aged metal-contaminated soils on plant growth and spectral reflectance. As a collaborated study, we also measured leaf-spectra of winter wheat and ryegrass, those were grown in two moderately As-contaminated soils with an aim to evaluate As-uptake and translocation in response to moisture regimes and nitrogen-phosphorus (NP) fertilization treatments.

Growth of barley was adversely affected with spiking of As at $100 \mathrm{mg} \mathrm{kg}^{-1}$ concentration and of metal-mixture (at $10 \mathrm{Cd}+150 \mathrm{~Pb}+100 \mathrm{As} ; \mathrm{mg} \mathrm{kg}^{-1}$ ). The growth of sunflower as well was inhibited in As-spiked soil (at $900 \mathrm{mg}$ $\mathrm{kg}^{-1}$ ) and in-situ metal-contaminated soils. Metal concentrations of studied metals were relatively higher in roots than above-ground parts in both the studies. Results of the VNIR hyperspectral data collected from barley and sunflower demonstrate that it is feasible to make use of leaf reflectance spectra, the considered vegetation indices and the $C R$ band depths for monitoring the physiological stress caused by phytoaccumulation of metals at phytoremediation sites. Barley leaf-spectra show the influence of As-spiking only, causing spectral changes in visible and infrared domains mostly, as apparent from the significant correlation between leaves-As and reflectance spectra. Similarly, spectral variations were quite observable with an increased visible and decreased NIR reflectance for sunflower grown in As-spiked soil at concentration of $900 \mathrm{mg} \mathrm{kg}^{-1}$, and in both natural metal-contaminated soils. Vegetation indices allied to changes in chlorophyll and water absorption features and band depths analysis of CR reflectance showed significant correlations to leaf-As concentrations in both the studies, and can be used to distinguish metal-stressed plants. For example, decrease in the values of chlorophyll indices and shifting of red-edge inflection points toward shorter wavelengths, so called blue-shift, occurred in both the studies particularly for higher levels of As and metal-mixture treatments, and for natural metalcontaminated soils in case of sunflower as well. The partial least square (PLS) and multiple linear regression models (leave-one-out cross validation method) respectively based on first derivatives of reflectance spectra and combination of studied vegetation indices and CR band depths have revealed the potential use of hyperspectral reflectance data to estimate leaf-metal, here leaf-As particularly in both the studies. With this, the spectral reflectance and so the relevant spectral features at leaf scale could offered an easy and simple way to assess physiological plant status and metal-concentration. The observed changes in reflectance spectra of wheat and ryegrass leaves were attributed mainly to moisture regimes and soil types (for ryegrass) and to nitrogenphosphorus fertilizations and soil types (for wheat). For instance, relatively higher visible and lower NIR reflectance of wheat leaves was observed for phosphorus applied at $3.2 \mathrm{mM} \mathrm{kg}^{-1}$ to loamy soils under flooded moisture regime.

To summarize, Eucalyptus camaldulensis, the model tree tested in lysimeter studies seems well-suited in phytostabilization of polluted soil substrate using CDI. We further suggest that EDTA-assisted remediation and stabilization using fast growing, salinity resistant trees under CDI is feasible with little leaching of metals of concern. The CDI with RO water further widens the scope of this 
remediation technique. The soil VNIR reflectance spectroscopy was appeared unfeasible (notably for the tested soil dataset and metals) for estimation of metal-contamination in soils. The outcome of the barley and sunflower studies demonstrate that the ground-based proximal spectral sensing of plant leaves appears to be an effective tool for monitoring metal hyperaccumulators to determine the metal-induced plant stresses, and thus to optimize a phytoremediation program. 


\section{SAMENVATTING}

Een verhoogde concentratie van bepaalde giftige metalen zoals $\mathrm{Cd}, \mathrm{Pb}$, en $\mathrm{As}$ in landbouwgronden is ongewenst (of deze nu van natuurlijke of antropogene bronnen afkomstig zijn) en dit is een mondiaal milieuprobleem. Rekening houdend met de mate van verontreiniging van toxische metalen in de bodemwater-lucht ecosystemen en de nadelige gevolgen daarvan op levende organismen (met inbegrip van menselijke wezens!) is een efficiënte en allesinclusieve strategie voor de sanering van met metalen verontreinigde locaties van groot belang voor de hedendaagse geïndustrialiseerde omgeving. Vergeleken met de conventionele 'graaf-en-stort' aanpak in bodemsanering, lijkt fytoremediatie (hier, fyto-extractie) of fytostabilisatie een economisch en ecologisch duurzaam alternatief te zijn voor de sanering van verontreinigde bodems. In het eerste deel van dit werk hebben we fyto-extractie en fytostabilisatie strategieën van bomen getest. Fytoextractie vereist dat de metalen oplossen en door de plant van de wortel naar het bovengronds gedeelte van de plant verplaatst worden, terwijl fytostabilisatie streeft naar de vermindering van uitspoeling van metaal-complexen door de migratie van water in de bodem te reduceren.

Om de fyto-extractie strategie te kunnen bestuderen van Eucalyptus camaldulensis in Cd-verontreinigd sediment, hebben we het aanpassingsvermogen van de bomen getest door ze te laten groeien in een hydrocultuur in combinatie met organische liganden, EDTA en S,S-EDDS. Jonge geacclimatiseerde $E$. camaldulensis boompjes werden gedurende een maand blootgesteld aan ofwel 4,5 of $89 \mu \mathrm{M} C d$, met of zonder EDTA of EDDS in concentraties van $0,1,1$ en $5 \mathrm{mM}$. Terwijl het gewicht van de controle zaailingen met $19 \%$ toenam, was het gewicht van de zaailingen die in hogere concentraties $\mathrm{Cd}$ groeiden $60 \%$ lager dan de controle zaailingen. Het grootste deel van de opgenomen Cd was geïmmobiliseerd in de wortels. Voorts hadden de twee organische liganden in een concentratie van 0,1 mM geen of een positief effect op de groei van de zaailingen, maar dit werd een negatief effect bij $1 \mathrm{mM}$ en dodelijk bij $5 \mathrm{mM}$. Een belangrijke conclusie voor hydrocultuur studies is dat de resultaten niet de bewering ondersteunen dat $E$. camaldulensis, zelfs met de aanwezigheid van een ligand, geschikt zou zijn voor het opschonen van bodem of sediment verontreinigd met metalen (fytoextractie). De boom kan echter wel geschikt zijn voor stabilisatie (fytostabilisatie) vanwege de accumulatie van de verontreinigende stof in de wortels.

Om fytostabilisatie te kunnen onderzoeken is een landbouwkundig scenario bedacht met 'control deficit irrigation' (CDI). Dit werd gedaan met behulp van 220-L lysimeters gevuld met zand en een biosolids mengsel vervuild met metalen. De toepasbaarheid van $E$. camaldulensis werd getest als opslagmedium voor zware metalen en voor de weerstand tegen combinaties van metalen, organische liganden en watertekorten. De CDI werd toegepast 
om uitspoeling van liganden en ligand-metaalcomplexen in de wortelzone te minimaliseren. De bomen werden geïrrigeerd met leidingwater of gedesaliniseerd (RO) water met en zonder een 4-maal daagse toevoeging van EDTA, EDDS en citroenzuur in concentraties van $2 \mathrm{~mm}$. Uit de resultaten bleek dat EDDS en citraat totaal ineffectief waren in het verbeteren van metaal oplosbaarheid en opname door de planten. EDTA verhoogde de metaalconcentratie in de bodemoplossing evenals in de Eucalyptus bladeren. In het kraanwater CDI regime in de lysimeter tolereerden de bomen het zoutgehalte tot $>30 \mathrm{dS} \mathrm{m}-1$, en als RO water werd gebruikt verminderde het zoutgehalte sterk. Terwijl in hydrocultuur studies EDTA en EDDS al giftig waren voor jonge boompjes bij een concentratie van $>1 \mathrm{mM}$, kon EDTA concentraties van $>60 \mathrm{mM}$ bereiken in de lysimeter bodemoplossing zonder dat merkbare symptomen van stress aangetoond konden worden. In de incubatie studie waarin getest werd wat er gebeurt met de liganden in de lysimeterbodem, bleek dat de afbraak van EDTA aanzienlijk langzamer was dan de afbraak van EDDS (met halfwaardetijden van respectievelijk 27 dagen en 5-11 dagen).

Op vervuilde locaties waar fytoremediatie plaatsvindt, moeten de prestaties van de behandeling en de ecologische risico's worden beoordeeld. Een succesvolle fytoremediatie vereist dat de bodem gereinigd wordt tot een niveau dat voldoet aan de milieuvoorschriften. Bovendien moeten in een levensvatbaar fytoremediatie systeem de remediërende planten worden geobserveerd om te bevestigen dat zij gezond zijn, actief groeien en dat zij de verontreiniging opnemen en/of stabiliseren. In het tweede deel van dit werk testen we eerst de bruikbaarheid van zichtbaar en nabij-infrarode (VNIR) reflectie spectroscopie voor de kwantificering van bodemgebonden metalen in kunstmatige en in-situ verontreinigde bodems. Uit vergelijkend onderzoek tussen de spectra bleek dat er geen significante spectrale absorptiekenmerken voorkwamen, noch voor de bodem met toegevoegd $\mathrm{Cd}, \mathrm{Pb}$, en $\mathrm{As}$ in concentraties van 20, 1200, en $900 \mathrm{mg} \mathrm{kg}^{-1}$, noch voor natuurlijke verontreinigde grond met dezelfde metalen in concentraties van 30,3019, en $5725 \mathrm{mg} \mathrm{kg}^{-1}$. Het enige waargenomen verschil tussen de spectra was een lagere VNIR reflectie voor de meest verontreinigde bodems. Voor de natuurlijke verontreinigde bodems bestonden significante Pearson correlaties tussen metaalconcentratie en continuüm verwijderd (CR) reflectie spectra; als ook tussen metaalconcentraties en andere bodem variabelen zoals totaal Fe, klei en organische stof. Deze intercorrelaties zouden de basis kunnen zijn voor indirecte voorspelling van de bodemmetalen met behulp van spectrale absorptiekenmerken. Daarom zijn spectrale gegevens (gemeten spectra, eerste afgeleiden, en CR reflectie spectra) als input gebruikt in 'partial least square regression models'. Hoewel de cross-gevalideerde bodem-metaal modellen een aanvaardbare determinatiecoëfficiënt $\left(R^{2}\right)$ hadden, was de 'root mean square error (RMSE) zo groot dat de modellen niet betrouwbaar waren.

Vervolgens hebben we VNIR reflectie spectroscopie gebruikt om potplanten te observeren in fytoremediatie studies, en relaties te leggen tussen veranderingen in de spectrale eigenschappen van bladeren en metaal geïnduceerde stress, en die gebruikt voor de kwantificering van metaalconcentraties in de bladeren gebaseerd op regressiemodellen. Verschillende metalen en metalloïden zoals $\mathrm{Cd}, \mathrm{Pb}$, en As zijn niet noodzakelijk of gunstig voor planten; ze zijn juist giftig voor de meeste landplanten zodra 
er teveel van aanwezig is in het bodem-plant systeem. De toxiciteit van metalen in planten omvat biochemische en interne structurele veranderingen, en het werd aangenomen dat metaal-toxiciteit de spectrale eigenschappen van planten aanzienlijk kan wijzigen. Om spectrale wijzigingen als gevolg van fytoaccumulatie op bladniveau te kunnen vaststellen, werden twee experimenten uitgevoerd: 1) een experiment met gerstplanten die werden blootgesteld aan kunstmatig verontreinigde bodem met drie niveaus van elk Cd (1, 5 en $\left.10 \mathrm{mg} \mathrm{kg}^{-1}\right)$, Pb (25, 75 en $\left.150 \mathrm{mg} \mathrm{kg}^{-1}\right)$, As (5, 50 en $100 \mathrm{mg}$ $\mathrm{kg}^{-1}$ ) en hun respectievelijke metaalmengsels, en 2) een experiment met zonnebloemen (M5 mutanten met een verbeterde metaal-fytoextractie en tolerantie), waarbij hogere concentraties werden gebruikt van Cd (10 en 20 $\mathrm{mg} \mathrm{kg}^{-1}$ ), Pb (1200 mg kg-1), As (100 en $900 \mathrm{mg} \mathrm{kg}^{-1}$ ) en een metaal-mengsel $\left(20 \mathrm{Cd}+1200 \mathrm{~Pb}+900 \mathrm{As}, \mathrm{mg} \mathrm{kg}^{-1}\right)$. Daarnaast werd ook de invloed getest van het verschil tussen natuurlijke verontreinigde grond en kunstmatig verontreinigde grond op plantgroei en bladreflectie van de zonnebloemplanten. Als onderdeel van een gezamenlijke studie hebben we ook bladreflectie van wintertarwe en raaigras gemeten, die werden gekweekt in twee matig Asverontreinigde bodems met als doel om As-opname en translocatie te evalueren in reactie op verschillende vocht regimes en stikstof-fosfor (NP) bemesting.

De groei van gerst werd nadelig beïnvloed door toevoeging van As op $100 \mathrm{mg}$ $\mathrm{kg}^{-1}$ en door het metaal-mengsel (bij $10 \mathrm{Cd}+\mathrm{Pb}+150100 \mathrm{As}, \mathrm{mg} \mathrm{kg}^{-1}$ ). De groei van zonnebloem werd ook geremd in verhoogde As concentraties (900 $\mathrm{mg} \mathrm{kg}^{-1}$ ) en in de natuurlijke verontreinigde grond. In beide studies waren de metaalconcentraties van onderzochte metalen hoger in de wortels dan in de bovengrondse delen. De VNIR hyperspectrale data van gerst en zonnebloem tonen aan dat het mogelijk is om de fysiologische stress veroorzaakt door fytoaccumulatie van metalen bij fytoremediatie waar te nemen in de spectra, bepaalde vegetatie-indices en bepaalde CR banddiepten. In de bladspectra van de gerstplanten was alleen de invloed van As waar te nemen, vooral als spectrale veranderingen in zichtbare en infrarode gebieden, zoals blijkt uit de significante correlatie tussen de concentratie As in de bladeren en de reflectie spectra. Ook in de zonnebloemspectra konden spectrale variaties gerelateerd worden aan As; dit was te zien aan een verhoogde zichtbare reflectie en een verlaagde NIR reflectie voor planten in bodem met een concentratie van 900 $\mathrm{mg} \mathrm{kg}^{-1} \mathrm{As}$, en in de natuurlijke verontreinigde grond. Vegetatie indices gerelateerd aan veranderingen in chlorofyl en waterabsorptie, en banddiepte analyse van $C R$ reflectie vertoonden significante correlaties met As concentraties in de bladeren. Dit kan worden gebruikt om gestreste planten te onderscheiden van de gezonde planten. Zo vond in beide studies een vermindering van de waarden van de chlorofyl indices plaats en een verschuiving van de Red Edge richting kortere golflengtes (de zogenaamde blauwe verschuiving) bij hogere As-waarden en de metaal-mengsels, als ook bij de natuurlijke verontreinigde grond waar de zonnebloem in groeide. Door middel van PLS regressie en meervoudige lineaire regressie modellen (leaveone-out kruismethode validatie) gebaseerd op de eerste afgeleiden van de spectra en een combinatie van vegetatie indices en CR banddiepten, kon de concentratie metalen (in het bijzonder As) in bladeren geschat worden. Hiermee kunnen de spectrale reflectie en de relevante spectrale kenmerken op bladniveau op een gemakkelijke en eenvoudige manier gebruikt worden om de 
fysiologie en metaalconcentratie in planten te beoordelen. De waargenomen veranderingen in de reflectie spectra van tarwe en raaigrasbladeren werden voornamelijk toegeschreven aan vochtregimes en bodemtypes (voor raaigras) en stikstof-fosfor bemesting en bodemtypes (voor tarwe). Zo werd een relatief hogere zichtbare reflectie en lagere NIR reflectie van tarwebladeren waargenomen voor $3,2 \mathrm{mM} \mathrm{kg}{ }^{-1}$ fosfor in een overstroomd leemgrond regime.

Om samen te vatten, Eucalyptus camaldulensis, de model boom getest in de lysimeter studies, lijkt goed geschikt te zijn voor fytostabilisatie van vervuilde grond met gebruikt van CDI. We suggereren verder dat remediatie en stabilisatie met behulp van EDTA en met gebruik van snel groeiende, zoutresistente bomen onder CDI is haalbaar met weinig uitspoeling van metalen. De CDI met RO water breidt het toepassingsgebied van deze saneringstechniek nog verder uit. De bodem VNIR reflectie spectroscopie lijkt niet bruikbaar te zijn voor de schatting van metaalverontreinigingen in de bodem (met name voor de geteste bodem dataset en metalen). De uitkomsten van de gerst en zonnebloem studies tonen aan dat 'proximal spectral sensing' van de bladeren van deze planten gebruikt kan worden om plant stress op te sporen in metaalhyperaccumulators, waardoor fytoremediatie programmas geoptimaliseerd kunnen worden. 


\section{ACKNOWLEDGEMENT}

\section{Let me be grateful to people who make me happy}

In Sept 2009, I came to a town named 'Enschede' (lies a few kilometres from Germany) in the Netherland, in receipt of an Erasmus Mundus (EMECW lot-15 India) scholarship from European Commission to pursue PhD. The opportunity came all of a sudden, but has turned out to be a career defining moment. Here and now, I am delighted that I could complete the PhD research with satisfactory outcome in form of this dissertation - which is indeed a long and strenuous research work of five years, was performed at various institutions in Israel, Netherlands and Germany - and it is surely not ended without support, guidance and efforts of many local and global 'peers'. I started out my general indebtedness for everyone, who was associated with me for all my research and dissertation writings.

To begin with, my first and foremost whole-hearted acknowledgements to the Professor Dr. Freek D. van Der Meer, Vice-Chairman of Department of Earth System Analysis, ITC-University of Twente. I am so grateful and feel blessed to have you as my PhD promoter, and for showing your confidence in me. Dank $u$ zeer for continuous support and the leeway you gave me to design and execute the research work. Whatsoever I learnt in field of hyperspectral remote sensing at ITC is because of you! Together with, I take this opportunity to gratefully acknowledge the financial support received toward my PhD program from European Commission as EMECW lot-15 India scholarship 2009-12 and ITC research fund. I'm so grateful to Ministry of Human Resource Development, Government of India and Ministry of Foreign Affairs, Government of Israel for granting me Israeli Government scholarship towards part of my doctorate research work in Israel. The entire research works would have only be possible with these monetary supports!

This dissertation could never explored depths without the guidance of my copromoters at ITC-UT: Dr. David G. Rossiter and Dr. Marleen F. Noomen. I would like to express my sincere thanks to both of you for your most enlightening correspondence and constructive suggestions that have provided me strengths for bringing out research publications. My special thanks to you David for your educative accompany during field campaign to the Saxony State, Germany.

I owe my heartiest gratitude to other mentor, Dr. Pinchas Fine, Head of Department of Soil Chemistry and Plant Nutrition at Volcani Centre in Israel. I've had an excellent research experience of phytoremediation with you at Volcani Centre, and I really glad to be associated with a person like you! I've no words to express my gratefulness for your big-heartedness and many inspiring scientific discussions we shared. Instead, let me recite here only Hebrew words: תודה רבה לך "Todah raba!" Herewith, I would like to acknowledge 
all those who have helped me with hydroponic and lysimeter studies at Volcani Centre: In particular, special thanks to Ms. Anna Beriozkin - for generous technical support at laboratory; Mr. Tibor - for experimental arrangement, you really can fix everything; Dr. Nir Artzmon and Mr. Yoshi Moshe - for invaluable help throughout both the studies.

I am equally obliged to the research collaborators in Germany: (i) Dr. Ingo Müller (Saxon State Office for Environment, Agriculture and Geology, Freiberg) and his team for untiring assistance during field campaign for collecting soils from contaminated sites in Saxon State, and (ii) Dr. Gert E. Dudel (TU Dresden, Tharandt) for providing with me glass-house 'prüffeld' facilities and all possible resources to carry out pot-experiments. Both of you were such nice persons to collaborate with! Besten Dank!

I spent nearly 10 months at Campus of Technical University Dresden in a small town named 'Tharandt', and I've been fortunate with having kind people around me, and all of you made mine and my family's stay in Tharandt pretty memorable! I am explicitly indebted to you Dr. Carsten Brackhage for your overwhelming supports in transport of bulk soils from Melptiz $(110 \mathrm{~km}$ from Tharandt) to the prüffeld, and in laid-out of pot-studies. Thanks a lot for all your enthusiasm! I specially be grateful to: Dr. Jörg Schaller - for lot many scientific discussions we had, and it was pleasant time with you; Mr. Arndt Weiske and Ms. Gisela Ciesielski - for technical assistance with plant and soil chemical analyses; Mr. Sebastian Dietrich and Ms. Ingrid - you helped me many times especially during off-days/holidays, you drove me to the prüffeld and irrigated the plants; Mr. Keydel, prüffeld in-charge - you looked after the pot studies in my absence; and the Secretariat - for your administrative support and assistance in getting accommodation and kindergarten for my daughter in Tharandt. I specially be thankful to you Dr. Rolf Herzig, PhytotechFoundation, Bern, Switzerland for providing with me the seeds of sunflower M5 mutant lines - M5/R4-R6/15-35-190-04-M5.

I consider it a great honor to be a part of ITC-Earth System Analysis department, and my sincere thanks go to all the faculties of ITC-ESA. I am sincerely thankful to Dr. Boudewijn de Smeth - for all possible eases you've extended during soil chemical and spectroscopic analyses at ITC geoscience laboratory. I as well greatly appreciate your support in timely transport of ASD FieldSpec to the Tharandt. Thanks to you Ms. Christie Agema - for your help with administrative matters. Moreover, many wonderful people made my stay at ITC-UT and in Enschede truly worthwhile and memorable. My sincere acknowledgement goes to you: Dr. Paul van Dijk and Ms. Loes Colenbrander for all administrative assistance pertaining to $\mathrm{PhD}$ program and especially the scholarship issues; Ms. Marion Pierik - for timely help with financial things; Ms. Theresa van den Boogaard - for kind support in preparation of VISA, residence permit, and family reunion related documents; and all administrators and receptionists at ITC-hotel - you're all so kind and gracious to me during the stay at ITC-hotel. ITC-UT is in the true sense an international institution! And I myself feel fortunate to be here and met students from all corners of world. I'm thankful to my office-mates, Mila (Bulgaria), Saba and Shafique (Pakistan) and Sanchez (Colombia) for making the workplace vibrant and enjoyable; it was indeed a pleasure meeting you Valentina (Italy) and Samjana (Nepal)! 
Very special words of thankfulness to Indian friends at ITC-UT, with whom I and my family enjoyed our stay in Enschede. We feel like at home in Enschede because of you people only! धन्यवाद (dhanyavād) and शुक्रिया (śukriyā) to all of you (alphabetical to avoid any kind of rank) - Anandita, Debanjan, Divyani, Gaurav-Yamini, Kailash-Meena, Mitava, Pankaj Jaiswal, Pankaj Warwadekar, Pravin-Maitreyi, Priyasmita, Remi, Rishi, Sandeep, Sejal, Shekar, SP Negi, Saibal, Tanmoy, Tapas, Umesh, Vikram-Asmita. The potluck parties, excursions, shopping, celebrations of Indian festivals, birthday parties, discussions over coffee-breaks, and ecstasy in day to day living were all greatly appreciated!

Finally, utterance of gratitude towards my parents, brother, wife 'Neetu', children 'Sai' and 'Teerth' is beyond the words and language! This dissertation would not have been possible without their warm love, continued patience, and endless support.

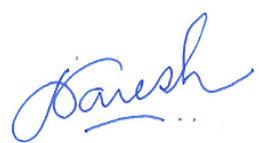

(Pareshkumar H. Rathod) 


\section{AUTHOR'S BIOGRAPHY}

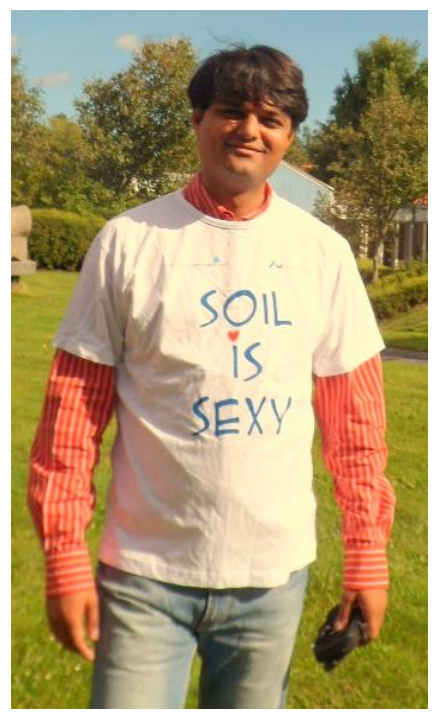

Pareshkumar H. Rathod was born on January $18^{\text {th }}, 1979$ in a Botad district in Gujarat State, India. He received his Bachelor of Agriculture and Master of Agriculture with specialization in Soil Science and Agricultural Chemistry respectively in year 2000 and 2003 from Gujarat Agricultural University (now Anand Agricultural University, Gujarat State, India).

From thereon, he worked as research fellow at Department of Soil Science of B. A. College of Agriculture at same university, on a project of evaluation of manurial quality of gammairradiated sewage sludge for three years from 2003-06. He was selected for Israeli Government Scholarship-2006/07 by Ministry of Human Resource Development, Government of India, and worked as a Research Scholar at Volcani Centre, Agricultural Research Organization, Bet-Dagan, Israel. In Israel, he associated with Dr. Pinchas Fine in a project aimed to an integrated approach to the remediation of polluted river sediments.

In Sept 2009, he was awarded with Erasmus Mundus External Cooperation Window (EMECW) lot-15 India scholarship to pursue doctorate degree under the supervision of Professor Dr. Freek D. van Der Meer at Department of Earth System Analysis, Faculty of Faculty of Geo-information Science and Earth Observation (ITC), University of Twente, The Netherlands. His doctorate research aimed at phytoremediation of metal contaminated soils and their monitoring using remote sensing tools. This dissertation is the final product of his doctorate research with some significant outcomes published in peerreviewed journals. 


\section{LIST OF SUPPORTING PUBLICATIONS}

This dissertation is based on following peer-reviewed scientific publications.

1. Paresh H. Rathod, David G. Rossiter, Marleen F. Noomen and Freek D. van der Meer (2013). Proximal spectral sensing to monitor phytoremediation of metal-contaminated soils. International Journal of Phytoremediation, 15 (5): 405-426.

DOI: $10.1080 / 15226514.2012 .702805$.

2. Pinchas Fine, Paresh H. Rathod*, Anna Beriozkin and Uri Mingelgrin (2013). Uptake of cadmium by hydroponically grown, mature Eucalyptus camaldulensis saplings and the effect of organic ligands. International Journal of Phytoremediation, 15 (6): 585-601.

DOI: $10.1080 / 15226514.2012 .723061$ (*shared first authorship).

3. Pinchas Fine, Paresh H. Rathod*, Anna Beriozkin and Amir Hass (2014). Chelant-enhanced heavy metal uptake by Eucalyptus trees under controlled deficit irrigation. Science of the Total Environment, 493: 9951005. DOI: 10.1016/j.scitotenv.2014.06.085. (*shared first authorship).

4. Paresh H. Rathod, Carsten Brackhage, Freek D. Van der Meer, Ingo Müller, Marleen F. Noomen, David G. Rossiter and Gert E. Dudel (2015). Spectral changes in the leaves of barley plant due to phytoremediation of metals - results from a pot study. European Journal of Remote Sensing, 48: 283-302. DOI: 10.5721/EuJRS20154816.

5. Paresh H. Rathod, Freek D. Van der Meer, Ingo Müller and Boudewijn de Smeth (2016). Analysis of visible and near infrared spectral reflectance for assessing metals in soil. Environmental Monitoring and Assessment, 188 (10): article no. 558. DOI: 10.1007/s10661-016-5568-9.

\section{Submitted article}

6. Paresh H. Rathod, Carsten Brackhage, Ingo Müller, Rolf Herzig, Freek D. Van der Meer and Marleen F. Noomen (2016). Assessing metal-induced changes in the visible and near infrared spectral reflectance of leaves - A pot study with sunflower (Helianthus annuus L.). Submitted to Journal of Indian Society of Remote Sensing (submitted manuscript\# ISRS-D-1600285; under review). 


\section{APPENDIX}

A permission letter from Dr. Pinchas Fine (Head, Department of Soil Chemistry, and Plant Nutrition, Institute of Soil, Water and Environmental Sciences, Agricultural Research Organization, The Volcani Centre, Israel) first author of two research publications that are incorporated in the chapter \#2 and \#3 of present dissertation. 


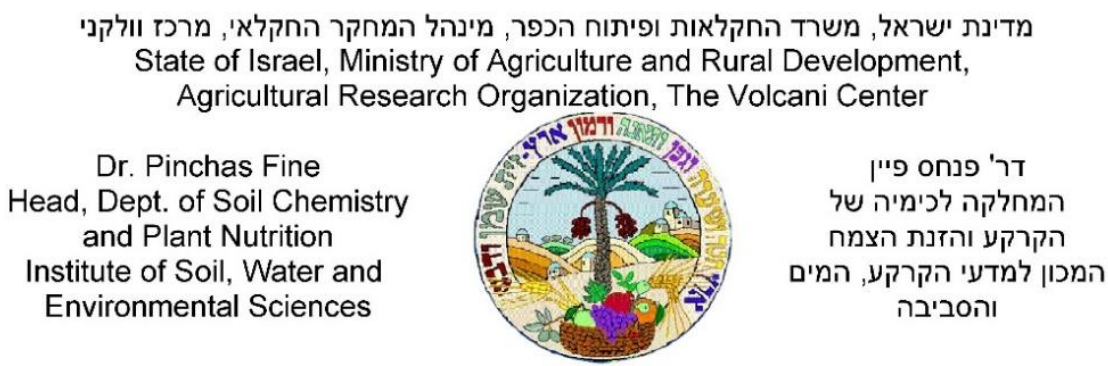

$21 / 05 / 2015$

To:

Prof. Dr. Freek van der Meer, Promoter

Department of Earth System Analysis

Faculty of Geo-information Science and Earth Observation

University of Twente, Enschede, The Netherlands.

and the Examining Committee, University of Twente

Subject: Permission letter to Mr. Pareshkumar H. Rathod, a PhD candidate at ITC, UT

I am writing this letter whole-heartedly in support of Mr. Pareshkumar Rathod for the consideration of research work done on "Cadmium phytoremediation using Eucalyptus trees" in Israel for his $\mathrm{PhD}$ dissertation at ITC, University of Twente, The Netherlands. Mr. Rathod associated for $>2$-yrs with me as research scholar in an Italian-Israeli cooperation project on "An Integrated Approach to the Remediation of Polluted River Sediments.

Mr. Rathod has my permission to include the following two research papers (jointly published from above-said project), of which I was a lead-author, in his doctoral dissertation.

1. Pinchas Fine, Paresh H. Rathod, Anna Beriozkin and Uri Mingelgrin (2013). Uptake of cadmium by hydroponically grown, mature Eucalyptus camaldulensis saplings and the effect of organic ligands. International Journal of Phytoremediation, 15 (6): 585-601.

2. Pinchas Fine, Paresh H. Rathod, Anna Beriozkina and Amir Hass (2014). Chelant-enhanced heavy metal uptake by Eucalyptus trees under controlled deficit irrigation. Science of the Total Environment, 493: 995-1005

With this permission letter, I authorize the inclusion of these publications in Mr. Rathod's $\mathrm{PhD}$ dissertation and certify that (i) the declaration made by Mr. Rathod in the dissertation (in the above spirit) correctly reflects the extent of his immense contribution to these works, and (ii) Mr. Rathod has significantly contributed in the said publications, i.e. for both the hydroponic and lysimeter studies he had done major portion of the work including setting-up of the experiments and conducting them, chemical analyses of plant, soil and water samples, collection of ancillary observations, and preparation of manuscripts.

The letter has been shown to all co-authors of said research papers and they concur with my opinions.

I will be happy to provide further information regarding Mr. Rathod and his research work done here, should it be required.

I wish him all success in his endeavor.

Sincerely

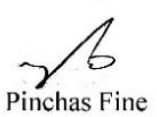

ת" ת"ד 6 בית דגן 50250 ;

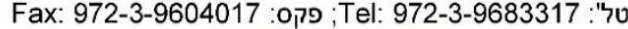

email: finep@volcani.agri.gov.il

http://www.agri.gov.il/ 


\section{ITC DISSERTATION LIST}

The complete list of ITC dissertations is online on the ITC webpage:

https://www.itc.nl/Pub/research_programme/Research-review-andoutput/PhD-Graduates.aspx

This dissertation has number 294. 


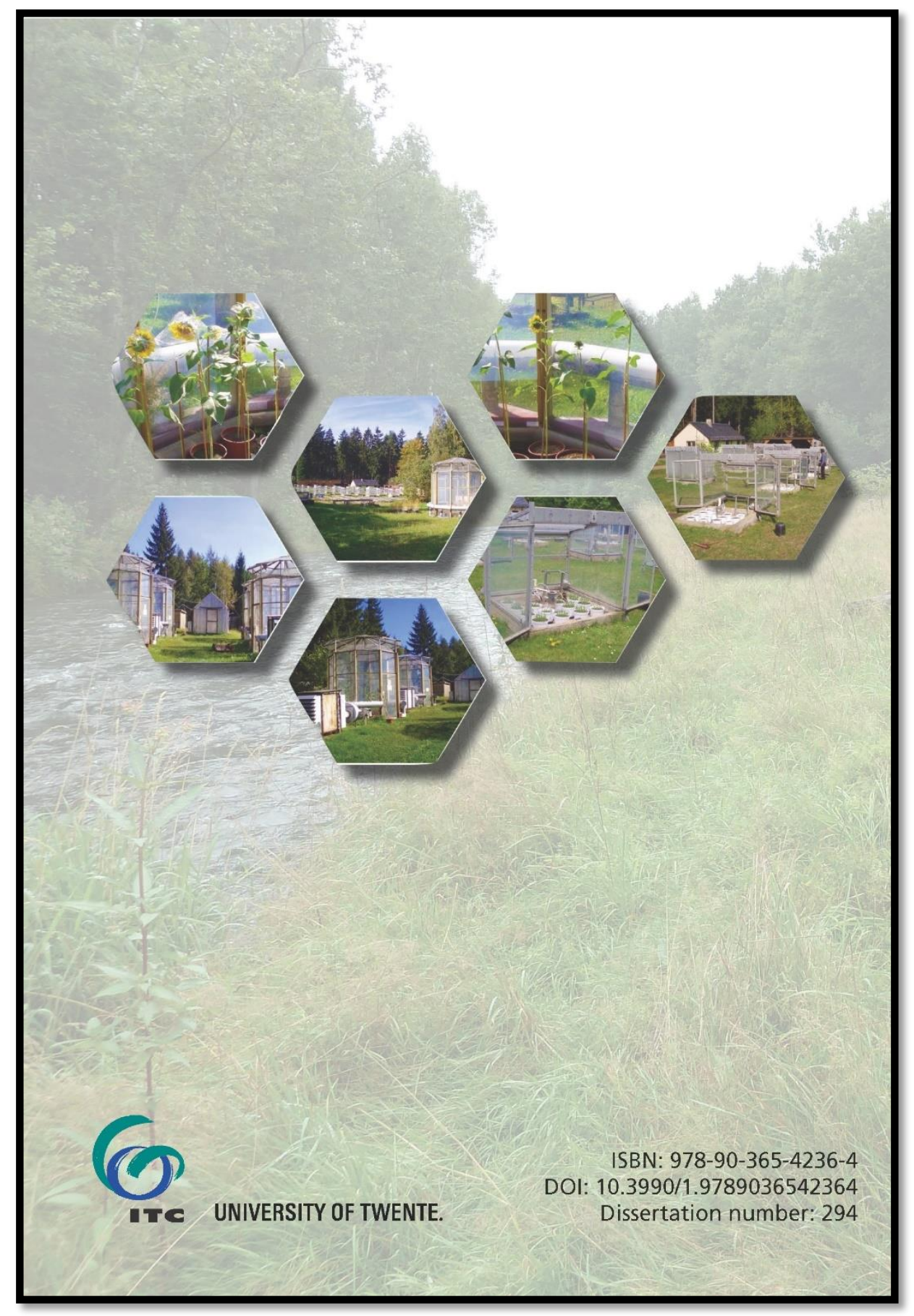

